Universidad de Salamanca-CSIC

Departamento de Microbiología y Genética

Instituto de Biología Funcional y Genómica
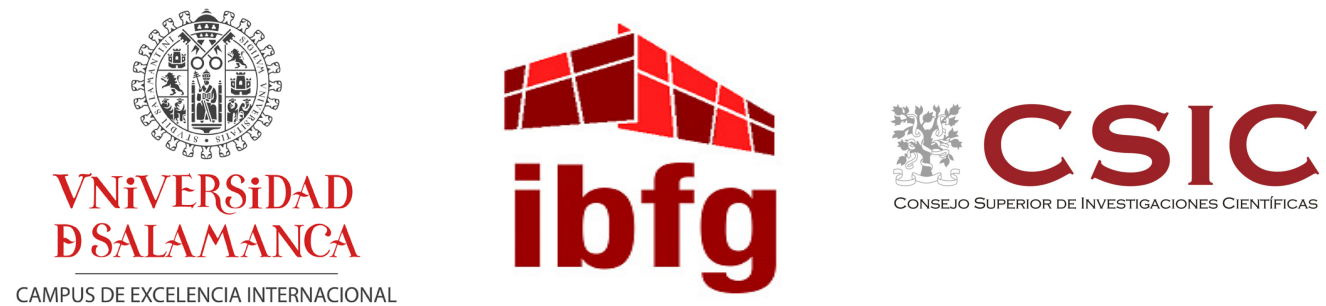

\title{
Identificación de nuevos reguladores del ciclo celular en
} Schizosaccharomyces pombe

\author{
Nathalia Chica Balaguera
}

2014

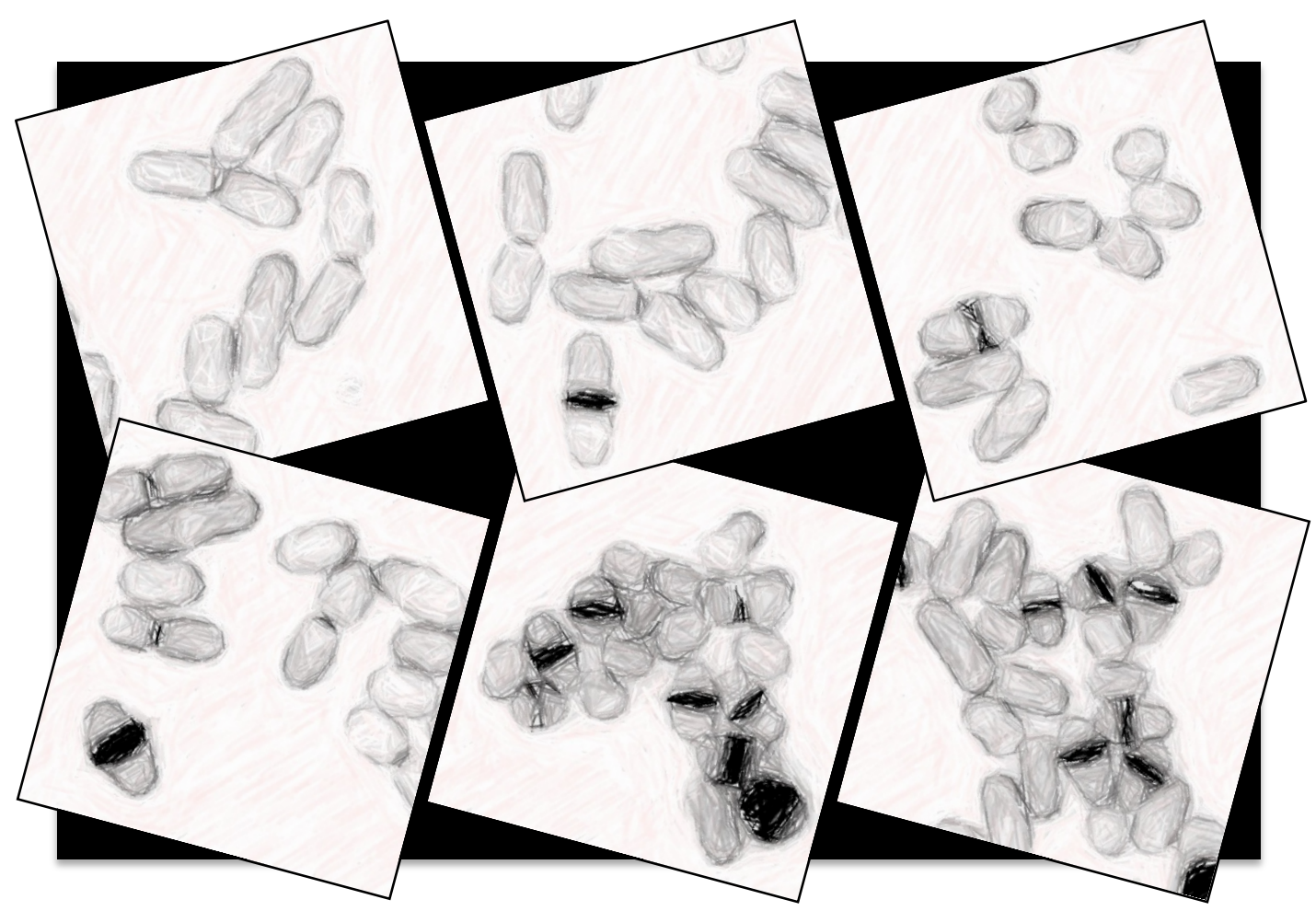


Universidad de Salamanca-CSIC

Departamento de Microbiología y Genética

Instituto de Biología Funcional y Genómica
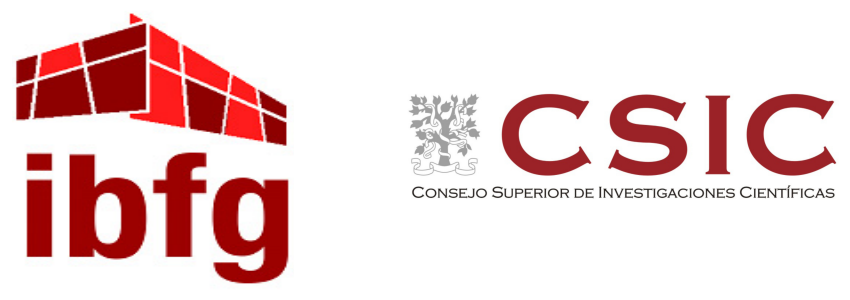

\section{Identificación de nuevos reguladores del ciclo celular en Schizosaccharomyces pombe}

\section{Nathalia Chica Balaguera}


Universidad de Salamanca-CSIC Departamento de Microbiología y Genética Instituto de Biología Funcional y Genómica
筷 CSIC ibfg

Dr. D. Luis Fernández Lago, Profesor Titular y Director del Departamento de Microbiología y Genética de la Universidad de Salamanca

\section{CERTIFICA:}

Que la memoria titulada "Identificación de nuevos reguladores del ciclo celular en Schizosaccharomyces pombe" presentada por la licenciada $D^{a}$. Nathalia Chica Balaguera para optar al grado de Doctor en Biología por la Universidad de Salamanca, ha sido realizada bajo la dirección del Dr. Sergio Moreno Pérez en el Centro Mixto de Biología Funcional y Genómica, CSICUniversidad de Salamanca (Departamento de Microbiología y Genética).

Y para que así conste, expide el certificado en Salamanca, a 25 de Febrero de 2014 


\section{Universidad de Salamanca-CSIC Departamento de Microbiología y Genética

Dr. D. Sergio Moreno, Profesor de Investigación del Consejo Superior de Investigaciones Científicas

\section{CERTIFICA:}

Que la memoria titulada "Identificación de nuevos reguladores del ciclo celular en Schizosaccharomyces pombe" presentada por la licenciada $\mathrm{D}^{\mathrm{a}}$. Nathalia Chica Balaguera para optar al grado de Doctor en Biología por la Universidad de Salamanca, ha sido realizada bajo su dirección en el Centro Mixto de Biología Funcional y Genómica, CSIC-Universidad de Salamanca (Departamento de Microbiología y Genética).

Y para que así conste, expide el certificado en Salamanca, a 25 de Febrero de 2014

Fdo. Sergio Moreno Pérez

Director de la Tesis 


\section{Universidad de Salamanca-CSIC Departamento de Microbiología y Genética

Dr. D. Javier Botet Rodríguez, Investigador del Instituto de biología Funcional y Genómica

\section{CERTIFICA:}

Que la memoria titulada "Identificación de nuevos reguladores del ciclo celular en Schizosaccharomyces pombe" presentada por la licenciada $D^{a}$. Nathalia Chica Balaguera para optar al grado de Doctor en Biología por la Universidad de Salamanca, ha sido realizada bajo su dirección en el Centro Mixto de Biología Funcional y Genómica, CSIC-Universidad de Salamanca (Departamento de Microbiología y Genética).

Y para que así conste, expide el certificado en Salamanca, a 25 de Febrero de 2014

Fdo. Javier Botet Rodríguez

Codirector de la Tesis 
Universidad de Salamanca-CSIC Departamento de Microbiología y Genética Instituto de Biología Funcional y Genómica
警CSIC ibfg

Dr. D. Francisco del Rey Iglesias, Catedrático del Departamento de Microbiología y Genética de la Universidad de Salamanca

\section{CERTIFICA:}

Que la memoria titulada "Identificación de nuevos reguladores del ciclo celular en Schizosaccharomyces pombe" presentada por la licenciada $D^{a}$. Nathalia Chica Balaguera para optar al grado de Doctor en Biología por la Universidad de Salamanca, ha sido realizada bajo la dirección del Dr. Sergio Moreno Pérez en el Centro Mixto de Biología Funcional y Genómica, CSICUniversidad de Salamanca (Departamento de Microbiología y Genética).

Y para que así conste, expide el certificado en Salamanca, a 25 de Febrero de 2014

Fdo. Francisco del Rey Iglesias

Tutor de la Tesis 
Esta tesis doctoral ha sido financiada por una beca predoctoral de Formación de Personal Investigador (FPI) del Ministerio de Economía y Competitividad del Gobierno de España con referencia BES-2009-025690 y asociada al proyecto de investigación BFU2008-01808 en el Organismo 


\section{A Mis papás A mis chicos A Marina}



Índice 
Índice

\section{INTRODUCCION}

1. División celular en eucariotas 1

$\begin{array}{ll}1.1 \text { El ciclo celular } & 1\end{array}$

1.2 Sistemas que controlan el ciclo celular 2

1.3 El ciclo de vida de Schizosaccharomyces pombe 3

1.4 Schizosaccharomyces pombe como un modelo en biología celular

1.5 Mutantes de ciclo: cdc y wee

2. El control del ciclo celular en S. pombe: mecanismos $\begin{array}{ll}\text { moleculares } & 7\end{array}$

$\begin{array}{ll}2.1 \text { El complejo Cdk-ciclina } & 7\end{array}$

$\begin{array}{lc}\text { 2.1.1 Las ciclinas } & 8\end{array}$

2.1.2 La fosforilación de Cdc2 9

2.2 Reguladores de la Cdk 11

2.2.1 La quinasa Wee1 11

2.2.2. La quinasa Mik1 12

2.2.3 La fosfatasa Cdc25 13

2.3 Los puntos de control (checkpoints) del ciclo mitótico 15

2.3.1 Transición G1/S $\quad 15$

2.3.2 Transición G2/M 15

2.3.3 Transición Metafase-Anafase $\quad 15$

2.4 Un único oscilador mitótico $\quad 16$

3. Señales que controlan el ciclo celular 17

$\begin{array}{ll}3.1 \text { Señales nutricionales } & 17\end{array}$ 
Índice

3.2 Respuesta a estrés

4. Antagonistas de la actividad Cdk-ciclina

4.1 Fosfatasa tipo 2A (PP2A) 23

$\begin{array}{ll}4.2 \text { Fosfatasa tipo } 1(\text { PP1) } & 25\end{array}$

OBJETIVOS $\quad 29$

\section{RESULTADOS APARTADO I}

1. Identificación de una red de interacciones genéticas asociadas al ciclo celular en S. pombe 33

1.1 Escrutinio masivo de sintéticos letales (SGA)

1.2 Estimación del crecimiento relativo (RG) e identificación del

espectro de las interacciones genéticas

1.3 Validación de resultados y normalización de los valores

$\begin{array}{ll}\text { de crecimiento relativo } & 38\end{array}$

1.3.1 Efecto de la ejecución del escrutinio por fases 37

1.3.2 Efecto de genes diana ligados al gen de interés 39

1.3.3 Efecto de borde, espacial y del mutante vecino en la placa 39

1.4 Red de interacciones genéticas con los mutantes wee1-50 y cdc2-3w 41

2. Análisis funcional de la red de sintéticos letales con wee1-50 y cdc2-3w

3. Caracterización comprensiva de los mutantes no esenciales identificados como elementos que interaccionan con wee1-50 y cdc2-3w 


\section{RESULTADOS APARTADO II}

\section{Identificación del gen $p p a 2^{+}$como un regulador de} ciclo en S. pombe

1.1. La deleción de $p p a 2^{+}$genera células mas pequeñas que la cepa silvestre

1.2 El mutante de deleción de la fosfatasa tipo $2 A$ ppa $2 \Delta$ es sintético

letal con wee1-50

1.3. La deleción de ppa2 $\Delta$ rescata parcialmente el fenotipo

del mutante termosensible cdc25-22

2. Identificación de dos nuevos reguladores de la entrada a mitosis en $\mathrm{S}$. pombe

2.1 Identificación del homólogo funcional de Ensa y Arrp19 en

S. pombe

2.2 Las células del mutante igo1 $\Delta$ se dividen a un tamaño celular mayor que las de la cepa silvestre

2.3 La ausencia de igo1+ agrava el fenotipo del mutante

termosensible cdc25-22

\section{La función biológica de Igo1 esta sujeta a} una modulación nutricional

3.1 El fenotipo de retraso en la entrada a mitosis del mutante

igo1 $\Delta$ se acentúa bajo estrés por nitrógeno 
Índice

3.2 Igo1 induce la entrada a mitosis en $S$. pombe en respuesta

a una limitación de nitrógeno

3.3 El retraso de entrada a mitosis en células que carecen de

Igo1 no es dependiente de la actividad de Rad3 pero si de Cdc25

4. Caracterización de la ruta Greatwall-ENSA en

S.pombe

4.1 Identificación del ortólogo funcional de Greatwall en

S. pombe

4.2 La doble deleción de las quinasas Ppk18 y Cek1 reproducen

el fenotipo de la ausencia de Igo1

86

4.3 Ppk18 actúa por encima de lgo1

4.4 El papel de Igo1 implica la inhibición de PP2A-pab1

5. La actividad de Igo1 como respuesta a un cambio nutricional

5.1 La actividad de Igo1 depende del sitio de fosforilación

S64 (Ser)

5.2 El estado de fosforilación de Igo1 depende de un cambio nutricional

5.3 La fosforilación de Igo1 en la S64 depende de Ppk18

5.4 La sobreexpresión de Ppk18 induce entrada a mitosis

y un cese en el crecimiento a través de Igo1

\section{La ruta Ppk18-Igo1-PP2A es un sensor nutricional}


6.2 La proteína quinasa $\mathrm{A}$ (PKA) regula negativamente la

activación de Igo1

7. La actividad de Igo1 es independiente de otros

mecanismos de regulación de entrada a mitosis en S. pombe

DISCUSIÓN

APARTADO I

1. Mapa funcional de la regulación de la Cdk en S. pombe

2. Análisis de la composición de la redes de interacción genética identificadas

3. Nuevos reguladores del ciclo celular en S. pombe:

Predicción de función y relaciones

APARTADO II

1. Ppk18 (Greatwall) e Igo1 (Ensa) actúan como reguladores positivos de la entrada a mitosis en S. pombe

2. La ruta Greatwall-Ensa-PP2A coordina la entrada a mitosis como respuesta a estrés nutricional en $S$. pombe

3. TORC1 (Tor2) y la proteína quinasa A (PKA) regulan negativamente la actividad de la ruta Greatwall-Ensa en S. pombe

CONCLUSIONES

MATERIAL SUPLEMENTARIO

Tabla S1 
Índice

Tabla S4

Tabla S5

Tabla S6

Tabla S7

Tabla S8 164

Tabla 59 165

Tabla S10

Tabla S11

Tabla S12

Figura S1

\section{MATERIALES Y MÉTODOS}

1. Microorganismos utilizados

1.1 Cepas de Schizosaccharomyces pombe

1.2 Cepas de Escherichia coli

2. Medios y condiciones de cultivo

2.1 Cultivos de S. pombe

2.2 Cultivos de E. Coli

3.1.1 Marcaje de los mutantes wee (cepas de interés)

3.1.2 Colección de los mutantes no esenciales de 
3.2 Obtención de los dobles mutantes para el análisis

genético

3.2.1. Genotipos de las cepas parentales

3.2.2 Nomenclatura de las placas

3.2.3 Medios y condiciones de crecimiento

3.2.5 Preparación de las cepas diana (target) y de interés (query)

3.2.6 Cruce entre cepas diana (target) y de interés (query)

3.2.8 Enriquecimiento de esporas y eliminación de parentales haploides y diploides

3.2.10 Selección de los dobles mutantes

3.2.13 Estimación del crecimiento de los dobles mutantes

sobre agar

3.3.1 Algoritmo de crecimiento relativo y 
3.3.2 Pre-procesamiento y normalización

4. Análisis fenotípico de los mutantes que interactúan con wee 1-50 y cdc2-3w

4.1 Estado morfológico y citológico

5.2 Estrés por nitrógeno. Medición del tamaño celular y ensayos bioquímicos

5.3 Estrés por glucosa. 
8.2 Integración de la construcción KanMX6-p3nmt1-3HA en

el locus $p p k 18^{+}$

9.9 Mutagénesis dirigida: construcción del mutante 
9.9.1 Construcción de la cepa igo1::ura4+

10.1.2 Obtención del anticuerpo fosfo-específico anti-S64-Igo1

10.2.1 Preparación de extractos proteicos

en condiciones desnaturalizantes

10.2.2. Valoración de la concentración de proteína en

los extractos totales

11.2.2 Mediciones celulares in vivo mediante tinción 
Índice

11.2.3 Ensayos de time-lapse con fluorescencia

12. Citometría de flujo

12.1 Fijación y tinción de las células

12.2 Adquisición y análisis de resultados

13. Tratamiento informático y estadístico de los datos

13.1 Análisis informático del escrutinio

13.2 Análisis de secuencias

13.3 Análisis estadístico 
Introducción 


\section{División celular en eucariotas}

\subsection{El ciclo celular}

La división o reproducción celular es un proceso fundamental para las células. Su coordinación con el crecimiento celular, determina el éxito evolutivo en todos los organismos. En el caso de los organismos eucariotas, la división celular engloba una secuencia de eventos, denominados en su conjunto ciclo celular, el cual conduce a la generación de dos células hijas. Estas células hijas, en organismos unicelulares generan nuevas identidades y en organismos multicelulares, asociaciones especializadas de células que originan tejidos y órganos.

Con el fin de evitar el fracaso, la célula eucariota distribuye el ciclo celular en cuatro eventos discretos que le permite manejarlo con precisión y fiabilidad. En orden de ocurrencia, éstos eventos son: i) la fase $\mathbf{G 1}$ (del inglés Gap1), donde se acopla el crecimiento celular con la síntesis del ARN y de proteínas; ii) la fase $\mathbf{S}$ (del inglés Synthesis), donde replica el ADN y duplica los cromosomas; iii) la fase G2 (del inglés Gap2), donde continúa con la síntesis de proteínas y crece hasta un tamaño ideal para llevar a cabo la mitosis; iv) la fase $\mathbf{M}$, último evento que incluye la repartición del material genético en dos células hijas (mitosis) y la división del citoplasma (citoquinesis). Los primeros tres eventos son conocidos en conjunto como interfase.

Durante la fase $\mathrm{S}$, múltiples proteínas separan las dos hebras del ADN, para exponer sus sitios de origen de la replicación a la maquinaria encargada de duplicar el material genético en la célula. En dichos sitios, esta maquinaria se desplaza a lo largo de ambas hebras en sentidos contrarios y origina las copias correspondientes a cada una. A continuación, se incrementa la producción de proteínas llamadas histonas, que se encargan de empaquetar el ADN en estructuras denominadas cromosomas. Asimismo, dichas proteínas estabilizan los cromosomas, manteniendo unidas ambas copias. El principal objetivo de la mitosis, es distribuir el material replicado en dos células hijas. De esta forma, antes de dar inicio a esta, la célula sufre cambios estructurales en el ADN, que implican condensar la cromatina recién replicada y hasta entonces dispersa en el núcleo, en cromatina condensada (profase mitótica). Este evento es necesario para 


\section{Introducción}

permitir a la célula avanzar desde interfase hacia mitosis. Cada cromosoma se compone de dos cromátides hermanas, que se encuentran unidos a una red de microtúbulos. Esta red de microtúbulos, antes organizada a lo largo del citoplasma, se reorganiza en el huso mitótico, que consiste en una estructura bipolar que emana de dos estructuras llamadas centrosomas (previamente duplicado en interfase). Dicho huso se encarga de separar las cromátides hermanas en direcciones opuestas hacia los polos de la célula, durante la transición metafase-anafase, para llevar a cabo el proceso conocido como segregación cromosómica y originar los nuevos núcleos de las células hijas. Seguido a la mitosis, la célula se divide físicamente a través de la citoquinesis y a continuación, se reconstruye la estructura física de las nuevas células. Paralelamente a estos procesos, los componentes citoplasmáticos como macromoléculas, ARNs y orgánulos son duplicados a lo largo del ciclo celular, para luego ser repartidos equitativamente en cada célula hija durante la citoquinesis. En la mayoría de los organismos, los eventos discretos del ciclo celular están acoplados con el crecimiento celular. De esta manera, la masa celular se duplica pero el tamaño permanece aproximadamente constante. En muchos tipos de células, el crecimiento y la división no esta coordinada, por ejemplo en oocitos de mamíferos, neuronas y células del músculo (revisado en Nasmyth, 1999 y Morgan, 2007).

\subsection{Sistemas que controlan el ciclo celular}

Para vigilar que cada fase ocurra con fidelidad y bajo un orden y un tiempo adecuado, la célula cuenta con sistemas de comprobación que frenan o avanzan las diferentes fases del ciclo celular. Esto es realizado en sitios específicos llamados puntos de control (en inglés checkpoints), situados en la fase G1 tardía, la transición G2/M y en mitosis, en la transición metafase-anafase (Hartwell y Weinert, 1989).

La eficiencia de estos sistemas de control, reside en una serie de mecanismos que contribuyen a la regulación de la actividad de complejos llamados Cdks (del inglés cyclindependent kinases). La transición de una fase a otra, obedece a las oscilaciones en la actividad de estos complejos, que a su vez dependen de estados de fosforilación de la subunidad catalítica (quinasa) y de cambios en la cantidad de la subunidad reguladora (ciclina). En eucariotas superiores, múltiples complejos Cdk-ciclina se encargan de mantener la ejecución y la periodicidad de las fases, mientras que en eucariotas inferiores dichos complejos son menos diversificados (Tabla 1). En conjunto, estos componentes junto con los mecanismos de regulación, constituyen el sistema de control 
del ciclo celular (Morgan, 1997; Ubersax et al., 2003).

Tabla 1. Complejos Cdk-ciclina en eucariotas

\begin{tabular}{l|l|l}
\hline Especies & Quinasas & Ciclinas (asociada a cada Cdk) \\
\hline S. pombe & Cdc2 & Puc1, Cig1, Cig2, Cdc13 \\
S. cerevisiae & Cdc28 & Cnl1,2,3 y Clb1,2,3,4,5,6, \\
D. melanogaster & Cdk1 & A,B, B3, E \\
& Cdk2 & E,A \\
X. laevis & Cdk4 & D \\
& Cdk1 & A,B \\
H. Sapiens & Cdk2 & A,E \\
& Cdk1 & A,B \\
& Cdk2 & E \\
& Cdk4 & D1,D2,D3 \\
\hline Revisado en Morgan, 2007 & D1,D2,D3 \\
\hline
\end{tabular}

\subsection{El ciclo de vida de Schizosaccharomyces pombe}

La levadura de fisión es un organismo eucariota unicelular con forma cilíndrica, que mide $14 \mu \mathrm{m}$ de longitud y entre 3 y $4 \mu \mathrm{m}$ de diámetro cuando crece en medio rico. Como lo dice su nombre, se divide por fisión binaria dando lugar a dos células hijas de igual tamaño. Al igual que el resto de eucariotas, presenta un ciclo celular en el que alterna el crecimiento con la división celular. Normalmente, las células son haploides, pero diploidizan cuando las condiciones nutricionales empobrecen (Egel, 2004). El tamaño de su genoma es de 13,8 Mb y está distribuido entre tres cromosomas (I con 5,7 Mb; II con 4,6 Mb y III con 3,5 Mb) y el ADN mitocondrial (20kb) (Lang et al., 1987; Wood et al., 2002).

En comparación con otros organismos, su ciclo celular se caracteriza por tener una fase G1 muy corta y una fase G2 mas larga (Mitchison y Creanor, 1971). En crecimiento exponencial, la fase $S$ comienza antes de que la citoquinesis haya terminado (Figura 1). De lo anterior se deduce, que a pesar de ser un organismo haploide, esta levadura permanece la mayor parte del tiempo del ciclo celular con dos copias del material genético (pseudodiploide), sobrellevando así los riesgos de tener una sola copia. 


\section{Introducción}

Asimismo, el principal checkpoint del ciclo celular reside en la transición $\mathrm{G} 2 / \mathrm{M}$, en la cual el tamaño celular dependiente de nutrientes es monitorizado (Fantes, 1977; Fantes y Nurse, 1977). De esta forma, una célula de $S$. pombe puede variar su tamaño celular en función de la disponibilidad de nutrientes. Si los nutrientes en el medio son abundantes, la célula crece durante la fase G2 hasta alcanzar el tamaño celular adecuado antes de la división celular. Por el contrario, cuando los nutrientes son limitados las células disminuyen el tiempo de duración de la fase G2, aceleran la entrada a mitosis y en consecuencia reducen su tamaño. Para mantener la homeostasis del tamaño celular, la levadura de fisión extiende la fase G1 y a su vez activa el segundo checkpoint de tamaño de la transición G1/S (Fantes, 1977, Nurse y Thuriaux, 1977).

En S. pombe, como respuesta a la privación de nutrientes, se dan dos alternativas. Si en el cultivo solo hay células del mismo tipo sexual ( $h+0 h-)$, se bloquean en $\mathrm{G} 1$ o en

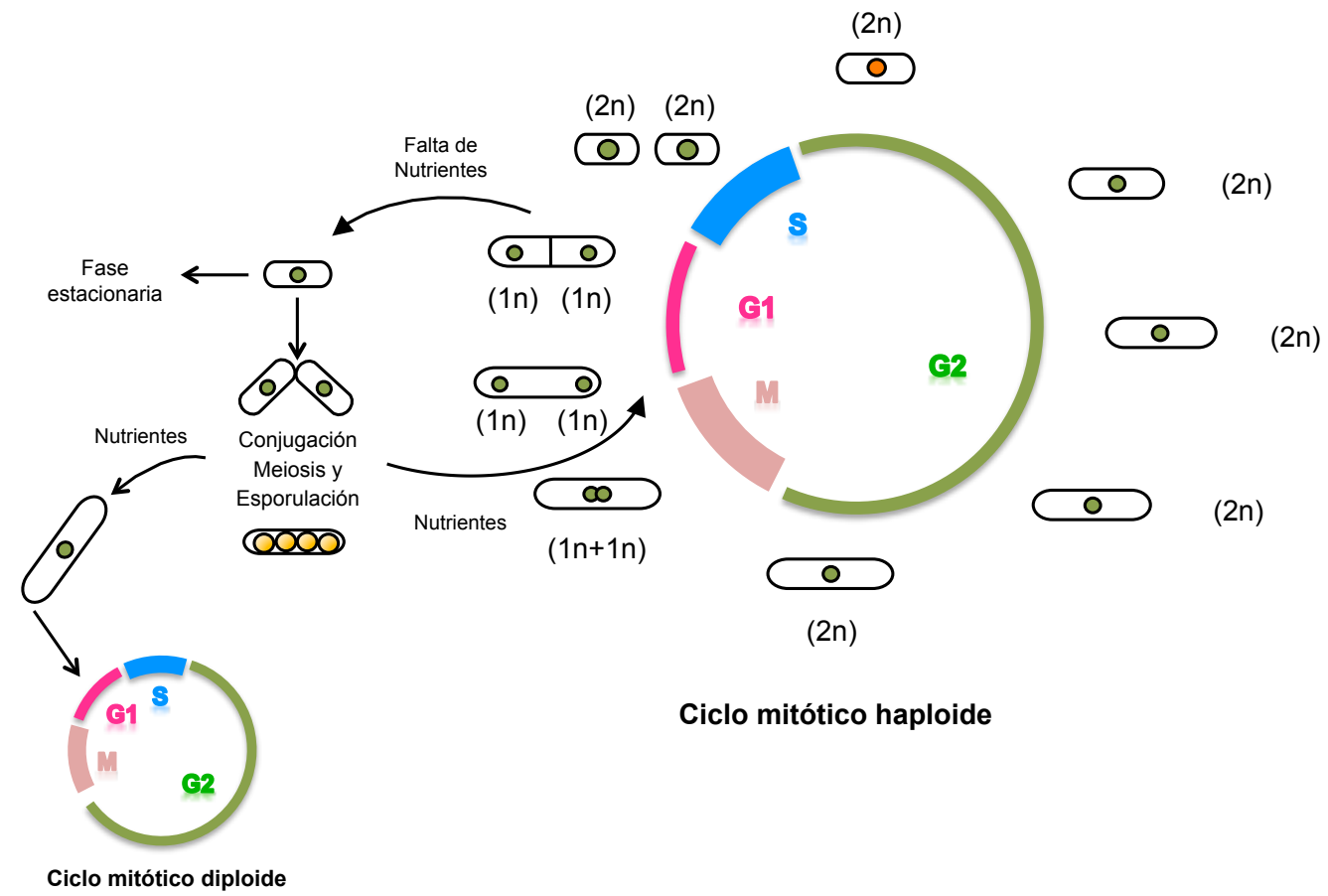

Figura 1. Esquema del ciclo celular y del ciclo de vida de $S$. pombe. El ciclo celular de $S$. pombe se caracteriza por tener una fase G1 corta y una fase G2 más larga. En crecimiento exponencial, la fase $S$ empieza antes de que haya terminado la citoquinesis. Cuando los nutrientes se agotan las células de tipo sexual opuesto conjugan y forman un cigoto diploide que entra a meiosis y esporula. Si el cigoto diploide detecta condiciones favorables en el medio, entra en ciclo mitótico. Cuando el medio empobrece de nuevo, entra a meiosis y esporula. 
G2, dependiendo de la temperatura y del recurso limitante, nitrógeno o carbono (Costello et al., 1986).

Por el contario, si hay dos células de tipo sexual opuesto $\left(\mathrm{h}^{+} \mathrm{y} \mathrm{h}^{-}\right)$, se bloquean en G1 y a continuación inician la conjugación para dar lugar a un cigoto, que entrará en ciclo meiótico y formará un asca con cuatro esporas haploides. Si estas esporas encuentran un ambiente propicio, germinarán y entrarán de nuevo en el ciclo mitótico. Si no, se mantendrán en dicho estado hasta entonces (Egel, 1989; Egel, 2004). El estado diploide es muy inestable y sólo puede mantenerse si el cigoto detecta un medio rico antes de llevar a cabo la meiosis (MacNeill y Nurse, 1997).

\subsection{Schizosaccharomyces pombe como un modelo en biología celular}

Evolutivamente, la levadura de fisión se separó de su relativo, Saccharomyces cerevisiae, hace más de 400 millones de años (Sipiczki, 2000), por lo que se ha sugerido que el comportamiento biológico de $S$. pombe es mas similar al resto de eucariotas que a la levadura de la cerveza (Wood et al., 2002). S. pombe tiene proporcionalmente mas genes conservados en animales que los que tiene $S$. cerevisiae; sin embargo en algunos casos, cada una comparte genes con los metazoos que la otra levadura carece. Ambas levaduras comparten entre sí un $75 \%$ de genes identificados como ortólogos (Dixon et al., 2008). A pesar de esto, presentan características que les hacen diferentes en su biología. Entre estas, destacan algunas como el hecho de que las células de $S$. pombe se dividen por fisión, mientras que las de $S$. cerevisiae lo hace por gemación. Sumado a esto, en $S$. pombe la conjugación y la meiosis están acopladas, y en consecuencia sólo el cigoto manifiesta el estado diploide, mientras que en S. cerevisiae se encuentran desacopladas y las células vegetativas pueden ser tanto haploides como diploides. Por otro lado, las células de $S$. pombe permanecen mas tiempo en fase $G 2$, mientras que las de $S$. cerevisiae en fase G1. De igual forma, algunos aspectos moleculares no conservados en $S$. cerevisiae, le sitúan mas cercana a los metazoos, por ejemplo la presencia de múltiples intrones en los genes, la expresión génica controlada por una maquinaria similar a la del ARN interferente (RNAi), mecanismos epigenéticos que controlan los cambios en la estructura de la cromatina y la regulación del ciclo celular a través del control de la transición G2/M (revisado en Sunnerhagen, 2002 y Wood et al., 2006). 


\section{Introducción}

De acuerdo a lo anterior, S. pombe demuestra ser un mejor modelo para estudiar algunos procesos celulares fundamentales conservados en eucariotas superiores, incluyendo dinámica de la cromatina y regulación del ciclo celular. De igual forma, la levadura de fisión tiene ventajas como modelo para el estudio de la biología celular y molecular, debido a que: i) es un sistema genético manejable y fácilmente manipulable en el laboratorio, ii) es posible seguir su ciclo celular en un tiempo corto, iii) es estable en estado haploide, permitiendo la evaluación del fenotipo que producen las mutaciones recesivas, iv) los genes esenciales pueden ser caracterizados mediante mutaciones condicionales dependientes de temperatura y $\mathbf{v}$ ) en consecuencia de la era postgenómica, se ha convertido en un organismo ideal para estudiar las interacciones genéticas a gran escala (revisado en Forsburg y Nurse, 1991; Forsburg, 2005; Dixon et al., 2009).

\subsection{Mutantes de ciclo: $c d c$ y wee}

Los estudios genéticos relacionados al estudio del ciclo celular con S. pombe, han permitido aislar mutantes que se bloquean en un punto concreto del ciclo celular o tienen un ciclo celular alterado, sugiriendo que sus funciones son esenciales para la progresión celular. El ciclo celular mitótico en las células de $S$. pombe es fácil de seguir, ya que existe una correlación entre la longitud celular y la fase del ciclo en la que se encuentran las células.

Teniendo en cuenta esta particularidad, los primeros mutantes del ciclo celular que se identificaron fueron los mutantes cdc (del inglés cell división cycle) (Nurse et al., 1976). Los genes implicados en estas mutaciones son esenciales, lo que significa que estos mutantes son condicionales. A temperatura restrictiva, estos mutantes se bloquean en un punto del ciclo celular pero pueden seguir creciendo, lo que significa que su fenotipo principal son células mas alargadas que la cepa silvestre. La identificación de estos, permitió establecer la existencia de checkpoints que determinan la progresión de una fase a otra y que a su vez son dependientes funcionalmente de los genes alterados para ser completados. Paul Nurse, también identificó los mutantes wee (del vocablo escocés wee que significa pequeño), cuya característica principal es que presentan una fase G2 corta y por ende, que llevan a cabo la división celular a un tamaño celular reducido (Nurse, 1975; Nurse y Thuriaux, 1980). Existen dos clases de mutantes wee: i) aquellos que obvian el control de la proteína fosfatasa Cdc25, ya sea por producir en 


\section{Introducción}

exceso esta proteína (OP-cdc25) o por alterar a Cdc2 (cdc2-3w y cdc2-4w) de tal forma que ya no requiere de la actividad de Cdc25, y ii) aquellos que eliminan el control de wee $1^{+}$, ya sea por inactivación de la proteína quinasa Wee1 (wee1-50), sobreproducción de la proteína quinasa Cdr1/Nim1 (OP-cdr1) o alteración de la proteína Cdc2 de tal manera que la hace insensible a la actividad de Wee1 (Enoch y Nurse, 1990; revisado en MacNeill y Nurse, 1989). Con la caracterización de estos mutantes, se estableció la función de los genes $w e e 1^{+}$y $c d c 2^{+}$en $S$. pombe sobre el control del inicio de la mitosis. Finalmente, Russell y Nurse en 1986 y 1987a, completaron la colección identificando alelos mutantes para el gen $c d c 25^{+}$y wee $1^{+}$, definiendo así a Cdc25 y Wee1 como los reguladores positivos y negativos respectivamente de Cdc2 en la entrada a mitosis.

\section{El control del ciclo celular en S. pombe: mecanismos moleculares}

El control del ciclo celular consiste en una serie de eventos bioquímicos que dirigen el orden de ocurrencia de las fases y el tiempo de duración de las mismas. Los componentes claves de este sistema son los complejos Cdk-ciclina y sus principales reguladores en G2, conocidos en S. pombe como Wee1, Mik1 y Cdc25. Estos complejos Cdk-ciclina son los encargados de llevar a cabo todo la progresión del ciclo celular a través de oscilaciones en su actividad quinasa, y a su vez de actuar como eje central en la conexión entre la maquinaria principal de regulación del ciclo celular y otros procesos celulares. Estos procesos son mantenidos por capas de regulación secundarias, que constituyen el sistema global de integración entre la información extracelular con las rutas de señalización intracelulares (revisado en Morgan, 2007).

En su mayoría se encuentran conservados evolutivamente en todos los organismos eucariotas, los cuales fueron por primera vez dilucidados en los trabajos realizados por los investigadores Lee Hartwell y Paul Nurse, usando como modelos a S. cerevisiae y $S$. pombe respectivamente.

\subsection{El complejo Cdk-ciclina}

En todos los organismos, la maquinaria principal del ciclo celular es un complejo enzimático constituido por dos tipos de proteínas: las Cdks (subunidad catalítica) y las ciclinas (subunidad reguladora). Su actividad es modulada por inhibidores específicos y cambios en la fosforilación de la subunidad catalítica que responde a estímulos como 


\section{Introducción}

disponibilidad de nutrientes, tamaño celular y mecanismos de activación de los checkpoints del ciclo. A diferencia de otros eucariotas, las células de S. pombe poseen una única Cdk codificada por el gen $c d c 2^{+}$(Simanis y Nurse, 1986). La regulación en los niveles de actividad permite la progresión irreversible desde la fase $\mathrm{G} 1$ a la fase $\mathrm{S}, \mathrm{y}$ desde la fase G2 a mitosis. En particular, la replicación del ADN y la mitosis es controlada a través de la unión de Cdc2 a las ciclinas Cig2 y Cdc13, respectivamente. La unión a otras dos ciclinas Cig1 y Puc1 controla la progresión por fase G1 (Hagan et al, 1988; Bueno et al, 1991; Bueno y Russell, 1993; Martín-Castellanos et al, 2000). Estudios de la actividad de la Cdk y su dependencia a las ciclinas, han demostrado que Cdc13 es la única ciclina relevante para dirigir la ejecución completa del ciclo celular en este organismo (Fisher y Nurse, 1996; Martín-Castellanos et al., 2000; Coudreuse y Nurse, 2010).

\subsubsection{Las ciclinas}

Las ciclinas fueron identificadas como proteínas que oscilan en su abundancia a lo largo del ciclo celular a través de eventos que incluyen síntesis de proteínas y degradación (Evans et al., 1983). Estas se acumulan durante periodos específicos del ciclo celular, que son regulados a través de un dominio denominado caja de ciclinas (del inglés cyclin box). En células de eucariotas superiores, se han identificado múltiples ciclinas, que regulan el ciclo celular dependiendo de dónde y cuándo son expresadas, permitiendo una mayor flexibilidad en el control del ciclo celular y en la modulación de la actividad de la Cdk (van der Voet et al., 2009).

En particular, en $S$. pombe se han identificado 4 ciclinas, incluyendo a Puc1 y tres ciclinas tipo B Cig1, Cig2 y Cdc13. Para su acoplamiento con Cdc2, las ciclinas reconocen un motivo conocido como PSTAIR, que corresponden a los aminoácidos conservados en este dominio (Jeffrey et al., 1995; Pavletich, 1999). A lo largo del ciclo, la cantidad de Cdc2 permanece constante mientras que los niveles de las ciclinas oscilan, lo que implica que la actividad específica de Cdc2 es determinada en parte por su ciclina asociada. De esta forma, Puc1 se une a Cdc2 para regular la entrada a fase S, Cig1 y Cig2 para regular la progresión por fase $S$ y Cdc13 la entrada a mitosis (Fisher y Nurse, 1995). Cig2 es la principal ciclina en la fase de replicación del ADN, la cual se acumula durante la fase G1 tardía y desaparece a la salida de la fase $S$ (Mondesert et al., 1996). En el caso de Cdc13, sus niveles se mantienen bajos durante la fase $\mathrm{G} 1$, incrementan en 
al., 1989). Adicional a su caja de ciclinas, esta contiene un motivo de destrucción (del inglés destruction-box motifs) que dirige su proteólisis en dos pasos, ubiquitinación y degradación por parte del complejo APC-Ste9 y del proteosoma $26 \mathrm{~S}$ respectivamente (Yamaguchi et al., 1997; Kitamura et al., 1998). Cdc13 y Cdc2 colocalizan en el núcleo. Aunque Cdc2 no se degrada durante la mitosis, en ausencia de Cdc13, esta no se localiza en el núcleo, indicando que Cdc13 no sólo regula la actividad de Cdc2 uniéndose a ella, sino que también regula su localización (Booher y Beach, 1989).

Por otro lado, a la salida de mitosis se acumula la proteína Rum1, un inhibidor de la actividad del complejo Cdc2-Cdc13 y Cdc2-Cig2, que se une físicamente a Cdc13 para dirigir su proteólisis durante la fase G1 (Correa-Bordes et al., 1997). Cuando las células progresan desde fase $\mathrm{G} 1$ hacia fase $\mathrm{S}$, el complejo Cdc2-Cig1 fosforila a Rum1 y promueve su degradación por el complejo SCF, lo que a su vez permite que el complejo Cdc2-Cig2 induzca la entrada en fase $S$ y a su vez inhiba la actividad del complejo APCSte9 (Benito et al., 1998; Blanco et al., 2000). Otros estudios han señalado que el complejo Cdc2-Puc1 también fosforila a Rum1 a finales de la fase G1 (Martín-Castellanos et al., 2000).

\subsubsection{La fosforilación de Cdc2}

En la levadura de fisión, el complejo $\mathrm{Cd} 2-\mathrm{Cdc} 13$ es regulado a través de una fosforilación activadora en el residuo Thr167 (T167) (Gould et al., 1991; Fleig et al., 1992), equivalente a la Thr169 en S. cerevisiae y la Thr161 en la Cdk de mamíferos, y de una fosforilación inhibitoria en el residuo Tyr15 (Y15) cercano al sitio de unión del ATP (Gould y Nurse, 1989).

En un primer evento, la T167 es fosforilada tras de la unión de Cd2 a Cdc13 (Gould et al., 1991). La T167 esta ubicada dentro del T-loop de la quinasa y su fosforilación induce un reordenamiento en el sitio de unión a sus sustratos y a su vez fortalece la interacción con la ciclina (Ducommun et al., 1991; Russo et al., 1996). Esta fosforilación es catalizada por enzimas llamadas quinasas activadoras de la Cdk (CAKs, del inglés CDK-Activating Kinase) y no se encuentra regulada por modificaciones reversibles como normalmente ocurre en este tipo de modificaciones post-traduccionales. En S. pombe existen dos tipos de proteínas CAKs: el complejo esencial Mcs6, homólogo del complejo Cdk7-ciclina $\mathrm{H}$ en eucariotas superiores y Csk1, una proteína que no es esencial y es or- 


\section{Introducción}

tóloga de Cak1 en S. cerevisiae. Ambos activan a Cdc2, pero Csk1 a su vez es capaz de activar a Mcs6 (Damagnez, et al., 1995 y Lee et al., 1999). Por el contrario, también existen proteínas inhibidoras CKIs (del inglés Cyclin dependent Kinase Inhibitor), las cuales se unen in vivo a la Cdk, a la ciclina o el complejo Cdk/ciclina con el fin de impedir la activación de las CAKs o competir con la ciclinas por la unión a la quinasa (revisado en Arellano y Moreno, 1997 y Blanco, 2001).

$\begin{array}{lll}\text { Start } & \text { G2/M M/A }\end{array}$

\begin{tabular}{|l|l|l|l|}
\hline G1 & S & G2 & M \\
\hline
\end{tabular}

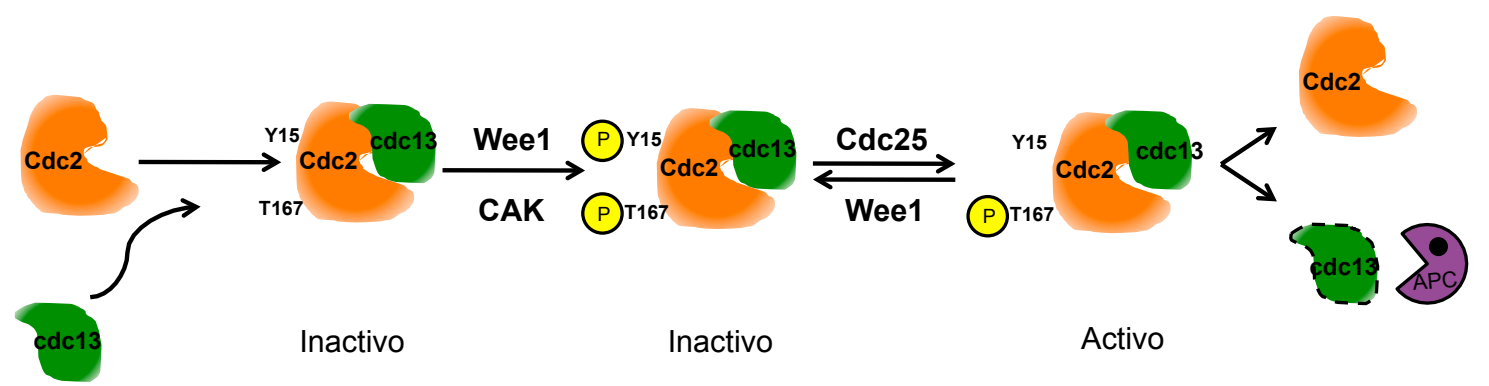

Figura 2. Regulación por fosforilación del complejo Cdc2-Cdc13. Durante la transición G1/S, la célula inicia la síntesis de la ciclina Cdc13, lo que permite que Cdc2 se una ésta. A continuación la CAK fosforila la T167, esencial para su activación. La actividad del dímero es reprimida mediante la fosforilación en la Tyr15 por parte de Wee1 y Mik1. En la fase G2 la fosforilación en la Tyr15 es revertida por la fosfatasa Cdc25 para activar el complejo e inducir la entrada a mitosis. En la transición metafase/anafase el complejo Cdc2-cdc13 se inactiva por degradación de la ciclina.

En un segundo evento, establecido como el principal mecanismo de control de la entrada a mitosis, la quinasa Wee1 (Russell y Nurse, 1987a; Featherstone y Russell, 1991) y la fosfatasa Cdc25 (Millar et al. 1991), fosforilan y desfosforilan la Y15 respectivamente. Igualmente, como un sistema de reserva, la quinasa Mik1 (Lundgren et al., 1991) y la fosfatasa Pyp3 (Millar et al., 1992), cumplen un papel secundario al desempeñado por Wee1 y Cdc25 comparativamente. La fosforilación en la Y15 es importante para la coordinación entre la replicación y la entrada a mitosis, ya que dicho checkpoint promueve esta fosforilación para prevenir la activación de la Cdk antes de que el ADN este totalmente replicado (O' Connell et al., 1997) (Figura 2). 


\subsection{Reguladores de la Cdk}

\subsubsection{La quinasa Wee1}

La quinasa Wee1 actúa como un elemento regulador negativo de la entrada a mitosis. La inactivación de esta, provoca la división celular a un tamaño celular reducido (Nurse y Thuriaux, 1980) mientras que la sobreexpresión genera células alargadas (Russell y Nurse, 1987a). El primer inhibidor de Wee1 aislado en S. pombe fue Cdr1, también conocido como Nim1 (del inglés New Inducer of Mitosis) (Russell y Nurse, 1987b). De acuerdo a evidencias genéticas en las cuales, la sobreexpresión de Cdr1 rescata el fenotipo de células que carecen de $c d c 25^{+}$e induce a las células a entrar a mitosis prematuramente y por el contrario, la pérdida de $c d r 1^{+}$retrasa la mitosis $\mathrm{e}$ incrementa la longitud de las células, se propuso que Cdr1 actúa como un regulador positivo de la mitosis. Parker et al., (1993) demostraron que Cdr1 es una quinasa que inhibe a Wee1 mediante una fosforilación directa. Más adelante, Kanoh y Russell, (1998) identificaron a Cdr2, un homólogo de Cdr1, mediante un escrutinio de sintéticos letales con $c d c 25-22$ a $25^{\circ} \mathrm{C}$. En el mismo sentido que $c d r 1^{+}$, la deleción de $c d r 2^{+}$genera un retraso en la transición $\mathrm{G} 2 / \mathrm{M}$ más severo que la de $c d r 1^{+}$. Estas mismas conclusiones fueron avaladas por Breeding et al., 1998.

A partir de esto, Cdr2 cobró importancia frente a Cdr1 y los mecanismos moleculares de su regulación se dilucidaron con los trabajos de Martin y Berthelot-Grosjean (2009) y Moseley et al., (2009). Sus conclusiones, permitieron identificar una nueva ruta de señalización que acopla la percepción entre el tamaño celular y la división celular en $S$. pombe. Como parte de estos resultados, ambos grupos identificaron a Pom1, una quinasa reguladora de la actividad de Wee1 que actúa por encima de Cdr1/Cdr2. La actividad de Pom1 depende de su abundancia y localización a lo largo del córtex celular, es decir que de acuerdo a su modelo, en una célula pequeña, Pom1 se dispone en un gradiente de concentración que provienen desde los polos, para inhibir a Cdr1 y Cdr2 que se localizan en ese momento en la región media. Pero, cuando la célula alcanza un tamaño óptimo, los niveles descienden, permitiendo que la inhibición de Wee1 por parte de las dos quinasas se lleve a cabo. Entonces, de acuerdo su modelo, Pom1 desde los polos proporciona una medida de la longitud celular para regular la entrada a mitosis mediante la ruta de señalización Pom1-Cdr2-Cdr1-Wee1-Cdc2, la cual constituye una cascada de quinasas que debe apagarse para promover la entrada mitosis. 


\section{Introducción}

Recientemente, se ha identificado una nueva proteína llamada Nod1 cuya función es controlar el tamaño celular en el momento de la división. La deleción de nod1+ genera células alargadas e interacciones genéticas con los reguladores de Wee1. Su papel biológico consiste en reclutar el factor intercambiador de nucleótido de guanina Gef2 y a su vez ensamblarlo en el anillo de citoquinesis. El modelo planteado sugiere que la ruta Gef2-Mid1-BIt1 activa a Wee1 en interfase (Jourdain et al., 2013). Teniendo en cuenta estos estudios y otros, actualmente se sugiere que los factores que coordinan el tamaño celular con la entrada a mitosis, son factores que actúan por encima de Wee1 y a su vez participan en el sitio de división. Entre estos factores, se encuentran Cdr2, Cdr1, Gef2, Klp8, Blt1, Mid1, Nod1, Skb1, Nif1 y Fin1 (Wu y Russell, 1997; Paoletti y Chang, 2000; Morrell et al., 2004; Moseley et al., 2009; Martin y Berthelot-Grosjean, 2009; Ye et al., 2012; Grallert et al., 2012; Jourdain et al., 2013; Deng y Moseley, 2013).

Aunque Wee1 fue identificado por primera vez en S. pombe, pocos estudios han sido realizados sobre su regulación espacio-temporal, en comparación con otros organismos. Wee1 es una proteína nuclear (Aligue et al., 1997), que en la fase G2 tardía se localiza cerca de una estructura homóloga al centrosoma en levaduras, conocida como cuerpo polar del huso (del inglés Spindle Pole Body, SPB). De esta forma, su localización temporal en el SPB tiene como fin mantener inactiva a Cdc2-Cdc13 y a su vez evitar el ensamblaje del huso mitótico (Masuda et al., 2011). Esta última función, es asociada con la inactivación de Plo1 (Polo quinasa), sobre la cual se ha sugerido que podría participar en un sistema de retroalimentación positivo, en el cual Plo1 aumenta la actividad de Cdc25 a través de su propia activación por Cdc2 (Mulvihill et al., 1999; Tanaka et al., 2001), de igual manera como se ha observado en células animales (revisado en Perry y Kornbluth, 2007).

\subsubsection{La quinasa Mik1}

Mik1 fue identificada como una quinasa relacionada a Wee1. Las primeras evidencias genéticas que la situaron como un elemento regulador de la entrada a mitosis fueron, primero que la deleción de $m i k 1^{+}$no manifiesta ningún fenotipo y sin embargo la eliminación de esta en un fondo que carece de actividad Wee1 provoca letalidad (wee150 mik1 $\Delta$ ) y segundo que esta letalidad puede ser rescatada por mutaciones en Cdc2 (Lundgren et al., 1991; Lee et al., 1994). No obstante, a partir de estas evidencias aún se pensaba que Mik1 simplemente sustituía la ausencia de Wee1. 


\section{Introducción}

Más adelante, Mik1 fue catalogada, más que como una proteína redundante a Wee1, como una quinasa cuya función era cooperar con Wee1 para prevenir una entrada prematura a mitosis. En el caso de Wee1, esta controla el acoplamiento entre el tamaño y la división celular, ya que se ha visto que las células de los mutantes wee entran a mitosis más pequeñas. Sin embargo, en el caso de las células mutantes de mik1 $1 \Delta$ esto no sucede. El mutante mik1 $\Delta$ sólo manifiesta fenotipo en ausencia de wee1+, el cual es conocido como catástrofe mitótica (Russell y Nurse, 1986). Esto implica que Mik1 no acopla el crecimiento a la división celular pero si la replicación del ADN a la entrada a mitosis. En apoyo a esta idea, se ha visto que Mik1 es regulada positivamente por el checkpoint del daño en el ADN, incrementando sus niveles a través de la quinasa Chk1 (Baber-Furnari et al., 2000). En la actualidad, se conoce que $m i k 1^{+}$, es un gen que es regulado por el factor de transcripción MCB-DSC1, (del inglés Mlul Cell cycle Box-DNA Synthesis Control), equivalente a E2F en mamíferos, el cual controla la expresión de otros genes en la transición $\mathrm{G} 1 / \mathrm{S}$, con el fin de prevenir una mitosis prematura en las células de S. pombe ( $\mathrm{Ng}$ SS et al., 2001). La reunión de todas estas observaciones ha permitido definir un papel más que secundario para Mik1, en el cual esta inhibe la actividad del complejo Cdc2-Cdc13 a través de la fosforilación de Y15 con el fin de impedir la progresión hacia mitosis mientras la replicación del ADN no esté finalizada. De aquí, que la función de Mik1 se encuentre conservada a lo largo de la evolución, al igual que su expresión periódica en el ciclo celular (Fernández et al., 2012).

\subsubsection{La fosfatasa Cdc25}

Cdc25 es la principal fosfatasa que revierte la fosforilación de la Y15 de Cdc2 por parte de Wee1 y Mik1. Es una proteína esencial y conservada (Russell, et al., 1989; Sadhu et al., 1990; Kakizuka et al., 1991; Millar et al., 1991). Con las primeras observaciones en mutantes termosensibles $c d c 25$-ts, cuyas células mueren bloqueadas en G2 y que a su vez, dicho fenotipo puede ser rescatado por mutantes wee, se despertó el interés sobre Cdc25, como una proteína implicada en el control mitótico en $S$. pombe (Fantes, 1979; Russell y Nurse, 1986; Russell et al., 1989). Cdc25 se acumula en el núcleo en G2 (Moreno et al., 1990; López-Girona et al., 1999). En ausencia de Cdc25, Pyp3 puede compensar su función aunque de forma menos eficiente (Millar et al., 1992).

En Xenopus y humanos, se ha demostrado que la actividad de Cdc25 es regulada a través de fosforilaciones por parte del complejo Cdk-ciclina $\mathrm{B}$ y por quinasas tipo polo, las 


\section{Introducción}

cuales son importantes para iniciar el sistema de retroalimentación positivo de activación de Cdk1 (Hoffmann et al., 1993; Qian et al., 2001). De igual manera, Cdc25 también es regulada por fosforilaciones inhibitorias cuando el ADN está dañado o cuando aún no ha sido replicado en su totalidad. En estos casos, Cdc25 es fosforilada por dos quinasas, Chk1 y Cds1 (Furnari et al., 1997; Zeng et al., 1998), las cuales promueven que Cdc25 sea excluida del núcleo (Kumagai y Dunphy, 1999). En células de mamíferos se ha visto que el complejo 14-3-3 (Rad24 y Rad25) asegura que Cdc25 no sea desfosforilado durante el bloqueo, por lo que la proteína se estabiliza y se inactiva.

En general, la regulación de Cdc25 ha sido estudiada en detalle empleando como modelo biológico a Xenopus y humanos. Recientemente, se han hecho aportes para $S$. pombe en ese sentido. Mediante análisis mutagénicos, se ha evaluado los aportes de las fosforilaciones de la Cdk sobre Cdc25 (Lu et al., 2012). De acuerdo a su modelo experimental y matemático, Cdc25 es fosforilada en múltiples sitios por la Cdk con el fin de dirigir con precisión la entrada a mitosis, pero no regular su abundancia ni su localización.

En relación a la degradación de Cdc25, la fosfatasa Clp1, homóloga a la familia de fosfatasas tipo Cdc14 en mamíferos, desfosforila a Cdc25 a la salida de mitosis, desestabilizándola y dirigiéndola hacia su degradación a través del complejo promotor de la anafase APC (Esteban et al., 2004). En esta degradación también participan las ubiquitina ligasas Pub1 y Pub2, las cuales prolongan la desestabilización de Cdc25 (Nefsky y Beach, 1996; Esteban et al., 2004).

Análisis genéticos en $S$. pombe, han demostrado que existe una conexión entre el control de la entrada a mitosis a través de Cdc25 y la respuesta a estreses ambientales. En respuesta a cambios nutricionales, la MAP quinasa Sty1, componente de la ruta de respuesta a estrés (SRP), es capaz de activar a Cdc25 a través de Polo quinasa en el SPB (Shiozaki y Russell, 1995a; 1995b; Petersen y Nurse, 2007). En este sentido, la SRP induce la fosforilación de Plo1 en la S402, y a su vez promueve el reclutamiento de esta en el SPB (Figura 4). Dicho reclutamiento es mediado por Cut12, de ahí que mutantes deficientes en la actividad de Cdc25 sean capaces de progresar a mitosis por hiperactivación de Cut12 (Petersen y Hagan 2005). En otro contexto, la quinasa Srk1 interactúa con Cdc25 y la fosforila en los mismos sitios de fosforilación que Chk1 y Cds1, provocando la acumulación de esta en el citoplasma en respuesta a estrés osmótico, e 


\section{Introducción}

incluso en un ciclo celular sin perturbaciones (López-Avilés et al., 2005).

\subsection{Los puntos de control (checkpoints) del ciclo mitótico}

El ciclo celular en la levadura de fisión y en la mayoría de los organismos está coordinado por tres puntos de control que residen en la transición G1/S, G2/M y metafase-anafase.

\subsubsection{Transición G1/S}

Este punto de control se sitúa antes de la entrada en fase S. En las levaduras se denomina Start (del inglés, inicio) y en células animales punto de restricción. En este punto se coordina la maquinaria del ciclo celular con el crecimiento y la disponibilidad de nutrientes. El principal regulador de esta fase, es la proteína Rum1, la cual se encarga de inhibir la asociación del complejo Cdc2-Cdc13 y Cdc2-Cig2. Una vez las células alcanzan un tamaño crítico, se produce la degradación de Rum1 y la consecuente progresión hacia fase $S$.

\subsubsection{Transición G2/M}

Debido a que las células de S. pombe pasan el $70 \%$ del ciclo celular en fase G2, esta transición es la más significativa. La fosforilación de la Y15 de la Cdc2 mantiene las células en fase $\mathrm{G} 2$, al menos hasta que repliquen todo el genoma y alcancen un tamaño adecuado. Una vez superado estos requisitos, la desfosforilación de la Cdc2 y a su vez la entrada a mitosis es irreversible. En un ciclo celular sin perturbaciones, el control de tamaño opera muy cerca de la entrada a mitosis y a su vez constituye la interfase de comunicación entre la maquinaria del ciclo celular y el ambiente que rodea a la célula.

\subsubsection{Transición Metafase-Anafase}

La degradación de Cdc13 se inicia cuando se produce el alineamiento correcto de los cromosomas en la placa metafásica. Dicho evento, en conjunto es llevado a cabo por la degradación de securina, que permite la activación de la separasa, para a su vez degradar las cohesinas que mantienen unidas las cromátides hermanas. Este punto de control mitótico asegura que la activación del complejo APC sólo ocurra, una vez todos los tres cromosomas estén unidos adecuadamente al huso mitótico. Una vez superado este punto, la inactivación de la Cdk induce el desensamblaje del huso, la inactivación de 


\section{Introducción}

la maquinaria de segregación cromosómica y por último la descondensación de los cromosomas.

\subsection{Un único oscilador mitótico}

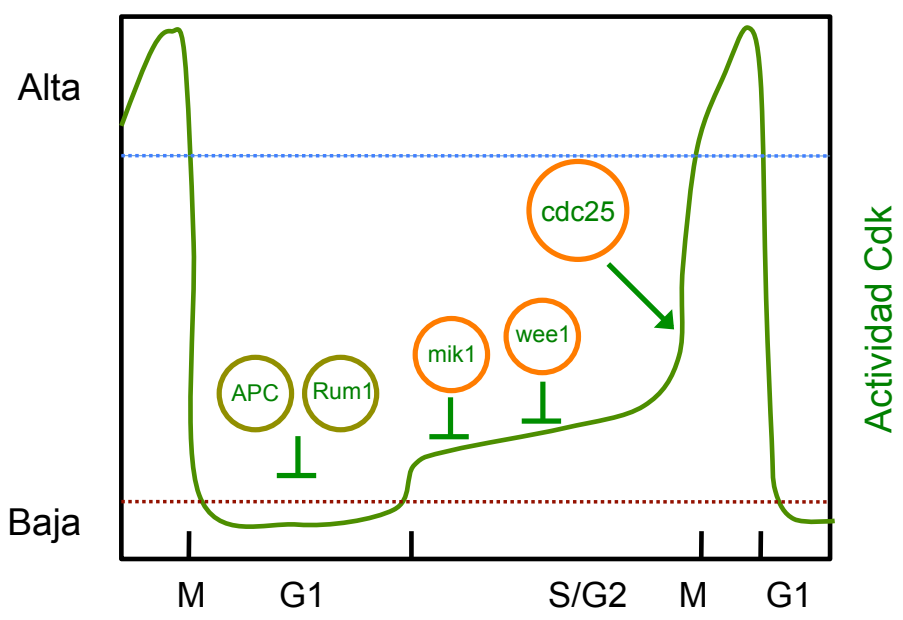

Fases del ciclo celular

Figura 3. Modelo matemático de la actividad de la Cdc2 a lo largo del ciclo celular. En la fase G1, la actividad de la Cdk se mantiene muy baja a través del complejo APC y Rum1 (línea roja). Los niveles de la actividad de la Cdk aumentan levemente por la formación del heterodímero Cdc2-Cdc13, sin embargo se actividad se mantiene reprimida por la acción de Mik1 y Wee1. En la fase G2, la fosfatasa Cdc25 promueve la actividad de la Cdk hasta que alcanza los niveles máximos a la entrada de mitosis (línea azul) (Coudreuse y

En S. pombe, Stern y Nurse (1996) y Coudreuse y Nurse (2010) plantearon un modelo cuantitativo sobre el control de Cdc2 en fase $S$ y mitosis. De acuerdo a este, diferentes niveles de actividad de Cdc2 regulan la progresión del ciclo celular. La fase S se inicia con un incremento de la actividad desde niveles basales a moderados con el fin de activar los orígenes de replicación del ADN. Seguidamente, la formación del complejo Cdc2-Cdc13 inhibe el reinicio de la fase S. En la fase G2, el incremento en cantidad de la Cdc13, eleva la actividad de la Cdk por limitación en sus inhibidores. Finalmente, un sistema de retroalimentación positivo, incrementa los niveles de actividad de la Cdk al máximo y provoca la entrada a mitosis. (Figura 3).

Según este modelo, la Cdk actúa como un oscilador con factores desencadenantes biestables. El término biestable se aplica a los sistemas de regulación, en los cuales la 
retroalimentación tiene el potencial de llevar un sistema de un extremo a otro en poco tiempo. Este proceder como sistema biestable, a su vez atribuye la irreversibilidad de las transiciones, es decir que una vez se alcanza el umbral necesario de actividad, las células ya no pueden evitar la progresión hacia la siguiente fase (revisado en Morgan, 2007). Estudios en relación a esto, sugieren que el sistema de retroalimentación es esencial para evitar que las oscilaciones siguientes se debiliten y por ende se altere el orden y el tiempo del ciclo celular (revisado en Pomerening et al., 2005).

Actualmente en $S$. pombe, se asume que en este sistema biológico se requiere un único oscilador mitótico, formado por el heterodímero Cdc2-Cdc13. El resto de ciclinas son prescindibles para regular este sistema biestable. Para probar esto, Coudreuse y Nurse, 2010, construyeron una proteína fusión Cdc2-Cdc13 regulada transcripcionalmente bajo el promotor de Cdc13, y a su vez delecionaron el resto de ciclinas. Aunque inicialmente, esta proteína aún es regulada por el sistema de proteólisis de la Cdc13, el inhibidor Rum1 y las fosforilaciones inhibitorias de Wee1 y Mik1, ellos demuestran que son innecesarios para promover los ciclos de replicación y mitosis en las células de $S$. pombe, siempre y cuando la actividad catalítica de la proteína fusión aún pueda ser regulable. Dicha regulación sobre la Cdk es posible, si la proteína fusión posee un alelo as (del inglés analog-sensitive), con el cual estos autores observaron que si se manipulan los niveles de la actividad de la Cdk, es posible inducir un ciclo celular con una secuencia de eventos errónea.

En resumen, el ciclo celular de $S$. pombe puede dirigirse con un único complejo Cdc2-Cdc13, sin embargo aún queda abierta la pregunta como un único oscilador podría mantener la conexión entre la división celular y las fluctuaciones en el ambiente extracelular.

\section{Señales que controlan el ciclo celular}

\subsection{Señales nutricionales}

Bajo condiciones ricas en nutrientes, las células de $S$. pombe se dividen; sin embargo cuando se agotan los nutrientes, las células dejan de dividirse y se bloquean en fase G1 y si, conviven en el mismo entorno, células de tipo sexual opuestos, se induce la conjugación y posterior entrada a meiosis. 


\section{Introducción}

Actualmente en la mayoría de eucariotas, se asume que el principal elemento que controla la regulación del ciclo celular como respuesta a cambios nutricionales, es TOR (Target Of Rapamycin). Mediante un análisis genético en $S$. cerevisiae, TOR fue identificado como diana de la rapamicina, una droga empleada para inmunosuprimir pacientes trasplantados (Heitman et al., 1991). El modo de acción de la droga consiste en que, ésta se une a la proteína FKBP12 (Fkh1 en la levadura de fisión) para formar un complejo, que a su vez inhibe a TOR. Las proteínas TOR han sido identificadas en la mayoría de eucariotas, sin embargo las levaduras poseen dos genes TOR (Tor1 y Tor2) y los animales solo uno (revisado en Jacinto, 2008). Tanto en levaduras como en mamíferos, las proteínas TOR forman parte de los complejos conocidos como TORC1 y TORC2 (Hara et al., 2002; Kim et al, 2002). Los componentes de cada complejo son resumidos en la Tabla 2.

Tabla 2. Componentes de TORC1 y TORC2 en levaduras y mamíferos

\begin{tabular}{l|l|l|l}
\hline & S. pombe & S. cerevisiae & Mamíferos \\
\hline TORC1 & Tor2 & TOR1 o TOR2 & mTOR \\
& Mip1 & KOG1 & Raptor \\
& Wat1/Pop3 & LST8 & mLST8 \\
& Tco89 & TCO89 & --- \\
& Toc1 & --- & --- \\
\hline TORC2 & --- & --- & PRAS40 \\
& Tor1 & TOR2 & mTOR \\
& Sin1 & AVO1 & hSIN1 \\
& --- & AVO2 & --- \\
& Ste20 & AVO3 & Rictor \\
& Wat1/Pop3 & LST8 & mLST8 \\
& Bit61 & BIT61 & PRR5 \\
\hline
\end{tabular}

Información obtenida en Otsubo y Yamamato, 2008.

En la levadura de fisión, TORC1 regula procesos como traducción, biogénesis de ribosomas, autofagia, transcripción y metabolismo, mientras que TORC2 regula la organización de la actina. TORC1, es sensible a rapamicina y TORC2 no. En general, la rapamicina no inhibe el crecimiento celular en $S$. pombe, pero sí afecta la conjugación, aunque no la entrada a fase estacionaria (Weisman et al., 1997). El gen tor $1^{+}$, no es esencial, sin embargo, su deleción genera células alargadas y no permite que las células se bloqueen bien en fase $\mathrm{G} 1$, generando esterilidad. Tanto en mamíferos como en $S$. cerevisiae, se ha identificado el módulo de señalización TOR-PDK1-AGC quinasa, el cual es necesario para promover el crecimiento y el desarrollo sexual bajo situaciones de 
estrés. Dicho módulo en S. pombe, está compuesto por Tor1-Ksg1 (PDK1 homólogo) y Gad8 (AGC quinasa) (Matsuo et al., 2003). Por el contrario, el gen Tor2, si es esencial para crecimiento vegetativo. Los mutantes termosensibles tor2-ts se bloquean en fase G1 a temperatura restrictiva, independiente del medio de crecimiento, y en un fondo sexual homotálico su inactivación induce la conjugación prematuramente (Alvarez y Moreno et al., 2006; Uritani et al., 2006; Weisman et al., 2007; Matsuo et al., 2007). Asimismo, las GTPasas de la familia Rag han sido implicadas en la activación de TORC1 en Drosophila y mamíferos en respuesta a aminoácidos. En $S$. pombe, un ejemplo de esto es la GTPasa Rhb1 (homólogo de Rheb) la cual aumenta la actividad de Tor2, al igual que en células de eucariotas superiores. La ausencia de Rhb1 induce bloqueo en la fase G1 y la expresión de genes necesarios para la conjugación, debido a que se inactiva Tor2 (Matsuo et al., 2007; Mach et al., 2000). Otro ejemplo de esto, son las GTPasas Gtr1 y Gtr2, previamente activadas por el factor intercambiador de nucleótido de guanina (GEF) Vam6, las cuales estimulan el crecimiento e inhiben la diferenciación sexual a través de la activación de Tor2 (Valbuena et al., 2012). A partir de esto, se deduce que existe un módulo de activación de TOR conservado evolutivamente en los eucariotas.

De acuerdo a lo anterior, Tor1 y Tor2 parecen tener funciones opuestas. En apoyo a esta idea, en un análisis de expresión del mutante tor2-ts, se observó un incremento en la expresión de genes codificantes para permeasas y transportadores (Matsuo et al., 2007) mientras que en el doble mutante tor1 $\Delta$ tsc $2 \Delta$ se redujo la expresión de los mismos (Weisman et al., 2007), por lo que se propuso de igual forma, que Tor1 junto con Tsc1/2 regulan positivamente la incorporación de aminoácidos, mientras que Tor2 la regula negativamente. Sin embargo, otros resultados como que la ausencia de una no suprime el defecto de la otra, y que el fenotipo del doble mutante resulta en un efecto aditivo, sugiere que sus funciones podrían estar coordinadas (Ikai et al., 2011).

Actualmente, en $S$. pombe se asume que la ruta de respuesta a estrés MAPK (SRP) conecta la señalización TOR y la progresión mitótica. Dicha conexión es relevante en el control de la entrada a mitosis, dependiente del estado nutricional de las células. Cuando las células de $S$. pombe, son transferidas desde una fuente rica en nitrógeno (glutamato) a una pobre (prolina), la actividad Tor1 se reduce y a su vez se induce la activación de Sty1 para promover entrada a mitosis a través de la activación de Cdc25 y Cdc2. Esto significa que las células proliferan, a través de la actividad de Tor1. Dicha actividad es llevada a cabo como parte del complejo TORC1, siendo la inhibición de Tor1 la que 


\section{Introducción}

promueve la entrada a mitosis bajo estrés nutricional (Figura 4) (Pertersen y Nurse, 2007; Hartmuth y Petersen, 2009).

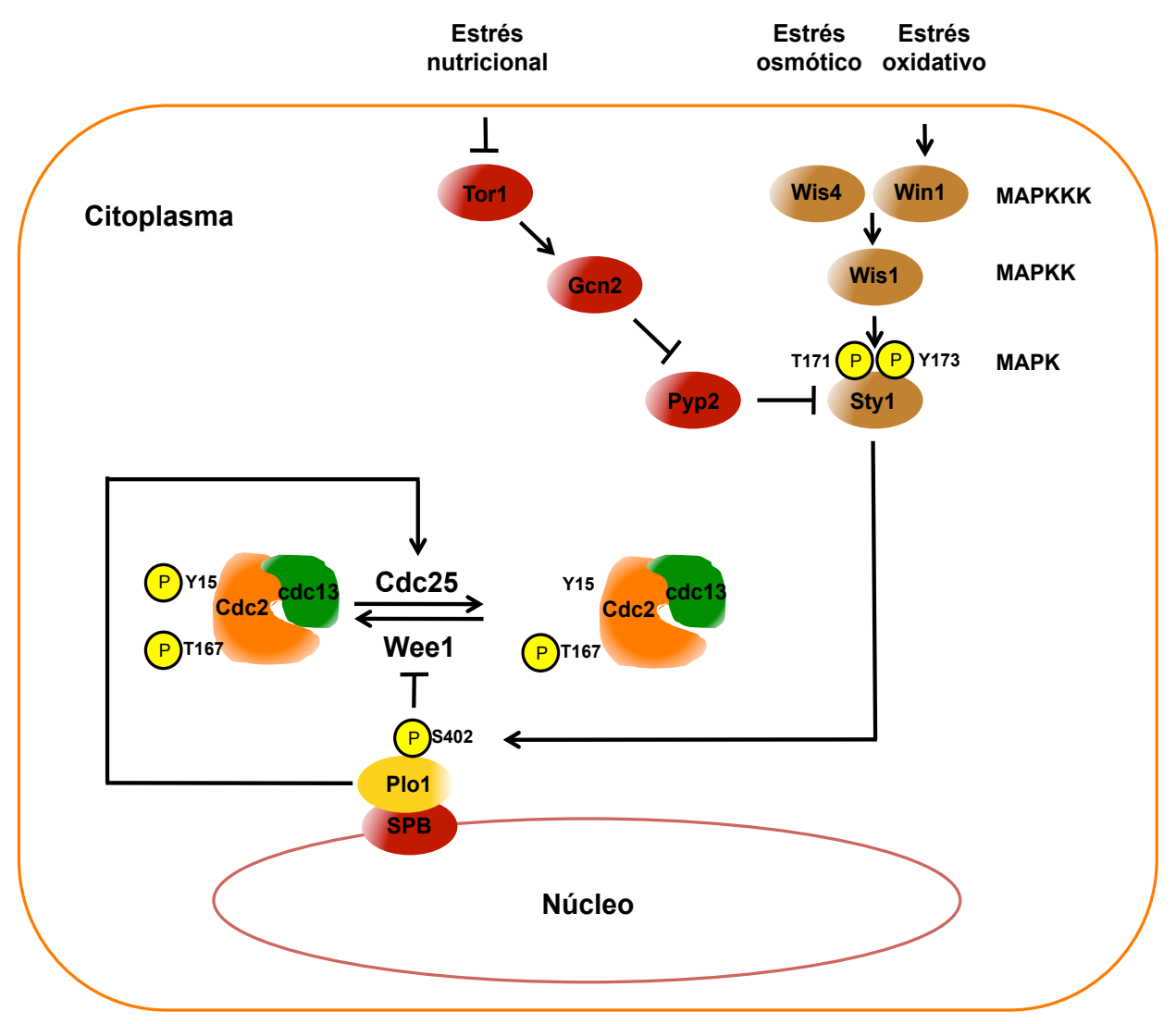

Figura 4. Señales que controlan el ciclo celular de S. pombe. Como respuesta a cambios en la fuente de nitrógeno, el complejo TORC1 (Tor1) activa la quinasa Sty1 para favorecer la entrada a mitosis a través de la activación de Plo1 y Cdc25 en el SPB. Como respuesta a otros tipos de estrés, la cascada de MAP quinasas activa a Sty1 para favorecer la progresión mitótica de la misma forma.

La privación de nitrógeno también induce el estado de quiescencia, conocido también como estado $\mathrm{G} 0$, en el caso de que no haya células de tipo sexual opuesto. En $S$. cerevisiae, se conoce que TORC1 y PKA, son los elementos claves que regulan este estado y a su vez determinan la esperanza de vida o CLS (del inglés Chronological LifeSpan) de las células. Un descenso en la actividad de TORC1 y de la proteína quinasa A (PKA), causan un cese en el crecimiento junto con la entrada a quiescencia. Igualmente, las quinasas Snf1 y Pho85 actúan como reguladores de este programa celular (Wilson et al., 1996; Wanke et al., 2005). En S. pombe, la conexión molecular entre las rutas dependientes de la limitación de nitrógeno y/o glucosa y quiescencia permanecen poco exploradas. Sin embargo, dos trabajos recientes en el campo, sugieren 
una conservación de los mecanismos moleculares del control de la quiescencia en ambos organismos. Zuin et al., 2010 proponen que la activación de Sty1, dependiente de TORC1 y PKA es indispensable para prolongar la esperanza de vida de las células de $S$. pombe y Matsuzawa et al., 2012, sugieren que Ssp2, la quinasa homóloga a Snf1, también actúa en la levadura de fisión, como un regulador del programa de transcripción dependiente de glucosa en fase exponencial.

De igual manera, PKA también cumple un papel importante en la coordinación del crecimiento y la división celular en $S$. pombe. PKA es una serina/treonina quinasa, cuya actividad depende de la concentración de AMP cíclico (cAMP). En general, los niveles de cAMP son altos cuando las células están creciendo exponencialmente y estos a su vez, dependientes de la adenilato ciclasa, una enzima que se encarga de catalizar la reacción de ATP (adenosin trifosfato) a AMPc. A altas concentraciones de cAMP, éste se une a la subunidad reguladora del complejo PKA, provocando la liberación de esta y exponiendo a su vez el sitio activo de la subunidad catalítica. Por el contrario, a bajas concentraciones de cAMP, la enzima permanece intacta y la subunidad catalítica continúa unida a la subunidad reguladora. En S. pombe, la adenilato ciclasa es codificada por el gen $c y r 1^{+}$y en el caso del complejo PKA, la subunidad catalítica es codificada por el gen pka $1^{+}$y la reguladora por $\operatorname{cgs} 1^{+}$(Maeda et al., 1990; Maeda et al., 1994). Los mutantes deficientes de $p k a 1^{+}$y $c y r 1^{+}$presentan células más pequeñas e inician su programa de desarrollo sexual incluso en medio rico (Kawamukai et al., 1991; Valbuena y Moreno, 2010). Por el contrario, los mutantes de deleción cgs1 $\triangle$ son estériles, ya que la actividad de PKA en estos mutantes es constitutivamente activa.

Cuando los niveles de glucosa son limitantes se inactiva PKA. Las células de $S$. pombe presentan un fenotipo semi-wee cuando las células crecen a una concentración de glucosa equivalente a las concentraciones de azúcar en la sangre de los humanos (4 $\mathrm{mM} ; 0,08 \%$ ). Cuando la glucosa se reduce hasta niveles de inanición (de 2,2 a 1,7 mM de glucosa disponible), se induce la entrada a quiescencia. Si la reducción de glucosa es progresiva, las células prolongan más su esperanza de vida (CLS) tras la quiescencia que aquellas sometidas a un cambio abrupto (revisado en Pluskal et al., 2011). La quinasa Ssp1, homóloga de la quinasa dependiente de calcio y calmodulina en mamíferos (CaMK) junto con Sds23, un inhibidor de la fosfatasa tipo $2 \mathrm{~A}$ y la relativa Ppe1, se han propuesto como elementos que actúan aguas abajo de la actividad de PKA en S. pombe, y que son necesarios para sobrellevar la proliferación celular bajo limitación 


\section{Introducción}

de glucosa y a su vez extender la viabilidad de la fase estacionaria (Hanyu et al., 2009; Jang et al., 2013).

\subsection{Respuesta a estrés}

Sty1 también cumple un papel en el control del ciclo celular frente a otros tipos de estrés ambiental tales como radiación UV, estrés osmótico, oxidativo, entre otros (Figura 4) (revisado en Petersen, 2009 y Pérez y Cansado, 2010). La activación de Sty1, en este contexto, está a cargo de dos reguladores aguas arriba de la MAPKK Wis1, llamados Wis4/Wak1 y Win1. Las células que carecen de estos reguladores, son incapaces de proliferar bajo estas condiciones de estrés (Shieh et al, 1998). De esta forma, la cascada de quinasas Wis4-Win1-Wis1 (Módulo MAPK) controlan la activación de Sty1 en respuesta a varios tipo de estrés, pero no en respuesta a estrés nutricional, ya que se ha visto que en esta última caso su activación es dependiente de la quinasa Gcn2 y la fosfatasa específica de tirosinas Pyp2 (Petersen y Nurse, 2007). Bajo estrés térmico, la activación de Sty1 depende de la inhibición transitoria de otra fosfatasa de la misma familia, Pyp1. Después del estrés, para retornar a los niveles basales de Sty1, otras fosfatasas, pertenecientes a la familia tipo $2 \mathrm{C}$, Ptc1 y Ptc3, se encargan de inactivar a Sty1 mediante la desfosforilación de la T171 (Nguyen et al, 1999).

La activación de Sty1 ante situaciones de estrés es necesaria, no solo porque reajusta la progresión del ciclo celular y permite la adaptación de las células al estímulo, sino también porque induce la expresión de genes indispensables para la respuesta al estrés CESR (del inglés Core Environmental Stress Response), los cuales son dependientes de la actividad del factor de transcripción Atf1 (Takeda et al., 1995; Chen et al., 2003).

\section{Antagonistas de la actividad Cdk-ciclina}

En un sistema biestable, como el mencionado anteriormente, debe existir un evento de fosforilación y uno de desfosforilación que regule la estabilidad del mismo y su vez determine el estado de actividad de los sustratos implicados. La fosforilación de una proteína es un evento que debe ocurrir con rapidez y a su vez debe ser reversible. Este mecanismo requiere menos consumo energético que otros con síntesis y degradación, 


\section{Introducción}

por lo que la célula utiliza este sistema como uno de los principales de regulación para el ciclo celular, el crecimiento, el desarrollo, la supervivencia, etc. (revisado en Novak et al., 2010).

La entrada y la salida de mitosis en $S$. pombe, es un buen ejemplo de procesos celulares que se basan en eventos de fosforilación y desfosforilación. Durante décadas, la regulación de esta transición se ha centrado en el papel de las Cdks y las ciclinas, sin embargo ciertos estudios han sugerido un papel importante para las proteínas fosfatasas, como antagonistas de la Cdk. En este contexto, la actividad de la Cdk, no sólo induce la entrada a mitosis sino que también dirige la condensación de los cromosomas, la formación del huso mitótico, la unión de los cromosomas al mismo y finalmente la activación del complejo APC, que se mantiene inactivo por el SAC (del inglés Spindle Assembly Checkpoint) mediante la inhibición de Cdc20, otro componente del APC. Cuando los cromosomas se han alineado correctamente, se libera Cdc20 y se activa APC, el cual inicia una serie de eventos que permiten la salida de mitosis, incluyendo una oleada de desfosforilación, en parte dirigida por la degradación de Cdc13 y a su vez inactivación del complejo Cdc2-Cdc13. Por otra parte, durante esta salida, proteína fosfatasas terminan de contrarrestar la actividad de CDK, revirtiendo la fosforilación de sus sustratos.

Durante la última década, empleando diferentes modelos biológicos, se han realizado importantes avances en la definición de las funciones de las principales familias de fosfatasas, incluyendo la fosfatasa serina/treonina PP1 y PP2A y las fosfatasas específicas de tirosinas Cdc14, que podrán contribuir a la desfosforilación de los sustratos de la Cdk.

\subsection{Fosfatasa tipo 2A (PP2A)}

La proteína fosfatasa tipo 2A o PP2A cumple funciones en la regulación de múltiples procesos como crecimiento celular, diferenciación, respuesta al daño del ADN y regulación de la progresión mitótica, siendo una de las fosfatasas más abundantes de células animales (revisado en Wurzenberger y Gerlich, 2011). Las holoenzimas PP2A comprenden una familia de serina/treonina fosfatasas, las cuales se componen de una subunidad catalítica $(C)$, una subunidad estructural $(A)$ y una subunidad reguladora (B) (Janssens et al., 2008). Hasta ahora, en humanos se han identificado dos subunidades $C$ 


\section{Introducción}

( $\alpha$ y $\beta$ ), dos A ( $\alpha$ y $\beta$ ) y cuatro familias de subunidades B: B55/B, B56/B', B" (PR72) y B'" (PR93) (Eichnorn et al, 2009). En S. pombe se han identificado dos subunidades catalíticas ppa $2^{+}$y $p p a 1^{+}$(Kinoshita et al, 1990), una subunidad estructural esencial paa $1^{+}$ y tres reguladoras $p a b 1^{+}$, par1 $1^{+}$y par2 ${ }^{+}$(Kinoshita et al., 1996) (Jiang y Halberg, 2000). De forma similar a las quinasas, estas fosfatasas poseen una subunidad catalítica (C) y una reguladora $(B)$, junto con una estructural $(A)$. Su actividad es regulada en función de la subunidad reguladora asociada y de eventos de fosforilación y metilación de la subunidad catalítica (Janssens y Goris, 2001) y en humanos se han identificado más de 70 complejos PP2A.

En vertebrados, el complejo PP2A-B56-Shugosina colocaliza en la región pericentromérica con el fin de mantener desfosforilado el anillo de cohesinas hasta la transición metafase-anafase y por consiguiente mantener unidas las cromátides hermanas (Hauf et al., 2005; Kitajima et al., 2006; Tang et al., 2006).

En S. cerevisiae, la salida de mitosis es controlada por el complejo PP2A-Cdc55, el cual promueve la retención de Cdc14 en el nucléolo mediante la desfosforilación transitoria de Net1 (Yellman et al., 2006). Cdc14 es una fosfatasa dual encargada de dirigir la salida de mitosis a través de la inactivación directa de Cdk1 y a su vez de la desfosforilación de múltiples sustratos, previamente fosforilados por esta última, como reguladores del huso mitótico (Ase1), el complejo pasajero del cromosoma (Sli15) y el complejo APC/Cdc20 (Visintin et al., 1998; Higuchi et al., 2005; Mirchenko et al., 2010). La función de Cdc14 no parece estar conservada en otros organismos, ya que en la levadura de fisión, el homólogo de Cdc14, Clp1/Flp1 contribuye al control de la citoquinesis y a la inactivación de Cdc25 (Cueille et al., 2001; Esteban et al., 2004).

En células animales, se ha observado in vitro que el complejo PP2A-B55ס revierte fosforilaciones de Cdk1 (Mochida et al., 2009). La inactivación de PP2A durante mitosis fue observada por primera vez en extractos de Xenopus laevis y mas tarde fue confirmada en células humanas, sugiriendo que su actividad también es regulada. Un elemento clave de la regulación de la actividad de PP2A es la quinasa Greatwall, cuyo homólogo en mamíferos es conocido como MASTL (del inglés Microtubule-Associated Ser/Thr kinase-Like). Greatwall regula la actividad de PP2A-B55ס indirectamente, mediante la fosforilación de dos proteínas conocidas como Ensa y Arrp19, las cuales se unen al complejo y lo inhiben. Esto, induce dos eventos, por un lado la disminución de la 


\section{Introducción}

la actividad de la fosfatasa, y por ende la fosforilación de múltiples sustratos necesarios para la progresión hacia mitosis, y por otro lado la amplificación del sistema de retroalimentación positivo de la Cdk1-ciclina B (Gharbi-Ayachi et al., 2010; Mochida et al., 2010; Manchado et al., 2010; Wang et al., 2011).

En S. pombe se ha identificado a PP2A como una fosfatasa con múltiples funciones que incluyen regulación de la progresión hacia mitosis (Kinoshita et al., 1990), de la citoquinesis (Jiang et al., 2001; Lahoz et al., 2010; Goyal y Simanis, 2012), de la segregación de los cromosomas (Kitajima et al., 2006) y de la morfogénesis (Kinoshita et al., 1996).

\subsection{Fosfatasa tipo 1 (PP1)}

PP1 es otra de las fosfatasas mas abundantes en células animales y regula procesos como metabolismo del glicógeno, transcripción, polaridad celular, daño en el ADN y progresión del ciclo celular entre otros. Para su función es necesaria la formación de un heterodímero que contiene una de las cuatro isoformas, presentes en células animales, como PP1a, PP1 $\beta$, PP1y1 y PP1y2 junto con una de las múltiples subunidades reguladores existentes. En células humanas se han identificado cerca de 180 complejos PP1 (revisado en Wurzenberger y Gerlich, 2011). En este caso, la subunidad reguladora determina su especificidad de sustrato, su localización y su actividad fosfatasa (Virshup y Shenolikar, 2009).

En extractos de huevos de Xenopus y en células de ratón inmunodeplecionados para PP1, se ha descrito un retraso en la desfosforilación de los sustratos de CDK, sugiriendo un papel directo de PP1 como antagonista de la actividad CDK en salida de mitosis. Por otro lado, tanto en humanos como en Xenopus, se ha observado que las subunidades catalíticas de PP1a y PP1y1 son negativamente reguladas por la $\mathrm{Cdk}$, indicando un sistema de regulación conservado. Cuando la actividad Cdk es reducida, PP1 promueve una salida prematura de mitosis, ya que PP1 es capaz de autodesfosforilarse y liberarse de su inhibidor conocido como inhibidor 1 (Wu et al., 2009). Debido a que en experimentos de copurificación de sustratos de Cdk, a partir de células de Xenopus o mamíferos, se ha observado interacción con PP2A pero no con PP1, es posible que su papel sea coordinar la actividad de PP2A más que desfosforilar sustratos Cdk directamente (revisado en Wurzenberger y Gerlich, 2011). 


\section{Introducción}

PP1 se ha propuesto como un potencial activador de la actividad de la PP2A-B55 en la ruta Greatwall-Ensa-Arrp19, ya sea como activador directo de esta o como inhibidor de Greatwall y sus dianas, sin embargo esto aún no ha sido evaluado experimentalmente (revisado en Domingo-Sananes et al., 2011).

El homólogo de PP1 en S. pombe, Dis2 se ha asociado a diferentes funciones como segregación de los cromosomas, reinicio del ciclo celular tras la activación del checkpoint del daño en el ADN y recientemente en la inhibición de la progresión hacia mitosis, sobre la cual se ha propuesto que Dis2 se encarga de mantener las células en fase G2 hasta que estén preparadas para dividirse, mediante el silenciamiento de la actividad del SPB, lugar dónde se generan señales importantes para la activación del sistema de retroalimentación de la Cdk (por ej. Plo1, Cdc25) (Grallert et al., 2013). Esta última función, sugiere que PP1 más que un antagonista de la Cdk, es un cooperador que favorece que esta alcance sus niveles mas altos de actividad.

Debido a la variabilidad y redundancia de los complejos fosfatasas observada en diferentes modelos biológicos, todavía no es posible pensar en que exista un único complejo fosfatasa que se encargue de regular la progresión del ciclo celular, en un sentido opuesto al de los complejos Cdk-ciclinas. 


\section{Objetivos}


Objetivos

1. Identificar la red de interacciones genéticas con $c d c 2$ y wee1 mediante un escrutinio masivo de sintéticos letales (SGA), generados tras el cruce de la colección de mutantes de deleción de $S$. pombe con los mutantes wee1-50 y $c d c 2-3 w$.

2. Caracterizar la ruta Greatwall-Ensa-PP2A en S. pombe. 


\section{Resultados Apartado I}




\section{Identificación de una red de interacciones genéticas asociadas al ciclo celular en S. pombe}

En organismos eucariotas, el ciclo celular está regulado por una red de proteínas que aseguran el orden y la direccionalidad de los eventos de la división celular. Esta red de proteínas incluye principalmente a las ciclinas y quinasas dependientes de ciclinas (Cdks).

La levadura de fisión, $S$. pombe, posee una única y esencial Cdk, llamada Cdc2, que se asocia a cuatro diferentes ciclinas (Puc1, Cig1, Cig2, y Cdc13) dependiendo de la fase del ciclo (Hagan et al., 1988; Bueno et al, 1991; Bueno y Russell, 1993; MartínCastellanos et al., 2000). Sin embargo, se ha descrito que Cdc13 es la única ciclina esencial para dirigir la ejecución completa del ciclo celular en este organismo (Fisher y Nurse, 1996; Martín-Castellanos et al., 2000; Coudreuse y Nurse, 2010).

En general, en G2, Cdc2 se asocia a Cdc13 para promover la entrada a mitosis (Moreno et al., 1989). Durante la fase $S$ y la $G 2$ temprana, la actividad del complejo Cdc2/Cdc13 se mantiene reprimida por la fosforilación en el residuo de la Y15, por parte de las quinasas Mik1 y Wee1 (Gould y Nurse, 1989; Featherstone y Russell, 1991; Lundgren et al., 1991). Durante la fase G2 tardía, la fosfatasa Cdc25 desfosforila a Cdc2 en la Y15 y activa el complejo Cdc2-Cdc13, induciendo así la entrada en mitosis (Enoch y Nurse, 1991; Millar et al., 1991). Más adelante, en anafase, Cdc13 se degrada por del complejo APC/Ste9, que mantiene bajos los niveles de Cdc13 (Blanco et al., 2000). Igualmente, para mantener las células en fase $\mathrm{G} 1$ y evitar una entrada prematura en fase $\mathrm{S}$, el inhibidor Rum1 se une físicamente a Cdc2 (Moreno y Nurse, 1994; Correa-Bordes y Nurse, 1995). Finalmente, cuando las células alcanzan un tamaño adecuado, se produce la inactivación de Ste9 y la degradación de Rum1, permitiendo una nueva formación del complejo Cdc2-Cdc13 y una nueva ronda del ciclo celular mitótico (Benito et al., 1998; Kitamura et al., 1998; Blanco et al., 2000).

Lo anteriormente descrito constituye en $S$. pombe la capa primaria de regulación de la maquinaria central de su ciclo celular. No obstante, existen capas secundarias que conectan ésta maquinaria con otros procesos celulares que aún no han sido plenamente 


\section{Resultados-Apartado I}

descritas.

\subsection{Escrutinio masivo de sintéticos letales (SGA)}

El primer objetivo de este trabajo fue identificar y caracterizar una red de interacción genética global conectada directamente con la maquinaria del ciclo celular de S. pombe. Para abordar este objetivo, se empleó la técnica de genómica funcional Synthetic Genetic Array (SGA) Analysis (Tong et al., 2001; Dixon et al., 2008; Dixon et al., 2009) y que en este estudio denominamos Escrutinio Sistemático de Sintéticos Letales (SGA), con el fin de identificar genes cuyos productos están relacionados funcionalmente con el sistema Wee1-Cdc2-Cdc25.

Como punto de partida, se utilizaron dos mutantes de interés (del inglés query mutant) y 3346 mutantes diana (del inglés target mutant), los cuales sirvieron como herramienta en la construcción sistemática de los dobles mutantes necesarios para el análisis global de las interacciones sintéticas genéticas. En particular, se emplearon como cepas de interés los mutantes de ciclo celular wee1-50 y cdc2-3w de $S$. pombe (Fantes, 1981; Russell y Nurse, 1986) y como cepas diana la colección de mutantes de deleción no esenciales de $\boldsymbol{S}$. pombe v3.0, generada por el consorcio KRIBB-BioneerCRUK (Kim et al., 2010; Spirek et al., 2010).

Dado que la colección de mutantes de deleción fue construida con el marcador de selección kanMX4, con el fin de facilitar la selección de los dobles mutantes, se construyeron las cepas de interés wee1-50:natMX6 leu1-32 (S2147) y cdc2-3w:natMX6 (S2165) con el gen marcador natMX6, que confiere resistencia al antibiótico nourseotricina en $S$. pombe. Adicionalmente, para descartar problemas de crecimiento 0 de conjugación de los mutantes cepas diana, se construyó la cepa wee1 $1^{+}$:natmX6 leu1-32 (S2176) y se utilizó como control.

Inicialmente, para obtener la matriz de dobles mutantes las cepas de interés fueron cruzadas con los 3346 mutantes de deleción no esenciales, que representan el $68 \%$ de los marcos de lectura abierta que codifican para una proteína en el genoma y el $93,5 \%$ de los genes no esenciales de S. pombe (Kim et al., 2010). Seguidamente, se llevaron a cabo una serie de pasos que incluyeron: i) enriquecimiento de esporas a través de la eliminación de parentales haploides y diploides mediante estrés térmico, ii) germinación y 
iii) dos rondas de selección de los dobles mutantes en medio líquido y sólido con G418 y ClonNat, con el fin de potenciar la selección (Ver Figura 1, sección 3.2.11 de Materiales y Métodos). En el caso de los cruces con el mutante wee1-50, el último paso de selección sobre agar se realizó a temperatura permisiva $\left(25^{\circ} \mathrm{C}\right)$ y temperatura restrictiva $\left(35^{\circ} \mathrm{C}\right)$ con el fin de evaluar el efecto de la inactivación de la quinasa wee1+, mientras que en el caso de los cruces con el mutante $c d c 2-3 w$ se llevo a cabo a $25^{\circ} \mathrm{C}$. Los dobles mutantes producto del cruce control se seleccionaron a ambas temperaturas.

\subsection{Estimación del crecimiento relativo (RG) e identificación del espectro de las interacciones genéticas}

Tras lo anterior, se obtuvieron matrices con los dobles mutantes ordenados en 96 puntos por cuadruplicado, lo cual aportó reproducibilidad a los resultados finales del escrutinio. A partir de estas matrices, se estimó visualmente el crecimiento de los dobles mutantes en comparación con su respectivo cruce control. La estimación relativo del crecimiento de los dobles mutantes se realizó en función de la densidad de la colonia y se definió teniendo en cuenta el crecimiento de cada mutación implicada (por ej. crecimiento de la cepa diana versus crecimiento de la cepa de interés) (Mani et al., 2008; Phillips, 2008). Para esto, en primer lugar se asignó un valor de crecimiento a cerca de 17.000 colonias que correspondieron a los dobles mutantes producto de las cinco selecciones efectuadas en el escrutinio. El crecimiento se cuantificó mediante una escala arbitraria de puntuación que abarcó un rango entre cero y cinco, siendo cero el valor para un crecimiento tipo silvestre y cinco para un crecimiento nulo. Una vez estimados estos valores, se calculó el crecimiento relativo de los dobles mutantes, mediante una comparación cuantitativa entre el valor de crecimiento del mutante doble y el mutante diana, producto del cruce entre las cepas de la colección de mutantes de deleción y la cepa silvestre, dónde el crecimiento del mutante doble (CMD) fue restado al crecimiento del mutante sencillo (CMS), tomando en consideración la misma temperatura de incubación para ambos crecimientos. Tras la aplicación del algoritmo RG (del inglés relative growth), se obtuvo un rango de puntuación que delimitó el espectro de interacciones genéticas esperadas. Dicho rango comprendió valores negativos y positivos desde cero, con un máximo de cinco en ambos casos. En la Figura 1, se resume la estrategia empleada para identificar las interacciones genéticas. La interpretación de estos valores se hizo de acuerdo a los modelos propuestos por Mani et al., 2008 y Phillips et al., 2008. De tal manera que los valores negativos se obtuvieron cuando el doble 


\section{Resultados-Apartado I}

mostró un defecto en el crecimiento más extremo que el esperado, y los positivos cuando el doble mutante manifestó un crecimiento más rápido, clasificándose los primeros como sintéticos letales y sintéticos enfermos, y los segundos como supresores, que el esperado y se definieron como supresores.

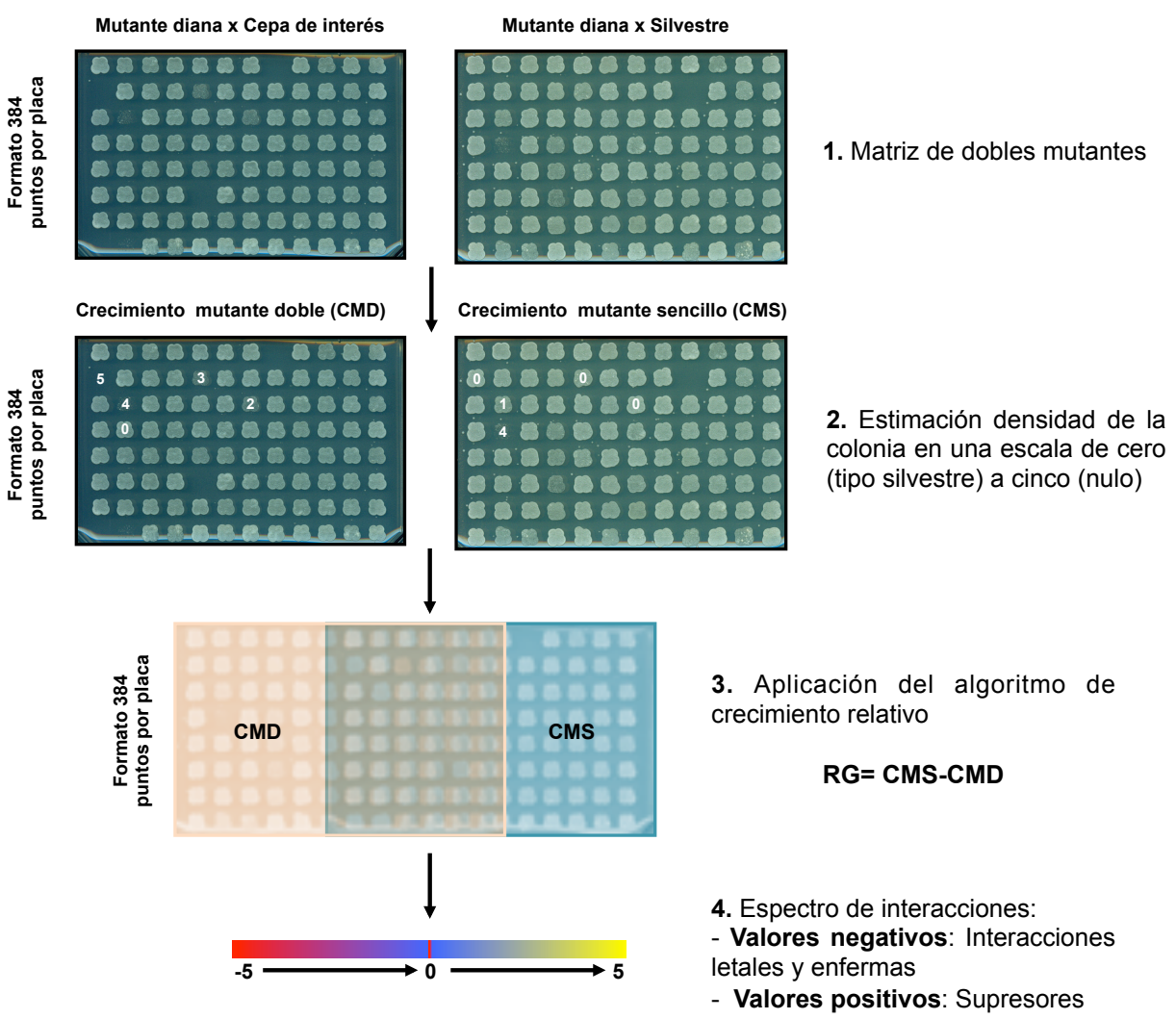

Figura 1. Estrategia empleada para la identificación de los genes con interacciones negativas y positivas con wee1-50 y cdc2-3w. Para esto, i) se construyeron las matrices con los dobles mutantes en formato de 384 puntos por placa a partir de los cruces entre los mutantes wee1-50 y cdc2-3w y los 3346 mutantes de deleción no esenciales de $S$. pombe, junto con el cruce control; ii) se estimó la densidad de la colonia empleando una escala arbitraria de cero a cinco, siendo cero un crecimiento silvestre y cinco un

La interpretación de estos valores se hizo de acuerdo a los modelos propuestos por Mani et al., 2008 y Phillips et al., 2008. De tal manera que los valores negativos se obtuvieron cuando el doble mutante mostró un defecto en el crecimiento más extremo que el esperado, y los positivos cuando el doble mutante manifestó un crecimiento más rápido, clasificándose los primeros como sintéticos letales y sintéticos enfermos, y los segundos como supresores, que el esperado y se definieron como supresores.

\subsection{Validación de resultados y normalización de los valores de crecimiento}




\section{Resultados-Apartado I}

La versión 3.0 de la colección de mutantes de deleción de S.pombe está comprendida por la versión 2.0 que incluye 3005 mutantes y la versión Upgraded que incluye 341 nuevos mutantes y 206 mutantes reconstruidos, que en su totalidad corresponden a los 3346 mutantes de deleción de la versión mas actual que existe hasta el momento.

Para la realización del escrutinio, se dividió la v2.0 en tres grupos y junto con la versión Upgraded, se ejecutó la primera ronda del escrutinio en 4 fases. De los 3346 mutantes de deleción escrutados, se identificaron 677 mutantes, que en combinación con el mutante wee1-50 o cdc2-3w o ambos, manifestaron un fenotipo en la viabilidad celular alterado (Figura 2). En el caso de las cepas redundantes entre la v2.0 y la Upgraded, el valor de crecimiento por duplicado fue tenido en cuenta para determinar el efecto de la reconstrucción de las cepas sobre las interacciones.

En general, las interacciones fueron corroboradas repitiendo el SGA por duplicado (Figura 2). Los 677 mutantes se redistribuyeron manualmente en una nueva matriz de 96 pocillos y tras dos rondas de validación, se analizó el crecimiento relativo obtenido en cada caso. Para corregir sistemáticamente el sesgo en las observaciones e identificar los posibles falsos negativos o falsos positivos presentes, se tuvo en cuenta la reproducibilidad en las mediciones y la influencia de diferentes factores experimentales definidos para escrutinios de sintéticos letales a gran escala (Collins et al., 2006; Baryshnikova et al., 2010; Wagih et al., 2013).

Los factores tenidos en cuenta en este estudio incluyen: i) efecto de la ejecución del escrutinio por fases (en inglés specific batch effects), ii) efecto de genes ligados, donde los dobles mutantes son raramente generados, iii) efecto del crecimiento cerca de colonias con una interacción negativa, donde las colonias tienen un mayor acceso a los nutrientes, exhibiendo un crecimiento mas rápido (en inglés effect of neighbouring mutant) y iv) efecto de borde, donde las colonias tienen mayor acceso a nutrientes y crecen mejor en comparación con las colonias del centro (en inglés plate edge effect). Asimismo, se tuvo en cuenta la coherencia entre los datos de crecimiento en líquido en YES y YES con G418 de las cepas de la colección y el cruce control. 


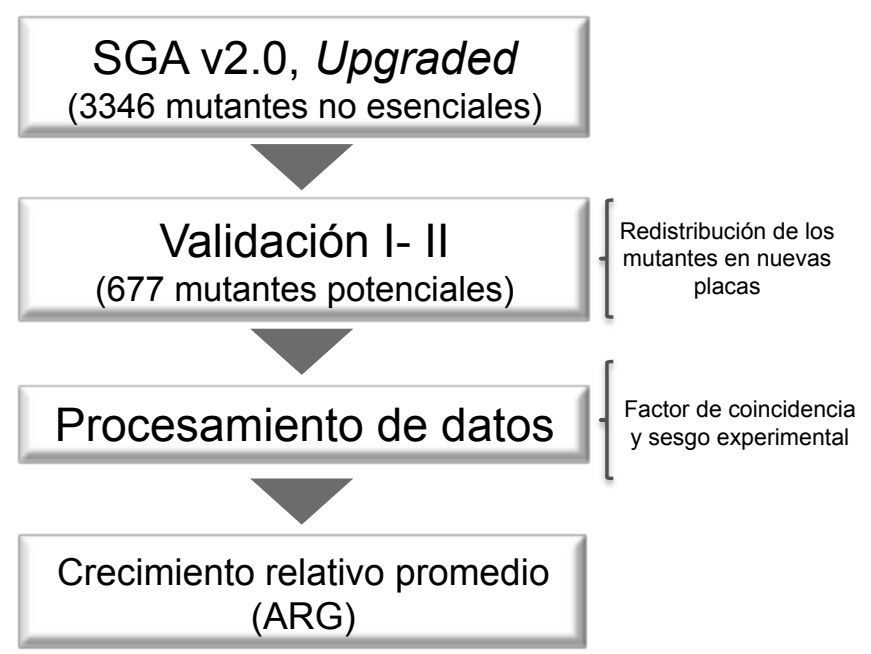

Figura 2. Esquema de la estrategia de validación y normalización de los resultados obtenidos en el escrutinio de sintéticos letales. De 3346 mutantes no esenciales escrutados, se identificaron 677 mutantes potenciales cuyo crecimiento relativo fue validado mediante redistribución de los mutantes en nuevas placas

\subsubsection{Efecto de la ejecución del escrutinio por fases}

Para valorar la reproducibilidad de las validaciones del escrutinio, en primer lugar se aplicó un criterio que se denominó factor de coincidencia, en el cual se tuvo en cuenta para cada uno de los 677 mutantes identificados, las veces que se reprodujo su valoración de interacción negativa o positiva (RG) sin importar el valor absoluto. De esta manera se definieron, tres categorías para las interacciones negativas (SL) y tres categorías para las positivas (SUP), donde SL3 y SUP3 indica que el valor se reprodujo en las tres validaciones realizadas, SL2 y SUP2 en dos de las tres, y SL1 y SUP1 en una de la tres.

Todos los mutantes con un factor de coincidencia SL1 y SUP1 fueron descartados por manifestar un fenotipo de interacción ambiguo. Para los mutantes pertenecientes a la categoría SL3 y SUP3, se calculó la media aritmética con los tres valores de crecimiento estimados y se aproximó por exceso hacia la unidad, definiéndose así el valor de crecimiento 
relativo promedio (del inglés Averaged Relative Growth). A continuación para las categorías SL2 y SUP2, se eliminó el valor alejado de la tendencia de los dos restantes y se calculó la media aritmética. Adicionalmente, para corregir la variabilidad entre los puntajes obtenidos por cada validación y el sesgo en el ARG, se midió el coeficiente de varianza (CV) (ver sección 3.3.3 de Materiales y Métodos).

\subsubsection{Efecto de genes diana ligados al gen de interés}

Para eliminar potenciales falsos positivos, se identificaron los genes diana ligados a los genes de interés, estableciendo $200 \mathrm{~Kb}$ como distancia crítica, de acuerdo a lo descrito por Collins et al., 2010 para S. pombe. Entre los genes que formaron parte de la red de interacción de sintéticos letales con wee1-50, se descartaron cinco genes anotados en Pombase hasta la fecha como aah3, ers1, rp/1202, wee1 y SPCC16C4.10 entre los genes sintéticos letales con $c d c 2-3 w$, se suprimieron 19 genes anotados como adn1, aht1, aim22, ask1, fic1, hhf2, hht2, mep33, pht1, rps402, sre1, tom7, shy1, uсp8, SPBC17A3.06, SPBC83.05, SPBC83.11, SPBC83.16c y SPBC83.17.

\subsubsection{Efecto de borde, espacial y del mutante vecino en la placa}

Se analizó el efecto de borde y el efecto espacial en la placa, estimando la frecuencia de interacciones observadas, según el valor del RG por cada fila y cada columna de la placa empleada para la primera validación del escrutinio (8 filas x 12 columnas).

Según lo descrito por Wagih et al., 2013 en un escrutinio masivo de interacciones genéticas se esperaría una reducción en el número de las interacciones negativas hacia los extremos de la placa por la mayor disponibilidad de nutrientes en comparación con el centro de la placa y a su vez un incremento de las interacciones positivas.

De acuerdo a la Figura 3, los resultados de este análisis indicaron una ligera reducción en la frecuencia de las interacciones negativas observadas con wee1-50 y $c d c 2-3 w$ hacia el borde de la placa. Sin embargo, dicha reducción no coincidió con un incremento acusado de las mismas interacciones hacia el centro de la placa ni con un patrón de distribución que indicara un efecto espacial debido a cambios en el grosor del medio.

De igual forma, al analizar la distribución de las interacciones supresoras con wee150 y cdc2-3w (Figura 4), no se observó un incremento significativo de estas asociado a la 


\section{Resultados-Apartado I}

reducción de las interacciones negativas hacia el borde de la placa ni a su vez con un efecto espacial. Por otra parte, para reducir el efecto de la colonia vecina durante el proceso de ejecución del escrutinio, antes de llevar a cabo la segunda y la tercera ronda de validación de los resultados, se reasignó manualmente una nueva posición a cada uno de los 677 mutantes identificadas preliminarmente. Dicho efecto fue observado en la primera ronda del escrutinio para algunas interacciones positivas, sin embargo no fue decisivo ya que muchas de las interacciones se reprodujeron en las siguientes validaciones.
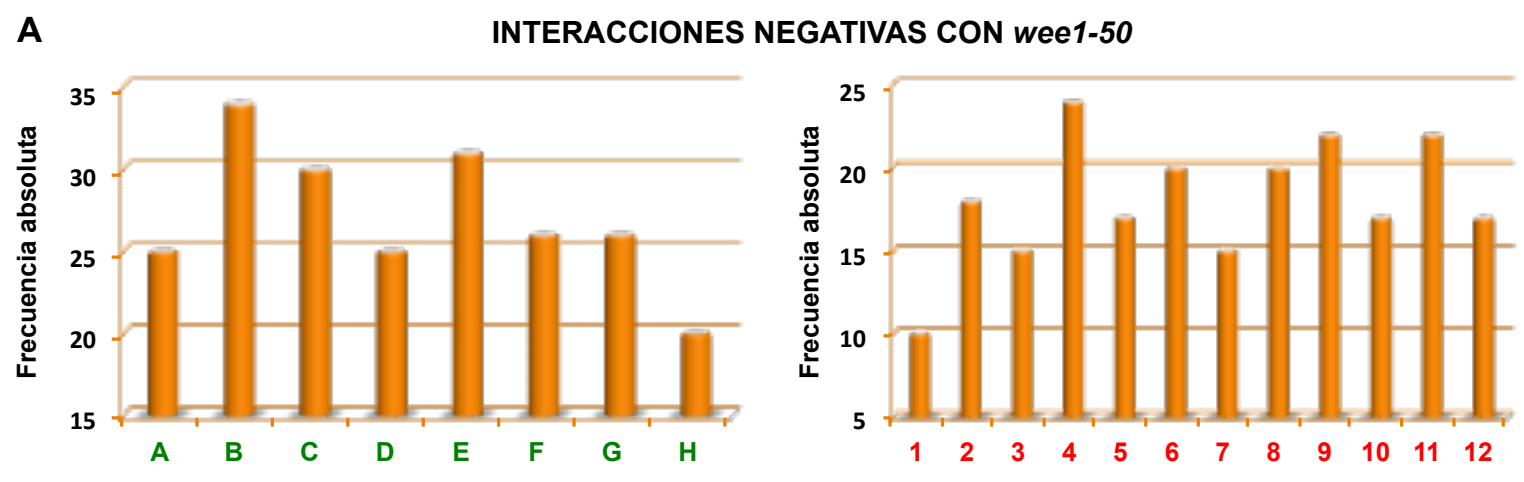

B

INTERACCIONES NEGATIVAS CON cdc2-3w
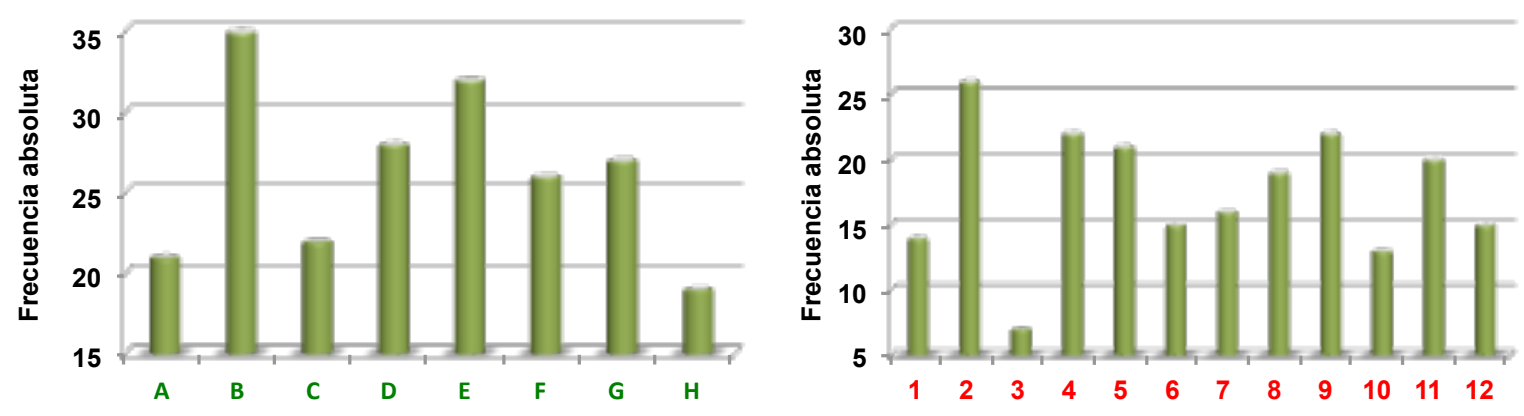

Figura 3. Estimación de la frecuencia absoluta de las interacciones negativas identificadas con wee150 (A) y cdc2-3w (B) por columnas (números) y filas (letras) de acuerdo a la manera como se ordena una placa de 96 pocillos.

Tras el análisis de los factores mencionados con anterioridad, se descartó el efecto espacial de placa y el efecto de borde como fuente de sesgo experimental y falsos resultados. La ausencia de estos efectos podría ser explicada por el tipo de metodología empleada en este escrutinio. Al contrario de un escrutinio robotizado donde la estimación del crecimiento se define en función del área de la colonia (Baryshnikova et al., 2010), en 
este escrutinio el uso de un replicador de 96 puntas de acero predefine el área de la colonia, y sólo permite la estimación del mismo en función de su densidad. De esta manera y de acuerdo a estos resultados, el efecto de borde y de placa afectaría el tamaño de la colonia pero no la densidad. Asimismo, es probable que el formato de 384 puntos (96 x 4) no genere tanta competencia en el crecimiento como el formato de 1536 colonias $(32 \times 84)$ de un escrutinio robotizado y en consecuencia que la frecuencia de las interacciones genéticas observadas aquí no se asocie a las perturbaciones metodológicas tratadas en este apartado. No obstante, el efecto de ejecución del escrutinio por fases, fue la principal fuente de falsos resultados, cuya influencia fue corregida no sólo mediante la normalización de los datos descrita en el apartado anterior sino mediante una inspección permanente de los resultados

A

INTERACCIONES SUPRESORAS CON wee1-50
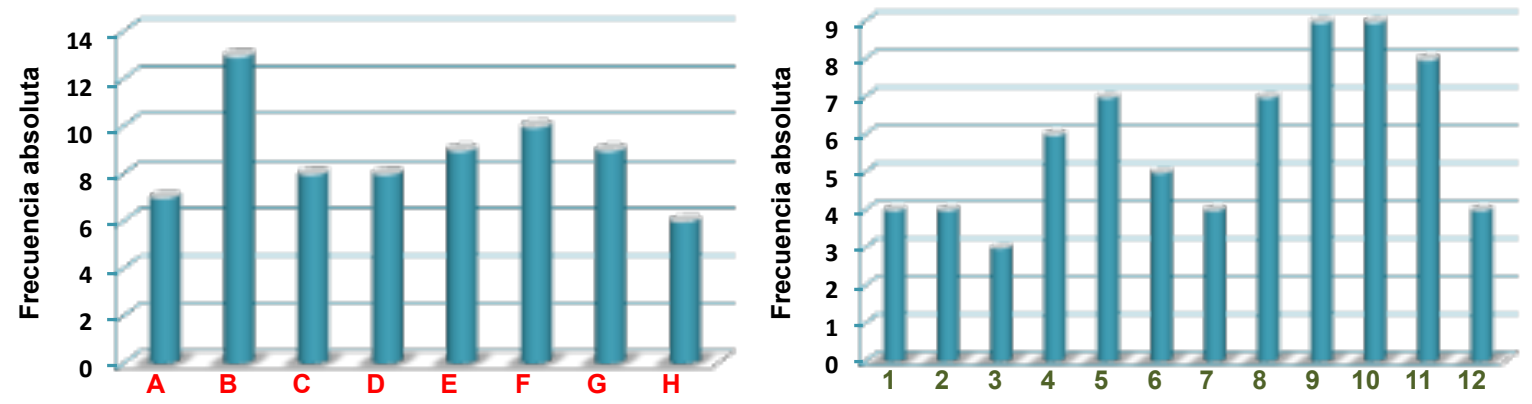

B

INTERACCIONES SUPRESORAS CON $c d c 2-3 w$
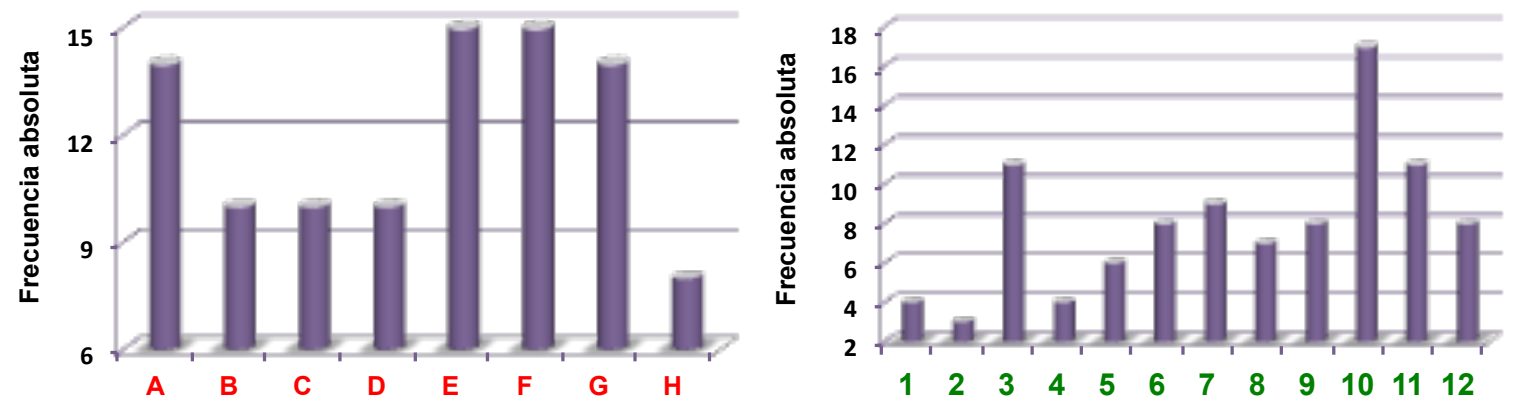

Figura 4. Estimación de la frecuencia absoluta de las interacciones positivas identificadas con wee150 (A) y cdc2-3w (B) por columnas (números) y filas (letras) de acuerdo a la manera como se ordena una placa de 96 pocillos.

1.4 Red de interacciones genéticas con los mutantes wee1-50 y cdc2-3w 


\section{Resultados-Apartado I}

Tras la estimación del ARG en función de la reproducibilidad de la valoración de crecimiento relativo y la eliminación de potenciales falsos positivos por el efecto de ligación de los genes entre sí, se identificó y cuantificó el espectro de interacciones negativas y positivas para los mutantes de interés wee $1-50$ a $35^{\circ} \mathrm{C}$ y $c d c 2-3 w$ a $25^{\circ} \mathrm{C}$ (Figura 5).

En total, se identificaron 593 mutantes con interacciones genéticas, los cuales serán analizados en diferentes módulos para facilitar la comprensión de la red de interacción. En el módulo de interacciones negativas, se identificaron 217 mutantes que interactuaron con el mutante wee $1-50$ a $35^{\circ} \mathrm{C}$ y 210 con el mutante $c d c 2-3 w$ a $25^{\circ} \mathrm{C}$. En el módulo de

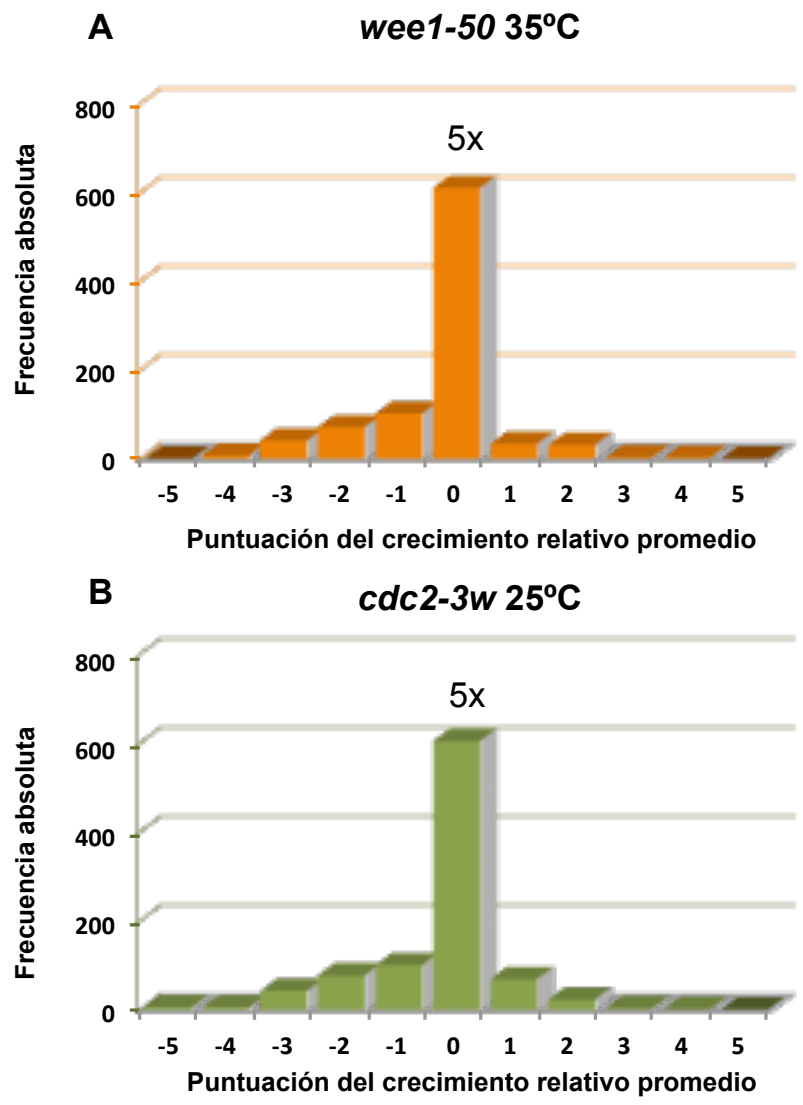

\begin{tabular}{|c|c|c|}
\hline Query & Negativas & Supresoras \\
\hline wee1-50 & 217 & 70 \\
\hline
\end{tabular}

\begin{tabular}{|c|c|c|}
\hline Query & Negativas & Supresoras \\
\hline cdc2-3w & 210 & 96 \\
\hline
\end{tabular}

Figura 5. Estimación cuantitativa del espectro de interacciones genéticas identificadas para los mutantes de interés wee1-50 (A) y cdc2-3w (B) mediante el escrutinio masivo de sintéticos letales (SGA). En el caso de las interacciones con un crecimiento relativo promedio igual a cero la frecuencia

En total, se identificaron 593 mutantes con interacciones genéticas, los cuales serán analizados en diferentes módulos para facilitar la comprensión de la red de interacción. 
En el módulo de interacciones negativas, se identificaron 217 mutantes que interactuaron con el mutante wee $1-50$ a $35^{\circ} \mathrm{C}$ y 210 con el mutante $c d c 2-3 w$ a $25^{\circ} \mathrm{C}$. En el módulo de las interacciones positivas, se identificaron 70 mutantes con wee1-50 a $35^{\circ} \mathrm{C}$ y 96 con $c d c 2-3 w$ a $25^{\circ} \mathrm{C}$. De acuerdo a la Figura 5 , la distribución de las interacciones fue similar a un patrón de distribución normal con una ligera asimetría en ambos casos hacia las interacciones negativas. Para este escrutinio, sólo el $8 \%$ y el $9,14 \%$ de un total de 3346 mutantes de deleción no esenciales para $S$. pombe, mostraron algún tipo de interacción genética con wee1-50 y cdc2-3w respectivamente.
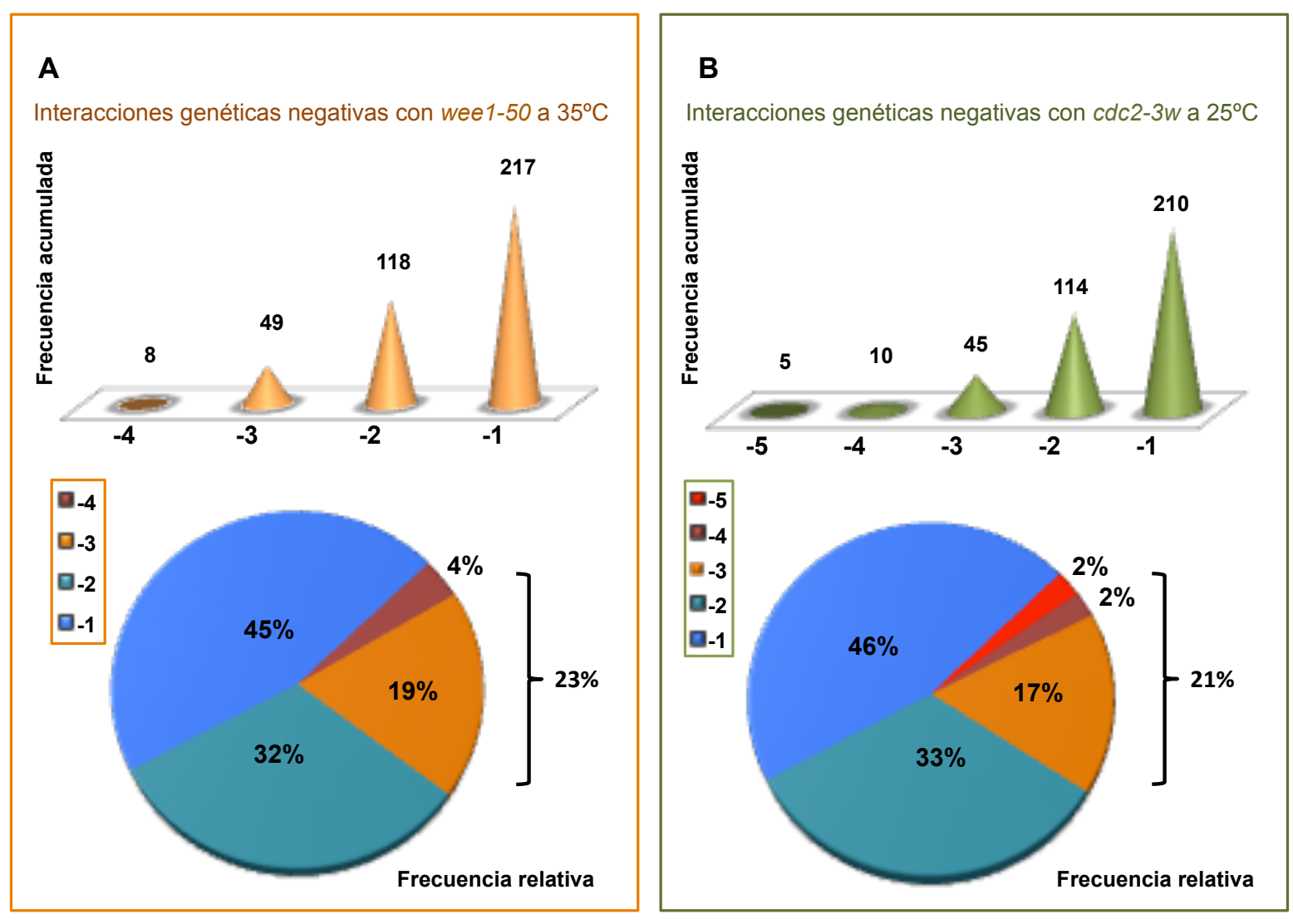

Figura 6. Estimación de la frecuencia absoluta acumulada y relativa de las interacciones negativas con wee1-50 (A) y cdc2-3w (B), de acuerdo al crecimiento relativo promedio estimado. Las categorías mas representadas en ambos casos corresponden a una puntuación comprendida entre -1 y -2 . Las menos representadas entre -5 y -3 ( $23 \%$ con wee $1-50$ y $21 \%$ con $c d c 2-3 w)$.

Desglosando los módulos de interacción negativa, se observó que las interacciones genéticas fuertes en un rango entre -5 y -3 para wee1-50 y cdc2-3w, fueron menos frecuentes y solo estuvieron representados en un $23 \%$ y $21 \%$ respectivamente (Figura 6 ) y por el contario que las interacciones genéticas débiles, entre $\mathbf{- 2} \mathbf{y} \mathbf{- 1}$, englobaron el $77 \%$ y el $79 \%$. 
A

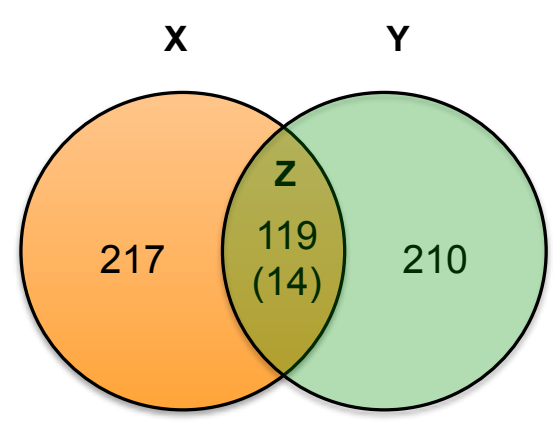

p-value: $6 \times 10^{-93}$
B

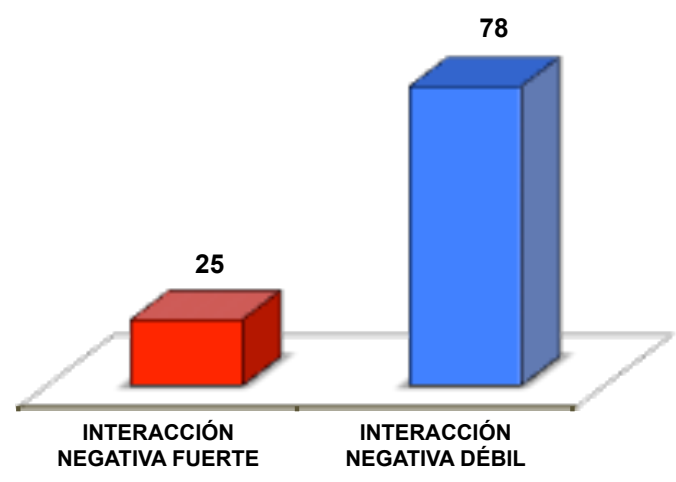

Genes comunes con interacción negativa (119)

Interacciones comunes con el mismo tipo de interacción negativa (103)

Interacciones comunes con una interacción genética con cada cepa de interés (16)

Figura 7. (A) Comparación entre las listas de los genes con interacciones negativas con wee1-50 y cdc2-3w, encontrados en el escrutinio masivo de sintéticos letales. El grado de solapamiento por azar fue de $6 \times 10^{-93}$ y el número de interacciones en común esperadas de 14. (B) Frecuencia y grados de

Curiosamente, aunque el número de interacciones negativas para wee1-50 fue similar al número para $c d c 2-3 w$, la red de interacción no es común a ambos. Al comparar las listas de los genes implicados, se observó que 119 de un total de 427 mutantes, compartía algún tipo de interacción con los dos mutantes de interés. Dicho número de interacciones en común, fue estadísticamente significativo de acuerdo al grado de solapamiento observado ( $p$-valor: $6 \times 10^{93}$ ) y al número de interacciones esperadas por azar (14) (Figura 7).

De los 119 genes observados como comunes, 103 mostraron el mismo grado de interacción para ambas cepas de interés, es decir que 25 de ellos mostraron una interacción negativa fuerte y 78 una interacción negativa débil tanto con wee1-50 como con $c d c 2-3 w$. De los 16 mutantes restantes, 8 fueron fuertes con wee1-50 y débiles con cdc2-3w, y 8 fuertes con $c d c 2-3 w$ y débiles con wee1-50 (Tabla 1). 
Tabla 1. Lista de genes en común con wee1-50 y cdc2-3w, que manifestaron un grado de interacción genética diferente con cada cepa de interés.

\begin{tabular}{|c|c|c|c|c|}
\hline Nombre ORF & Nombre gen & $\begin{array}{l}\text { Interacción } \\
\text { wee1-50 } 35^{\circ} \mathrm{C}\end{array}$ & $\begin{array}{l}\text { Interacción } \\
\text { cdc } 2-3 w 25^{\circ} \mathrm{C}\end{array}$ & Descripción funcional \\
\hline SPBPB2B2.01 & SPBPB2B2.01 & Negativa Fuerte & Negativa Débil & $\begin{array}{l}\text { Transportador de aminoácidos } \\
\text { (amino acid permease predicted) }\end{array}$ \\
\hline SPAC6F6.01 & $\operatorname{cch} 1$ & Negativa Fuerte & Negativa Débil & $\begin{array}{l}\text { Canal de calcio Cch1 } \\
\text { (calcium channel) }\end{array}$ \\
\hline SPCC1223.15c & spc19 & Negativa Fuerte & Negativa Débil & $\begin{array}{l}\text { Subunidad Spc19 del complejo DASH } \\
\text { (DASH complex subunit Spc19) }\end{array}$ \\
\hline SPAC222.14c & SPAC222.14c & Negativa Fuerte & Negativa Débil & $\begin{array}{l}\text { Proteína de unión a GTP } \\
\text { (GTP binding protein predicted) }\end{array}$ \\
\hline SPAC23A1.07 & $S P A C 23 A 1.07$ & Negativa Fuerte & Negativa Débil & $\begin{array}{l}\text { Proteína Ubiqutina ligasa E3 } \\
\text { (ubiquitin-protein ligase E3 predicted) }\end{array}$ \\
\hline SPAC25G10.06 & rps2801 & Negativa Fuerte & Negativa Débil & $\begin{array}{l}\text { Proteína } 40 \text { S ribosomal S28 } \\
\text { (40S ribosomal protein S28 predicted) }\end{array}$ \\
\hline SPCC550.14 & $v g / 1$ & Negativa Fuerte & Negativa Débil & $\begin{array}{l}\text { Proteína de unión a ARN } \\
\text { (vigilin predicted) }\end{array}$ \\
\hline SPBC32F12.05c & cwf12 & Negativa Fuerte & Negativa Débil & $\begin{array}{l}\text { Proteína Cwf12 que forma complejo con Cdc5 } \\
\text { (complexed with Cdc5 protein Cwf12) }\end{array}$ \\
\hline SPBP8B7.28c & stc1 & Negativa Débil & Negativa Fuerte & $\begin{array}{l}\text { Proteína de unión a cromatina } \\
\text { (LIM-like protein linking chromatin modification to RNAi, } \\
\text { Stc1) }\end{array}$ \\
\hline$S P B C 25 H 2.15$ & $S P B C 25 H 2.15$ & Negativa Débil & Negativa Fuerte & $\begin{array}{l}\text { Proteína de maduración del SSU-rARN } \\
\text { (SSU-rRNA maturation protein Tsr4 homolog } 1 \\
\text { predicted) }\end{array}$ \\
\hline SPBC336.03 & efc25 & Negativa Débil & Negativa Fuerte & $\begin{array}{l}\text { Factor de intercambio de GDP por GTP } \\
\text { (Ras1 guanyl-nucleotide exchange factor Efc25) }\end{array}$ \\
\hline$S P B C 16 C 6.03 c$ & SPBC16C6.03c & Negativa Débil & Negativa Fuerte & $\begin{array}{l}\text { Proteína de ensamblaje del ribosoma } \\
\text { (ribosome assembly protein predicted) }\end{array}$ \\
\hline SPBC16E9.14c & $\operatorname{zrg} 17$ & Negativa Débil & Negativa Fuerte & $\begin{array}{l}\text { Transportador de zinc en membrana } \\
\text { (cation diffusion family zinc membrane transporter) }\end{array}$ \\
\hline SPBC29A3.05 & vps71 & Negativa Débil & Negativa Fuerte & $\begin{array}{l}\text { Subunidad del complejo Srw1 } \\
\text { (Swr1 complex subunit Vps71) }\end{array}$ \\
\hline SPBC3B9.13c & rpp102 & Negativa Débil & Negativa Fuerte & $\begin{array}{l}\text { Proteína ribosomal } 60 \mathrm{~S} \\
\text { (60S acidic ribosomal protein A3) }\end{array}$ \\
\hline SPBC83.18c & fic1 & Negativa Débil & Negativa Fuerte & $\begin{array}{l}\text { Proteína con dominio } \mathrm{C} 2 \\
\text { (C2 domain protein Fic1) }\end{array}$ \\
\hline SPAC660.11 & $\operatorname{tcg} 1$ & Supresor fuerte & Supresor débil & $\begin{array}{l}\text { Proteína de unión a ARN } \\
\text { (single-stranded telomeric binding protein Tgc1) }\end{array}$ \\
\hline SPAC23C11.04 & pnk1 & Supresor fuerte & Supresor débil & $\begin{array}{l}\text { Quinasa/fosfatasa } \\
\text { (DNA Kinase/phosphatase) }\end{array}$ \\
\hline SPAC824.04 & SPAC824.04 & Supresor débil & Supresor fuerte & $\begin{array}{l}\text { Proteína de unión a ARN } \\
\text { (WD repeat protein predicted) }\end{array}$ \\
\hline
\end{tabular}

En el análisis de los módulos con interacciones positivas, se observó el mismo patrón descrito para las interacciones negativas, donde las interacciones positivas débiles fueron mas frecuentes que las fuertes. De esta manera, del total de genes identificados con un wee1-50, el 94\% correspondió a las interacciones positivas débiles (puntuaciones 


\section{Resultados-Apartado I}

de interacción 1 y 2) y el $6 \%$ a las interacciones positivas fuertes (puntuación de interacción 3 y 4). Del mismo modo, en el caso de cdc2-3w las débiles representaron el $96 \%$ y las fuertes sólo el $4 \%$ (Figura 8 ).

Cuando se compararon las listas entre wee1-50 y cdc2-3w, se observaron 25 mutantes comunes (Figura 9), de los cuales 22 mostraron una interacción positiva débil en ambos casos y de los tres restantes, dos fueron fuertes con wee1-50 y débiles con cdc2-3w y uno fuerte con $c d c 2-3 w$ y débil con wee1-50 (Tabla 1). De acuerdo al grado solapamiento ( $p$-valor: $2 \times 10^{-17}$ ) y al número de interacciones por azar (2), los genes en común con interacciones positivas fueron producto de un evento estadísticamente significativo.
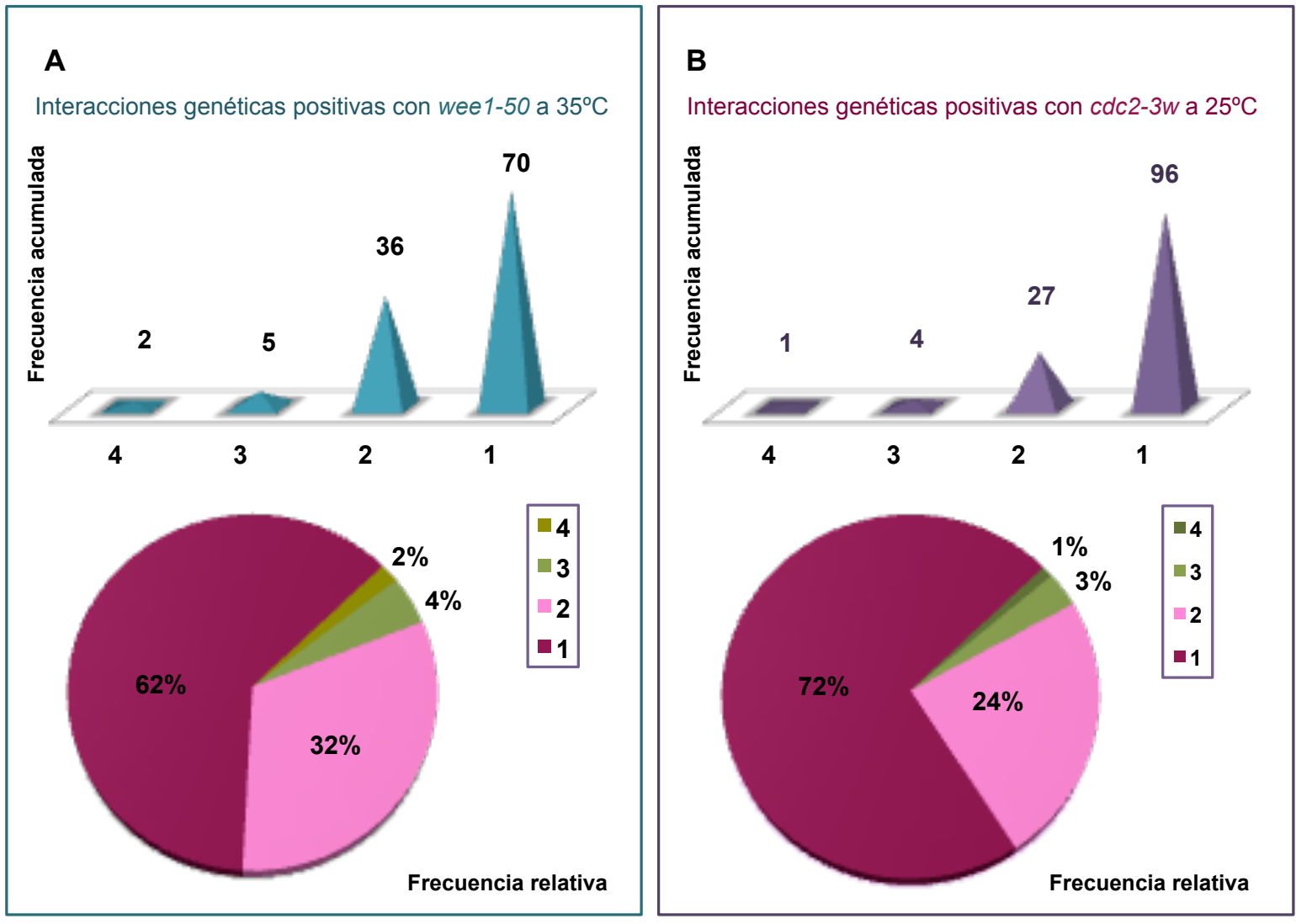

Figura 8. Estimación de la frecuencia absoluta acumulada y relativa de las interacciones positivas con wee1-50 (A) y cdc2-3w (B) de acuerdo al crecimiento relativo promedio estimado. Las categorías mas representadas en ambos casos corresponden a un puntaje comprendido entre 1 y 2.

En las Tablas S1 y S2 (material suplementario), se presenta la lista completa de los genes identificados, distribuidos según cada módulo de interacción (negativo y positivo) y la cepa de interés wee $1-5035^{\circ} \mathrm{C}$ y cdc $2-3 w 25^{\circ} \mathrm{C}$. 


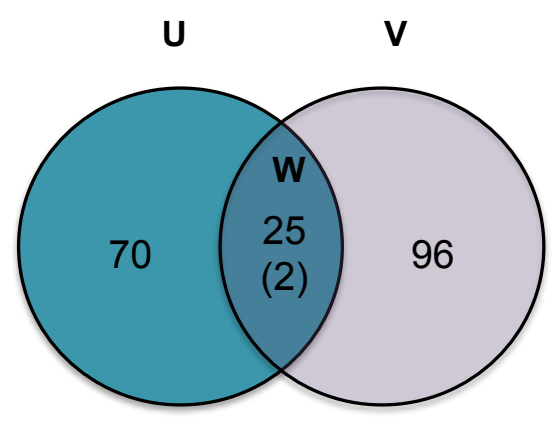

p-value: $2 \times 10^{-17}$
Grupo U. Interacciones genéticas positivas con wee $1-50$ a $35^{\circ} \mathrm{C}(70)$

Grupo V. Interacciones genéticas positivas con cdc2-3w a $25^{\circ} \mathrm{C}(96)$

Grupo W. Genes con una interacción positiva común con ambos mutantes de interés (25)

Figura 9. Comparación entre las listas de los genes con interacciones positivas con wee1-50 y cdc2$3 w$, encontrados en el escrutinio masivo de sintéticos letales. El grado de solapamiento calculado como un $p$-valor fue de $2 \times 10^{-17}$ y el número de interacciones en común esperadas por azar de 2 .

\section{Análisis funcional de la red de sintéticos letales con wee1-50 y cdc2-3w}

En esta memoria se discute el significado de las interacciones negativas observadas con wee1-50 y cdc2-3w, en particular de aquellas con un valor de interacción entre -5 y -2 (232), y que son descritas aquí como interacciones fuertes en su mayoría. Por otra parte, las interacciones positivas identificadas no serán analizadas ni discutidas con posterioridad y sólo serán presentadas como un recurso de interés obtenido para nuestro grupo de investigación (Tabla S1 y S2; material suplementario).

Inicialmente, se comprobaron las interacciones observadas mediante un análisis de esporas al azar (RSA). De acuerdo a la metodología, se comparó la viabilidad de las colonias del doble mutante con la de los mutantes sencillos (diana y de interés) y a su vez con el cruce control, teniendo en cuenta el número y tamaño de las mismas. En el caso de wee1-50 se llevó a cabo el análisis a $35^{\circ} \mathrm{C}$ y para $c d c 2-3 w$ a $25^{\circ} \mathrm{C}$. El cruce control fue analizado en ambos casos a $25^{\circ} \mathrm{C}$. Como resultado, se clasificaron las interacciones en dos categorías: i) interacción sintética letal (del inglés synthetic lethal), dónde no se observaron colonias creciendo en el medio doblemente selectivo, y ii) interacción sintética enferma fuerte (del inglés synthetic sick), dónde se observó una inhibición del crecimiento de las colonias y/o un número menor respecto a los parentales (Figura 10). 


\section{Resultados-Apartado I}

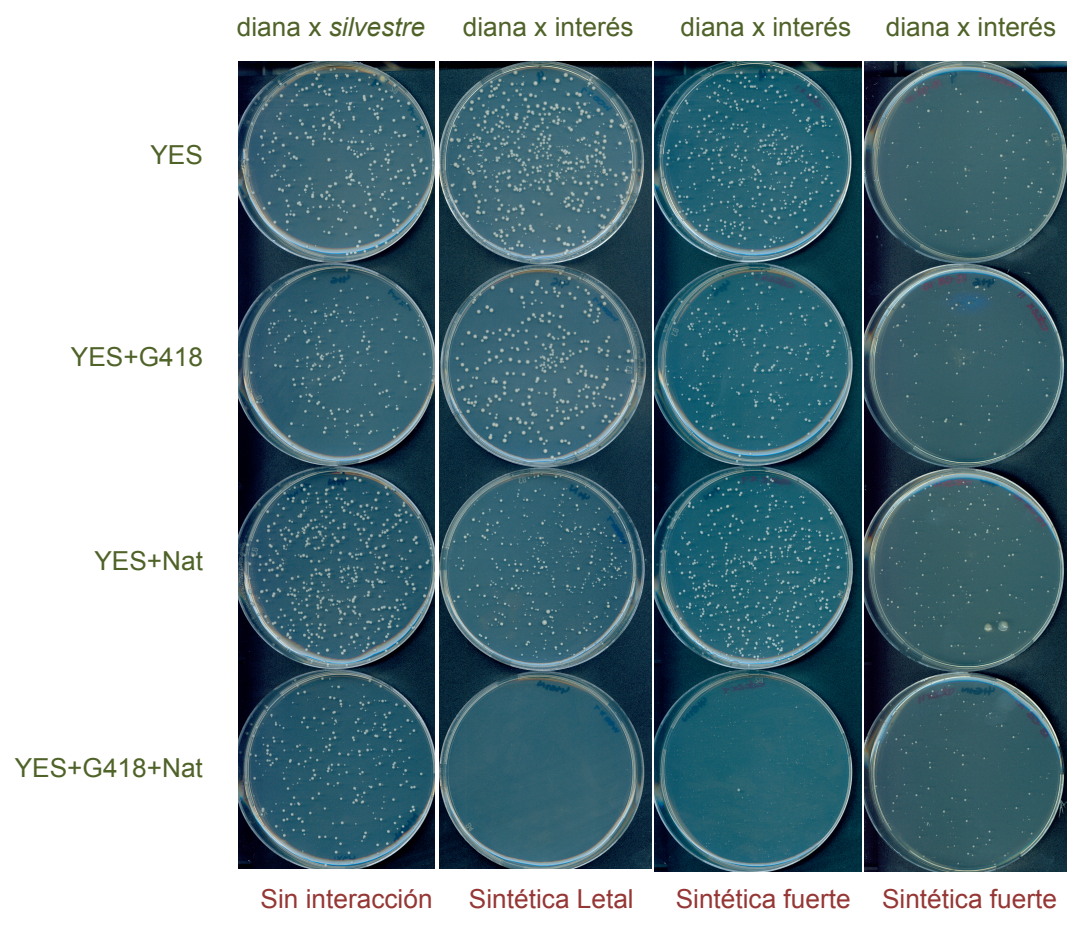

Figura 10. Categorías cualitativas observadas en el análisis de esporas al azar (RSA) para los genes identificados con wee1-50 y cdc2-3w en un rango de puntuación entre -5 y -2 con el SGA.

De los 118 mutantes identificados con wee1-50 con una interacción entre -4 y -2, se seleccionaron 72 aleatoriamente para el análisis y se confirmaron 68 en total. Las 4 interacciones restantes no fueron confirmadas, debido a que el crecimiento de las esporas en medio selectivo con G418 fue más lento que en el resto de medios, impidiendo realizar una comparación fiable. En el caso de las interacciones con cdc2-3w, se seleccionaron 41 mutantes de un total de 114 con un puntuación entre -5 y -2 y se confirmaron 27. Las 14 interacciones restantes, no pudieron ser confirmadas por las mismas razones (Tabla S3; material suplementario). De los resultados anteriores, se infiere que el escrutinio masivo de sintéticos letales confirmado mediante esta metodología presenta un valor predictivo positivo cercano al $95 \%$ para wee1-50 y al $67 \%$ para $c d c 2-3 w$. Respecto a las interacciones no confirmadas (6\% para wee1-50 y el 33\% para $c d c 2-3 w)$ no fueron eliminadas del análisis posterior, ya que se consideró que los resultados no fueron concluyentes.

Para el análisis de la red de interacción, inicialmente se asoció un proceso biológico manualmente a los 232 genes identificados con wee1-50 y cdc2-3w (Tabla S4 y S5; 
Resultados-Apartado I

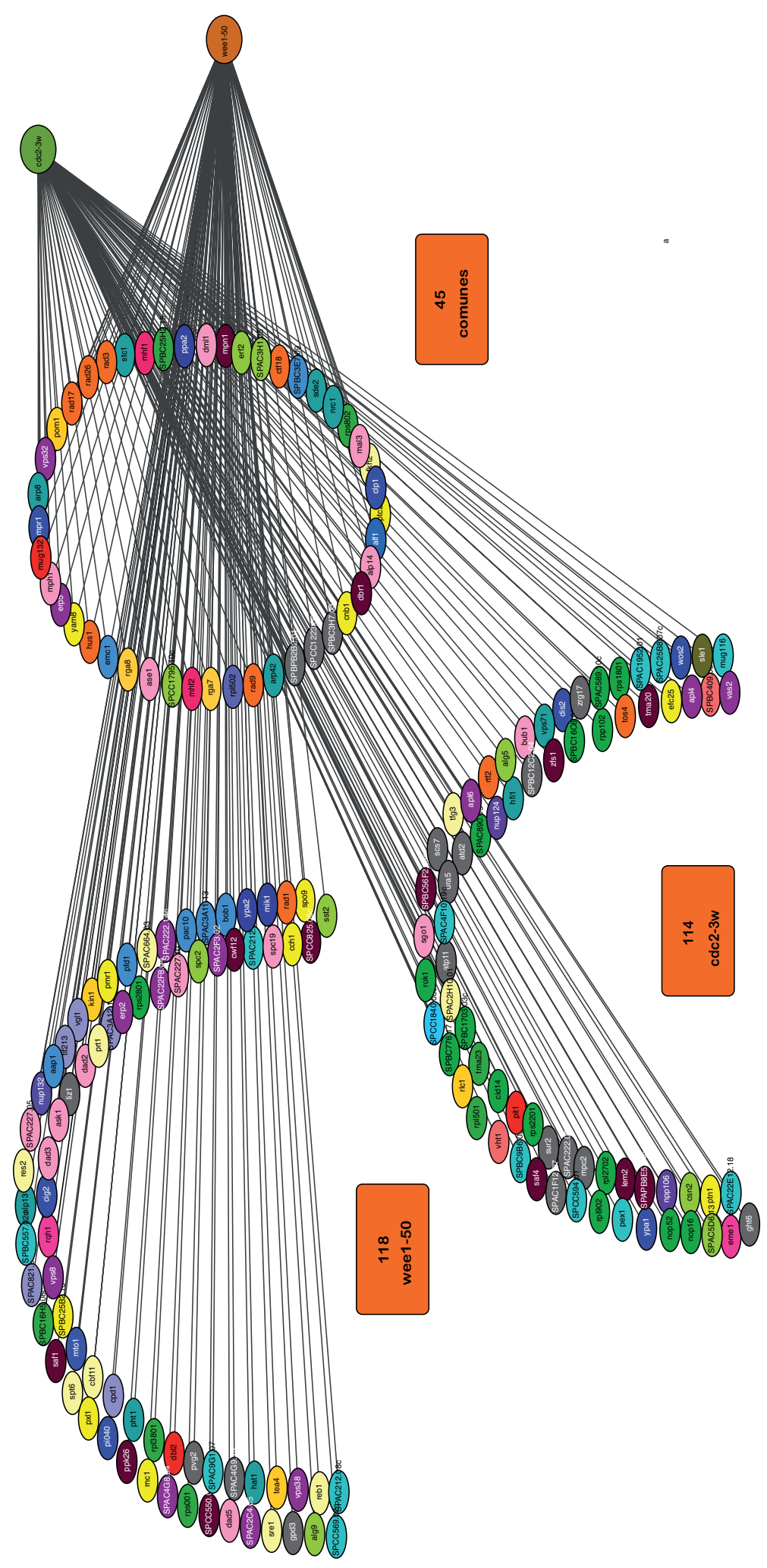

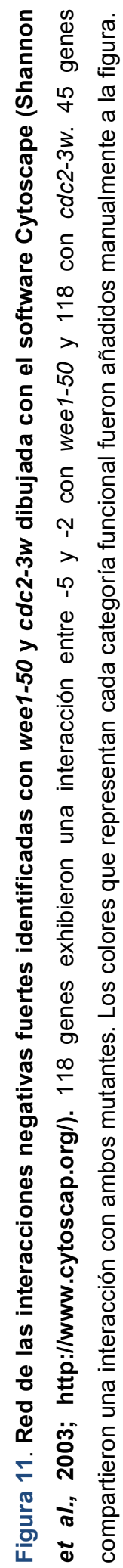




\section{Resultados-Apartado I}

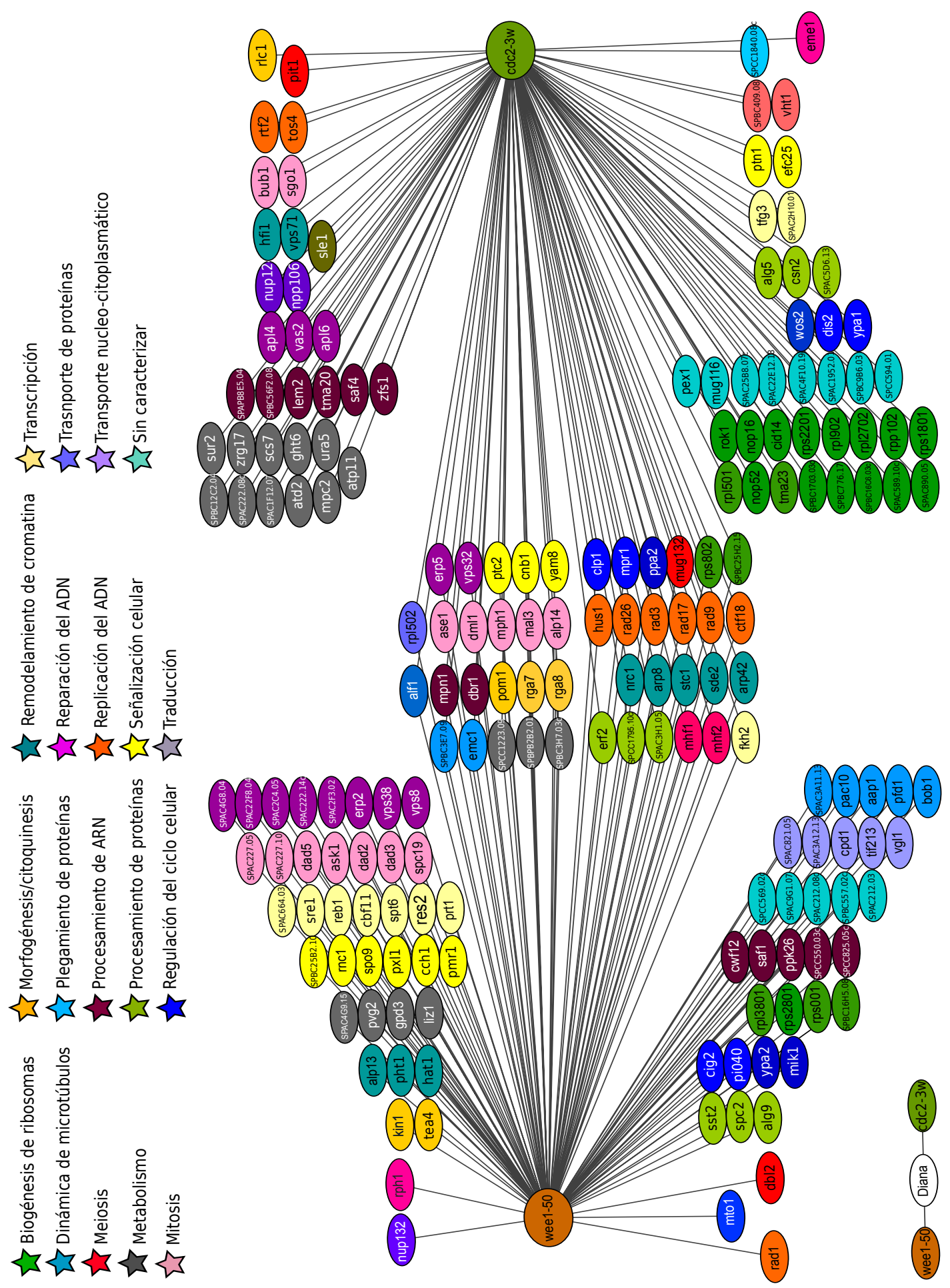

Figura 12. Red de las interacciones negativas fuertes identificadas con wee1-50 y cdc2-3w organizada de acuerdo a la función biológica descrita en la base de datos Pombase (Wood et al., 2012; http://www.pombase.org/) y el número de elementos que las conforman. En total, se identificaron 18 categorías funcionales y una con elementos cuya función aún no ha sido identificada. 
material suplementario), de acuerdo a lo descrito o inferido por homología en la base de datos Pombase (Wood et al., 2012; http://www.pombase.org/) y en la literatura.

En la Figura 11, creada con la herramienta bioinformática Cytoscape (Shannon et al., 2003) se visualiza la red de interacción con wee1-50 y cdc2-3w, en la cual la distancia entre los mutantes de interés y los diana representa el grado de interacción observada. Entre los 232 elementos representados, 114 corresponden a genes que interaccionan con cdc2-3w y 118 con wee1-50. Del total, 45 muestran una interacción común para ambos. En la Figura 12 se organizan dichos genes de acuerdo a su función biológica y el número de elementos que conforman las mismas.

Los genes de la red de interacción con wee1-50, se clasificaron en 18 grupos funcionales siendo las categorías más representadas mitosis $(12 / 118)$ y transporte de proteínas (9/118). Asimismo, con $c d c 2-3 w$, los genes se distribuyeron en 19 grupos dónde las categorías de biogénesis de ribosomas (20/114) y metabolismo (14/114) fueron las más representadas. Adicionalmente, se identificaron 5 y 8 genes sin función asignada o predicha hasta ahora para wee1-50 y cdc2-3w respectivamente (Figura 13).

Las interacciones comunes representaron 15 categorías, que en orden de abundancia fueron: replicación (6/45), mitosis (5/45), remodelación de cromatina (5/45), regulación del ciclo celular (3/45), señalización celular (3/45); morfogénesis/citoquinesis (3/45), procesamiento de proteínas (3/45), plegamiento de proteínas (3/45), biogénesis de ribosomas (3/45), metabolismo (3/45), transporte de proteínas (2/45), reparación del ADN (2/45), procesamiento de ARN (2/45), meiosis (1/45) y transcripción (1/45). Dado que a través del análisis anterior solo es posible destacar las funciones biológicas presentes en la red pero no el grado de representación de cada categoría con respecto al genoma, se realizó un análisis GO de cada red, empleando la herramienta Gene list Analyser (Wellcome Trust Sanger Institute). Dichas herramientas trabajan sobre la base de los términos GO anotados de forma extensiva para cerca del 98,3\% (Aslett y Wood, 2006) del genoma de S. pombe por el consorcio Gene Ontology (Ashbuner et al., 2002; http://www.geneontology.org).

En la Tabla 2 y 3 se describe, para la red de interacción con wee1-50 y cdc2-3w respectivamente, el enriquecimiento significativo de los procesos, componentes y localizaciones celulares observados en el análisis con Gene list analyser. Para el caso de 


\section{Resultados-Apartado I}

A

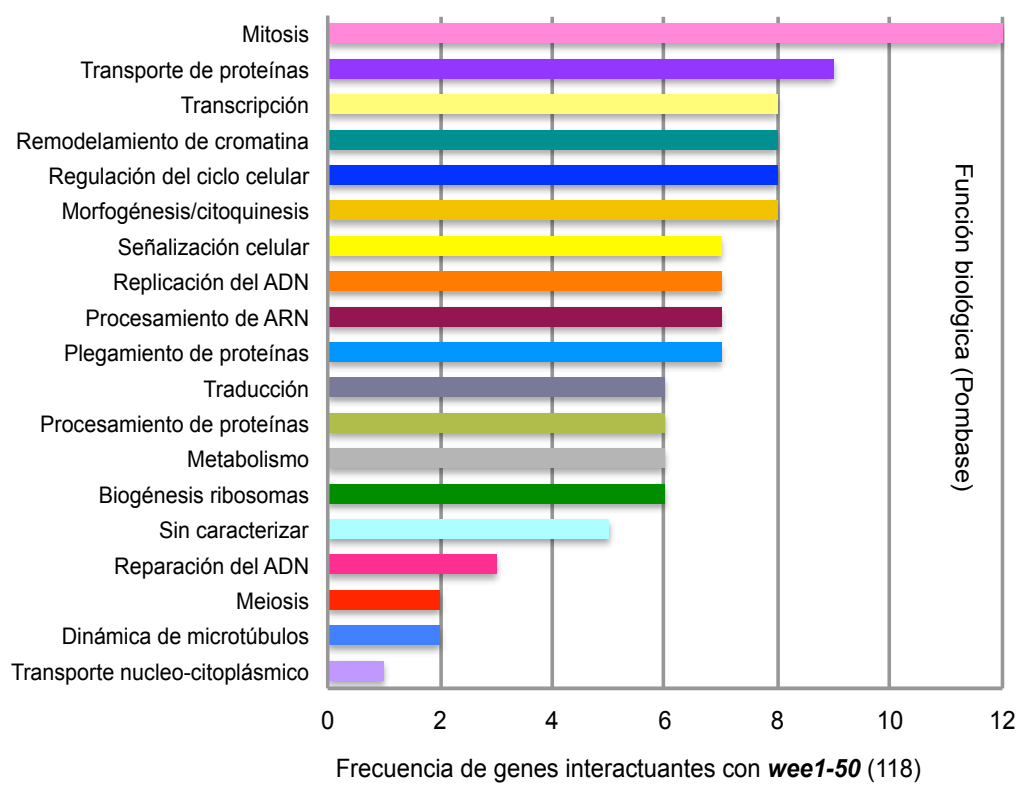

B

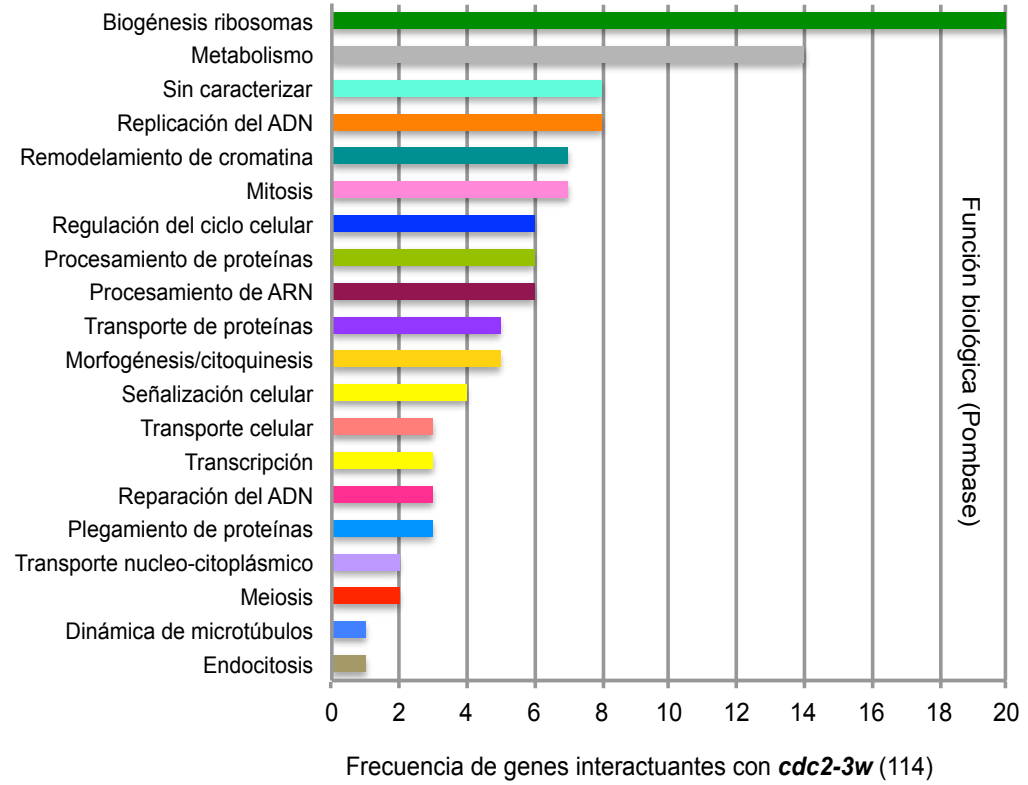

Figura 13. Clasificación funcional de los genes interactuantes con wee1-50 (A) y cdc2-3w (B), según anotaciones en Pombase y literatura. Se identificaron 18 y 19 categorías funcionales para la red de wee1- 
wee1-50, de un total de cinco procesos sobrerrepresentados, tres mostraron un $p$-valor menor de 0,05 , siendo estos ciclo celular (28/118), biogénesis y organización del citoesqueleto (17/118) y transducción de señales (23/118). Por otro lado, el análisis GO asociado a componentes celulares indicó que el cromosoma (22/118) y el centro de organización de microtúbulos (7/118) presenta sobrerrepresentación para esta red (Tabla s6; material suplementario).

Tabla 2. Términos GO de procesos y componentes sobrerrepresentados en la red de interacción con wee1-50.

\begin{tabular}{l|c|c|c}
\hline \multicolumn{1}{c|}{ Categoría GO (Proceso) } & $\begin{array}{c}\text { Enriquecimiento } \\
\text { en la red }\end{array}$ & $\begin{array}{c}\text { Enriquecimiento en el } \\
\text { genoma de S. pombe }\end{array}$ & p-valor \\
\hline Ciclo celular & $23,73 \%$ & $6,80 \%$ & $7 \times 10^{-7}$ \\
Biogénesis y organización del citoesqueleto & $14,41 \%$ & $3,45 \%$ & $3 \times 10^{-5}$ \\
Transducción de señales & $19,50 \%$ & $6,15 \%$ & $3,2 \times 10^{-5}$ \\
\hline Biogénesis y organización de organelos & $20,34 \%$ & $10,15 \%$ & $1,5 \times 10^{-2}$ \\
Plegamiento de proteínas & $23,73 \%$ & $12,92 \%$ & $1,6 \times 10^{-2}$ \\
\hline \multicolumn{1}{c|}{ Categoría Go (Componente) } & Enriquecimiento & Enriquecimiento en el & $\boldsymbol{p}$-valor \\
\hline Cromosoma & $18,64 \%$ & genoma de S. pombe & $6,83 \%$ \\
Centro de organización de microtúbulos & $5,93 \%$ & $1,05 \%$ & $4,3 \times 10^{-4}$ \\
\hline
\end{tabular}

Las celdas resaltadas destacan aquellos términos $\mathrm{GO}$ con un nivel de significancia menor de 0,05, corregido por el test FDR. Análisis realizado mediante la herramienta Gene list Analyser de Sanger (http://www.sanger.ac.uk/cgibin/PostGenomics/S_pombe/GLA/GLA_input).

Para validar estos resultados, se realizó un análisis adicional empleando el complemento BiNGO (del inglés The Biological Networks Gene Ontology tool) para Cytoscape (Maere et al., 2005), a través del cual las relaciones entre los términos GO sobrerrepresentados y sus genes fueron visualizados en el contexto de la jerarquía GO. Dicho contexto, coincidió con los resultados arrojados con la herramienta Gene list Analyser y a su vez facilitó la interpretación de los mismos.

En la Figura 14, el tamaño de los nódulos es proporcional al número de genes presentes en cada uno y asimismo el color obedece al $p$-valor correspondiente a cada 


\section{Resultados-Apartado I}

categoría. En otras palabras, el color blanco representa aquellos nódulos con un $p$-valor estadísticamente no significativo, el color amarillo con un $p$-valor igual al fijado para el test, en este caso igual a 0,005 , y el color naranja a aquellas categorías con un $p$-valor cinco veces mas pequeño que el anterior ( $p$-valor igual a 0,001). La Tabla S7 (ver material del suplementario) presenta los valores obtenidos para cada categoría en la red de wee1-50. Debido a la interdependencia de las categorías funcionales, en la jerarquía GO para wee1-50 se observaron diferentes procesos biológicos que fueron interpretados a la luz del otro análisis. En nuestro caso, tanto la herramienta Gene list Analyzer como BiNGO, coincidieron en resaltar la sobrerrepresentación de tres ramas de la jerarquía: i) ciclo celular y su regulación (ver cell cycle regulation), incluyendo la regulación de la división nuclear y la regulación negativa de la actividad quinasa; ii) puntos de control de la progresión del ciclo celular (ver cell cycle checkpoint) incluyendo organización del huso mitótico y control del daño del ADN durante fase $S$, y iii) localización celular, incluyendo localización y orientación de los cromosomas y anclaje de los microtúbulos a los cromosomas. Adicionalmente, se observó una sobrerrepresentación particular en la categoría ensamblaje de la tubulina y regulación de la señalización celular.

En relación de los términos GO asociados a componentes celulares, destacaron: i) el complejo DASH (codificado por los genes $s p c 19^{+}$, dad $^{+}$, dad $^{+}$, dad $^{+}$y ask $1^{+}$) cuya función es prevenir la estabilización de la unión microtúbulo-cinétocoro en $S$. pombe (Liu et al., 2005; Sanchez-Perez et al., 2005) y en S. cerevisiae (Cheeseman et al., 2001); ii) el complejo prefoldina $\left(b o b 1^{+}, S P A C 227.10\right.$, SPAC3A11.1 y SPAC227.05) cuya función principal es dirigir el plegamiento de las proteínas en bacterias y otros eucariotas (Gong et al., 2009; Ohtaki et al., 2010) y iii) el complejo Rad9/Rad1/Hus1 (en inglés checkpoint clamp complex), el cual dirige su actividad hacia los sitios dañados del ADN (Kaur et al., 2001; Parrilla-Castellar et al., 2004). En cuanto a la función molecular, el término GO más enriquecido fue unión a tubulina (del inglés tubulin binding), que hace referencia a proteínas con la capacidad de unirse y estabilizar microtúbulos según QuickGO (Binns et al., 2009) tales como Alp4, Mal3, Ase1 y Mto1. De acuerdo a ambos análisis, la red de interacción con wee1-50 no sólo involucra procesos relacionados directamente con la regulación del ciclo celular de acuerdo a lo esperado, sino que a su vez conecta con los procesos de señalización celular y procesos de dinámica de los microtúbulos, sugiriendo que ambos procesos están intercomunicados con la progresión espacio-temporal del ciclo celular. 


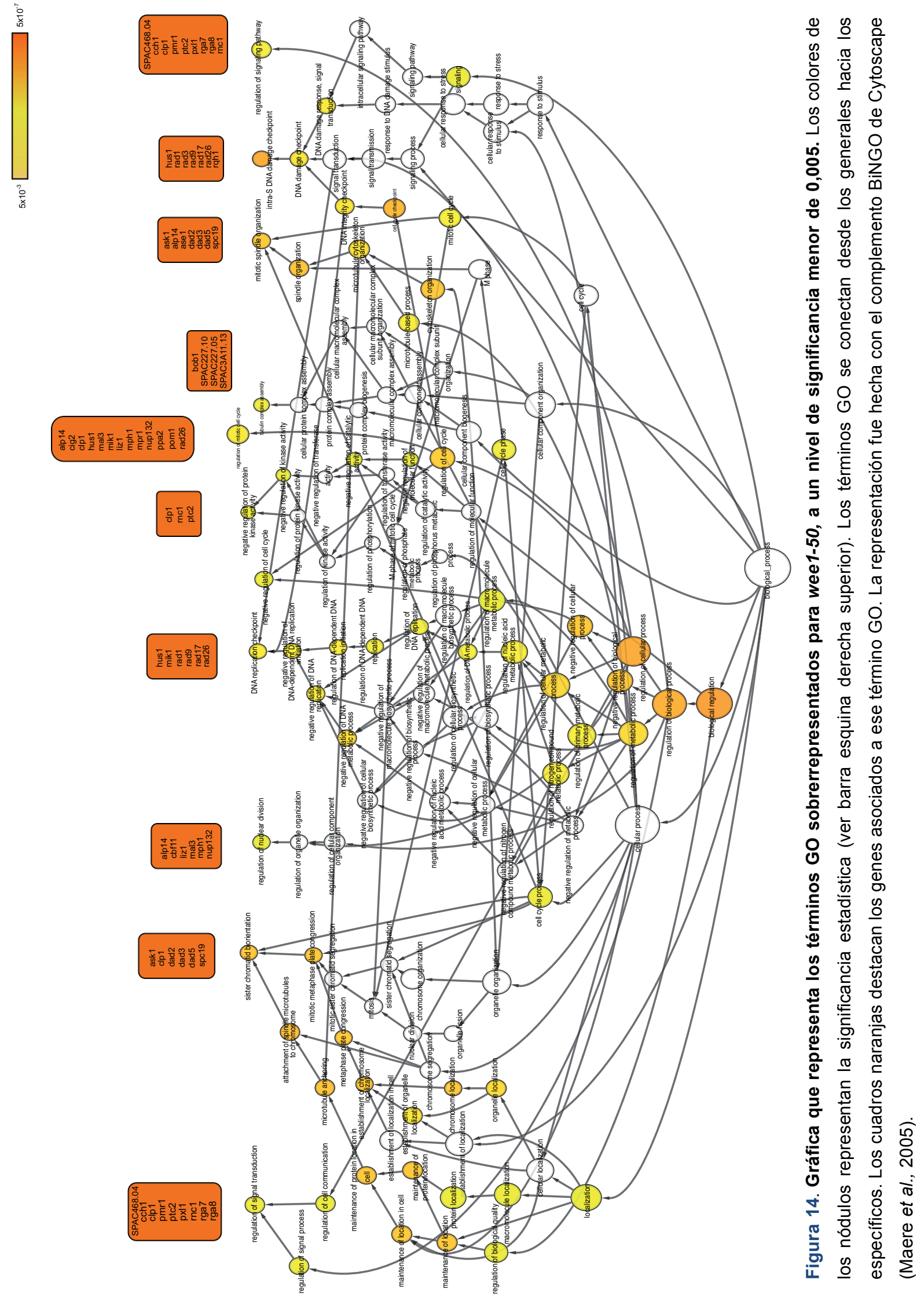




\section{Resultados-Apartado I}

A continuación y de forma similar, se realizó el análisis GO con Gene list analyzer para la red con cdc2-3w (Tabla 3) y con BiNGO (Figura 15). Dicho análisis arrojó un enriquecimiento muy significativo ( $p$-valor menor que $1 \times 10^{-5}$ ) para los procesos relacionados con ciclo celular (22/114), señalización celular (21/114) y la actividad fosfatasa (5/114). Respecto a los componentes y localizaciones celulares se encontró un enriquecimiento de genes asociados a microtúbulos (3/114) y proteínas localizados en el nucléolo (15/114) (Tabla S8, material suplementario).

Tabla 3. Términos GO de procesos y componentes sobrerrepresentados en la red de interacción con $c d c 2-3 w$.

\begin{tabular}{lccc}
\hline \multicolumn{1}{c}{ Categoría Go (Proceso) } & $\begin{array}{c}\text { Enriquecimiento } \\
\text { en la red }\end{array}$ & $\begin{array}{c}\text { Enriquecimiento en el } \\
\text { genoma de S. pombe }\end{array}$ & p-valor \\
\hline Ciclo celular & $21,05 \%$ & $6,86 \%$ & $4,9 \times 10^{-5}$ \\
Señalización celular & $20,18 \%$ & $6,15 \%$ & $4,9 \times 10^{-5}$ \\
Actividad fosfatasa (desfosforilación) & $4,39 \%$ & $0,54 \%$ & $3,2 \times 10^{-5}$ \\
\hline \multicolumn{1}{c}{ Categoría Go (Componente) } & Enriquecimiento & Enriquecimiento en el & p-valor \\
\hline Microtúbulos & en la red & genoma de S. pombe & $4,38 \times 10^{-2}$ \\
\hline Categoría Go (Localización) & $2,64 \%$ & $0,21 \%$ & $\boldsymbol{p}$-valor \\
\hline Nucleolo & Enriquecimiento & Enriquecimiento en el & genoma de S. pombe \\
\hline
\end{tabular}

Las celdas resaltadas destacan aquellos términos GO con un nivel de significancia menor de 0,05, corregido por el test FDR. Análisis realizado mediante la herramienta Gene list Analyzer de Sanger. (http://www.sanger.ac.uk/cgibin/PostGenomics/S_pombe/GLA/GLA_input). Los términos GO describen procesos, componentes o localización específica. En el caso de la actividad fosfatasa, el término desfosforilación entre paréntesis corresponde a un término GO parental asociado, que ha sido identificado manualmente dentro de la jerarquía (Carbon et al., 2009; http://www.geneontology.org/).

Este análisis, resalta el enriquecimiento de la categoría relacionada con la actividad fosfatasa (Clp1, Dis2, Ppa2, Ptc2, y Ptn1), dónde dicho evento ha sido relacionado en células eucariotas, con la salida de mitosis, actuando de manera antagonista a la actividad de la CDK a lo largo del ciclo mitótico (Wolf et al., 2007; Fisher et al., 2012). Los procesos de ciclo celular y señalización celular también estuvieron sobrerrepresentados en el análisis de la jerarquía GO (BiNGO) para cdc2-3w (Tabla s9, material suplementario). De acuerdo a este último, la sobrerrepresentación se observó en las ramas de los términos $\mathrm{GO}$ asociados a procesos de regulación del ciclo celular, 
Resultados-Apartado I

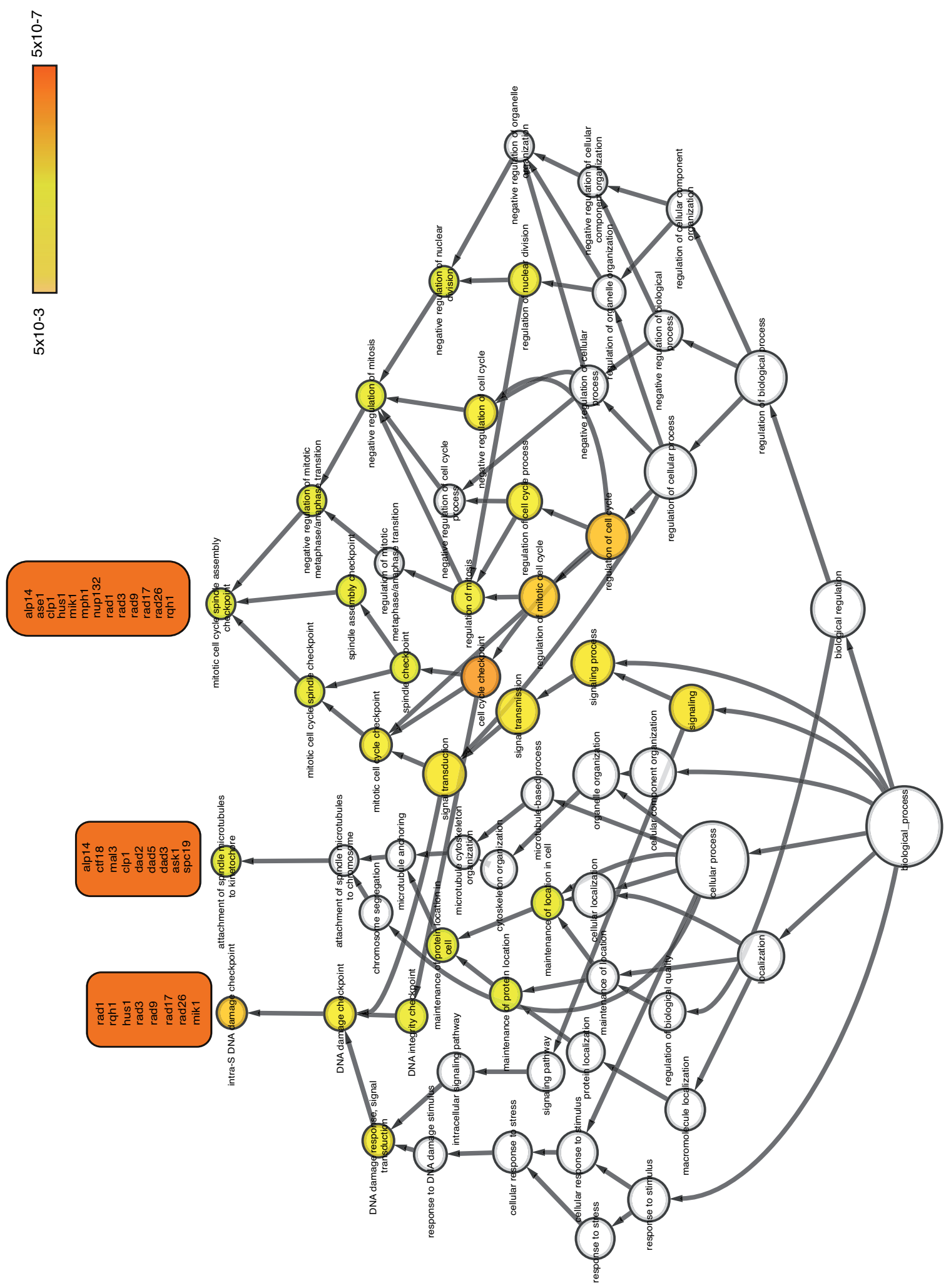

Figura 15. Gráfica que representa los términos GO sobrerrepresentados para $c d c 2-3 w$, a un nivel de significancia menor de $\mathbf{0 , 0 0 5}$. Los colores de los nódulos representan la significancia estadística (ver barra esquina derecha superior). La representación fue hecha con el complemento BiNGO de Cytoscape (Maere et 


\section{Resultados-Apartado I}

como puntos de control que incluye el de integridad del ADN y el de ensamblaje del huso mitótico. Como resultado adicional del con BiNGO, se destaca el enriquecimiento del proceso de unión de los microtúbulos a los cinetocóros.

\section{Caracterización comprensiva de los mutantes no esenciales identificados como elementos que interaccionan con wee1-50 y cdc2-3w}

Entre los mutantes con interacciones negativas identificados se seleccionaron 138 de la red de wee1-50 y 49 de cdc2-3w, una interacción genética más fuerte $(-5$ y -2$)$ y una función biológica mas relevante dentro de la red. Estos mutantes sencillos se sometieron a la evaluación de: i) su estado morfológico mediante tinciones de la pared celular y el septo con calcoflúor y observaciones poblacionales en campo claro ii) su estado citológico mediante tinciones de núcleo con DAPI y iii) su estado de la dinámica del ciclo celular mediante un análisis por citometría utilizando yoduro de propidio. Este análisis fue realizado en medio rico (YES) y medio mínimo estándar $(\mathrm{EMM})$ a $30^{\circ} \mathrm{C}$ a células en fase exponencial. El criterio de significancia biológica de los mutantes implicó la selección de algunos mutantes con una puntuación de interacción igual a -1. Para resumir los fenotipos mutantes obtenidos, se categorizaron manualmente los mutantes seleccionados de acuerdo a los fenotipos más observados en cada caso. Según las variaciones del aspecto morfológico encontradas, la clasificación fue: (0) células silvestres (1) células pequeñas (2) células largas, (3) células multiseptadas, (4) células curvadas, (5) formas heterogéneas, dónde se observaron subpoblaciones con diferentes morfologías ( $p$. ej. células pequeñas, largas, redondas, etc.) y (6) pérdida de polaridad.

Para el estado citológico, los fenotipos se clasificaron en: (0) silvestre, (1) núcleos fragmentados, (2) fenotipo de corte de núcleo (cut phenotype), (3) septación aberrante ( $p$. ej. células con uno y/o dos núcleos al lado de uno o múltiples septos) (4) células sin núcleo, (5) núcleos descondensados, (6) septos múltiples (7) células multiseptadas, (8) células multinucleadas (p. ej. células binucleadas o células con varios núcleos sin septo) y 9) cromosomas con retraso en la segregación (lagging chromosomes).

Las células de $S$. pombe crecidas en YES y en EMM presentan un contenido 2C, debido a que no completan la citoquinesis hasta el inicio de la fase $S$ (Sabatinos y Forsburg, 2009). Por lo tanto, a partir de un análisis de citometría de flujo convencional, es complejo investigar fenotipos de ciclo provocados por la ausencia de un gen. Para evitar esto, se 
realizó un análisis del ciclo celular empleando la metodología descrita por Knutsen et al., 2011, el cual permite distinguir entre células mononucleadas (fase G2) y binucleadas (fase G1) y a su vez explorar en detalle la progresión por el ciclo de las células. A su vez permite eliminar el efecto de agregación, a pesar del tratamiento de sonicación en la preparación de las muestras, que da lugar a problemas de pérdida de información o mala interpretación de los resultados.

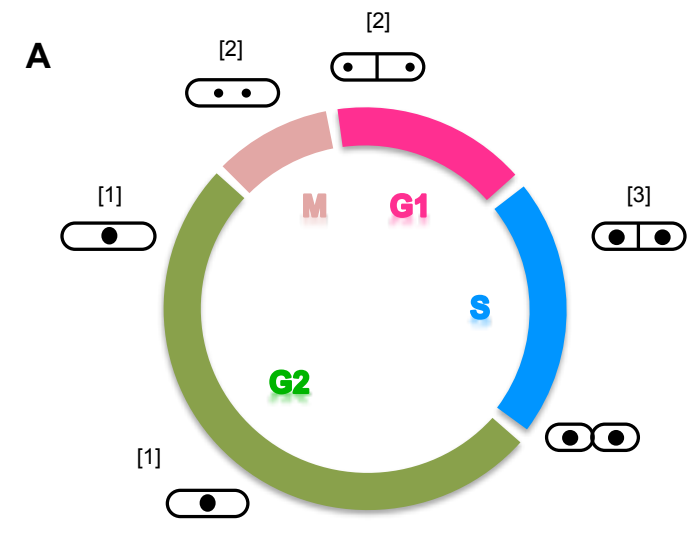

B

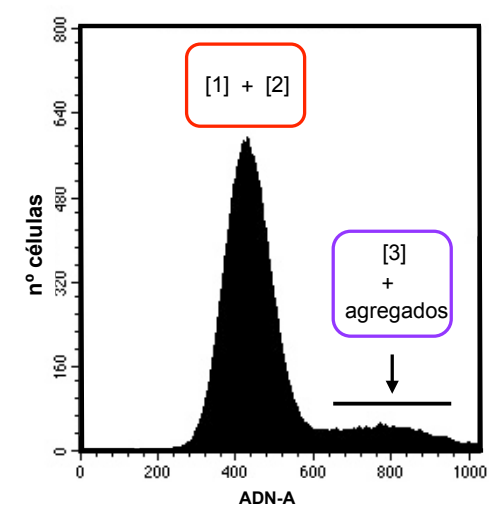

C

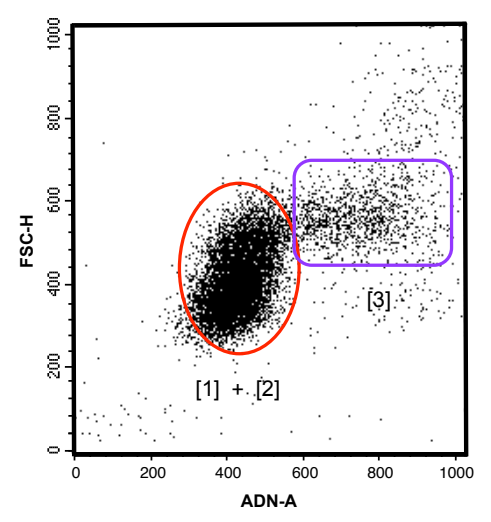

D
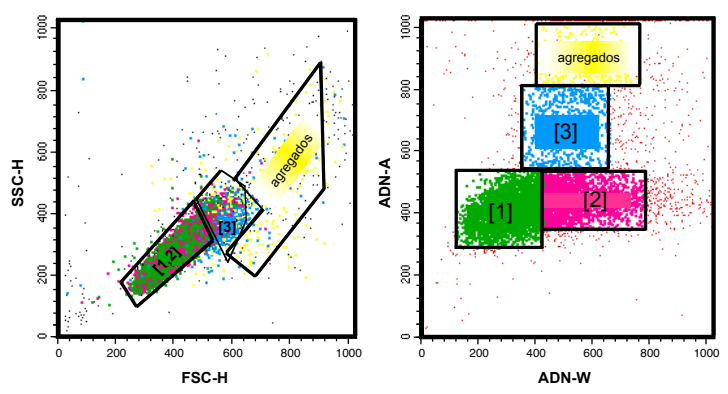

Figura 16. Análisis de la dinámica de ciclo celular de los mutantes con interacciones genéticas con wee1-50 y cdc2-3w. La figura A muestra un esquema del ciclo celular de células de $S$. pombe en crecimiento exponencial. Las figuras $\mathbf{B}$ y $\mathbf{C}$ representan citogramas que comparan $\mathrm{n}^{\circ}$ de células y ADN-A y FSC-H y ADN-A respectivamente. La figura $D$ representa citogramas que comparan FSC-H y SSC-H y ADN-A y ADN$W$ respectivamente. Los recuadros que delimitan las subpoblaciones son llamados ventanas.

En la Figura 16 se muestra un ejemplo de análisis de ciclo celular bajo esta metodología. Dicha figura muestra un citograma que compara el parámetro ADN-W vs ADN-A. En este caso, una célula binucleada se localiza hacia la derecha de la señal del ADN-W con respecto a una mononucleada y a su vez una célula con contenido $1 \mathrm{C}$ más baja que una $2 \mathrm{C}$ en la señal del $\mathrm{ADN}-\mathrm{A}$. De esta forma se distinguen 3 subpoblaciones: 


\section{Resultados-Apartado I}

1) células en fase $G 2$ con un núcleo de contenido $2 C, 2$ ) células en $G 1$ o mitosis tardía con dos núcleos de contenido $1 \mathrm{C}$ cada uno y 3 ) células en fase $S$ con un contenido entre $2 \mathrm{C}$ y $4 \mathrm{C}$. Las células agregadas son identificadas en el citograma que compara el parámetro FSC (tamaño) con SSC (complejidad) y posteriormente omitidas en el análisis mediante ventanas.

Posterior a este análisis se clasificaron los fenotipos del ciclo celular en función de su contenido y de la progresión de las fases: (0) células silvestres, dónde el citograma combina las subpoblaciones 1 y 3 (1) células con población en G1, dónde el citograma combina las subpoblaciones 1 y 2 , y (2) células con una menor población de células en fase $S$, posiblemente debido a una citoquinesis adelantada, (3) células grandes en fase $S$, debido a un probable retraso en replicación y citoquinesis y (4) células grandes en fase G2, por posible retraso en la entrada a mitosis. Asimismo, se corroboró mediante este análisis los datos de tamaño observado en el análisis de morfología y citología.

La Tabla S10 y S11 (ver material suplementario), resume los resultados de las tres aproximaciones empleadas en la caracterización comprensiva de los mutantes sintéticos letales o enfermos con wee1-50 o cdc2-3w respectivamente. A su vez, estos se distribuyen de acuerdo al análisis funcional descrito anteriormente.

\section{Predicción de una red genética complementaria}

Finalmente, se investigó si era posible predecir la existencia de nuevas interacciones genéticas que revelaran conexiones entre los genes identificados en común como sintéticos letales o fuertes con wee1-50 y cdc2-3w. Para esto, se empleó la herramienta PInt (del inglés Pombe Interactome) desarrollada por Pancaldi et al., 2012, la cual predice con base en el algoritmo SVM (del inglés Supported Vector Machine) o RF (del inglés Random Forest), una posible red de interacciones entre los genes identificados, que podrían guiar la búsqueda de la relación funcional entre estos genes y la maquinaria de regulación del ciclo celular. Estos algoritmos tienen en cuenta las interacciones genéticas y físicas descritas para $S$. pombe y $S$. cerevisiae en la base de datos BioGRID hasta la fecha (Stark et al., 2006). Asimismo, predicen las interacciones de acuerdo a características descritas de las proteínas, incluyendo sus propiedades físicas y químicas, la posición física en el cromosoma, los términos GO superslim, las condiciones de expresión y la colocalización. Los autores de esta herramienta afirman, que de acuerdo a 
la relación de interacciones predichas e identificadas experimentalmente, esta herramienta tiene un valor positivo de predicción del $73 \%$.

En consecuencia, dicha predicción imita, en cierto sentido, los resultados de un análisis genético E-MAP (del inglés epistatic miniarray profiles), el cual identifica interacciones positivas ( $p$. ej. interacción proteína-proteína) y negativas, junto con el grado de severidad, observadas tras la combinación por parejas de un grupo de genes (Schuldiner et al., 2006; Collins et al., 2010). Mediante el uso de la metodología E-MAP se han identificado interactomas genéticos, que describen el equilibrio molecular y celular para el genoma de S. pombe (Roguev et al., 2008; Ryan et al., 2012) y S. cerevisiae (Costanzo et al., 2010).

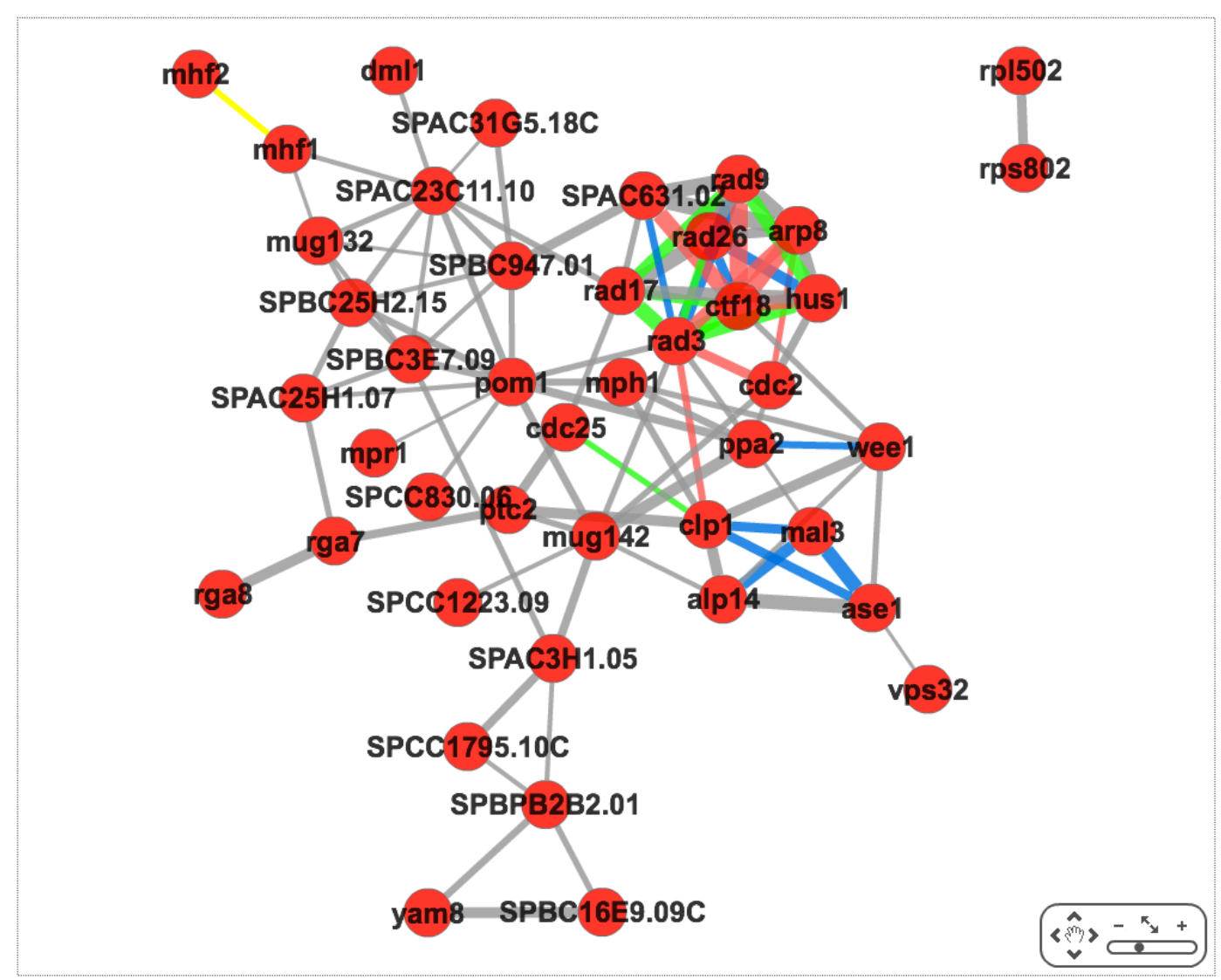

Figura 17. Red de interacción, predicha con la herramienta PInt (Pancaldi et al., 2012), entre los genes comunes identificados para la red con wee1-50 y cdc2-3w. Las proteínas de interés son representados en la red como nódulos rojos, cuya significancia de interacción es dependiente del grosor de la línea que los une. Las predicciones son contrastadas con la base de datos BioGRID (Stark et al., 2006) y presentan un pvalor menor de 0,05. Aquellas que han sido experimentalmente identificadas son ilustradas en verde y azul si se refieren a interacciones proteína-proteína o interacciones genéticas negativas descritas en $S$. pombe 


\section{Resultados-Apartado I}

En este caso, la predicción se realizó para los 45 genes identificados en común junto con los genes wee1, cdc2 y cdc25 para dirigir la misma hacia el sistema de regulación de entrada a mitosis. En total se identificaron 247 interacciones con un p-valor por encima de 0,05 en ambas pruebas estadísticas (Figura S1; material suplementario). El uso de ambos algoritmos tuvo como objetivo la obtención de resultados mas fiables (Tabla S11; material suplementario). La representación de la Figura 17, incluye las 100 interacciones con el nivel de significancia mas alto ( $p$-valor SVM $>0,74$ y RF $>0,54$ ). 


\section{Resultados Apartado II}




\section{Identificación del gen $p p a 2^{+}$como un regulador de ciclo en $S$. pombe}

Como se ha comentado en la introducción, el ciclo celular se compone de una serie de eventos que son regulados temporalmente a través de oscilaciones en la actividad de la quinasa dependiente de ciclina (Cdk1) (Nurse, 1990). El hecho de que el ciclo celular requiera eventos moleculares dependientes de fosforilación, plantea la existencia de fosfatasas que contrarresten dichas fosforilaciones y por lo tanto que la división celular requiera una coordinación crítica entre proteínas quinasas y proteínas fosfatasas (Uhlman et al., 2011; Mochida y Hunt, 2012). Aunque aún no se conoce en particular las fosfatasas encargadas de desfosforilar los sustratos de la Cdk durante el ciclo celular, Mochida et al., (2009) identificaron en Xenopus una forma activa del complejo fosfatasa PP2A, conocida como PP2A-B55ס con un patrón de actividad inverso a la Cdk, siendo esta alta durante interfase y baja durante mitosis. Asimismo, también en Xenopus, se propuso que la actividad de PP2A-B55ס, es regulada por una quinasa denominada Greatwall (Gwl), cuya función es inactivarla a la entrada mitosis y durante ésta, para promover la fosforilación de los sustratos Cdk-ciclina B (Vigneron et al., 2009, Casthilo et al., 2009). Dicha inactivación, al menos a la entrada de mitosis, es llevada a cabo a través de dos potentes inhibidores de PP2A-B55ס conocidos en Xenopus como Ensa y Arrp-19 (Garbi-Ayachi et al., 2010; Mochida et al., 2010). Hasta ahora, modelos análogos de esta regulación se han propuesto en otros organismos como Drosophila (Wang et al., 2010), humanos (Voets y Wolthuis, 2010) y S. cerevisiae (Juanes et al., 2013), sin embargo dicho modelo aún no ha sido identificado en la levadura de fisión $S$. pombe.

\subsection{La deleción de $p p a 2^{+}$genera células mas pequeñas que la cepa silvestre}

Para entender el papel de la fosfatasa tipo 2A en el ciclo celular, se examinó el fenotipo de deleción de las subunidades $p p a 2^{+}$y $p p a 1^{+}$en $S$. pombe. Para ello, se reemplazó la ORF del gen $p p a 2^{+}$y ppa $1^{+}$por el cassette natMx 6 y kanMX6 respectivamente y se analizó el tamaño celular de ambos mutantes, tomando como referencia células en estado de septación (Mitchison, 2003). En la Figura 1, se observa que tanto la deleción del gen $p p a 1^{+}$como la de $p p a 2^{+}$tienen un tamaño menor que la cepa silvestre, sin embargo dicho efecto es mas acentuado en las células mutantes que carecen de $p p a 2^{+}$. Estos resultados, sugieren la que subunidad catalítica Ppa2 tiene un papel mas relevante 


\section{Resultados-Apartado II}

en el control del ciclo celular con respecto a Ppa1. Lo anterior se encuentran en la línea de lo observado por Kinoshita et al., 1990 y Navarro y Nurse, 2012.

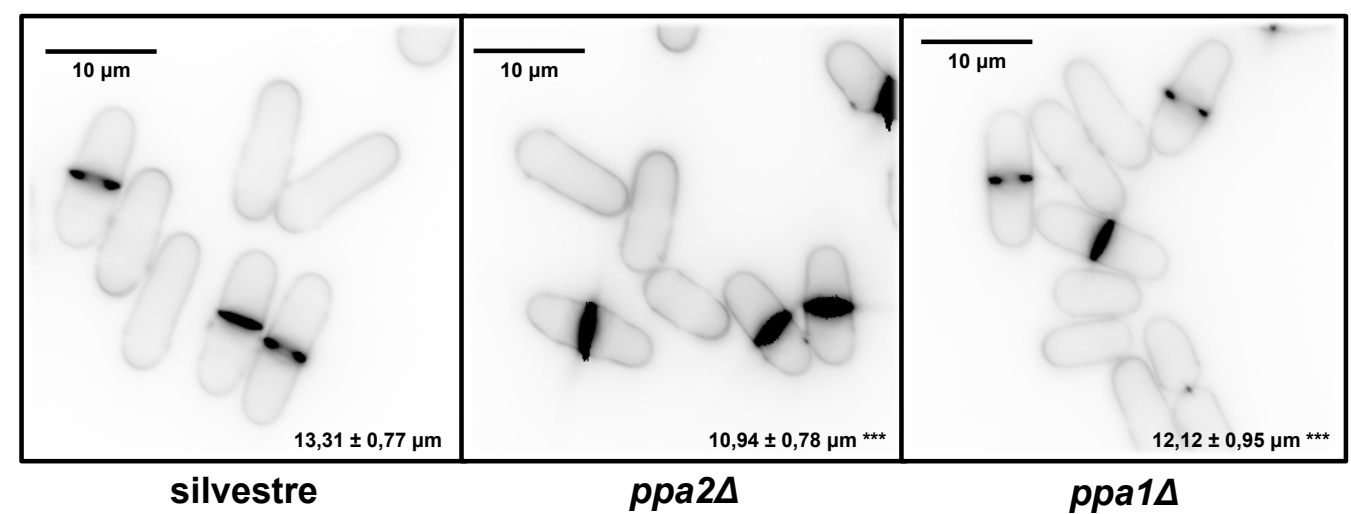

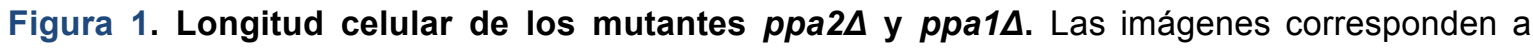
células crecidas en YES a $32^{\circ} \mathrm{C}$ exponencialmente, que fueron teñidas in vivo con blankophor. La longitud celular es representada como la media (en $\mu \mathrm{m}$ ) de 100 células septadas \pm la desviación estándar. ${ }^{* * *}$ indica una diferencia significativa ( $p$-valor $<0,001$ determinado mediante el test $T$ de Student) entre el mutante y la cepa silvestre.

Las células mutantes ppa2 $\Delta$ son más pequeñas que las cepas silvestres, sugiriendo un fenotipo de ciclo asociado a una fase G2 mas corta. De acuerdo al efecto de la deleción observado en ambos mutantes, la subunidad catalítica $p p a 2^{+}$desempeña un papel mas relevante en el ciclo celular de $S$. pombe con respecto a ppa $1^{+}$.

\subsection{El mutante de deleción de la fosfatasa tipo $2 \mathrm{~A}$ ppa2 $\Delta$ es sintético letal con}

Según Kinoshita et al., 1990 y Navarro y Nurse, 2012, los genes $p p a 1^{+}$and $p p a 2^{+}$ están implicados en el control del ciclo celular de $S$. pombe. De acuerdo a lo observado en nuestro escrutinio, los dobles mutantes ppa2 $\Delta$ wee1-50 y ppa2 $\Delta$ cdc2-3w son sintéticos letales. No obstante, los mutantes sencillos wee1-50 y cdc2-3w no están afectados en su viabilidad. Cuando el mutante termosensible wee1-50 se crece a $35^{\circ} \mathrm{C}$, se inactiva la proteína Wee1, y en consecuencia la fase G2 se acorta y las células se dividen a un tamaño menor con respecto a la cepa silvestre. En el caso de cdc2-3w, dicha mutación es equivalente a una hiperactivación de Cdc25, por lo que al igual que wee1-50 las células reducen su tamaño. Para comprobar la interacción genética del gen ppa $2^{+}$con el mutante wee1-50 observada en el escrutinio, se realizó un ensayo de viabilidad en placa (medio YEP-agar) en un rango de temperatura entre $25^{\circ} \mathrm{C}$ a $36^{\circ} \mathrm{C}$. Como se ilustra en la Figura 2A, el doble mutante wee1-50 ppa2 $\Delta$ presenta una 
A

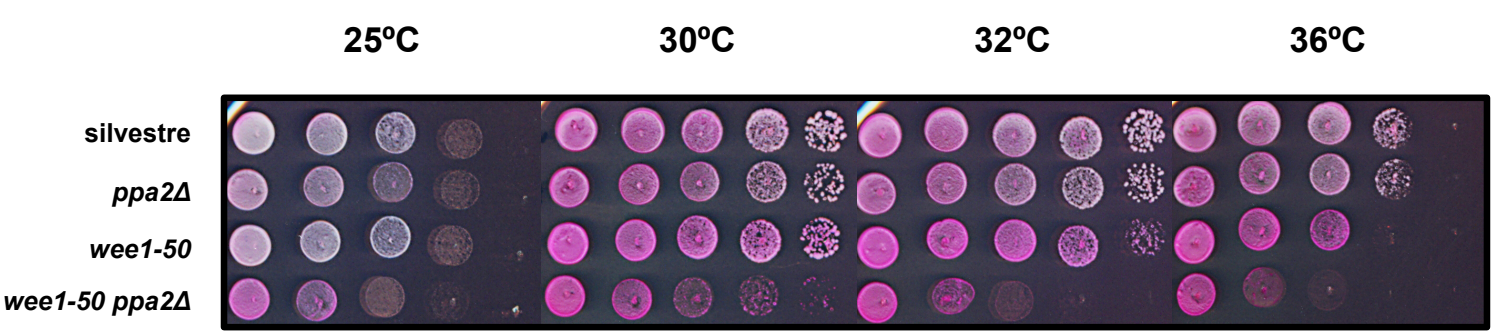

B

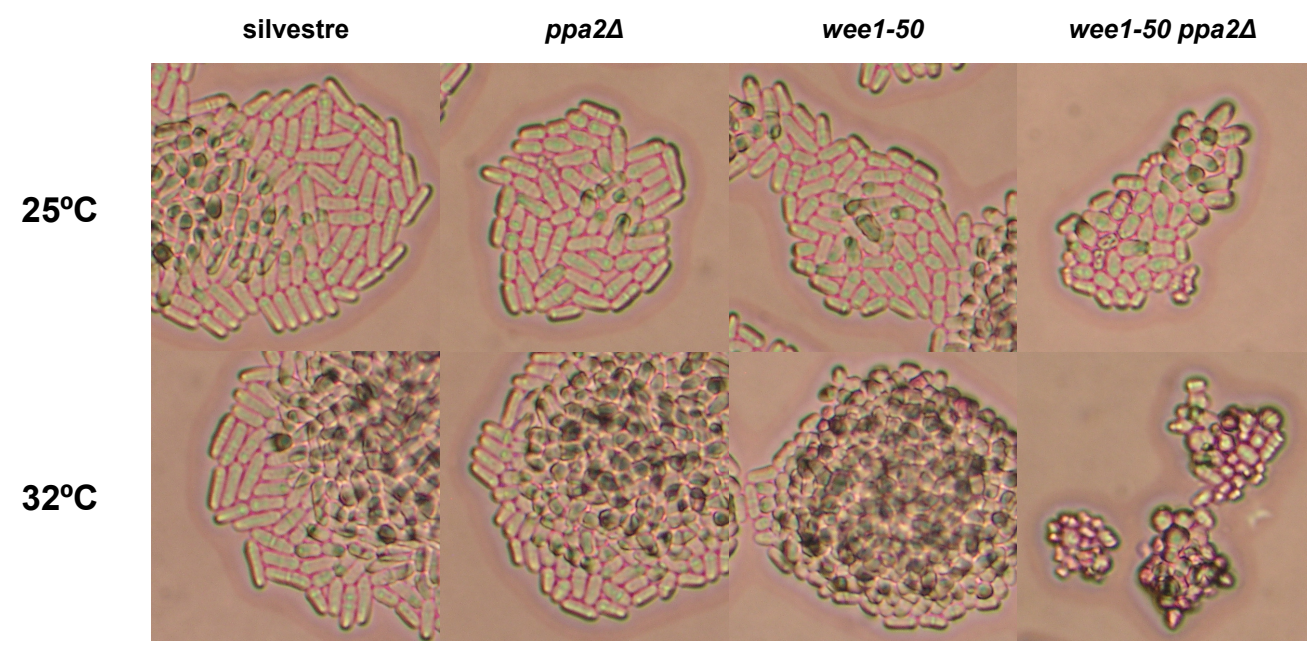

Figura 2. Interacción genética entre ppa2 $\Delta$ y wee1-50. La deleción del gen $p p a 2^{+}$en el fondo genético wee1-50 induce pérdida de viabilidad. (A) Ensayo de viabilidad en placas de YEP (YESAgar con floxina $\mathrm{B}$ ) desde $25^{\circ} \mathrm{C}$ a $36^{\circ} \mathrm{C}$. Las imágenes corresponden a 72 horas de crecimiento. (B) Microcolonias de 16 horas de crecimiento en YEP a $25^{\circ} \mathrm{C}$ y $32^{\circ} \mathrm{C}$.

inhibición en el crecimiento a partir de $32^{\circ} \mathrm{C}$ en comparación con la cepa silvestre y los parentales. De igual manera, en la Figura 2B se observa que el doble mutante tiene un tamaño más pequeño que wee1-50, incluso a $25^{\circ} \mathrm{C}$.

El mutante ppa2 $\Delta$ en combinación con wee1-50 es letal, debido a una reducción en el tamaño celular del doble mutante que genera un acortamiento inviable de la fase G2.

\subsection{La deleción de ppa2s rescata parcialmente el fenotipo del mutante}

Las células de $S$. pombe que portan el alelo termosensible cdc25-22 se bloquean al final de la fase $\mathrm{G} 2$ cuando se crecen a la temperatura restrictiva de $36^{\circ} \mathrm{C}$. Como se ha observado, la ausencia del gen ppa $2^{+}$genera un acortamiento en la fase $\mathrm{G} 2$, por lo cual se podría esperar que la pérdida de su actividad atenué los defectos del mutante cdc2522. Para probar esta hipótesis, se examinó el fenotipo del doble mutante ppa2 $\Delta$ cdc25-22 


\section{Resultados-Apartado II}

empleando la misma aproximación anterior. En dicho experimento, se observó que las células del doble mutante ppa2 $\Delta$ cdc25-22 presentan una ligera reducción en el tamaño celular en comparación con el mutante cdc25-22 (Figura 3B), sugiriendo que la falta de actividad de la fosfatasa Ppa2 aparentemente incrementa la actividad de Cdc25.

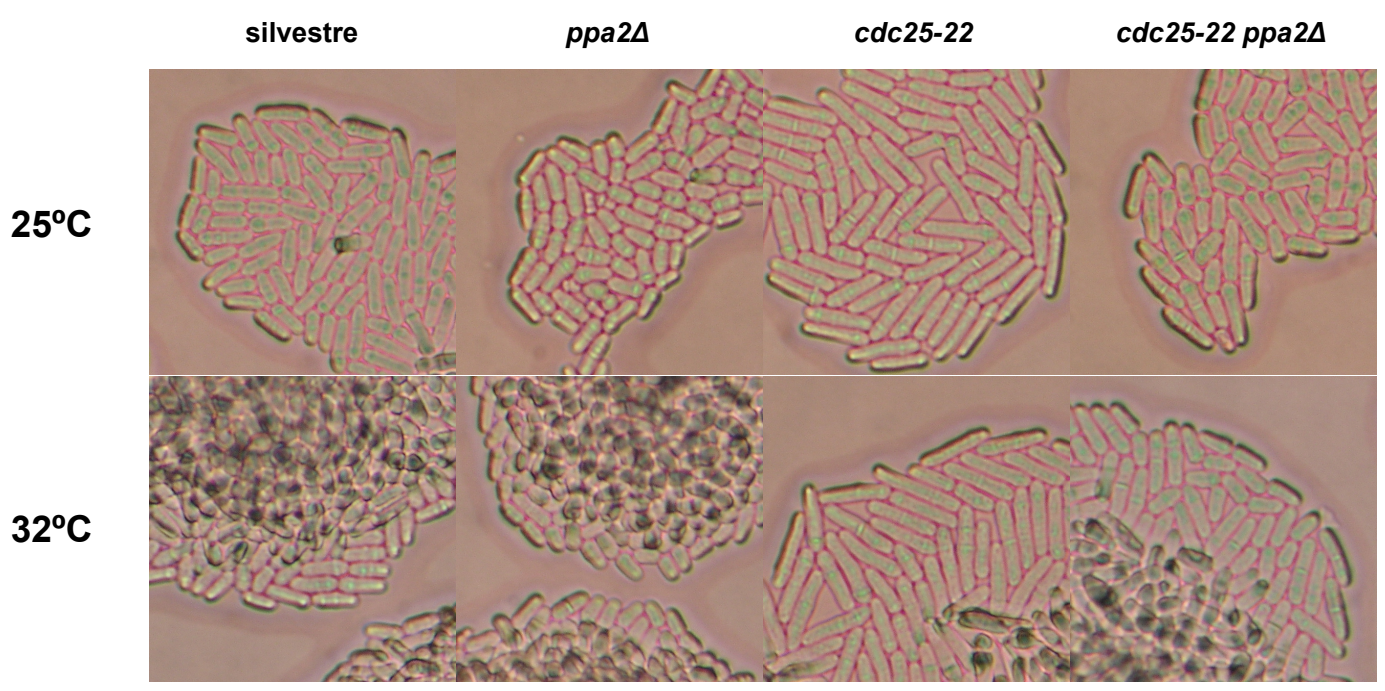

Figura 3. Interacción genética entre ppa2s y cdc25-22. La ausencia de $p p a 2^{+}$suprime parcialmente el incremento de la longitud celular del mutante $c d c 25-22$. Microcolonias de 16 horas de crecimiento en YES-Agar con floxina $\mathrm{B}$ a $25^{\circ} \mathrm{C}$ y $32^{\circ} \mathrm{C}$.

El fenotipo de alargamiento del mutante termosensible cdc25-22 es suprimido parcialmente por la deleción del gen $\mathrm{ppa}^{+}{ }^{+}$, indicando una relación funcional en la actividad de estas proteínas.

A partir de los resultados expuestos en el apartado 1, se sugiere que la proteína fosfatasa PP2A podría tener un papel asociado al ciclo celular en S.pombe y que dicho papel estaría relacionado a una regulación negativa de la entrada a mitosis.

2. Identificación de dos nuevos reguladores de la entrada a mitosis en S. pombe

\subsection{Identificación del homólogo funcional de Ensa y Arrp19 en S. pombe}




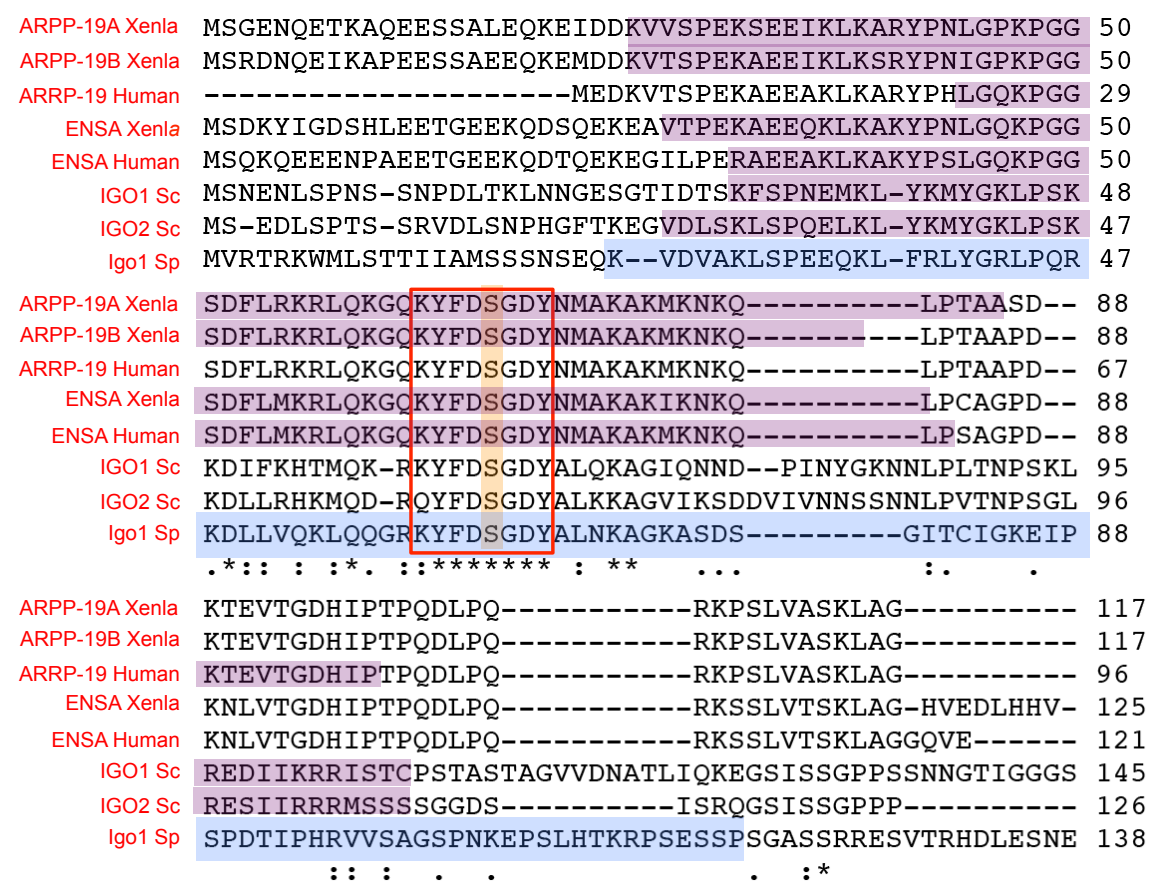

Figura 4. Alineamiento de las secuencias de los homólogos de Ensa y Arrp19 en humanos, Xenopus y levaduras. El ortólogo potencial de Ensa y Arrp-19 en S. pombe es Igo1. El dominio endosulfina para Igo1 $(\mathrm{Sp})$ es señalado en azul, para el resto de organismos en violeta

Hasta el momento se ha demostrado que el fenotipo de deleción del gen $p p a 2^{+}$se asocia a alteraciones del ciclo celular. Dicho papel se encuentra en la línea de lo observado en otros eucariotas, dónde la ruta Greatwall-Ensa desempeña una función importante frente a la actividad de PP2A-B55 contra fosforilaciones catalizadas por la Cdk durante mitosis (Vigneron et al., 2010; Mochida et al., 2009). Ensa y Arrp-19 son miembros de una familia de proteínas conservadas evolutivamente. Para identificar la proteína homóloga a éstas en $S$. pombe, se realizó una análisis de homología BLAST (http://blast.ncbi.nlm.nih.gov/) empleando las secuencias codificantes para las versiones humanas y de Xenopus. A partir de este análisis, se identificó una proteína con un $38 \%$ de identidad, llamada Mug134 o Igo1 (SPAC10F6.16), de acuerdo al nombre establecido para sus ortólogos IGO1/IGO2 (Initiation of G zerO) en S. cerevisiae. Conforme a la base de datos Pombase (http://www.pombase.org), el producto codificado por SPAC10F6.16 es bastante pequeño (139 aminoácidos), no es esencial y aún no ha sido caracterizado en S. pombe. Para evitar confusiones, en esta memoria se hará referencia a esta proteína 


\section{Resultados-Apartado II}

como Igo1, ya que el nombre Mug134, asignado como principal, es un error de curación de esta base. La verdadera proteína Mug134 corresponde al producto codificado por la ORF SPAC10F6.15 (Martín-Castellanos et al., 2005).

Como producto del alineamiento de las secuencias, se observa la presencia de un dominio central conservado en todas las especies analizadas, llamado dominio endosulfina (Figura 4). A su vez, dicho dominio contiene el sitio de fosforilación por Greatwall formado por la región consenso KYFDSGDY y que ha sido previamente descrito por Garbi-Ayachi et al., 2010; Mochida et al., 2010.

\subsection{Las células del mutante igo1 $\Delta$ se dividen a un tamaño celular mayor que las de la cepa silvestre}

Para confirmar que el gen igo $1^{+}$es el ortólogo funcional de Ensa y Arrp-19, se evaluó si la deleción de igo $1^{+}$podría provocar un fenotipo de ciclo que se ajustara con su función inhibitoria de la actividad del complejo PP2A-B55ס. Recordemos que este complejo contrarresta la actividad Cdk y mantiene las células en interfase como regulador negativo de la actividad de Cdc25 y positivo de la actividad de Wee1. Con este objetivo, se crecieron células de la cepa silvestre y cinco clones de la cepa mutante igo1::kanMX6 en YES a $25^{\circ} \mathrm{C}$ hasta alcanzar una D.O ${ }_{(595 \mathrm{~nm})}$ entre 0,5 y 0,6. A continuación, se realizaron mediciones de la longitud celular a células septadas y se estudió su perfil de ciclo celular mediante una análisis de citometría de flujo (FACS). Como resultado, el análisis de FACS (Figura 5B) señaló un ligero incremento del tamaño celular del mutante igo1 $\Delta$ con respecto a la cepa silvestre, que fue consistente en todos los clones analizados. De acuerdo a las mediciones en la longitud celular, la ausencia de igo $1^{+}$incrementa el tamaño en un $10 \%$ con respecto a la cepa silvestre bajo estas condiciones (Figura 5A). En relación al contenido de $A D N$, no se encontraron diferencias con la cepa silvestre (Figura 5B).

La deleción de igo $1^{+}$genera un ligero incremento en la longitud celular de S. pombe en condiciones estándar de crecimiento. Esto apoya la hipótesis de que Igo1 actúa como un regulador positivo de la entrada a mitosis. 
A

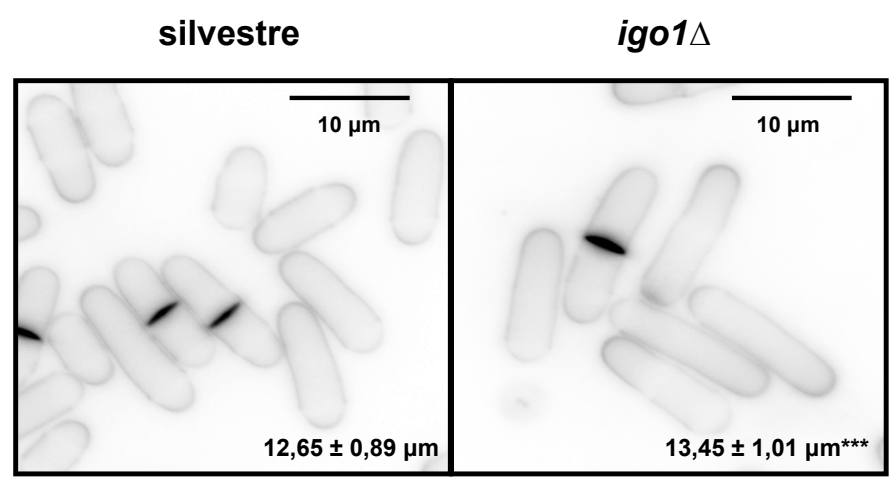

B

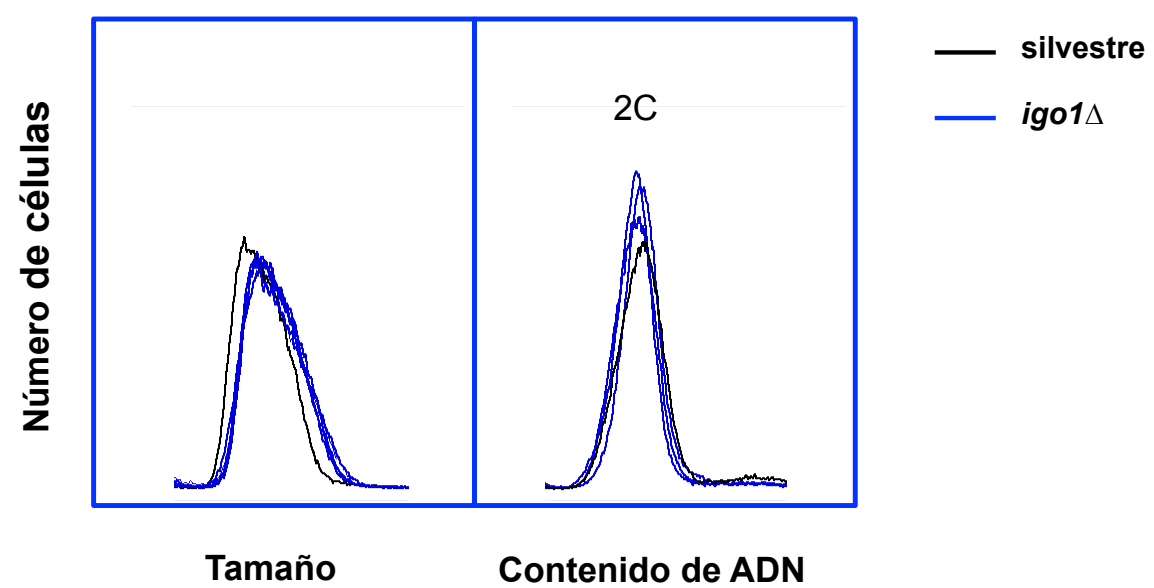

Figura 5. Análisis fenotípico del mutante de deleción igo1s. La deleción del gen $i g \circ 1^{+}$ incrementa la longitud celular de S. pombe. Las células crecieron hasta fase exponencial en YES a $25^{\circ} \mathrm{C}$. Para las mediciones celulares, se realizó una tinción in vivo con blankophor. La longitud celular es representada como la media (en $\mu \mathrm{m}$ ) de 100 células septadas \pm la desviación estándar. *** indica una diferencia significativa $(p$-valor $<0,001)$ entre el mutante y la cepa silvestre.

\subsection{La ausencia de igo1+ agrava el fenotipo del mutante termosensible cdc25-22}

Para continuar con el estudio de lgo1 como un posible regulador positivo de la entrada a mitosis, se probó si la deleción de igo ${ }^{+}$era capaz agravar el fenotipo de pérdida de viabilidad del mutante termosensible cdc25-22. Con este fin, se evaluó la viabilidad del doble mutante $c d c 25-22$ igo1 $\Delta$ en placas de YEP-agar incubadas a $25^{\circ} \mathrm{C}$, $30^{\circ} \mathrm{C}, 32^{\circ} \mathrm{C}$ y $36^{\circ} \mathrm{C}$ en comparación con las cepas silvestre y parentales. Igualmente, se realizó un seguimiento del crecimiento de las células al microscopio después de 16 horas de crecimiento en placa. 


\section{Resultados-Apartado II}

A

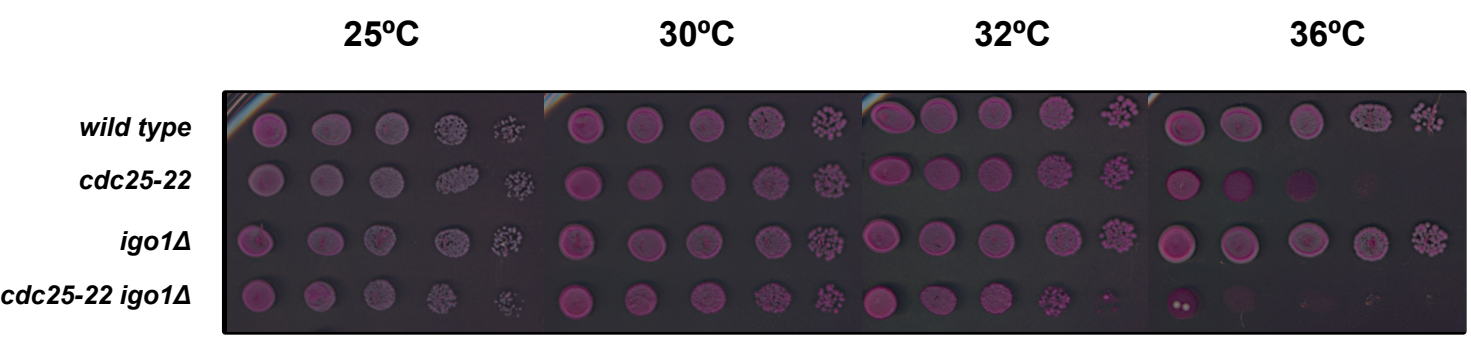

B

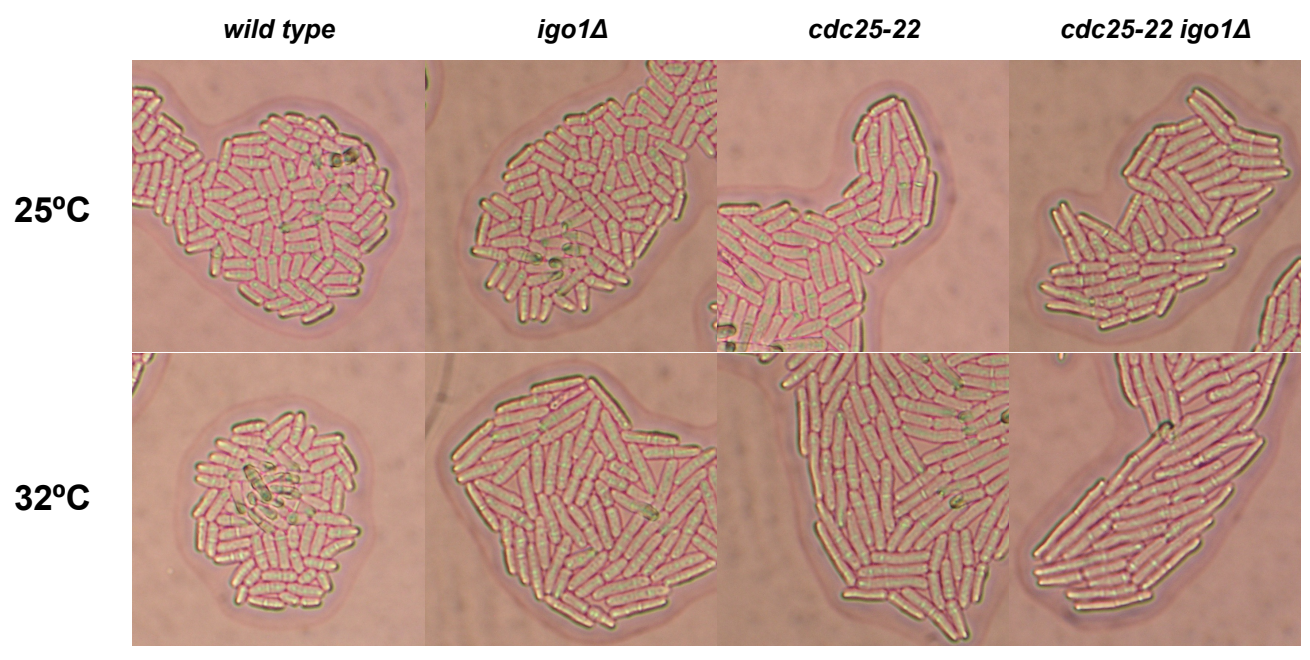

Figura 6. Interacción genética entre igo1 y y cdc25-22. La ausencia de igo $1^{+}$agrava el fenotipo del mutante cdc25-22. (A) Ensayo de viabilidad en placas de YEP (YES-Agar con floxina B) desde $25^{\circ} \mathrm{C}$ a $36^{\circ} \mathrm{C}$. Las imágenes corresponden a 48 horas de crecimiento. (B) Microcolonias de 16 horas de crecimiento en YEP a $25^{\circ} \mathrm{C}$ y $32^{\circ} \mathrm{C}$.

Tabla 1. Análisis epistático entre $c d c 25-22$ y igo1 $\triangle$ en $Y E S$ a $25^{\circ} \mathrm{C}$ y $30^{\circ} \mathrm{C}$

\begin{tabular}{c|c||c|c}
\hline Cepa (YES) & $\begin{array}{c}\text { Longitud celular } \\
(\mu \mathrm{m} \pm \mathrm{d} . \mathrm{e})\end{array}$ & Cepa (YES) & $\begin{array}{c}\text { Longitud celular } \\
(\boldsymbol{\mu m} \pm \text { d.e) }\end{array}$ \\
\hline$c d c 25-22 \mathbf{2 5}^{\circ} \mathrm{C}$ & $21,2 \pm 2,01$ & $c d c 25-22 \mathbf{3 0 ^ { \circ } \mathrm { C }}$ & $24,1 \pm 3,61$ \\
\hline$c d c 25-22$ igo $1 \Delta \mathbf{2 5}^{\circ} \mathrm{C}$ & $21,8 \pm 4,16$ & $c d c 25-22$ igo $1 \Delta \mathbf{3 0} \mathrm{C}$ & $31,1 \pm 7,12^{* *}$ \\
\hline
\end{tabular}

La longitud celular es representada como la media (en $\mu \mathrm{m})$ de 100 células septadas \pm la desviación estándar. ** indica una diferencia significativa ( $p$-valor $<0,01)$ entre el mutante cdc2522 y el doble con igo1 1 . 
En la Figura $6 \mathrm{~A}$ se observa como la ausencia de $i g 01^{+}$agrava la pérdida de viabilidad del mutante $c d c 25-22$ a $32^{\circ}$ y $36^{\circ} \mathrm{C}$. De acuerdo a las observaciones de células en monocapa (Figura 6B), el doble mutante cdc25-22 igo1 $\Delta$ presenta un incremento en la longitud celular que es sólo evidente a $32^{\circ} \mathrm{C}$. Para verificar si este efecto también se presenta a temperaturas inferiores de $32^{\circ} \mathrm{C}$, se midió el tamaño celular en YES a $25^{\circ} \mathrm{C}$ y $30^{\circ} \mathrm{C}$ y se confirmó que el incremento se induce a partir de los $30^{\circ} \mathrm{C}$ (Tabla 1 ).

La deleción de igo $1^{+}$agudiza la pérdida de viabilidad del mutante termosensible cdc25-22 a partir de $32^{\circ} \mathrm{C}$ e incrementa su longitud celular desde $30^{\circ} \mathrm{C}$. Esto sugiere que Igo1 regula positivamente a Cdc25.

\subsection{La ausencia de Igo1 suprime la reducción de tamaño del mutante wee1-50}

A

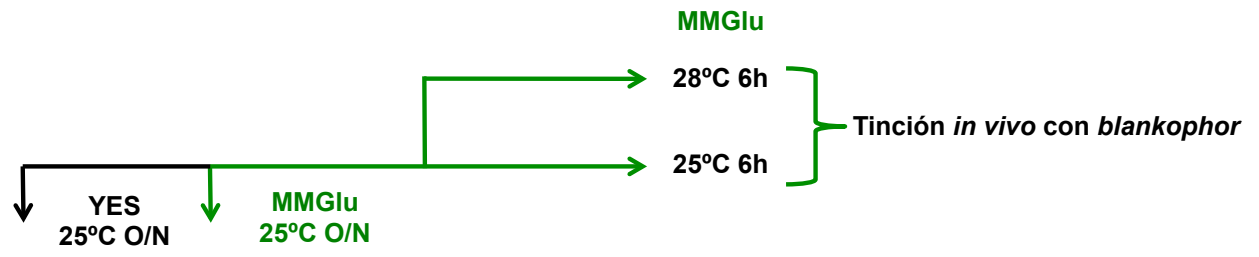

B

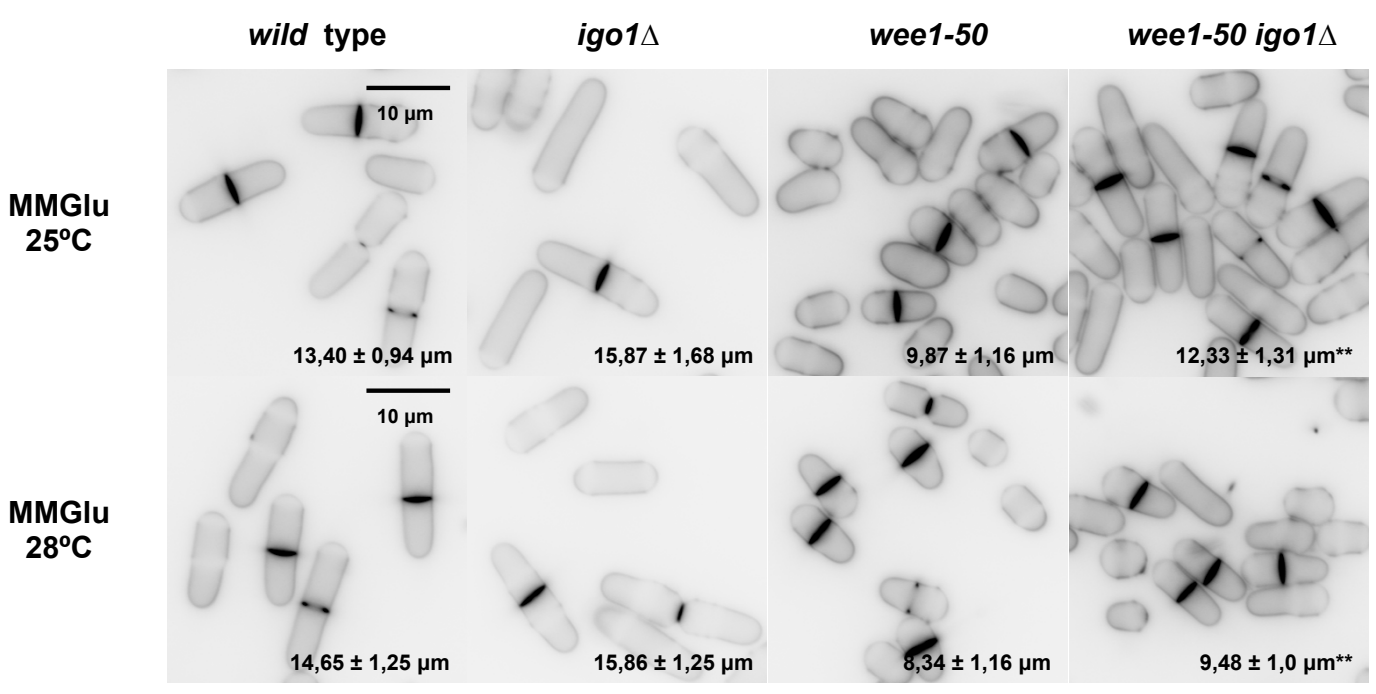

Figura 7. La ausencia de igo1 ${ }^{+}$suprime la reducción del tamaño celular del mutante wee1-50 en MMGlu a $25^{\circ} \mathrm{C}$ y $28^{\circ} \mathrm{C}$. (A) Las células de la cepa silvestre y los mutantes wee1-50, igo1 $\Delta$ y wee1-50 igo1 $\Delta$ se crecieron exponencialmente en YES a $25^{\circ} \mathrm{C}$, luego se transfirieron a MMGlu durante una noche y al día siguiente se dividieron en dos alícuotas, que posteriormente se incubaron en MMGlu a $25^{\circ} \mathrm{C}$ y $28^{\circ} \mathrm{C}$ durante 6 horas. (B) Las células se tiñeron con blankophor. La longitud celular es representada como la media (en $\mu \mathrm{m}$ ) de 100 células septadas \pm la desviación estándar. ${ }^{* * *}$ indica una diferencia significativa entre wee1-50 y wee1-50 igo1 $\Delta$ ( $p$-valor $<0,001$ determinado mediante el test T de Student 


\section{Resultados-Apartado II}

Cuando se transfieren células del mutante termosensible wee1-50 desde $25^{\circ} \mathrm{C}$ a $36^{\circ} \mathrm{C}$ se produce una entrada prematura a mitosis por inactivación de la quinasa Wee1. Si Igo1 actúa como un regulador positivo, se esperaría que su ausencia rescate dicha entrada prematura. Para probar esta hipótesis, se realizó un ensayo de medición celular en MMGlu a partir de un cultivo de la cepa wee1-50 igo1 $\Delta$ creciendo exponencialmente a $25^{\circ} \mathrm{C}$ y $28^{\circ} \mathrm{C}$ (Figura $7 \mathrm{~A}$ ). La comparación del tamaño celular se efectuó frente a la cepa silvestre y los mutantes parentales. En la Figura 7B se observa que el mutante wee1-50 manifiesta una reducción en el tamaño celular desde $25^{\circ} \mathrm{C}$ y que dicha reducción es suprimida hasta niveles casi silvestres por la ausencia de $i g 01^{+}$. De igual forma se observa, que la longitud celular del mutante igo1 incrementa 2,5 $\mu \mathrm{m}$ (Figura 7B) con respecto a la longitud observada en YES $25^{\circ} \mathrm{C}$ (Figura $5 \mathrm{~A}$ ).

La deleción de $i g o 1^{+}$suprime el fenotipo del mutante wee1-50 a $25^{\circ} \mathrm{C}$ y en medio restrictivo aumenta el retraso en la fase G2 de las células igo1 $\Delta$.

A partir de los resultados obtenidos en el apartado 2, se propone que Igo1 regula positivamente la actividad de Cdc25 y negativamente la actividad de Wee1.

\section{La función biológica de Igo1 esta sujeta a una modulación nutricional}

\subsection{El fenotipo de retraso en la entrada a mitosis del mutante igo1 $\Delta$ se acentúa bajo estrés por nitrógeno}

En el apartado anterior se observó que la deleción de $i g o 1^{+}$presenta un fenotipo contrario al de la deleción de $p p a 2^{+}$, el cual se incrementa en condiciones nutricionales restrictivas. En S. pombe, se ha reportado que el acoplamiento entre el tamaño y la progresión del ciclo celular depende la disponibilidad de nutrientes. Cuando las células son transferidas desde un medio con una fuente de nitrógeno fácilmente asimilable a un medio mas pobre, las células avanzan hacia mitosis y proliferan a un tamaño celular reducido (Fantes y Nurse, 1977; Petersen y Nurse, 2007). De igual manera, la fase G1 se expande, como respuesta fisiológica al estrés nutricional, para favorecer la conjugación y diferenciación celular. Para investigar el efecto de un cambio nutricional sobre el ciclo celular de $S$. pombe en presencia y ausencia de $i g o 1^{+}$se realizó un análisis de citometría a células creciendo en diferentes fuentes de nitrógeno o en ausencia de este. Con 
fin, inicialmente se crecieron células en YES a $25^{\circ} \mathrm{C}$ y se transfirieron luego a MM con amonio (EMM), dónde se mantuvieron en fase exponencial durante una noche. Al día siguiente, se transfirieron las células a medio MM con: i) amonio 100mM (EMM), ii) glutamato $20 \mathrm{mM}$ (MMGlu), iii) isoleucina $20 \mathrm{mM}$ (MMI), iv) fenilalanina $20 \mathrm{MM}$ (MMF) y v) sin fuente de nitrógeno (MM-N). (Figura 8A). Se recogieron muestras durante ocho horas, en intervalos de dos horas, y una última a las 24 horas.

A

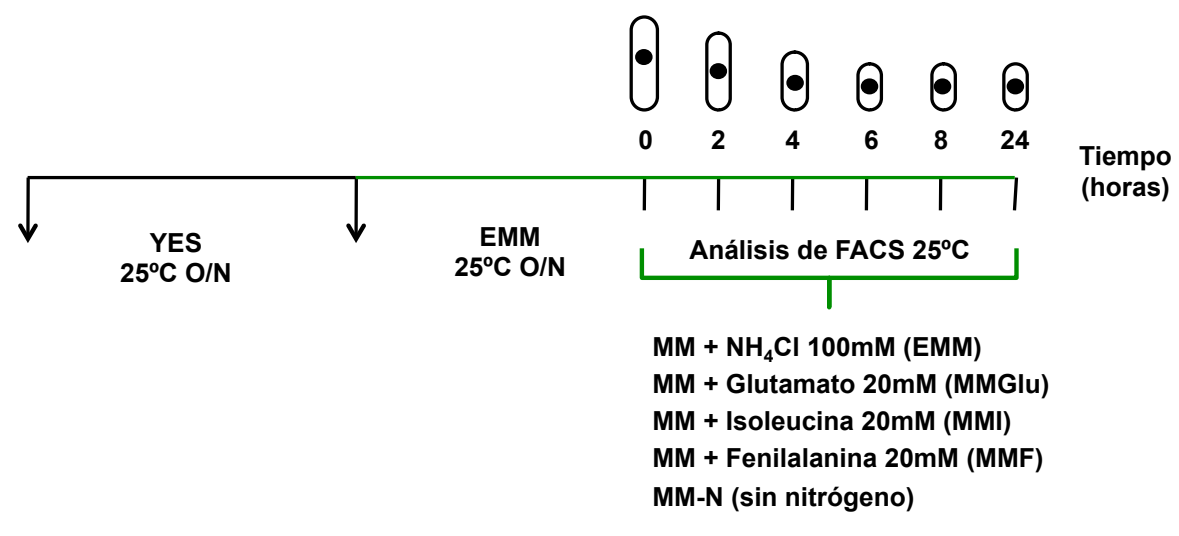

B

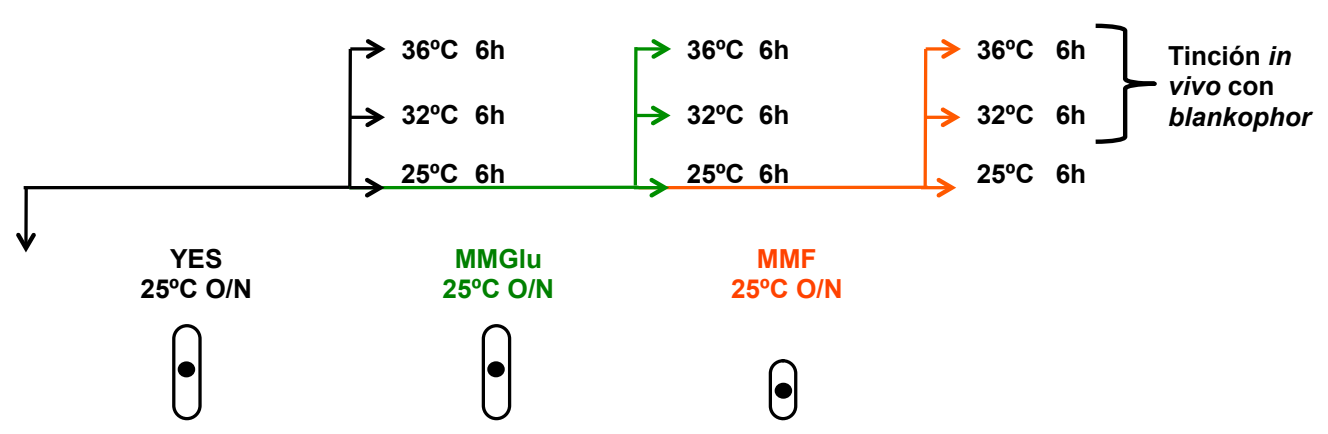

Figura 8. Metodología empleada para evaluar el fenotipo de igo1 $\Delta$ bajo estrés nutricional (A) Análisis de FACS. Las células de la cepa silvestre y el mutante igo $1 \Delta$ se crecieron exponencialmente en YES $25^{\circ} \mathrm{C}$, durante 24 horas. Luego se lavaron por filtración y se inocularon en EMM. A la mañana siguiente se lavaron de nuevo y se inocularon en 5 condiciones a $25^{\circ} \mathrm{C}$ (desde EMM hasta MM-N). Se tomaron muestras para ser analizadas por FACS, cada 2 horas, hasta 8 horas y a las siguientes 24 horas. (B). Determinación del tamaño celular. Las células de la cepa silvestre y el mutante igo $1 \Delta$ se crecieron en YES a $25^{\circ} \mathrm{C}$ durante 24 horas. A la mañana siguiente se dividió el cultivo en tres alícuotas que se sometieron a tres condiciones experimentales (YES $25^{\circ} \mathrm{C}$; YES $32^{\circ} \mathrm{C}$, YES $36^{\circ} \mathrm{C}$ ). Un cultivo adicional de YES $25^{\circ} \mathrm{C}$ se mantuvo como preinóculo, para ser transferido a MMGlu y MMF repitiendo el procedimiento anterior. 


\section{Resultados-Apartado II}
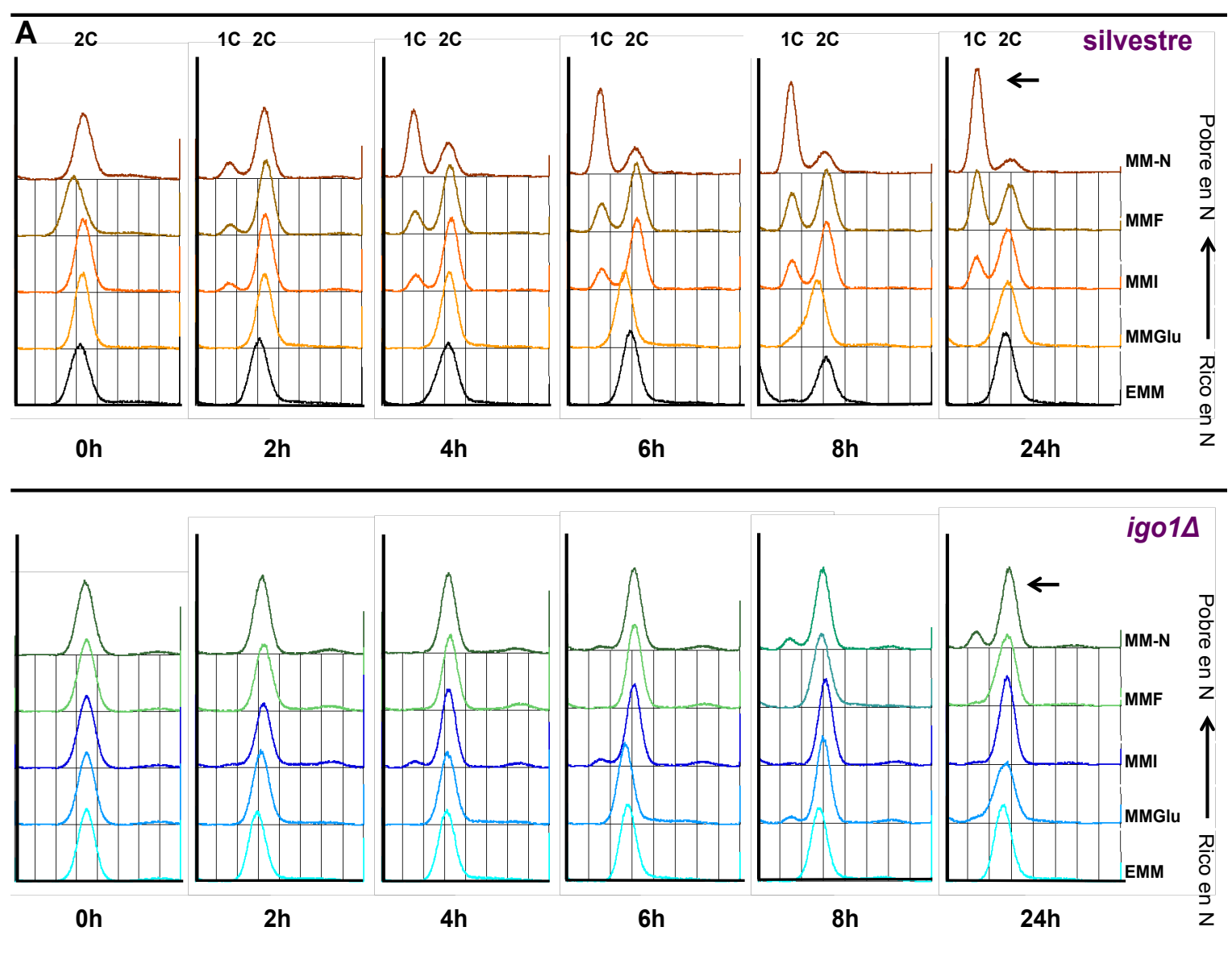


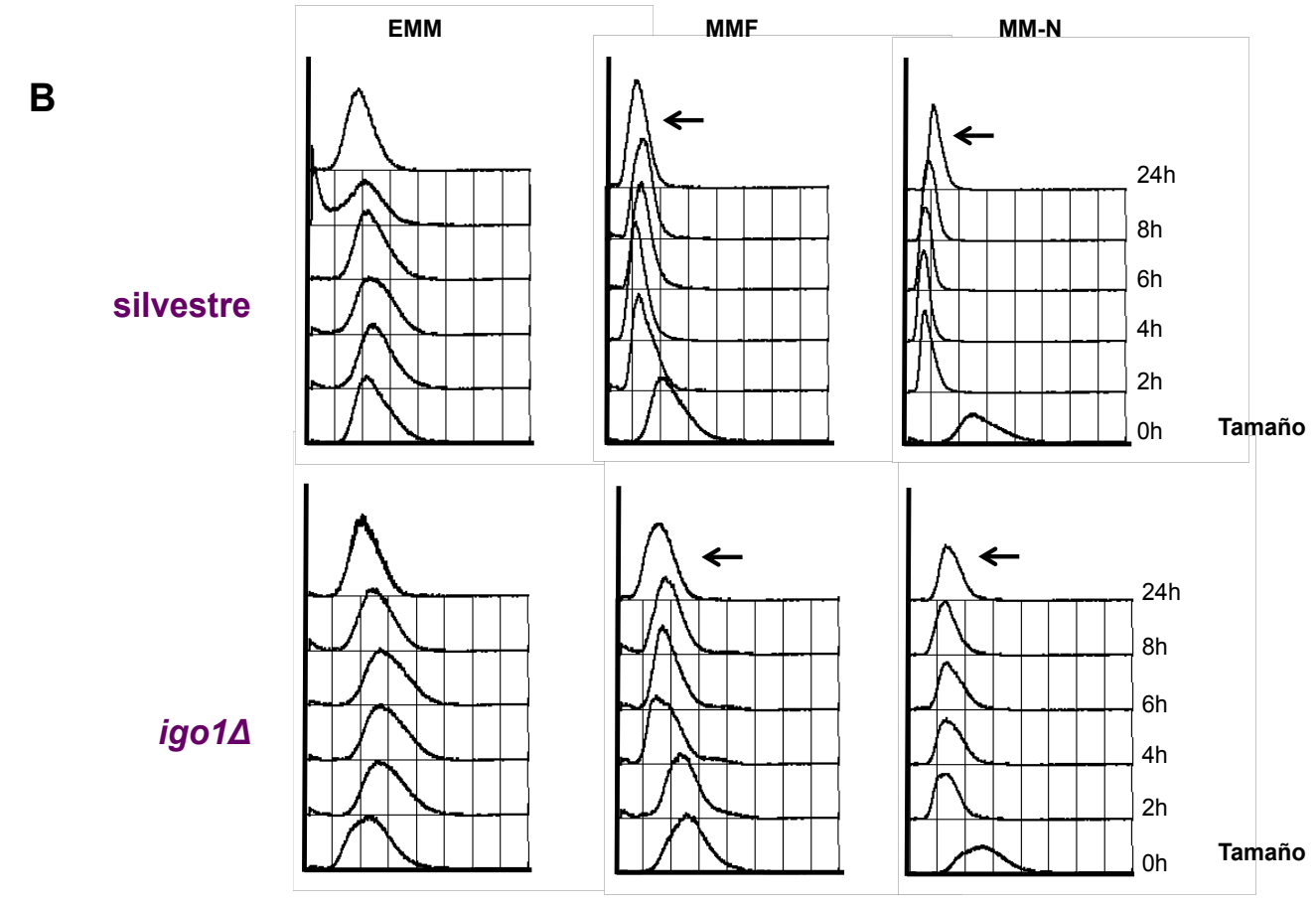

Figura 9. El mutante igo1 no reduce su tamaño ni acumula población celular en fase G1 bajo estrés por nitrógeno. (A) Análisis de la progresión del ciclo celular (contenido de ADN) durante 24 horas de la cepa silvestre y la cepa mutante igo1 1 desde una condición rica en nitrógeno hasta condiciones pobres y de privación de nitrógeno (EMM: amonio 100mM; MMGlu: glutamato 20mM; MMI: isoleucina 20mM; MMF: fenilalanina 20mM; MM-N: sin nitrógeno). (B) Análisis del tamaño celular durante 24 horas de la cepa silvestre y la cepa mutante igo1 $\Delta$ en condiciones ricas de nitrógeno (EMM), condiciones pobres en nitrógeno (MMF) y privación de nitrógeno (MM-N).

De acuerdo a la Figura 9A, la cepa silvestre acumula células en fase G1 en los medios con una fuente de nitrógeno pobre como isoleucina y fenilalanina, mientras que el mutante igo $1 \Delta$ no responde al cambio nutricional. Del mismo modo, las células mutantes igo1s tampoco se bloquean en la fase G1 como una cepa silvestre en condiciones de ausencia de nitrógeno. En la Figura 9B, se observa como las células del mutante igo1 $\Delta$ no reducen su tamaño al igual que la cepa silvestre en MMF y MM-N. Este mismo comportamiento también es advertido en MMI (datos no mostrados). Posteriormente, con el fin de estas observaciones, se evaluó si dicho efecto se mantiene a otras temperaturas como $32^{\circ} \mathrm{C}$ y $36^{\circ} \mathrm{C}$, empleando esta vez sólo MMF como fuente de nitrógeno pobre, ya que el comportamiento en isoleucina fue similar (Figura 8B). 


\section{Resultados-Apartado II}

A

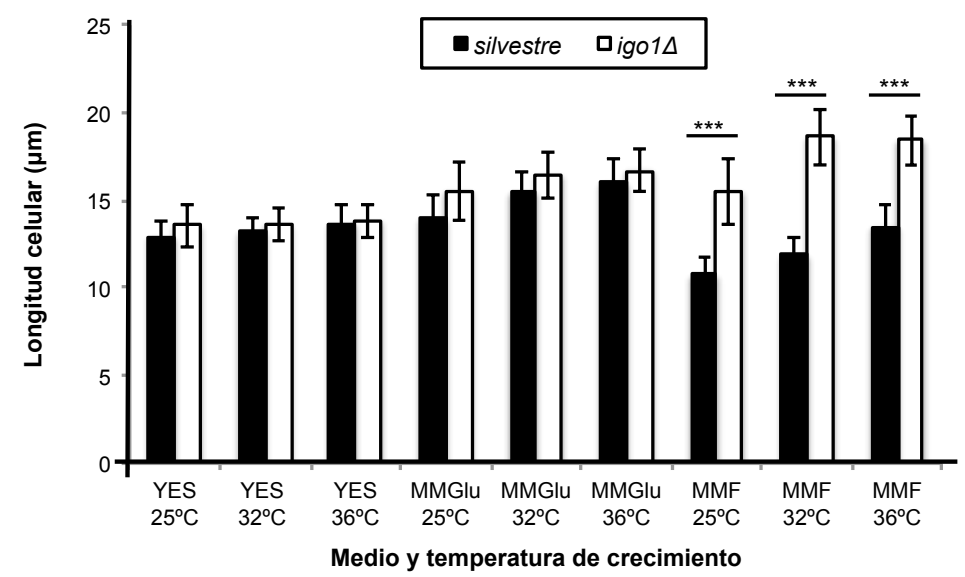

B

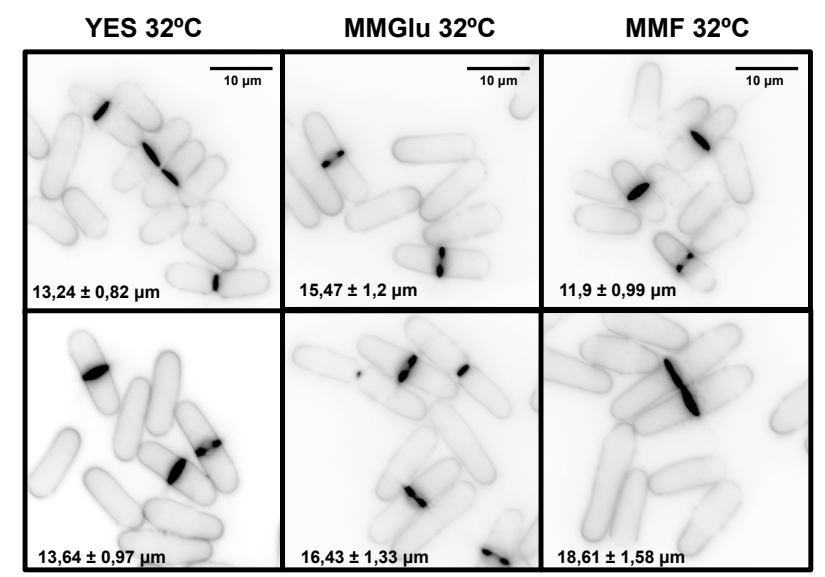

Figura 10. El fenotipo del mutante igo1 $\Delta$ se acentúa en MMF independientemente de la temperatura de crecimiento. (A) Representación de la longitudes celulares de la cepa silvestre y el mutante igo1 $\Delta$ en YES, MMGlu y MMF a tres temperaturas $25^{\circ} \mathrm{C}, 32^{\circ} \mathrm{C}$ y $36^{\circ} \mathrm{C}$. ${ }^{* * *}$ indican un $p$-valor 0,001 . (B) Imágenes de células teñidas in vivo con blankophor, que ilustran el fenotipo de igo1 $1 \Delta$ asociado a su longitud celular en los diferentes medios a $32^{\circ} \mathrm{C}$.

Como se aprecia en la Figura 10, las células del mutante igo1 muestran un incremento significativo en la longitud celular con respecto a la cepa silvestre en MMF. Dicho incremento muestra la misma relación en todas las temperaturas (entre 1,4 y 1,6 veces más), sugiriendo que dicho fenotipo es independiente de la temperatura de crecimiento. En relación al resto de condiciones, el incremento es menos significativo.

El fenotipo de igo1 incrementa a medida que el medio de cultivo es mas pobre en nitrógeno, sugiriendo que el gen $i g o 1^{+}$es esencial para promover la entrada a mitosis bajo estrés nutricional por nitrógeno en $S$. pombe. 


\subsection{Igo1 induce la entrada a mitosis en S. pombe en respuesta a una limitación de nitrógeno}

Estudios que han analizado el patrón de comportamiento en el tamaño y la división celular bajo condiciones que modulan el control nutricional en $S$. pombe, han demostrado que un cambio de una buena fuente de nitrógeno a una mas pobre, genera una entrada repentina en mitosis y una reducción del tamaño celular. En ese sentido, se quiso estudiar si lgo1 desempeña un papel en la entrada a mitosis inducida por limitación de nitrógeno. Para obtener datos al respecto, se delecionó el gen $i g 01^{+}$a una cepa silvestre que portaba una fusión de la proteína fluorescente mcherry con la subunidad a-tubulina codificada por el gen $a t b 2^{+}$y una fusión de la GFP con la proteína histona H3 codificada por el gen $h h t 2^{+}$. Con dicha cepa y su parental, se ejecutó un ensayo de time-lapse durante dos horas a $32^{\circ} \mathrm{C}$, con el cual se registró el comportamiento in vivo de una mitosis en estas cepas y a su vez, la frecuencia relativa de células que llevaron a cabo mitosis, tras un cambio desde MMGlu a MMF a $32^{\circ} \mathrm{C}$, como se describe en la Figura $12 \mathrm{~A}$. Para acondicionar las células al experimento, después del cambio a MMF, se realizó adicionalmente, una pre-incubación de 20 minutos en agitación a la misma temperatura. Los videos de este experimento pueden encontrarse en el DVD adjunto anotados como mcherryatb2_hht2GFP_wt y mcherryatb2_hht2GFP_igo1_MMGlu a MMF 32 $\mathrm{C}$. Estos videos corresponden a imágenes tomadas en intervalos de 2 minutos durante dos horas bajo temperatura controlada $\left(32^{\circ} \mathrm{C}\right)$. A su vez, estos son el resultado de la proyección máxima de siete planos tomados cada $0,5 \mu \mathrm{m}$. El núcleo se visualiza en verde por la construcción Hht2:GFP y los microtúbulos en rojo por la construcción mcherry:Atb2. Tras este experimento, se obtuvo que un $52 \%$ de las células silvestres analizadas entraron a mitosis con respecto a un $5,4 \%$ de las células mutantes en $i g o 1^{+}(n=100)$, sugiriendo que $i g o 1^{+}$es esencial para entrar a mitosis bajo estas condiciones.

Para obtener una estadística mas precisa del porcentaje de células que entran en mitosis debido a un cambio nutricional, se empleó una aproximación mas convencional, en dónde células silvestres e igo1 1 se transfirieron de MMGlu a MMF a $32^{\circ} \mathrm{C}$, y se siguieron durante 4 horas cada 20 minutos. En cada tiempo se fijaron células y posteriormente, se tomaron fotografías de estas con los núcleos teñidos con DAPI y los septos con blankophor. A partir de estas imágenes, se cuantificó el porcentaje de células en mitosis y el porcentaje de células en división. 


\section{Resultados-Apartado II}

A
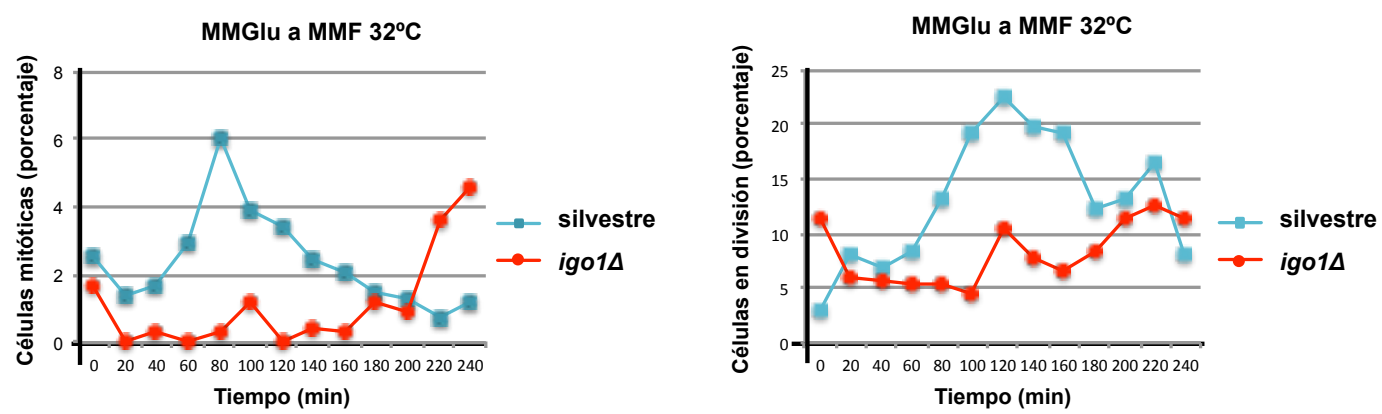

B
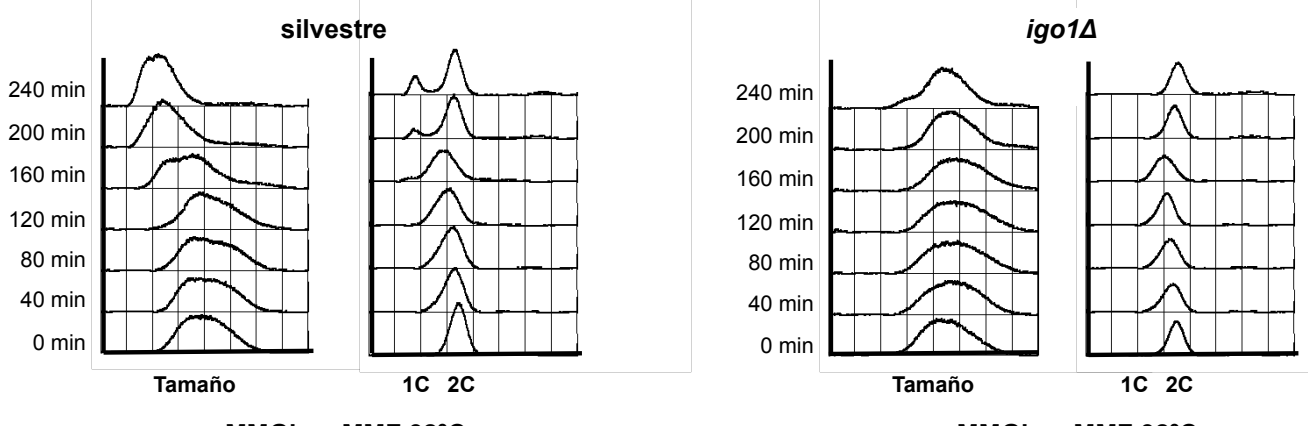

MMGlu a MMF $32^{\circ} \mathrm{C}$

MMGlu a MMF $32^{\circ} \mathrm{C}$

Figura 11. La actividad de Igo1 es necesaria en una entrada a mitosis inducida por limitación de nitrógeno. Células silvestres y del mutante igo1 $\Delta$ se transfirieron a MMF mediante filtración desde un cultivo de MMGlu crecido exponencialmente. Las muestras para tinción con DAPI (A) y análisis de FACS (B) se fijaron cada 20 minutos durante cuatro horas a $32^{\circ} \mathrm{C}$. El número de células analizadas fue $\geq 250$.

En la Figura $11 \mathrm{~A}$ se observa como las células silvestres, tras el cambio de fuente de nitrógeno, manifiestan un incremento en el porcentaje de células mitóticas a los 80 minutos y otro en el porcentaje de células en división a las 120 minutos. Por el contrario, las células que carecen de igo $1^{+}$no muestran una alteración significativa en la proporción de células que entran a mitosis, excepto entre los 200 y 240 minutos finales del experimento. Los análisis de FACS, muestran como la cepa silvestre, mas no la mutante, acumula células en fase G1 a los 160 minutos, a la vez que reduce su tamaño celular (Figura 11B) Ambos experimentos nos permiten concluir, que en un cambio desde MMGlu a MMF se induce una entrada mitosis que requiere de la actividad de lgo1. 
La células de $S$. pombe requieren de lgo1 para progresar hacia mitosis en situaciones dónde la calidad de la fuente de nitrógeno empeora rápidamente.

\subsection{El retraso de entrada a mitosis en células que carecen de lgo1 no es dependiente de la actividad de Rad3 pero si de Cdc25}

Rad3, el homólogo de ATR en mamíferos, es una quinasa reguladora que es esencial en la detección de daño en el ADN y la activación del checkpoint que conduce a una parada del ciclo celular antes de la mitosis (Seaton et al., 1992; Marthino et al.,1998). En mamíferos, se ha visto que ATM, otro de los homólogos de Rad3, se activa por altas concentraciones de cloruro de sodio, posiblemente como una respuesta ante la acumulación de roturas del ADN de doble cadena (Irarrazabal et al., 2004). Sin embargo, en la levadura de fisión esta respuesta a estrés osmótico no ha sido demostrada. Por otro lado, análisis en la expresión génica en $S$. pombe han mostrado que Rad3 es regulado positivamente cuando las células se someten a diferentes estreses ambientales (Chen et al., 2003). No obstante, Rad3 aún no ha sido relacionado a algún tipo de estrés nutricional.

Una posibilidad es que el retraso en fase G2 manifestado por las células que carecen de $i g o 1^{+}$, se deba a una activación del punto de control del daño en el ADN. Para abordar esta hipótesis se construyó el doble mutante igo1::natMX6 rad3::kanmX6 y se comparó el tamaño celular de este doble mutante con las cepas parentales y silvestre en MMF. Para llevar a cabo este análisis, se crecieron las células de acuerdo a la metodología ilustrada en la Figura $12 \mathrm{~A}$ y se tomaron muestras para tinciones in vivo con blankophor y análisis de FACS de cultivos en fase exponencial.

En los resultados se observa (Figura 12C y D) que el mutante de deleción rad3 $\Delta$ reduce su tamaño celular de manera similar a la cepa silvestre, y su vez que acumula población en fase G1 en mayor porcentaje que la cepa silvestre, probablemente debido a un acortamiento mayor de la fase $\mathrm{G} 2$. El doble mutante rad3 $\Delta$ igo1 $\Delta$, el comportamiento de $\operatorname{rad} 3 \Delta$ se suprime por la ausencia de igo $1^{+}$, reflejando un comportamiento fenotípico de ciclo similar al del mutante sencillo igo1 $\Delta$. Por otro lado, las mediciones celulares indican que el tamaño del doble mutante fue igual al mutante igo1 $\Delta$. (Figura 12B y 12C). Igualmente, mediante una tinción de DAPI, se analizó el estado citológico de los 


\section{Resultados-Apartado II}

A

- Tinción in vivo con blankophor y Análisis de FACS

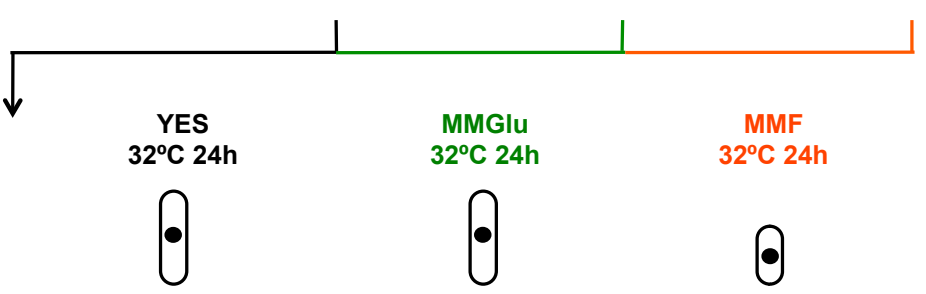

B
silvestre
igo1s
$\operatorname{rad} 3 \Delta$
$\operatorname{rad} 3 \Delta \operatorname{igo1\Delta }$

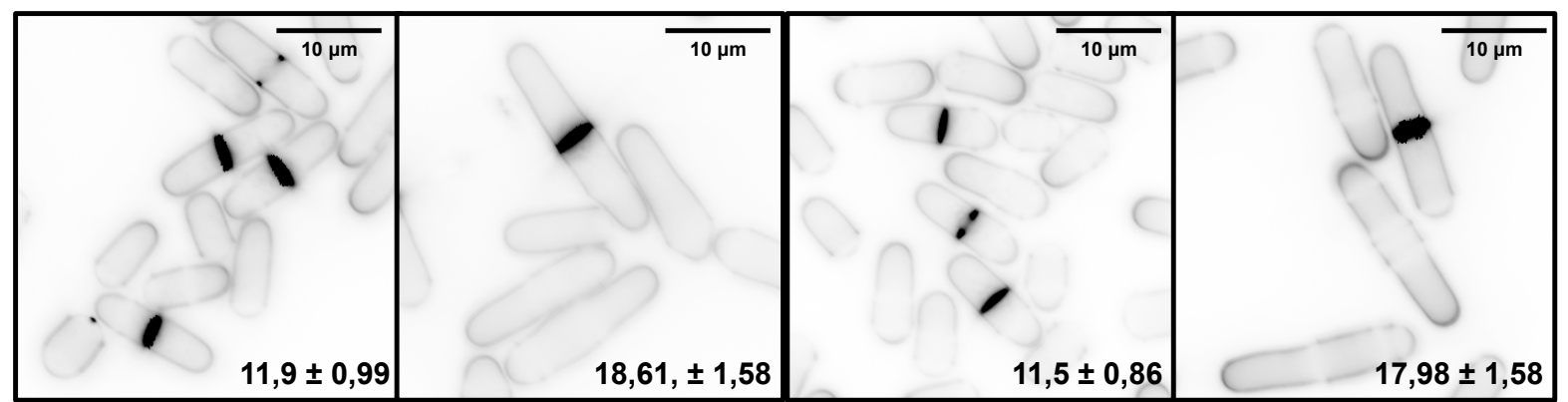

MMF $32^{\circ} \mathrm{C}$

C

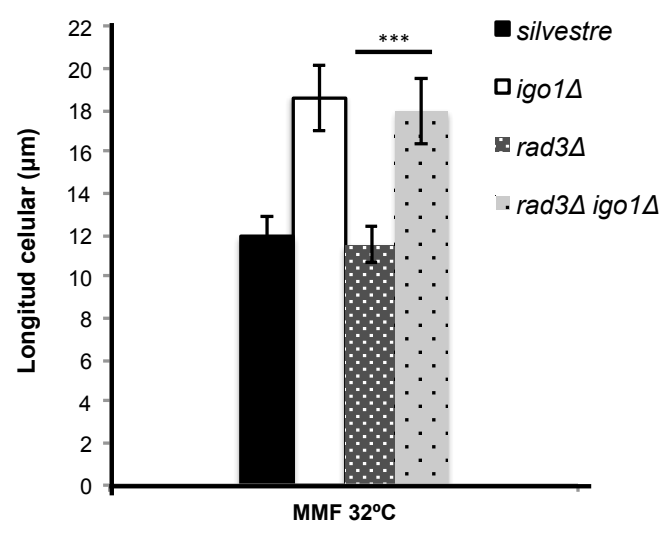

D

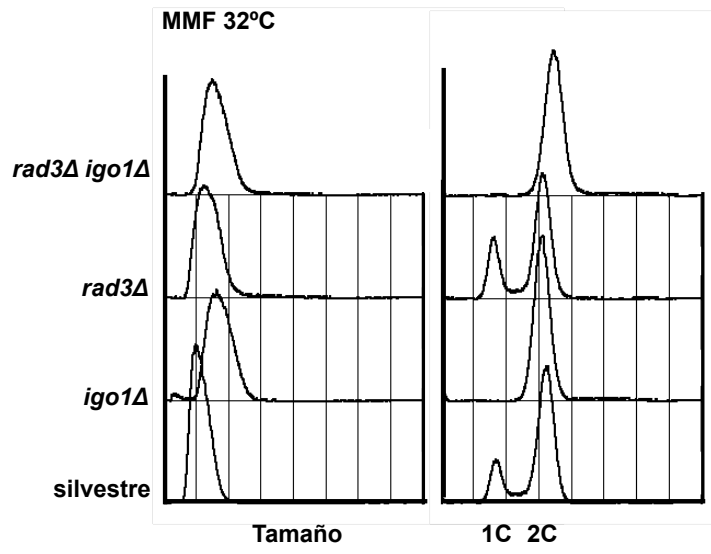

Figura 12. Análisis epistático entre las cepas rad $3 \Delta$ e igo1 $1 \Delta$ en $M M F$ a $32^{\circ} \mathrm{C}$. (A) Células silvestres y mutantes se crecieron en YES a $32^{\circ} \mathrm{C}$ en fase exponencial durante 24 horas. Luego, se transfirieron a MMGlu y se repitió el mismo procedimiento hasta crecer en MMF. Se tomaron muestras en MMF para tinción con blankophor y análisis de FACS. (B) Las medidas corresponden a 100 células septadas $(\mu \mathrm{m}) \pm$ la desviación estándar. (C) Representación estadística de la longitud celular observada para rad3 3 en comparación con rad3 $\Delta$ igo1 $\Delta .{ }^{* * *}$ indican un $p$-valor $<0,001$. (D) Análisis de FACS de células silvestres y mutantes igo1 $\Delta$, $\operatorname{rad} 3 \Delta, \operatorname{rad} 3 \Delta$ igo $1 \Delta$ crecidas en MMF $32^{\circ} \mathrm{C}$. 
se hayan divido tras una replicación anómala. De este experimento se concluye, que la ausencia de rad $^{+}$no causa ningún fenotipo sobre la progresión del ciclo celular en MMF y que la mutación dominante es la ausencia de igo ${ }^{+}$.

El retraso en la entrada a mitosis bajo estrés nutricional no es dependiente de la actividad de Rad3.

\section{A}

silvestre

igo1s

$c d c 2-3 w$

$c d c 2-3 w$ igo1s

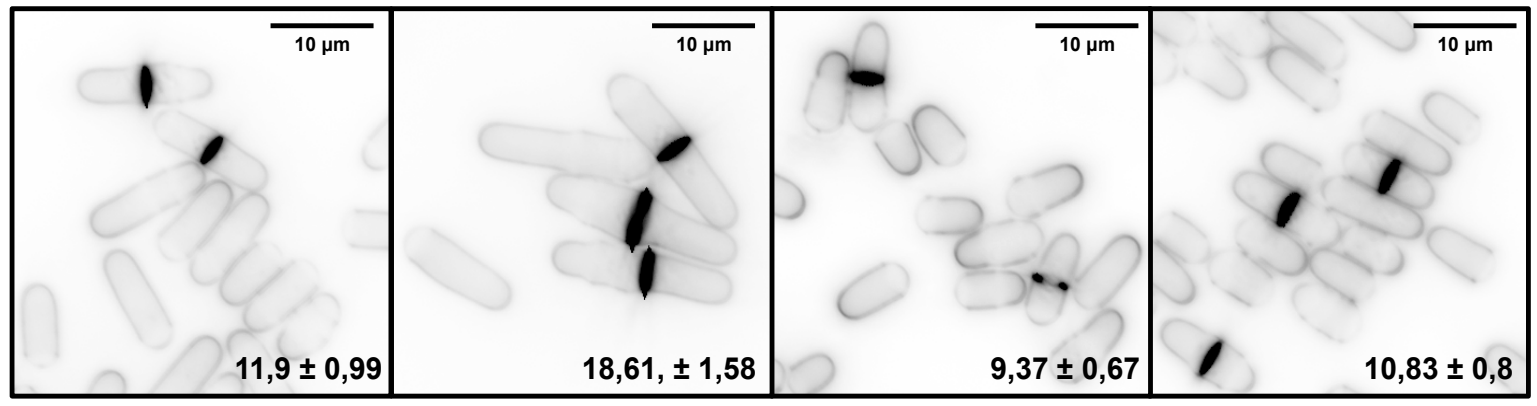

MMF $32^{\circ} \mathrm{C}$

C

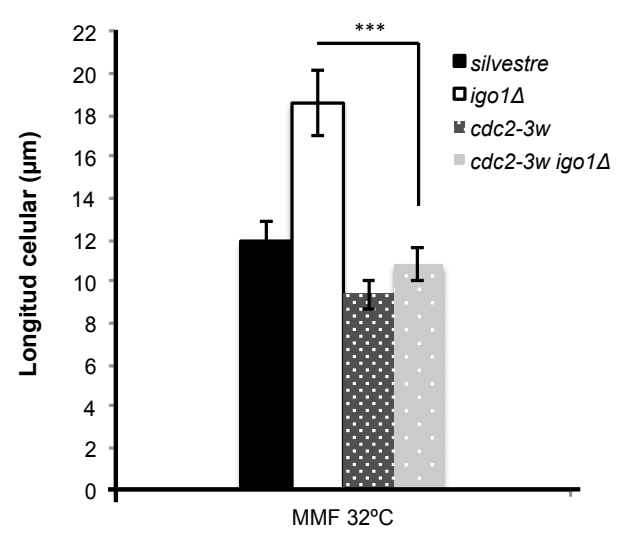

D

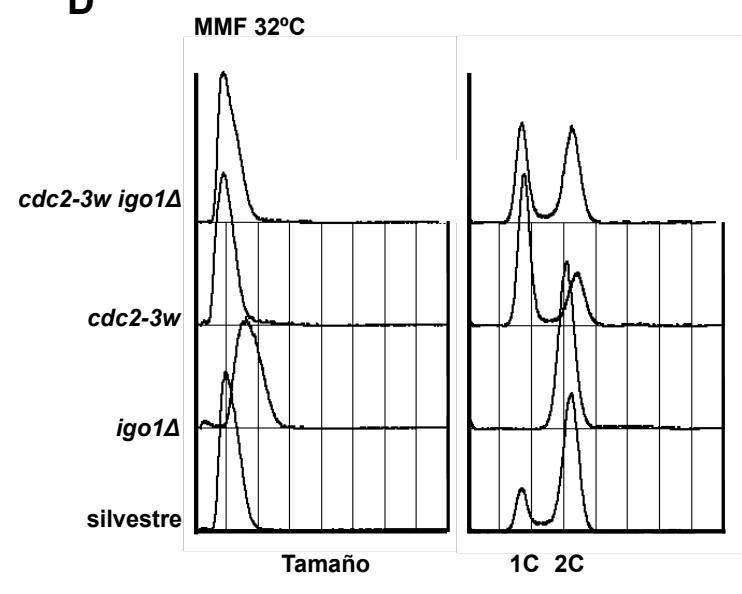

Figura 13. Análisis epistático entre las cepas cdc2-3w e igo1 en MMF $32^{\circ} \mathrm{C}$ (A) Las medidas corresponden a 100 células septadas $(\mu \mathrm{m}) \pm$ la desviación estándar. (C) Representación estadística de la longitud celular observada para $c d c 2-3 w$ en comparación con $c d c 2-3 w$ igo1 $\Delta .{ }^{* * *}$ indican un $p$-valor $<0,001$. (D) Análisis de FACS de células silvestres y mutantes igo1 $\Delta, c d c 2-3 w$, cdc2-3w igo1 $\Delta$ crecidas en MMF $32^{\circ} \mathrm{C}$. 


\section{Resultados-Apartado II}

Aunque preliminarmente, ya se observó que la ausencia de lgo1 rescata la reducción de tamaño del mutante termosensible wee1-50 a $25^{\circ} \mathrm{C}$, probablemente debido a una activación parcial de Wee1, dicho experimento no descarta que esta supresión, también sea el resultado de una inactivación de Cdc25. Para resolver esta cuestión, se abordó nuevamente la idea de que Igo1 podría regular la actividad de Wee1 pero esta vez en el fondo genético $c d c 2-3 w$, que es insensible a variaciones en la actividad de Cdc25 pero aún sensible a la de Wee1 (Thuriaux et al., 1978; Thuriaux y Nurse, 1990). Para esto, se construyó el doble mutante $c d c 2-3 w$ igo1 1 y se creció junto con las cepas control en MMF (Ver metodología del experimento en la Figura 13A). A continuación, se determinó la longitud celular y se analizó el perfil de ciclo.

De acuerdo al análisis de FACS (Figura 13D), la cepa cdc2-3w acumula una mayor población de células en fase $\mathrm{G} 1$ con respecto al silvestre, probablemente por una entrada prematura a mitosis y consecuentemente una reducción de tamaño controlada por dos vías: i) limitación de nitrógeno y ii) imitación de la sobreexpresión de Cdc25, debido a la mutación en Cdc2 que porta el alelo condicional cdc2-3w. En el caso del doble mutante cdc2-3w igo1 , dicho porcentaje de células acumuladas en fase G1 es intermedio al observado entre la cepa silvestre y la cepa mutante $c d c 2-3 w$. En relación al tamaño celular, el doble mutante tiene un ligero incremento. Ambas observaciones pueden ser explicadas, a través de la idea de que Igo1 controla tanto la actividad de Wee1 como la de Cdc25, indirectamente a través de PP2A.

El fenotipo de retraso en la entrada a mitosis del mutante igo1 $\Delta$ es suprimido por la mutación condicional $c d c 2-3 w$ bajo condiciones de estrés nutricional.

\section{Caracterización de la ruta Greatwall-ENSA en S.pombe}

\subsection{Identificación del ortólogo funcional de Greatwall en S. pombe}

Greatwall, también conocida como MASTL en humanos, fue descubierta por primera vez en Drosophila, como una quinasa esencial para mitosis (Yu et al., 2004; BettencourtDias et al., 2004). De acuerdo a estos estudios, los mutantes de Greatwall manifiestan un retraso en la condensación de los cromosomas junto con defectos de segregación cromosómica en los neuroblastos de las larvas descritos por Archambault et al., en 2007. 
Actualmente, existen evidencias tanto en Xenopus como en humanos de que Greatwall antagoniza la actividad de PP2A-B55ס y de su homólogo PP2A-Twins en Drosophila (Castilho et al., 2009; Burgess et al., 2010; Rangone et al., 2011; Wang et al., 2011). Greatwall pertenece a la familia $A G C$ que son un grupo diverso de serina/treonina proteínas quinasas (Pearce et al., 2010). De acuerdo al trabajo de Yu et al., 2004, la quinasa Greatwall de Drosophila es bastante similar a la de humanos, mientras que un poco mas distante de sus ortólogos en levaduras RIM15 (S.cerevisiae) o cek $1^{+}$de $S$. pombe. Con el fin de identificar el ortólogo funcional de Greatwall en $S$. pombe, realizamos una búsqueda BLAST (http://blast.ncbi.nlm.nih.gov/Blast.cgi) usando la secuencia de la proteína Greatwall de Xenopus, Drosophila y humanos. En los tres casos identificamos a las quinasas Ppk18 y Cek1, con un identidad de secuencia del $53 \%$ (Evalue $\left.2 \times 10^{-45}\right)$ y el $50 \%$ (E-value $2 \times 10^{-44}$ ) respectivamente (Tabla 2 ).

Tabla 2. Potenciales homólogos de Greatwall identificados por homología en su secuencia proteica mediante BLAST

\begin{tabular}{|c|c|c|c|c|}
\hline Proteína & Dominio quinasa $^{(b)}$ & Inserto quinasa ${ }^{(b)}$ & $\begin{array}{l}\text { Porcentaje } \\
\text { Identidad (a) }^{\text {(a) }}\end{array}$ & $\begin{array}{l}\text { E-value } \\
\text { (a) }\end{array}$ \\
\hline Cek1_s. pombe & $586-737 ;$; 848-1025 & 111 aa & $53 \%$ & $1 \times 10^{-43}$ \\
\hline Ppk18_S. pombe & $564-714 ; 824-947$ & 110 aa & $50 \%$ & $2 \times 10^{-44}$ \\
\hline Rim15_S.cerevisiae & $791-942 ; 1137-1282$ & 195 aа & $47 \%$ & $4 \times 10^{-42}$ \\
\hline
\end{tabular}

(a) Análisis BLAST (http://blast.ncbi.nlm.nih.gov/Blast.cgi). (b) Información obtenido en la base de datos InterPro (http://www.ebi.ac.uk/interpro). Búsquedas realizadas el día 24 de Enero de 2014.

Los productos que codifican $c e k 1^{+}$y $p p k 18^{+}$, no son esenciales pero sí bastantes grandes (Cek1 con 1338 aminoácidos; Ppk18 con 1318 aminóacidos). Su dominio quinasa se encuentra separado por un inserto al igual que sus ortólogos en eucariotas superiores. A diferencia de estos, Cek1 y Ppk18 poseen un dominio CheY-like que actúa como un regulador de la transcripción dependiente de señales ambientales (Skerker et al., 2005). Dicho dominio también está presente en Rim15, el ortólogo funcional de Greatwall en S. cerevisiae (Figura 14).

Ppk18 y Cek1 fueron identificados como los potenciales ortólogos funcionales de Greatwall en S. pombe. 


\section{Resultados-Apartado II}

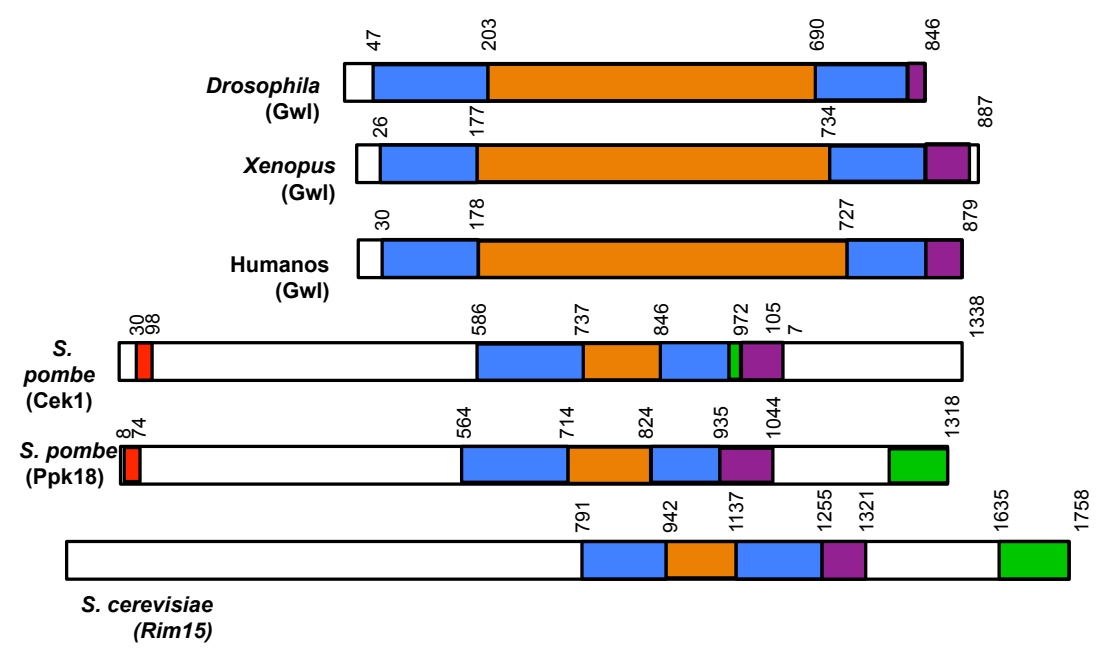

Figura 14. Estructura de las proteínas Greatwall desde levaduras hasta eucariotas superiores. Todas las proteínas presentan un dominio quinasa (recuadro azul) dividido en dos regiones por un inserto (recuadro naranja). Las proteínas Greatwall de Drosophila, Xenopus y humanos se encuentran mas conservadas con respecto a sus homólogos en levaduras. Los potenciales ortólogos de Greatwall en S. pombe presentan un dominio PAS (rojo) y un dominio CheY-like (verde), implicados en transducción de señales. La estructura de las proteínas fue dibujada de acuerdo a la información obtenida en la base de datos InterPro (http://www.ebi.ac.uk/interpro).

\subsection{La doble deleción de la quinasas Ppk18 y Cek1 reproducen el fenotipo de la ausencia de Igo1}

Hasta el momento ninguna de estas quinasas han sido relacionadas con un papel en entrada a mitosis, por lo que nuestro siguiente objetivo fue evaluar esta relación.

Inicialmente, se construyó la cepa ppk18::kanMX6 y el doble mutante cek1::ura4+ ppk18::kanMX6 ura4D-18. Con dichas cepas mutantes y la cepa de deleción cek1::ura4+ ura $4 D-18$ se analizó el fenotipo de ausencia de $p p k 18^{+}$y $c e k 1^{+}$bajo limitación de nitrógeno (MMF $32^{\circ} \mathrm{C}$ ). El experimento fue realizado siguiendo la metodología representada en la Figura 12A. En este, se analizó el tamaño celular de los mutantes

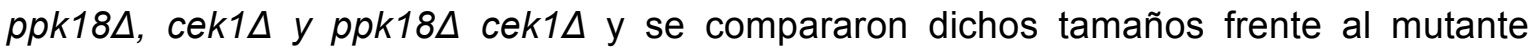
igo1 y y la cepa silvestre. De igual forma, se analizó la progresión del ciclo celular en cada uno mediante citometría de flujo. 
A MMF $32^{\circ} \mathrm{C}$ silvestre

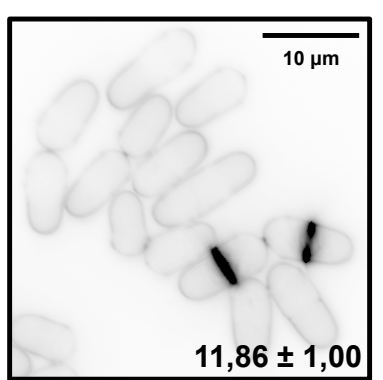

$11,86 \pm 1,00$ igo1s

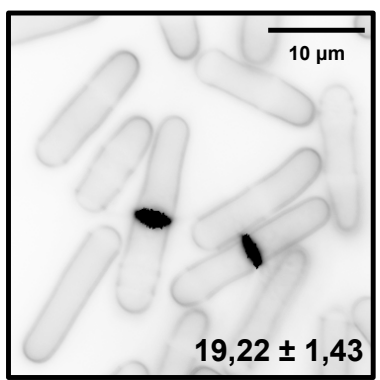

$19,22 \pm 1,43$

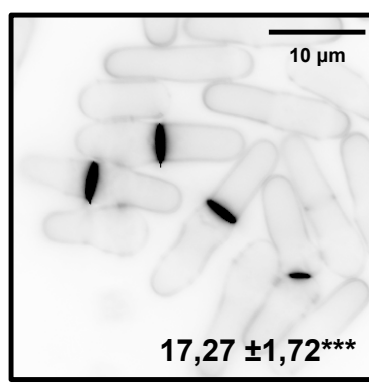

ppk18

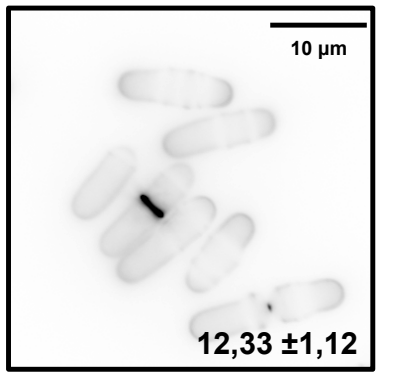

cek14

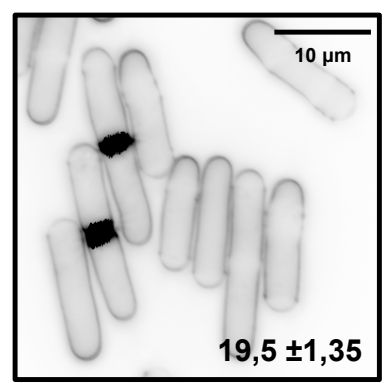

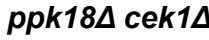

Figura 15. La deleción de ppk18 ${ }^{+}$imita el fenotipo del mutante igo1s bajo estrés por nitrógeno. (A) Las medidas corresponden a células septadas que crecieron de acuerdo a la metodología ilustrada en la Figura 12A. La longitud celular es representada en $\mu \mathrm{m} \pm$ la desviación estándar $(n=100)$. ${ }^{* *}$ indica una diferencia significativa con $p$-valor <0,001 entre la cepa silvestre y el mutante ppk18D (B) Análisis de FACS de los mutantes cek1 $1, p p k 18 \Delta$, ppk18 cek1 $\Delta$ en comparación con la cepa silvestre y el mutante de igo $1 \Delta$ en MMF a $32^{\circ} \mathrm{C}$.

El mutante cek1 $\Delta$ manifestó un comportamiento similar al observado por una cepa silvestre en estas condiciones, salvo por un ligero incremento en la longitud celular que no fue estadísticamente significativo ( $p$-valor $>0,001$ ) (Figura 15A). Por el contrario, la deleción de $p p k 18^{+}$presentó un fenotipo casi idéntico al de la deleción de igo $1^{+}(17,27 \pm$ $1,72 \mu \mathrm{m}$ frente a 19,22 $\pm 1,43 \mu \mathrm{m}$ respectivamente). La diferencia observada entre el

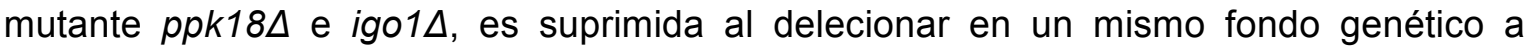
Ppk18 y Cek1 $(19,5 \pm 1,35 \mu \mathrm{m})$. Al contrastar el análisis de FACS, se observó como la cepa silvestre y el mutante cek1 $\Delta$ acumularon una población de células en fase $\mathrm{G} 1$, de

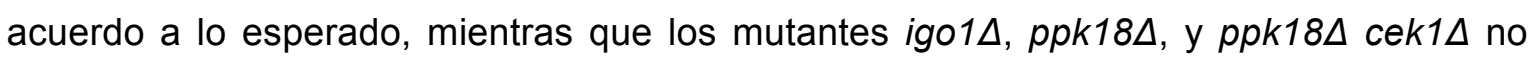
(Figura 15B). Por tanto, Ppk18, pero no Cek1, parece ser la quinasa principal que acelera la entrada a mitosis bajo limitación de nitrógeno y que el papel de Cek1 podría ser interpretado como secundario, por el hecho de que el fenotipo de deleción del doble 


\section{Resultados-Apartado II}

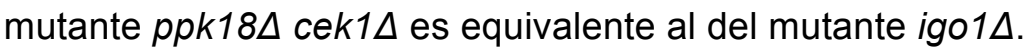

La deleción de $\operatorname{cek} 1^{+}$no genera ningún fenotipo asociado al ciclo celular, mientras que la deleción de $p p k 18^{+}$incrementa el tamaño celular. Dicho incremento es similar al manifestado por la ausencia de $i g 01^{+}$cuando se combinan ambas mutaciones.

\subsection{Ppk18 actúa por encima de Igo1}

A

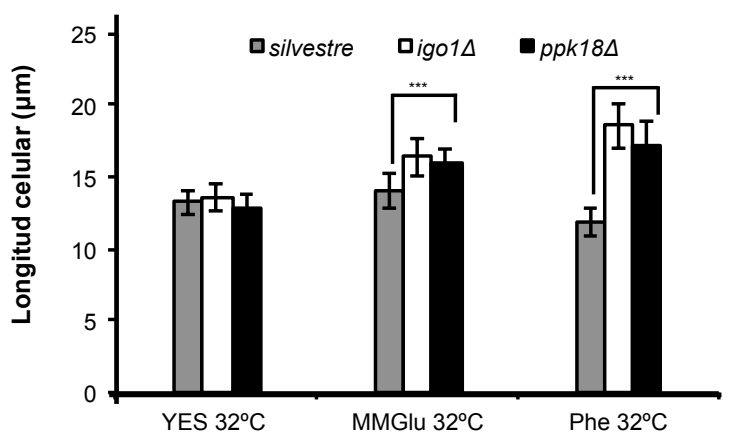

C

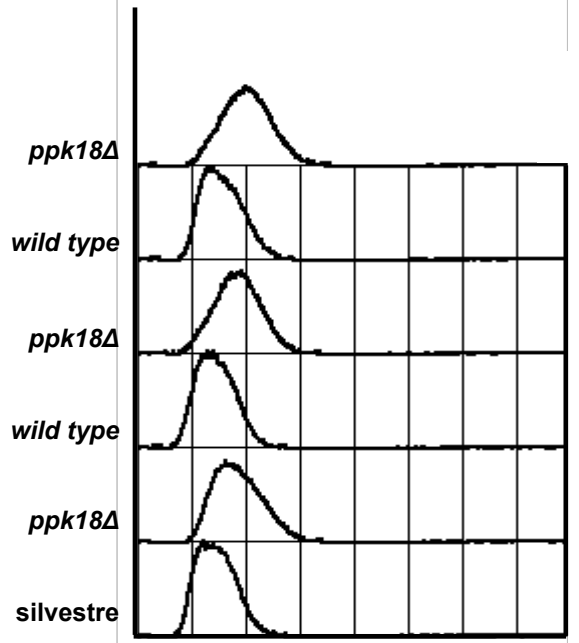

Tamaño
B
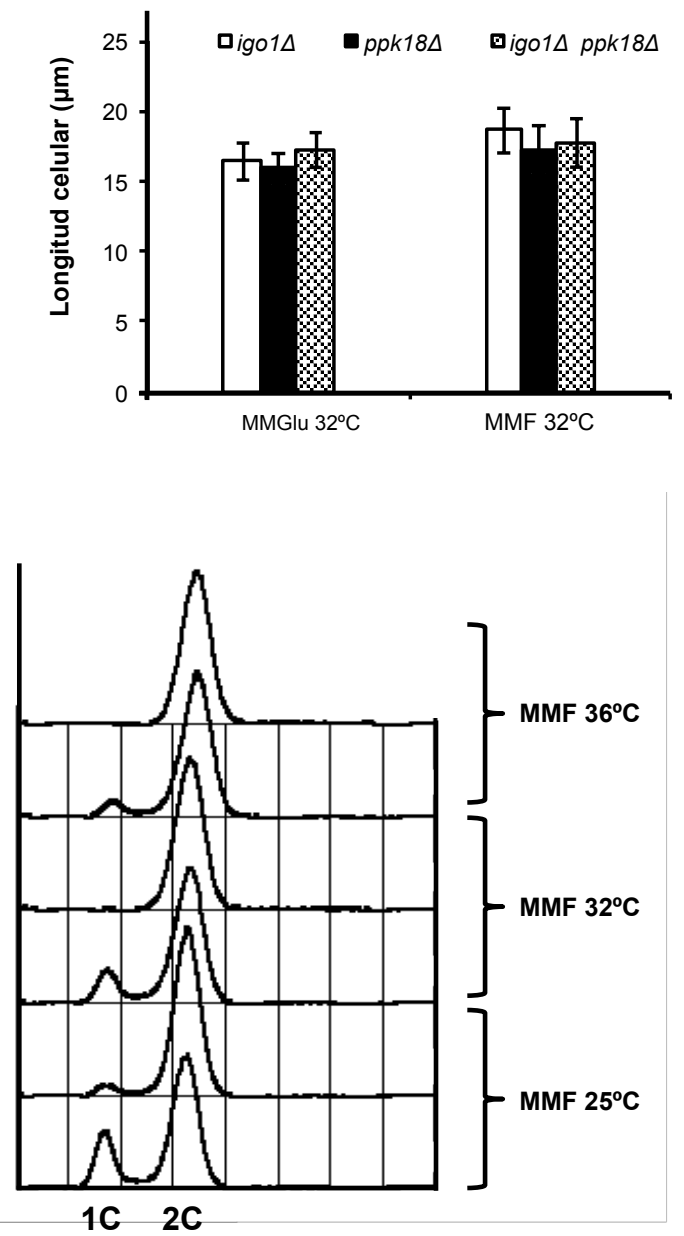

Figura 16. Ppk18 actúa por encima de Igo1 controlando la entrada en mitosis bajo estrés nutricional

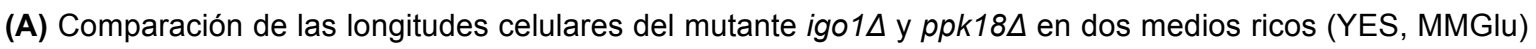
y un medio pobre (MMF) a $32^{\circ} \mathrm{C}$. La longitud celular es representada en $\mu \mathrm{m} \pm$ la desviación estándar $(\mathrm{n}=100)$. *** indica una diferencia significativa con $p$-valor $<0,001$. (B) Análisis epistático entre ppk18 $\Delta$ e igo1 $\Delta$ en MMGlu y MMF a $32^{\circ} \mathrm{C}$. (C) Análisis de FACS del mutante ppk18 en comparación con la cepa silvestre en MMF a $25^{\circ} \mathrm{C}, 32^{\circ} \mathrm{C}$ y $36^{\circ} \mathrm{C}$. 
A partir de aquí, dado que Ppk18 podría actuar en la misma vía de Igo1, se analizó la longitud del mutante ppk18 18 en medio rico YES, medio restrictivo MMGlu y medio pobre MMF a $32^{\circ} \mathrm{C}$. Los datos obtenidos se compararon con los datos de longitud celular obtenidos para el mutante igo1 $\Delta$ y la cepa silvestre en el experimento del apartado 3.1 (Figura 11A). Aunque las mediciones sólo se realizaron en las condiciones mencionadas para el mutante $p p k 18 \Delta$, en paralelo se crecieron cultivos de la cepa silvestre y ppk18 $\Delta$ para un posterior análisis de FACS en MMF a $25^{\circ} \mathrm{C}, 32^{\circ} \mathrm{C}$ y $36^{\circ} \mathrm{C}$.

En la Figura $16 \mathrm{~A}$ se aprecia como el comportamiento fenotípico, en términos de

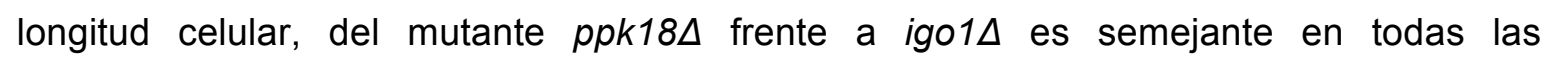
condiciones contrastadas. Por otro lado, el análisis de FACS muestra como el retraso en

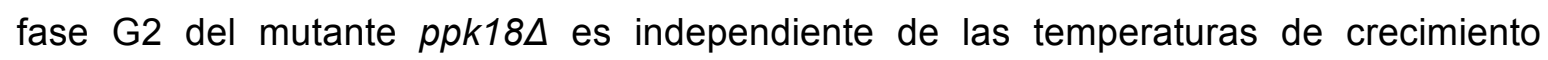
(Figura 16C).

Para evaluar a que nivel Ppk18 actúa en la ruta de acción de Igo1, se construyó el

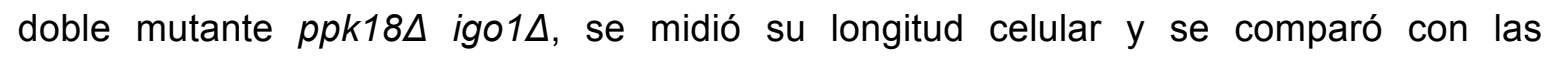
longitudes celulares de sus parentales (Figura 16B). En los resultados de este análisis, se

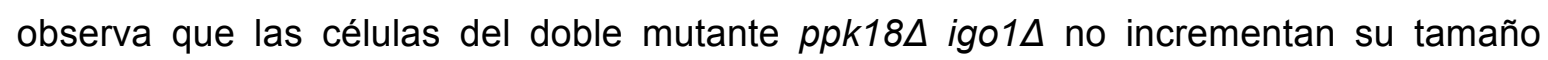
celular con respecto a los mutante sencillos, indicando que el gen igo ${ }^{+}$es epistático frente al gen ppk18 ${ }^{+}$. Lo anterior, permite ubicar a ambas proteínas dentro de la misma ruta bioquímica y a su vez concluir que Ppk18 actúa por encima de Igo1.

De acuerdo a los análisis genéticos anteriores, la quinasa Ppk18 actúa por encima de Igo1, controlando la progresión hacia mitosis bajo estrés nutricional en S. pombe.

\subsection{El papel de Igo1 implica la inhibición de PP2A-pab1}

Las fosfoproteínas PP2A son enzimas multiméricas obligadas cuya especificidad de sustrato depende de la subunidad reguladora (B) que está asociada a la subunidad catalítica (C). En Xenopus, la actividad de las endosulfinas (Ensa/Arrp-19) es específica para las especies de PP2A que contienen la subunidad B55, es decir que no inhiben complejos PP2A que contienen otros tipos de subunidades reguladoras como B56ع, B56Y o B"/PR48 (Mochida et al., 2010). De la misma forma, en S. cerevisiae los ortólogos IGO1/IGO2, previamente activados por RIM15 (ortólogo de Greatwall en S. cerevisiae) se unen al complejo PP2A-Cdc55 (Bontron et al., 2012; Juanes et al., 2013). 


\section{Resultados-Apartado II}

Actualmente, se conoce que el gen que codifica el homólogo de la subunidad reguladora B55 en S. pombe es $p a b 1^{+}$. Dicho gen fue aislado mediante PCR usando secuencias conservadas en la B55 humana y de Drosophila. Su deleción genera células redondas que tienen afectada la pared celular, el citoesqueleto y la esporulación. De acuerdo a estos fenotipos y otros relacionados a Pab1, hasta ahora el complejo PP2Apab1 regula funciones de polaridad y citoquinesis en las células de $S$. pombe (Kinoshita et al., 1996; Lahoz et al., 2010; Bernal et al., 2012; Goyal y Simanis, 2012).

Teniendo en cuenta lo anterior, el siguiente objetivo fue evaluar si la actividad del módulo Ppk18-Igo1 inhibe la actividad del complejo PP2A-pab1 para promover la entrada a mitosis bajo estrés nutricional en $S$. pombe. Si fuera así, al eliminar tanto la subunidad reguladora Pab1 como la subunidad catalítica principal Ppa2, debería suprimir el fenotipo de deleción de Igo1. Para ello, se crecieron los cultivos hasta fase exponencial en MMGlu y MMF (Figura 12A) y se compararon los fenotipos del mutante ppa2 $\Delta$ y pab1 $\Delta$ en combinación con igo1 $1 \Delta$.

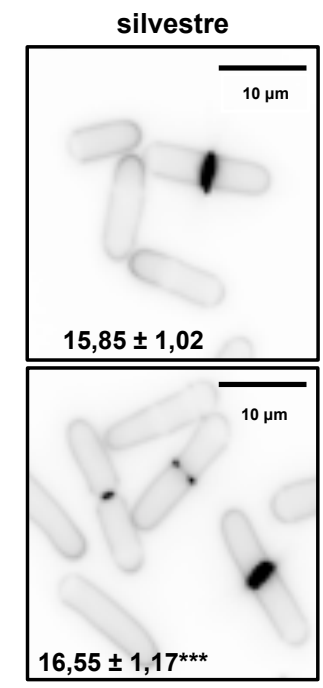

igo14

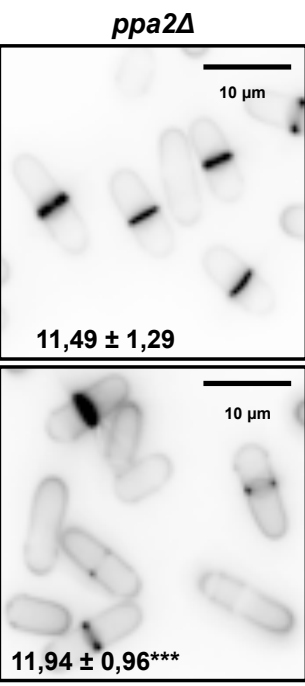

ppa2d igo1ム

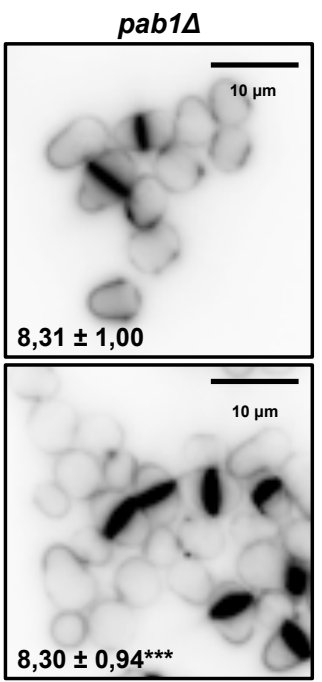

pab14igo1s

Figura 17. La ausencia de $\mathrm{ppa2}^{+}$y $\mathrm{pab1}^{+}$suprime el fenotipo del mutante igo1 $\Delta$. Las imágenes corresponden a células en crecimiento exponencial en MMG a $32^{\circ} \mathrm{C}$ teñidas con blankophor. La longitud celular es representada en $\mu \mathrm{m} \pm$ la desviación estándar $(n=100) .{ }^{* * *}$ indica una diferencia significativa con $p$ valor $<0,001$. 
Los resultados fueron consistentes con la idea anterior, ya que el doble mutante igo1 $\Delta$ ppa $2 \Delta$ o el doble igo1 $\Delta$ pab1 $\Delta$ suprimió el fenotipo del mutante igo1 $\Delta$ (Figura 17 ). Este comportamiento también fue observado en MMF. Adicionalmente en el mismo medio, se observó lisis celular en el mutante pab1 $\Delta$ y el doble igo1 $\Delta$ pab1 $\Delta$, sugiriendo que la actividad de Pab1 es esencial en estas condiciones (datos no mostrados). De lo anterior, se concluye que el incremento del tamaño celular por la ausencia de Igo1 es dependiente de la actividad del complejo PP2A-pab1 en condiciones de estrés nutricional.

El fenotipo de deleción de igo $1^{+}$observado bajo estrés por nitrógeno, es suprimido por la deleción del gen que codifica la subunidad catalítica $p p a 2^{+}$y del gen $p a b 1^{+}$que codifica para la subunidad reguladora B55 del complejo PP2A en S. pombe.

A partir de los resultados obtenidos en el apartado 4, se propone que la ruta Ppk18Igo1-PP2A-pab1 controlan la entrada a mitosis en condiciones de estrés por nitrógeno.

\section{La actividad de Igo1 como respuesta a un cambio nutricional}

\subsection{La actividad de Igo1 depende del sitio de fosforilación S64 (Ser)}

Las proteínas Ensa y Arpp-19 humanas son fosforiladas in vitro por la quinasa AGC Greatwall en la S67 y S62 respectivamente. En el caso de sus homólogos en Xenopus el sitio correspondiente es la S67. Dicha fosforilación es la responsable de promover la unión y la inhibición del complejo PP2A-B55ס en extractos de oocitos de Xenopus en interfase. Otros sitios de fosfo-regulación para Ensa y Arrp-19 han sido descritos: S109 por PKA y T28 y S28 por Cdk1 (Mochida et al., 2010; Garbi-Ayachi et al., 2010, Mochida, 2013).

De acuerdo a lo anterior, se procedió a evaluar si la actividad de lgo1 depende de la fosforilación por el ortólogo de Greatwall en S. pombe (Figura 18D). Para ello, se construyó un mutante no fosforilable (igo1-S64A) y a su vez un mutante fosfo-mimético (igo1-S64E). En una primera aproximación, se analizó el perfil de ciclo celular de ambos mutantes en MMGlu y MMF $32^{\circ} \mathrm{C}$. Para ello, se tomaron muestras de cultivos crecidos hasta fase exponencial siguiendo la metodología ilustrada en la Figura 12A. 


\section{Resultados-Apartado II}

A

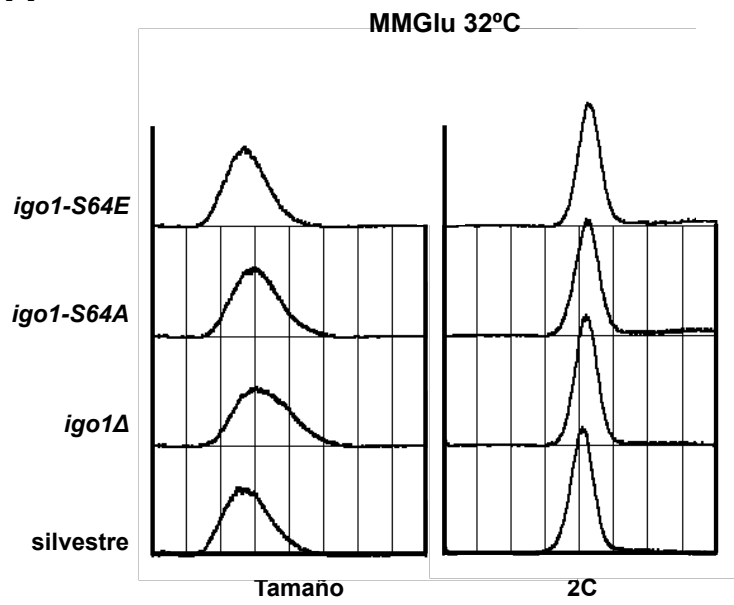

MMGlu $32^{\circ} \mathrm{C}$

B

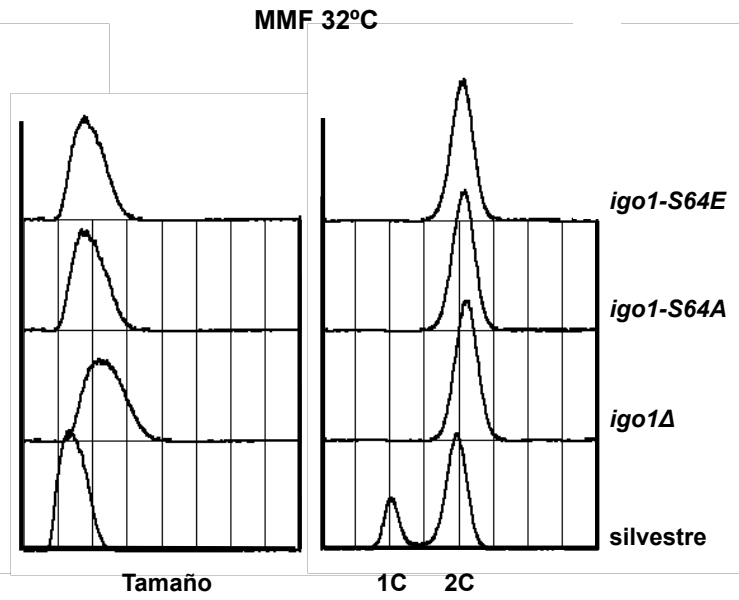

C

silvestre
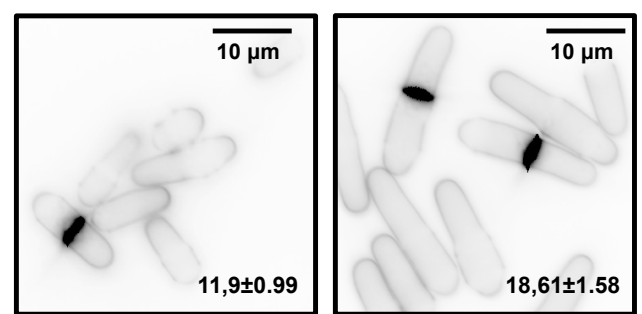

igo1-S64A

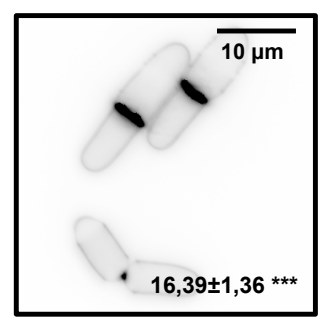

D

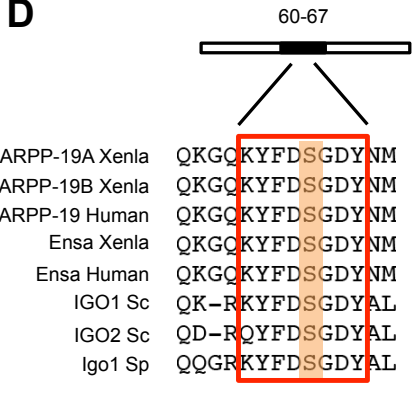

MMF $32^{\circ} \mathrm{C}$

Figura 18. La actividad de igo1 depende de la S64. (A-B) Análisis de FACS de los mutantes igo1-S64A y igo1-S64E en comparación con la cepa silvestre y el mutante igo1 $\Delta$ en MMGlu y MMF a $32^{\circ} \mathrm{C}$. (C) Las imágenes corresponden a células silvestres y mutantes igo1 $\Delta$ e igo1-S64A, crecidas exponencialmente en MMF a $32^{\circ} \mathrm{C}$. La longitud celular es representada en $\mu \mathrm{m} \pm$ la desviación estándar $(n=100)$. ${ }^{* * *}$ indica una diferencia significativa con $p$-valor <0,001 (D). Secuencia proteica de los homólogos de Ensa y Arpp-19 desde eucariotas superiores hasta levaduras, alrededor del sitio de fosforilación por Greatwall (Mochida et al., 2010; Garbi-Ayachi et al., 2010; Juanes et al., 2013). Xenla=Xenopus laevis; Human=Humanos; Sc= S. cerevisiae; $\mathrm{Sp}=\mathrm{S}$. pombe.

En este experimento (Figura 19A), se observó como tanto el mutante igo1-S64A como igo1-S64E exhibieron un perfil de ciclo similar al del mutante de igo1 $\Delta$. Ambos comportamientos fueron interpretados como una pérdida de funcionalidad de Igo1. En el caso del mutante igo1-S64A, dicho fenotipo era el esperado, sin embargo en el caso de igo1-S64E se esperaba obtener un fenotipo de hiperactividad de Igo1, que indujera una entrada prematura a mitosis, lo cual no pudo ser confirmado. De aquí en adelante solo se analizó el mutante igo1-S64A. 
En una segunda aproximación, se midieron las células del mutante igo1-S64A en condiciones de estrés nutricional (MMF, Figura 13A) y se comparó con el tamaño del mutante de deleción igo1 $\Delta$ y la cepa silvestre (Figura 19B). Como resultado, el mutante igo1-S64A manifestó un incremento en la longitud celular aunque no en la misma medida que la ausencia de $i g o 1^{+}$, indicando que dicho sitio es necesario para la actividad de lgo1. Por otro lado, también se mutó a Ala (A) el sitio equivalente de fosforilación por Cdk1 en Igo1 (S31) y un posible sitio de fosforilación por CDK, no conservado en otros organismos, hacia el C-terminal de la proteína (S102). Individualmente, no se observó ningún fenotipo asociado al ciclo celular en los mutantes analizados (igo1-S31A y igo1S102A) (datos no mostrados).

\section{La Serina 64 es importante para la actividad de la proteína lgo1 en S. pombe.}

\subsection{El estado de fosforilación de Igo1 depende de un cambio nutricional}

El siguiente objetivo de este trabajo se centró en el estudio de la regulación de lgo1 bajo estrés nutricional. Para ello, se generaron dos anticuerpos policlonales, uno contra la región carboxilo terminal (CGASSRRESVTRHDLE) y otro contra el péptido fosforilado en la S64 (CGRKYFDSpGDYALNK) de la proteína lgo1 (Ver sección 10.1 de Materiales y Métodos).

En una primera aproximación al estudio de la regulación de Igo1, se analizaron los niveles de la proteína en células silvestres que crecieron inicialmente en condiciones ricas en nitrógeno como YES y MMGlu y luego en condiciones pobres de nitrógeno como MMF a $32^{\circ} \mathrm{C}$. Como controles negativos se emplearon células que carecen del gen igo $1^{+}$ y células que portan el alelo fosfo-nulo igo1-S64A.

El primero de los anticuerpos, llamado anti-Igo1, inmunodetecta en Western Blot una proteína de un peso molecular similar al teórico (14 KDa) que está ausente en los extractos que carecen del gen igo1 $1^{+}$. El anticuerpo anti-Igo1-P S64 detecta específicamente la fosforilación de este residuo que esta ausente en los extractos del mutante no fosforilable igo1-S64A (Figura 19). En los extractos silvestres de células que crecieron en MMF, incrementaron los niveles de la proteína al igual que la fosforilación específica de la S64. Estos resultados sugieren que Igo1 es una fosfoproteína, cuyo estado de fosforilación depende de la calidad de la fuente de nitrógeno en la que crecen 


\section{Resultados-Apartado II}

las células de S. pombe.

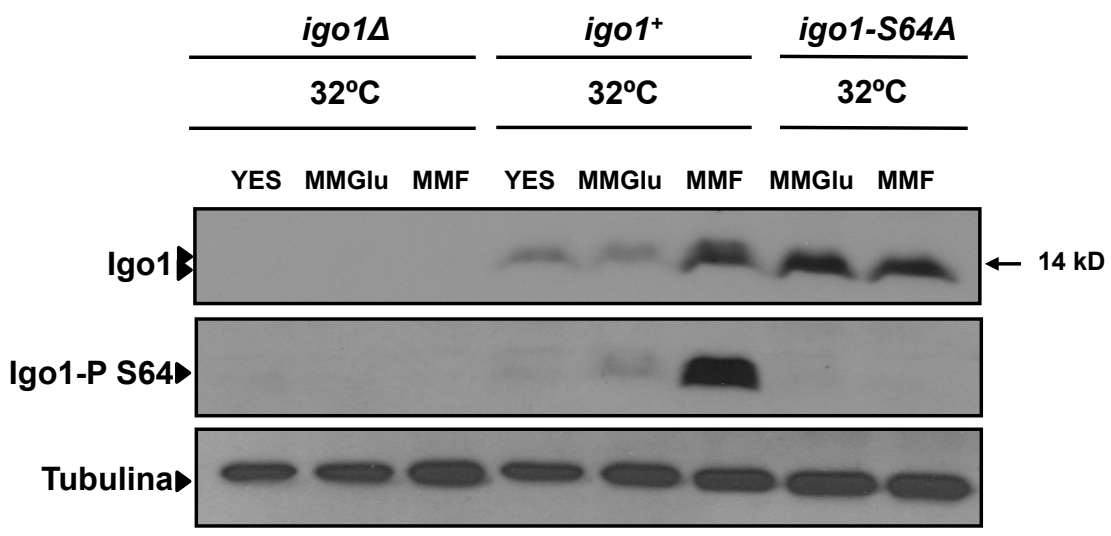

Figura 19. Los niveles y la fosforilación de Igo1 depende de una señalización nutricional. Se determinó el nivel de lgo1 y de su fosforilación en distintos medios. Los extractos corresponden a células crecidas en medio rico (YES), medio mínimo con glutamato (MMGlu) y medio mínimo con fenilalanina (MMF) a $32^{\circ} \mathrm{C}$. En cada medio las células crecieron en fase exponencial durante 24 horas (Ver metodología en la Figura 12A). Se emplearon como extractos control, células de los mutantes igo1 1 e igo1-S64A crecidos en MMGlu y MMF a $32^{\circ} \mathrm{C}$.

Figura 20. Los niveles y la fosforilación de Igo1 depende de una señalización nutricional. Se determinó el nivel de lgo1 y de su fosforilación en distintos medios. Los extractos corresponden a células crecidas en medio rico (YES), medio mínimo con glutamato (MMGlu) y medio mínimo con fenilalanina (MMF) a $32^{\circ} \mathrm{C}$. En cada medio las células crecieron en fase exponencial durante 24 horas (Ver metodología en la Figura 12A). Se emplearon como extractos control, células de los mutantes igo1 1 e igo1-S64A crecidos en MMGlu y MMF a $32^{\circ} \mathrm{C}$.

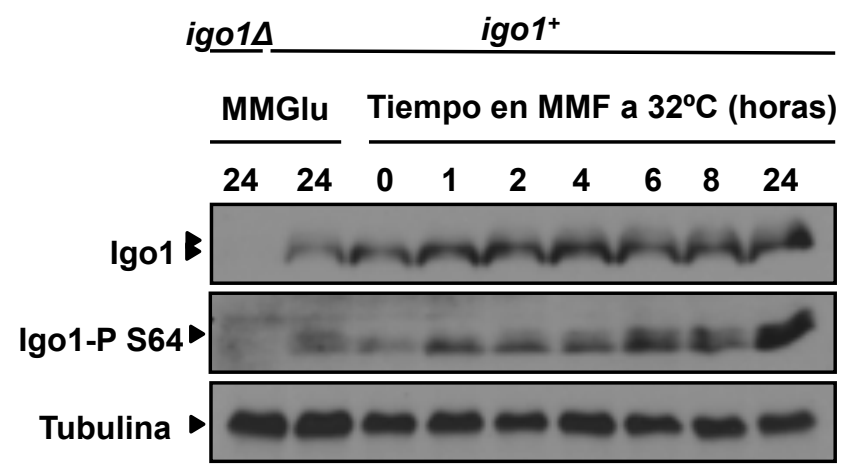

Figura 20. Los niveles y la fosforilación de Igo1 se inducen rápidamente bajo un cambio nutricional. Los extractos corresponden a células silvestres que se transfirieron mediante filtración, desde un cultivo crecido exponencialmente en MMGlu a MMF. Se empleó como extracto control, células de la cepa mutante igo1 $\Delta$ crecidas en $\mathrm{MMG}$ a $32^{\circ} \mathrm{C}(24$ horas en fase exponencial). 
En la Figura 20 se observa como los niveles y la fosforilación en la S64 de lgo1 incrementan una hora después del cambio nutricional. A partir de ese punto, los niveles de Igo1 permanecen constantes y la fosforilación se acumula progresivamente hasta la 24 horas en MMF. Esta fosforilación es equivalente en tiempo, a la observada en el experimento de la Figura 19.

Los niveles de lgo1 y la fosforilación de la S64 se inducen rápidamente bajo un cambio nutricional. Dicha fosforilación se mantiene mientras las células continúen experimentando limitación en la fuente de nitrógeno.

\subsection{La fosforilación de Igo1 en la S64 depende de Ppk18}

De acuerdo a lo demostrado hasta ahora, la proteína lgo1 se activa por fosforilación en condiciones de estrés por nitrógeno. Con el fin de evaluar si dicha fosforilación es dependiente de la actividad de Ppk18, se examinaron extractos proteicos de células silvestres y células mutantes que carecían de los genes $p p k 18^{+}$y $\operatorname{cek} 1^{+}$en condiciones de estrés por nitrógeno (MMF), frente a la situación sin estrés (YES). La metodología empleada se ilustra en la Figura $21 \mathrm{~A}$.

En la Figura 21B, se observa que la fosforilación de lgo1 esta ausente en los mutantes que carecen del gen $p p k 18^{+}$pero no $c e k 1^{+}$, sugiriendo que la fosforilación de Igo1 es solo dependiente de la quinasa Ppk18.

La fosforilación de lgo1 en el residuo Ser64 es dependiente de la actividad de la quinasa Ppk18 pero no de la quinasa Cek1.

\subsection{La sobreexpresión de Ppk18 induce entrada a mitosis y un cese en el crecimiento a través de Igo1}

Para investigar si la sobreexpresión de Ppk18 podría la entrada a mitosis, se empleó el promotor inducible del gen $n m t 1^{+}$. Existen tres versiones de este promotor, nombradas en orden descendiente según la capacidad de inducción de la transcripción nmt1, nmt41, $n m t 81$ (Maundrell, 1990). En este experimento, se integró la construcción nmt1

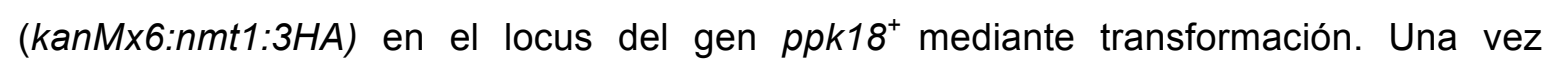
integrado el promotor, se delecionó el gen igo $1^{+}$mediante un cruce genético. 


\section{Resultados-Apartado II}

A

- Muestras para análisis de proteínas (Wb)

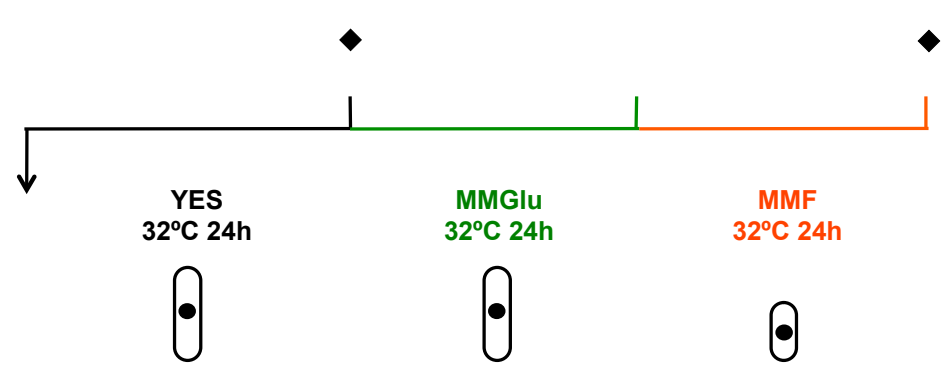

B

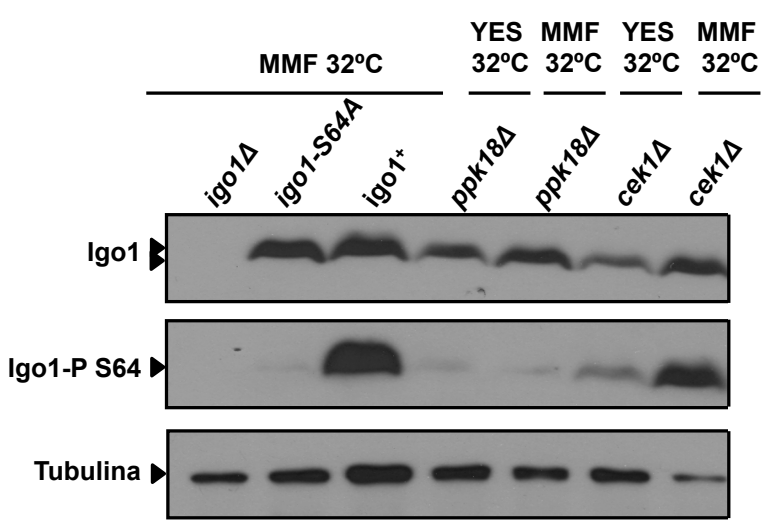

Figura 21. La fosforilación de Igo1 en la S64 es dependiente de la actividad de la quinasa Ppk18. (A) Metodología empleada para obtener los extractos proteicos del western blot de la Figura 21B. Se crecieron células en YES exponencialmente a $32^{\circ} \mathrm{C}$, luego en MMGlu y finalmente en MMF durante 24 horas (B) Mediante Western Blot se analizó la fosforilación en la S64 y los niveles de lgo1 en los fondos mutantes ppk18 y cek1 $\Delta$ en YES y MMF a $32^{\circ} \mathrm{C}$. Como controles, se emplearon extractos de células silvestres, igo1 $\Delta$ e igo1-S64A en MMF a $32^{\circ} \mathrm{C}$.

Para la ejecución del experimento, se tuvo en cuenta que los promotores $\mathrm{nmt}$, después de la eliminación de la tiamina del medio, no inducen la transcripción hasta que la célula agote la tiamina endógena, y a su vez que dicho evento solo ocurre entre las 10 y 12 horas dependiendo de la temperatura del cultivo (Forsburg, 1993; Maundrell, 1993). Por lo tanto, se crecieron cultivo de ambas cepas junto con la cepa silvestre, en MMGlu a $32^{\circ} \mathrm{C}$ hasta fase exponencial en presencia de tiamina (MMGlu $+\mathrm{T}$, condiciones de represión). Seguidamente, se dividió el cultivo en dos y uno de estos se mantuvo en el mismo medio y el resto de células se recogieron por centrifugación, se lavaron dos veces con MMGlu sin tiamina y se inocularon en MMGlu sin tiamina (MMGlu $-\mathrm{T}$, condiciones de inducción). Se recogieron muestras para análisis por FACS y de proteína al tiempo 0 y 12 horas de iniciar la inducción, y de ahí en adelante cada 2 horas hasta las 20 horas. 
Igualmente, en cada tiempo se realizó una tinción in vivo con blankophor con el fin de analizar la evolución de la morfología celular de las cepas mutantes durante el experimento (Figura 22A).

En primer lugar, a través de las tinciones in vivo se observa como las células que sobreexpresan Ppk18 en un fondo silvestre igo $1^{+}$reducen su tamaño a las 14 horas hasta alcanzar un aspecto ovoide tras 16 horas de inducción (Figura 22C). Alrededor de las 18 horas, se observa un retraso del $50 \%$ en el tiempo de generación con respecto a la cepa silvestre, que concluye con un cese en el crecimiento. Al final del experimento, dichas células imitan el aspecto de una célula de $S$. pombe cuando es sometida a privación de nitrógeno. Contrario a esto, las células que sobreexpresan Ppk18 en ausencia de igo $1^{+}$ no reducen su tamaño, sino que muestran un aspecto similar a igo1 $\Delta$ hasta las 18 horas.

Mediante el análisis de citometría (FACS), se observó que la sobreexpresión de Ppk18 fue consistente con una entrada a mitosis y una reducción del tamaño a tiempos tempranos Durante los últimos tiempos, las células se tornan redondas y se agregan, posiblemente por inhibir funciones adicionales del complejo PP2A (Figura 22D).

Finalmente, se realizó un Western Blot empleando el anticuerpo que reconoce los tres epítopos consecutivos de la hemaglutinina del virus de la influenza (anti-HA) (Figura 22B). Con este análisis se confirmó que ambas cepas sobreexpresaron la forma 3HA-Ppk18 y que la inducción basal se mantuvo en condiciones de represión, de acuerdo a lo esperado con en esta clase de promotor (Forsburg, 1993; Maundrell, 1993). Igualmente empleando el anticuerpo anti-Igo1 y anti-Igo1-P-S64, seguimos los niveles de Igo1 y su fosforilación durante la inducción de expresión de Ppk18. La fosforilación se produce después de las 16 horas de inducción y los niveles de Igo1 son constantes.

La sobreexpresión de Ppk18 induce una entrada prematura a mitosis y una reducción en el tamaño celular a través de la fosforilación de lgo1.

A partir de los resultados obtenidos en el apartado 5, se propone que la actividad de Ppk18 induce la entrada a mitosis a través de la fosforilación del residuo S64 de lgo1 y que dicha fosforilación es dependiente de un estrés nutricional. 


\section{Resultados-Apartado II}

A

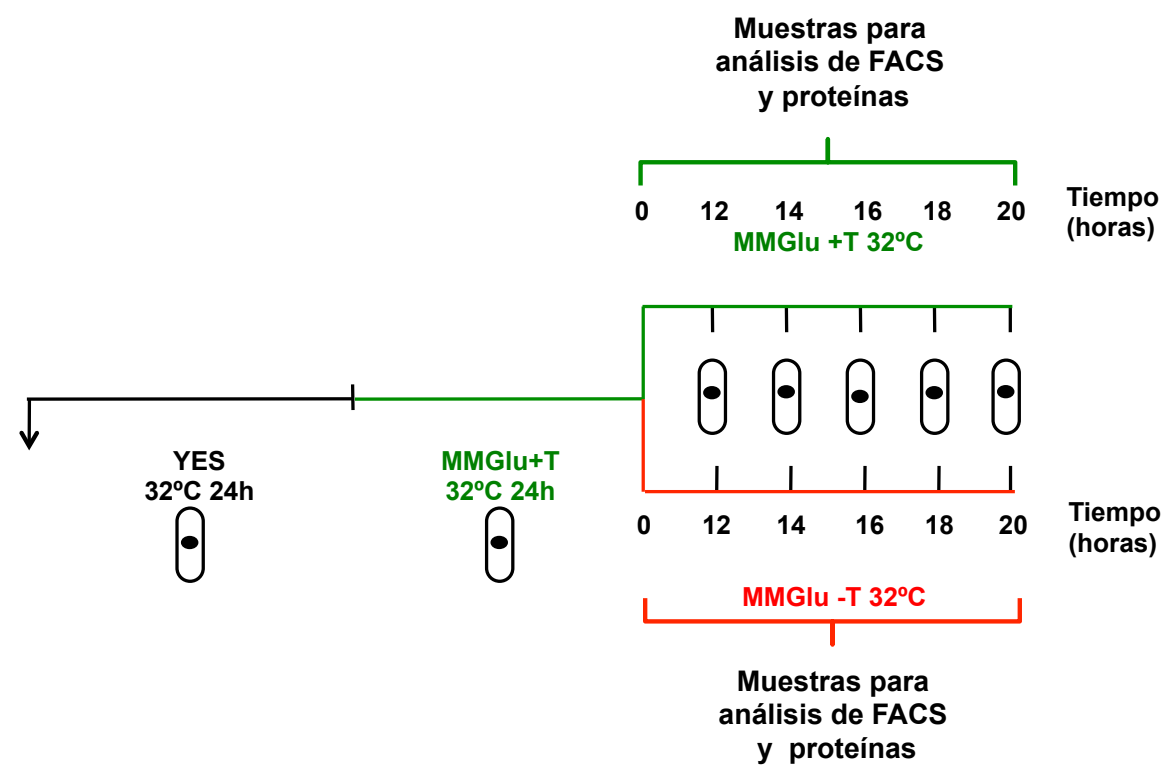

B

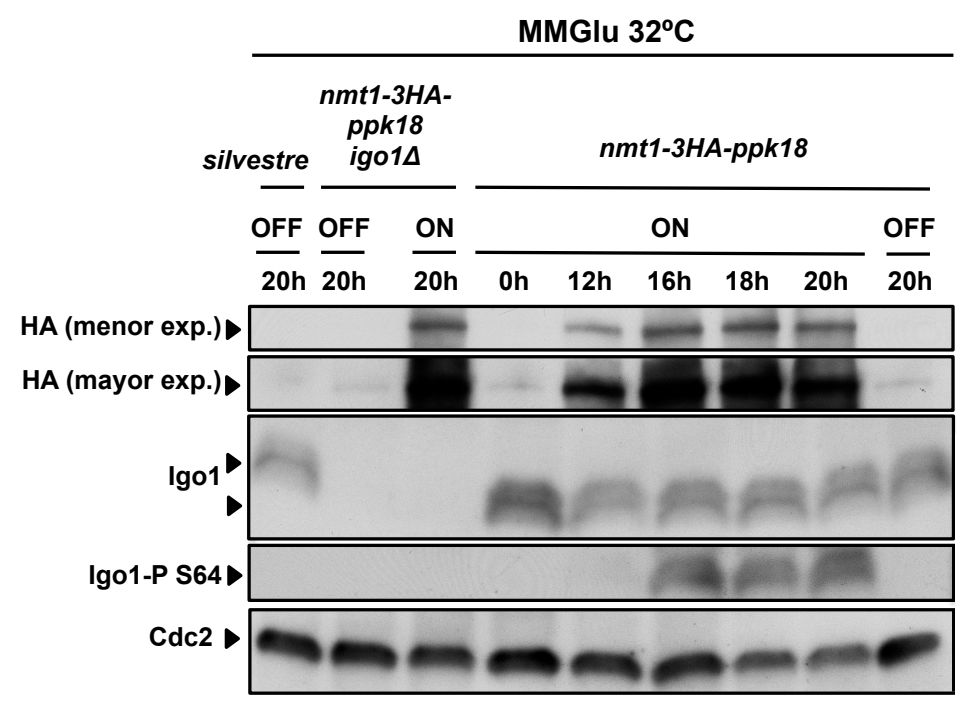


C

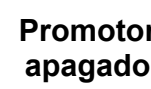

Promotor apagado encendido
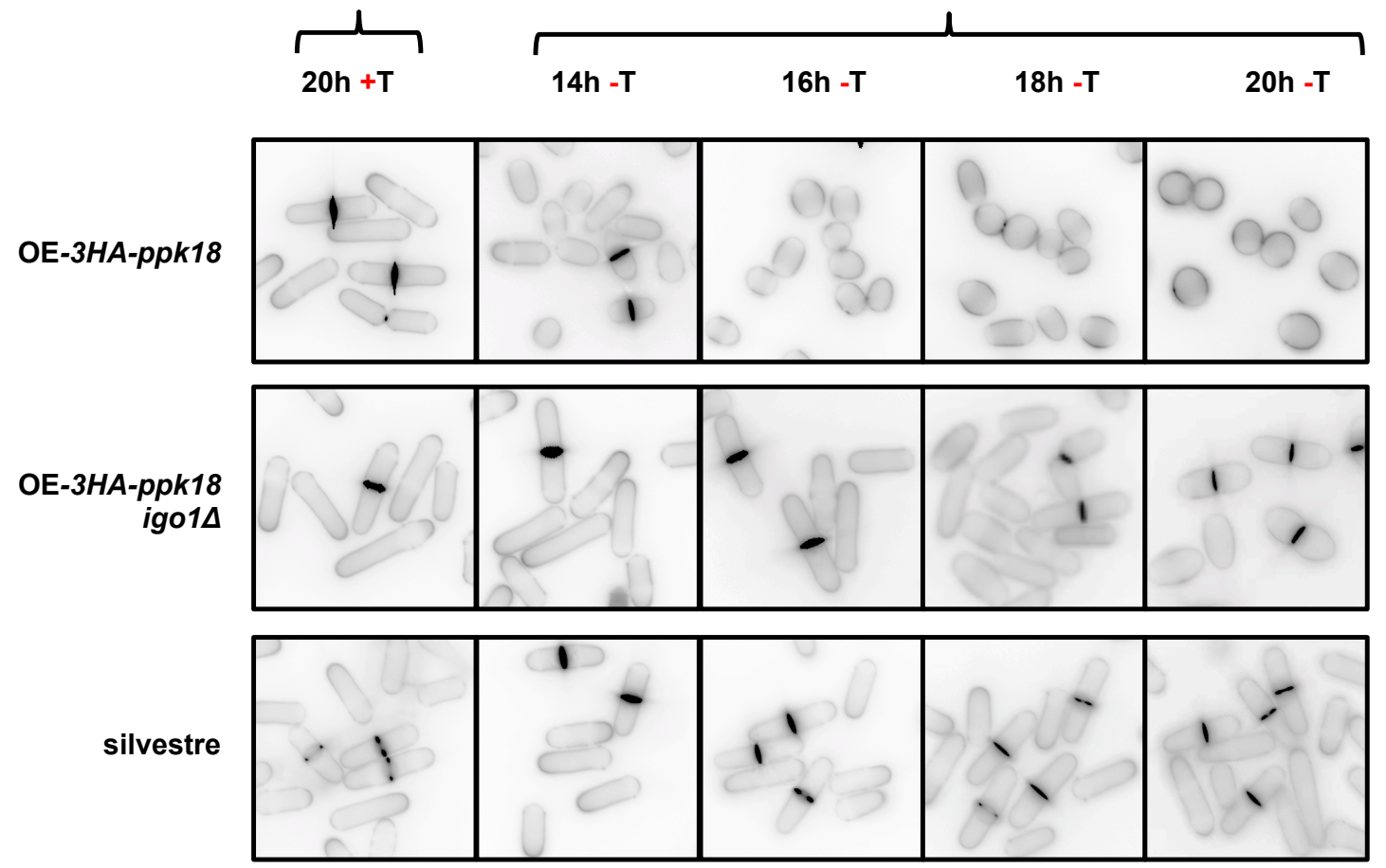

D

silvestre

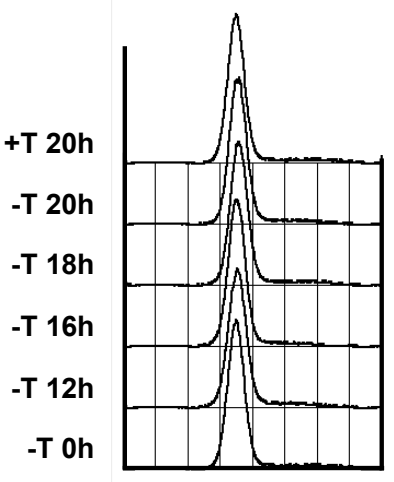

1C 2C
OE 3HA-ppk18

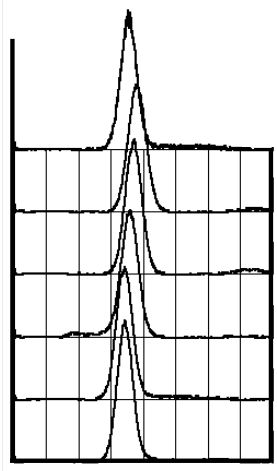

1C 2C
OE 3HA-ppk18 igo1ه

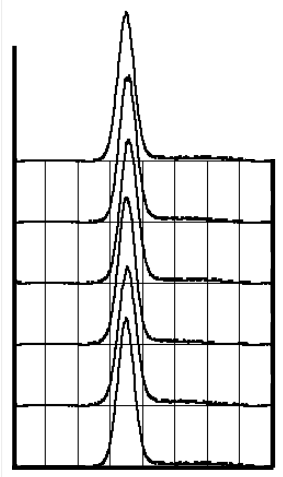

1C 2C

Figura 22. La sobreexpresion de Ppk18 induce entrada a mitosis y un cese en el crecimiento a través de Igo1. (A) Las células que sobrexpresan Ppk18 en presencia y ausencia de igo1, se mantuvieron reprimidas en $\mathrm{MMGlu}+\mathrm{T}$ durante 24 horas a $32^{\circ} \mathrm{C}$. A continuación, se transfirieron a MMGlu $-\mathrm{T}$ durante 20 horas. Se recogieron muestras para análisis de FACS, de proteínas y tinciones in vivo con blankophor cada 2 horas, desde las 12 hasta las 20 horas. (B) Western blot mostrando los niveles y la fosforilación de Igo1 en la S64. Como control negativo, se emplearon extractos de células reprimidas en ausencia y en presencia de igo $1^{+}$. Como control de carga se siguieron los niveles de Cdc2. (C) Las imágenes corresponden a células teñidas con blankophor. (D) Análisis de FACS de la cepa silvestre, la sobrexpresora de Ppk18 en presencia y ausencia de Igo1. 


\section{Resultados-Apartado II}

\section{La ruta Ppk18-Igo1-PP2A es un sensor nutricional}

TOR (del inglés Target of Rapamycin) es una quinasa muy conservada entre los eucariotas, cuya función es controlar el crecimiento y el tamaño celular en respuesta a cambios en el ambiente nutricional (Wullschieger et al., 2006). La levadura S. pombe posee dos quinasas Tor1 (TORC2) y Tor2 (TORC1), siendo esta última esencial (Weisman et al., 2001). La pérdida de Tor2 inhibe el crecimiento celular y promueve la diferenciación celular, imitando la respuesta celular por privación de nitrógeno (Alvarez y Moreno, 2006; Urani et al., 2006; Matsuo et al., 2007) mientras que los mutantes Tor1 son estériles e incapaces de parar en fase G1 bajo las mismas condiciones (Weisman et al., 2007). Aunque aparentemente la función de Tor1 es opuesta a la de Tor2, se ha propuesto que el control en la entrada a mitosis inducido por estrés nutricional, es regulado por ambas proteínas, Tor1 a través de la ruta de estrés MAPK quinasa (Shiozaki y Russell, 1995; Petersen y Nurse, 2007; Hartmuth y Petersen, 2008) y Tor2 a través de un mecanismo aún desconocido (Petersen y Nurse, 2007).

Por otro lado, se ha visto que la regulación del ortólogo de Greatwall Rim15 en S. cerevisiae es dependiente del complejo TORC1 y de la proteína quinasa A (PKA). En una situación de abundancia de nutrientes, ambas quinasas inactivan a Rim15 y el factor transcripcional necesario para la supervivencia (Pedruzzi et al., 2003; Talarek et al., 2010; Luo et al., 2011). Dicha transcripción es llevada a cabo por los factores Msn2/4 y Gis1 a través de la activación de la vía Rim15-Igo1/2 y la consecuente inhibición del complejo PP2A-Cdc55 (Bontron et al., 2012).

\subsection{TORC1 (Tor2) regula negativamente la activación de Igo1}

De acuerdo a estos antecedentes y debido a que la sobreexpresión de Ppk18 promueve la entrada a mitosis imitando una situación de estrés nutricional y que las células del mutante igo1 tienen defectos opuestos a los observados en un mutante defectuoso de Tor2, nuestro siguiente objetivo fue evaluar si la actividad de TORC1 podría regular negativamente la activación del módulo Ppk18-Igo1. Para responder a esto, se determinó el efecto de la inactivación de Tor2 en ausencia de igo $1^{+}$, utilizando el mutante termosensible tor2-51 (Alvarez y Moreno, 2006). En otras palabras, se construyó 
el doble mutante tor2-51 igo $1 \Delta$, se crecieron las células a temperatura restrictiva $\left(32^{\circ} \mathrm{C}\right)$ y se comparó el tamaño celular de este frente a sus parentales. Para este experimento, las células de los mutantes correspondientes se crecieron hasta fase exponencial en YES a $25^{\circ} \mathrm{C}$, a continuación se dividieron los cultivos en dos y se incubaron a temperatura permisiva $\left(25^{\circ} \mathrm{C}\right)$ y semi-restrictiva $\left(32^{\circ} \mathrm{C}\right)$ (Figura $\left.23 \mathrm{~A}\right)$.

A

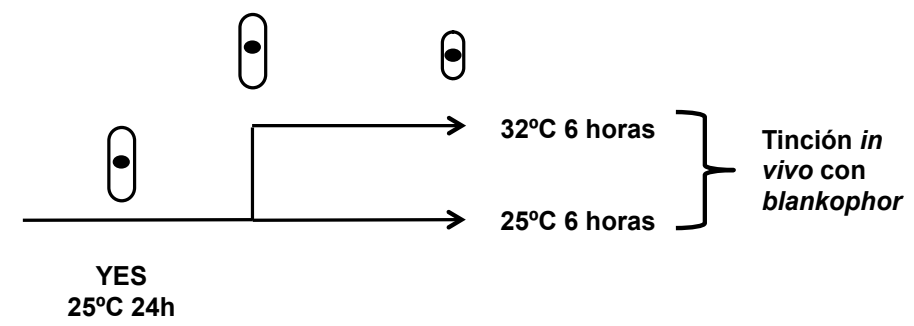

B

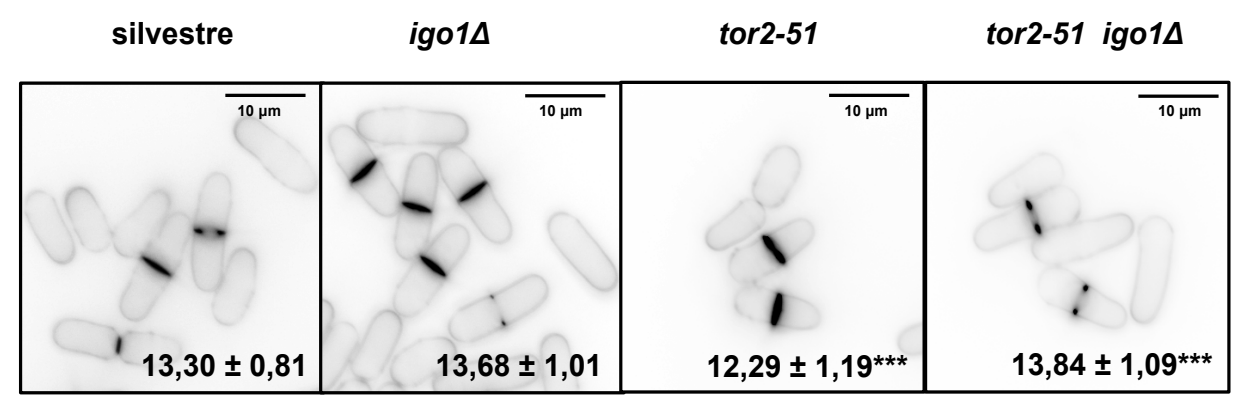

YES $32^{\circ} \mathrm{C}$

C

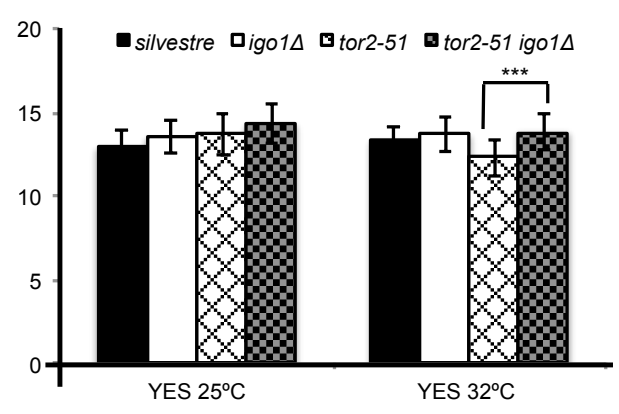

Figura 23. La activación de Igo1 es dependiente de la actividad de TORC1. (A) Células silvestres y del mutante tor2-51, se crecieron en YES a $25^{\circ} \mathrm{C}$ durante 24 horas. A continuación, se dividieron en dos cultivos y uno de ellos se transfirió a $32^{\circ} \mathrm{C}$ (temperatura semi-restrictiva) y el restante se mantuvo a $25^{\circ} \mathrm{C}$. Tras 6 horas, se tomaron muestras para medir su longitud celular. (B) Las imágenes corresponden a células teñidas

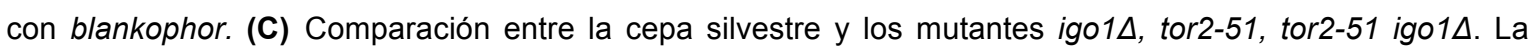
longitud celular es representada en $\mu \mathrm{m} \pm$ la desviación estándar $(n=100)$. *** indica una diferencia significativa con $p$-valor $<0,001$. 


\section{Resultados-Apartado II}

Como muestra la Figura 23B y 23C, las células del mutante tor2-51 reducen su tamaño mientras estas mismas células en ausencia de $i g o 1^{+}$no, sugiriendo que lgo1 podría estar actuando por debajo del complejo TORC1. De acuerdo a lo observado por Valbuena et al., 2012, la privación de nitrógeno produce una disminución de la actividad Tor2, que puede ser medida a través de la fosforilación de la Rps6 (Nakashima et al., 2009). Por lo tanto, se decidió comprobar si dicho fenómeno también era dependiente de la reducción en la calidad de la fuente de nitrógeno. Para ello, se crecieron células silvestres y del mutante igo $1 \triangle$ en YES a $32^{\circ} \mathrm{C}$ exponencialmente y luego se transfirieron sucesivamente a MMGlu, MMF y finalmente a MM sin nitrógeno. Las muestras fueron tomadas a las 24 horas en todas las condiciones, a excepción de MM sin nitrógeno dónde fue tomada a la hora (Figura 24A).

A

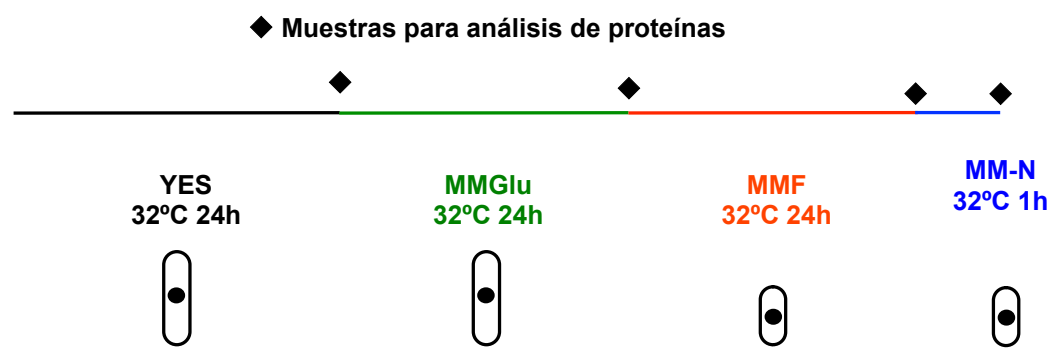

B

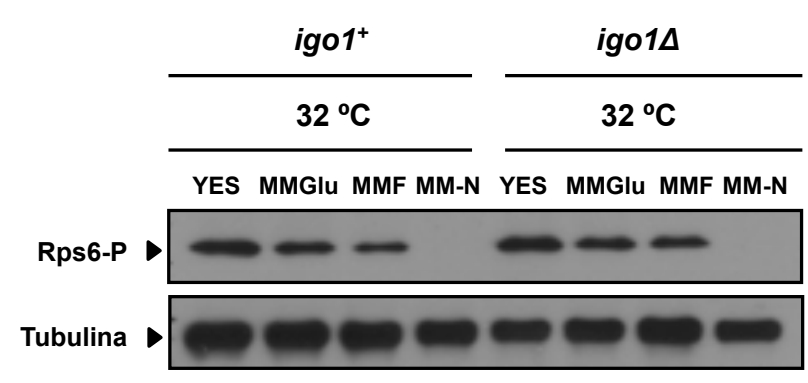

Figura 24. La actividad de TORC1 disminuye tras una reducción de nitrógeno. (A) Células silvestres y mutantes igo1 se crecieron exponencialmente desde YES hasta MM-N, realizando cambios sucesivos de medios a $32^{\circ} \mathrm{C}$. Muestras para análisis de proteínas se recogieron a las 24 horas en todos los casos, excepto en MM-N, en el cual la muestra se tomó tras una hora en privación de nitrógeno. (B) Mediante Western Blot se analizó la fosforilación de Rps6, como medida de la actividad de TORC1 en un fondo silvestre e igo1A. 
A

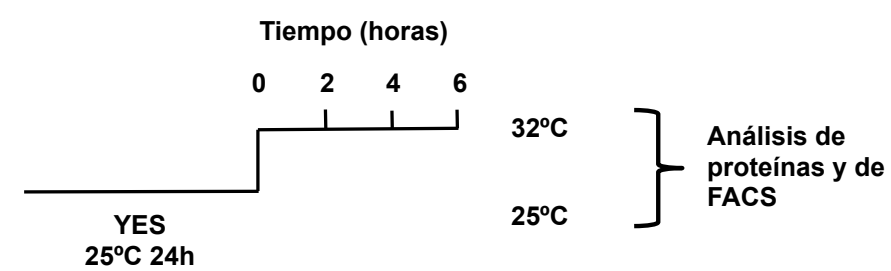

B

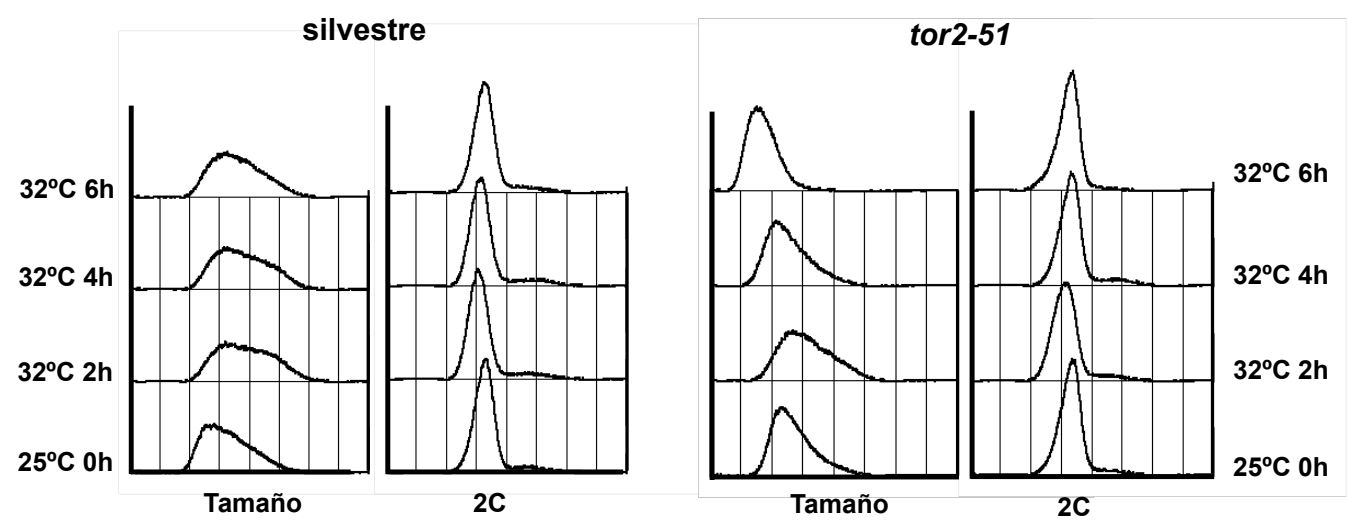

C

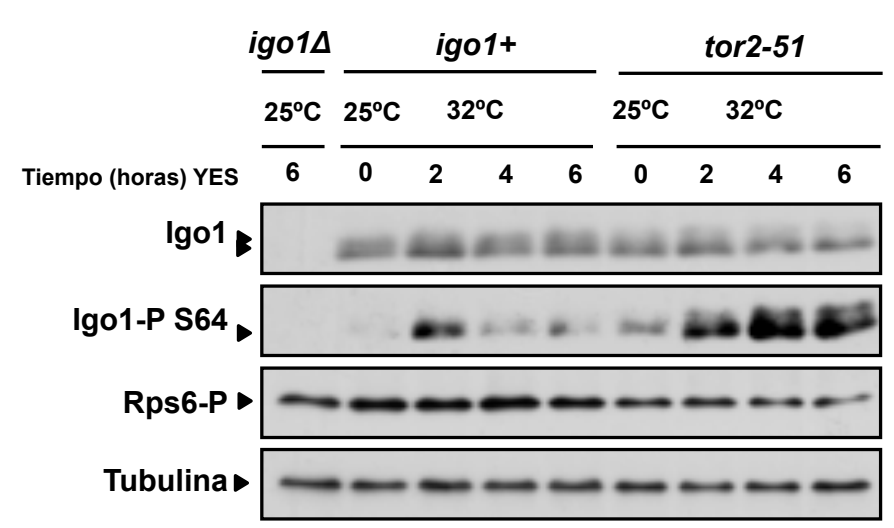

Figura 25. La fosforilación de Igo1 se induce a medida que la actividad de TORC1 disminuye. (A) Células silvestres y del mutante tor2-51 se crecieron en YES a $25^{\circ} \mathrm{C}$ durante 24 horas. Luego, se transfirieron desde $25^{\circ} \mathrm{C}$ a $32^{\circ} \mathrm{C}$ durante 6 horas. Se tomaron muestras cada dos horas para análisis de FACS y de proteínas. El tiempo cero horas fue tomado antes del incremento de temperatura. (B) Análisis de FACS correspondiente a la inactivación de Tor2-51 a $32^{\circ} \mathrm{C}$ durante 6 horas. La comparación es hecha frente a la cepa silvestre. (C) Mediante Western Blot, se analizó los niveles y la fosforilación de lgo1 durante la inactivación progresiva de la actividad de Tor2 (TORC1). Como control de actividad de Tor2 se evaluó la fosforilación de Rps6. Como controles negativos se usaron extractos de células del mutante igo1 $\triangle$ en YES a $25^{\circ} \mathrm{C}$ y extractos de la cepa silvestre sometidas al mismo cambio de temperatura. 


\section{Resultados-Apartado II}

En dicho experimento, se observa una reducción progresiva de la actividad de Tor2 asociada a la reducción de nitrógeno tanto en las células silvestres como en las del mutante igo1 $\Delta$ (Figura 24B), sugiriendo que exponer las células a crecer en medio MMF es equivalente a reducir la actividad de Tor2.

Teniendo en cuenta el anterior resultado, se evaluó si la inactivación de Tor2 podría dar lugar a una activación de Igo1 dependiente de Ppk18. Para ello, se crecieron células silvestres y del mutante tor2-51 en YES a $25^{\circ} \mathrm{C}$ hasta fase exponencial y se transfirieron a $32^{\circ} \mathrm{C}$ durante 6 horas (Figura 25A). Se tomaron muestras a 0, 2, 4 y 6 horas. De acuerdo al análisis de FACS, la inactivación de Tor2 promueve una reducción de tamaño evidente hasta las 6 horas, tiempo en el cual aún la fase G1 permanece críptica (Figura 25B). La Figura 25C muestra como la inactivación de Tor2 induce la fosforilación de la S64 de Igo1, incluso desde niveles basales de actividad $\left(25^{\circ} \mathrm{C}\right)$ en comparación con la cepa silvestre, indicando una activación dependiente de la actividad de Tor2. De igual manera, se observa como el incremento de temperatura desde $25^{\circ} \mathrm{C}$ a $32^{\circ} \mathrm{C}$ induce un pulso de fosforilación de Igo1 tras una hora. Tras la adaptación de las células a la temperatura, esta fosforilación vuelve a ser basal extractos de células del mutante igo1 1 en YES a $25^{\circ} \mathrm{C}$ y extractos de la cepa silvestre sometidas al mismo cambio de temperatura.

Por tanto, la limitación de nitrógeno induce la disminución de la actividad de Tor2 y a su vez induce la fosforilación de lgo1.

\subsection{La proteína quinasa A (PKA) regula negativamente la activación de lgo1}

La actividad de la proteína quinasa dependiente de cAMP (PKA), constituye otra ruta de señalización celular que controla el crecimiento en respuesta a nutrientes (Shabb et al., 2001). En la levadura de fisión, PKA dirige la proliferación e inhibe la diferenciación sexual. La deleción de $p k a 1^{+}$genera células pequeñas y promueve el desarrollo sexual en medio rico (Yamawaki-Kataota et al., 1989; Maeda et al., 1994; Valbuena y Moreno, 2010). Dado que la activación de Igo1 es dependiente de una caída en la actividad de Tor2, de igual forma podría ser dependiente de la actividad de PKA, como se ha sugerido en $S$. cerevisiae en el contexto de la quiescencia.

Para analizar esta hipótesis, en una primera aproximación se evaluó el comportamiento 
de la deleción del gen igo $1^{+}$por separado y en combinación con la deleción de pka $1^{+}$en una situación de limitación por glucosa. Para ello, se construyó el doble mutante pka1ム igo1 $1 \Delta$ y se comparó su tamaño celular frente a sus parentales y la cepa silvestre. Durante el experimento, se redujo progresivamente la glucosa disponible en el medio, analizando el tamaño celular de las cepas en YES Glucosa 3\%, YES Glucosa 0,15\% y EMM Glucosa $0,1 \%$ (Figura 26A). Las muestras para tinción con blankophor fueron tomadas una vez transcurridas 6 horas en cada medio. Paralelamente, se tomaron muestras para análisis de FACS. Los medios con mas baja glucosa fueron suplementados con glicerol $3 \%$ para evitar estrés osmótico.

La Figura 26B muestra que la cepa silvestre reduce el tamaño celular en MM con glucosa $0,1 \%$, hasta niveles pka1 $\Delta$, sugiriendo que la actividad de Pka1 se reduce sólo cuando las células crecen en 1/20 de la concentración glucosa estándar empleada en el laboratorio. Bajo estas mismas condiciones, las células que carecen de igo $1^{+}$no reducen su tamaño como la cepa silvestre y dicho tamaño celular se mantiene en un fondo que carece de $\mathrm{pka}^{+}$, indicando que, en una situación de estrés por glucosa, la ausencia de $i g o 1^{+}$provoca un retraso en la fase $\mathrm{G} 2$ e igualmente, que la entrada a mitosis provocada por la inactivación de $p k a 1^{+}$es dependiente de la actividad de Igo1. En el análisis de FACS realizado, se observa un solo pico $2 \mathrm{C}$ para todas las cepas evaluadas (datos no mostrados).

De la misma forma que se equiparó la disminución de la actividad de Tor2 con la reducción del nitrógeno, para este caso se asumió que la reducción en la fuente de glucosa sería equivalente a una caída en la actividad de PKA. Para comprobar esto, se analizó la fosforilación de Igo1 en un cambio nutricional por glucosa. Para ello, se crecieron células en EMM Glucosa $2 \%$ exponencial a $32^{\circ} \mathrm{C}$ y a continuación se dividió el el cultivo para crecerlas paralelamente en EMM Glucosa $2 \%$ y EMM Glucosa 0,1\%. Se tomaron muestras al cabo de 6 horas (Figura 27A). Como resultado de la reducción en la cantidad de glucosa, se indujo la fosforilación de lgo1, sugiriendo que su actividad no sólo es dependiente de Tor2 sino también de PKA (Figura 27B). Asimismo, se observa como la reducción de glucosa inhibe la fosforilación de Rps6 a través de TORC1, sugiriendo que al disminuir la glucosa en el medio, también se inactiva TORC1. Como control de la caída de la actividad de PKA en este experimento, se midió la longitud celular de la cepa silvestre y el mutante igo1 $1 \Delta$ y se confirmó nuevamente lo observado en la Figura 26B, una reducción del tamaño celular de la cepa silvestre y una menos pronunciada 


\section{Resultados-Apartado II}

A

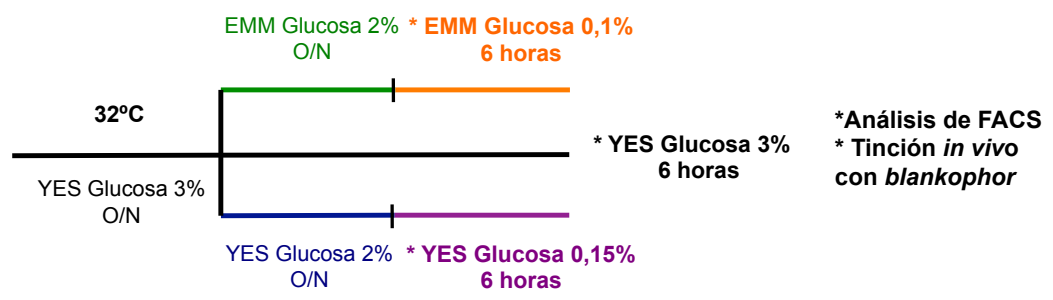

B

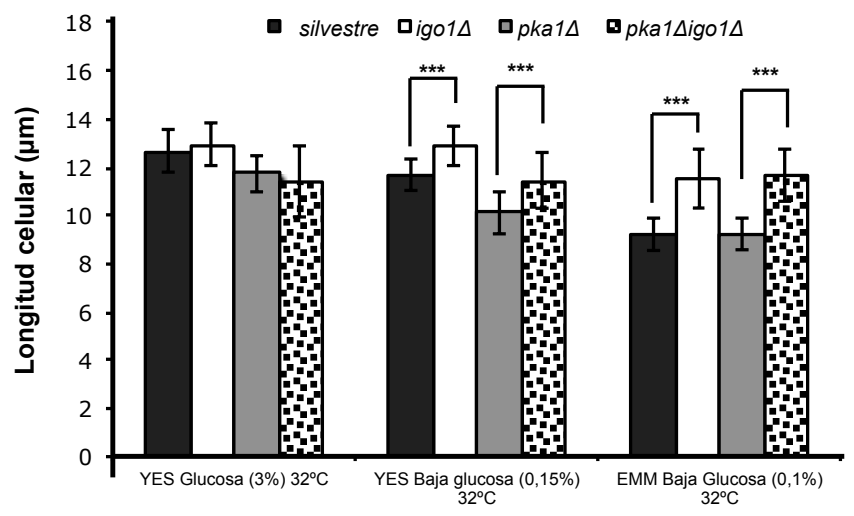

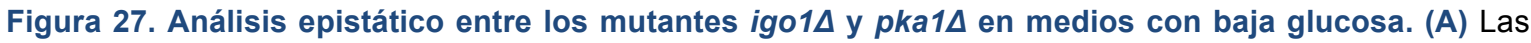

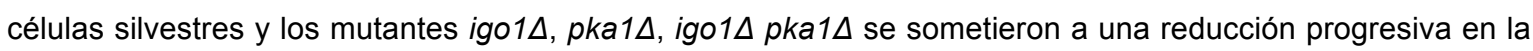
cantidad de glucosa a $32^{\circ} \mathrm{C}$ durante 6 horas en cada condición. Se añadió glicerol $3 \%$ para evitar estrés osmótico por reducción en los niveles glucosa. Las muestras se recogieron para tinción in vivo con

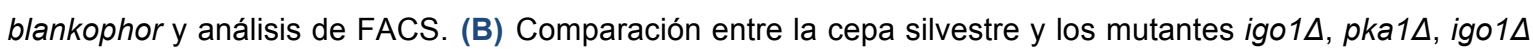
pka1 $\Delta$. La longitud celular es representada en $\mu \mathrm{m} \pm$ la desviación estándar $(\mathrm{n}=100) .{ }^{* * *}$ indica una diferencia significativa con $p$-valor $<0,001$.

en el mutante. De igual forma, se analizó el perfil de FACS, con el cual se observa como las células a pesar de reducir su tamaño no expanden la fase $\mathrm{G} 1$, sugiriendo que el bloqueo final de estas células ocurre en fase G2 (Figura 27C).

Igo1 es necesario para acelerar la entrada a mitosis en baja glucosa, lo cual sugiere que la fosforilación y la activación de lgo1 es dependiente de una reducción en la actividad de TORC1 y PKA.

A partir de los resultados obtenidos en el apartado 6, se propone que TORC1 (Tor2) y PKA regulan negativamente la activación de Igo1. 
A

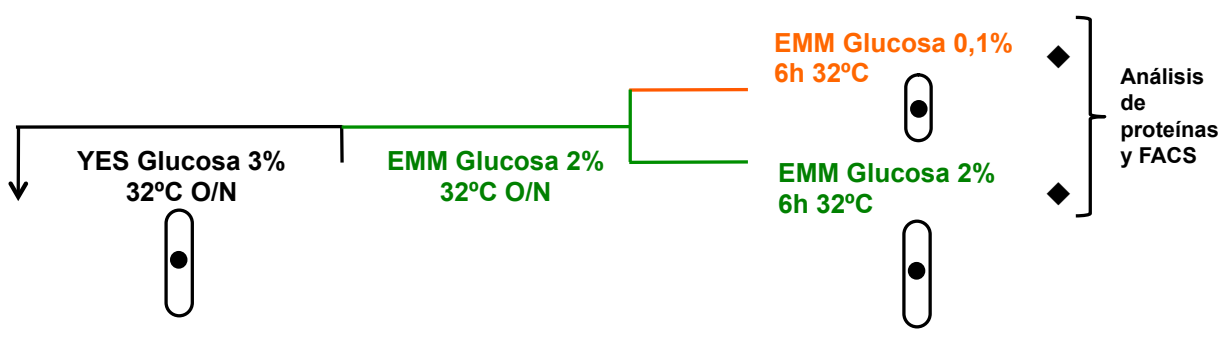

B

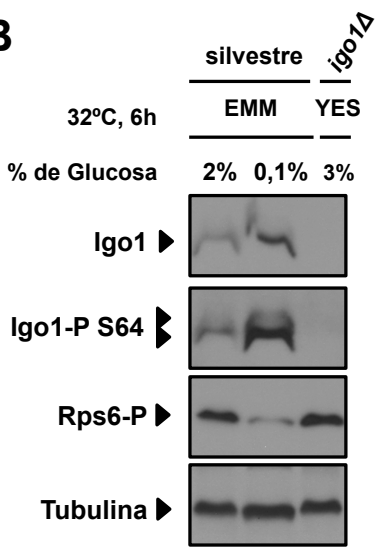

C

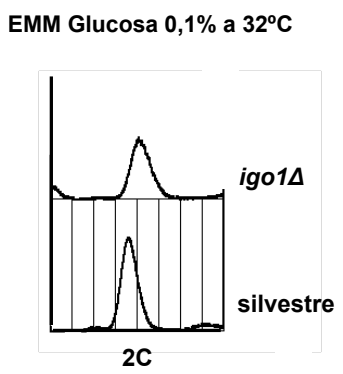

D

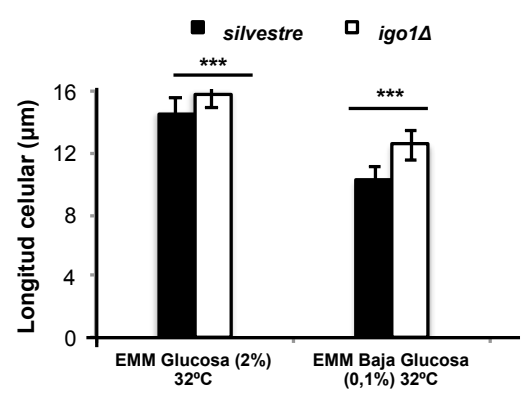

Figura 28. La actividad de Igo1 es dependiente de estrés por glucosa. (A) Células de la cepa silvestre y del mutante igo1 1 , se crecieron en medios ricos en glucosa (YES Glucosa 3\% y EMM Glucosa 2\%). Luego, se dividieron en dos cultivos que se sometieron por separado a crecer en una condición óptima de glucosa (EMM Glucosa $2 \%$ ) y en una pobre (EMM Glucosa $2 \%$ ) a $32^{\circ} \mathrm{C}$. Se añadió glicerol $3 \%$ para evitar estrés osmótico. Se recogieron muestras después de 6 horas, para análisis de FACS y proteína. (B) Mediante Western Blot se analizó los niveles y la fosforilación de lgo1 y de Rps6. Como control negativo, se empleó un extracto de células de igo1 en YES Glucosa $3 \%$ a $32^{\circ} \mathrm{C}$, recogido tras 6 horas de crecimiento en fase exponencial.

\section{La actividad de Igo1 es independiente de otros mecanismos de} regulación de entrada a mitosis en $S$. pombe

Otras rutas de control de la entrada mitosis se han propuesto en S. pombe. Una de ellas, es la ruta de señalización que acopla el crecimiento con la división celular a través de la cascada de quinasas Pom1-Cdr1/Cdr2-Wee1. De acuerdo al modelo, en interfase Pom1 favorece la actividad de Wee1 a través de la inhibición de las quinasas Cdr1/Cdr2 hasta que las células alcancen el tamaño apropiado para una división celular exitosa (Bähler y Nurse, 2001; Martin y Berthelot-Grosjean, 2009; Moseley et al., 2009). Otra, mencionado con anterioridad, es la señalización TOR que regula la entrada a mitosis a través de la ruta de estrés MAPK y Polo quinasa en respuesta a estrés por 


\section{Resultados-Apartado II}

nutrientes (Petersen y Nurse, 2007).

Con el fin de evaluar si lgo1 podría actuar como un módulo independiente de la actividad de estas rutas, se combinó la deleción de igo1 $1 \Delta$ con los mutantes pom1 $\operatorname{cdr} 1 \Delta$, sty $1 \Delta$ y pyp2 $2 \Delta$ y realizamos un análisis epistático de acuerdo a variaciones en el tamaño celular. Para ello, las células se crecieron hasta fase exponencial en MMGlu y MMF a $32^{\circ} \mathrm{C}$ y se tiñeron con blankophor (ver metodología, Figura 12A). En la Tabla 3, se indican los valores de longitud celular observado en cada mutante.

En MMG, la combinación de la mutación de cdr1 $\Delta$ o pom $1 \Delta$ con igo1 $\Delta$ es aditiva, ya que en el primer caso incrementa la longitud celular en el doble mutante con respecto a sus parentales y en el segundo es intermedia. Lo mismo se observa con la combinación igo1 $1 \Delta$ sty $1 \Delta$, sugiriendo que ambas rutas controlan la entrada a mitosis en una situación de estrés por nitrógeno. En el caso con el gen $p y p 2^{+}$, las células del doble mutante son tan largas como la deleción de $i g o 1^{+}$, sugiriendo una compensación por la pérdida de actividad de Sty1 en estas condiciones, que será mejor analizada en la discusión. Esto mismo ha sido observado en MMF, excepto con $s t y 1^{+}$, ya que las células del mutante sencilla y en combinación con igo1 $\Delta$, son inviables en estas condiciones. De acuerdo a la interpretación de estas interacciones, se propone que la actividad de lgo1 a través de la ruta Ppk18-Igo1-PP2A, es independiente de los otros módulos conocidos como reguladores de la entrada mitosis en $S$. pombe.

De acuerdo a los análisis epistáticos expuestos, la actividad de la ruta Ppk18-lgo1PP2A es independiente de la actividad Pom1-Cdr1/Cdr2-Wee1 o de Pyp2-Sty1-Cdc25 en S. pombe. 
Tabla 3. Análisis epistático entre igo1ه y otros reguladores de mitosis en MMG y MMF a $32^{\circ} \mathrm{C}$

\begin{tabular}{|c|c|c|c|c|c|}
\hline Cepa & $\begin{array}{l}\text { Long. celular MMG } \\
\qquad(\mu \mathrm{m} \pm \mathrm{d} . \mathrm{e})\end{array}$ & $p$-valor & $\begin{array}{l}\text { Long. celular MMF } \\
\qquad(\mu \mathrm{m} \pm \mathrm{d} . \mathrm{e})\end{array}$ & $p$-valor & $\begin{array}{l}\text { Interacción } \\
\text { genética }\end{array}$ \\
\hline silvestre & $15,46 \pm 1,12$ & --- & $11,9 \pm 0,99$ & --- & ---- \\
\hline$i g o 1 \Delta$ & $16,43 \pm 1,33$ & -- & $18,61 \pm 1,58$ & --- & --- \\
\hline $\operatorname{cdr1\Delta }$ & $17,33 \pm 1,12$ & $10^{-12}$ & $16,88 \pm 1,54$ & $10^{-19}$ & --- \\
\hline cdr1s igo1s & $18,75 \pm 1,3$ & $10^{-32}$ & $20,62 \pm 1,38$ & $10^{-26}$ & $\begin{array}{c}\text { Aditiva en } \\
\text { MMG y MMF }\end{array}$ \\
\hline pom1s & $12,95 \pm 1,52$ & $10^{-41}$ & $10,19 \pm 1,25$ & $10^{-84}$ & -- \\
\hline pom1s igo1s & $14,42 \pm 1,94$ & $10^{-17}$ & $13,68 \pm 1,29$ & $10^{--61}$ & $\begin{array}{c}\text { Aditiva en } \\
\text { MMG y MMF }\end{array}$ \\
\hline pyp2 $2 \Delta$ & $14,63 \pm 1,3$ & $10^{-25}$ & $13,34 \pm 1,3$ & $10^{-63}$ & -- \\
\hline 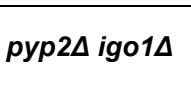 & $16,99 \pm 1,27$ & $10^{-5}$ & $17,1 \pm 1,8$ & $10^{-13}$ & $\begin{array}{c}\text { Aditiva en } \\
\text { MMF }\end{array}$ \\
\hline sty1 $1 \Delta$ & $22,74 \pm 1,39$ & $10^{-67}$ & Inviable & -- & --- \\
\hline sty1 1 igo1 & $26,59 \pm 2,29$ & $10^{-68}$ & Inviable & --- & $\begin{array}{c}\text { Aditiva en } \\
\text { MMG y MMF }\end{array}$ \\
\hline
\end{tabular}

La longitud celular es representada como la media (en $\mu \mathrm{m}$ ) de 100 células septadas \pm la desviación estándar. El p-valor fue calculado, mediante el test T de Student, para una muestra entre la longitud del mutante igo1 1 y las longitudes de cada uno de los mutantes analizados. El nivel de significancia empleado fue de $1 \times 10^{-5}$. 


\section{Discusión}




\section{APARTADO I}

\section{Mapa funcional de la regulación de la Cdk en S. pombe}

En S. pombe se han construido 4865 mutantes de deleción (99\% de los marcos de lectura abierta) incluyendo 1268 para genes esenciales y 3597 para genes no esenciales (Kim et al., 2010; Spirek et al., 2010). El gran número de genes no esenciales sugiere que las células de $S$. pombe poseen múltiples mecanismos de tolerancia que han evolucionado sobre la base de la redundancia funcional de los genes. Esta redundancia ha impedido la caracterización de ciertos genes, ya que su simple interrupción no es suficiente para generar un fenotipo interpretable.

Tong et al., en 2001 desarrollaron la aproximación de genómica funcional SGA que permite la construcción masiva de dobles mutantes y la identificación de interacciones sintéticas letales fundamentalmente. La principal ventaja de llevar a cabo un escrutinio masivo de sintéticos letales (SGA), es que la redundancia funcional puede ser resuelta mediante la identificación de genes que se tornan esenciales para la viabilidad celular en ausencia de otro gen (sintéticos letales) o la identificación de genes cuyas mutaciones agravan la penetrancia fenotípica de una mutación en un segundo gen (sintético enfermo).

En este estudio, se construyeron cerca de 7000 dobles mutantes, cruzando la v3.0 de la colección de genes no esenciales de $S$. pombe (KRIBB-Bioneer-CRUK) con los mutantes wee1-50 y $c d c 2-3 w$, con el fin de analizar sus interacciones genéticas e identificar nuevos genes reguladores del ciclo celular en $S$. pombe. Las interacciones genéticas se establecieron puntuando visualmente el crecimiento celular de los dobles mutantes y normalizándolo en función del crecimiento de sus parentales (Figura 1 ver, Resultados Apartado I). Entre las parejas genéticas analizadas, se identificaron 593 mutantes con interacciones genéticas negativas o positivas según el caso (Figura 5 ver, Resultados Apartado I). La mayoría de los dobles mutantes mostraron un perfil de interacción neutro (puntuación igual a cero), en el cual éstos mostraban la misma viabilidad que el mutante sencillo. Estas observaciones experimentales concuerdan con el modelo neutral de las interacciones genéticas, el cual asume que normalmente dos 


\section{Discusión}

genes no se afectan funcionalmente entre sí y que las interacciones genéticas ocurren en baja frecuencia (Tong et al., 2001; Pan et al., 2004; Schuldiner et al., 2005).

El análisis de los mutantes identificados fue realizado por grupos que se denominaron módulos de interacción. En el módulo de interacciones genéticas negativas, se identificaron 217 y 210 mutantes con wee1-50 y cdc2-3w; y en el módulo de interacciones positivas, se identificaron 70 y 96 supresoras con wee1-50 y cdc2-3w respectivamente (Figura 6 y 8 ver, Resultados Apartado I). Con base en la puntuación de interacción obtenida, se determinó el grado de las interacciones para cada módulo (Figura 6 y 8 ver, Resultados Apartado I). Tanto en el módulo de interacciones negativas como el de las positivas, se observó que la gran parte de elementos que los conforman, son mutantes que manifiestan interacciones débiles con las cepas de interés, probablemente por la presencia de otros genes que aumentan la tolerancia al desequilibrio funcional y mantienen la viabilidad de la célula. Esta característica ha sido observada en otras redes de interacción identificadas en $C$. elegans y $S$. cerevisiae (Byrne et al., 2007; Costanzo et al., 2010; Poyatos, 2011).

Durante la fase G2 en $S$. pombe, la regulación de la actividad del complejo Cdc2Cdc13 depende principalmente de la quinasa Wee1 y la fosfatasa Cdc25 (Russell y Nurse, 1986 y 1987a). Las células que portan el alelo condicional wee1-50 entran prematuramente en mitosis por una reducción en la actividad de la quinasa Wee1 cuando crecen a $35^{\circ} \mathrm{C}$, mientras que las que portan la mutación cdc2-3w avanzan prematuramente hacia mitosis por una mutación en la Cdc2 (C67Y) que imita la sobreexpresión de la fosfatasa Cdc25 (Booher y Beach, 1986; Carr et al., 1989). En este estudio, la interpretación que damos a los sintéticos letales identificados, varía en función de la naturaleza de los alelos empleados en el escrutinio (por ej. alelos nulos, condicionales e hiperactivos). Con wee1-50, las interacciones negativas se explican por la alteración de una proteína que actúa en una ruta independiente a la de la quinasa Wee1 o por la alteración de una proteína que funciona en su misma ruta, ya que la actividad de Wee1 a $35^{\circ} \mathrm{C}$ no está completamente inhibida. Esto indica que los genes sintéticos letales con wee1-50 actúan como posibles reguladores positivos de la actividad de Wee1, ya sea por encima de esta quinasa (por ej. Pom1; Martin y Berthelot-Grosjean, 2009; Moseley et al., 2009) o en una ruta paralela de regulación de la entrada a mitosis (por ej. Ppa2 como regulador negativo de la proteína Cdc25; Kinoshita et al., 1993 o Mik1 como una proteína redundante a la función de Wee1; Lundgren et al., 1991; Lee et al., 1994). 
Con $c d c 2-3 w$, las interacciones negativas se explican como resultado de la alteración de una proteína que actúa como regulador positivo de Wee1, ya que se asume que este mutante es insensible a cambios en la actividad de Cdc25, pero aún sensible a la actividad de Wee1 (Russell y Nurse, 1986; Sveiczer et al., 1999). Por tanto, en un mutante wee1-50 la sinteticidad letal proviene de un desequilibrio tanto en la actividad Wee1 y Cdc25, mientras que en el mutante $c d c 2-3 w$ sólo por un desequilibrio en la regulación de la actividad de Wee1.

Si esto es así, es posible que las 119 interacciones negativas identificadas en común con wee1-50 y cdc2-3w, sean la consecuencia de una alteración en la regulación negativa de la entrada a mitosis a través de un mecanismo presente en los dos mutantes (regulación de la actividad de Wee1), mientras que las 98 únicas a wee1-50 y las 91 a cdc2-3w estén subordinadas a características específicas de cada uno (Figura 7 ver, Resultados Apartado I). En células humanas se ha propuesto que Wee1 mantiene la estabilidad genómica a través de la regulación negativa de complejos que participan en la respuesta al daño en el ADN como Mus81-Eme1 (Domínguez-Kelly et al., 2011). Por tanto, estas interpretaciones sobre la sinteticidad letal podrían ser trasladadas a otros contextos biológicos, en los cuales la quinasa Wee1 cumpla una función celular adicional al control de la entrada a mitosis. Sin embargo dichas funciones aún no han sido demostradas en S. pombe.

Si es cierto que el mutante $c d c 2-3 w$ es insensible a la regulación de Cdc25, cabría esperar que parte de las interacciones negativas, como producto de la alteración de la función de Cdc25, sólo resulten con el fondo genético wee1-50. Mientras que si la mutación $c d c 2-3 w$ imita una hiperactivación de la $\mathrm{Cdk}$, las interacciones negativas exclusivas con este mutante, sean el resultado de la ausencia de proteínas que reprimen la activación del complejo Cdc2-Cdc13, (por ej. proteínas involucradas en la regulación de factores que controlan la síntesis y la degradación de ciclinas (APC-Ste9; Kitamura et al., 1998; Blanco et al., 2000) o en la regulación de inhibidores de la Cdk (CKIs; Rum1 y Sic1; Sánchez-Díaz et al., 1998). Lkh1, el primer regulador positivo reportado para Rum1 (Yu et al., 2013), presentó una interacción negativa débil con wee1-50 (Tabla S1 ver, Material Suplementario), lo que sugiere la existencia de otros reguladores aún no descritos. 


\section{Discusión}

La Figura 12 (ver, Resultados Apartado I) permite visualizar las interacciones negativas fuertes comunes y únicas a cada cepa de interés. En el caso de aquellas únicas con $c d c 2-3 w$, el número elevado de genes asociados con biogénesis de ribosomas sugiere la existencia de una coordinación entre los niveles de actividad de la Cdk y la maquinaria de traducción en $S$. pombe. Como apoyo a esta hipótesis, se ha propuesto que la actividad de Wee1 es necesaria para retrasar la entrada a mitosis en respuesta a la inhibición de la síntesis de proteínas en S. pombe (Suda et al., 2000), lo cual sugiere que una actividad alta de la Cdk bajo una síntesis de proteínas comprometida podría causar la pérdida de viabilidad.

Teniendo en cuenta que ambos mutantes wee presentan una fase G2 mas corta y células más pequeñas en comparación con la cepa silvestre (Nurse, 1975; Nurse y Thuriaux, 1980; Fantes 1981), la sinteticidad letal de estos mutantes se pueden explicar: i) si las células no tienen suficiente tiempo para completar la replicación del ADN antes de iniciar la mitosis, como sucede en los mutantes del checkpoint de replicación o el mutante mik1 $\triangle$ (Rad 1,3,9,17 y Hus1; Figura 12 ver, Resultados Apartado I) los cuales mueren por catástrofe mitótica (Russell y Nurse, 1986; Lundgren et al., 1991; Enoch et al., 1992; Rowley, 1992) (ver categoría replicación; Tabla S1 y S2); ii) si la fase G1 es muy corta como sucede en el doble mutante wee 1-50 rum $1 \Delta$, que muere muy pequeño (Moreno y Nurse, 1994) (ver categoría regulación del ciclo celular; Tabla S1 y S2), iii) si hay problemas de segregación cromosómica que acaban en catastrófe mitótica, como sucede cuando se elimina el gen esencial Mcl1 en un fondo wee1-50 (Williams y McIntosh, 2002) (ver categoría reparación del ADN y mitosis; Tabla S1 y S2), iv) cuando el control G2/M sea importante para evitar la citoquinesis (Liu et al., 2000) (ver categoría morfogénesis y citoquinesis; Tabla S1 y S2).

Mediante el uso de técnicas derivadas del SGA, tales como el E-MAP (del inglés Epistatic miniarray profiles) y el CGA (del inglés Chemical Genetic Array), se han identificado interactomas genéticos, que describen globalmente el equilibrio molecular y celular en S. pombe (Frost et al., 2012; Ryan et al., 2012) y en S. cerevisiae (Costanzo et al., 2010) y una red que conecta la función de la CDK con múltiples procesos celulares en S. cerevisiae (Zimmermann et al., 2011) respectivamente. En S. pombe aún no se ha realizado el primer escrutinio de sintéticos letales que involucre mutantes del ciclo celular. No obstante, un escrutinio que consistió en la identificación de mutantes con células pequeñas, reveló la existencia de rutas de control de la entrada a mitosis independientes 
de la ruta de estrés y la ruta que coordina el tamaño con la división (Navarro y Nurse, 2012). De los 18 genes identificados, sólo 5 fueron comunes a nuestros datos (zfs $1^{+}$, pom $\left.1^{+}, c / p 1^{+}, s n f 5^{+}, p p a 2^{+}\right)$, sugiriendo que otros fenotipos adicionales a un tamaño celular reducido pueden provocar la pérdida de viabilidad en mutantes tipo wee.

Teniendo en cuenta que el $97 \%$ de los genes identificados en este escrutinio, tiene un ortólogo conservado en eucariotas superiores (Tabla S4 y S5 ver, Material Suplementario), las redes de interacción presentadas aquí deberían ser extrapolables a otros organismos, con el fin de proporcionar una nueva visión sobre las capas de regulación de la Cdk conservadas a lo largo en la evolución. Debido a que los elementos del control de la transición G2/M en la levadura de fisión, funcionalmente son más similares a los de las células humanas que a los de S.cerevisiae, la principal utilidad de estos resultados, es que permite identificar nuevos reguladores de ciclo celular en células animales.

\section{Análisis de la composición de las redes de interacción genética identificadas}

Como se ha mencionado, la transición G2/M es regulada por la actividad de Wee1 y Cdc25, cuya actividad está regulada por elementos que actúan cerca de la capa primaria de regulación, pero también en capas secundarias que conectan con la maquinaria central del ciclo celular. Estas capas secundarias pueden definir procesos y componentes celulares, que pueden ser identificados mediante un análisis de ontología genética (del inglés Gene Ontology, GO). Para identificar estas capas, se emplearon las herramientas Gene list Analyzer del Instituto Wellcome Trust Sanger y BiNGO (Tabla 2 y 3; Figura 14 y 15 ver, Resultados Apartado I). En conjunto, estos análisis funcionales señalaron que la regulación de la progresión hacia mitosis, requiere fundamentalmente de tres procesos, la integridad del ADN, la segregación cromosómica y la señalización celular. Estas observaciones se apoyan en interacciones identificadas en nuestro escrutinio que ya han sido previamente descritas en S. pombe como: i) la dependencia entre la replicación y la mitosis a través de las proteínas Rad (Enoch et al., 1992; al-Khodairy y Carr, 1992 y alKhodairy et al., 1994); ii) el checkpoint del huso mitótico a través de la fosforilación de Bub1 por la Cdk (Yamaguchi et al., 2003) y iii) la actividad de proteínas fosfatasas como antagonistas de la actividad de la Cdk (Novak et al., 2010b; Domingo-Sananes et al., 2011) a través de proteínas conocidas como PP2A (Ppa2) (Kinoshita et al., 1993) y Clp1 


\section{Discusión}

(Wolfe et al., 2004; Esteban et al., 2004).

La determinación de estas capas de regulación, podrían predecir la función de genes que aún permanecen sin un papel asociado al ciclo celular, como es el caso del gen $r n c 1^{+}$( $r n c 1 \Delta$ es sintético letal con wee1-50 y no con cdc2-3w; Tabla S1 ver, Material Suplementario), cuyo producto génico es una proteína de unión a ARN que regula negativamente la actividad de Pmk1 a través de la fosfatasa Pmp1 (Sugiura et al., 2003). Pmk1 es una de las MAP quinasas que regula la integridad de la pared celular (Toda et al., 1996) que a su vez es parcialmente regulada por la quinasa Sty1, el principal elemento de la ruta de estrés en S. pombe (Madrid et al., 2006). De acuerdo a resultados preliminares de nuestro grupo, en un análisis de expresión realizado al mutante $r n c 1 \Delta$, se observó una sobreexpresión de genes necesarios para la conjugación, lo cual podría ser justificado a través de una activación del factor de trascripción Atf1 mediada por la actividad de Sty1 (Shiozaki y Russell, 1996). Sty1 ha sido implicada en control del ciclo celular, ya que su actividad favorece la activación de Cdc25 vía Polo quinasa (Plo1) (Petersen y Nurse, 2007) Nuestros análisis funcionales ubican a Rnc1 con la proteína fosfatasa Clp1 (Tabla S7 ver Material Suplementario), lo cual sugiere que Rnc1 a través de Sty1-Cdc25 podría tener un papel como regulador negativo de la actividad de la Cdk, al igual que Clp1 a través de la regulación negativa de la actividad de Cdc25 (Esteban et al., 2004). Debido a que el gen $r n c 1^{+}$es un potencial candidato como regulador del ciclo celular, también deberían serlo otros genes $\left(p x / 1^{+}, c c h 1^{+}, y a m 8^{+}, c n b 1^{+}\right.$, entre otros) que se agrupan junto con este en la categoría funcional de señalización celular (Figura 12 ver, Resultados Apartado I).

\section{Nuevos reguladores del ciclo celular en S. pombe: Predicción de} función y relaciones

Según Mani et al., 2008, las mutaciones combinadas en dos genes producen un fenotipo que puede revelar relaciones funcionales entre genes, entre rutas y entre módulos de acción. Los datos que provienen de escrutinios masivos de interacciones genéticas (p. ej. E-MAP, SGA) pueden integrarse para predecir funciones celulares e interacciones gen-gen, gen-proteína y proteína-proteína desconocidas. La aplicación de esta estrategia en este estudio (Figura 17 ver, Resultados Apartado I; Tabla S11 y Figura S1 ver, Material Suplementario) reveló múltiples características en la red de nuestro escrutinio, entre las cuales destacamos tres como ejemplo. 
En la primera, se observa como el módulo de los genes asociados a replicación $(\mathrm{rad} 9 / \mathrm{hus} 1 / \mathrm{rad} 26 / \mathrm{rad} 3 / \mathrm{rad} 17)$ interactúa entre sí y conecta con $c d c 2^{+}$a través de rad9+ o

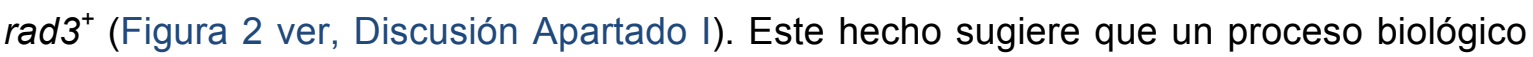
común (p. ej. replicación), es soportado por la actividad de estas proteínas y la actividad de la CDK, de acuerdo a lo descrito por al-Khodairy y Carr, 1992; Walworth et al., 1993 y Rhind y Russell, 1998.

En la segunda, se observa una relación funcional entre $\operatorname{arp} 8^{+}$y SPAC631.02 (Figura 1, ver Discusión Apartado I), dos genes cuyos productos están asociadas al remodelamiento de la cromatina (Hogan et al., 2010; Garabedian et al., 2012; Wang et al., 2013). De igual manera, estos dos genes extienden su relación hacia el módulo de acción de los genes $m h f 1^{+}$y $m h f 2^{+}$(Figura 1 ver, Discusión Apartado I), cuyas proteínas participan en la reparación del daño en el ADN en S. pombe (Bhattacharjee et al., 2013) y en la segregación cromosómica según sus ortólogos humanos CENP-S y CENP-X (Amano et al., 2009). A su vez, en esta última relación, sirven como puente cuatros genes (Figura 1 ver, Discusión Apartado I), cuyas funciones aún no han sido caracterizadas en S. pombe (SPBC947.01, SPAC23C11.10, dm/1 ${ }^{+}$y mug132 ${ }^{+}$). Estas relaciones funcionales, sugieren que bien estas proteínas desempeñan múltiples funciones asociadas al remodelamiento de cromatina, segregación cromosómica y reparación del $A D N$, o que sus funciones se relacionan con los tres procesos celulares a través de elementos comunes a estas (por ej. estructura y función de nucleosomas). Esta predicción puede apoyarse en parte por el fenotipo de células largas y retraso en citoquinesis y/o replicación observado en los mutantes SPBC947.01A y SPAC23C11.10A, a través de nuestra caracterización comprensiva.

En la tercera, se observa la interacción de cdc2 con reguladores del ciclo celular (Figura 2 ver, Discusión Apartado I). Para la mayoría de estos genes, su función biológica y los mecanismos moleculares de su regulación han sido descritos. Tanto la subunidad reguladora de la fosfatasa tipo $2 \mathrm{~A}$ (PP2A) codificada por el gen $p p a 2^{+}$, como la proteína quinasa codificada por el gen pom 1 han sido descritas como reguladores negativos de la entrada a mitosis en S. pombe. (Martin y Berthelot-Grosjean , 2009; Moseley et al., 2009; Kinoshita et al., 1993). En el caso de Pom1, el mecanismo molecular está definido, ya que regula la actividad de Wee1, sin embargo en el caso de Ppa2 el mecanismo es aún impreciso, ya que la regulación directa de esta sobre Cdc2 aun no ha sido demostrada (Kinoshita et al., 1993). La relación funcional entre los genes $p p a 2^{+} \operatorname{con} r a d 3^{+}$y $m p h 1^{+}$, 


\section{Discusión}

también sugiere un papel de la proteína fosfatasa en el control de la replicación del ADN (Jimenez et al., 1992; Seaton et al., 1992) y el control del ensamblaje del huso mitótico (He et al., 1998) respectivamente. Ppa2 podría regular la actividad de Cdc2 no sólo a la entrada de mitosis sino a lo largo de todo el ciclo mitótico en $S$. pombe, actuando como un regulador clave en las capas secundarias que conectan con el sistema Wee1-Cdc2Cdc25. Las anteriores reflexiones le hacen un elemento interesante para abordar.
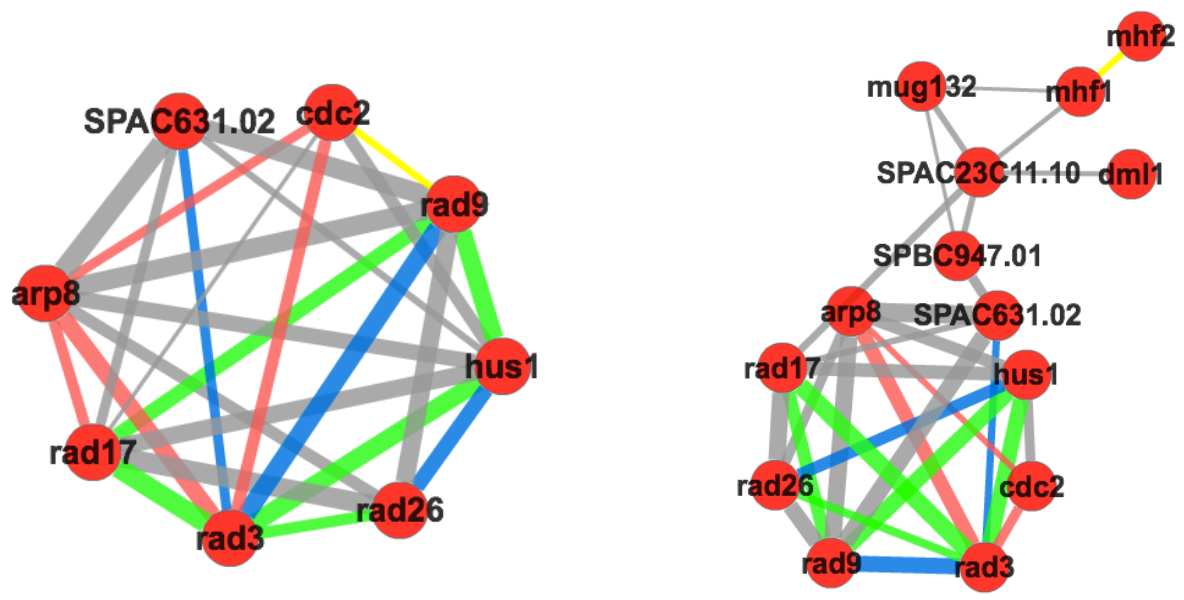

Figura 1. Módulo de interacción entre los mutantes rad y otros genes asociados a replicación y remodelamiento de cromatina. Estas imágenes han sido tomadas desde la web de los autores (http://www.bahlerlab.info/). Nota: El gen SPAC631.02 actualmente se encuentra anotado en Pombase como bdf2 (proteína de remodelamiento de cromatina-función descrita), SPBC947.01 como alf1 (proteína asociada a microtúbulos- función predicha) y SPAC23C11.10 como mpn1 (proteína de procesamiento de mARN-función predicha).

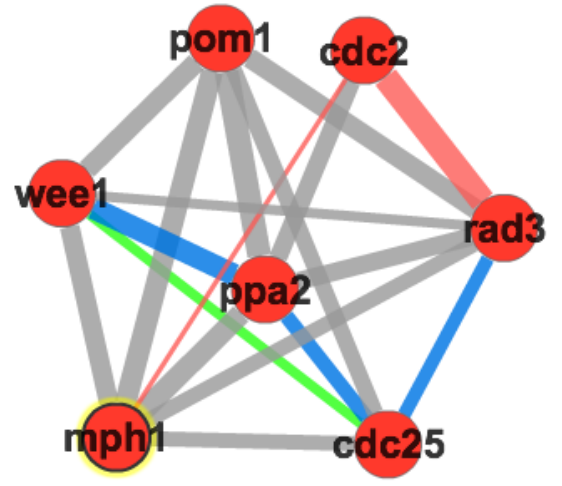

Figura 2. Módulo de interacción entre el gen ppa2 y los genes que controlan la entrada a mitosis como wee1, cdc25 y cdc2. Esta imagen ha sido modificada de su original obtenida desde la web de los autores (http://www.bahlerlab.info/). 
Por último, basados en estas interpretaciones es posible argumentar que las interacciones negativas observadas con wee1-50 o cdc2-3w, se deben mas a una descompensación en la actividad de grupos de genes, que a la ausencia de un gen en particular. De ahí que la esencialidad de estos genes no dependa de su función individual sino de su participación conjunta en un determinado proceso celular (redundancia funcional).

Siguiendo este ejemplo, análisis de este tipo merecen ser empleados para entender y visualizar el significado de las relaciones funcionales entre la maquinaria de regulación de entrada a mitosis y los genes identificados en el escrutinio, junto con evidencias experimentales que apoyen dichas predicciones. 


\section{Discusión}

\section{APARTADO II}

\section{Ppk18 (Greatwall) e Igo1 (Ensa) actúan como reguladores positivos de la entrada a mitosis en $S$. pombe}

Los complejos Cdk-ciclina controlan el ciclo celular eucariótico y en el caso de $S$. pombe una única Cdk, llamada Cdc2, es suficiente para regularlo. Los niveles de la Cdk varían a lo largo del ciclo celular y a su vez confiere direccionalidad a los eventos que lo componen. Uno de los sistemas de control más estudiado en este modelo, comprende la regulación de la actividad del complejo Cdc2-Cdc13 durante la transición G2/M. Dicha actividad se mantiene levemente reprimida desde la transición G1/S hasta mediados de la fase G2, mediante fosforilación de la Cdc2 en la Y15 por parte de las quinasas Mik1 y Wee1. Cerca de la transición $\mathrm{G} 2 / \mathrm{M}$, esta actividad se dispara hasta niveles máximos a través de dos mecanismos moleculares: i) desfosforilación de Cdc2 en el residuo Y15 a cargo de la fosfatasa Cdc25 y ii) autoamplificación de la activación a través de un mecanismo de retroalimentación positivo, propio de la Cdk, que potencia la activación de Cdc25 y la inhibición de Wee1. La integración de datos obtenidos en los últimos cinco años, a partir del estudio de nuevos elementos que incluyen la proteína fosfatasa tipo $2 \mathrm{~A}$ (PP2A) y las proteínas Greatwall y Arrp19 y Ensa, en diferentes modelos biológicos como S. cerevisiae, Xenopus, Drosophila y mamíferos han generado una nueva perspectiva de como las células coordinan y regulan esta transición.

En 2009, Mochida et al., y Vigneron et al., identificaron a la proteína fosfatasa PP2A unida a la subunidad B55ס, como un componente molecular necesario para regular la entrada a mitosis y salida desde ésta en Xenopus. Según los primeros autores, esta fosfatasa se encarga de desfosforilar proteínas en mitosis, previamente fosforiladas por la CDK en la transición G2/M o en profase, ya que la depleción de PP2A-B55ס acelera la entrada a mitosis y retrasa la salida en extractos de oocitos. Los segundos autores, propusieron que la actividad de PP2A es inhibida por la quinasa Greatwall (MAST-L en humanos) con el fin de asegurar la actividad del complejo Cdc2-ciclina $B$ y del mecanismo de retroalimentación positivo.

En S. pombe se han identificado dos subunidades catalíticas del complejo PP2A: $p p a 2^{+}$y ppa $1^{+}$(Kinoshita et al, 1990). Nuestras observaciones sobre los mutantes de 
deleción de ambos genes han demostrado que la actividad del complejo PP2A en $S$. pombe, también regula negativamente la entrada a mitosis, ya que ambos mutantes presentan células más pequeñas que la cepa silvestre, aunque en mayor medida en el caso del mutante ppa2 $\Delta$. Este resultado implica que en este contexto, la subunidad Ppa1 cumple un papel secundario frente a Ppa2. Los resultados de los análisis epistáticos realizados con el mutante ppa2 $\Delta$ y los mutantes de ciclo wee1-50 y cdc25-22, sugieren que en la levadura de fisión, los complejos PP2A regulan positivamente la actividad de Wee1 y negativamente la actividad de Cdc25. La pérdida de viabilidad que provoca la ausencia de $p 2^{+}$al mutante wee1-50 junto con la supresión parcial al fenotipo de incremento de la longitud celular del mutante ts cdc25-22 fueron previamente reportados por Kinoshita et al., 1990. Navarro y Nurse, 2012 también han identificado a Ppa2 como un gen regulador de la transición G2/M. Sin embargo, hasta ahora sobre el papel de Ppa2 en la entrada a mitosis no se ha profundizado mas allá de estos resultados genéticos en la levadura de fisión.

La quinasa Greatwall es un regulador negativo de la actividad del complejo PP2AB55ס en la transición G2/M (Castilho et al., 2009), como consecuencia de la actividad de dos proteínas Ensa y Arrp19 (Mochida et al., 2010 y Gharbi-Ayachi et al., 2010). Un papel in vivo solo ha sido demostrado para Arrp19 (Gharbi-Ayachi et al., 2010). Los resultados presentados en este trabajo identifican a Igo1, como el ortólogo de estas proteínas. Igo1 no es esencial, pero su deleción es suficiente para generar células ligeramente más largas que el silvestre, contrario a lo observado en células que carecen de Ppa2. El mutante igo1 $\Delta$ es capaz de suprimir el fenotipo de wee1-50 al igual que incrementar el fenotipo de pérdida de viabilidad, por bloqueo en la fase G2 del mutante cdc25-22, de forma opuesta a la ausencia de ppa2 ${ }^{+}$. Asimismo, hemos identificado a la quinasa Ppk18 como el ortólogo de Greatwall (ver más adelante). La deleción de Ppk18 genera células largas como el mutante igo1 entrada a mitosis. Estos resultados, nos permiten proponer a Igo1 y a Ppk18 como dos nuevos reguladores positivos de la transición $\mathrm{G} 2 / \mathrm{M}$ en $S$. pombe. Estos resultados coincide con el modelo biológico que propone que la ruta Gwl-Ensa favorece la actividad de la Cdk en la entrada a mitosis por contrarrestar la actividad de la fosfatasa PP2A-B55ס en Xenopus (Figura 1 ver, Discusión Apartado II) y en humanos (Voets y Wolthuis, 2010). 


\section{Discusión}

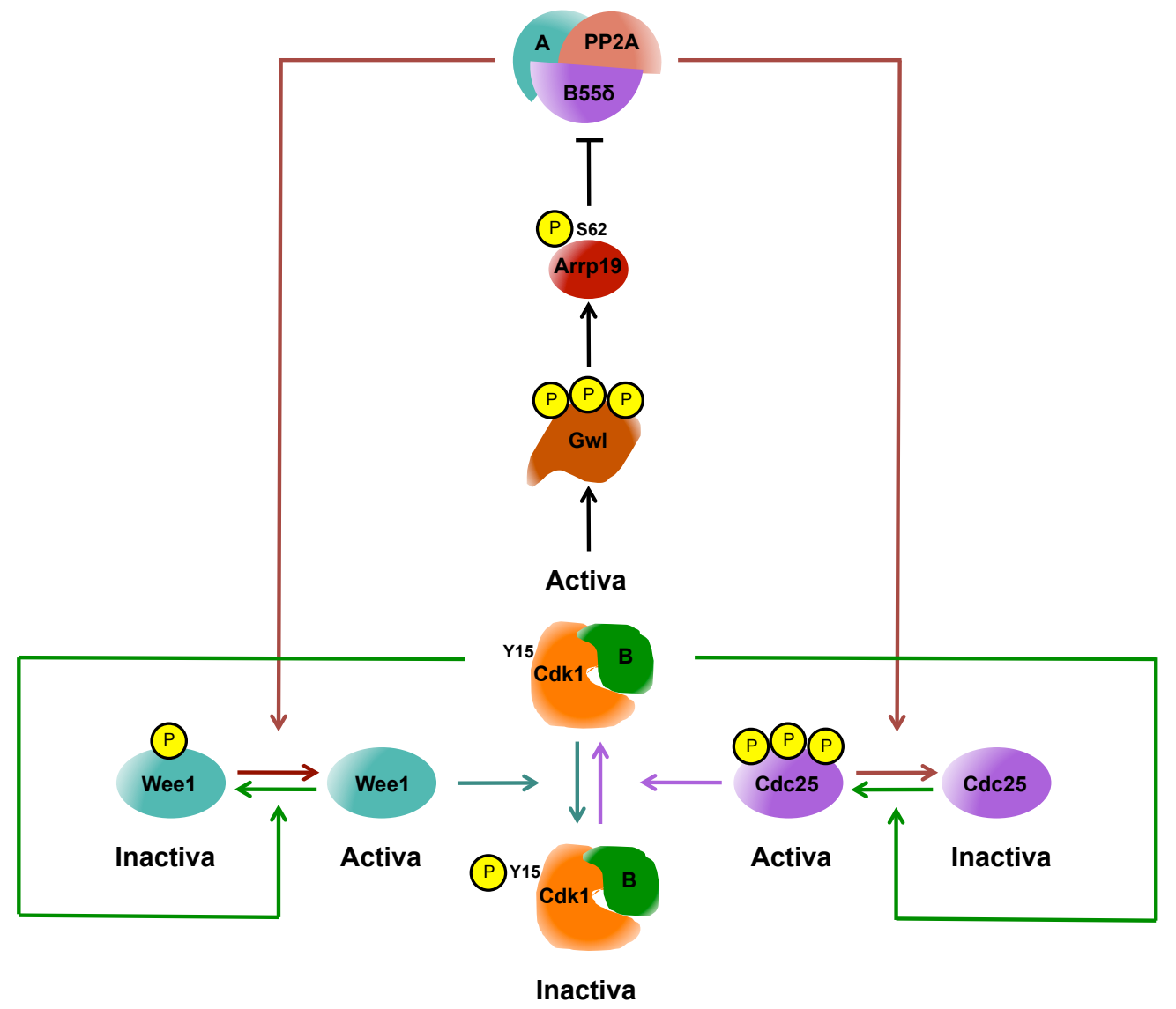

Figura 1. La ruta Greatwall-Ensa-PP2A-B55ס induce entrada a mitosis en Xenopus. El complejo PP2AB55ס mantiene los oocitos de Xenopus en interfase mediante la activación de Wee1 y la inactivación de Cdc25. Para que las células progresen a mitosis, la CDK, como parte del mecanismo de retroalimentación positivo, activa a Greatwall, que a su vez fosforila a Arrp19 en la S62 (también a Ensa in vitro). Arrp19 activa inhibe al heterotrímero PP2A-B55ס con el fin de favorecer la actividad del complejo Cdk1-ciclina B y la fosforilación de sus sustratos Wee1 (forma inactiva) y Cdc25 (forma activa). (Mochida et al., 2009; Vigneron

\section{La ruta Greatwall-Ensa-PP2A coordina la entrada a mitosis como respuesta a estrés nutricional en $S$. pombe}

El hecho de que los ortólogos de Greatwall y Ensa no sean esenciales en S. pombe contrario a lo visto en células animales, sugiere que la entrada a mitosis en este organismo está regulada por diferentes mecanismos moleculares, dónde unos pueden llegar a ser más relevantes que otros en determinadas condiciones fisiológicas. En este trabajo hemos demostrado que la ruta Gwl-Ensa está conservada en S. pombe y que su función se hace más relevante a medida que se limitan los nutrientes. Los resultados discutidos a continuación junto con los anteriores sugieren que esta ruta es importante para 
para dirigir la entrada a mitosis a través de la inhibición de la fosfatasa PP2A-B55ס, como respuesta a un estrés nutricional.

En el mutante igo1 , el fenotipo de retraso de la fase G2 se acentúa bajo estrés por nitrógeno, lo cual pude explicar la incapacidad del mutante de acumular población en fase G1 cuando crece en una fuente pobre en nitrógeno (fenilalanina). Realizando un seguimiento in vivo de la entrada a mitosis hemos demostrado que Igo1 induce la entrada a mitosis en situaciones dónde la calidad de nitrógeno empeora rápidamente. En ausencia de nitrógeno las células mutantes reducen su tamaño (aunque no hasta niveles silvestres) y no se bloquean en fase G1 con la misma eficiencia que una cepa silvestre. Estas observaciones, aparentemente contradictorias, pueden sugerir o i) que las células de $S$. pombe tienen mecanismos adicionales para dirigir la entrada a mitosis en respuesta a la carencia de nutrientes (Petersen y Nurse, 2007) y/o ii) o que las células mutantes no tienen tiempo de acumular biomasa (sólo dos rondas de división) del mismo modo a como la acumulan en una situación dónde las divisiones mitóticas son sucesivas. Por tanto, en la primera situación lgo1 induce la entrada a mitosis y mantiene una proliferación continua a un tamaño celular reducido y en la segunda lgo1 es al menos, una de las vías empleadas por la célula para salir del ciclo mitótico.

La eliminación de la quinasa Rad3 (ATR en mamíferos) a células que carecen de Igo1 permitió descartar que el retraso en la fase G2 fuera una consecuencia de la activación del checkpoint de daño al ADN o de una activación de Rad3 asociada a estrés nutricional, la cual aún no ha sido reportado (Irarrazabal et al., 2004; Chen et al., 2003). A una conclusión similar llegaron los autores que identificaron por primera vez a Greatwall, tras demostrar que el fenotipo de cromosomas descondensados de los mutantes Gwl no era el resultado de la activación del checkpoint de replicación sino de la falta de activación de la condensina por parte del complejo Cdk-ciclina (Yu et al., 2004). Por otro lado, el retraso en la fase $\mathrm{G} 2$ de igo1 $\Delta$ fue suprimido por el mutante $c d c 2-3 w$, indicando que la actividad de Cdc25 está por debajo de la actividad de Igo1. Un efecto similar fue descrito por Yu et al., 2006, al observar que una Cdk1 constitutivamente activa era capaz de suprimir el defecto de entrada a mitosis en ausencia de Greatwall. En la línea de estos resultados, Zhao et al., 2008 demostraron que la actividad de Greatwall regula la fosforilación de Cdc25, lo cual también fue sugerido por Vigneron et al., 2009 y Casthilo et al., 2009. En este caso, proponemos que Igo1 requiere de la activación de Cdc25 para inducir la entrada a mitosis bajo estrés por nitrógeno. 


\section{Discusión}

Mediante un análisis de homología, identificamos a Ppk18 y Cek1 como posibles ortólogos de Greatwall. Hasta ahora a Ppk18 no se la había atribuido ninguna función asociada al ciclo celular (Bimbó et al., 2005), mientras que Cek1 se había relacionado con la progresión de NETO, el cambio de crecimiento monopolar a bipolar que ocurre en la fase G2 (Koyano et al., 2010) y la progresión metafase-anafase (Samejima y Yanagida, 1994). Individualmente, la deleción de $p p k 18^{+}$genera células largas, pero la de cek1+ no. No obstante, la doble deleción genera células tan largas como las de igo1 en

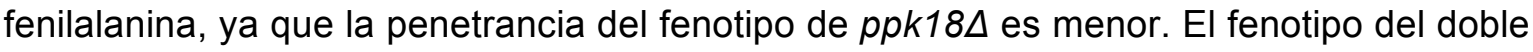

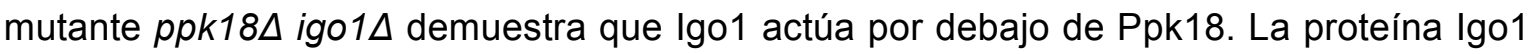
tiene conservado el sitio de fosforilación por Greatwall (S64) y con el análisis del mutante fosfonulo S64A hemos confirmado, tal como se ha observado en Xenopus, que su actividad depende en parte de este sitio de fosforilación S64 (Ser) y asimismo, que la fosforilación del mismo depende de Ppk18, y no de Cek1 aparentemente. Arrp19 y Ensa también son fosforilados in vitro por la proteína quinasa A PKA (S109) y por Cdk2 (T28 y S28 en Ensa y Arrp19 respectivamente) (Gharbi-Ayachi et al., 2010; Mochida et al., 2010). Igo1 tiene conservado el sitio de fosforilación por Cdk y otro potencial (S102), sin embargo los mutantes fosfonulos de estos sitios por separado no generan ningún fenotipo en el tamaño celular. Sería interesante probar si la combinación de ambos genera alguna pérdida de funcionalidad, ya que se ha propuesto que al menos Greatwall requiere de la Cdk para su activación (Yu et al., 2006; Vigneron et al., 2011). Recientemente en Xenopus, se ha reportado que la fosforilación combinada de Ensa en los sitios Cdk y Greatwall y PKA y Greatwall podría dirigir una modulación gradual de la actividad de PP2A-B55ס (Mochida et al., 2013). Esto es interesante, puesto que la activación de la ruta Ppk18-Igo1 bajo estrés nutricional también podría estar regulada de esta manera (ver más adelante). Al sobreexpresar a Ppk18, se observó una reducción del tamaño celular, lo cual apoya la idea de que Ppk18 induce la entrada a mitosis. A tiempos largos, dicha sobreexpresión causó el cese del crecimiento celular, sin embargo el bloqueo no ocurrió en la fase G1, lo que indica que estas células al crecer en condiciones ricas en nutrientes (glutamato) son capaces de pasar el start y bloquearse en G2 durante su último ciclo. Los tiempos largos de sobreexpresión, inducen en las células pérdida de polaridad y acumulación de dobletes, sugiriendo que para favorecer la actividad del complejo PP2A-pab1 en la regulación de la morfogénesis y la citoquinesis (Lahoz et al., 2010; Bernal et al., 2012) se requiere posiblemente de la inactivación de Ppk18.

Por otro lado, con un análisis epistático hemos mostrado que el retraso en la fase G2 
del mutante igo1 $\Delta$ es dependiente de la actividad de Ppa2 y Pab1, lo cual sugiere que Igo1 probablemente inhibe la actividad de este complejo al igual que en Xenopus, dónde se ha demostrado que las proteínas Arrp19 y Ensa promueven la entrada a mitosis a oocitos en interfase (Gharbi-Ayachi et al., 2010 y Mochida et al., 2010) mediante la interacción física entre la subunidad B55ס y la subunidad C, y la consecuente inhibición de su sitio catalítico (Mochida, 2013). En S. cerevisiae, Igo1/lgo2 interactúan genéticamente y físicamente con Cdc55 (el homólogo de las isoformas de B55ס), lo cual ha sido demostrado en diferentes contextos biológicos (Talarek et al., 2010; Bontron et al., 2013; Juanes et al., 2013).

\section{TORC1 (Tor2) y la proteína quinasa A (PKA) regulan negativamente la actividad de la ruta Greatwall-Ensa en $S$. pombe}

Las proteínas TORC1 y PKA son elementos que controlan el crecimiento celular en respuesta a nutrientes en levaduras. En S. cerevisiae la inactivación de TORC1 o PKA detienen el crecimiento celular y las células bloquean el ciclo celular en la fase G1 y posteriormente entran en estado de quiescencia (G0). Los mecanismos que controlan esta entrada a quiescencia involucran a Rim15, el ortólogo de Greatwall en este organismo. La activación de Rim15 requiere de su acumulación en el núcleo. TORC1 a través de Sch9 (Sck1 y Sck2 en S.pombe) y el complejo Pho80-85 fosforilan a Rim15 en la S1061 y la T1075 respectivamente (Pedruzzi et al., 2003; Wanke et al., 2005) para promover su exporte hacia el citoplasma, dónde PKA la mantiene secuestrada (Reinders et al., 1998; Pedruzzi et al., 2003). La función principal de Rim15 es regular la entrada a quiescencia y prolongar la esperanza de vida tras este estado, a través de la inactivación de PP2A-Cdc55 vía Igo1/lgo2. En este contexto PP2A-Cdc55 reprime la expresión de genes relacionados con estrés nutricional por inactivación de los factores de transcripción Gis1 y Msn2/4 (Bontron et al., 2013). Por otro lado se ha descrito que en las células de la levadura de fisión, la proteína PKA regula negativamente la entrada mitosis a través de Cdc25. Lo que sugiere que dicho evento podría ser a través de la actividad de Igo1 (Kishimoto y Yamashita, 2000).

De acuerdo con nuestros resultados, los niveles de Igo1 y la fosforilación en la S64 dependen de una señalización nutricional. Dicha señalización es regulada por TORC1

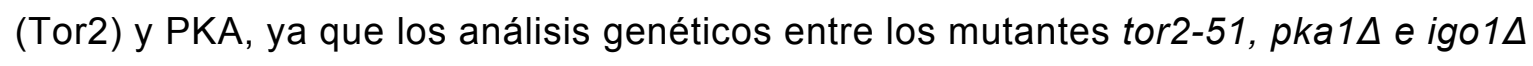




\section{Discusión}

demuestran que Igo1 actúa por debajo de TORC1 (Tor2) y de PKA. El descenso en la actividad del complejo TORC1 (Tor2) por el cambio nutricional desde una fuente rica en nitrógeno (glutamato) a una pobre (fenilalanina) induce la fosforilación de lgo1 en la S64. De igual manera, la reducción en la concentración de glucosa induce también dicha fosforilación. Así, proponemos que la actividad de Igo1 es regulada negativamente por el complejo TORC1 (Tor2) y la proteína quinasa $A(P K A)$ en $S$. pombe al igual que ocurre en S. cerevisiae.

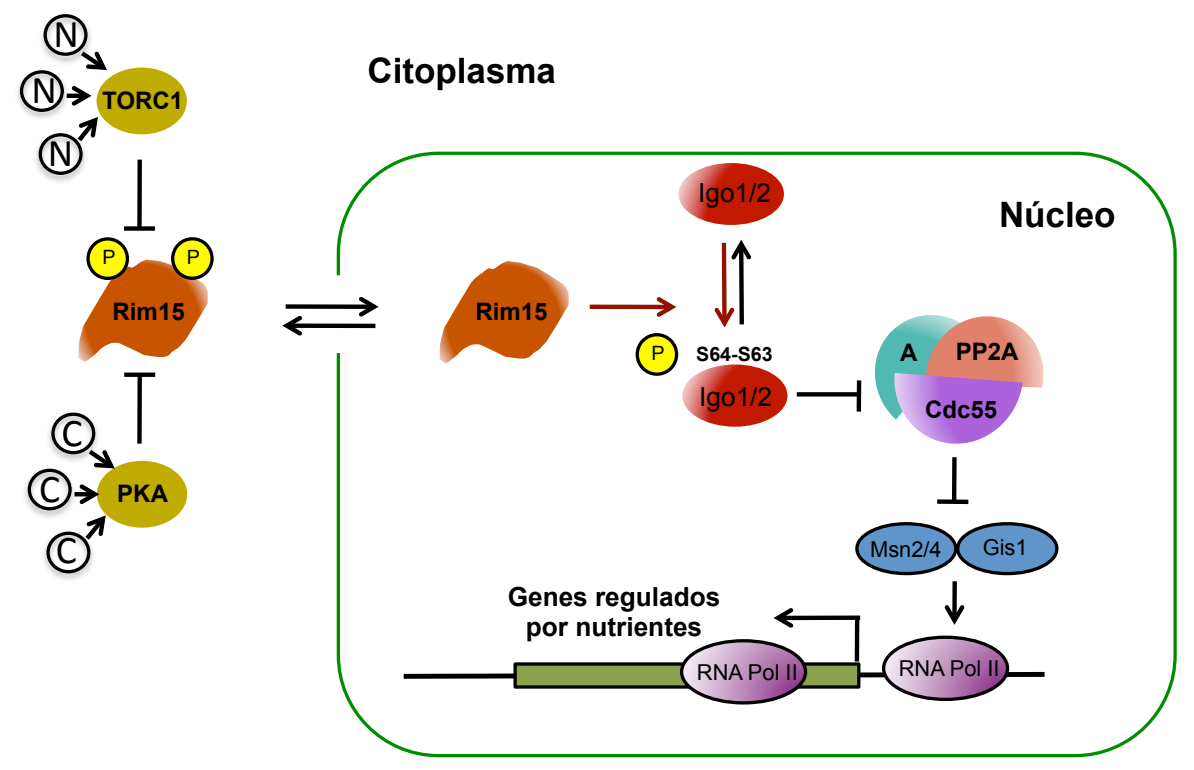

Figura 2. Ruta Greatwall-Ensa induce y mantiene la quiescencia en $\mathbf{S}$. cerevisiae. En células creciendo exponencialmente, Rim15 (Greatwall) se mantiene excluido del núcleo mediante fosforilaciones inhibitorias por parte del complejo TORC1 y la proteína quinasa A. Cuando las células detectan una reducción de nutrientes se inactivan TORC1 y PKA. Rim15 entra al núcleo y fosforila a las proteínas Igo1 e Igo2 en la S64 y S63 respectivamente. Igo1/lgo2 activas inhiben al complejo PP2A-Cdc55 para inducir la transcripción de genes regulados por nutrientes por parte de los factores Msn2/4 y Gis1. Igo1/lgo2 también se encargan de proteger de la degradación a los mRNAs de estos genes (Talarek et al., 2010; Bontron et al., 2013). Este programa transcripcional es importante para mantener la viabilidad de las células en G0.

Teniendo en cuenta que la fosforilación de Igo1 es dependiente de Ppk18, nosotros defendemos la idea de que el complejo TORC1 y la proteína PKA regulan negativamente la actividad del módulo Ppk18-Igo1. En S. cerevisiae, se ha propuesto que TORC1 podría activar selectivamente a la proteína PKA para dirigir su actividad quinasa sobre ciertos sustratos. Según Shabb, 2001 y Budovskaya et al., 2005, el sitio consenso de fosforilación dependiente de TORC1, es RRxS. Sería importante determinar si estos si estos sitios están presentes en Ppk18, y asimismo si la S1061 de Rim15 se encuentra se 
conservada. Como se mencionó anteriormente, Igo1 posee un sitio PKA (S128) cercano al de sus ortólogos Ensa y Arrp19 (S109). Una posibilidad a tener en cuenta es que TORC1 y/o PKA podrían fosforilar tanto a Ppk18 como a lgo1 para potenciar la inhibición de la ruta. Sin embargo, en este caso la regulación por PKA en nuestro modelo sería negativa, contrario a lo propuesto para Ensa (Mochida, 2013). El hecho de que en $S$. cerevisiae, la ruta Greatwall-Ensa dirija la entrada a quiescencia, sugiere que en $S$. pombe también pueda ocurrir a través de esta vía, ya que se ha visto que las quinasas Cek1 y Ppk18 se requieren para extender la esperanza de vida tras la quiescencia (CLS, del inglés Chronological LifeSpan) (Chen et al., 2013).

En otro contexto de S. cerevisiae, contrario al modelo de Xenopus, se asume que el papel de la fosfatasa PP2A-Cdc55 (ortólogo de PP2A-B55ס) consiste en promover la entrada a mitosis y prevenir la salida (Jiang, 2006). Esto es así, porque PP2A-Cdc55 desfosforila e inhibe a Swe1 (el ortólogo de Wee1) (Yang et al., 2000) y a su vez desfosforila y activa a Mih1 (el ortólogo de Cdc25) (Pal et al., 2008), en sentido contrario a lo descrito para las células animales y las de $S$. pombe. Teniendo en cuenta estas diferencias mecanísticas, se ha propuesto que Igo1 e Igo2, previamente activados por Rim15, actúan como reguladores positivos de la actividad de PP2A-Cdc55 y de la entrada a mitosis (Juanes et al., 2013). Sin embargo, estos autores no relacionan la localización y activación de Rim15 dependiente de TORC1 y PKA en este contexto. En S. pombe, se ha propuesto diferentes mecanismos que coordinan la entrada a mitosis con el ambiente nutricional, incluyendo la ruta Pom1-Cdr1-Wee1 (Martin y Berthelot-Grosjean, 2009; Moseley et al., 2009) y la ruta Tor1-Sty-Plo1-Cdc25 (Petersen y Hagan, 2005; Petersen y Nurse, 2009). Nuestros resultados, demuestran que la ruta Greatwall-ENSA es un sensor nutricional que actúa independientemente de ambas rutas, ya que los dobles mutantes entre igo $1 \Delta$ y sty $1 \Delta$ o igo $1 \Delta$ y cdr1 $1 \Delta$ muestran fenotipos aditivos.

\section{Modelo biológico}

Proponemos un modelo por el cual el papel fisiológico de la ruta Greatwall-EnsaPpa2-Pab1 en $S$. pombe es regular la entrada a mitosis en respuesta a la disponibilidad de nutrientes (Figuras 3 y 4 ver, Discusión Apartado II). Asimismo, nuestro modelo unifica los mecanismos moleculares que gobiernan la funcionalidad de este módulo tanto en células animales como en $S$. cerevisiae. Por otro lado, destaca la adaptación de la ruta Greatwall-Ensa a la biología celular de cada organismo a lo largo de la evolución. 


\section{Discusión}

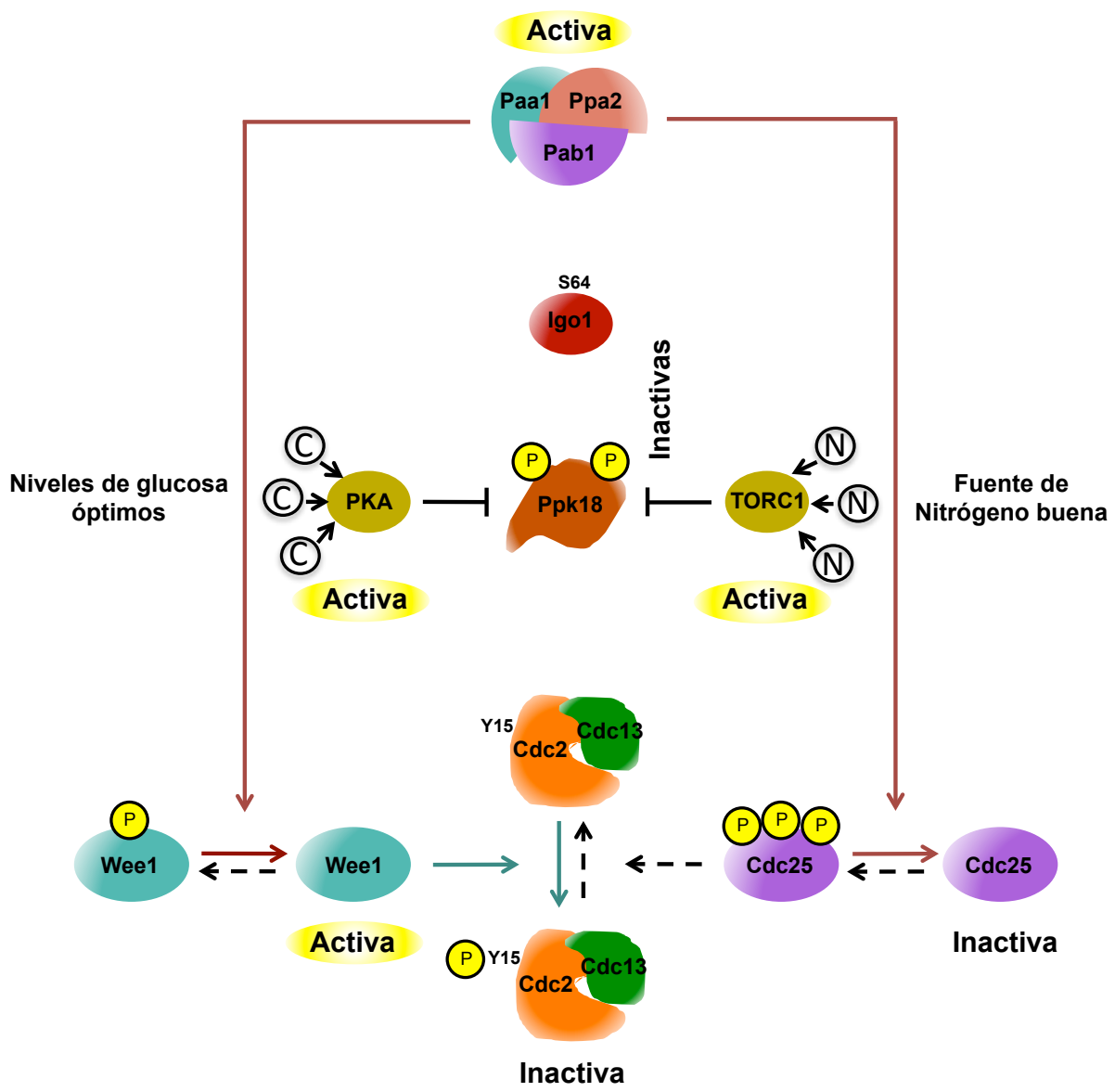

Figura 3. Entrada a mitosis sin estrés nutricional en $\boldsymbol{S}$. pombe. Cuando las células crecen en una fuente de nitrógeno buena y niveles de glucosa óptimos, el complejo TORC1 (Tor2) y la proteína quinasa A (PKA) mantienen apagada la ruta Greatwall-Ensa, probablemente mediante la fosforilación de Ppk18 (Gwl). En G2, el complejo PP2A-Pab1 inhibe la activación de Cdc2 al desfosforilar a Cdc25 (inactivo) y a Wee1 (activo). La entrada a mitosis ocurre por mecanismos independientes a Ppk18 e Igo1. 
Discusión

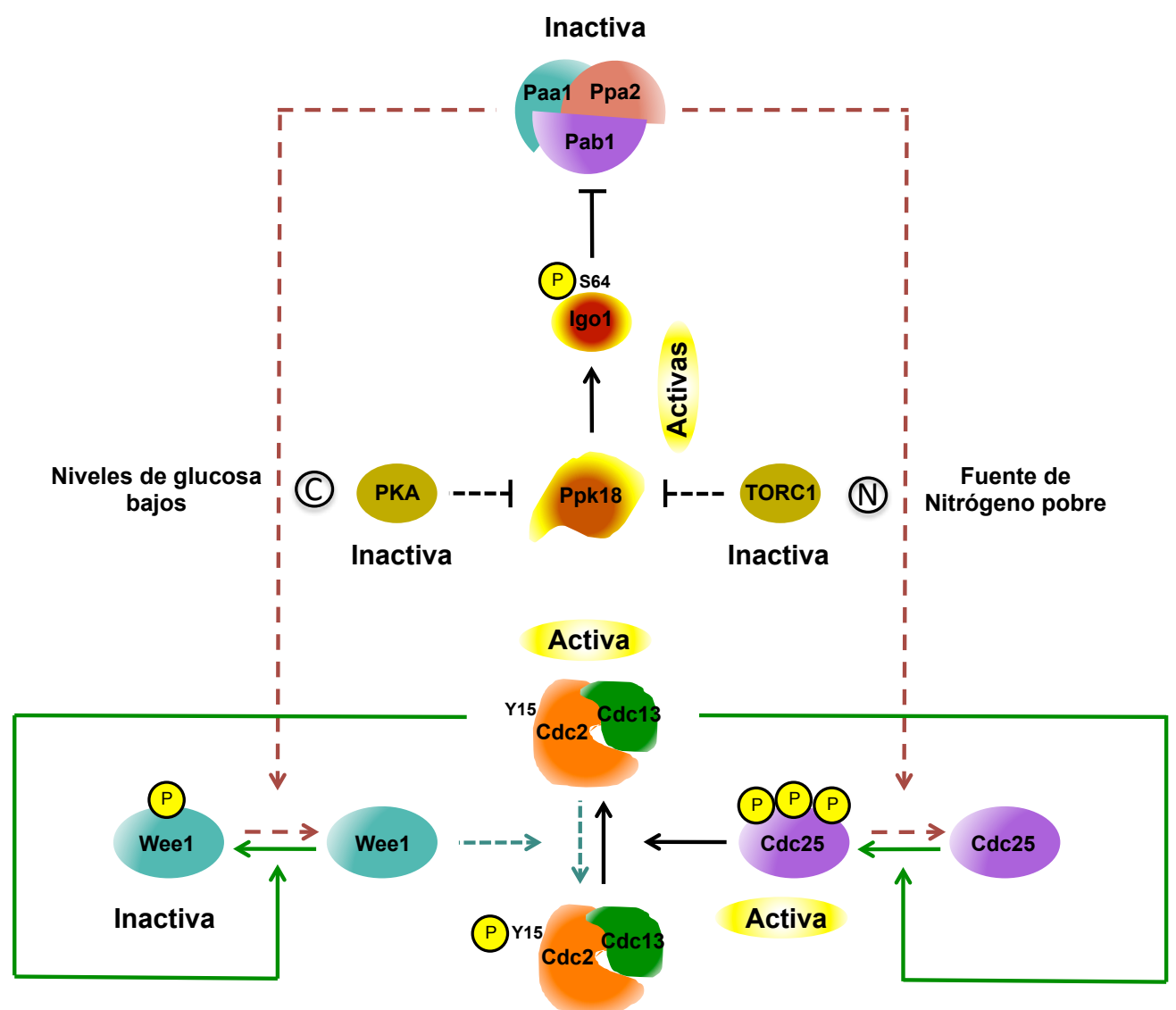

Figura 4. Entrada a mitosis bajo estrés nutricional en $S$. pombe. Cuando se produce una reducción en los niveles de nitrogeno o la fuente de glucosa, el complejo TORC1 (Tor2) y la proteína quinasa A (PKA) se inactivan. A continuación Ppk18 (Gwl) se activa y a su vez activa a lgo1 (Ensa) mediante fosforilación en la S64. Igo1 inhibe al complejo PP2A-Pab1 y favorece la inactivación de Wee1 y la activación de Cdc25. El sistema de retroalimentación positiva del complejo Cdc2-Cdc13 se potencia. Finalmente las células entran a mitosis como respuesta al cambio nutricional. Si el descenso en los nutrientes no es completamente limitante, las células proliferan con un tamaño celular reducido, de lo contrario se bloquean en la fase G1. 


\section{Discusión}

En el sistema antagónico Cdc2-PP2A, la ruta Greatwall-Ensa sería la responsable de empujar la balanza hacia el lado de la quinasa y favorecer la entrada a mitosis en un contexto de respuesta a limitación de nutrientes. Así, en células creciendo bajo condiciones nutricionales óptimas, el complejo TORC1 (Tor2) y la proteína PKA mantienen inhibida la ruta Greatwall-Ensa, probablemente mediante fosforilación de Ppk18 (Figura 3 ver, Discusión Apartado II); y cuando las células detectan condiciones pobres en nutrientes, la inhibición de TORC1 y PKA desencadena la activación de la ruta Greatwall-Ensa y la consecuente inhibición del complejo PP2A-Pab1. Dicha inhibición contribuye a la actividad del complejo Cdc2-Cdc13 y la fosforilación de sus sustratos, tales como Wee1 y Cdc25, lo cual a su vez induce la entrada acelerada en mitosis como respuesta al estrés nutricional (Figura 4 ver, Discusión Apartado II). De esta manera, esta señalización se integra en el mecanismo amplificador del sistema de retroalimentación positiva de la Cdk en S. pombe (Boke y Hagan, 2011).

Todos los resultados presentados en esta memoria, aportan una nueva visión sobre los mecanismos moleculares que controlan la ruta Greatwall-Ensa-PP2A, que no necesariamente tienen por qué estar ausentes en eucariotas superiores. 
Conclusiones 
1. Sólo el $9 \%$ de los genes no esenciales de $S$. pombe, manifestaron algún tipo de interacción genética con wee1-50 y cdc2-3w, sugiriendo que la regulación del ciclo celular depende de mecanismos específicos.

2. La mayoría de las interacciones genéticas identificadas fueron débiles, indicando que existe redundancia funcional en la regulación del ciclo celular que podrían compensar la pérdida de viabilidad.

3. La redes de interacción identificadas en este análisis sugieren que en las células de $S$. pombe existe una coordinación entre la maquinaria del ciclo celular, la replicación del $A D N$, la segregación cromosómica, la citoquinesis y rutas de señalización que controlan tamaño, estrés, etc.

4. El análisis genético realizado entre los genes identificados en el escrutinio de sintéticos letales es una herramienta útil para predecir nuevas funciones $\mathrm{y}$ entender el significado de sus interacciones con wee1-50 y cdc2-3w.

5. La ruta Greatwall-Ensa-PP2A-Pab1 coordina la entrada a mitosis con el ambiente nutricional del medio de cultivo en S. pombe. En medios ricos PPA2-Pab1 está activa, retrasa la entrada en mitosis y las células son mas largas, mientras que en medios pobres se activa Greatwall y Ensa inhibe a PP2A-Pab1 produciéndose una aceleración de la entrada en mitosis y un acortamiento del tamaño celular.

6. La ruta Greatwall-Ensa está regulada negativamente por la actividad del complejo TORC1 (Tor2) y la proteína quinasa A (PKA) en células de S. pombe.

7. La ruta Greatwall-Ensa-PP2A-Pab1 es parte del mecanismo del sistema de amplificación positivo del complejo Cdc2-Cdc13 que regula la entrada en mitosis. 
Material

Suplementario 
Tabla S1. Genes que interactúan genéticamente con wee1-50 a $35^{\circ} \mathrm{C}$

\begin{tabular}{|c|c|c|c|c|c|c|c|}
\hline $\begin{array}{c}\text { Sintético } \\
\text { letal/enfermo }\end{array}$ & Nombre ORF & Nombre Gen & $\begin{array}{l}\text { Puntuación } \\
\text { (SGA) }\end{array}$ & $\begin{array}{c}\text { Sintético } \\
\text { letal/enfermo }\end{array}$ & Nombre ORF & Nombre Gen & $\begin{array}{c}\text { Puntuación } \\
\text { (SGA) }\end{array}$ \\
\hline 1 & $S P B C 216.05$ & $\operatorname{rad} 3$ & -4 & 111 & SPAC17A5.02c & $d b r 1$ & -2 \\
\hline 2 & $S P B P B 2 B 2.01$ & SPBPB2B2.01 & -4 & 112 & SPBC354.12 & gpd3 & -2 \\
\hline 3 & SPAC19B12.10 & sst2 & -4 & 113 & $S P B C 1198.11 c$ & reb1 & -2 \\
\hline 4 & $S P A C 14 C 4.13$ & $\operatorname{rad} 17$ & -4 & 114 & SPAC1834.05 & $\operatorname{alg} 9$ & -2 \\
\hline 5 & SPAC9E9.08 & $\operatorname{rad} 26$ & -4 & 115 & SPAC212.08c & $S P A C 212.08 c$ & -2 \\
\hline 6 & SPAC11G7.06c & mug132 & -4 & 116 & SPCC569.02c & SPCC569.02c & -2 \\
\hline 7 & $S P B C 36.06 c$ & spo9 & -4 & 117 & SPCC $825.05 c$ & SPCC 825.05c & -2 \\
\hline 8 & SPAPB1A10.09 & ase 1 & -4 & 118 & $S P A C 23 C 11.10$ & $m p n 1$ & -2 \\
\hline 9 & $S P B C 23 G 7.08 c$ & rga7 & -3 & 119 & SPAC5D6.13 & SPAC5D6.13 & -1 \\
\hline 10 & SPAC20G4.04C & hus1 & -3 & 120 & SPCC285.15c & rps2802 & -1 \\
\hline 11 & SPAC1952.07 & rad1 & -3 & 121 & SPAC823.05c & $\operatorname{tg} 2$ & -1 \\
\hline 12 & SPAC664.07c & rad9 & -3 & 122 & SPBC $3 H 7.07 c$ & ser2 & -1 \\
\hline 13 & $S P A C 13 A 11.01 c$ & rga8 & -3 & 123 & SPAC31A2.02 & $\operatorname{trm} 112$ & -1 \\
\hline 14 & SPAC6F6.01 & $\operatorname{cch} 1$ & -3 & 124 & $S P B C 56 F 2.10 c$ & alg5 & -1 \\
\hline 15 & SPBC660.14 & mik1 & -3 & 125 & SPAC1D4.11c & Ikh1 & -1 \\
\hline 16 & $S P C C 1223.15 c$ & spc19 & -3 & 126 & $S P B C 342.01 \mathrm{C}$ & alg 6 & -1 \\
\hline 17 & SPBC215.02 & $b o b 1$ & -3 & 127 & SPAC1486.04c & alm1 & -1 \\
\hline 18 & SPAC2F7.03c & pom1 & -3 & 128 & SPBC336.03 & efc25 & -1 \\
\hline 19 & $S P B C 32 F 12.05 c$ & $c w f 12$ & -3 & 129 & SPBC342.05 & $c r b 2$ & -1 \\
\hline 20 & SPAC631.02 & $b d f 2$ & -3 & 130 & SPAC4G8.05 & ppk14 & -1 \\
\hline 21 & SPBC947.01 & alf1 & -3 & 131 & $S P B C 1685.01$ & pmp1 & -1 \\
\hline 22 & $S P B C 2 D 10.16$ & $m h f 1$ & -3 & 132 & $S P B C 15 C 4.01 \mathrm{C}$ & oca3 & -1 \\
\hline 23 & SPAC31G5.18c & sde 2 & -3 & 133 & SPAC $3 H 5.12 c$ & rp/501 & -1 \\
\hline 24 & SPAC1782.05 & ура2 & -3 & 134 & SPBC776.17 & $S P B C 776.17$ & -1 \\
\hline 25 & SPAC30C2.06c & $d m / 1$ & -3 & 135 & SPCC1494.08c & SPCC1494.08c & -1 \\
\hline 26 & $S P B C 16 H 5.07 c$ & ppa2 & -3 & 136 & SPAC10F6.08c & SPAC10F6.08c & -1 \\
\hline 27 & SPAC23D3.09 & $\operatorname{arp} 42$ & -3 & 137 & SPAC140.02 & gar2 & -1 \\
\hline 28 & SPAC18G6.15 & $\mathrm{mal} 3$ & -3 & 138 & SPAC4F8.01 & $\operatorname{did} 4$ & -1 \\
\hline 29 & SPAC212.03 & SPAC212.03 & -3 & 139 & SPCC794.11C & SPCC794.11C & -1 \\
\hline 30 & $S P B C 106.01$ & $m p h 1$ & -3 & 140 & SPAC3H1.11 & $h s r 1$ & -1 \\
\hline 31 & SPAC $3 A 11.13$ & SPAC3A11.13 & -3 & 141 & SPAPB1E7.06c & eme1 & -1 \\
\hline 32 & SPAC3H8.07c & pac10 & -3 & 142 & SPBC354.10 & def1 & -1 \\
\hline 33 & SPAC2F3.02 & SPAC2F3.02 & -3 & 143 & SPCC594.01 & SPCC594.01 & -1 \\
\hline 34 & $S P B C 11 C 11.09 c$ & rp/502 & -3 & 144 & SPCC1919.05 & SPCC1919.05 & -1 \\
\hline 35 & SPAC25H1.07 & emc1 & -3 & 145 & SPAC1B1.04C & SPAC1B1.04C & -1 \\
\hline 36 & SPAC $3 A 12.13 c$ & SPAC3A12.13C & -3 & 146 & SPAC1783.08c & $r p / 1502$ & -1 \\
\hline 37 & SPAC1F5.08c & yam8 & -3 & 147 & SPBC3B9.13c & rpp102 & -1 \\
\hline 38 & SPCC550.14 & $v g / 1$ & -3 & 148 & SPAC1783.02c & vps66 & -1 \\
\hline 39 & SPCC 576.12c & $m h f 2$ & -3 & 149 & SPAC7D4.12C & SPAC7D4.12c & -1 \\
\hline
\end{tabular}




\begin{tabular}{|c|c|c|c|c|c|c|c|}
\hline $\begin{array}{c}\text { Sintético } \\
\text { letal/enfermo }\end{array}$ & Nombre ORF & Nombre Gen & $\begin{array}{l}\text { Puntuación } \\
\text { (SGA) }\end{array}$ & $\begin{array}{c}\text { Sintético } \\
\text { letal/enfermo }\end{array}$ & Nombre ORF & Nombre Gen & $\begin{array}{l}\text { Puntuación } \\
\text { (SGA) }\end{array}$ \\
\hline 41 & $S P B C 902.02 c$ & ctf18 & -3 & 151 & SPAC1610.01 & $S P A C 1610.01$ & -1 \\
\hline 42 & $S P A C 222.14 c$ & $S P A C 222.14 c$ & -3 & 152 & SPBC29A3.05 & vps71 & -1 \\
\hline 43 & SPAC227.10 & SPAC227.10 & -3 & 153 & SPCC1223.06 & tea 1 & -1 \\
\hline 44 & SPAC22F8.04 & SPAC22F8.04 & -3 & 154 & SPBPJ4664.06 & gpt1 & -1 \\
\hline 45 & SPAC25G10.06 & rps2801 & -3 & 155 & $S P C C 74.02 c$ & $S P C C 74.02 C$ & -1 \\
\hline 46 & $S P B C 31 E 1.02 c$ & pmr1 & -3 & 156 & $S P B C 337.15 c$ & $\operatorname{coq} 7$ & -1 \\
\hline 47 & SPBC4F6.06 & kin1 & -3 & 157 & SPAC $3 H 8.05 c$ & $m m s 1$ & -1 \\
\hline 48 & SPAC1071.04c & $s p c 2$ & -3 & 158 & SPBPB2B2.14C & SPBPB2B2.14C & -1 \\
\hline 49 & SPAC664.03 & SPAC664.03 & -3 & 159 & SPBC 1539.10 & nop16 & -1 \\
\hline 50 & SPCC830.06 & $c n b 1$ & -2 & 160 & $S P A C 31 A 2.15 c$ & $d c c 1$ & -1 \\
\hline 51 & SPBC17G9.09 & tif213 & -2 & 161 & $S P C C 24 B 10.18$ & $S P C C 24 B 10.18$ & -1 \\
\hline 52 & SPAC17A5.08 & erp2 & -2 & 162 & $S P B C 18 H 10.13$ & rps1402 & -1 \\
\hline 53 & SPAC4F10.02 & aap1 & -2 & 163 & SPCC162.12 & tco89 & -1 \\
\hline 54 & $S P B C 2 G 2.01 C$ & $\operatorname{liz1}$ & -2 & 164 & SPCC970.05 & rp/3601 & -1 \\
\hline 55 & SPBC530.05 & prt1 & -2 & 165 & SPAC14C4.06c & SPAC $14 C 4.06 \mathrm{C}$ & -1 \\
\hline 56 & SPAC1805.04 & nup132 & -2 & 166 & SPCC1235.13 & ght6 & -1 \\
\hline 57 & $S P B C 27.02 C$ & ask1 & -2 & 167 & SPAC1D4.09c & $r t f 2$ & -1 \\
\hline 58 & SPAC227.05 & SPAC227.05 & -2 & 168 & SPAC22F8.09 & $\operatorname{rrp} 16$ & -1 \\
\hline 59 & $S P B C 16 G 5.15 c$ & $f k h 2$ & -2 & 169 & SPAC22E12.18 & SPAC22E12.18 & -1 \\
\hline 60 & SPAC14C4.16 & dad3 & -2 & 170 & SPBC3B8.10c & nem1 & -1 \\
\hline 61 & SPAC1805.07c & dad2 & -2 & 171 & SPBC19G7.06 & $m b \times 1$ & -1 \\
\hline 62 & SPBC $3 H 7.03 c$ & SPBC $3 H 7.03 c$ & -2 & 172 & SPCC613.06 & rp/902 & -1 \\
\hline 63 & $S P A C 22 F 3.09 c$ & res2 & -2 & 173 & SPCC1682.12c & ubp16 & -1 \\
\hline 64 & SPAPB2B4.03 & $\operatorname{cig} 2$ & -2 & 174 & $S P B C 23 G 7.16$ & ctr6 & -1 \\
\hline 65 & SPCC1223.09 & SPCC1223.09 & -2 & 175 & SPAC23H4.17c & srb10 & -1 \\
\hline 66 & SPAC23H4.12 & alp13 & -2 & 176 & SPAC222.08c & SPAC222.08c & -1 \\
\hline 67 & SPAC2G11.12 & rqh1 & -2 & 177 & $S P B C 660.17 c$ & $S P B C 660.17 c$ & -1 \\
\hline 68 & $S P B C 725.02$ & mpr1 & -2 & 178 & SPAC4G9.16c & $r p / 901$ & -1 \\
\hline 69 & $S P B C 557.02 c$ & SPBC557.02c & -2 & 179 & SPAC227.17c & $S P A C 227.17 c$ & -1 \\
\hline 70 & SPAC821.05 & SPAC821.05 & -2 & 180 & $S P B C 106.12 c$ & SPBC106.12c & -1 \\
\hline 71 & $S P A C 17 A 2.06 c$ & vps8 & -2 & 181 & SPCC1235.11 & $m p c 1$ & -1 \\
\hline 72 & $S P B C 16 H 5.08 c$ & $S P B C 16 H 5.08 C$ & -2 & 182 & $S P B C 56 F 2.08 c$ & $S P B C 56 F 2.08 c$ & -1 \\
\hline 73 & SPCC663.11 & saf1 & -2 & 183 & SPBC649.03 & rhp14 & -1 \\
\hline 74 & $S P B C 25 B 2.10$ & $S P B C 25 B 2.10$ & -2 & 184 & $S P B C 83.18 c$ & fic1 & -1 \\
\hline 75 & SPAC664.02c & $\operatorname{arp} 8$ & -2 & 185 & $S P A C 24 B 11.09$ & $m p c 2$ & -1 \\
\hline 76 & SPBC4F6.12 & $p \times / 1$ & -2 & 186 & SPAC22F8.02c & $p v g 5$ & -1 \\
\hline 77 & SPCC895.07 & alp14 & -2 & 187 & SPAC4F10.14c & btf3 & -1 \\
\hline 78 & SPBP8B7.28c & stc1 & -2 & 188 & $S P B C 428.02 c$ & еса39 & -1 \\
\hline 79 & SPAC1F7.01c & spt6 & -2 & 189 & SPAC16E8.01 & shd1 & -1 \\
\hline 80 & SPCC $417.07 c$ & mto1 & -2 & 190 & $S P B C 16 E 9.14 C$ & $\operatorname{zrg} 17$ & -1 \\
\hline 81 & SPCC736.08 & $c b f 11$ & -2 & 191 & $S P B C 32 F 12.11$ & $\operatorname{tdh} 1$ & -1 \\
\hline 82 & SPAC9G1.12 & cpd1 & -2 & 192 & SPCC1682.14 & rp/1902 & -1 \\
\hline
\end{tabular}




\begin{tabular}{|c|c|c|c|c|c|c|c|}
\hline $\begin{array}{c}\text { Sintético } \\
\text { letal/enfermo }\end{array}$ & Nombre ORF & Nombre Gen & $\begin{array}{l}\text { Puntuación } \\
\text { (SGA) }\end{array}$ & $\begin{array}{c}\text { Sintético } \\
\text { letal/enfermo }\end{array}$ & Nombre ORF & Nombre Gen & $\begin{array}{l}\text { Puntuación } \\
\text { (SGA) }\end{array}$ \\
\hline 83 & SPAC3H1.05 & SPAC3H1.05 & -2 & 193 & SPAC17C9.07 & alg 8 & -1 \\
\hline 84 & SPBC17A3.06 & SPBC17A3.06 & -2 & 194 & SPCC4B3.15 & mid1 & -1 \\
\hline 85 & $S P B C 336.14 C$ & ppk26 & -2 & 195 & SPCC $306.02 c$ & SPCC $306.02 c$ & -1 \\
\hline 86 & $S P C C 757.09 c$ & rnc1 & -2 & 196 & SPAC1142.08 & $f h / 1$ & -1 \\
\hline 87 & $S P B C 11 B 10.10 c$ & pht1 & -2 & 197 & $S P B C 1105.04 C$ & cbp1 1 & -1 \\
\hline 88 & SPBC25H2.15 & $S P B C 25 H 2.15$ & -2 & 198 & SPCC74.05 & $r p / 2702$ & -1 \\
\hline 89 & SPCC1795.10c & SPCC1795.10c & -2 & 199 & SPAC1851.03 & $c k b 1$ & -1 \\
\hline 90 & SPBC $3 E 7.09$ & SPBC3E7.09 & -2 & 200 & $S P B C 1734.12 c$ & alg12 & -1 \\
\hline 91 & SPBC577.02 & rp/3801 & -2 & 201 & SPAC144.02 & iec1 & -1 \\
\hline 92 & SPCC1223.11 & $p t c 2$ & -2 & 202 & SPCC1682.08c & SPCC1682.08c & -1 \\
\hline 93 & SPAC4G8.04 & SPAC4G8.04 & -2 & 203 & SPAC31G5.19 & $a b o 1$ & -1 \\
\hline 94 & SPBC685.06 & $r p s 001$ & -2 & 204 & SPAC6B12.07c & SPAC6B12.07c & -1 \\
\hline 95 & SPCC550.03c & SPCC $550.03 c$ & -2 & 205 & $S P B C 16 C 6.03 c$ & $S P B C 16 C 6.03 c$ & -1 \\
\hline 96 & $S P C C 553.01 c$ & $d b / 2$ & -2 & 206 & SPBC725.15 & ura5 & -1 \\
\hline 97 & SPAC27E2.07 & $p v g 2$ & -2 & 207 & SPAC2F3.08 & sut1 & -1 \\
\hline 98 & SPAC9G1.07 & SPAC9G1.07 & -2 & 208 & SPBC609.02 & ptn1 & -1 \\
\hline 99 & SPBC16E9.09c & SPBC16E9.09c & -2 & 209 & SPAPB17E12.08 & SPAPB17E12.08 & -1 \\
\hline 100 & SPAC4G9.15 & erp5 & -2 & 210 & SPAC1093.01 & ppr5 & -1 \\
\hline 101 & SPCC417.02 & dad5 & -2 & 211 & SPBC27B12.08 & $\operatorname{sip} 1$ & -1 \\
\hline 102 & SPAC2C4.05 & SPAC2C4.05 & -2 & 212 & SPBPB2B2.13 & gal1 & -1 \\
\hline 103 & SPAC139.06 & hat1 & -2 & 213 & SPAC13G7.02C & ssa1 & -1 \\
\hline 104 & $S P A C 1782.09 c$ & clp1 & -2 & 214 & SPAC25A8.01C & $f f t 3$ & -1 \\
\hline 105 & $S P B C 1706.01$ & tea4 & -2 & 215 & SPAC1071.02 & $m m s 19$ & -1 \\
\hline 106 & $S P B C 19 C 2.09$ & sre1 & -2 & 216 & $S P B C 32 F 12.08 \mathrm{C}$ & duo1 & -1 \\
\hline 107 & SPAC1142.07C & vps32 & -2 & 217 & SPBPB10D8.07c & SPBPB10D8.07c & -1 \\
\hline 108 & SPBC18H10.19 & vps38 & -2 & & & & \\
\hline 109 & SPAC521.05 & rps802 & -2 & & & & \\
\hline 110 & SPBC3H7.09 & mug142 & -2 & & & & \\
\hline Supresor & Nombre ORF & Nombre Gen & $\begin{array}{l}\text { Puntuación } \\
\text { (SGA) }\end{array}$ & Supresor & Nombre ORF & Nombre Gen & $\begin{array}{l}\text { Puntuación } \\
\text { (SGA) }\end{array}$ \\
\hline 1 & SPCC1450.03 & SPCC1450.03 & 1 & 36 & SPCC1322.10 & SPCC1322.10 & 2 \\
\hline 2 & SPBC16C6.04 & $d b / 6$ & 1 & 37 & $S P B C 36.07$ & $i k i 3$ & 2 \\
\hline 3 & SPCC16C4.20c & SPCC16C4.20c & 1 & 38 & $S P B C 365.10$ & arp5 & 2 \\
\hline 4 & SPCC1682.01 & $q c r 9$ & 1 & 39 & SPAC10F6.13c & SPAC10F6.13c & 2 \\
\hline 5 & SPAC23C11.04C & pnk1 & 1 & 40 & SPAC3F10.02C & trk1 & 2 \\
\hline 6 & SPCC550.15c & SPCC $550.15 c$ & 1 & 41 & SPAC4C5.02c & ryh1 & 2 \\
\hline 7 & SPAC17G8.13c & mst2 & 1 & 42 & SPBC 8D2.17 & $S P B C 8 D 2.17$ & 2 \\
\hline 8 & SPCC1739.15 & $w t f 21$ & 1 & 43 & SPAC16A10.03C & SPAC16A10.03C & 2 \\
\hline 9 & SPAPB21F2.03 & $s / x 9$ & 1 & 44 & SPCC1672.04C & SPCC1672.04c & 2 \\
\hline 10 & SPCC970.07c & raf2 & 1 & 45 & SPAC $30 C 2.02$ & $m m d 1$ & 2 \\
\hline 11 & SPAC19B12.04 & $r p s 3001$ & 1 & 46 & SPBC18H10.07 & SPBC18H10.07 & 2 \\
\hline
\end{tabular}




\begin{tabular}{|c|c|c|c|c|c|c|c|}
\hline 12 & $S P B C 31 F 10.14 C$ & hip3 & 1 & 47 & $S P B C 30 D 10.10 c$ & tor1 & 2 \\
\hline 13 & $S P B C 19 G 7.17$ & SPBC19G7.17 & 1 & 48 & $S P B C 2 G 2.03 c$ & $s b h 1$ & 2 \\
\hline 14 & SPCC24B10.12 & cgi121 & 1 & 49 & SPAC23E2.01 & fep1 & 2 \\
\hline 15 & SPAC12G12.13c & cid14 & 1 & 50 & SPAC3G9.03 & rp/2301 & 2 \\
\hline 16 & $S P B C 19 C 7.02$ & $u b r 1$ & 1 & 51 & SPAC20G4.07c & sts1 & 2 \\
\hline 17 & SPBC16A3.18 & cip1 & 1 & 52 & SPAC31A2.13C & sft1 & 2 \\
\hline 18 & SPAC1687.23c & SPAC1687.23c & 1 & 53 & $S P B C 19 C 2.14$ & $s m d 3$ & 2 \\
\hline 19 & SPAC1071.08 & rpp203 & 1 & 54 & SPAC31G5.21 & SPAC31G5.21 & 2 \\
\hline 20 & $S P B C 21 C 3.01 \mathrm{C}$ & vps13a & 1 & 55 & SPAC57A10.02 & $c d r 2$ & 2 \\
\hline 21 & $S P B C 1347.02$ & fkbp39 & 1 & 56 & $S P B C 1306.02$ & $S P B C 1306.02$ & 2 \\
\hline 22 & $S P B C 23 E 6.02$ & rrp2 & 1 & 57 & SPAC1527.02 & sft2 & 2 \\
\hline 23 & SPCC1739.10 & mug33 & 1 & 58 & $S P B C 1703.12$ & ubp9 & 2 \\
\hline 24 & $S P B C 1921.07 c$ & sgf29 & 1 & 59 & SPCC1739.07 & cti1 & 2 \\
\hline 25 & $S P B C 8 D 2.04$ & hht2 & 1 & 60 & SPAC13C5.07 & $\operatorname{rad} 32$ & 2 \\
\hline 26 & $S P B C 3 H 7.10$ & elp6 & 1 & 61 & SPAC824.02 & bst1 & 2 \\
\hline 27 & SPBC337.09 & erg28 & 1 & 62 & SPAC31F12.01 & $z d s 1$ & 2 \\
\hline 28 & SPAC1F3.03 & SPAC1F3.03 & 1 & 63 & SPAC13G6.09 & SPAC13G6.09 & 2 \\
\hline 29 & SPAC26A3.16 & $d p h 1$ & 1 & 64 & $S P C C 31 \mathrm{H} 12.05 \mathrm{C}$ & $s d s 21$ & 2 \\
\hline 30 & SPAC17H9.13c & SPAC17H9.13c & 1 & 65 & SPAC222.04c & ies6 & 2 \\
\hline 31 & SPAC15A10.11 & ubr11 & 1 & 66 & SPAC630.14c & tup12 & 3 \\
\hline 32 & SPAC17H9.10c & $d d b 1$ & 1 & 67 & SPBC660.11 & $\operatorname{tcg} 1$ & 3 \\
\hline 33 & SPAC1687.12c & $\operatorname{coq} 4$ & 1 & 68 & SPAC11D3.18c & SPAC11D3.18c & 3 \\
\hline 34 & SPBC947.10 & $d s c 1$ & 1 & 69 & $S P B C 8 D 2.03 c$ & hhf2 & 4 \\
\hline 35 & SPCC790.02 & pep3 & 2 & 70 & SPAC824.04 & SPAC824.04 & 4 \\
\hline
\end{tabular}


Tabla S2. Genes que interactúan genéticamente con $c d c 2-3 w$ a $25^{\circ} \mathrm{C}$

\begin{tabular}{|c|c|c|c|c|c|c|c|}
\hline $\begin{array}{l}\text { Sintético } \\
\text { letal/enfermo }\end{array}$ & Nombre ORF & Nombre Gen & $\begin{array}{l}\text { Puntuación } \\
\text { (SGA) }\end{array}$ & $\begin{array}{c}\text { Sintético } \\
\text { letal/enfermo }\end{array}$ & Nombre ORF & Nombre Gen & $\begin{array}{l}\text { Puntuación } \\
\text { (SGA) }\end{array}$ \\
\hline 1 & SPAC5D6.10c & mug116 & -5 & 106 & SPCC1235.13 & ght6 & -2 \\
\hline 2 & SPAC $30 C 2.06 \mathrm{c}$ & $d m / 1$ & -5 & 107 & SPAC22E12.18 & SPAC22E12.18 & -2 \\
\hline 3 & SPBC409.08 & SPBC409.08 & -5 & 108 & SPBC3H7.09 & mug142 & -2 \\
\hline 4 & SPAC1A6.07 & sle1 & -5 & 109 & SPCC74.05 & $r p / 2702$ & -2 \\
\hline 5 & SPAC9E9.13 & wos2 & -5 & 110 & $S P A C 23 C 11.10$ & mpn1 & -2 \\
\hline 6 & SPBC16H5.07C & ppa2 & -4 & 111 & SPAC18G6.10 & lem2 & -2 \\
\hline 7 & SPAC25B8.07c & SPAC25B8.07C & -4 & 112 & SPAPB $8 E 5.04 \mathrm{C}$ & SPAPB8E $5.04 \mathrm{C}$ & -2 \\
\hline 8 & $S P B C 25 H 2.15$ & $S P B C 25 H 2.15$ & -4 & 113 & SPCC1739.14 & npp106 & -2 \\
\hline 10 & SPBP8B7.28C & $s t c 2$ & -4 & 115 & $S P B C 32 F 12.05 c$ & cwf12 & -1 \\
\hline 11 & $S P B C 216.05$ & $\mathrm{rad} 3$ & -3 & 116 & SPAC17A5.08 & erp2 & -1 \\
\hline 12 & SPAC9E9.08 & $\operatorname{rad} 26$ & -3 & 117 & SPAC222.14C & SPAC222.14c & -1 \\
\hline 13 & SPAC14C4.13 & $\operatorname{rad} 17$ & -3 & 118 & $S P C C 24 B 10.18$ & $S P C C 24 B 10.18$ & -1 \\
\hline 14 & SPAC2F7.03c & pom1 & -3 & 119 & SPAC14C4.06c & SPAC14C4.06c & -1 \\
\hline 15 & SPAC1952.01 & rad1 & -3 & 120 & SPAC22F8.09 & $\operatorname{rrp} 16$ & -1 \\
\hline 16 & SPAC1142.07c & vps32 & -3 & 121 & SPAC3G6.06c & rad2 & -1 \\
\hline 17 & SPAC664.02c & $\operatorname{arp} 8$ & -3 & 122 & SPCC1682.14 & $r p / 1902$ & -1 \\
\hline 18 & $S P B C 725.02$ & mpr1 & -3 & 123 & SPBC19F8.08 & rps401 & -1 \\
\hline 19 & SPAP27G11.06c & vas2 & -3 & 124 & $S P B C 215.03 c$ & $\operatorname{csn} 1$ & -1 \\
\hline 21 & $S P B C 106.01$ & mph1 & -3 & 126 & SPBP $16 F 5.05 c$ & SPBP16F5.05c & -1 \\
\hline 22 & SPCP1E11.06 & ap/4 & -3 & 127 & SPAC2OH4.07 & rhp57 & -1 \\
\hline 23 & SPBC16E9.09c & erp5 & -3 & 128 & $S P B C 14 C 8.03$ & fma2 & -1 \\
\hline 24 & SPAC1F5.08c & yam8 & -3 & 129 & SPAC1039.08 & SPAC1039.08 & -1 \\
\hline 25 & SPAC20G4.04C & hus1 & -3 & 130 & SPAC17H9.13c & SPAC17H9.13c & -1 \\
\hline 26 & SPBC336.03 & efc25 & -3 & 131 & SPBC342.05 & crb2 & -1 \\
\hline 27 & SPAP14E8.02 & tos 4 & -3 & 132 & $S P B C 3 H 7.07 c$ & ser2 & -1 \\
\hline 28 & SPAC25H1.07 & emc1 & -3 & 133 & SPAC $31 \mathrm{G} 5.17 \mathrm{c}$ & rps1001 & -1 \\
\hline 29 & SPBC29A3.05 & vps71 & -3 & 134 & SPAC212.08c & SPAC212.08c & -1 \\
\hline 30 & $S P B C 3 B 9.13 c$ & rpp102 & -3 & 135 & $S P B C 32 F 12.11$ & $t d h 1$ & -1 \\
\hline 31 & $S P B C 16 C 6.03 c$ & $S P B C 16 C 6.03 c$ & -3 & 136 & SPCC126.08c & $S P C C 126.08 c$ & -1 \\
\hline 32 & $S P B C 1718.07 c$ & $z f s 1$ & -3 & 137 & SPAC $3 \mathrm{H} 5.07$ & rp/702 & -1 \\
\hline 33 & SPBC31F10.12 & tma20 & -3 & 138 & SPBC15C4.05 & SPBC15C4.05 & -1 \\
\hline 34 & $S P B C 12 C 2.04$ & $S P B C 12 C 2.04$ & -3 & 139 & SPAC $323.05 c$ & SPAC323.05c & -1 \\
\hline 35 & $S P B C 16 D 10.11 c$ & rps1801 & -3 & 140 & SPAC6F6.01 & cch1 & -1 \\
\hline 36 & SPBC887.18c & hfi1 & -3 & 141 & SPAC9G1.12 & cpd1 & -1 \\
\hline 37 & SPAC30D $11.04 C$ & nup124 & -3 & 142 & SPAC31G5.19 & $a b o 1$ & -1 \\
\hline 38 & $S P A C 13 A 11.01 C$ & rga8 & -3 & 143 & SPAC6B12.07c & SPAC6B12.07C & -1 \\
\hline 39 & SPAPB1A10.09 & ase 1 & -3 & 144 & SPBP8B7.06 & rpp201 & -1 \\
\hline
\end{tabular}




\begin{tabular}{|c|c|c|c|c|c|c|c|}
\hline $\begin{array}{c}\text { Sintético } \\
\text { letal/enfermo }\end{array}$ & Nombre ORF & Nombre Gen & $\begin{array}{l}\text { Puntuación } \\
\text { (SGA) }\end{array}$ & $\begin{array}{c}\text { Sintético } \\
\text { letal/enfermo }\end{array}$ & Nombre ORF & Nombre Gen & $\begin{array}{l}\text { Puntuación } \\
\text { (SGA) }\end{array}$ \\
\hline 40 & SPCC1795.10c & SPCC1795.10c & -3 & 145 & SPCC825.05c & SPCC825.05c & -1 \\
\hline 41 & SPCC576.12c & $m h f 1$ & -3 & 146 & $S P B C 32 F 12.02$ & rec14 & -1 \\
\hline 42 & SPAC589.10c & SPAC589.10c & -3 & 147 & SPBC1778.02 & rap1 & -1 \\
\hline 43 & $S P B C 23 G 7.08 \mathrm{C}$ & rga7 & -3 & 148 & SPAC25G10.06 & rps2801 & -1 \\
\hline 44 & $S P B C 11 C 11.09 c$ & rp/502 & -3 & 149 & SPCC550.14 & $v g / 1$ & -1 \\
\hline 45 & SPBC16E9.14C & $\operatorname{zrg} 17$ & -3 & 150 & $S P C C 285.15 c$ & rps2802 & -1 \\
\hline 46 & SPAC664.07c & $\operatorname{rad} 9$ & -2 & 151 & SPBC 4F6.12 & $p \times 11$ & -1 \\
\hline 47 & SPAC890.05 & SPAC890.05 & -2 & 152 & SPAC23D3.03C & $S P A C 23 D 3.03 c$ & -1 \\
\hline 48 & SPAC922.07c & atd2 & -2 & 153 & SPCP1E11.10 & SPCP1E11.10 & -1 \\
\hline 49 & SPAC23D3.09 & arp42 & -2 & 154 & SPAC16E8.08 & SPAC16E8.08 & -1 \\
\hline 50 & SPBPB2B2.01 & SPBPB2B2.01 & -2 & 155 & $S P B C 17 D 1.06$ & $d b p 3$ & -1 \\
\hline 51 & SPCC1223.09 & SPCC1223.09 & -2 & 156 & $S P B C 1773.01$ & far8 & -1 \\
\hline 52 & SPBC $3 H 7.03 c$ & SPBC $3 H 7.03 \mathrm{C}$ & -2 & 157 & SPAC1071.07c & rps 1502 & -1 \\
\hline 53 & SPBC776.02c & dis2 & -2 & 158 & SPCC 962.04 & rps1201 & -1 \\
\hline 54 & SPAC22H12.02 & $\operatorname{tfg} 3$ & -2 & 159 & $S P B C 365.14 c$ & uge 1 & -1 \\
\hline 55 & SPCC1322.12C & bub1 & -2 & 160 & SPCC1739.10 & mug33 & -1 \\
\hline 56 & SPCC830.06 & cnb1 & -2 & 161 & $S P B C 1706.01$ & tea4 & -1 \\
\hline 57 & SPAC19G12.08 & scs7 & -2 & 162 & SPAC9G1.03C & rp/3001 & -1 \\
\hline 58 & SPBC56F2.10c & alg5 & -2 & 163 & SPCC569.02C & SPCC569.02c & -1 \\
\hline 59 & $S P B C 725.15$ & ura5 & -2 & 164 & SPAC4F10.14C & $b t f 3$ & -1 \\
\hline 60 & SPAC1D4.09c & $r t f 2$ & -2 & 165 & SPCC285.09c & cgs2 & -1 \\
\hline 61 & SPAC17A5.02C & $d b r 1$ & -2 & 166 & SPAC1805.04 & nup132 & -1 \\
\hline 62 & SPCC895.07 & alp14 & -2 & 167 & SPBC530.05 & prt1 & -1 \\
\hline 63 & SPAC4F10.19c & SPAC4F10.19c & -2 & 168 & SPAC1805.07c & dad2 & -1 \\
\hline 64 & SPAC23H3.06 & ap/6 & -2 & 169 & SPCC1223.06 & tea1 & -1 \\
\hline 65 & SPBP35G2.03c & sgo 1 & -2 & 170 & SPCC736.08 & $c b f 11$ & -1 \\
\hline 66 & SPCC1840.08c & SPCC1840.08c & -2 & 171 & SPBPJ4664.06 & gpt1 & -1 \\
\hline 67 & $S P B C 947.01$ & alf1 & -2 & 172 & SPCC $417.07 c$ & mto1 & -1 \\
\hline 68 & SPBC776.17 & SPBC776.17 & -2 & 173 & SPAC31A2.02 & $\operatorname{trm} 112$ & -1 \\
\hline 69 & $S P C C 1223.11$ & $p t c 2$ & -2 & 174 & SPAC1486.04C & alm1 & -1 \\
\hline 70 & SPAC926.03 & $r l c 1$ & -2 & 175 & SPAPB17E12.05 & rp/3703 & -1 \\
\hline 71 & SPBC56F2.08c & SPBC56F2.08c & -2 & 176 & SPAC2C4.05 & SPAC2C4.05 & -1 \\
\hline 72 & SPAC22F3.08C & rok1 & -2 & 177 & SPAC25G10.03 & zip1 & -1 \\
\hline 73 & SPAC $3 A 12.12$ & atp11 & -2 & 178 & SPBC1718.03 & ker1 & -1 \\
\hline 74 & $S P A C 2 H 10.01$ & SPAC2H10.01 & -2 & 179 & $S P B C 119.12$ & rud3 & -1 \\
\hline 75 & $S P B C 1703.03 c$ & $S P B C 1703.03 c$ & -2 & 180 & SPAC1071.02 & $m m s 19$ & -1 \\
\hline 76 & SPAC $3 H 5.12 c$ & rpl501 & -2 & 181 & $S P B C 409.19 c$ & $S P B C 409.19 c$ & -1 \\
\hline 77 & SPAC $1782.09 c$ & clp1 & -2 & 182 & $S P B C 1685.13$ & fhn 1 & -1 \\
\hline 78 & SPAC1952.02 & $\operatorname{tma} 23$ & -2 & 183 & $S P B C 776.11$ & rp/2801 & -1 \\
\hline 79 & SPAC1B3.16C & $v h t 1$ & -2 & 184 & $S P B C 12 D 12.07 C$ & $\operatorname{tr} \times 2$ & -1 \\
\hline 80 & SPBC9B6.03 & SPBC9B6.03 & -2 & 185 & SPAC $3 C 7.08 \mathrm{C}$ & elf1 & -1 \\
\hline 81 & SPBC18H10.10c & cwc16 & -2 & 186 & SPAC $17 D 4.03 c$ & cis4 & -1 \\
\hline
\end{tabular}




\begin{tabular}{|c|c|c|c|c|c|c|c|}
\hline $\begin{array}{l}\text { Sintético } \\
\text { letal/enfermo }\end{array}$ & Nombre ORF & Nombre Gen & $\begin{array}{l}\text { Puntuación } \\
\text { (SGA) }\end{array}$ & $\begin{array}{c}\text { Sintético } \\
\text { letal/enfermo }\end{array}$ & Nombre ORF & Nombre Gen & $\begin{array}{l}\text { Puntuación } \\
\text { (SGA) }\end{array}$ \\
\hline 82 & SPAC1F12.07 & SPAC1F12.07 & -2 & 187 & SPBC21H7.04 & $d b p 7$ & -1 \\
\hline 83 & SPBC16G5.15c & $f k h 2$ & -2 & 188 & $S P C C 1223.05 c$ & rp/3702 & -1 \\
\hline 84 & SPCC594.01 & SPCC594.01 & -2 & 189 & SPAC823.10c & SPAC823.10c & -1 \\
\hline 85 & SPAC18G6.15 & $\mathrm{mal} 3$ & -2 & 190 & SPAC644.14C & rhp51 & -1 \\
\hline 86 & SPAC521.05 & rps802 & -2 & 191 & $S P C C 1223.15 c$ & spc19 & -1 \\
\hline 87 & SPCC613.06 & rp/902 & -2 & 192 & SPAC22F8.04 & SPAC22F8.04 & -1 \\
\hline 88 & SPAC222.08c & $S P A C 222.08 c$ & -2 & 193 & SPAC $3 H 8.05 c$ & $m m s 1$ & -1 \\
\hline 89 & SPAC24B11.09 & $m p c 2$ & -2 & 194 & SPCC1919.05 & ski3 & -1 \\
\hline 90 & SPAC12G12.13c & cid14 & -2 & 195 & SPBC685.06 & rps001 & -1 \\
\hline 91 & SPAC $3 C 7.06 \mathrm{c}$ & pit1 & -2 & 196 & SPCC550.03c & SPCC $550.03 c$ & -1 \\
\hline 92 & $S P A C 22 A 12.04 C$ & rps2201 & -2 & 197 & SPCC1682.12C & ubp 16 & -1 \\
\hline 93 & $S P B C 887.15 c$ & sur2 & -2 & 198 & SPAC2F7.08c & snf5 & -1 \\
\hline 94 & SPCC553.03 & pex1 & -2 & 199 & SPCC1235.15 & dga1 & -1 \\
\hline 95 & SPAC4F10.04 & ура1 & -2 & 200 & SPAC140.02 & gar2 & -1 \\
\hline 96 & SPBC9B6.07 & nop52 & -2 & 201 & SPCC1494.08c & SPCC1494.08c & -1 \\
\hline 97 & SPAC631.02 & $b d f 2$ & -2 & 202 & SPAC1783.08c & $r p / 1502$ & -1 \\
\hline 98 & SPAC31G5.18C & sde2 & -2 & 203 & $S P B C 25 \mathrm{H} 2.08 \mathrm{C}$ & $m r s 2$ & -1 \\
\hline 99 & SPBC $3 E 7.09$ & SPBC3E7.09 & -2 & 204 & $S P B C 18 H 10.13$ & rps 1402 & -1 \\
\hline 100 & $S P B C 1539.10$ & nop16 & -2 & 205 & SPCC285.14 & $\operatorname{trs} 130$ & -1 \\
\hline 101 & $S P B C 902.02 c$ & ctf18 & -2 & 206 & $S P B C 337.15 c$ & $\operatorname{coq} 7$ & -1 \\
\hline 102 & SPAC $3 \mathrm{H} 1.05$ & SPAC3H1.05 & -2 & 207 & SPAC328.10c & rps502 & -1 \\
\hline 103 & SPAC5D6.13 & SPAC5D6.13 & -2 & 208 & SPAC8E11.02C & $\operatorname{rad} 24$ & -1 \\
\hline 104 & SPAPB1E7.06C & eme1 & -2 & 209 & SPAC $977.05 c$ & SPAC977.05c & -1 \\
\hline 105 & SPBC609.02 & ptn1 & -2 & 210 & $S P B C 1604.03 c$ & $S P B C 1604.03 c$ & -1 \\
\hline Supresor & Nombre ORF & Nombre Gen & $\begin{array}{l}\text { Puntuación } \\
\text { (SGA) }\end{array}$ & Supresor & Nombre ORF & Nombre Gen & $\begin{array}{l}\text { Puntuación } \\
\text { (SGA) }\end{array}$ \\
\hline 1 & SPAC14C4.01C & SPAC14C4.01C & 1 & 49 & $S P B C 651.11 C$ & apm3 & 1 \\
\hline 2 & SPCC $16 C 4.10$ & SPCC $16 C 4.10$ & 1 & 50 & SPAC664.15 & caf4 & 1 \\
\hline 3 & $S P B C 12 D 12.06$ & srb11 & 1 & 51 & SPCC4G3.08 & psk1 & 1 \\
\hline 4 & $S P C C 74.02 c$ & SPCC74.02C & 1 & 52 & $S P B C 1347.02$ & fkbp39 & 1 \\
\hline 5 & SPAC25B8.18 & SPAC25B8.18 & 1 & 53 & SPCC1919.01 & ppk34 & 1 \\
\hline 6 & SPCC1020.13c & SPCC1020.13c & 1 & 54 & SPBC337.09 & $\operatorname{erg} 28$ & 1 \\
\hline 7 & $S P B C 336.13 c$ & $S P B C 336.13 c$ & 1 & 55 & SPAC823.05c & tlg2 & 1 \\
\hline 8 & SPCC553.12c & SPCC553.12c & 1 & 56 & SPAC6F12.03c & fsv1 & 1 \\
\hline 9 & $S P A C 23 C 11.04 C$ & pnk1 & 1 & 57 & SPAC607.06c & SPAC607.06c & 1 \\
\hline 10 & SPCC $306.02 c$ & SPCC $306.02 c$ & 1 & 58 & SPCC $16 C 4.14 C$ & $s f c 4$ & 1 \\
\hline 11 & SPCC320.06 & SPCC 320.06 & 1 & 59 & SPCC126.04C & sgf73 & 1 \\
\hline 12 & SPAC57A10.12c & ura3 & 1 & 60 & SPAC31F12.01 & $z d s 1$ & 1 \\
\hline 13 & $S P B C 19 C 2.02$ & $p m t 1$ & 1 & 61 & SPCC553.01c & $d b / 2$ & 1 \\
\hline 14 & SPCC 320.14 & SPCC 320.14 & 1 & 62 & SPAC $17 H 9.10 c$ & $d d b 1$ & 1 \\
\hline 15 & SPAC $3 C 7.10$ & pex13 & 1 & 63 & SPCC1450.03 & SPCC1450.03 & 1 \\
\hline
\end{tabular}




\begin{tabular}{|c|c|c|c|c|c|c|c|}
\hline Supresor & Nombre ORF & Nombre Gen & $\begin{array}{l}\text { Puntuación } \\
\text { (SGA) }\end{array}$ & Supresor & Nombre ORF & Nombre Gen & $\begin{array}{l}\text { Puntuación } \\
\text { (SGA) }\end{array}$ \\
\hline 16 & SPCC31H12.05c & $s d s 21$ & 1 & 64 & SPAC2F7.07c & cph2 & 1 \\
\hline 17 & $S P B C 16 C 6.04$ & $d b / 6$ & 1 & 65 & SPAC9.13c & cwf16 & 1 \\
\hline 18 & SPAC26H5.05 & mga2 & 1 & 66 & SPBP8B7.09c & los1 & 1 \\
\hline 19 & SPCC $31 \mathrm{H} 12.03 \mathrm{C}$ & tho1 & 1 & 67 & SPCP20C8.01c & $S P C P 20 C 8.01 \mathrm{C}$ & 1 \\
\hline 20 & SPAPYUG7.03c & mid2 & 1 & 68 & $S P B C 354.12$ & gpd3 & 1 \\
\hline 21 & $S P B C 21 C 3.20 c$ & git1 & 1 & 69 & $S P B C 2 G 2.03 c$ & sbh1 & 1 \\
\hline 22 & SPAC15A10.11 & ubr11 & 1 & 70 & SPAC15A10.06 & SPAC15A10.06 & 2 \\
\hline 23 & SPCC622.08c & hta1 & 1 & 71 & $S P B C 16 A 3.07 c$ & $n r m 1$ & 2 \\
\hline 24 & SPBC27B12.08 & $\operatorname{sip} 1$ & 1 & 72 & $S P B C 16 E 9.12 C$ & pab2 & 2 \\
\hline 25 & SPAC16E8.01 & shd1 & 1 & 73 & $S P A C 22 F 8.12 c$ & shf1 & 2 \\
\hline 26 & SPAC25B8.19c & loz1 & 1 & 74 & $S P B C 428.02 c$ & еса39 & 2 \\
\hline 27 & SPBC4C3.12 & sep1 & 1 & 75 & SPBC651.02 & $S P B C 651.02$ & 2 \\
\hline 28 & SPCC1235.02 & bio2 & 1 & 76 & SPAC $8 F 11.02 c$ & $d p h 3$ & 2 \\
\hline 29 & $S P B C 1539.08$ & arf6 & 1 & 77 & SPCC24B10.12 & cgi121 & 2 \\
\hline 30 & $S P B C 1105.05$ & exg1 & 1 & 78 & SPAC824.02 & bst1 & 2 \\
\hline 31 & $S P B C 19 C 7.02$ & $u b r 1$ & 1 & 79 & SPCC970.07c & raf2 & 2 \\
\hline 32 & SPAC17A5.07c & ulp2 & 1 & 80 & $S P B C 839.15 c$ & ef1a-c & 2 \\
\hline 33 & SPAC13G7.13c & msa1 & 1 & 81 & SPAC222.04C & ies6 & 2 \\
\hline 34 & $S P B C 56 F 2.05 c$ & $S P B C 56 F 2.05 c$ & 1 & 82 & SPAC1F3.03 & SPAC1F3.03 & 2 \\
\hline 35 & $S P B C 365.10$ & $\operatorname{arp5}$ & 1 & 83 & SPCC1682.01 & qcr9 & 2 \\
\hline 36 & SPAC664.04C & rps1602 & 1 & 84 & $S P B C 1198.11 C$ & reb1 & 2 \\
\hline 37 & SPCC1393.08 & SPCC1393.08 & 1 & 85 & SPCC1672.04c & SPCC1672.04c & 2 \\
\hline 38 & SPAC3A11.02 & cps3 & 1 & 86 & $S P B C 29 A 3.10 c$ & atp14 & 2 \\
\hline 39 & $S P B C 1921.01 \mathrm{C}$ & rp/3701 & 1 & 87 & $S P C C 126.15 c$ & $\sec 65$ & 2 \\
\hline 40 & SPBC4F6.06 & kin1 & 1 & 88 & SPAC824.04 & SPAC824.04 & 2 \\
\hline 41 & SPBC $3 H 7.10$ & elp6 & 1 & 89 & $S P B C 15 C 4.01 \mathrm{C}$ & oca3 & 2 \\
\hline 42 & SPAC15E1.03 & rp/42 & 1 & 90 & SPBC1703.12 & ubp9 & 2 \\
\hline 43 & $S P C C 23 B 6.01 C$ & $S P C C 23 B 6.01 c$ & 1 & 91 & SPBC660.11 & $\operatorname{tcg} 1$ & 2 \\
\hline 44 & SPCC364.05 & $v p s 3$ & 1 & 92 & SPCC18B5.05c & SPCC18B5.05c & 2 \\
\hline 45 & SPCC188.02 & par1 & 1 & 93 & SPAC20G4.07c & sts 1 & 3 \\
\hline 46 & SPAC589.02c & med13 & 1 & 94 & $S P A C 2 F 3.12 c$ & plp1 & 3 \\
\hline 47 & SPAC25H1.05 & теи29 & 1 & 95 & SPBC409.20c & psh3 & 3 \\
\hline 48 & SPAC $30 C 2.02$ & $m m d 1$ & 1 & 96 & SPAC1006.03c & red1 & 4 \\
\hline
\end{tabular}


Tabla S3. Interacciones genéticas con wee1-50 y cdc2-3w analizadas por RSA

\begin{tabular}{|c|c|c|c|c|c|c|c|c|c|}
\hline $\begin{array}{l}\text { Cepa de } \\
\text { Interés }\end{array}$ & Nombre ORF & Nombre Gen & SGA & RSA & $\begin{array}{l}\text { Cepa de } \\
\text { Interés }\end{array}$ & Nombre ORF & Nombre Gen & SGA & RSA \\
\hline wee1-50 & $S P B C 27.02 C$ & ask1 & -2 & Letal & wee1-50 & SPBC16H5.07c & рра2 & -3 & Sintético fuerte \\
\hline wee1-50 & SPAC1805.07c & dad2 & -2 & Letal & wee1-50 & $S P C C 1223.11$ & ptc2 & -2 & Sintético fuerte \\
\hline wee1-50 & SPCC895.07 & alp14 & -2 & Letal & wee1-50 & $S P B C 11 B 10.10 c$ & pht1 & -2 & Sintético fuerte \\
\hline wee1-50 & SPBC $3 E 7.09$ & SPBC $3 E 7.09$ & -2 & Letal & wee1-50 & SPBC902.02c & ctf18 & -3 & Sintético fuerte \\
\hline wee1-50 & $S P B C 336.14 c$ & ppk26 & -2 & Letal & wee1-50 & SPBC16E9.09c & erp5 & -2 & Sintético fuerte \\
\hline wee1-50 & SPAC19B12.10 & sst2 & -4 & Letal & wee1-50 & SPAC9G1.07 & SPAC9G1.07 & -2 & Sintético fuerte \\
\hline wee1-50 & SPAC14C4.13 & $\operatorname{rad} 17$ & -4 & Letal & wee1-50 & SPCC550.14 & $v g / 1$ & -3 & Sintético fuerte \\
\hline wee1-50 & SPCC 830.06 & $c n b 1$ & -2 & Letal & wee1-50 & $S P B C 16 G 5.15 C$ & $f k h 2$ & -2 & Sintético fuerte \\
\hline wee1-50 & SPCC $757.09 c$ & $r n c 1$ & -2 & Letal & wee1-50 & SPCC736.08 & $c b f 11$ & -2 & Sintético fuerte \\
\hline wee1-50 & SPBC530.05 & prt1 & -2 & Letal & wee1-50 & $S P B C 18 H 10.19$ & vps38 & -2 & Sintético fuerte \\
\hline wee1-50 & SPAC1805.04 & nup132 & -2 & Letal & wee1-50 & SPBC4F6.06 & kin1 & -3 & No confirmada \\
\hline wee1-50 & $S P B C 16 H 5.08 c$ & $S P B C 16 H 5.08 c$ & -2 & Letal & wee1-50 & $S P B C 32 F 12.05 c$ & cwf12 & -3 & No confirmada \\
\hline wee1-50 & $S P B C 25 H 2.15$ & $S P B C 25 H 2.15$ & -2 & Letal & wee1-50 & SPBC31E1.02C & $p m r 1$ & -3 & No confirmada \\
\hline wee1-50 & SPBC947.01 & alf1 & -3 & Letal & wee1-50 & SPAC $3 A 12.13 c$ & SPAC $3 A 12.13 c$ & -3 & No confirmada \\
\hline wee1-50 & SPAPB1A10.09 & ase 1 & -4 & Letal & wee1-50 & SPBP8B7.28c & stc1 & -2 & No confirmada \\
\hline wee1-50 & $S P C C 1223.15 c$ & spc19 & -3 & Letal & $c d c 2-3 w$ & SPAC11G7.06c & mug132 & -3 & Letal \\
\hline wee1-50 & $S P B C 106.01$ & mph1 & -3 & Letal & $c d c 2-3 w$ & SPAC2F7.03c & pom1 & -3 & Letal \\
\hline wee1-50 & SPAC14C4.16 & dad3 & -2 & Letal & $c d c 2-3 w$ & $S P B C 23 G 7.08 \mathrm{C}$ & rga7 & -3 & Letal \\
\hline wee1-50 & SPAC13A11.01C & rga8 & -3 & Letal & $c d c 2-3 w$ & SPBC3E7.09 & SPBC $3 E 7.09$ & -2 & Letal \\
\hline wee1-50 & $S P B C 23 G 7.08 c$ & rga7 & -3 & Letal & $c d c 2-3 w$ & $S P B C 887.18 c$ & hfi1 & -3 & Letal \\
\hline wee1-50 & SPAC2F7.03c & pom1 & -3 & Letal & $c d c 2-3 w$ & $S P B C 2 D 10.16$ & $m h f 1$ & -4 & Letal \\
\hline wee1-50 & $S P B C 1706.01$ & tea4 & -2 & Letal & $c d c 2-3 w$ & SPCC830.06 & $c n b 1$ & -2 & Letal \\
\hline wee1-50 & $S P B C 215.02$ & bob1 & -3 & Letal & $c d c 2-3 w$ & $S P A C 22 F 3.08 c$ & rok1 & -2 & Sintético débil \\
\hline wee1-50 & SPAC $3 A 11.13$ & SPAC3A11.13 & -3 & Letal & $c d c 2-3 w$ & SPAC19G12.08 & scs7 & -2 & Sintético débil \\
\hline wee1-50 & SPAC $3 H 8.07 c$ & pac10 & -3 & Letal & $c d c 2-3 w$ & $S P B C 106.01$ & $m p h 1$ & -3 & Sintético débil \\
\hline wee1-50 & SPAC17A5.02c & $d b r 1$ & -2 & Letal & $c d c 2-3 w$ & $S P B C 336.03$ & $e f c 25$ & -3 & Sintético débil \\
\hline wee1-50 & $S P B C 660.14$ & mik1 & -3 & Letal & $c d c 2-3 w$ & SPAC926.03 & $r l c 1$ & -2 & Sintético débil \\
\hline wee1-50 & SPAC1782.05 & ура2 & -3 & Letal & $c d c 2-3 w$ & SPBC31F10.12 & tma20 & -3 & Sintético débil \\
\hline wee1-50 & $S P B C 17 A 3.06$ & SPBC17A3.06 & -2 & Letal & $c d c 2-3 w$ & SPAC3H1.05 & SPAC3H1.05 & -2 & Sintético débil \\
\hline wee1-50 & SPAC31G5.18c & sde2 & -3 & Letal & $c d c 2-3 w$ & SPAC664.02c & $\operatorname{arp} 8$ & -3 & Sintético débil \\
\hline wee1-50 & SPAC631.02 & $n r c 1$ & -3 & Letal & $c d c 2-3 w$ & SPAC631.02 & nrc1 & -2 & Sintético débil \\
\hline wee1-50 & $S P B C 2 D 10.16$ & $m h f 1$ & -3 & Letal & $c d c 2-3 w$ & SPAC31G5.18c & $s d e 2$ & -2 & Sintético débil \\
\hline wee1-50 & SPCC576.12c & $m h f 2$ & -3 & Letal & $c d c 2-3 w$ & SPAC14C4.13 & $\operatorname{rad} 17$ & -3 & Sintético débil \\
\hline wee1-50 & SPBC216.05 & $\mathrm{rad} 3$ & -4 & Letal & $c d c 2-3 w$ & SPAP14E8.02 & tos 4 & -3 & Sintético débil \\
\hline wee1-50 & SPAC9E9.08 & $\operatorname{rad} 26$ & -4 & Letal & $c d c 2-3 w$ & SPAC664.07c & $\operatorname{rad} 9$ & -2 & Sintético débil \\
\hline wee1-50 & SPAC20G4.04c & hus1 & -3 & Letal & $c d c 2-3 w$ & SPAPB1A10.09 & ase 1 & -3 & Sintético fuerte \\
\hline wee1-50 & SPAC664.07c & $\operatorname{rad} 9$ & -3 & Letal & $c d c 2-3 w$ & SPCC 895.07 & alp14 & -2 & Sintético fuerte \\
\hline wee1-50 & SPAC6F6.01 & $\operatorname{cch} 1$ & -3 & Letal & $c d c 2-3 w$ & $S P A C 13 A 11.01 C$ & rga8 & -3 & Sintético fuerte \\
\hline wee1-50 & SPAC1F5.08c & yam8 & -3 & Letal & $c d c 2-3 w$ & $S P B C 216.05$ & $\mathrm{rad} 3$ & -3 & Sintético fuerte \\
\hline
\end{tabular}




\begin{tabular}{|c|c|c|c|c|c|c|c|c|c|}
\hline $\begin{array}{l}\text { Cepa de } \\
\text { Interés }\end{array}$ & Nombre ORF & Nombre Gen & SGA & RSA & $\begin{array}{l}\text { Cepa de } \\
\text { Interés }\end{array}$ & Nombre ORF & Nombre Gen & SGA & RSA \\
\hline wee1-50 & SPBC17G9.09 & tif213 & -2 & Letal & $c d c 2-3 w$ & SPAC20G4.04C & hus1 & -3 & Sintético fuerte \\
\hline wee1-50 & SPAC821.05 & SPAC821.05 & -2 & Letal & $c d c 2-3 w$ & SPAC1F5.08c & yam8 & -3 & Sintético fuerte \\
\hline wee $1-50$ & SPAC9G1.12 & cpd1 & -2 & Letal & $c d c 2-3 w$ & $S P B C 1703.03 c$ & $S P B C 1703.03 c$ & -2 & No confirmada \\
\hline wee1-50 & SPAC664.03 & SPAC664.03 & -3 & Letal & $c d c 2-3 w$ & $S P B C 12 C 2.04$ & $S P B C 12 C 2.04$ & -3 & No confirmada \\
\hline wee1-50 & SPAC1F7.01C & spt6 & -2 & Letal & $c d c 2-3 w$ & SPAC922.07c & atd2 & -2 & No confirmada \\
\hline wee1-50 & SPAC2F3.02 & SPAC2F3.02 & -3 & Letal & $c d c 2-3 w$ & $S P B P 35 G 2.03 c$ & sgo1 & -2 & No confirmada \\
\hline wee1-50 & $S P A C 222.14 c$ & SPAC222.14C & -3 & Letal & $c d c 2-3 w$ & SPAC18G6.15 & mal3 & -2 & No confirmada \\
\hline wee $1-50$ & SPAC17A5.08 & erp2 & -2 & Letal & $c d c 2-3 w$ & $S P B C 56 F 2.08 c$ & $S P B C 56 F 2.08 c$ & -2 & No confirmada \\
\hline wee1-50 & SPAC17A2.06c & vps8 & -2 & Letal & $c d c 2-3 w$ & $S P B C 29 A 3.05$ & vps 71 & -3 & No confirmada \\
\hline wee1-50 & SPAC1142.07c & vps32 & -2 & Letal & $c d c 2-3 w$ & SPBC902.02c & ctf18 & -2 & No confirmada \\
\hline wee1-50 & SPCC $417.07 c$ & mto1 & -2 & Sintético fuerte & $c d c 2-3 w$ & $S P C C 1223.11$ & $p t c 2$ & -2 & No confirmada \\
\hline wee1-50 & SPAC11G7.06c & mug132 & -4 & Sintético fuerte & $c d c 2-3 w$ & SPAC4F10.19c & SPAC $4 F 10.19 c$ & -2 & No confirmada \\
\hline wee $1-50$ & $S P B C 2 G 2.01 \mathrm{C}$ & liz1 & -2 & Sintético fuerte & $c d c 2-3 w$ & SPBP $8 B 7.28 \mathrm{C}$ & stc1 1 & -4 & No confirmada \\
\hline wee1-50 & SPAC18G6.15 & $\mathrm{mal} 3$ & -3 & Sintético fuerte & $c d c 2-3 w$ & $S P B C 1718.07 c$ & $z f_{s} 1$ & -3 & No confirmada \\
\hline wee1-50 & SPBC4F6.12 & $p x / 1$ & -2 & Sintético fuerte & $c d c 2-3 w$ & $S P B C 16 G 5.15 c$ & $f k h 2$ & -2 & No confirmada \\
\hline wee1-50 & $S P B C 1 D 7.01$ & $p f d 1$ & -3 & Sintético fuerte & $c d c 2-3 w$ & SPAC30D $11.04 c$ & nup124 & -3 & No confirmada \\
\hline wee1-50 & SPAC1834.05 & alg9 & -2 & Sintético fuerte & & & & & \\
\hline
\end{tabular}


Tabla S4. Genes con un puntuación de interacción entre -4 y -2 con wee1-50 a $35^{\circ} \mathrm{C}$ clasificados manualmente de acuerdo a lo anotado en Pombase y en la literatura

\begin{tabular}{|c|c|c|c|c|c|}
\hline Nombre ORF & Nombre Gen & $\begin{array}{l}\text { Puntuación } \\
\text { (SGA) }\end{array}$ & Descripción funcional & Función Biológica & Ortología \\
\hline SPAC25G10.06 & rps2801 & -3 & $40 S$ ribosomal protein S28 (predicted) & Biogénesis ribosomas & Levaduras/Humanos \\
\hline$S P B C 16 H 5.08 c$ & $S P B C 16 H 5.08 \mathrm{C}$ & -2 & ribosome biogenesis ATPase, Arb family ABCF2-like (predicted) & Biogénesis ribosomas & Levaduras/Humanos \\
\hline$S P B C 25 H 2.15$ & $S P B C 25 H 2.15$ & -2 & SSU-rRNA maturation protein Tsr4 homolog 1 (predicted) & Biogénesis ribosomas & Levaduras/Humanos \\
\hline SPBC577.02 & rp/3801 & -2 & $60 S$ ribosomal protein $L 38$ (predicted) & Biogénesis ribosomas & Levaduras/Humanos \\
\hline SPBC685.06 & rps001 & -2 & 40 S ribosomal protein $S O A(p 40)$ & Biogénesis ribosomas & Levaduras/Humanos \\
\hline SPAC521.05 & rps802 & -2 & $40 S$ ribosomal protein $S 8$ (predicted) & Biogénesis ribosomas & Levaduras/Humanos \\
\hline SPBC947.01 & alf1 & -3 & ATP-dependent microtubule severing protein (predicted) & Dinámica de microtúbulos & Levaduras/Humanos \\
\hline SPCC417.07c & mto1 & -2 & MT organizer Mto1 & Dinámica de microtúbulos & Levaduras/Humanos \\
\hline SPAC11G7.06c & mug132 & -4 & S. pombe specific UPF0300 family protein 3 & Meiosis & Levadura de Fisión \\
\hline SPCC553.01c & $d b / 2$ & -2 & meiotic chromosome segregation protein Db/2 & Meiosis & Levaduras/Humanos \\
\hline SPBPB2B2.01 & SPBPB2B2.01 & -4 & amino acid permease (predicted) & Metabolismo & Levaduras/Humanos \\
\hline$S P B C 2 G 2.01 C$ & liz1 & -2 & pantothenate transporter Liz1 & Metabolismo & Levaduras/Humanos \\
\hline SPBC3H7.03c & SPBC3H7.03c & -2 & 2-oxoglutarate dehydrogenase (lipoamide) (predicted) & Metabolismo & Levaduras/Humanos \\
\hline SPAC27E2.07 & pvg2 & -2 & galactose residue biosynthesis protein Pvg2 & Metabolismo & Levadura de Fisión \\
\hline SPAC4G9.15 & SPAC4G9.15 & -2 & ketoreductase (predicted) & Metabolismo & Levaduras/Humanos \\
\hline SPBC354.12 & gpd3 & -2 & glyceraldehyde 3-phosphate dehydrogenase & Metabolismo & Levaduras/Humanos \\
\hline SPAPB1A10.09 & ase1 & -4 & antiparallel microtubule cross-linking factor Ase 1 & Mitosis & Levaduras/Humanos \\
\hline SPCC1223.15c & spc19 & -3 & DASH complex subunit Spc19 & Mitosis & Levaduras/Humanos \\
\hline SPAC18G6.15 & mal3 & -3 & EB1 family Mal3 & Mitosis & Levaduras/Humanos \\
\hline SPAC30C2.06c & $d m / 1$ & -3 & mitochondrial inheritance GTPase, tubulin-like (predicted) & Mitosis & Levaduras/Humanos \\
\hline SPBC106.01 & $m p h 1$ & -3 & dual specificity protein kinase Mph1 & Mitosis & Levaduras/Humanos \\
\hline SPAC227.10 & SPAC227.10 & -3 & prefoldin subunit 2 (predicted) & Mitosis & Levaduras/Humanos \\
\hline$S P B C 27.02 c$ & ask1 & -2 & DASH complex subunit Ask1 & Mitosis & Levaduras/Humanos \\
\hline SPAC227.05 & SPAC227.05 & -2 & prefoldin subunit 4 (predicted) & Mitosis & Levaduras/Humanos \\
\hline SPAC14C4.16 & dad3 & -2 & DASH complex subunit Dad3 & Mitosis & Levaduras/Humanos \\
\hline
\end{tabular}




\begin{tabular}{|c|c|c|c|c|c|}
\hline Nombre ORF & Nombre Gen & $\begin{array}{l}\text { Puntuación } \\
\text { (SGA) }\end{array}$ & Descripción funcional & Función Biológica & Ortología \\
\hline SPAC1805.07c & dad2 & -2 & DASH complex subunit Dad2 & Mitosis & Levaduras/Humanos \\
\hline SPCC895.07 & alp14 & -2 & TOG ortholog Alp14 & Mitosis & Levaduras/Humanos \\
\hline SPCC417.02 & dad5 & -2 & DASH complex subunit Dad5 & Mitosis & Levaduras/Humanos \\
\hline$S P B C 36.06 c$ & spo9 & -4 & farnesyl pyrophosphate synthetase & Morfogénesis/citoquinesis & Levaduras/Humanos \\
\hline SPAC13A11.01C & rga8 & -3 & Rho-type GTPase activating protein Rga8 & Morfogénesis/citoquinesis & Levaduras/Humanos \\
\hline$S P B C 23 G 7.08 c$ & $\operatorname{rga7}$ & -3 & Rho-type GTPase activating protein Rga7 & Morfogénesis/citoquinesis & Levaduras/Humanos \\
\hline SPAC2F7.03c & pom1 & -3 & DYRK family protein kinase Pom1 & Morfogénesis/citoquinesis & Levaduras/Humanos \\
\hline SPBC4F6.06 & kin1 & -3 & microtubule affinity-regulating kinase Kin1 & Morfogénesis/citoquinesis & Levaduras/Humanos \\
\hline SPCC1223.09 & SPCC1223.09 & -2 & uricase (predicted) & Morfogénesis/citoquinesis & Humanos \\
\hline SPBC4F6.12 & $p x / 1$ & -2 & paxillin-like protein Pxl1 & Morfogénesis/citoquinesis & Levaduras/Humanos \\
\hline SPBC1706.01 & tea4 & -2 & tip elongation aberrant protein Tea4 & Morfogénesis/citoquinesis & Levaduras/Humanos \\
\hline SPBC215.02 & bob1 & -3 & prefoldin subunit 5 (predicted) & Plegamiento de proteínas & Levaduras/Humanos \\
\hline SPAC3A11.13 & SPAC3A11.13 & -3 & prefoldin subunit 6 (predicted) & Plegamiento de proteínas & Levaduras/Humanos \\
\hline SPAC3H8.07C & pac10 & -3 & prefoldin subunit 3 Pac10 (predicted) & Plegamiento de proteínas & Levaduras/Humanos \\
\hline SPAC25H1.07 & emc1 & -3 & ER membrane protein complex subunit Emc1 (predicted) & Plegamiento de proteínas & Levaduras/Humanos \\
\hline$S P B C 1 D 7.01$ & pfd1 & -3 & prefoldin subunit 1 (predicted) & Plegamiento de proteínas & Levaduras/Humanos \\
\hline SPAC4F10.02 & aap1 & -2 & aspartyl aminopeptidase Aap1 & Plegamiento de proteínas & Levaduras/Humanos \\
\hline SPBC3E7.09 & SPBC3E7.09 & -2 & Sad1-UNC-like protein involved protein folding in the ER (predicted) & Plegamiento de proteínas & Levaduras/Humanos \\
\hline SPBC32F12.05c & cwf12 & -3 & complexed with Cdc5 protein Cwf12 & Procesamiento de ARN & Levaduras/Humanos \\
\hline SPCC663.11 & saf1 & -2 & splicing associated factor Saf1 & Procesamiento de ARN & Levaduras/Humanos \\
\hline SPBC336.14C & ppk26 & -2 & serine/threonine protein kinase, PAN complex subunit, Ppk26 & Procesamiento de ARN & Levaduras/Humanos \\
\hline SPCC550.03c & SPCC550.03c & -2 & Ski complex RNA helicase Ski2 (predicted) & Procesamiento de ARN & Levaduras/Humanos \\
\hline SPAC17A5.02C & $d b r 1$ & -2 & RNA lariat debranching enzyme Dbr1 & Procesamiento de ARN & Levaduras/Humanos \\
\hline SPCC $825.05 c$ & SPCC $825.05 c$ & -2 & splicing coactivator SRRM1 (predicted) & Procesamiento de ARN & Humanos \\
\hline SPAC23C11.10 & mpn1 & -2 & RNA processing protein (predicted) & Procesamiento de ARN & Levaduras/Humanos \\
\hline SPAC19B12.10 & sst2 & -4 & human AMSH/STAMBP protein homolog, ubiquitin specific-protease & Procesamiento de proteínas & Humanos \\
\hline SPAC1071.04c & $s p c 2$ & -3 & signal peptidase subunit Spc2 (predicted) & Procesamiento de proteínas & Levaduras/Humanos \\
\hline
\end{tabular}




\begin{tabular}{|c|c|c|c|c|c|}
\hline Nombre ORF & Nombre Gen & $\begin{array}{l}\text { Puntuación } \\
\text { (SGA) }\end{array}$ & Descripción funcional & Función Biológica & Ortología \\
\hline SPAC3H1.05 & SPAC3H1.05 & -2 & CAAX prenyl protease (predicted) & Procesamiento de proteínas & Levaduras/Humanos \\
\hline SPCC1795.10c & SPCC1795.10c & -2 & Sed5 Vesicle Protein Svp26 (predicted) & Procesamiento de proteínas & Levaduras/Humanos \\
\hline SPBC3H7.09 & erf2 & -2 & palmitoyltransferase Erf2 & Procesamiento de proteínas & Levaduras/Humanos \\
\hline SPAC1834.05 & alg9 & -2 & mannosyltransferase complex subunit Alg9 (predicted) & Procesamiento de proteínas & Levaduras/Humanos \\
\hline SPBC660.14 & mik1 & -3 & mitotic inhibitor kinase Mik1 & Regulación del ciclo celular & Levaduras/Humanos \\
\hline SPAC1782.05 & ура2 & -3 & protein phosphatase type $2 A$ regulator, PTPA family Ypa2 & Regulación del ciclo celular & Levaduras/Humanos \\
\hline$S P B C 16 H 5.07 c$ & ppa2 & -3 & serine/threonine protein phosphatase Ppa2 & Regulación del ciclo celular & Levaduras/Humanos \\
\hline SPAPB2B4.03 & $\operatorname{cig} 2$ & -2 & G1/S-specific B-type cyclin Cig2 & Regulación del ciclo celular & Levaduras/Humanos \\
\hline SPBC725.02 & mpr1 & -2 & histidine-containing response regulator phosphotransferase Mpr1 & Regulación del ciclo celular & Levaduras/Humanos \\
\hline SPBC17A3.06 & pi040 & -2 & phosphoprotein phosphatase (predicted) & Regulación del ciclo celular & Levaduras/Humanos \\
\hline SPAC $1782.09 c$ & clp1 & -2 & Cdc14-related protein phosphatase Clp1/Flp1 & Regulación del ciclo celular & Levaduras/Humanos \\
\hline SPAC23D3.09 & $\operatorname{arp} 42$ & -3 & SWI/SNF and RSC complex subunit Arp42 & $\begin{array}{l}\text { Remodelamiento de } \\
\text { cromatina }\end{array}$ & Levaduras/Humanos \\
\hline SPAC31G5.18c & sde2 & -3 & silencing defective protein Sde2 & $\begin{array}{l}\text { Remodelamiento de } \\
\text { cromatina }\end{array}$ & Humanos \\
\hline SPAC631.02 & $n r c 1$ & -3 & bromodomain protein (predicted) & $\begin{array}{l}\text { Remodelamiento de } \\
\text { cromatina }\end{array}$ & Levaduras/Humanos \\
\hline SPAC23H4.12 & alp13 & -2 & MRG family Clr6 histone deacetylase complex subunit Alp13 & $\begin{array}{l}\text { Remodelamiento de } \\
\text { cromatina }\end{array}$ & Levaduras/Humanos \\
\hline SPAC664.02c & arp8 & -2 & actin-like protein, Ino80 complex subunit Arp8 & $\begin{array}{l}\text { Remodelamiento de } \\
\text { cromatina }\end{array}$ & Levaduras/Humanos \\
\hline SPBP8B7.28C & stc1 & -2 & LIM-like protein linking chromatin modification to RNAi, Stc1 & $\begin{array}{l}\text { Remodelamiento de } \\
\text { cromatina }\end{array}$ & Levadura de Fisión \\
\hline$S P B C 11 B 10.10 c$ & pht1 & -2 & histone $H 2 A$ variant $H 2 A . Z$, Pht1 & $\begin{array}{l}\text { Remodelamiento de } \\
\text { cromatina }\end{array}$ & Levaduras/Humanos \\
\hline SPAC139.06 & hat1 & -2 & histone acetyltransferase Hat1 & $\begin{array}{l}\text { Remodelamiento de } \\
\text { cromatina }\end{array}$ & Levaduras/Humanos \\
\hline$S P B C 2 D 10.16$ & $m h f 1$ & -3 & FANCM-MHF complex subunit Mhf1 & Reparación del ADN & Levaduras/Humanos \\
\hline SPCC576.12c & $m h f 2$ & -3 & FANCM-MHF complex subunit Mhf2 & Reparación del ADN & Levaduras/Humanos \\
\hline SPAC2G11.12 & rqh1 & -2 & RecQ type DNA helicase Rqh1 & Reparación del ADN & Levaduras/Humanos \\
\hline SPBC216.05 & $\operatorname{rad} 3$ & -4 & ATR checkpoint kinase Rad3 & Replicación del ADN & Levaduras/Humanos \\
\hline SPAC14C4.13 & $\operatorname{rad} 17$ & -4 & RFC related checkpoint protein Rad17 & Replicación del ADN & Levaduras/Humanos \\
\hline SPAC9E9.08 & $\operatorname{rad} 26$ & -4 & ATRIP, ATR checkpoint kinase regulatory subunit Rad26 & Replicación del ADN & Levaduras/Humanos \\
\hline
\end{tabular}




\begin{tabular}{|c|c|c|c|c|c|}
\hline Nombre ORF & Nombre Gen & $\begin{array}{c}\text { Puntuación } \\
\text { (SGA) }\end{array}$ & Descripción funcional & Función Biológica & Ortología \\
\hline SPAC1952.07 & rad1 & -3 & checkpoint clamp complex protein Rad1 & Replicación del ADN & Levaduras/Humanos \\
\hline SPAC20G4.04C & hus1 & -3 & checkpoint clamp complex protein Hus1 & Replicación del ADN & Levaduras/Humanos \\
\hline SPAC664.07c & $\operatorname{rad} 9$ & -3 & checkpoint clamp complex protein Rad9 & Replicación del ADN & Levaduras/Humanos \\
\hline SPBC902.02c & ctf18 & -3 & RFC-like complex subunit Ctf18 & Replicación del ADN & Levaduras/Humanos \\
\hline SPAC6F6.01 & $\operatorname{cch} 1$ & -3 & calcium channel Cch1 & Señalización celular & Levaduras/Humanos \\
\hline SPAC1F5.08c & yam8 & -3 & calcium channel regulatory subunit Yam8 & Señalización celular & Levaduras/Humanos \\
\hline$S P B C 31 E 1.02 c$ & pmr1 & -3 & P-type ATPase, calcium transporting Pmr1 & Señalización celular & Levaduras/Humanos \\
\hline SPCC830.06 & $c n b 1$ & -2 & calcineurin regulatory subunit (calcineurin B) & Señalización celular & Levaduras/Humanos \\
\hline SPCC1223.11 & ptc2 & -2 & protein phosphatase $2 \mathrm{C} \mathrm{Ptc2}$ & Regulación del ciclo celular & Levaduras/Humanos \\
\hline$S P B C 25 B 2.10$ & SPBC25B2.10 & -2 & Usp (universal stress protein) family protein & Señalización celular & Hongos \\
\hline SPCC757.09c & rnc1 & -2 & RNA-binding protein that suppresses calcineurin deletion Rnc1 & Señalización celular & Levaduras/Humanos \\
\hline SPBC16E9.09c & erp5 & -2 & COPII vesicle coat component Erp5/Erp6 (predicted) & Señalización celular & Levaduras/Humanos \\
\hline SPAC212.03 & SPAC212.03 & -3 & hypothetical protein & Sin caracterizar & Levadura de Fisión \\
\hline SPBC557.02c & SPBC557.02c & -2 & conserved fungal protein & Sin caracterizar & Levadura de Fisión \\
\hline SPAC9G1.07 & SPAC9G1.07 & -2 & sequence orphan & Sin caracterizar & Levadura de Fisión \\
\hline SPAC212.08C & SPAC212.08c & -2 & GPI anchored protein (predicted) & Sin caracterizar & Levaduras/Humanos \\
\hline SPCC569.02C & SPCC569.02c & -2 & S. pombe specific UPF0321 family protein 2 & Sin caracterizar & Levadura de Fisión \\
\hline$S P B C 11 C 11.09 c$ & rp/502 & -3 & $60 S$ ribosomal protein $L 5$ & Traducción & Levaduras/Humanos \\
\hline SPAC3A12.13C & SPAC3A12.13C & -3 & translation initiation factor elF3j (p35) & Traducción & Levaduras/Humanos \\
\hline SPCC550.14 & vgl1 & -3 & vigilin (predicted) & Traducción & Levaduras/Humanos \\
\hline SPBC17G9.09 & tif213 & -2 & translation initiation factor elF2 gamma subunit (predicted) & Traducción & Levaduras/Humanos \\
\hline SPAC821.05 & SPAC821.05 & -2 & translation initiation factor elF3h $(p 40)$ & Traducción & Humanos \\
\hline SPAC9G1.12 & $c p d 1$ & -2 & tRNA (m1A) methyltransferase complex catalytic subunit Cpd1 & Traducción & Levaduras/Humanos \\
\hline SPAC664.03 & SPAC664.03 & -3 & RNA polymerase II associated Paf1 complex (predicted) & Transcripción & Levaduras/Humanos \\
\hline SPBC530.05 & prt1 & -2 & transcription factor (predicted) & Transcripción & Levaduras/Humanos \\
\hline SPBC16G5.15C & fkh2 & -2 & forkhead transcription factor Fkh2 & Transcripción & Levaduras/Humanos \\
\hline SPAC22F3.09c & res2 & -2 & MBF transcription factor complex subunit Res2 & Transcripción & Levaduras/Humanos \\
\hline
\end{tabular}




\begin{tabular}{|c|c|c|c|c|c|}
\hline Nombre ORF & Nombre Gen & $\begin{array}{l}\text { Puntuación } \\
\text { (SGA) }\end{array}$ & Descripción funcional & Función Biológica & Ortología \\
\hline SPAC1F7.01C & spt6 & -2 & nucleosome remodeling protein Spt6 & Transcripción & Levaduras/Humanos \\
\hline SPCC736.08 & $c b f 11$ & -2 & $\mathrm{CBF} 1 / \mathrm{S} u(H) / L A G-1$ family transcription factor $\mathrm{Cbf11}$ & Transcripción & Humanos \\
\hline$S P B C 19 C 2.09$ & sre1 & -2 & sterol regulatory element binding protein, transcription factor Sre 1 & Transcripción & Humanos \\
\hline$S P B C 1198.11 C$ & reb1 & -2 & RNA polymerase I transcription termination factor Reb1 & Transcripción & Levaduras/Humanos \\
\hline SPAC2F3.02 & SPAC2F3.02 & -3 & ER protein translocation subcomplex subunit Sec72 (predicted) & Transporte de proteínas & Levaduras/Humanos \\
\hline SPAC222.14C & SPAC222.14C & -3 & GTP binding protein Sey1 (predicted) & Transporte de proteinas & Levaduras/Humanos \\
\hline SPAC22F8.04 & SPAC22F8.04 & -3 & triose phosphate transporter (predicted) & Transporte de proteinas & Levaduras/Humanos \\
\hline SPAC17A5.08 & erp2 & -2 & COPII-coated vesicle component Erp2/3/4 (predicted) & Transporte de proteínas & Levaduras/Humanos \\
\hline SPAC17A2.06C & vps8 & -2 & WD repeat protein Vps8 (predicted) & Transporte de proteinas & Levaduras/Humanos \\
\hline SPAC4G8.04 & SPAC4G8.04 & -2 & GTPase activating protein (predicted) & Transporte de proteínas & Levaduras/Humanos \\
\hline SPAC2C4.05 & SPAC2C4.05 & -2 & cornichon family protein (predicted) & Transporte de proteínas & Levaduras/Humanos \\
\hline SPAC1142.07c & vps32 & -2 & ESCRT III complex subunit Vps32 & Transporte de proteínas & Levaduras/Humanos \\
\hline$S P B C 18 H 10.19$ & vps38 & -2 & phophatidylinositol 3-kinase complex subunit Vps38 & Transporte de proteínas & Levaduras/Humanos \\
\hline SPAC1805.04 & nup132 & -2 & nucleoporin Nup132 & $\begin{array}{l}\text { Transporte nucleo- } \\
\text { citoplásmico }\end{array}$ & Levaduras/Humanos \\
\hline
\end{tabular}


Tabla S5. Genes con un puntuación de interacción entre -4 y -2 con $c d c 2-3 w$ a $25^{\circ} \mathrm{C}$ clasificados manualmente de acuerdo a lo anotado en Pombase. y en la literatura

\begin{tabular}{|c|c|c|c|c|c|}
\hline Nombre ORF & Nombre Gen & $\begin{array}{l}\text { Puntuación } \\
\text { (SGA) }\end{array}$ & Descripción funcional & Función Biológica & Ortología \\
\hline SPBC1703.03c & $S P B C 1703.03 c$ & -2 & armadillo repeat protein (predicted) & Biogénesis ribosomas & Levaduras/Humanos \\
\hline SPAC22F3.08c & rok1 & -2 & ATP-dependent RNA helicase Rok1 (predicted) & Biogénesis ribosomas & Levaduras/Humanos \\
\hline SPBC25H2.15 & SPBC25H2.15 & -4 & SSU-rRNA maturation protein Tsr4 homolog 1 (predicted) & Biogénesis ribosomas & Levaduras/Humanos \\
\hline SPBC3B9.13c & rpp102 & -3 & $60 S$ acidic ribosomal protein $A 3$ & Biogénesis ribosomas & Levaduras/Humanos \\
\hline$S P B C 16 C 6.03 c$ & SPBC16C6.03c & -3 & ribosome assembly protein (predicted) & Biogénesis ribosomas & Levaduras/Humanos \\
\hline$S P B C 16 D 10.11 C$ & rps1801 & -3 & 40S ribosomal protein S18 (predicted) & Biogénesis ribosomas & Levaduras/Humanos \\
\hline SPAC589.10c & SPAC589.10c & -3 & ribosomal-ubiquitin fusion protein Ubi5 (predicted) & Biogénesis ribosomas & Levaduras/Humanos \\
\hline$S P B C 11 C 11.09 C$ & rp/502 & -3 & $60 S$ ribosomal protein $L 5$ & Biogénesis ribosomas & Levaduras/Humanos \\
\hline SPAC890.05 & SPAC890.05 & -2 & ribosome biogenesis protein, G-patch domain, PINX1 family (predicted) & Biogénesis ribosomas & Levaduras/Humanos \\
\hline SPBC776.17 & SPBC776.17 & -2 & rRNA processing protein Rrp7 (predicted) & Biogénesis ribosomas & Levaduras/Humanos \\
\hline SPAC3H5.12C & rp/501 & -2 & $60 S$ ribosomal protein L5 (predicted) & Biogénesis ribosomas & Levaduras/Humanos \\
\hline SPAC1952.02 & $\operatorname{tma} 23$ & -2 & ribosome biogenesis protein Tma23 (predicted) & Biogénesis ribosomas & Levaduras/Humanos \\
\hline SPAC521.05 & rps802 & -2 & $40 S$ ribosomal protein $S 8$ (predicted) & Biogénesis ribosomas & Levaduras/Humanos \\
\hline SPCC613.06 & rp/902 & -2 & $60 S$ ribosomal protein $L 9$ & Biogénesis ribosomas & Levaduras/Humanos \\
\hline SPAC12G12.13c & $\operatorname{cid} 14$ & -2 & poly $(A)$ polymerase Cid14 & Biogénesis ribosomas & Levaduras/Humanos \\
\hline SPAC22A12.04C & rps2201 & -2 & 40 S ribosomal protein $\mathrm{S} 15 \mathrm{a}$ (predicted) & Biogénesis ribosomas & Levaduras/Humanos \\
\hline SPBC9B6.07 & nop52 & -2 & nucleolar protein Nop52 family (predicted) & Biogénesis ribosomas & Levaduras/Humanos \\
\hline SPBC1539.10 & nop16 & -2 & ribosome biogenesis protein Nop16 (predicted) & Biogénesis Ribosomas & Levaduras/Humanos \\
\hline SPCC74.05 & rp/2702 & -2 & $60 S$ ribosomal protein L27 (predicted) & Biogénesis Ribosomas & Levaduras/Humanos \\
\hline SPBC947.01 & alf1 & -2 & ATP-dependent microtubule severing protein (predicted) & Dinámica de microtúbulos & Levaduras/Humanos \\
\hline SPAC1A6.07 & sle1 & -5 & eisosome assembly protein Seg1 & Endocitosis & Levaduras \\
\hline SPAC11G7.06c & mug132 & -3 & S. pombe specific UPF0300 family protein 3 & Meiosis & Levadura de fisión \\
\hline SPAC3C7.06C & pit1 & -2 & serine/threonine protein kinase, meiotic Pit1 & Meiosis & Levaduras/Humanos \\
\hline SPBC12C2.04 & $S P B C 12 C 2.04$ & -3 & NAD binding dehydrogenase family protein & Metabolismo & Humanos \\
\hline SPAC922.07c & atd2 & -2 & aldehyde dehydrogenase (predicted) & Metabolismo & Levaduras/Humanos \\
\hline
\end{tabular}




\begin{tabular}{|c|c|c|c|c|c|}
\hline Nombre ORF & Nombre Gen & $\begin{array}{l}\text { Puntuación } \\
\text { (SGA) }\end{array}$ & Descripción funcional & Función Biológica & Ortología \\
\hline SPAC19G12.08 & $\operatorname{scs} 7$ & -2 & sphingosine hydroxylase Scs7 & Metabolismo & Levaduras/Humanos \\
\hline SPBC16E9.14C & $\operatorname{zrg} 17$ & -3 & cation diffusion family zinc membrane transporter Zrg17 & Metabolismo & Levaduras \\
\hline SPBPB2B2.01 & SPBPB2B2.01 & -2 & amino acid permease (predicted) & Metabolismo & Levaduras \\
\hline SPCC1223.09 & SPCC1223.09 & -2 & uricase (predicted) & Metabolismo & Humanos \\
\hline SPBC3H7.03c & SPBC3H7.03c & -2 & 2-oxoglutarate dehydrogenase (lipoamide) (predicted) & Metabolismo & Levaduras/Humanos \\
\hline SPBC725.15 & ura5 & -2 & orotate phosphoribosyltransferase Ura5 & Metabolismo & Levaduras/Humanos \\
\hline SPAC3A12.12 & atp11 & -2 & F1-ATPase chaperone Atp11 (predicted) & Metabolismo & Levaduras/Humanos \\
\hline SPAC1F12.07 & SPAC1F12.07 & -2 & phosphoserine aminotransferase (predicted) & Metabolismo & Levaduras/Humanos \\
\hline SPAC222.08c & SPAC222.08c & -2 & glutamine aminotransferase subunit (predicted) & Metabolismo & Levaduras \\
\hline SPAC24B11.09 & $m p c 2$ & -2 & mitochondrial pyruvate transmembrane transporter subunit Mpc2 & Metabolismo & Levaduras/Humanos \\
\hline$S P B C 887.15 c$ & sur2 & -2 & sphingosine hydroxylase Sur2 & Metabolismo & Levaduras \\
\hline SPCC1235.13 & ght6 & -2 & hexose transporter Ght6 & Metabolismo & Levaduras \\
\hline SPBP35G2.03c & sgo1 & -2 & inner centromere protein, shugoshin, Sgo1 & Mitosis & Levaduras/Humanos \\
\hline SPAC18G6.15 & mal3 & -2 & EB1 family Mal3 & Mitosis & Levaduras/Humanos \\
\hline SPAPB1A10.09 & ase1 & -3 & antiparallel microtubule cross-linking factor Ase 1 & Mitosis & Levaduras/Humanos \\
\hline SPCC895.07 & alp14 & -2 & TOG ortholog Alp14 & Mitosis & Levaduras/Humanos \\
\hline$S P B C 106.01$ & mph1 & -3 & dual specificity protein kinase Mph1 & Mitosis & Levaduras/Humanos \\
\hline SPAC30C2.06c & $d m / 1$ & -5 & mitochondrial inheritance GTPase, tubulin-like (predicted) & Mitosis & Levaduras/Humanos \\
\hline SPCC1322.12c & bub1 & -2 & serine/threonine protein kinase Bub1 & Mitosis & Levaduras/Humanos \\
\hline SPAC2F7.03c & pom1 & -3 & DYRK family protein kinase Pom1 & Morfogénesis/citoquinesis & Levaduras/Humanos \\
\hline$S P B C 23 G 7.08 C$ & rga7 & -3 & Rho-type GTPase activating protein Rga7 & Morfogénesis/citoquinesis & Levaduras/Humanos \\
\hline SPAC13A11.01C & rga8 & -3 & Rho-type GTPase activating protein Rga8 & Morfogénesis/citoquinesis & Levaduras \\
\hline SPBC336.03 & efc25 & -3 & Ras1 guanyl-nucleotide exchange factor Efc25 & Morfogénesis/citoquinesis & Levaduras/Humanos \\
\hline SPAC926.03 & $r l c 1$ & -2 & myosin II regulatory light chain $R / c 1$ & Morfogénesis/citoquinesis & Levaduras/Humanos \\
\hline SPAC25H1.07 & emc1 & -3 & ER membrane protein complex subunit Emc1 (predicted) & Plegamiento de proteínas & Levaduras/Humanos \\
\hline SPCC1840.08c & SPCC1840.08c & -2 & protein disulfide isomerase (predicted) & Plegamiento de proteínas & Levaduras \\
\hline SPBC3E7.09 & SPBC3E7.09 & -2 & Sad1-UNC-like protein involved protein folding in the ER (predicted) & Plegamiento de proteínas & Levaduras/Humanos \\
\hline
\end{tabular}




\begin{tabular}{|c|c|c|c|c|c|}
\hline Nombre ORF & Nombre Gen & $\begin{array}{c}\text { Puntuación } \\
\text { (SGA) }\end{array}$ & Descripción funcional & Función Biológica & Ortología \\
\hline SPBC56F2.08c & $S P B C 56 F 2.08 C$ & -2 & RNA-binding protein (predicted) & Procesamiento de ARN & Levaduras \\
\hline$S P B C 1718.07 c$ & $z f s 1$ & -3 & $\mathrm{CCCH}$ tandem zinc finger protein, human Tristetraprolin homolog Zfs 1 & Procesamiento de ARN & Levaduras/Humanos \\
\hline SPBC31F10.12 & $\operatorname{tma} 20$ & -3 & RNA-binding protein Tma20 (predicted) & Procesamiento de ARN & Levaduras/Humanos \\
\hline SPAC17A5.02C & $d b r 1$ & -2 & RNA lariat debranching enzyme Dbr1 & Procesamiento de ARN & Levaduras/Humanos \\
\hline$S P B C 18 H 10.10 c$ & saf4 & -2 & splicing associated factor Saf4 & Procesamiento de ARN & Humanos \\
\hline SPAC18G6.10 & lem2 & -2 & LEM domain protein Heh1/Lem2 & Procesamiento de ARN & Levaduras/Humanos \\
\hline SPAC23C11.10 & mpn1 & -2 & RNA processing protein (predicted) & Procesamiento de ARN & Levaduras/Humanos \\
\hline SPAC3H1.05 & SPAC3H1.05 & -2 & CAAX prenyl protease (predicted) & Procesamiento de proteínas & Levaduras/Humanos \\
\hline SPCC1795.10c & SPCC1795.10c & -3 & Sed5 Vesicle Protein Svp26 (predicted) & Procesamiento de proteínas & Levaduras/Humanos \\
\hline$S P B C 56 F 2.10 c$ & alg5 & -2 & dolichyl-phosphate beta-glucosyltransferase Alg5 (predicted) & Procesamiento de proteínas & Levaduras/Humanos \\
\hline SPAPB17E12.04C & $\operatorname{csn} 2$ & -2 & COP9/signalosome complex subunit Csn2 & Procesamiento de proteínas & Levaduras/Humanos \\
\hline SPAC5D6.13 & SPAC5D6.13 & -2 & Golgi phosphoprotein 3 family (predicted) & Procesamiento de proteínas & Levaduras/Humanos \\
\hline SPBC3H7.09 & erf2 & -2 & palmitoyltransferase Erf2 & Procesamiento de proteínas & Levaduras/Humanos \\
\hline SPBC776.02c & dis2 & -2 & serine/threonine protein phosphatase PP1 & Regulación del ciclo celular & Levaduras/Humanos \\
\hline SPAC1782.09c & $c / p 1$ & -2 & Cdc14-related protein phosphatase Clp1/Flp1 & Regulación del ciclo celular & Levaduras/Humanos \\
\hline SPAC4F10.04 & yра1 & -2 & protein phosphatase type $2 A$ regulator, PTPA family Ypa1 & Regulación del ciclo celular & Levaduras/Humanos \\
\hline SPAC9E9.13 & wos2 & -5 & p23 homolog, predicted co-chaperone Wos2 & Regulación del ciclo celular & Levaduras/Humanos \\
\hline SPBC16H5.07C & ppa2 & -4 & serine/threonine protein phosphatase Ppa2 & Regulación del ciclo celular & Levaduras/Humanos \\
\hline SPBC725.02 & mpr1 & -3 & histidine-containing response regulator phosphotransferase Mpr1 & Regulación del ciclo celular & Levaduras \\
\hline SPBC887.18c & hfi1 & -3 & SAGA complex subunit Hfi1 & Remodelamiento de cromatina & Levaduras/Humanos \\
\hline SPBC29A3.05 & vps71 & -3 & Swr1 complex subunit Vps71 & Remodelamiento de cromatina & Levaduras/Humanos \\
\hline SPBP8B7.28c & stc1 & -4 & LIM-like protein linking chromatin modification to RNAi, Stc1 & Remodelamiento de cromatina & Levadura de fisión \\
\hline SPAC664.02c & arp8 & -3 & actin-like protein, Ino80 complex subunit Arp8 & Remodelamiento de cromatina & Levaduras/Humanos \\
\hline SPAC631.02 & $n r c 1$ & -2 & bromodomain protein (predicted) & Remodelamiento de cromatina & Levaduras/Humanos \\
\hline SPAC31G5.18c & sde2 & -2 & silencing defective protein Sde2 & Remodelamiento de cromatina & Humanos \\
\hline SPAC23D3.09 & $\operatorname{arp} 42$ & -2 & SWI/SNF and RSC complex subunit Arp42 & Remodelamiento de cromatina & Levaduras/Humanos \\
\hline$S P B C 2 D 10.16$ & $m h f 1$ & -4 & FANCM-MHF complex subunit Mhf1 & Reparación del ADN & Levaduras/Humanos \\
\hline
\end{tabular}




\begin{tabular}{|c|c|c|c|c|c|}
\hline Nombre ORF & Nombre Gen & $\begin{array}{l}\text { Puntuación } \\
\text { (SGA) }\end{array}$ & Descripción funcional & Función Biológica & Ortología \\
\hline SPCC576.12c & $m h f 2$ & -3 & FANCM-MHF complex subunit Mhf2 & Reparación del ADN & Levaduras/Humanos \\
\hline SPAPB1E7.06c & eme1 & -2 & Holliday junction resolvase subunit Eme1 & Reparación del ADN & Levaduras/Humanos \\
\hline SPBC902.02C & ctf18 & -2 & RFC-like complex subunit Ctf18 & Replicación del ADN & Levaduras/Humanos \\
\hline$S P B C 216.05$ & $\operatorname{rad} 3$ & -3 & ATR checkpoint kinase Rad3 & Replicación del ADN & Levaduras/Humanos \\
\hline SPAC9E9.08 & $\operatorname{rad} 26$ & -3 & ATRIP, ATR checkpoint kinase regulatory subunit Rad 26 & Replicación del ADN & Levaduras/Humanos \\
\hline SPAC20G4.04C & hus1 & -3 & checkpoint clamp complex protein Hus1 & Replicación del ADN & Levaduras/Humanos \\
\hline SPAC14C4.13 & rad17 & -3 & RFC related checkpoint protein Rad17 & Replicación del ADN & Levaduras/Humanos \\
\hline SPAP14E8.02 & tos 4 & -3 & FHA domain protein Tos4 (predicted) & Replicación del ADN & Levaduras/Humanos \\
\hline SPAC664.07c & $\operatorname{rad} 9$ & -2 & checkpoint clamp complex protein Rad9 & Replicación del ADN & Levaduras/Humanos \\
\hline SPAC1D4.09c & $r t f 2$ & -2 & replication termination factor Rtf2 & Replicación del ADN & Humanos \\
\hline SPCC830.06 & cnb1 & -2 & calcineurin regulatory subunit (calcineurin B) & Señalización celular & Levaduras/Humanos \\
\hline SPCC1223.11 & ptc2 & -2 & protein phosphatase $2 \mathrm{C}$ Ptc2 & Señalización celular & Levaduras/Humanos \\
\hline SPAC1F5.08c & yam8 & -3 & calcium channel regulatory subunit Yam8 & Señalización celular & Levaduras \\
\hline SPBC609.02 & ptn1 & -2 & phosphatidylinositol-3,4,5-trisphosphate3-phosphatase Ptn1 & Señalización celular & Levaduras/Humanos \\
\hline SPAC4F10.19c & SPAC4F10.19c & -2 & zf-HIT protein Hit1 (predicted) & Sin caracterizar & Levaduras/Humanos \\
\hline SPAC5D6.10c & mug116 & -5 & sequence orphan & Sin caracterizar & Levadura de fisión \\
\hline SPAC25B8.07C & SPAC25B8.07C & -4 & hypoxia induced family protein & Sin caracterizar & Levaduras/Humanos \\
\hline SPAC1952.01 & SPAC1952.01 & -3 & Pig-U (predicted) & Sin caracterizar & Levaduras/Humanos \\
\hline SPBC9B6.03 & SPBC9B6.03 & -2 & zf-FYVE type zinc finger protein & Sin caracterizar & Levaduras/Humanos \\
\hline SPCC594.01 & SPCC594.01 & -2 & DUF1769 family protein & Sin caracterizar & Levadura de fisión \\
\hline SPCC553.03 & pex1 & -2 & AAA family ATPase Pex1 (predicted) & Sin caracterizar & Levaduras/Humanos \\
\hline SPAC22E12.18 & SPAC22E12.18 & -2 & conserved fungal protein & Sin caracterizar & Levaduras \\
\hline SPBC16G5.15c & fkh2 & -2 & forkhead transcription factor Fkh2 & Transcripción & Levaduras \\
\hline SPAC22H12.02 & $\operatorname{tfg} 3$ & -2 & transcription factor TFIIF complex subunit Tfg3 & Transcripción & Levaduras/Humanos \\
\hline SPAC2H10.01 & SPAC2H10.01 & -2 & transcription factor, zf-fungal binuclear cluster type (predicted) & Transcripción & Hongos \\
\hline SPBC409.08 & $S P B C 409.08$ & -5 & spermine family transporter (predicted) & Transporte celular & Levaduras \\
\hline SPAC1B3.16c & vht1 & -2 & vitamin $\mathrm{H}$ transporter Vth1 & Transporte celular & Levaduras \\
\hline
\end{tabular}




\begin{tabular}{|c|c|c|c|c|c|}
\hline Nombre ORF & Nombre Gen & $\begin{array}{l}\text { Puntuación } \\
\text { (SGA) }\end{array}$ & Descripción funcional & Función Biológica & Ortología \\
\hline SPAPB8E5.04C & SPAPB8E5.04C & -2 & Niemann-Pick disease type C2 protein hE1 homolog (predicted) & Transporte celular & Levaduras/Humanos \\
\hline SPAC1142.07c & vps32 & -3 & ESCRT III complex subunit Vps32 & Transporte de proteínas & Levaduras/Humanos \\
\hline SPAP27G11.06c & vas2 & -3 & AP-1 adaptor complex sigma subunit Aps 1 & Transporte de proteinas & Levaduras/Humanos \\
\hline SPCP1E11.06 & ap/4 & -3 & AP-1 adaptor complex gamma subunit Ap/4 & Transporte de proteínas & Levaduras/Humanos \\
\hline SPBC16E9.09c & erp5 & -3 & COPII vesicle coat component Erp5/Erp6 (predicted) & Transporte de proteinas & Levaduras/Humanos \\
\hline SPAC23H3.06 & ap/6 & -2 & AP-3 adaptor complex subunit Apl6 (predicted) & Transporte de proteínas & Levaduras/Humanos \\
\hline SPAC30D11.04C & nup124 & -3 & nucleoporin Nup124 & $\begin{array}{l}\text { Transporte nucleo- } \\
\text { citoplásmico }\end{array}$ & Levaduras/Humanos \\
\hline SPCC1739.14 & npp106 & -2 & nucleoporin Npp106 & $\begin{array}{l}\text { Transporte nucleo- } \\
\text { citoplásmico }\end{array}$ & Levaduras/Humanos \\
\hline
\end{tabular}


Tabla S6. Análisis funcional de la red de interacciones genéticas de wee1-50 con Gene list anayser

\begin{tabular}{|c|c|c|c|c|c|c|}
\hline $\begin{array}{l}\text { Ciclo celular } \\
(28 / 118)\end{array}$ & $\begin{array}{l}\text { Biogénesis y organización del } \\
\text { citoesqueleto (17/118) }\end{array}$ & $\begin{array}{c}\text { Señalización celular } \\
(23 / 118)\end{array}$ & $\begin{array}{c}\text { Biogénesis y organización de } \\
\text { organelos }(24 / 118)\end{array}$ & $\begin{array}{l}\text { Plegamiento de } \\
\text { proteínas }(28 / 118)\end{array}$ & $\begin{array}{l}\text { Cromosoma } \\
(22 / 118)\end{array}$ & $\begin{array}{l}\text { Centro de organización de } \\
\text { microtúbulos }(7 / 118)\end{array}$ \\
\hline SPBC16G5.15C & SPAC18G6.15 & SPBC17A3.06 & SPBC16G5.15C & SPBC215.02 & SPAC139.06 & SPAPB1A10.09 \\
\hline SPBC660.14 & SPAPB1A10.09 & SPCC757.09C & SPAC139.06 & SPAC3A11.13 & SPAC1F7.01C & SPCC417.07C \\
\hline SPAC18G6.15 & SPCC1223.15C & $S P A C 13 A 11.01 C$ & SPAC18G6.15 & SPAC18G6.15 & SPCC1223.15C & $S P B C 106.01$ \\
\hline SPAPB1A10.09 & $S P A C 13 A 11.01 C$ & $S P B C 216.05$ & SPAC1F7.01C & SPAPB1A10.09 & SPBC216.05 & SPAC1805.07C \\
\hline SPCC1223.15C & SPCC417.07C & $S P B C 725.02$ & $S P B C 1198.11 C$ & SPCC757.09C & $S P B C 106.01$ & SPCC895.07 \\
\hline SPCC417.07C & $S P B C 902.02 C$ & $S P B C 106.01$ & SPCC1223.15C & $S P A C 13 A 11.01 C$ & SPAC20G4.04C & SPAC1782.09C \\
\hline$S P B C 216.05$ & SPCC417.02 & SPAC20G4.04C & SPAC664.02C & SPCC417.07C & SPAC664.02C & $S P B C 27.02 C$ \\
\hline$S P B C 725.02$ & $S P B C 1706.01$ & SPAC2F7.03C & $S P B C 11 B 10.10 C$ & $S P B C 216.05$ & $S P B C 11 B 10.10 C$ & \\
\hline$S P B C 106.01$ & $S P B C 23 G 7.08 C$ & $S P B C 336.14 C$ & SPAC631.02 & $S P B C 725.02$ & SPAC631.02 & \\
\hline SPAC20G4.04C & SPAC1805.07C & SPAC2G11.12 & SPCC553.01C & SPAC20G4.04C & $S P B C 902.02 C$ & \\
\hline$S P B C 902.02 C$ & SPCC895.07 & SPBC23G7.08C & $S P B C 902.02 C$ & SPAC2F7.03C & SPCC417.02 & \\
\hline SPCC417.02 & SPAC1782.09C & $S P B C 19 C 2.09$ & SPCC417.02 & SPAC3H8.07C & SPAC23H4.12 & \\
\hline SPAC2G11.12 & $S P B C 27.02 C$ & SPAC4G8.04 & SPAC23H4.12 & SPAC23H4.12 & $S P A C 2 G 11.12$ & \\
\hline SPAC22F3.09C & SPAC1782.05 & SPAC1782.09C & SPAC2G11.12 & $S P B C 1706.01$ & SPAC1805.07C & \\
\hline SPAC1805.07C & SPAC14C4.16 & SPAC9E9.08 & SPAC22F3.09C & $S P A C 2 G 11.12$ & SPCC895.07 & \\
\hline SPCC895.07 & $S P B C 4 F 6.12$ & SPCC830.06 & SPAC1805.07C & SPAC22F3.09C & SPAC1782.09C & \\
\hline SPAC1805.04 & $S P B C 4 F 6.06$ & SPAC1952.07 & SPAC30C2.06C & $S P B C 1 D 7.01$ & $S P B C 27.02 C$ & \\
\hline SPAC1782.09C & & $S P B C 16 H 5.07 C$ & SPAC664.03 & SPCC895.07 & SPAC1952.07 & \\
\hline SPAC9E9.08 & & SPAC2C4.05 & SPCC736.08 & SPAC1805.04 & SPAC23D3.09 & \\
\hline$S P B C 27.02 C$ & & SPBC $4 F 6.12$ & SPAC1782.09C & SPAC1782.09C & SPAC14C4.16 & \\
\hline SPAC1952.07 & & SPAC664.07C & SPCC550.14 & SPAC1952.07 & SPAC664.07C & \\
\hline SPBC $16 H 5.07 C$ & & SPCC1223.11 & $S P B C 27.02 C$ & SPAC227.05 & SPAC14C4.13 & \\
\hline SPAC1782.05 & & SPAC14C4.13 & SPAC23D3.09 & SPBC4F6.12 & & \\
\hline SPAC14C4.16 & & & SPAC14C4.16 & SPAPB2B4.03 & & \\
\hline SPBC4F6.12 & & & & SPAC227.10 & & \\
\hline SPAPB2B4.03 & & & & SPBC36.06C & & \\
\hline SPAC664.07C & & & & SPAC664.07C & & \\
\hline SPAC14C4.13 & & & & SPBC685.06 & & \\
\hline
\end{tabular}


Tabla S7. Análisis funcional de la red de interacción genéticas de wee1-50 con BiNGO

\begin{tabular}{|c|c|c|c|c|c|c|}
\hline GO ID & Descripción & $p$-val & corr $p$-val & cluster freq & total freq & Genes \\
\hline 65007 & biological regulation & $3,45 \mathrm{E}-10$ & $4,72 \mathrm{E}-02$ & $53 / 9754.6 \%$ & $1313 / 523225.0 \%$ & $\begin{array}{c}\text { SPCC550.03C MIK1 SPAC3A12.13C RAD9 LIZ1 VGL1 RNC1 ASE1 CLP1 } \\
\text { MPH1 RAD26 PPK26 SPAC664.03 RQH1 TIF213 NUP132 RAD1 SPC19 CIG2 } \\
\text { RAD3 PMR1 RAD17 ARPP2 CCH1 MAL3 SPT6 TEA4 HUS1 KIN1 HAT1 } \\
\text { SPAC821.05 CTF18 DAD2 POM1 DAD5 ASK1 REB1 DAD3 ALP14 PXL1 } \\
\text { YAM8 SPAC4G8.04 FKH2 RES2 RGA8 RGA7 PPA2 ALP13 SPCC1795.10C } \\
\text { CBF11 SRE1 MPR1 PTC2 }\end{array}$ \\
\hline 50794 & regulation of cellular process & $3,08 \mathrm{E}-09$ & $9,47 \mathrm{E}-02$ & $46 / 9747.4 \%$ & $1088 / 523220.7 \%$ & $\begin{array}{c}\text { ARP42 SPCC550.03C SPT6 MAL3 CCH1 TEA4 HUS1 KIN1 MIK1 HAT1 } \\
\text { SPAC3A12.13C RAD9 LIZ1 SPAC821.05 VGL1 RNC1 ASE1 CLP1 MPH1 } \\
\text { POM1 RAD26 REB1 ALP14 PXL1 PPK26 YAM8 SPAC664.03 SPAC4G8.04 } \\
\text { RQH1 FKH2 TIF213 RGA8 RES2 RGA7 NUP132 PPA2 ALP13 CIG2 RAD1 } \\
\text { RAD3 CBF11 SRE1 PMR1 MPR1 PTC2 RAD17 }\end{array}$ \\
\hline 31573 & intra-S DNA damage checkpoint & $3,45 \mathrm{E}-09$ & $1,25 \mathrm{E}-01$ & $7 / 977.2 \%$ & $15 / 52320.2 \%$ & RAD1 RAD3 HUS1 RQH1 RAD9 RAD17 RAD26 \\
\hline 50789 & regulation of biological process & $6,63 \mathrm{E}-09$ & $1,35 \mathrm{E}-01$ & $46 / 9747.4 \%$ & $1113 / 523221.2 \%$ & $\begin{array}{c}\text { ARP42 SPCC550.03C SPT6 MAL3 CCH1 TEA4 HUS1 KIN1 MIK1 HAT1 } \\
\text { SPAC3A12.13C RAD9 LIZ1 SPAC821.05 VGL1 RNC1 ASE1 CLP1 MPH1 } \\
\text { POM1 RAD26 REB1 ALP14 PXL1 PPK26 YAM8 SPAC664.03 SPAC4G8.04 } \\
\text { RQH1 FKH2 TIF213 RGA8 RES2 RGA7 NUP132 PPA2 ALP13 CIG2 RAD1 } \\
\text { RAD3 CBF11 SRE1 PMR1 MPR1 PTC2 RAD17 }\end{array}$ \\
\hline 75 & cell cycle checkpoint & 1,99E-08 & 1,74E-01 & $13 / 9713.4 \%$ & $98 / 52321.8 \%$ & $\begin{array}{l}\text { ALP14 RQH1 HUS1 MIK1 RAD9 NUP132 RAD1 RAD3 ASE1 CLP1 MPH1 } \\
\text { RAD26 RAD17 }\end{array}$ \\
\hline 51313 & $\begin{array}{c}\text { attachment of spindle microtubules to } \\
\text { chromosome }\end{array}$ & $4,79 \mathrm{E}-08$ & $2,06 \mathrm{E}-01$ & $9 / 979.2 \%$ & $42 / 52320.8 \%$ & ALP14 SPC19 CTF18 MAL3 CLP1 DAD2 DAD5 DAD3 ASK1 \\
\hline 34453 & microtubule anchoring & $7,38 \mathrm{E}-08$ & $2,06 \mathrm{E}-01$ & $9 / 979.2 \%$ & $44 / 52320.8 \%$ & ALP14 SPC19 CTF18 MAL3 CLP1 DAD2 DAD5 DAD3 ASK1 \\
\hline 7051 & spindle organization & $9,09 \mathrm{E}-08$ & $2,06 \mathrm{E}-01$ & $9 / 979.2 \%$ & $45 / 52320.8 \%$ & ALP14 SPC19 MAL3 ASE1 DAD2 DAD5 DAD3 ASK1 MTO1 \\
\hline 48519 & negative regulation of biological process & 1,32E-07 & $2,06 \mathrm{E}-01$ & $21 / 9721.6 \%$ & $309 / 52325.9 \%$ & $\begin{array}{l}\text { ALP14 PXL1 ARP42 RQH1 HUS1 MIK1 HAT1 RAD9 PPA2 NUP132 RAD1 } \\
\text { VGL1 RNC1 CLP1 CBF11 SRE1 MPH1 POM1 RAD26 RAD17 REB1 }\end{array}$ \\
\hline 32507 & maintenance of protein location & 1,99E-07 & $2,06 \mathrm{E}-01$ & $10 / 9710.3 \%$ & $64 / 52321.2 \%$ & ALP14 SPC19 CTF18 MAL3 CLP1 SPCC1795.10C DAD2 DAD5 DAD3 ASK1 \\
\hline 45185 & manteinance of protein location & $2,31 \mathrm{E}-07$ & $2,06 \mathrm{E}-01$ & $10 / 9710.3 \%$ & $65 / 52321.2 \%$ & ALP14 SPC19 CTF18 MAL3 CLP1 SPCC1795.10C DAD2 DAD5 DAD3 ASK1 \\
\hline 48523 & negative regulation of cellular process & $2,89 \mathrm{E}-07$ & $2,06 \mathrm{E}-01$ & $20 / 9720.6 \%$ & $295 / 52325.6 \%$ & $\begin{array}{c}\text { ALP14 PXL1 ARP42 RQH1 HUS1 MIK1 HAT1 RAD9 PPA2 NUP132 RAD1 } \\
\text { VGL1 RNC1 CLP1 CBF11 MPH1 POM1 RAD26 RAD17 REB1 }\end{array}$ \\
\hline 7010 & cytoskeleton organization & $2,95 \mathrm{E}-07$ & $2,06 \mathrm{E}-01$ & $17 / 9717.5 \%$ & $215 / 52324.1 \%$ & $\begin{array}{c}\text { ALP14 PXL1 MAL3 TEA4 KIN1 RGA8 RGA7 SPC19 CTF18 ASE1 CLP1 DAD2 } \\
\text { POM1 DAD55 DAD3 MTO1 ASK1 }\end{array}$ \\
\hline 7052 & mitotic spindle organization & $2,99 \mathrm{E}-07$ & $2,06 \mathrm{E}-01$ & $7 / 977.2 \%$ & $26 / 52320.4 \%$ & ALP14 SPC19 ASE1 DAD2 DAD5 DAD3 ASK1 \\
\hline 51651 & maintenance of location in cell & $3,11 \mathrm{E}-07$ & $2,06 \mathrm{E}-01$ & $10 / 9710.3 \%$ & $67 / 52321.2 \%$ & ALP14 SPC19 CTF18 MAL3 CLP1 SPCC1795.10C DAD2 DAD5 DAD3 ASK1 \\
\hline 51235 & maintenance of location & $3,59 \mathrm{E}-07$ & $2,06 \mathrm{E}-01$ & $10 / 9710.3 \%$ & $68 / 52321.2 \%$ & ALP14 SPC19 CTF18 MAL3 CLP1 SPCC1795.10C DAD2 DAD5 DAD3 ASK1 \\
\hline 7080 & mitotic metaphase plate congression & $3,65 \mathrm{E}-07$ & $2,06 \mathrm{E}-01$ & $6 / 976.1 \%$ & $17 / 52320.3 \%$ & $S P C 19$ CLP1 DAD2 DAD5 DAD3 ASK1 \\
\hline 51310 & metaphase plate congression & $3,65 \mathrm{E}-07$ & $2,45 \mathrm{E}-01$ & $6 / 976.1 \%$ & $17 / 52320.3 \%$ & SPC19 CLP1 DAD2 DAD5 DAD3 ASK1 \\
\hline 51303 & $\begin{array}{c}\text { establishment of chromosome } \\
\text { localization }\end{array}$ & $3,65 \mathrm{E}-07$ & $2,45 \mathrm{E}-01$ & $6 / 976.1 \%$ & $17 / 52320.3 \%$ & SPC19 CLP1 DAD2 DAD5 DAD3 ASK1 \\
\hline 50000 & chromosome localization & $3,65 \mathrm{E}-07$ & $3,29 \mathrm{E}-01$ & $6 / 976.1 \%$ & $17 / 52320.3 \%$ & $S P C 19$ CLP1 DAD2 DAD5 DAD3 ASK1 \\
\hline 31134 & sister chromatide biorientation & $3,65 \mathrm{E}-03$ & $7,04 \mathrm{E}-01$ & $6 / 976.1 \%$ & $17 / 52320.3 \%$ & SPC19 CLP1 DAD2 DAD5 DAD3 ASK1 \\
\hline 42729 & DASH complex & $4,63 \mathrm{E}-07$ & $7,39 \mathrm{E}-01$ & $5 / 975.1 \%$ & $10 / 52320.1 \%$ & SPC19 DAD2 DAD5 DAD3 ASK1 \\
\hline 794 & condensed nuclear chromosome & $4,75 \mathrm{E}-07$ & $8,91 \mathrm{E}-01$ & $10 / 9710.3 \%$ & $70 / 52321.3 \%$ & ALP14 SPC19 RAD1 HUS1 DAD2 MPH1 RAD9 DAD5 DAD3 ASK1 \\
\hline
\end{tabular}




\begin{tabular}{|c|c|c|c|c|c|c|}
\hline GO ID & Descripción & $p$-val & corr $p$-val & cluster freq & total freq & Genes \\
\hline 51726 & regulation of cell cycle & $6,65 \mathrm{E}-07$ & $1,22 \mathrm{E}+00$ & $19 / 9719.5 \%$ & $282 / 52325.3 \%$ & $\begin{array}{c}\text { ALP14 MAL3 RQH1 HUS1 MIK1 RAD9 LIZ1 NUP132 PPA2 CIG2 RAD1 RAD3 } \\
\text { ASE1 CLP1 MPH1 POM1 MPR1 RAD26 RAD17 }\end{array}$ \\
\hline 793 & condensed chromosome & $1,48 \mathrm{E}-06$ & $1,22 \mathrm{E}+00$ & $11 / 9711.3 \%$ & $98 / 52321.8 \%$ & ALP14 SPC19 RAD1 CLP1 HUS1 DAD2 MPH1 RAD9 DAD5 DAD3 ASK1 \\
\hline 16272 & prefoldin complex & 1,62E-06 & $1,36 \mathrm{E}+00$ & $4 / 974.1 \%$ & $6 / 52320.1 \%$ & BOB1 SPAC227.10 SPAC3A11.13 SPAC227.05 \\
\hline 31323 & regulation of cellular metabolic process & $2,03 E-06$ & $1,64 \mathrm{E}+00$ & $30 / 9730.9 \%$ & $672 / 523212.8 \%$ & $\begin{array}{c}\text { ARP42 SPCC550.03C SPT6 HUS1 MIK1 HAT1 SPAC3A12.13C RAD9 } \\
\text { SPAC821.05 VGL1 RNC1 CLP1 REB1 RAD26 PXL1 SPAC664.03 } \\
\text { SPAC4G8.04 RQH1 FKH2 TIF213 RGA8 RES2 RGA7 ALP13 RAD1 CIG2 } \\
\text { CBF11 SRE1 PTC2 RAD17 }\end{array}$ \\
\hline 19222 & regulation of metabolic process & $2,95 \mathrm{E}-06$ & $2,29 \mathrm{E}+00$ & $30 / 9730.9 \%$ & $684 / 523213.0 \%$ & $\begin{array}{c}\text { ARP42 SPCC550.03C SPT6 HUS1 MIK1 HAT1 SPAC3A12.13C RAD9 } \\
\text { SPAC821.05 VGL1 RNC1 CLP1 REB1 RAD26 PXL1 SPAC664.03 } \\
\text { SPAC4G8.04 RQH1 FKH2 TIF213 RGA8 RES2 RGA7 ALP13 RAD1 CIG2 } \\
\text { CBF11 SRE1 PTC2 RAD17 } \\
\end{array}$ \\
\hline 51640 & organelle localization & $2,98 \mathrm{E}-06$ & $2,62 \mathrm{E}+00$ & $10 / 9710.3 \%$ & $85 / 52321.6 \%$ & SPC19 SPBC16H5.08C DML1 ASE1 CLP1 DAD2 DAD5 DAD3 ASK1 MTO1 \\
\hline 51053 & $\begin{array}{c}\text { negative regulation of DNA metabolic } \\
\text { process }\end{array}$ & $3,45 \mathrm{E}-06$ & $2,77 \mathrm{E}+00$ & $8 / 978.2 \%$ & $51 / 52320.9 \%$ & RAD1 HUS1 RQH1 MIK1 RAD9 REB1 RAD17 RAD26 \\
\hline 226 & microtubule cytoskeleton organization & $4,29 \mathrm{E}-06$ & $2,77 \mathrm{E}+00$ & $11 / 9711.3 \%$ & $109 / 52322.0 \%$ & ALP14 SPC19 CTF18 MAL3 ASE1 CLP1 DAD2 DAD5 DAD3 ASK1 MTO1 \\
\hline 30896 & checkpoint clamp complex & $6,18 \mathrm{E}-06$ & $3,73 \mathrm{E}+00$ & $3 / 973.0 \%$ & $3 / 52320.0 \%$ & RAD1 HUS1 RAD9 \\
\hline 51656 & establishment of organelle localization & $7,27 \mathrm{E}-06$ & $4,20 \mathrm{E}+00$ & $9 / 979.2 \%$ & $74 / 52321.4 \%$ & SPC19 SPBC16H5.08C ASE1 CLP1 DAD2 DAD5 DAD3 ASK1 MTO1 \\
\hline 77 & DNA damage checkpoint & $8,13 \mathrm{E}-06$ & $4,38 \mathrm{E}+00$ & $7 / 977.2 \%$ & $41 / 52320.7 \%$ & RAD1 RAD3 HUS1 RQH1 RAD9 RAD17 RAD26 \\
\hline 31570 & DNA integrity checkpoint & $8,17 \mathrm{E}-06$ & $4,38 \mathrm{E}+00$ & $8 / 978.2 \%$ & $57 / 52321.0 \%$ & RAD1 RAD3 HUS1 RQH1 MIK1 RAD9 RAD17 RAD26 \\
\hline 42770 & $\begin{array}{l}\text { DNA damage response, signal } \\
\text { transduction }\end{array}$ & $1,13 \mathrm{E}-05$ & $4,95 \mathrm{E}+00$ & $7 / 977.2 \%$ & $43 / 52320.8 \%$ & RAD1 RAD3 HUS1 RQH1 RAD9 RAD17 RAD26 \\
\hline 7346 & regulation of mitotic cell cycle & $1,31 \mathrm{E}-05$ & $4,95 \mathrm{E}+00$ & $13 / 9713.4 \%$ & $171 / 52323.2 \%$ & $\begin{array}{l}\text { ALP14 MAL3 HUS1 MIK1 LIZ1 NUP132 PPA2 CIG2 CLP1 MPH1 POM1 MPR1 } \\
\text { RAD26 }\end{array}$ \\
\hline 76 & DNA replication checkpoint & $1,44 \mathrm{E}-05$ & $4,95 \mathrm{E}+00$ & $6 / 976.1 \%$ & $30 / 52320.5 \%$ & RAD1 HUS1 MIK1 RAD9 RAD17 RAD26 \\
\hline 32297 & $\begin{array}{c}\text { negative regulation of DNA-dependent } \\
D N A \text { replication initiation }\end{array}$ & $1,44 \mathrm{E}-05$ & $4,95 \mathrm{E}+00$ & $6 / 976.1 \%$ & $30 / 52320.5 \%$ & RAD1 HUS1 MIK1 RAD9 RAD17 RAD26 \\
\hline 7017 & microtubule based-process & $1,75 \mathrm{E}-05$ & $6,21 \mathrm{E}+00$ & $11 / 9711.3 \%$ & $126 / 52322.4 \%$ & ALP14 SPC19 CTF18 MAL3 ASE1 CLP1 DAD2 DAD5 DAD3 ASK1 MTO1 \\
\hline 30174 & $\begin{array}{l}\text { regulation of } D N A-d e p e n d e n t D N A \\
\text { replication initiation }\end{array}$ & $1,76 \mathrm{E}-05$ & $6,25 \mathrm{E}+00$ & $6 / 976.1 \%$ & $31 / 52320.5 \%$ & RAD1 HUS1 MIK1 RAD9 RAD17 RAD26 \\
\hline 228 & nuclear chromosome & $1,79 \mathrm{E}-05$ & $6,25 \mathrm{E}+00$ & $19 / 9719.5 \%$ & $352 / 52326.7 \%$ & $\begin{array}{c}\text { ALP14 ARP42 SPT6 RQH1 ARP8 HUS1 PHT1 HAT1 RAD9 ALP13 RAD1 } \\
\text { SPC19 RAD3 DAD2 MPH1 DAD5 DAD3 RAD17 ASK1 }\end{array}$ \\
\hline 8156 & negative regulation of DNA replication & $1,79 \mathrm{E}-05$ & $6,25 \mathrm{E}+00$ & $7 / 977.2 \%$ & $46 / 52320.8 \%$ & RAD1 HUS1 MIK1 RAD9 REB1 RAD17 RAD26 \\
\hline 19219 & $\begin{array}{c}\text { regulation of nucleobase, nucleoside, } \\
\text { nucleotide and nucleic acid metabolic } \\
\text { process }\end{array}$ & $2,30 \mathrm{E}-05$ & $6,47 \mathrm{E}+00$ & $23 / 9723.7 \%$ & $494 / 52329.4 \%$ & $\begin{array}{c}\text { ARP42 PXL1 SPT6 SPAC664.03 SPAC4G8.04 RQH1 HUS1 FKH2 MIK1 HAT1 } \\
\text { RAD9 RGA8 RES2 RGA7 ALP13 RAD1 VGL1 RNC1 CBF11 SRE1 RAD26 } \\
\text { RAD17 REB1 }\end{array}$ \\
\hline 278 & mitotic cell cycle & $2,42 \mathrm{E}-05$ & $6,56 \mathrm{E}+00$ & $13 / 9713.4 \%$ & $181 / 52323.4 \%$ & $\begin{array}{c}\text { ALP14 RQH1 FKH2 RES2 SPC19 CIG2 ASE1 CLP1 DAD2 DAD5 RAD26 } \\
\text { ASK1 DAD3 }\end{array}$ \\
\hline 43234 & protein complex & $2,47 \mathrm{E}-05$ & $7,32 \mathrm{E}+00$ & $42 / 9743.2 \%$ & $1268 / 523224.2 \%$ & $\begin{array}{c}\text { ARP42 SPT6 MAL3 TEA4 HUS1 HAT1 SPAC3A12.13C SPAC227.05 RAD9 } \\
\text { SPAC821.05 CTF18 ASE1 CLP1 DAD2 VPS32 MPH1 SPAC3A11.13 DAD5 } \\
\text { DAD3 ASK1 ALP14 BOB1 PPK26 SPAC227.10 SPAC664.03 ARP8 RQH1 } \\
\text { FKH2 PHT1 RES2 SPAC2F3.02 NUP132 ALP13 VPS8 SPC19 RAD1 } \\
\text { SPBC3H7.03C RAD3 CPD1 SRE1 PTC2 RAD17 }\end{array}$ \\
\hline
\end{tabular}




\begin{tabular}{|c|c|c|c|c|c|c|}
\hline GO ID & Descripción & $p$-val & corr $p$-val & cluster freq & total freq & Genes \\
\hline 777 & condensed chromosome kinetochore & $2,48 \mathrm{E}-05$ & $7,35 \mathrm{E}+00$ & $8 / 978.2 \%$ & $66 / 52321.2 \%$ & ALP14 SPC19 CLP1 DAD2 MPH1 DAD5 DAD3 ASK1 \\
\hline 80090 & regulation of primary metabolic process & $2,62 \mathrm{E}-05$ & $7,86 \mathrm{E}+00$ & $27 / 9727.8 \%$ & $645 / 523212.3 \%$ & $\begin{array}{c}\text { ARP42 SPCC550.03C SPT6 HUS1 MIK1 HAT1 SPAC3A12.13C RAD9 } \\
\text { SPAC821.05 VGL1 RNC1 REB1 RAD26 PXL1 SPAC664.03 RQH1 } \\
\text { SPAC4G8.04 TIF213 FKH2 RGA8 RES2 RGA7 ALP13 RAD1 CBF11 SRE1 } \\
\text { RAD17 }\end{array}$ \\
\hline 51171 & $\begin{array}{l}\text { regulation of nitrogen compound } \\
\text { metabolic process }\end{array}$ & $2,71 \mathrm{E}-05$ & $8,06 \mathrm{E}+00$ & $23 / 9723.7 \%$ & $499 / 52329.5 \%$ & $\begin{array}{c}\text { ARP42 PXL1 SPT6 SPAC664.03 SPAC4G8.04 RQH1 HUS1 FKH2 MIK1 HAT1 } \\
\text { RAD9 RGA8 RES2 RGA7 ALP13 RAD1 VGL1 RNC1 CBF11 SRE1 RAD26 } \\
\text { RAD17 REB1 }\end{array}$ \\
\hline 5694 & chromosome & $3,09 E-05$ & $9,34 \mathrm{E}+00$ & $21 / 9721.6 \%$ & $433 / 52328.2 \%$ & $\begin{array}{l}\text { ALP14 ARP42 SPT6 RQH1 ARP8 HUS1 PHT1 HAT1 RAD9 ALP13 RAD1 } \\
\text { SPC19 CTF18 RAD3 CLP1 DAD2 MPH1 DAD5 DAD3 RAD17 ASK1 } \\
\end{array}$ \\
\hline 44454 & nuclear chromosome part & $3,16 \mathrm{E}-05$ & $9,37 \mathrm{E}+00$ & $18 / 9718.5 \%$ & $334 / 52326.3 \%$ & $\begin{array}{l}\text { ALP14 ARP42 SPT6 RQH1 ARP8 HUS1 PHT1 HAT1 RAD9 ALP13 RAD1 } \\
\text { SPC19 DAD2 MPH1 DAD5 DAD3 RAD17 ASK1 }\end{array}$ \\
\hline 776 & kinetochore & $3,44 \mathrm{E}-05$ & $1,08 \mathrm{E}+01$ & $8 / 978.2 \%$ & $69 / 52321.3 \%$ & ALP14 SPC19 CLP1 DAD2 MPH1 DAD5 DAD3 ASK1 \\
\hline 778 & $\begin{array}{c}\text { condensed nuclear chromosome } \\
\text { kinetochore }\end{array}$ & $3,60 \mathrm{E}-05$ & $1,08 \mathrm{E}+01$ & $7 / 977.2 \%$ & $51 / 52320.9 \%$ & ALP14 SPC19 DAD2 MPH1 DAD5 DAD3 ASK1 \\
\hline 51052 & regulation of DNA metabolic process & $4,25 \mathrm{E}-05$ & $1,11 \mathrm{E}+01$ & $8 / 978.2 \%$ & $71 / 52321.3 \%$ & RAD1 HUS1 RQH1 MIK1 RAD9 REB1 RAD17 RAD26 \\
\hline 35466 & regulation of signaling pathway & $4,34 \mathrm{E}-05$ & $1,17 \mathrm{E}+01$ & $9 / 979.2 \%$ & $92 / 52321.7 \%$ & PXL1 RNC1 CCH1 CLP1 SPAC4G8.04 RGA8 PMR1 RGA7 PTC2 \\
\hline 90329 & $\begin{array}{l}\text { regulation of DNA-dependent DNA } \\
\text { replication }\end{array}$ & $5,08 \mathrm{E}-05$ & $1,17 \mathrm{E}+01$ & $6 / 976.1 \%$ & $37 / 52320.7 \%$ & RAD1 HUS1 MIK1 RAD9 RAD17 RAD26 \\
\hline 779 & $\begin{array}{c}\text { condensed chromosome, centromeric } \\
\text { region }\end{array}$ & $5,21 \mathrm{E}-05$ & $1,26 \mathrm{E}+01$ & $8 / 978.2 \%$ & $73 / 52321.3 \%$ & ALP14 SPC19 CLP1 DAD2 MPH1 DAD5 DAD3 ASK1 \\
\hline 44427 & chromosomal part & $5,43 \mathrm{E}-05$ & $1,80 \mathrm{E}+01$ & $20 / 9720.6 \%$ & $415 / 52327.9 \%$ & $\begin{array}{c}\text { ALP14 ARP42 SPT6 RQH1 ARP8 HUS1 PHT1 HAT1 RAD9 ALP13 RAD1 } \\
\text { SPC19 CTF18 CLP1 DAD2 MPH1 DAD5 DAD3 RAD17 ASK1 } \\
\end{array}$ \\
\hline 6275 & regulation of DNA replication & $5,94 \mathrm{E}-05$ & $1,82 \mathrm{E}+01$ & $7 / 977.2 \%$ & $55 / 52321.0 \%$ & RAD1 HUS1 MIK1 RAD9 REB1 RAD17 RAD26 \\
\hline 780 & $\begin{array}{c}\text { condensed nuclear chromosome } \\
\text { centromeric region }\end{array}$ & $5,94 \mathrm{E}-05$ & $2,40 \mathrm{E}+01$ & $7 / 977.2 \%$ & $55 / 52321.0 \%$ & ALP14 SPC19 DAD2 MPH1 DAD5 DAD3 ASK1 \\
\hline 22403 & cell cycle phase & $6,50 \mathrm{E}-05$ & $3,11 \mathrm{E}+01$ & $17 / 9717.5 \%$ & $320 / 52326.1 \%$ & $\begin{array}{c}\text { ALP14 MAL3 RQH1 FKH2 RES2 SPC19 CIG2 CTF18 RAD3 ASE1 CLP1 DAD2 } \\
\text { DAD5 DAD3 RAD26 MTO1 ASK1 } \\
\end{array}$ \\
\hline 45786 & negative regulation of cell cycle & $9,40 \mathrm{E}-05$ & $3,27 \mathrm{E}+01$ & $7 / 977.2 \%$ & $59 / 52321.1 \%$ & ALP14 CLP1 MIK1 MPH1 POM1 PPA2 NUP132 \\
\hline 7021 & tubulin complex assembly & $9,64 \mathrm{E}-05$ & $3,30 \mathrm{E}+01$ & $4 / 974.1 \%$ & $14 / 52320.2 \%$ & BOB1 SPAC227.10 SPAC3A11.13 SPAC227.05 \\
\hline 15631 & tubulin binding & $1,30 \mathrm{E}-04$ & $3,30 \mathrm{E}+01$ & $4 / 974.1 \%$ & $15 / 52320.2 \%$ & ALP14 MAL3 ASE1 MTO1 \\
\hline 43086 & negative regulation of catalitic activity & $1,70 \mathrm{E}-04$ & $3,78 \mathrm{E}+01$ & $4 / 974.1 \%$ & $16 / 52320.3 \%$ & PXL1 RNC1 CLP1 PTC2 \\
\hline 22402 & cell cycle process & 1,82E-04 & $3,89 \mathrm{E}+01$ & $18 / 9718.5 \%$ & $382 / 52327.3 \%$ & $\begin{array}{c}\text { ALP14 PXL1 MAL3 RQH1 FKH2 RES2 SPC19 CIG2 CTF18 RAD3 ASE1 CLP1 } \\
\text { DAD2 DAD5 DAD3 RAD26 MTO1 ASK1 }\end{array}$ \\
\hline 9966 & regulation of signal transduction & $1,89 \mathrm{E}-04$ & $3,89 \mathrm{E}+01$ & 9/979.2\% & $111 / 52322.1 \%$ & PXL1 RNC1 CCH1 CLP1 SPAC4G8.04 RGA8 PMR1 RGA7 PTC2 \\
\hline 23051 & regulation of signaling process & $1,89 \mathrm{E}-04$ & $3,99 \mathrm{E}+01$ & $9 / 979.2 \%$ & $111 / 52322.1 \%$ & PXL1 RNC1 CCH1 CLP1 SPAC4G8.04 RGA8 PMR1 RGA7 PTC2 \\
\hline 44092 & $\begin{array}{l}\text { negative regulation of molecular } \\
\text { function }\end{array}$ & $2,20 \mathrm{E}-04$ & $4,04 \mathrm{E}+01$ & $4 / 974.1 \%$ & $17 / 52320.3 \%$ & PXL1 RNC1 CLP1 PTC2 \\
\hline 10646 & regulation of cell communication & $2,32 \mathrm{E}-04$ & $4,13 \mathrm{E}+01$ & $9 / 979.2 \%$ & $114 / 52322.1 \%$ & PXL1 RNC1 CCH1 CLP1 SPAC4G8.04 RGA8 PMR1 RGA7 PTC2 \\
\hline 33036 & macromolecule localization & $2,32 \mathrm{E}-04$ & $4,21 \mathrm{E}+01$ & $23 / 9723.7 \%$ & $573 / 523210.9 \%$ & $\begin{array}{c}\text { ALP14 PXL1 SPAC2C4.05 SST2 MAL3 TEA4 SPAC2F3.02 NUP132 VPS8 } \\
\text { SPC19 CTF18 VGL1 ASE1 CLP1 SPCC1795.10C DAD2 VPS32 MPH1 POM1 } \\
\text { DAD5 DAD3 MTO1 ASK1 }\end{array}$ \\
\hline
\end{tabular}




\begin{tabular}{|c|c|c|c|c|c|c|}
\hline GO ID & Descripción & $p$-val & corr $p$-val & cluster freq & total freq & Genes \\
\hline 32991 & macromolecular complex & $2,42 \mathrm{E}-04$ & $4,47 \mathrm{E}+01$ & $49 / 9750.5 \%$ & $1728 / 523233.0 \%$ & $\begin{array}{c}\text { SPAC227.05 SPAC3A12.13C RAD9 ASE1 CLP1 MPH1 SPAC3A11.13 RPSO01 } \\
\text { BOB1 PPRK26 SPAC664.03 SPAC227.10 RQH1 ARPP PHT1 RPL3801 NUP132 } \\
\text { VPS8 RAD1 SPC19 RAD3 CPD1 RAD 17 ARP42 MAL3 SPT6 TEA4 HUS1 } \\
\text { HAT1 SPAC821.05 CTF18 RPS2801 SPCC825.05C VPS32 DAD2 DAD5 ASK } \\
\text { DAD3 ALP14 CWF12 FKH2 RES2 SPAC2F3.02 ALP13 SPBC3H7.03C RPL502 } \\
\text { RPS802 SRE1 PTC2 }\end{array}$ \\
\hline 8104 & protein localization & $2,48 \mathrm{E}-04$ & $4,63 \mathrm{E}+01$ & $21 / 9721.6 \%$ & $500 / 52329.5 \%$ & $\begin{array}{c}\text { ALP14 PXL1 SPAC2C4.05 SST2 MAL3 TEA4 SPAC2F3.02 VPS8 SPC19 } \\
\text { CTF18 ASE1 CLP1 SPCC1795.10C DAD2 VPS32 MPH1 POM1 DAD5 DAD3 } \\
\text { MTO1 ASK1 }\end{array}$ \\
\hline 23052 & signaling & $2,58 \mathrm{E}-04$ & $4,86 \mathrm{E}+01$ & $17 / 9717.5 \%$ & $358 / 52326.8 \%$ & $\begin{array}{c}\text { ALP14 PPK26 RQH1 HUS1 MIK1 RAD9 NUP132 PPA2 RAD1 RAD3 SRE1 } \\
\text { MPH1 POM1 MPR1 PTC2 RAD26 RAD17 }\end{array}$ \\
\hline 65008 & regulation of biological quality & $2,66 \mathrm{E}-04$ & $4,86 \mathrm{E}+01$ & $16 / 9716.4 \%$ & $325 / 52326.2 \%$ & $\begin{array}{c}\text { ALP14 MAL3 YAM8 TEA4 RQH1 KIN1 SPC19 CTF18 CLP1 SPCC1795.10C } \\
\text { DAD2 PMR1 POM1 DAD5 ASK1 DAD3 }\end{array}$ \\
\hline 51783 & regulation of nuclear division & $2,86 \mathrm{E}-04$ & $4,90 \mathrm{E}+01$ & $6 / 976.1 \%$ & $50 / 52320.9 \%$ & ALP14 MAL3 CBF11 MPH1 LIZ1 NUP132 \\
\hline 60255 & $\begin{array}{c}\text { regulation of macromolecule metabolic } \\
\text { process }\end{array}$ & $3,00 \mathrm{E}-04$ & $4,63 \mathrm{E}-03$ & $23 / 9723.7 \%$ & $583 / 523211.1 \%$ & $\begin{array}{c}\text { SPCC550.03C ARP42 SPT6 SPAC664.03 RQH1 HUS1 FKH2 TIF213 MIK1 } \\
\text { HAT1 SPAC3A12.13C RAD9 RES2 ALP13 SPAC821.05 RAD1 VGL1 RNC1 } \\
\text { CBF11 SRE1 RAD26 RAD17 REB1 }\end{array}$ \\
\hline 6469 & $\begin{array}{c}\text { negative regulation of protein kinase } \\
\text { activity }\end{array}$ & $3,23 \mathrm{E}-04$ & $4,86 \mathrm{E}-03$ & $3 / 973.0 \%$ & $8 / 52320.1 \%$ & RNC1 CLP1 PTC2 \\
\hline 33673 & negative regulation of kinase activity & $3,23 \mathrm{E}-04$ & $4,86 \mathrm{E}-03$ & $3 / 973.0 \%$ & $8 / 52320.1 \%$ & RNC1 CLP1 PTC2 \\
\hline 51179 & localization & $3,30 \mathrm{E}-04$ & $4,90 \mathrm{E}-03$ & $34 / 9735.0 \%$ & $1044 / 523219.9 \%$ & $\begin{array}{c}\text { AAP1 SPBC16H5.08C SPAC2C4.05 SPAC222.14C SST2 CCH1 MAL3 TEA4 } \\
\text { LIZ1 VGL1 CTF18 SPAC22F8.04 DML } 1 \text { ASE1 CLP1 DAD2 VPS } 32 \text { MPH1 } \\
\text { POM1 DAD5 DAD } 18 \text { ASK1 MTO1 SPBPB2B2.01 ALP14 PXL1 YAM8 } \\
\text { SPAC4G8.04 SPAC2F3.02 NUP132 VPS8 SPC19 SPCC1795.10C PMR1 }\end{array}$ \\
\hline
\end{tabular}




\begin{tabular}{|c|c|c|c|c|}
\hline Ciclo celular (22/114) & Señalización celular (21/114) & Actividad fosfatasa (fosforilación) $(5 / 114)$ & Microtúbulos (3/114) & Nucleolo (15/114) \\
\hline SPBC16G5.15C & SPAC5D6.13 & $S P B C 776.02 C$ & SPAC18G6.15 & SPBP8B7.28C \\
\hline SPBC336.03 & SPBC336.03 & SPAC1782.09C & SPAPB1A10.09 & SPBC16C6.03C \\
\hline SPAC18G6.15 & SPAC13A11.01C & SPBC609.02 & SPCC895.07 & $S P B C 16 D 10.11 C$ \\
\hline SPAPB1A10.09 & $S P B C 216.05$ & $S P B C 16 H 5.07 C$ & & SPAC890.05 \\
\hline SPAP14E8.02 & SPBC725.02 & SPCC1223.11 & & SPBC776.17 \\
\hline$S P B C 216.05$ & SPBC106.01 & & & SPAC20G4.04C \\
\hline SPBC725.02 & SPAC20G4.04C & & & SPAC22F3.08C \\
\hline$S P B C 106.01$ & SPAC2F7.03C & & & $S P B C 1539.10$ \\
\hline SPAC20G4.04C & SPAC3C7.06C & & & SPCC613.06 \\
\hline SPBC902.02C & SPAPB1E7.06C & & & SPAC589.10C \\
\hline SPAPB1E7.06C & SPBC23G7.08C & & & SPAC12G12.13C \\
\hline SPAC926.03 & SPCC1322.12C & & & SPAC1782.09C \\
\hline SPCC895.07 & SPAC4F10.04 & & & SPAC1952.02 \\
\hline SPAPB17E12.04C & $S P B C 776.02 C$ & & & SPBC9B6.07 \\
\hline SPCC1322.12C & SPAC1782.09C & & & $S P B C 25 H 2.15$ \\
\hline$S P B C 776.02 C$ & SPAC9E9.08 & & & \\
\hline SPAC12G12.13C & SPBC609.02 & & & \\
\hline SPAC1782.09C & SPBC1718.07C & & & \\
\hline SPAC9E9.08 & SPCC830.06 & & & \\
\hline$S P B C 1718.07 C$ & SPBC16H5.07C & & & \\
\hline SPBC16H5.07C & SPAC664.07C & & & \\
\hline SPAC9E9.13 & SPCC1223.11 & & & \\
\hline SPAC664.07C & SPAC14C4.13 & & & \\
\hline SPAC14C4.13 & & & & \\
\hline
\end{tabular}


Tabla S9. Análisis funcional de la red de interacciones genéticas de $c d c 2-3 w$ con BiNGO

\begin{tabular}{|c|c|c|c|c|c|c|}
\hline GO ID & Descripción & $p$-val & corr p-val & cluster freq & total freq & Genes \\
\hline 75 & cell cycle checkpoint & $6,13 \mathrm{E}-10$ & $6,42 \mathrm{E}-07$ & $14 / 8915.7 \%$ & $98 / 52321.8 \%$ & $\begin{array}{c}\text { ALP14 HUS1 EME1 ZFS1 RAD9 CID14 DIS2 RAD3 ASE1 CLP1 } \\
\text { BUB1 MPH1 RAD26 RAD17 }\end{array}$ \\
\hline 51726 & regulation of cell cycle & $2,97 \mathrm{E}-08$ & $1,55 \mathrm{E}-05$ & $20 / 8922.4 \%$ & $282 / 52325.3 \%$ & $\begin{array}{l}\text { ALP14 MAL3 HUS1 EME1 ZFS1 RAD9 PPA2 CID14 DIS2 EFC25 } \\
\text { RAD3 ASE1 CLP1 BUB1 MPH1 POM1 WOS2 MPR1 RAD26 RAD17 }\end{array}$ \\
\hline 31573 & intra-S-DNA damage checkpoint & $9,05 \mathrm{E}-08$ & $3,16 \mathrm{E}-05$ & $6 / 896.7 \%$ & $15 / 52320.2 \%$ & RAD3 EME1 HUS1 RAD9 RAD17 RAD26 \\
\hline 7346 & regulation of mitotic cell cycle & $1,30 \mathrm{E}-07$ & $3,41 \mathrm{E}-05$ & $15 / 8916.8 \%$ & $171 / 52323.2 \%$ & $\begin{array}{c}\text { ALP14 MAL3 HUS1 ZFS1 PPA2 CID14 DIS2 EFC25 CLP1 BUB1 } \\
\text { MPH1 POM1 WOS2 MPR1 RAD26 }\end{array}$ \\
\hline 23052 & signaling & $1,49 \mathrm{E}-06$ & $3,11 \mathrm{E}-04$ & $20 / 8922.4 \%$ & $358 / 52326.8 \%$ & $\begin{array}{c}\text { ALP14 SPAC5D6.13 HUS1 EME1 ZFS1 RAD9 PPA2 CID14 DIS2 } \\
\text { PTN1 EFC25 RAD3 PIT1 BUB1 MPH1 POM1 PTC2 MPR1 RAD26 } \\
\text { RAD17 }\end{array}$ \\
\hline 7165 & signal transduction & $2,74 \mathrm{E}-06$ & $3,58 \mathrm{E}-04$ & $19 / 8921.3 \%$ & $339 / 52326.4 \%$ & $\begin{array}{c}\text { ALP14 HUS1 EME1 ZFS1 RAD9 PPA2 CID14 DIS2 PTN1 EFC25 } \\
\text { RAD3 PIT1 BUB1 MPH1 POM1 PTC2 MPR1 RAD26 RAD17 }\end{array}$ \\
\hline 23060 & signal transmision & $2,74 \mathrm{E}-06$ & $3,58 \mathrm{E}-04$ & $19 / 8921.3 \%$ & $339 / 52326.4 \%$ & $\begin{array}{c}\text { ALP14 HUS1 EME1 ZFS1 RAD9 PPA2 CID14 DIS2 PTN1 EFC25 } \\
\text { RAD3 PIT1 BUB1 MPH1 POM1 PTC2 MPR1 RAD26 RAD17 }\end{array}$ \\
\hline 23046 & signaling process & $2,74 \mathrm{E}-06$ & $3,58 \mathrm{E}-04$ & $19 / 8921.3 \%$ & $339 / 52326.4 \%$ & $\begin{array}{c}\text { ALP14 HUS1 EME1 ZFS1 RAD9 PPA2 CID14 DIS2 PTN1 EFC25 } \\
\text { RAD3 PIT1 BUB1 MPH1 POM1 PTC2 MPR1 RAD26 RAD17 }\end{array}$ \\
\hline 77 & DNA damage checkpoint & $4,57 \mathrm{E}-06$ & $5,31 \mathrm{E}-04$ & $7 / 897.8 \%$ & $41 / 52320.7 \%$ & DIS2 RAD3 EME1 HUS1 RAD9 RAD17 RAD26 \\
\hline 45786 & negative regulation of cell cycle & $5,57 \mathrm{E}-06$ & $5,83 \mathrm{E}-04$ & $8 / 898.9 \%$ & $59 / 52321.1 \%$ & CID14 ALP14 CLP1 BUB1 ZFS1 MPH1 POM1 PPA2 \\
\hline 42770 & $\begin{array}{c}\text { DNA damge response, signal } \\
\text { transduction }\end{array}$ & $6,37 \mathrm{E}-06$ & $6,05 \mathrm{E}-04$ & $7 / 897.8 \%$ & $43 / 52320.8 \%$ & DIS2 RAD3 EME1 HUS1 RAD9 RAD17 RAD26 \\
\hline 7093 & mitotic cell cycle checkpoint & $7,47 \mathrm{E}-06$ & $6,32 \mathrm{E}-04$ & $7 / 897.8 \%$ & $44 / 52320.8 \%$ & CID14 ALP14 HUS1 BUB1 ZFS1 MPH1 RAD26 \\
\hline 10564 & regulation of cell cycle process & $7,86 \mathrm{E}-06$ & $6,32 \mathrm{E}-04$ & $10 / 8911.2 \%$ & $103 / 52321.9 \%$ & CID14 ALP14 DIS2 MAL3 CLP1 BUB1 ZFS1 MPH1 POM1 MPR1 \\
\hline 7088 & regulation of mitosis & $1,36 \mathrm{E}-05$ & $1,01 \mathrm{E}-03$ & $7 / 897.8 \%$ & $48 / 52320.9 \%$ & CID14 ALP14 DIS2 MAL3 BUB1 ZFS1 MPH1 \\
\hline 51783 & regulation of nuclear division & $1,79 \mathrm{E}-05$ & $1,25 \mathrm{E}-03$ & $7 / 897.8 \%$ & $50 / 52320.9 \%$ & CID14 ALP14 DIS2 MAL3 BUB1 ZFS1 MPH1 \\
\hline 31570 & DNA integrity checkpoint & $4,31 \mathrm{E}-05$ & $2,82 \mathrm{E}-03$ & $7 / 897.8 \%$ & $57 / 52321.0 \%$ & DIS2 RAD3 EME1 HUS1 RAD9 RAD17 RAD26 \\
\hline 7094 & $\begin{array}{c}\text { mitotic cell cycle spindle assembly } \\
\text { checkpoint }\end{array}$ & $9,18 \mathrm{E}-05$ & $4,40 \mathrm{E}-03$ & $5 / 895.6 \%$ & $28 / 52320.5 \%$ & CID14 ALP14 BUB1 ZFS1 MPH1 \\
\hline 8608 & attachment of spindle microtublules & $9,18 \mathrm{E}-05$ & $4,40 \mathrm{E}-03$ & $5 / 895.6 \%$ & $28 / 52320.5 \%$ & ALP14 CTF18 MAL3 CLP1 BUB1 \\
\hline 71173 & attachment to kinetochore & $9,18 \mathrm{E}-05$ & $4,40 \mathrm{E}-03$ & $5 / 895.6 \%$ & $28 / 52320.5 \%$ & CID14 ALP14 BUB1 ZFS1 MPH1 \\
\hline 71174 & spindle assembly checkpoint & $9,18 \mathrm{E}-05$ & $4,40 \mathrm{E}-03$ & $5 / 895.6 \%$ & $28 / 52320.5 \%$ & CID14 ALP14 BUB1 ZFS1 MPH1 \\
\hline 32507 & maintenance of protein location in cell & $9,19 \mathrm{E}-05$ & $4,40 \mathrm{E}-03$ & $7 / 897.8 \%$ & $64 / 52321.2 \%$ & ALP14 CTF18 SPCC1840.08C MAL3 CLP1 SPCC1795.10C BUB1 \\
\hline 45185 & maintenance of protein location & $1,02 \mathrm{E}-04$ & $4,40 \mathrm{E}-03$ & $7 / 897.8 \%$ & $65 / 52321.2 \%$ & ALP14 CTF18 SPCC1840.08C MAL3 CLP1 SPCC1795.10C BUB1 \\
\hline 45841 & $\begin{array}{l}\text { negative regulation of mitotic } \\
\text { methaphase/anaphase }\end{array}$ & 1,09E-04 & $4,40 \mathrm{E}-03$ & $5 / 895.6 \%$ & $29 / 52320.5 \%$ & CID14 ALP14 BUB1 ZFS1 MPH1 \\
\hline 45839 & negative regulation of mitosis & $1,09 \mathrm{E}-04$ & $4,40 \mathrm{E}-03$ & $5 / 895.6 \%$ & $29 / 52320.5 \%$ & CID14 ALP14 BUB1 ZFS1 MPH1 \\
\hline 31577 & spindle checkpoint & $1,09 \mathrm{E}-04$ & $4,40 \mathrm{E}-03$ & $5 / 895.6 \%$ & $29 / 52320.5 \%$ & CID14 ALP14 BUB1 ZFS1 MPH1 \\
\hline 51784 & negative regulation of nuclear division & 1,09E-04 & $4,40 \mathrm{E}-03$ & $5 / 895.6 \%$ & $29 / 52320.5 \%$ & CID14 ALP14 BUB1 ZFS1 MPH1 \\
\hline 51651 & maintenance of location in cell & $1,23 \mathrm{E}-04$ & $4,78 \mathrm{E}-03$ & $7 / 897.8 \%$ & $67 / 52321.2 \%$ & ALP14 CTF18 SPCC1840.08C MAL3 CLP1 SPCC1795.10C BUB1 \\
\hline
\end{tabular}




\begin{tabular}{|c|c|c|c|c|c|c|c|c|c|c|c|c|c|c|c|}
\hline Nombre ORF & Nombre Gen & $\begin{array}{l}\text { Morf. } \\
\text { YES }\end{array}$ & $\begin{array}{c}\text { Morf. } \\
\text { MM }\end{array}$ & $\begin{array}{c}\text { Citología } \\
\text { YES }\end{array}$ & $\begin{array}{c}\text { Citología } \\
\text { MM }\end{array}$ & $\begin{array}{l}\text { Ciclo } \\
\text { YES }\end{array}$ & $\begin{array}{c}\text { Ciclo } \\
\text { MM }\end{array}$ & Nombre ORF & Nombre Gen & $\begin{array}{l}\text { Morf. } \\
\text { YES }\end{array}$ & $\begin{array}{c}\text { Morf. } \\
\text { MM }\end{array}$ & \begin{tabular}{|c|} 
Citología \\
YES
\end{tabular} & \begin{tabular}{|c|} 
Citología \\
MM
\end{tabular} & \begin{tabular}{|l|} 
Ciclo \\
YES \\
\end{tabular} & $\begin{array}{c}\text { Ciclo } \\
\text { MM } \\
\end{array}$ \\
\hline SPBC216.05 & $\operatorname{rad} 3$ & 0,1 & 0,1 & 0 & 0 & 0 & 0 & SPBC1D7.01 & SPBC1D7.01 & 0,4 & 0 & 0 & 0 & 0 & 0 \\
\hline SPAC9E9.08 & $\operatorname{rad} 26$ & 0 & 0 & 0 & 0 & 0 & 2 & SPAC25H1.07 & emc1 & 0 & 1 & 0 & 0 & 4 & 0 \\
\hline SPAC14C4.13 & $\operatorname{rad} 17$ & 0 & 0 & 0 & 0 & 0 & 0 & SPAC227.10 & SPAC227.10 & 0,4 & $0,1,4$ & 0,3 & 0,3 & 0 & 0 \\
\hline SPAC664.07c & $\operatorname{rad} 9$ & 0 & 0 & 0 & 0 & 0 & 0 & SPAC4F10.02 & aap1 & $0,1,3$ & $0,1,3$ & 0 & 0 & 0 & 0 \\
\hline SPAC20G4.04C & hus1 & 0 & 0 & 0 & 0 & 3,4 & 0 & SPAC227.05 & SPAC227.05 & 0 & 0 & 0 & 0 & 0 & 0 \\
\hline SPAC1952.07 & rad1 & 0 & 0 & 0 & 0 & 0 & 0 & SPBC3E7.09 & SPBC3E7.09 & 0 & 0 & 0 & 0 & 0 & 0 \\
\hline SPBC902.02C & ctf18 & 5 & 5 & 0 & 0 & 0 & 0 & $S P B C 15 C 4.01 \mathrm{C}$ & oca3 & 0 & 0 & 0 & 0 & 0 & 0 \\
\hline SPAC $31 A 2.15 c$ & $d c c 1$ & 0 & 1 & $0,2,3$ & $0,2,3$ & 0 & 0 & SPAC6F6.01 & $\operatorname{cch} 1$ & 0,2 & 0,2 & $0,3,8$ & $0,3,8$ & 0 & 0 \\
\hline SPAC664.03 & SPAC664.03 & 0,1 & 1 & 0,2 & 0,4 & 3,4 & 0 & SPAC1F5.08c & yam8 & 0 & 0 & 0 & 0 & 0 & 0 \\
\hline SPBC530.05 & SPBC530.05 & 0 & 1 & 0 & 0 & 3 & 3 & SPBC31E1.02c & pmr1 & 0,1 & 0,1 & 0 & 0 & 0 & 0 \\
\hline SPBC16G5.15c & $f k h 2$ & 1 & 1 & $0,2,3$ & 0 & 2 & 2 & SPCC830.06 & cnb1 & 3,6 & 3,6 & 8,7 & 8,7 & 0 & 0 \\
\hline SPAC1F7.01C & spt6 & 0 & 0,1 & 0 & 0 & 0 & 0 & $S P B C 25 B 2.10$ & $S P B C 25 B 2.10$ & 5 & 5 & 0,3 & 0,3 & 0 & 0 \\
\hline SPCC736.08 & cbf11 & $0,1,3$ & 0,1 & 0 & $0,2,3$ & 0 & 0 & SPCC757.09c & $r n c 1$ & 0 & 1 & 0 & 0 & 0 & 3 \\
\hline SPAC1142.08 & fhl1 & 0 & 0 & 0 & 0 & 0 & 2 & SPCC1223.11 & ptc2 & 0,1 & 1 & 0 & 0 & 0 & 0 \\
\hline SPAC3H1.11 & $h s r 1$ & 0,1 & 0,1 & 0 & 0 & 0 & 0 & SPBC1685.01 & pmp1 & 0 & 0 & 0,3 & 0,3 & 0 & 0 \\
\hline SPBC25H2.15 & SPBC25H2.15 & 4 & 0 & 0 & 0 & 0 & 3 & SPAC11G7.06c & mug132 & 0 & 0 & 0,3 & 0,3 & 0 & 0 \\
\hline SPBC1539.10 & nop16 & 0,1 & 1 & 0 & 0 & 2 & 0 & SPCC553.01C & SPCC553.01C & 0 & 0,3 & 0,3 & 0,3 & 0 & 0 \\
\hline$S P B C 776.17$ & SPBC776.17 & 0 & 0 & 0,5 & 0,5 & 0 & 0 & SPAC2F3.02 & SPAC2F3.02 & 5 & 5 & 0 & 0 & 0 & 0 \\
\hline SPAC140.02 & gar2 & 0,1 & 0,1 & 0 & 0 & 0 & 3 & SPAC22F8.04 & SPAC22F8.04 & 0,1 & 0,1 & 0,3 & 0,3 & 0 & 0 \\
\hline SPAC3H5.12C & rpl501 & 0,1 & 0,1 & 0,5 & 0,5 & 0 & 0 & SPAC222.14c & SPAC222.14C & 0 & 0 & 3 & 0 & 0 & 0 \\
\hline SPBC $3 B 9.13 \mathrm{C}$ & rpp102 & 0 & 0,1 & 0 & 0 & 0 & 0 & SPAC17A5.08 & SPAC17A5.08 & 5 & 5 & 0 & 0 & 0 & 3 \\
\hline SPAPB1A10.09 & ase 1 & 0 & 0 & 3 & 3 & 0 & 0 & SPBC18H10.19 & vps8 & 0 & 0 & 0 & 0 & 0 & 0 \\
\hline$S P C C 1223.15 c$ & spc19 & 3 & 0 & 3,5 & 3,5 & 4 & 3,4 & SPAC4G8.04 & SPAC4G8.04 & 0,1 & 0,1 & $0,3,7$ & $0,3,7$ & 0 & 0 \\
\hline SPAC18G6.15 & $\mathrm{mal} 3$ & 4 & 4 & 0,3 & 0,3 & 3,4 & 2 & SPCC794.11C & SPCC794.11c & 0 & 0,1 & 3 & 3 & 0 & 1 \\
\hline SPBC106.01 & $m p h 1$ & 5 & 5 & 0,3 & 0,3 & 0 & 0 & SPAC823.05c & tlg2 & 0 & 0 & 3 & 3 & 0 & 3 \\
\hline$S P B C 27.02 c$ & ask1 & 0,3 & 0,1 & $0,3,5$ & 3,5 & 4 & 4 & SPAC631.02 & nrc1 & 5 & 5 & 3 & 3 & 0 & 0 \\
\hline SPCC895.07 & alp14 & 4 & 4 & 3,5 & 3,5 & 4 & 0 & SPAC31G5.18c & sde2 & 0,1 & $0,1,6$ & 0 & 0 & 0 & 3 \\
\hline SPAC14C4.16 & dad3 & 6,7 & 6 & 3,5 & 3,5 & 0 & 2 & SPAC664.02c & arp8 & 0 & 0 & 0 & 0 & 0 & 3 \\
\hline SPAC1805.07c & dad2 & 6 & 0,2 & 5,3 & 5,3 & 4 & 4 & SPBP8B7.28c & stc1 & 0 & 0,1 & 0 & 0 & 0 & 0 \\
\hline SPBC $32 \mathrm{~F} 12.08 \mathrm{C}$ & duo1 & $0,1,4$ & 6,2 & 5,7 & 5,7 & 4 & 3,4 & $S P B C 11 B 10.10 c$ & pht1 & 5 & 5 & $8,3,6$ & $8,3,6$ & 0 & 0 \\
\hline SPCC417.02 & dad5 & 0,6 & 0 & 5,4 & $5,7,4$ & 0 & 1 & SPAC139.06 & hat1 & 0,1 & 0,1 & 0 & 0 & 0 & 0 \\
\hline SPBC2D10.16 & mhf1 & 5 & 5 & $1,5,3$ & $1,5,3$ & 3,4 & 3,4 & SPBC29A3.05 & vps71 & 5 & 5 & 3,7 & 3,7 & 4 & 0 \\
\hline SPCC576.12c & $m h f 2$ & 5 & 5 & $1,3,9$ & $1,3,9$ & 0 & 3 & SPAC25A8.01c & $f f t 3$ & 0,1 & 0,1 & 0 & 0 & 0 & 0 \\
\hline SPBC342.05 & crb2 & 0,2 & 0 & 0 & 0,4 & 0 & 0 & SPAC23D3.09 & $\operatorname{arp} 42$ & 0,2 & 5 & 0 & 0 & 0 & 0 \\
\hline SPAC 3 H8.05c & SPAC $3 \mathrm{H} 8.05 c$ & 0,7 & 0,7 & 4,7 & 4,7 & 3,4 & 4 & SPAC31G5.19 & SPAC31G5.19 & 0,2 & 5 & 3,8 & 3,8 & 0 & 0 \\
\hline SPAC1071.02 & $m m s 19$ & 0,1 & 1 & 0 & 0,6 & 0 & 3 & SPAC10F6.08c & $n h t 1$ & 0 & 0,1 & $0,3,8$ & $0,3,8$ & 0 & 0 \\
\hline SPBC354.10 & def1 & 0 & 0 & 0 & 0 & 0 & 3 & SPBC660.14 & mik1 & 5 & 0,1 & 0 & 0 & 0 & 0 \\
\hline SPAPB1E7.06c & eme1 & 0 & 0 & 0 & 0 & 0 & 0 & SPAC1782.05 & ура2 & 1,6 & 1,6 & 0 & 0 & 3 & 0 \\
\hline SPBC36.06c & spo9 & 0 & 0 & 0,3 & 0 & 3 & 0 & SPBC17A3.06 & pi040 & 0,1 & 0,1 & 0 & 0 & 0 & 0 \\
\hline
\end{tabular}




\begin{tabular}{|c|c|c|c|c|c|c|c|c|c|c|c|c|c|c|c|}
\hline Nombre ORF & Nombre Gen & $\begin{array}{l}\text { Morf. } \\
\text { YES }\end{array}$ & $\begin{array}{c}\text { Morf. } \\
\text { MM }\end{array}$ & $\begin{array}{c}\text { Citología } \\
\text { YES }\end{array}$ & \begin{tabular}{|c|}
$\begin{array}{c}\text { Citología } \\
\text { MM }\end{array}$ \\
\end{tabular} & $\begin{array}{l}\text { Ciclo } \\
\text { YES }\end{array}$ & $\begin{array}{c}\text { Ciclo } \\
\text { MM }\end{array}$ & Nombre ORF & Nombre Gen & $\begin{array}{c}\text { Morf. } \\
\text { YES }\end{array}$ & $\begin{array}{c}\text { Morf. } \\
\text { MM }\end{array}$ & \begin{tabular}{|c|}
$\begin{array}{c}\text { Citología } \\
\text { YES }\end{array}$ \\
\end{tabular} & $\begin{array}{c}\text { Citología } \\
\text { MM }\end{array}$ & \begin{tabular}{|l|} 
Ciclo \\
YES \\
\end{tabular} & \begin{tabular}{|c} 
Ciclo \\
MM
\end{tabular} \\
\hline SPAC13A11.01C & rga8 & 0 & 0 & 0 & 0 & 0 & 0 & SPAC1782.09c & clp1 & 5 & 5 & 9 & 9 & 3 & 0 \\
\hline SPAC2F7.03c & pom1 & 1,4 & 1,4 & 3,9 & 3,9 & 0 & 0 & SPCC550.14 & $v g / 1$ & 5 & 5 & 0 & 0 & 0 & 0 \\
\hline SPBC4F6.06 & kin1 & 3 & 3 & 8 & 8 & 0 & 0 & SPAC3A12.13c & SPAC3A12.13c & 1,6 & 1,6 & 0 & 0 & 0 & 0 \\
\hline SPBC4F6.12 & $p \times 11$ & 3,6 & 3,6 & 8,9 & 8,9 & 0 & 0 & SPBC17G9.09 & tif213 & $0,1,6$ & $0,1,6$ & 0 & 0 & 0 & 0 \\
\hline$S P B C 1706.01$ & tea4 & 0,4 & 0,4 & 0 & 0 & 0 & 0 & SPAC9G1.12 & cpd1 & 0,1 & 0,1 & 0 & 0 & 0 & 0 \\
\hline SPCC1223.06 & tea1 & 4 & 4 & 0 & 0 & 0 & 3 & $S P B C 11 C 11.09 c$ & rp/502 & 0,1 & 0,1 & 0 & 0 & 0 & 0 \\
\hline SPAC1486.04C & alm1 & 1 & 0,1 & 6 & 6 & 0 & 0 & SPAC31A2.02 & trm112 & $0,1,6$ & 6 & 0 & 0 & 0 & 0 \\
\hline SPBC83.18c & fic1 & $0,1,6$ & $0,1,6$ & $0,3,7$ & $0,3,7$ & 0 & 0 & $S P B C 32 F 12.05 c$ & cwf12 & 0,1 & 0,1 & 8,3 & 8,3 & 0 & 0 \\
\hline SPAC4G8.05 & ppk14 & 0,1 & 0,1 & 0,3 & 0 & 0 & 0 & SPAC23C11.10 & mpn1 & 0,2 & 2 & 0,8 & 0,8 & 3 & 3 \\
\hline SPBC947.01 & alf1 & 0,1 & 5 & 3,8 & 3 & 0 & 3 & SPCC550.03c & SPCC 550.03c & 0,1 & 0,1 & 0 & 0 & 0 & 0 \\
\hline SPCC $417.07 c$ & mto1 & 0,4 & 0,4 & 0 & 0 & 0 & 0 & SPCC663.11 & saf1 & 5 & 5 & 3,6 & 3,6 & 0 & 0 \\
\hline SPAC19B12.10 & sst2 & 0 & 0 & 0 & 0 & 0 & 0 & SPBC336.14c & ppk26 & 0,1 & 0,1 & 0 & 0 & 0 & 0 \\
\hline SPAC1071.04c & $s p c 2$ & 0,1 & 0,1 & 0 & 0 & 0 & 0 & SPCC74.02c & SPCC74.02C & 0,1 & 5 & $3,8,9$ & $3,8,9$ & 3,4 & 0 \\
\hline SPAC1783.02C & vps66 & 0,6 & 0,6 & 0 & 0 & 0 & 0 & SPBP35G2.14 & SPBP35G2.14 & $0,1,6$ & $0,1,6$ & 0,3 & 0,3 & 0 & 0 \\
\hline SPAC3H1.05 & SPAC3H1.05 & 0 & 0 & 0 & 0 & 2 & 0 & SPBC56F2.08c & SPBC56F2.08c & 0,1 & 0,1 & $0,3,6,9$ & $0,3,6,9$ & 0 & 0 \\
\hline SPCC1795.10c & SPCC1795.10c & 0 & 0 & 0,3 & 0,3 & 0 & 0 & SPAC1093.01 & ppr5 & 0 & 0,1 & 3 & 0 & 0 & 0 \\
\hline SPAC1834.05 & alg 9 & 0,1 & 0 & 0 & 0 & 4 & 0 & SPCC1682.08c & SPCC1682.08C & 0,1 & 0,1 & 0,3 & 0 & 0 & 0 \\
\hline SPBC3H7.09 & erf2 & $0,2,3$ & $0,2,3$ & 0 & 0 & 0 & 0 & SPAC1610.01 & SPAC1610.01 & 5 & 0,6 & 2,6 & 2,6 & 3,4 & 0 \\
\hline$S P B C 342.01 \mathrm{C}$ & alg 6 & 0 & 0 & 0,2 & $0,2,5$ & 3,4 & 0 & SPAC1B1.04C & SPAC1B1.04C & 0,1 & 5 & 0 & 0 & 0 & 1 \\
\hline$S P B C 56 F 2.10 c$ & alg5 & 0,1 & 0,1 & 0 & 0 & 0 & 0 & SPCC1919.05 & ski3 & $0,1,6$ & $0,1,6$ & 0,3 & 0 & 0 & 0 \\
\hline SPAC4F8.01 & $\operatorname{did} 4$ & 0,1 & 0,1 & 0,3 & 0,3 & 4 & 1 & SPAC1805.04 & nup132 & 0,6 & 0,6 & 0,3 & 0 & 0 & 0 \\
\hline SPAC5D6.13 & SPAC5D6.13 & 0 & 0 & 0 & 0 & 0 & 0 & $S P B C 2 G 2.01 \mathrm{C}$ & liz1 & 0 & 0 & $2,3,8$ & 2,3 & 3,4 & 0 \\
\hline SPAC17C9.07 & alg 8 & 0 & 0 & 0 & 0 & 3,4 & 0 & SPBC725.15 & ura5 & $0,1,6$ & $0,1,6$ & 0,3 & 0,3 & 0 & 0 \\
\hline SPBPJ4664.06 & gpt1 & 0,1 & 1 & $0,2,3$ & $0,2,3$ & 0 & 0 & SPBC337.15c & $\operatorname{cog} 7$ & 0,1 & 1 & 0 & 0 & 0 & 1 \\
\hline$S P B C 1734.12 c$ & alg12 & 0 & 0 & 0 & 0 & 0 & 0 & SPBPB2B2.14C & SPBPB2B2.14C & $0,1,6$ & 2 & 0,3 & 0 & 0 & 1 \\
\hline SPAC6B12.07c & SPAC6B12.07c & 0,1 & 1 & $0,3,6$ & $0,3,6$ & 0 & 0 & SPAC22E12.18 & SPAC22E12.18 & 0,1 & 0,1 & 0,3 & 0 & 0 & 0 \\
\hline SPBC215.02 & bob1 & 0,4 & 0,4 & 0 & 0 & 0 & 0 & SPAC7D4.12c & SPAC7D4.12C & 0 & 0 & 3 & 0 & 0 & 0 \\
\hline SPAC 3 H8.07c & pac10 & 0,3 & 0,3 & 0 & 0 & 2 & 0 & SPCC1494.08c & SPCC1494.08c & 0,1 & 1 & 0 & 0 & 0 & 0 \\
\hline SPAC3A11.13 & SPAC $3 A 11.13$ & 0 & 0 & 0 & 0 & 4 & 0 & SPCC594.01 & SPCC594.01 & 0,1 & 0,1 & 0,3 & 0,3 & 0 & 0 \\
\hline
\end{tabular}


Tabla S11. Caracterización comprensiva de los mutantes interactuantes con cdc2-3w

\begin{tabular}{|c|c|c|c|c|c|c|c|c|c|c|c|c|c|c|c|}
\hline Nombre ORF & Nombre Gen & $\begin{array}{l}\text { Morf. } \\
\text { YES }\end{array}$ & $\begin{array}{c}\text { Morf. } \\
\text { MM }\end{array}$ & $\begin{array}{c}\text { Citología } \\
\text { YES }\end{array}$ & $\begin{array}{c}\text { Citología } \\
\text { MM }\end{array}$ & $\begin{array}{l}\text { Ciclo } \\
\text { YES }\end{array}$ & $\begin{array}{c}\text { Ciclo } \\
\text { MM }\end{array}$ & Nombre ORF & Nombre Gen & $\begin{array}{l}\text { Morf. } \\
\text { YES }\end{array}$ & $\begin{array}{c}\text { Morf. } \\
\text { MM }\end{array}$ & \begin{tabular}{|c|} 
Citología \\
YES
\end{tabular} & $\begin{array}{c}\text { Citología } \\
\text { MM }\end{array}$ & $\begin{array}{l}\text { Ciclo } \\
\text { YES } \\
\end{array}$ & $\begin{array}{c}\text { Ciclo } \\
\text { MM }\end{array}$ \\
\hline SPBC15C4.05 & SPBC15C4.05 & $0,1,6$ & 1 & $0,3,6$ & $0,3,6$ & 0 & 0 & SPBC16E9.09c & SPBC16E9.09c & 0,1 & 0,1 & 0,3 & 0,3 & 3 & 7 \\
\hline SPAC1D4.09c & rtf2 & 0,1 & 0,1 & 0,3 & 0,3 & 0 & 0 & SPBC16E9.14c & zrg17 & 0,1 & 0,1 & $0,3,6$ & 0,3 & 0 & 0 \\
\hline SPAC8E11.02C & $\operatorname{rad} 24$ & 1 & 1 & 0 & 0 & 0 & 1,2 & SPBC $887.18 \mathrm{c}$ & hfi1 & $0,4,1$ & $0,4,1$ & 3 & 0,3 & 0 & 0 \\
\hline SPAP14E8.02 & tos 4 & 0,4 & 0,2 & 0 & 0 & 1 & 1 & SPAC12G12.13c & cid14 & $0,1,6$ & $0,1,6$ & 0,3 & 0,3 & 6 & 1 \\
\hline SPBC $16 C 6.03 c$ & SPBC $16 \mathrm{C} 6.03 \mathrm{c}$ & 0,1 & $0,1,6$ & 0,3 & 0 & 0 & 0 & SPAC4F10.04 & ура1 & 5 & 5 & 3 & 3,8 & 0 & 1 \\
\hline SPAC22F3.08c & rok1 & $0,1,6$ & $0,1,6$ & 0,3 & 0,3 & 0 & 0 & SPAC30D11.04c & nup124 & 0,4 & 0 & 0,3 & 0,3 & 0 & 0 \\
\hline SPAC 890.05 & SPAC890.05 & $0,1,6$ & $0,1,6$ & 0,3 & 0,3 & 0 & 0 & SPCC $1682.12 \mathrm{C}$ & ubp16 & 1 & 1 & 0 & 0 & 0 & 1 \\
\hline SPBP8B7.06 & rpp201 & $0,1,6$ & $0,1,6$ & 0,3 & 0,3 & 0 & 0 & SPBC215.03c & $\operatorname{csn} 1$ & 5 & 5 & 0,3 & 0,3 & 4 & 4 \\
\hline SPBC16D10.11c & rps1801 & $0,1,6$ & 0,1 & 0,3 & 0 & 0 & 0 & SPAPB17E12.04c & $\operatorname{csn} 2$ & 5 & 5 & 0,3 & 0,3 & 4 & 4 \\
\hline SPBC $1703.03 c$ & SPBC $1703.03 \mathrm{C}$ & $0,1,6$ & $0,1,6$ & 0,3 & 0,3 & 0 & 0 & SPCC1840.08c & SPCC1840.08c & $0,1,6$ & 1,6 & $0,3,8$ & 0,8 & 0 & 7 \\
\hline SPBP16F5.05c & SPBP $16 F 5.05 \mathrm{c}$ & 5 & $0,1,6$ & 0,3 & 0,3 & 3 & 1 & SPAC922.07c & atd2 & $0,1,6$ & 1,2 & 0,3 & 0,3 & 0 & 1 \\
\hline SPBC 685.06 & rps 001 & $0,1,6$ & $0,1,6$ & 0,3 & 0,3 & 0 & 2 & SPAC19G12.08 & $\operatorname{scs} 7$ & $0,1,6$ & $0,1,6$ & 0 & 0 & 0 & 1 \\
\hline SPBP35G2.03c & sgo1 & 0,6 & 0,6 & 0 & 0 & 0 & 1,2 & SPCC 1235.15 & dga1 & 1,6 & 1,6 & 0 & 0 & 0 & 1,2 \\
\hline SPAC2OH4.07 & rhp57 & $0,1,6$ & $0,1,6$ & 0,3 & 0,2 & 3 & 3 & SPCC 1739.14 & npp106 & $1,2,6$ & $1,2,6$ & 3,6 & 3,6 & 2 & 2 \\
\hline SPAC926.03 & rlc1 & $3,6,2$ & $3,6,2$ & 8,9 & 8,9 & 7 & 7 & SPBC1718.07c & zfs1 & 0,6 & 1,6 & 0,6 & 0,6 & 0 & 1 \\
\hline SPAC1142.07c & vps32 & $0,1,6$ & $0,1,6$ & 0 & 0 & 0 & 1,2 & SPBC32F12.02 & rec14 & 1 & 1 & 0,3 & 0,3 & 0 & 0 \\
\hline SPAC14C $4.06 c$ & SPAC $14 C 4.06 \mathrm{c}$ & 0,1 & 0,1 & $2,6,9$ & $0,6,9$ & 0 & 0 & SPAC3A12.12 & atp11 & 0,1 & 2,3 & 0 & 8 & 0 & 7 \\
\hline SPCC $825.05 c$ & SPCC $825.05 \mathrm{C}$ & $0,1,6$ & $0,1,6$ & 3 & 3 & 3,4 & 1 & SPBC12C2.04 & SPBC12C2.04 & 5 & 5 & 0,3 & 0 & 0 & 3 \\
\hline SPAC3G9.04 & ssu72 & 0,1 & 1 & 0,3 & 0 & 0 & 1,2 & SPCC 1739.10 & mug33 & $0,1,6$ & $0,1,6$ & 0,3 & 0,3 & 3 & 0 \\
\hline SPAC17A5.02C & $\mathrm{dbr} 1$ & 5 & 5 & 0,3 & $0,3,8$ & 3,4 & 3,4 & SPCC24B10.18 & SPCC24B10.18 & 5 & 5 & 0,6 & 0,3 & 0 & 0 \\
\hline SPBC18H10.10c & saf4 & 5 & 5 & 0,3 & 0,3 & 0 & 0 & SPBC9B6.03 & SPBC9B6.03 & 0,1 & $0,1,6$ & 0,3 & 0 & 0 & 1 \\
\hline SPBC31F10.12 & $\operatorname{tma} 20$ & 0,1 & 1 & 0 & 0,7 & 0 & 0 & SPAC4F10.19c & SPAC4F10.19c & $0,4,6$ & $0,4,6$ & 0 & 0 & 0 & 0 \\
\hline SPAC $3 C 7.06 \mathrm{c}$ & pit1 & 5 & 5 & 0 & 0 & 3 & 0 & SPAC $977.05 \mathrm{c}$ & SPAC $977.05 c$ & $0,1,6$ & $0,1,6$ & 0 & 0 & 0 & 0 \\
\hline SPAC23H3.06 & apl6 & 0,4 & 1 & 0,3 & 0,3 & 0 & 0 & SPBC $1604.03 c$ & SPBC $1604.03 c$ & $0,1,6$ & $0,1,6$ & 0,6 & 0,6 & 0 & 3 \\
\hline SPCP1E11.06 & apl4 & 0,1 & 1 & 0,3 & $0,3,6$ & 0 & 0 & & & & & & & & \\
\hline
\end{tabular}


Tabla S12. Parejas de interacciones predichas por PInt entre los genes comunes identificados en la red de interacciones genéticas negativas con wee1-50 y cdc2-3w

\begin{tabular}{|c|c|c|c|c|c|c|c|c|c|c|c|}
\hline Nombre Gen 1 & Nombre Gen 2 & RF & SVM & Nombre Gen 1 & Nombre Gen 2 & RF & SVM & Nombre Gen 1 & Nombre Gen 2 & RF & SVM \\
\hline $\mathrm{mal} 3$ & ase 1 & 0.637 & 0,980 & SPAC25H1.07 & SPBC3E7.09 & 0.55 & 0,759 & SPAC23C11.10 & ptc2 & 0.542 & 0,651 \\
\hline SPAC631.02 & arp8 & 0.717 & 0,966 & SPBPB2B2.01 & SPCC1795.10C & 0.544 & 0,759 & $\mathrm{mal} 3$ & mug142 & 0.503 & 0,649 \\
\hline ase 1 & alp14 & 0.678 & 0,953 & SPAC25H1.07 & pom1 & 0.533 & 0,756 & ppa2 & ptc2 & 0.556 & 0,648 \\
\hline $\operatorname{rad} 9$ & ctf18 & 0.78 & 0,950 & SPBC $3 E 7.09$ & SPBC947.01 & 0.548 & 0,756 & cdc25 & $\operatorname{rad} 3$ & 0.57 & 0,647 \\
\hline SPAC631.02 & ctf18 & 0.729 & 0,948 & $\mathrm{mal} 3$ & ppa2 & 0.529 & 0,756 & vps32 & yam8 & 0.536 & 0,644 \\
\hline $\mathrm{mal} 3$ & alp14 & 0.579 & 0,939 & pom1 & rad3 & 0.58 & 0,755 & $S P A C 23 C 11.10$ & mug142 & 0.545 & 0,644 \\
\hline $\operatorname{rad} 9$ & rad3 & 0.688 & 0,926 & $c d c 2$ & ppa2 & 0.569 & 0,754 & arp8 & SPBC3E7.09 & 0.522 & 0,642 \\
\hline $\operatorname{rad} 17$ & $\operatorname{rad} 3$ & 0.737 & 0,925 & mug132 & SPAC23C11.10 & 0.581 & 0,753 & $c d c 25$ & mug142 & 0.56 & 0,642 \\
\hline hus1 & rad3 & 0.682 & 0,924 & ctf18 & wee1 & 0.6 & 0,751 & $\operatorname{rad} 17$ & $c d c 2$ & 0.568 & 0,641 \\
\hline arp8 & ctf18 & 0.78 & 0,919 & yam8 & SPBPB2B2.01 & 0.647 & 0,750 & yam8 & SPAC23C11.10 & 0.517 & 0,641 \\
\hline SPAC631.02 & $\operatorname{rad} 9$ & 0.721 & 0,917 & arp8 & $c d c 2$ & 0.602 & 0,746 & $\operatorname{arp} 42$ & SPAC25H1.07 & 0.501 & 0,637 \\
\hline arp8 & $\operatorname{rad} 9$ & 0.748 & 0,915 & clp1 & mph1 & 0.63 & 0,745 & $d m / 1$ & $\operatorname{cch} 1$ & 0.517 & 0,636 \\
\hline rga8 & rga7 & 0.602 & 0,913 & pom1 & SPBC947.01 & 0.593 & 0,745 & mug132 & pom1 & 0.571 & 0,636 \\
\hline rad3 & ctf18 & 0.745 & 0,905 & SPBC16E9.09C & SPBPB2B2.01 & 0.593 & 0,741 & $d m / 1$ & rp/502 & 0.519 & 0,635 \\
\hline $\operatorname{rad} 17$ & $\operatorname{rad} 26$ & 0.752 & 0,899 & vps32 & ase 1 & 0.542 & 0,741 & rad3 & wee1 & 0.512 & 0,634 \\
\hline ppa2 & mug142 & 0.657 & 0,893 & $\operatorname{rad} 17$ & $c d c 25$ & 0.619 & 0,739 & $m p r 1$ & $S P B C 947.01$ & 0.623 & 0,634 \\
\hline clp1 & ptc2 & 0.624 & 0,888 & arp8 & $\operatorname{rad} 26$ & 0.717 & 0,739 & yаm 8 & $S P B C 25 H 2.15$ & 0.55 & 0,633 \\
\hline hus1 & ctf18 & 0.742 & 0,885 & SPAC25H1.07 & rga7 & 0.592 & 0,737 & $\operatorname{rad} 9$ & alp14 & 0.58 & 0,630 \\
\hline SPAC3H1.05 & mug142 & 0.538 & 0,883 & $\mathrm{mal} 3$ & cdc25 & 0.535 & 0,736 & hus1 & alp14 & 0.6 & 0,628 \\
\hline arp8 & rad3 & 0.69 & 0,883 & rad17 & arp8 & 0.689 & 0,734 & rga8 & $S P B C 25 H 2.15$ & 0.54 & 0,627 \\
\hline$c d c 25$ & ptc2 & 0.594 & 0,882 & $c d c 25$ & ppa2 & 0.515 & 0,734 & yam8 & $d m / 1$ & 0.537 & 0,625 \\
\hline hus1 & $\operatorname{rad} 9$ & 0.736 & 0,870 & arp42 & rga7 & 0.594 & 0,732 & rad17 & stc1 & 0.547 & 0,623 \\
\hline$c d c 2$ & $\operatorname{rad} 3$ & 0.584 & 0,867 & pom1 & wee 1 & 0.606 & 0,730 & $m p r 1$ & wee1 & 0.551 & 0,623 \\
\hline clp1 & mal3 & 0.601 & 0,864 & $S P B C 25 H 2.15$ & ptc2 & 0.54 & 0,729 & rga8 & $d m / 1$ & 0.585 & 0,621 \\
\hline $\operatorname{rad} 9$ & $\operatorname{rad} 26$ & 0.737 & 0,861 & $\operatorname{rad} 3$ & SPBC3E7.09 & 0.501 & 0,728 & mug132 & $d m / 1$ & 0.505 & 0,620 \\
\hline yam8 & SPBC16E9.09C & 0.64 & 0,859 & mug142 & SPCC1795.10C & 0.562 & 0,727 & $m p h 1$ & mug142 & 0.53 & 0,617 \\
\hline rga7 & ptc2 & 0.556 & 0,852 & pom1 & ase 1 & 0.601 & 0,724 & SPBC $3 E 7.09$ & ctf18 & 0.518 & 0,615 \\
\hline hus1 & arp8 & 0.669 & 0,850 & mug132 & mug142 & 0.561 & 0,724 & SPBC $3 \mathrm{H} 7.03 \mathrm{C}$ & wee1 & 0.533 & 0,615 \\
\hline SPAC3H1.05 & SPCC1795.10C & 0.565 & 0,848 & pom1 & alp14 & 0.623 & 0,724 & SPAC3H1.05 & $\operatorname{cch} 1$ & 0.518 & 0,615 \\
\hline clp1 & ase 1 & 0.62 & 0,848 & yam8 & $\operatorname{cch} 1$ & 0.607 & 0,720 & $\mathrm{mal} 3$ & yam 8 & 0.516 & 0,613 \\
\hline $\operatorname{rad} 17$ & rad9 & 0.692 & 0,847 & rga8 & $S P A C 23 C 11.10$ & 0.536 & 0,715 & SPAC23C11.10 & stc1 & 0.565 & 0,610 \\
\hline $\operatorname{cch} 1$ & SPBC16E9.09C & 0.554 & 0,841 & $\operatorname{cch} 1$ & rga7 & 0.558 & 0,715 & arp42 & $d m / 1$ & 0.559 & 0,604 \\
\hline $\operatorname{rad} 17$ & hus1 & 0.718 & 0,839 & SPAC25H1.07 & SPBPB2B2.01 & 0.547 & 0,713 & hus1 & pom1 & 0.608 & 0,603 \\
\hline pom1 & ppa2 & 0.579 & 0,838 & $\operatorname{rad} 9$ & wee1 & 0.575 & 0,713 & pom1 & rad9 & 0.57 & 0,603 \\
\hline hus1 & $\mathrm{rad} 26$ & 0.684 & 0,837 & rad17 & pom1 & 0.617 & 0,712 & pom1 & $\operatorname{rad} 26$ & 0.523 & 0,602 \\
\hline clp1 & wee1 & 0.649 & 0,835 & $S P A C 23 C 11.10$ & SPCC1795.10C & 0.546 & 0,711 & ctf18 & alp14 & 0.591 & 0,599 \\
\hline ppa2 & wee1 & 0.536 & 0,830 & mug142 & wee1 & 0.52 & 0,711 & ppa2 & mpr1 & 0.552 & 0,598 \\
\hline mph1 & ppa2 & 0.549 & 0,825 & cch1 & SPBC3E7.09 & 0.572 & 0,710 & ase 1 & mph1 & 0.506 & 0,597 \\
\hline ppa2 & rad3 & 0.506 & 0,822 & $\operatorname{arp} 42$ & SPBC947.01 & 0.575 & 0,708 & yam8 & ase1 & 0.521 & 0,597 \\
\hline$S P A C 23 C 11.10$ & pom1 & 0.563 & 0,818 & $S P A C 23 C 11.10$ & ppa2 & 0.515 & 0,708 & $\operatorname{arp} 42$ & alp14 & 0.508 & 0,595 \\
\hline
\end{tabular}




\begin{tabular}{|c|c|c|c|c|c|c|c|c|c|c|c|}
\hline Nombre Gen 1 & Nombre Gen 2 & RF & svm & Nombre Gen 1 & Nombre Gen 2 & RF & SVM & Nombre Gen 1 & Nombre Gen 2 & RF & SVM \\
\hline clp1 & $\operatorname{rad} 3$ & 0.576 & 0,817 & hus1 & SPAC631.02 & 0.575 & 0,708 & pom1 & ctf18 & 0.585 & 0,593 \\
\hline SPAC3H1.05 & SPBC3E7.09 & 0.536 & 0,816 & $S P A C 23 C 11.10$ & SPBPB2B2.01 & 0.539 & 0,707 & SPAC25H1.07 & SPBC16E9.09C & 0.55 & 0,592 \\
\hline $\operatorname{cch} 1$ & SPBPB2B2.01 & 0.642 & 0,815 & mph1 & SPBC947.01 & 0.523 & 0,705 & $d m / 1$ & $S P B C 25 H 2.15$ & 0.593 & 0,589 \\
\hline pom1 & SPBC $3 E 7.09$ & 0.553 & 0,815 & SPAC25H1.07 & SPAC $3 H 1.05$ & 0.528 & 0,705 & $c d c 25$ & $\operatorname{rad} 26$ & 0.595 & 0,588 \\
\hline SPAC631.02 & SPBC947.01 & 0.627 & 0,814 & SPBC3E7.09 & SPBPB2B2.01 & 0.525 & 0,705 & $c d c 25$ & wee1 & 0.547 & 0,579 \\
\hline ase 1 & wee 1 & 0.548 & 0,811 & rga8 & SPCC1795.10C & 0.507 & 0,704 & $S P A C 23 C 11.10$ & SPBC16E9.09C & 0.528 & 0,576 \\
\hline $\operatorname{rad} 17$ & SPAC23C11.10 & 0.549 & 0,810 & vps32 & $\mathrm{mal} 3$ & 0.549 & 0,701 & mug132 & $d b r 1$ & 0.52 & 0,573 \\
\hline pom1 & $S P B C 25 H 2.15$ & 0.581 & 0,807 & clp1 & mug142 & 0.556 & 0,700 & $S P B C 25 H 2.15$ & mug142 & 0.506 & 0,570 \\
\hline rad26 & rad3 & 0.602 & 0,806 & cdc2 & ctf18 & 0.656 & 0,700 & $d m / 1$ & alp14 & 0.576 & 0,568 \\
\hline SPAC631.02 & rad3 & 0.565 & 0,806 & ase 1 & mug142 & 0.506 & 0,697 & $d m / 1$ & SPCC1223.09 & 0.52 & 0,567 \\
\hline wee1 & alp14 & 0.509 & 0,801 & $\operatorname{rad} 9$ & $c d c 2$ & 0.595 & 0,697 & rga8 & pom1 & 0.508 & 0,566 \\
\hline hus1 & $c d c 2$ & 0.631 & 0,801 & SPBC3E7.09 & SPCC1795.10C & 0.507 & 0,696 & mph1 & ctf18 & 0.548 & 0,566 \\
\hline pom1 & mph1 & 0.6 & 0,798 & mhf1 & SPBPB2B2.01 & 0.513 & 0,696 & $\mathrm{rad} 9$ & mph1 & 0.556 & 0,564 \\
\hline mug142 & ptc2 & 0.551 & 0,795 & rps802 & $p t c 2$ & 0.524 & 0,696 & SPAC3H1.05 & rp/502 & 0.516 & 0,562 \\
\hline clp1 & alp14 & 0.69 & 0,790 & pom1 & ptc2 & 0.626 & 0,695 & clp1 & $f k h 2$ & 0.553 & 0,561 \\
\hline $\operatorname{rad} 3$ & mug142 & 0.555 & 0,790 & $c d c 25$ & ase 1 & 0.562 & 0,695 & clp1 & hus1 & 0.617 & 0,560 \\
\hline$c d c 2$ & mug142 & 0.567 & 0,790 & ppa2 & SPBC947.01 & 0.528 & 0,694 & ctf18 & SPBC947.01 & 0.575 & 0,559 \\
\hline $\operatorname{rad} 26$ & ctf18 & 0.679 & 0,789 & ppa2 & stc1 & 0.521 & 0,694 & $\operatorname{rad} 26$ & $c d c 2$ & 0.571 & 0,552 \\
\hline SPAC31G5.18C & SPBC947.01 & 0.559 & 0,785 & rps802 & mug142 & 0.502 & 0,692 & arp8 & ptc2 & 0.503 & 0,552 \\
\hline SPAC23C11.10 & SPBC947.01 & 0.567 & 0,782 & cch1 & SPCC1795.10C & 0.532 & 0,688 & fkh2 & ctf18 & 0.584 & 0,552 \\
\hline SPAC23C11.10 & $S P B C 25 H 2.15$ & 0.582 & 0,780 & mph1 & alp14 & 0.6 & 0,688 & $\mathrm{mal3}$ & hus1 & 0.52 & 0,552 \\
\hline pom1 & mug142 & 0.62 & 0,779 & yam8 & SPAC $3 H 1.05$ & 0.555 & 0,687 & yam8 & rga7 & 0.523 & 0,550 \\
\hline $\operatorname{rad} 17$ & ctf18 & 0.696 & 0,777 & SPAC $31 G 5.18 C$ & ppa2 & 0.545 & 0,681 & mpr1 & stc1 & 0.576 & 0,545 \\
\hline SPAC3H1.05 & SPBPB2B2.01 & 0.519 & 0,775 & SPCC1223.09 & ptc2 & 0.516 & 0,681 & mug142 & ctf18 & 0.544 & 0,544 \\
\hline SPAC25H1.07 & $S P B C 25 H 2.15$ & 0.555 & 0,773 & $m p h 1$ & $\operatorname{rad} 3$ & 0.549 & 0,679 & $\operatorname{rad} 17$ & SPBC $3 E 7.09$ & 0.547 & 0,544 \\
\hline mug132 & SPBC947.01 & 0.501 & 0,772 & yam8 & mug142 & 0.501 & 0,677 & pom1 & rps802 & 0.51 & 0,538 \\
\hline mug132 & $S P B C 25 H 2.15$ & 0.54 & 0,770 & clp1 & SPBC $3 H 7.03 C$ & 0.57 & 0,671 & SPAC631.02 & $\operatorname{rad} 26$ & 0.583 & 0,537 \\
\hline$S P B C 25 H 2.15$ & SPBC $3 E 7.09$ & 0.602 & 0,767 & $c d c 2$ & $p t c 2$ & 0.505 & 0,670 & $d b r 1$ & SPAC23C11.10 & 0.522 & 0,534 \\
\hline SPAC23C11.10 & $m h f 1$ & 0.55 & 0,766 & yam8 & SPCC1795.10C & 0.576 & 0,669 & $c d c 25$ & alp14 & 0.627 & 0,533 \\
\hline mug132 & $m h f 1$ & 0.509 & 0,766 & rga8 & SPBC $3 E 7.09$ & 0.587 & 0,669 & $\operatorname{rad} 9$ & mug142 & 0.556 & 0,533 \\
\hline mug142 & alp14 & 0.525 & 0,766 & rad3 & alp14 & 0.52 & 0,668 & hus1 & mug142 & 0.567 & 0,530 \\
\hline mug132 & SPBC3E7.09 & 0.529 & 0,764 & pom1 & rga7 & 0.653 & 0,668 & yam8 & ptc2 & 0.512 & 0,524 \\
\hline$S P A C 23 C 11.10$ & SPBC3E7.09 & 0.553 & 0,764 & $c d c 25$ & pom1 & 0.595 & 0,668 & hus1 & wee1 & 0.542 & 0,523 \\
\hline SPAC23C11.10 & SPAC31G5.18C & 0.514 & 0,763 & SPAC25H1.07 & SPCC1795.10C & 0.62 & 0,668 & $d m / 1$ & $m h f 1$ & 0.525 & 0,520 \\
\hline rps802 & rp/502 & 0.703 & 0,763 & $c d c 25$ & $m p h 1$ & 0.566 & 0,667 & pom1 & $d m / 1$ & 0.582 & 0,518 \\
\hline SPBC25H2.15 & SPBC947.01 & 0.542 & 0,763 & SPBC16E9.09C & SPCC1795.10C & 0.558 & 0,666 & mph1 & $c d c 2$ & 0.516 & 0,518 \\
\hline$m h f 1$ & $m h f 2$ & 0.593 & 0,761 & vps 32 & SPBPB2B2.01 & 0.518 & 0,664 & rgas & $\operatorname{arp} 42$ & 0.504 & 0,516 \\
\hline mph1 & wee1 & 0.577 & 0,760 & SPBC947.01 & wee 1 & 0.578 & 0,662 & $\operatorname{arp} 42$ & $S P B C 25 H 2.15$ & 0.539 & 0,513 \\
\hline pom1 & $m p r 1$ & 0.507 & 0,760 & SPAC25H1.07 & $\operatorname{cch} 1$ & 0.503 & 0,661 & ptc2 & wee 1 & 0.534 & 0,512 \\
\hline SPAC $23 C 11.10$ & $d m / 1$ & 0.555 & 0,760 & $c d c 25$ & rga7 & 0.546 & 0,659 & clp1 & pom1 & 0.623 & 0,509 \\
\hline clp1 & $c d c 25$ & 0.602 & 0,760 & $\operatorname{rad} 17$ & mph1 & 0.573 & 0,656 & $d m / 1$ & arp8 & 0.518 & 0,505 \\
\hline rad17 & SPAC631.02 & 0.588 & 0,759 & $d m / 1$ & SPBC3E7.09 & 0.657 & 0,656 & & & & \\
\hline mug142 & SPCC1223.09 & 0.535 & 0,759 & rga8 & SPBC947.01 & 0.557 & 0,652 & & & & \\
\hline
\end{tabular}




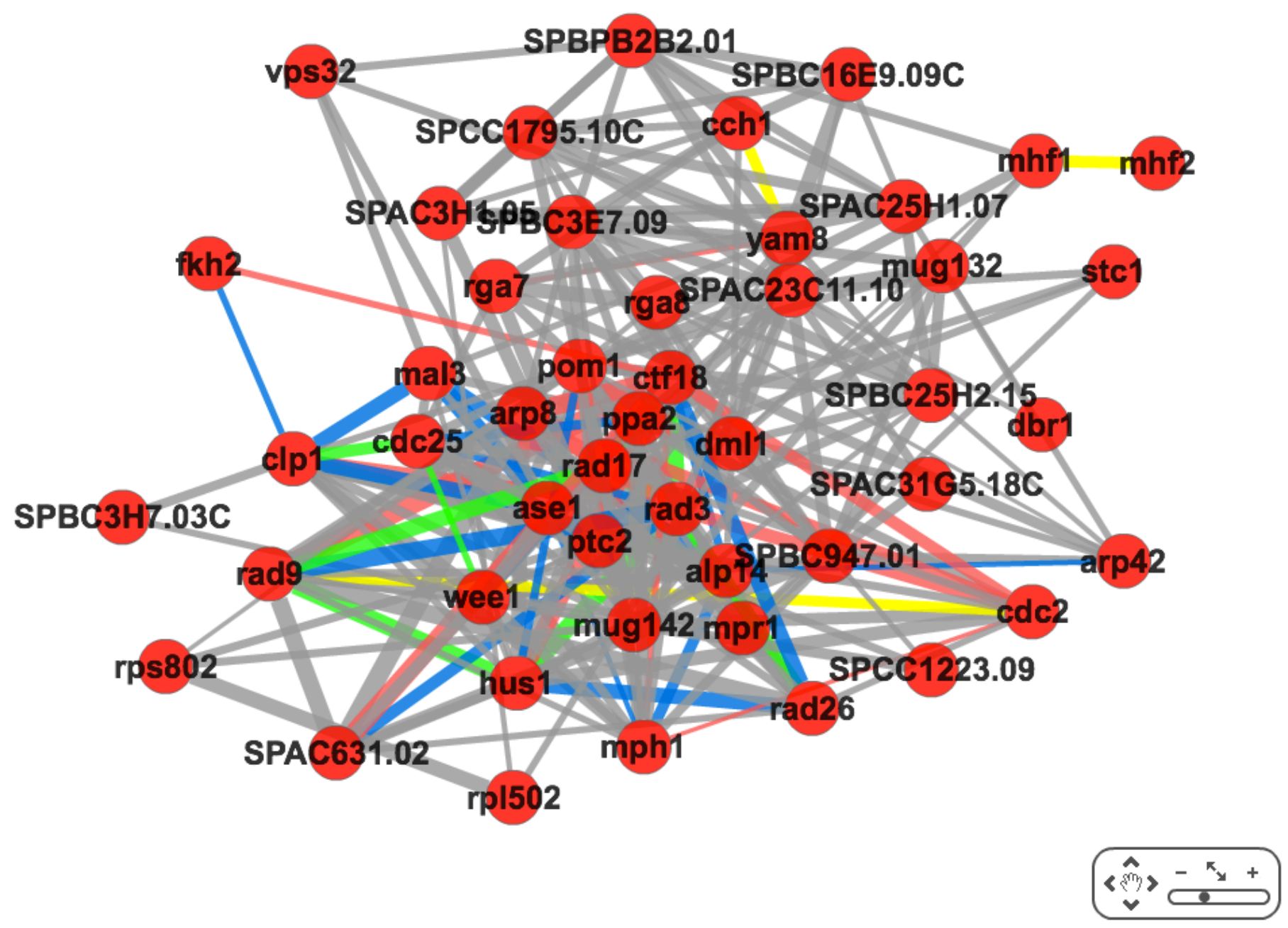


Materiales y métodos 


\section{Microorganismos utilizados}

\subsection{Cepas de Schizosaccharomyces pombe}

Para realizar este trabajo se utilizaron las cepas descritas en la Tabla 1.

Tabla 1. Cepas de Schizosaccharomyces pombe

\begin{tabular}{|c|c|c|}
\hline Cepa & Genotipo & Procedencia \\
\hline 1 & h- igo1::kanMX6 & Este trabajo \\
\hline 12 & $h+c d c 25-22$ igo1::kanMX6 & Este trabajo \\
\hline 15 & $h-c d c 25-22$ & Este trabajo \\
\hline 21 & $H+$ wee1-50 igo1::kanMX6 & Este trabajo \\
\hline 33 & $h+$ ppa2::natMX6 & Este trabajo \\
\hline 64 & $h+i g o 1:: k a n M X 6$ ppa2::natMX6 & Este trabajo \\
\hline 81 & $h$ - igo1::ura $4^{+}$ & Este trabajo \\
\hline 84 & $h-p a b 1:: k a n M X 6$ & Este trabajo \\
\hline 173 & $h-p p k 18:: k a n M X 6$ & Este trabajo \\
\hline 179 & $h+$ tor2-51:ura $4^{+}$ & Este trabajo \\
\hline 181 & $h$-tor2-51:ura4 ${ }^{+}$ura4-D18 igo1::kanMX6 & Este trabajo \\
\hline 193 & h-igo1::natMX6 & Este trabajo \\
\hline 199 & $h$ - igo1:igo1-S102A & Este trabajo \\
\hline 205 & h- igo1::natMX6 ppk18::kanMX6 & Este trabajo \\
\hline 224 & h- pka1::ura4 $4^{+}$ura4-D18 & Este trabajo \\
\hline 226 & $h+$ pka1::ura $4^{+}$ura4-D18 igo1::kanMX6 & Este trabajo \\
\hline 234 & $h+i g 01: i g o 1-S 64 E$ & Este trabajo \\
\hline 236 & $h+i g 01: i g 01-S 64 A$ & Este trabajo \\
\hline 242 & $h+$ wee1-50 ppa2::natMX6 & Este trabajo \\
\hline 245 & $h+$ cdc25-22 ppa2::natMX6 & Este trabajo \\
\hline 253 & h- igo1::NatMX6 pab1::kanMX6 & Este trabajo \\
\hline 259 & h- igo1::kanMX6 pom1::ura $4^{+}$ura4-D18 & Este trabajo \\
\hline 260 & $h$ - igo1::kanMX6 pyp2::ura4 ${ }^{+}$ura4-D18 & Este trabajo \\
\hline 262 & $h+$ pyp2::ura $4^{+}$ura $4 D-18$ & Este trabajo \\
\hline 264 & h? igo1::kanMX6 sty1::ura4 $4^{+}$ura4-D18 & Este trabajo \\
\hline 266 & $h ?$ sty1::ura $4^{+}$ura4-D18 & Este trabajo \\
\hline
\end{tabular}




\section{Materiales y Métodos}

\begin{tabular}{|c|c|c|}
\hline 269 & h? igo1::kanMX6 cdr1::natMX6 & Este trabajo \\
\hline 271 & $h+$ cek $1:: u r a 4^{+}$ura $4 D-18$ & Este trabajo \\
\hline 274 & $h+$ cek1::ura $4^{+}$ppk18::kanMX6 ura4-D18 & Este trabajo \\
\hline 275 & $h$ - kanMX6:nmt1:3HA-ppk18 & Este trabajo \\
\hline 277 & h- kanMX6:nmt1:3HA-ppk18 igo1::NatMX6 & Este trabajo \\
\hline 283 & $h-c d c 2-3 w:: n a t M X 6$ igo1::kanMX6 & Este trabajo \\
\hline 290 & h+ aur-mcherry:atb2 hht2:GFP:ura4+ ura4d-18 igo1::kanMX6 & Este trabajo \\
\hline 294 & $h-\operatorname{rad} 3:: k a n M X 6$ & Este trabajo \\
\hline 295 & h- rad3::kanMX6 igo1::natMX6 & Este trabajo \\
\hline S817 & $h$ - pom1::ura4+ ura4-D18 & Sergio Moreno \\
\hline S999 & $h+$ wee $1-50$ & Sergio Moreno \\
\hline S1000 & $h-$ wee $1-50$ & Sergio Moreno \\
\hline S2201 & $h-972$ & Sergio Moreno \\
\hline S2215 & $h-c d c 25-22$ & Sergio Moreno \\
\hline S2165 & $h-c d c 2-3 w: n a t M X 6$ & Sergio Moreno \\
\hline S2267 & $h+c d r 1: n a t M X 6$ & Francisco Navarro \\
\hline S2307 & $h+$ kanMX6:nmt1:3HA-ppk18 & Sergio Moreno \\
\hline S2308 & h- ppa1::kanMX6 & Sergio Moreno \\
\hline S2309 & $h+$ aur-mcherry:atb2 hht2:GFP:ura $4^{+}$ura $4 d-18$ & Sergio Moreno \\
\hline
\end{tabular}

\subsection{Cepas de Escherichia coli}

Se utilizó la cepa DH5a cuyo genotipo se describe en la Tabla 2. Se empleó para la producción del $A D N$ recombinante de igo $1^{+}$en el vector $p B l u e s c r i p t ~ S K+y$ su posterior mutagenización. Las células competentes se prepararon en el Instituto de Biología Funcional y Genómica (IBFG) siguiendo el protocolo descrito por Inoue et al. 1990.

Tabla 2. Cepas de Escherichia coli

\begin{tabular}{lll}
\hline Cepa & Genotipo & Procedencia \\
\hline DH5a & $F-\Phi 80 l a c Z \Delta M 15 \Delta$ (lacZYA-argF) U169 recA1 endA1 hsdR17 (rK- & IBFG \\
& $, m K+)$ phoA supE44 $\lambda-$ thi-1 gyrA96 relA1 \\
\hline
\end{tabular}

\section{Medios y condiciones de cultivo}

\subsection{Cultivos de S. pombe}


Para cultivar las células de S. pombe se emplearon los medios descritos en Moreno et al. 1991. Las células se crecieron en medio rico (YES) compuesto por extracto de levadura $0,5 \%$ y glucosa $3 \%$, suplementado con $250 \mathrm{mg} / \mathrm{l}$ de histidina, leucina, uracilo, adenina y lisina; y en medio mínimo (MM) compuesto por ftalato ácido de potasio 14,7 $\mathrm{mM}$, bifosfato de sodio $15,5 \mathrm{mM}$, glucosa $2 \%$, sales, vitaminas y minerales (Moreno et al. 1991). Dependiendo del caso, se utilizaron para el MM diferentes fuentes de nitrógeno como sales o aminoácidos incluyendo cloruro de amonio $93,5 \mathrm{mM}$, acido glutámico o glutamato $20 \mathrm{mM}$, isoleucina $20 \mathrm{mM}$ y fenilalanina $20 \mathrm{mM}$. En casos específicos, se empleó MM sin nitrógeno. Cuando fue necesario, el MM se suplementó con $225 \mu \mathrm{g} / \mathrm{ml}$ de adenina, uracilo o leucina dependiendo de las auxotrofías de las cepas. En los experimentos de sobreexpresión, se añadió al MM, tiamina $5 \mu \mathrm{g} / \mathrm{ml}$ para mantener reprimido el promotor nmt1 (Maundrell, 1990)

Para el crecimiento en placa se utilizaron los mismos medios a los que se añadió agar al 2\%. Como medio de esporulación se utilizó MEA (extracto de malta-agar). Como medio para comprobar la sensibilidad al calor o al frío y la diploidización se utilizó YESAgar con floxina B $5 \mathrm{mg} / \mathrm{ml}$ (YEP).

Todos las células de $S$. pombe se cultivaron en baños con una agitación constante de $110 \mathrm{rpm}$. Los preinóculos de cada ensayo se crecieron en medio rico YES y se agitaron en un incubador de aire a 200 rpm durante una noche. Cada vez que se inició un nuevo ensayo, las cepas fueron estriadas desde un stock en glicerol a $-80^{\circ} \mathrm{C}$ en placas de YES-agar y replicadas a YEP agar para comprobar si eran haploides o diploides. En ningún caso se mantuvieron guardadas a $4^{\circ} \mathrm{C}$, excepto para el escrutinio de sintéticos letales.

Los medios y las condiciones de cultivo utilizadas para el escrutinio de sintéticos letales, se describen en detalle en el apartado 3.2.3.

\subsection{Cultivos de E. Coli}

La estirpe de E.coli empleada se creció a $37^{\circ} \mathrm{C}$ en los medios y condiciones descritos en Sambrook et al. 1989.

\section{Escrutinio Sistemático de Sintéticos Letales (SGA)}




\section{Materiales y Métodos}

\subsection{Selección de mutaciones para el análisis genético}

Se seleccionaron los mutantes wee1-50 y cdc2-3w con el fin de identificar a gran escala la red de interacción genética entre los genes no esenciales y la maquinaria de regulación primaria del ciclo celular de $S$. pombe.

\subsubsection{Marcaje de los mutantes wee (cepas de interés) y cepa silvestre (cepa control)}

Para la construcción de la cepa de interés wee1-50:natMx6 se insertó el gen marcador natMX6 a $715 \mathrm{pb}$ corriente abajo del codón de parada de la fase de lectura abierta (ORF) del gen wee $1^{+}$mutado, delecionando la zona intergénica adyacente de 136 pb. En el caso de la cepa de interés cdc2-3w:natMX6, se insertó el gen marcador a 448 pb corriente abajo del codón de parada de la ORF del gen $c d c 2^{+}$mutado, delecionando una zona intergénica de $144 \mathrm{pb}$. La posición exacta del marcador se describe en la Tabla 3. El marcador de resistencia fue amplificado por PCR a partir del plásmido pFA6aNatMX6 utilizando los oligonucleótidos wee1-50:nat F1 y wee1-50:nat R1 y cdc2-3w:nat F1 y cdc2-3w:nat R1 respectivamente (Tabla 6). El fragmento de ADN generado de 1,4 $\mathrm{Kb}$, fue utilizado para transformar células de $S$. pombe auxotróficas para leucina en el fondo genético wee1-50 y prototróficas en el fondo cdc2-3w. La selección de los clones positivos se realizó mediante PCR y se secuenciaron para confirmar la integración correcta del marcador. Para la construcción de la cepa control se insertó el gen marcador natMX6 en el extremo $3^{\prime}$ del gen wee $1^{+}$silvestre, en la misma posición génica que para la cepa wee1-50 (Tabla 3) y transformando células de S. pombe auxotróficas para leucina. Finalmente, se realizó un cruce de las cepas marcadas con una cepa silvestre para confirmar que el gen marcador segregaba ligado al gen de interés y en la proporción adecuada.

\subsubsection{Colección de los mutantes no esenciales de deleción Bioneer (cepas diana)}

La colección de mutantes de deleción fue desarrollada en conjunto por la compañía coreana Bioneer y el Instituto de Investigaciones en Ciencias Biológicas y Biotecnología de Corea del Sur (KRIBB) en colaboración con el Dr. Paul Nurse, del Centro de Investigación 
investigación del Cáncer del Reino Unido. La versión 3.0 comprende 3346 cepas haploides que cubren aproximadamente el $93,5 \%$ de los genes no esenciales de $S$. pombe. Para su construcción, cada gen se eliminó y se reemplazó por un módulo de deleción mediante recombinación homóloga. Cada módulo contiene el gen marcador kanMX4, que confiere resistencia a la geneticina (G418), y una pareja de códigos de barras que identifica cada deleción como una entidad única (Kim et al., 2010; http://www.bioneer.com).

\subsection{Obtención de los dobles mutantes para el análisis genético}

\subsubsection{Genotipos de las cepas parentales}

Los genotipos de las cepas utilizadas en el escrutinio se detallan en la Tabla 3.

Tabla 3. Cepas parentales utilizadas en el escrutinio

\begin{tabular}{lcl}
\hline Tipo & Locus (natMX6) & Genotipo \\
\hline interés (query) & $725662 \ldots 725798$ & $h$ - wee1 ${ }^{+}:$natMX6 leu1-32 (S 2176) \\
interés (query) & $725662 \ldots 725798$ & $h$-wee1-50:natMX6 leu1-32 (S 2147) \\
interés (query) & $1502059 \ldots 1502202$ & $h$ - cdc2-3w:natMX6 (S 2165) \\
Colección (target) & ----- & $h+$ genX::kanMX6 ade6-M210 ura4-D18 leu1-32 \\
& & $h+$ genX::kanMX6 ade6-M216 ura4-D18 leu1-32 \\
\hline
\end{tabular}

Las cepas de la colección poseen dos genotipos, que son producto de la segregación de un cepa diploide que contiene los dos tipos de alelos ade6, identificada por sus autores como SP286 y cuyo genotipo es: $h+/ h+$ ade6-M210/ade6-M216 ura4D18/ura4-D18 leu1-32/leu1-32 (Kim et al., 2010; http://www.bioneer.com).

\subsubsection{Nomenclatura de las placas}

La colección y sus mutantes de deleción están distribuidos en 39 placas en formato de 96 pocillos. Las primeras 33 placas corresponden a la v2.0 de la colección (3004 mutantes) y las 6 restantes a la versión actualizada (341 mutantes nuevos y 206 reconstruidos), que en su conjunto corresponden a la v3.0. Cada cepa puede ser identificada por una coordenada que en su orden incluye: i) un número de placa; ii) una fila, designada por letras desde la $\mathrm{A}$ hasta la $\mathrm{H}$ y iii) una columna, numeradas del 1 al 12 . Por ejemplo, en la versión 2.0 de la colección, el mutante rad3 $\Delta$ se identifica por la coordenada 3G10, lo que significa que se ubica en la placa 3, fila G, columna 10. 


\section{Materiales y Métodos}

Para realizar el escrutinio y a su vez mantener la colección en su estado original se generaron tres copias de seguridad. Para la identificación de cada una, se marcó la cara frontal de cada placa con un rótulo que detalla la siguiente información: i) la versión de la colección (V2; V3 upgrade); ii) las siglas "SP" que abrevian el nombre Schizosaccharomyces pombe, iii) el número de la placa, iv) el medio de crecimiento de las células y el porcentaje de glicerol utilizado (YES+G418+Glic. 25\%) y iv) la copia de seguridad (Copy 1, Copy 2). En la cara lateral se resume la versión, el número de la placa y el medio junto con la fecha de inoculación de las cepas.

\subsubsection{Medios y condiciones de crecimiento}

Para generar las copias de seguridad las cepas diana se replicaron desde la colección original a placas de 96 pocillos (Nunclon ${ }^{\mathrm{TM}}$ 96U) con $80 \mu \mathrm{l}$ de YES líquido, utilizando un replicador de 96 puntas de acero (Nalgene Nunc Internacional). Seguidamente, se incubaron a $32^{\circ} \mathrm{C}$ durante tres días. Una vez crecidas, se completó el volumen de cada pocillo a $160 \mu \mathrm{l}$ con medio selectivo YES con geneticina G418 (100 $\mu \mathrm{g} / \mathrm{ml}$; Duchefa) y glicerol $50 \%$, y se almacenaron a $-80^{\circ} \mathrm{C}$. Una copia extra, con $160 \mu \mathrm{lde}$ YES, se almacenó a $4^{\circ} \mathrm{C}$ durante la primera fase del escrutinio como material de partida. Todas las copias de seguridad fueron selladas con tapas de aluminio (Thermowell sealing tapes; Sigma-Aldrich).

Las cepas de interés se mantuvieron a $-80^{\circ} \mathrm{C}$ y se aislaron en YES-Agar cada vez que fue necesario. Antes de ser cruzadas con la colección de mutantes, siempre se controló el genotipo comprobando su resistencia a nourseotricina en placas de YES-agar con ClonNat $(75 \mu \mathrm{g} / \mathrm{ml}$, Werner BioAgents); asimismo se controló la diploidización y su termosensibilidad verificando colonias rosas en YEP y el fenotipo wee con observaciones al microscopio desde colonia.

Para los cruces se utilizó $40 \mathrm{ml}$ de MEA servido en placas Omnitray (86x128 mm; Thermo Scientific).

\subsubsection{Concentración de drogas}

Para la comprobación de los mutantes sencillos (cepas de interés y diana) y la selección de los dobles mutantes (resultado final del escrutinio de sintéticos letales), se 
emplearon placas Omnitray con $40 \mathrm{ml}$ de YES-agar con G418 (Duchefa) a una concentración final de $100 \mu \mathrm{g} / \mathrm{ml}$ y ClonNat (Werner BioAgents) de $75 \mu \mathrm{g} / \mathrm{ml}$; y placas de 96 pocillos con $100 \mu \mathrm{l}$ de YES con G418 $100 \mu \mathrm{g} / \mathrm{ml}$.

\subsubsection{Preparación de las cepas diana (target) y de interés (query)}

Para facilitar el análisis de los resultados y el manejo del elevado número de placas, las 39 placas de la colección se dividieron en cuatro grupos y se realizó el escrutinio para cada grupo independientemente.

Para hacer un seguimiento del crecimiento de cada cepa de la colección, se realizaron lecturas de densidad óptica (D.O. 570nm) en YES a las $72 \mathrm{~h}$ y en YES con G418 $(100 \mu \mathrm{g} / \mathrm{ml})$ a las 48,72 y 120 horas utilizando un espectrofotómetro lector de placas de 96 pocillos Modelo Ultra Evolution Tecan.

Para generar los dobles mutantes las cepas diana se replicaron, al menos por duplicado, en placas de 96 pocillos con $100 \mu \mathrm{l}$ de YES y se incubaron a $30^{\circ} \mathrm{C}$ durante 48 horas. Paralelamente, se crecieron las cepas de interés en $15 \mathrm{ml}$ de YES a $25^{\circ} \mathrm{C}$ durante una noche y se mantuvieron en fase exponencial durante el día y la noche siguiente, calculando una D.O. (595n) final de 0,8 en un volumen de $50 \mathrm{ml}$.

\subsubsection{Cruce entre cepas diana (target) y de interés (query)}

Con los cultivos anteriores, se ajustó la densidad óptica de las cepas de interés a las cepas diana y se dispensaron en placas de 96 pocillos. A partir del mismo formato de 96 , se replicaron las cepas diana y de interés, una sobre otra, en placas Omnitray con MEA.

\subsubsection{Esporulación}

Las placas de MEA fueron incubadas a $25^{\circ} \mathrm{C}$ durante cuatro días para permitir la conjugación, meiosis y esporulación. La eficiencia de la conjugación se comprobó al tercer día, monitoreando la formación de ascas al microscopio.

\subsubsection{Enriquecimiento de esporas y eliminación de parentales haploides y diploides}

Tras cuatro días de incubación a $25^{\circ} \mathrm{C}$, las placas se transfirieron a $42^{\circ} \mathrm{C}$ y se 


\section{Materiales y Métodos}

mantuvieron en dicha temperatura durante cuatro días más. Para evitar la deshidratación de los medios durante todo el proceso las placas se mantuvieron bajo humedad constante.

\subsubsection{Germinación}

Para inducir la germinación de las esporas, las placas de MEA se replicaron a placas de YES-agar y se incubaron a $25^{\circ} \mathrm{C}$ durante dos días.

\subsubsection{Selección de los dobles mutantes}

La selección de los dobles mutantes, se efectuó en dos pasos: i) YES líquido con G418 y ClonNat a $25^{\circ} \mathrm{C}$ durante dos días, para favorecer el enriquecimiento de la población de dobles mutantes y ii) YES-agar con G418 y ClonNat, para visualizar y valorar el crecimiento de las colonias sobre agar.

En el último paso de selección, cada colonia se replicó 4 veces, incrementando el formato de ordenamiento de las colonias de 96 a 384 puntos por placa. Las temperaturas de incubación fueron dependientes del cruce, es decir aquellas placas con dobles mutantes producto del cruce entre la colección y el parental wee1-50, se incubaron a $25^{\circ} \mathrm{C}$ y $35^{\circ} \mathrm{C}$ como temperatura permisiva y restrictiva respectivamente, y aquellos dobles mutantes producto del cruce entre la colección y el parental $c d c 2-3 w$, se incubaron sólo a $25^{\circ} \mathrm{C}$. Los cruces control, entre la colección y la cepa silvestre marcada, se incubaron igualmente a $25^{\circ} \mathrm{C}$ y $35^{\circ} \mathrm{C}$.

\subsubsection{Visión en conjunto del protocolo del SGA}

La estrategia experimental empleada para llevar a cabo el escrutinio sistemático de sintéticos letales (SGA) se ilustra en la Figura 1.

\subsubsection{Digitalización de los resultados}

Para recopilar los resultados finales del escrutinio en formato digital, las placas finales con los dobles mutantes se escanearon tras 48 horas de incubación, utilizando un escáner modelo ScanMaker i900 MICROTEX. Las imágenes se adquirieron con una resolución de 300 ppp (puntos por pulgada ) y se almacenaron en formato TIFF. 


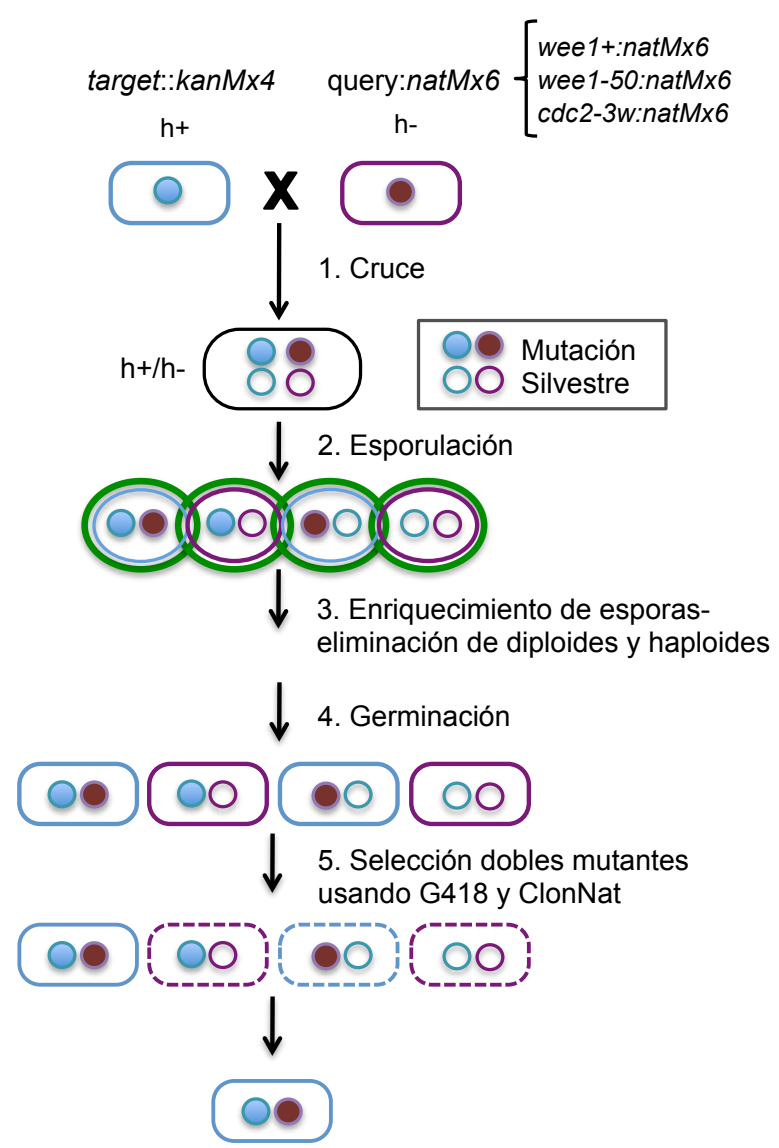

Figura 1. Esquema que resume el protocolo experimental del escrutinio de sintéticos letales realizado en este estudio. El término cepas target hace referencia a las cepas de la colección de deleción de $S$. pombe y el término query a las cepas de interés, para este caso los mutantes wee1-50 y cdc2-3w y la cepa control. Adaptado de Dixon et al., (2008).

\subsubsection{Estimación del crecimiento de los dobles mutantes sobre agar}

A pesar de que los resultados de las placas finales del escrutinio fueron digitalizados, la estimación del crecimiento de los dobles mutantes se hizo mediante inspección visual in situ. Para esto, se asignó a un total de 16.730 colonias un valor arbitrario de crecimiento, que fue definido en función de la densidad de la colonia. En su conjunto, dichos valores representaron una escala de cero a cinco, siendo cero el valor correspondiente a un crecimiento silvestre y cinco al correspondiente a un crecimiento nulo. Los valores intermedios reflejaron un crecimiento lento de la colonia.

En la Figura 2 se visualiza la escala de crecimiento utilizada para estimar el crecimiento de los dobles mutantes sobre agar. 


\section{Materiales y Métodos}

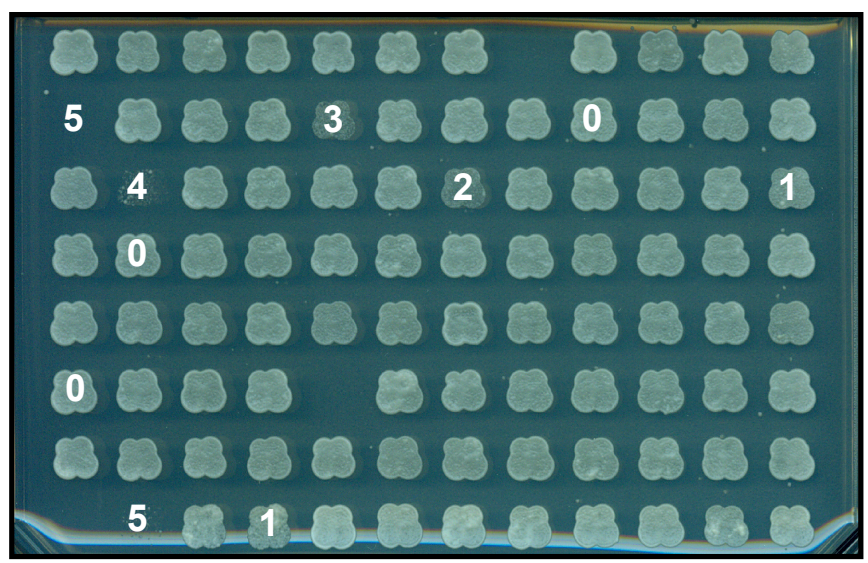

Figura 2. Estimación del crecimiento de los dobles mutantes sobre agar mediante una escala arbitraria de valores que representa el crecimiento de las colonias en función de la densidad. El rango está comprendido entre valores positivos de cero a cinco, siendo cero el valor correspondiente a un crecimiento similar al silvestre y cinco el correspondiente a un crecimiento nulo. La imagen representa los datos finales del escrutinio de sintéticos letales almacenados en formato digital.

\subsection{Procesamiento de datos}

\subsubsection{Algoritmo de crecimiento relativo y rango de puntuación}

Después de asignar un valor de crecimiento a cada colonia, se calculó el crecimiento relativo de los dobles mutantes, mediante una comparación cuantitativa entre el crecimiento del doble mutante (CMD) y el crecimiento del mutante sencillo o diana (CMS). La determinación del crecimiento del mutante diana fue el resultado del cruce entre los mutantes de la colección y la cepa silvestre, mientras que el crecimiento del mutante doble fue el resultado del cruce entre los mutantes de la colección y las cepas de interés.

El calculo del crecimiento relativo se llevó a cabo mediante el uso del algoritmo RG (del inglés Relative growth), dónde el crecimiento del mutante diana (CMD) fue restado al crecimiento del doble mutante (CMS), tomando en consideración la misma temperatura de incubación para ambos mutantes. En la Figura 3 se muestra un ejemplo de su uso.

A partir del uso del algoritmo RG, se generó un rango de puntuación de valores menores y mayores de cero, hasta cinco en ambos casos (Figura 4). Los valores negativos señalan aquellas interacciones que mostraron un fenotipo exacerbado con respecto al esperado, es decir aquellas capaces de agravar el fenotipo o causar la 
query_gen::KanMX4

$x$

wee1+:natMX6

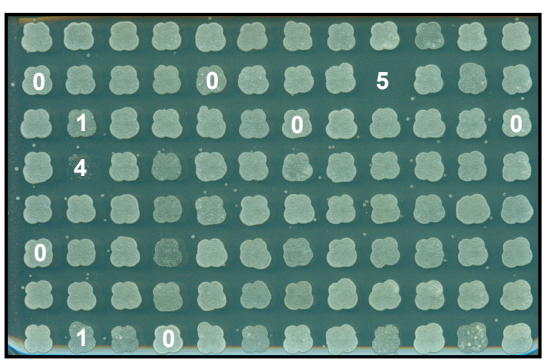

query_gen::KanMX4

target:natMX6

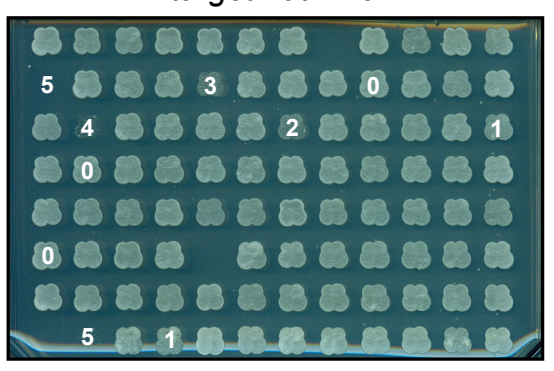

Crecimiento relativo $(\mathrm{RG})=\mathrm{CMD}-\mathrm{CMS}$

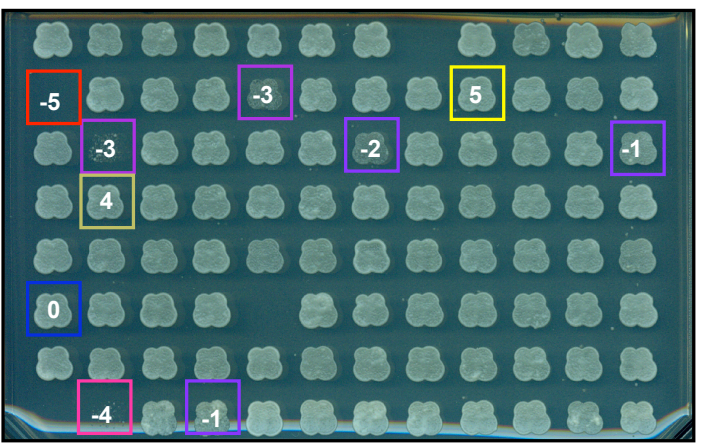

Figura 3. Ejemplo del uso del algoritmo de crecimiento relativo (RG), dónde el crecimiento del doble mutante (CMD) es sustraído al crecimiento del mutante sencillo (CMD).

muerte de los mutantes parentales, y los valores positivos indican aquellas interacciones capaces de atenuar el fenotipo esperado, es decir suprimir el defecto de crecimiento de los mismos o no empeorarlo. Dichas interacciones negativas fueron definidas bajo los términos sintética letal (del inglés synthetic lethal) y sintética enferma (del inglés synthetic sick) y supresora (del inglés suppressive) Adicionalmente, en este estudio incluimos las variantes fuerte y débil al término sintético enfermo.

\subsubsection{Pre-procesamiento y normalización}

Los datos finales de crecimiento relativo se anotaron en tablas de Excel comparando el resultado inspeccionado in situ con las imágenes adquiridas. Para la normalización y corrección de los falsos resultados en el escrutinio, se tuvieron en cuenta diferentes parámetros que incluyen: i) los datos de crecimiento en líquido en YES y YES con G418 de las cepas de la colección, ii) el fenotipo de crecimiento de las cepas de la colección en agar (Algoritmo RG), iii) diferencias de crecimiento en el tiempo, iv) el efecto de la 


\section{Materiales y Métodos}

ausencia de una colonia sobre la colonia vecina y v) el efecto de genes ligados, estableciendo $200 \mathrm{~Kb}$ como distancia crítica, de acuerdo a lo descrito por Collins et al., 2006.

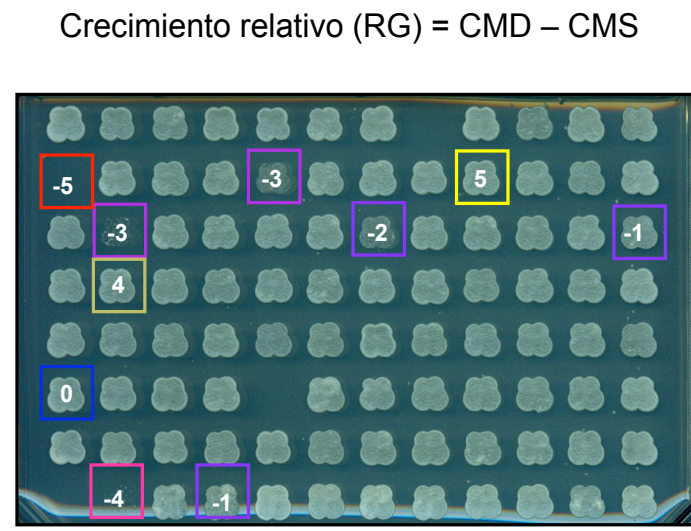

RANGO DE PUNTUACIÓN

\section{DEFINICIÓN DE LAS}

INTERACCIONES
-5: Letal

-4: Enfermo fuerte

-3: Enfermo fuerte

-2: Enfermo débil

-1 : Enfermo débil

0 : Ninguna interacción

+5 : Supresor

Figura 4. Rango de puntuación generado a partir de la aplicación del algoritmo RG. Los valores están comprendidos entre valores positivos y negativos desde cero con un máximo de cinco en ambos casos. Los valores negativos relacionan aquellas interacciones genéticas definidas como letal, enfermo fuerte o enfermo

\subsubsection{Control de calidad y grado de confianza}

Para validar los resultados preliminares obtenidos en el escrutinio, cada uno de los mutantes identificados se inocularon y se ordenaron de nuevo en placas de 96 pocillos. Con dichas placas se repitió el escrutinio siguiendo el mismo procedimiento resumido en el apartado 3.2.11. Este escrutinio se realizó por triplicado y finalmente, sólo se consideraron como positivos a aquellas interacciones con un resultado reproducible al menos en dos réplicas del escrutinio. La mayoría de los positivos fueron comprobados mediante un análisis de esporas al azar y cuya metodología se describe en el apartado 8.3.2. 
Teniendo en cuenta los resultados por triplicado, se calculó el crecimiento relativo promedio (del inglés Averaged Relative Growth; ARG) de las interacciones. Para corregir la variabilidad entre los valores obtenidos por cada validación en el SGA y el sesgo en el ARG, se calculó el coeficiente de varianza (CV). Para los genes pertenecientes a la categoría SL3 y SUP3 con un CV $\geq 0,5$, se eliminó el valor de interacción que se alejaba de la tendencia de los dos restantes y se recalculó la media aritmética sólo con dichos valores. Por último, en el caso de los genes pertenecientes a la categoría SL2 y SUP2 con un $C V \geq 0,5$, se definió el $A R G$ seleccionando únicamente el valor mas cercano a cero observado entre las dos validaciones que mostraron una reproducibilidad con el fin de evitar la sobreestimación del grado de interacción. En los casos con un $C V<0,5$, se mantuvo el ARG como producto del cálculo de la media aritmética entre los valores observados. En consecuencia, el RG fue normalizado a ARG en función de la susceptibilidad de la interacción a la variación entre los crecimientos relativos estimados dependientes de la ejecución de cada validación.

\section{Análisis fenotípico de los mutantes que interactúan con wee1-50 y cdc2-3w}

\subsection{Estado morfológico y citológico}

Con algunos mutantes identificados en el escrutinio, se realizó un análisis del estado morfológico y citológico mediante tinciones de la pared celular y el septo con calcoflúor, y del núcleo con DAPI respectivamente. Para esto, se fijaron células mutantes crecidas a $30^{\circ} \mathrm{C}$ hasta fase exponencial en medio YES y MM suplementado con adenina, leucina y uracilo.

\subsection{Estado de la dinámica del ciclo celular}

Para analizar el ciclo celular en los mutantes identificados en el escrutinio, se empleó una adaptación de la metodología desarrollada por Knutsen et al., 2011, con la cual es posible separar células en fase $\mathrm{G} 2$ con un contenido $2 \mathrm{C}$ de $\mathrm{ADN}$, de aquellas en fase $\mathrm{G} 1$ o mitosis tardía que también tienen el mismo contenido de ADN. Las condiciones y muestras experimentales fueron las mismas que las descritas en el apartado anterior.

\section{Ensayos bajo estrés nutricional}




\section{Materiales y Métodos}

\subsection{Estrés por nitrógeno. Análisis del ciclo celular}

Las células se crecieron en $15 \mathrm{ml}$ de medio rico YES durante una noche a $25^{\circ} \mathrm{C}$ y se mantuvieron en fase exponencial durante el día. Posteriormente, las células se lavaron dos veces con MM mediante filtración al vacío y se cambiaron a medio restrictivo (EMM) durante una noche para favorecer la adaptación de las células a los medios pobres. A la mañana siguiente, las células se lavaron de nuevo dos veces por filtración, pero esta vez con MM sin nitrógeno para eliminar los restos de nitrógeno anteriores. Se resuspendieron $2 \times 10^{6} \mathrm{cel} / \mathrm{ml}$ en matraces independientes con $40 \mathrm{ml}$ de EMM, MM con glutamato $20 \mathrm{mM}$, MM con leucina $20 \mathrm{mM}$, MM con fenilalanina $20 \mathrm{mM}$ y MM sin nitrógeno. Los cultivos se mantuvieron en fase exponencial hasta 24 horas a $25^{\circ} \mathrm{C}$ y se tomaron muestras a diferentes tiempos 0, 2, 4, 6, 8 y 24 horas. Las muestras se fijaron con etanol $70 \%$ y se almacenaron a $4^{\circ} \mathrm{C}$. Posteriormente se procesaron para su análisis por citometría y microscopía.

\subsection{Estrés por nitrógeno. Medición del tamaño celular y ensayos bioquímicos}

Los ensayos de medición celular bajo estrés por nitrógeno se realizaron en las siguientes condiciones experimentales: i) tres medios de cultivo incluyendo medio rico YES y MM con glutamato $20 \mathrm{mM}$ como una fuente rica en nitrógeno y MM con fenilalanina $20 \mathrm{mM}$ como una fuente pobre en nitrógeno; y ii) tres temperaturas $25^{\circ} \mathrm{C}, 32^{\circ} \mathrm{C}$ y $36^{\circ} \mathrm{C}$.

Para esto, se cultivaron células en $20 \mathrm{ml}$ de medio rico YES durante una noche a $25^{\circ} \mathrm{C}$ como preinóculo. Dicho preinóculo se dividió en 4 cultivos independientes con $20 \mathrm{ml}$ del mismo medio. Dos cultivos se incubaron a $25^{\circ} \mathrm{C}$, otro a $32^{\circ} \mathrm{C}$ y el restante a $36^{\circ} \mathrm{C}$. Cuando alcanzaron una D.O. ${ }_{(595 \mathrm{~nm})}$ igual a 0,5-0,6, se tiñó una muestra de cada cultivo in vivo con calcoflúor para determinar el tamaño celular, y se fijaron células para análisis por citometría de flujo. En paralelo, se dejó crecer uno de los cultivos incubados a $25^{\circ} \mathrm{C}$ hasta una D.O. (595nm) igual $0,8-0,9$ y se transfirieron las células a $20 \mathrm{ml}$ de $\mathrm{MM}$ glutamato 20 $\mathrm{mM}$, después de dos lavados con el mismo medio mediante filtración. Tras una noche, este preinóculo se dividió nuevamente en cuatro cultivos en MM glutamato $20 \mathrm{mM}$, de los cuales dos se incubaron a $25^{\circ} \mathrm{C}$, uno a $32^{\circ} \mathrm{C}$ y otro a $36^{\circ} \mathrm{C}$ hasta fase exponencial y seguidamente se tomaron muestras para una tinción con calcoflúor y un análisis por FACS. Finalmente, las células de uno de los cultivos incubados a $25^{\circ} \mathrm{C}$ se transfirieron a fenilalanina mediante filtración y se analizaron del mismo modo en fase exponencial. 


\subsection{Estrés por glucosa.}

Los ensayos de medición celular bajo estrés por glucosa se realizaron a $32^{\circ} \mathrm{C}$ en las siguientes condiciones experimentales: medio rico YES con glucosa $3 \%$, YES con glucosa $0,15 \%$ y MM con cloruro amónico y glucosa $0,1 \%$. La concentración de glucosa utilizada fue equivalente a $1 / 20$ de la estándar establecida para cada medio.

Como preinóculo las células se crecieron en $20 \mathrm{ml}$ de YES glucosa 3\% durante una noche. Se mantuvieron en fase exponencial durante el día y se transfirieron a tres nuevas condiciones: i) YES glucosa $3 \%$; ii) YES glucosa 2\%; iii) MM glucosa $2 \%$. Los dos últimas condiciones para adaptar las células a la condiciones finales de YES glucosa $0,1 \%$ y MM glucosa $0,1 \%$ respectivamente. Tras una noche de incubación, se lavaron las células por centrifugación dos veces con el medio siguiente y se inocularon nuevos cultivos de YES glucosa 3\%, YES glucosa 0,15\% y MM glucosa 0,1\% a una D.O. ${ }_{(595 \mathrm{~nm})}$ inicial de 0,2 . Finalmente, se mantuvieron durante 6 horas en fase exponencial y se tomaron muestras para mediciones celulares y citometría de flujo. En todos los casos, a pesar de utilizar concentraciones bajas de glucosa, los tiempos de generación fueron cercanos a los establecidos para el medio rico YES y MM estándar. Para evitar estrés osmótico se añadió a los medios bajos en glucosa glicerol 3\% según lo descrito en Bone et al., 1998 y Madrid et al., 2004.

\section{Ensayos de viabilidad en placa}

\subsection{Ensayos de gota en S. pombe}

Con el fin de observar una modulación en la temperatura restrictiva de las cepas ts en combinación con otra mutación, los ensayos se realizaron a cuatro temperaturas: $25^{\circ} \mathrm{C}, 30^{\circ} \mathrm{C}, 32^{\circ} \mathrm{C}$ y $36^{\circ} \mathrm{C}$ en placas de YEP-agar.

Para comprobar la termosensibilidad y garantizar el estado haploide de las cepas, se replicó una estría crecida previamente en YES-Agar a YEP-agar. Se seleccionó el clon adecuado de cada cepa y se inóculo un cultivo de $10 \mathrm{ml}$ que se mantuvo a $25^{\circ} \mathrm{C}$ durante una noche. Se ajustó la densidad del cultivo a una D.O. inicial de 0,1 (equivalente a $1 \times 10^{6}$ $\mathrm{cel} / \mathrm{ml}$ ) y se hicieron diluciones seriadas $1 / 10$ hasta $1 \times 10^{2} \mathrm{cel} / \mathrm{ml}$ en agua destilada estéril. De cada dilución se sembraron $5 \mu \mathrm{l}$ con una micropipeta multicanal (Finnpipette, Thermo 


\section{Materiales y Métodos}

scientific). Cada placa se incubó a las diferentes temperaturas.

Después de 16 horas de incubación, se adquirieron imágenes en monocapa de cada una de las cepas y condiciones evaluadas con una cámara digital Olympus C-5050 acoplada a un microscopio Olympus BX60, usando un objetivo 40x/0,40 AN. El crecimiento de las colonias se analizó hasta un periodo máximo de 72 horas.

\section{Técnicas de transformación}

\subsection{Transformación de S. pombe}

Para transformar células de $S$. pombe se siguió una modificación del método del acetato de litio (LiAc) descrito por Bähler et al., 1998. En cada transformación se emplearon $2 \times 10^{8}$ células de un cultivo en crecimiento exponencial y entre 10-20 $\mu \mathrm{g}$ de DNA. Para empezar se lavaron las células mediante centrifugación a $3000 \mathrm{rpm}$ durante 5 minutos a temperatura ambiente y se resuspendieron en una solución con acetato de litio (LiAc) $100 \mathrm{mM}$, Tris-HCl 10mM pH 8, EDTA $1 \mathrm{mM}$ y Sorbitol $1 \mathrm{M}$. Posteriormente, las células se incubaron en dicha solución durante 30 minutos a temperatura ambiente y tras una centrifugación se concentraron en un volumen de $100 \mu \mathrm{l}$. A este volumen se añadió 5 $\mu \mathrm{l}$ de $A D N$ de esperma de salmón previamente hervido y $10 \mu$ del ADN transformante. $A$ continuación, se incubó la mezcla durante 10 minutos a temperatura ambiente e inmediatamente se añadió $260 \mu \mathrm{l}$ de una solución de PEG 3,35 40\%, LiAc 1M y TE. Esta mezcla se mantuvo en incubación durante 45-60 minutos a temperatura ambiente y tras este periodo se añadió $43 \mu \mathrm{l}$ de DMSO a la mezcla y se aplicó un pulso de calor de 5 minutos a $42^{\circ} \mathrm{C}$. Después del pulso de calor, se centrifugaron las células a $2500 \mathrm{rpm}$ durante 5 minutos y se resuspendieron en $500 \mu \mathrm{l}$ de agua estéril. Finalmente, dicho volumen se dividió en tres partes iguales que fueron sembradas en YES-Agar e incubadas durante una noche a $25-32^{\circ} \mathrm{C}$. Después de una noche de recuperación de la células, se replicaron a placas de YES-Agar con los respectivos antibióticos según el marcador de selección integrado en el genoma (G418 y ClonNat). Las placas se incubaron a $25-32^{\circ} \mathrm{C}$ durante 3-6 días.

\subsection{Transformación de E. Coli}

Se siguió el protocolo descrito por Kushner (1978). Para esto, se descongelaron 70 $\mu \mathrm{l}$ de células competentes en hielo, se les añadió $5 \mu \mathrm{l}$ del ADN transformante y se incubaron 
durante 20 minutos. Seguidamente, se aplicó un pulso de calor de 90 segundos a $42^{\circ} \mathrm{C}$. Inmediatamente, se transfirieron a hielo y se mantuvieron en estas condiciones durante 1-2 minutos. Posteriormente, se añadió $400 \mu \mathrm{l}$ de medio de cultivo LB y se incubó la mezcla en agitación durante 1 hora a $37^{\circ} \mathrm{C}$. Finalmente, se resuspendieron las células en $100 \mu \mathrm{l}$ y se sembraron en placas de LB con el antibiótico frente al cual confiere resistencia el plásmido introducido, para este estudio ampicilina.

\section{Construcción de cepas de S. pombe}

\subsection{Deleción de genes}

Para delecionar $i g o 1^{+}, p p a 2^{+}, p a b 1^{+}$y $p p k 18^{+}$y para construir los mutantes sobreexpresores de $i g o 1^{+}, p p k 18^{+}$y $c d c 25^{+}$se siguieron los procedimientos descritos por Bähler et al, 1998

\subsubsection{Deleciones en un fondo genético haploide}

\subsubsection{Deleción de igo1 ${ }^{+}$}

El cassette de resistencia a la kanamicina kanMX6 fue amplificado por PCR a partir del plásmido pFA6A-kanMX6 (Bähler et al., 1998) utilizando los oligonucleótidos igo1-D1 e igo1-D2 (Tabla 5). Cada uno de estos, contiene 100 nucleótidos, dónde los primeros 80 del extremo 5' y el extremo 3' corresponden a la secuencia corriente arriba (upstream) del codón de inicio y corriente abajo (downstream) del codón de parada de la ORF igo ${ }^{+}$, respectivamente. Los restantes 20 nucleótidos corresponden a las secuencias flanqueantes del kanMX6 del plásmido. Dicho producto de PCR de 1,6 Kb fue utilizado para transformar S. pombe mediante recombinación homóloga. Para seleccionar aquellos clones con un reemplazamiento correcto, se llevaron a cabo reacciones de PCR de colonia con los oligonucleótidos igo1-C1 e igo1-C2, que anillan sobre los 200-300 nucleótidos inmediatamente anteriores al codón de inicio o posteriores al codón de parada de $i g o 1^{+}$. Asimismo, para construir algunos mutantes en un fondo de deleción de igo $1^{+}$, se intercambió el marcador kanMX6 por el natMX6 utilizando los oligonucleótidos swi-F1 y swi-R1.

\subsubsection{Deleción de ppa2 ${ }^{+}$}




\section{Materiales y Métodos}

\subsubsection{Deleción de ppa2 ${ }^{+}$}

En este caso, el gen $p p a 2^{+}$se reemplazó por el cassette de resistencia a la nourseotricina natMX6. Para esto, se utilizaron los oligonucleótidos ppa2-D1 y ppa2-D2 (Tabla 6) para amplificar dicho cassette a partir del plásmido pFA6A-natMX6 (Hentges et al., 2005). Para favorecer la amplificación se agregó DMSO 5\% a la reacción de PCR. EI producto de PCR de $1,2 \mathrm{~Kb}$ se empleó para transformar $S$. pombe y los clones recombinantes se comprobaron utilizando los oligonucleótidos ppa2-C1 y ppa2-C2 mediante PCR de colonia. Tomando ventaja de la existencia de un único sitio de restricción Nru1 en el gen marcador natMX6 y de su ausencia en la ORF del gen ppa2 ${ }^{+}$, se digirió el producto de PCR de 1,4 Kb amplificado con los oligonucleótidos mencionados anteriormente, y se seleccionó como clones positivos aquellos dónde la digestión enzimática generó dos fragmentos de 900 pb y 600 pb.

\subsubsection{Deleción de pab1 ${ }^{+}$}

Al igual que la deleción de igo $1^{+}$, la ORF de $p a b 1^{+}$se reemplazó por el marcador de resistencia a la kanamicina kanMX6. Para amplificar el cassette, a partir del plásmido pFA6A-kanMX6 (Bähler et al., 1998), se utilizaron los oligonucleótidos pab1-D1 y pab1D2 y se confirmó la integración en el genoma mediante PCR con los oligonucleótidos pab1-C1 y pab1-C2. Los dobles mutantes que incluyen la deleción de pab1 $1^{+}$fueron obtenidos siguiendo esta misma metodología.

\subsubsection{Deleción en un fondo genético diploide}

\subsubsection{Construcción del diploide $\mathrm{h}+/ \mathrm{h}$ -}

Se cruzaron los parentales con el genotipo descrito en la Tabla 4 en MEA a $32^{\circ} \mathrm{C}$ durante 18-20 horas. Seguidamente, se estrío el cruce en MM-Agar sin aminoácidos y se incubó a $32^{\circ} \mathrm{C}$ durante 2-3 días o hasta ver colonias muy pequeñas, las cuales fueron aisladas inmediatamente en YES-Agar a $32^{\circ} \mathrm{C}$. Una vez crecidas, se replicaron a YEPAgar y MEA, se incubaron a $25^{\circ} \mathrm{C}$ y finalmente se seleccionaron aquellas colonias con color rojo intenso y que formaron ascas acigóticas. El genotipo del diploide construido fue $h-/ h+$ ade6-M216/ade6-M210 ura4-D18/ura4-D18 leu1-32/leu1-32. 
Tabla 4. Cepas parentales para la construcción del diploide

\begin{tabular}{lll}
\hline Cepa & Genotipo & Procedencia \\
\hline S1348 & $h$ - ade6-M210 leu1-32 ura4-D18 & Sergio Moreno \\
S1349 & $h+$ ade6-M216 leu1-32 ura4-D18 & Sergio Moreno \\
\hline
\end{tabular}

\subsubsection{Deleción de ppk18 ${ }^{+}$}

Utilizando los oligonucleótidos ppk18-D1 y ppk18-D2 (Tabla 6) se amplificó el cassette kanMX6 a partir del plásmido pFA6A-kanMX6 (Bähler et al., 1998). Con el producto de PCR de $1,6 \mathrm{~Kb}$ se transformó la cepa diploide descrita en el apartado anterior. Se comprobaron los clones diploides con un reemplazamiento correcto mediante PCR de colonia utilizando los oligonucleótidos ppk18-C1 y ppk18-C2. Tras esta comprobación, se indujo la esporulación en aquellos clones positivos y se seleccionaron los clones haploides resistentes a geneticina entre los productos meióticos obtenidos. Finalmente, se comprobaron dichos haploides por PCR de colonia utilizando los mismos oligonucleótidos.

\subsection{Integración de la construcción KanMX6-p3nmt1-3HA en el locus ppk18+}

En este caso, la amplificación de la construcción KanMX6-p3nmt1-3HA con las zonas de homología para su integración en el extremo $5^{\prime}$ del gen $p p k 18^{+}$, se llevó a cabo utilizando los oligonucleótidos OE Ppk18-F1 y OE 3HA-Ppk18-R1. Para dirigir la recombinación homóloga en el extremo $5^{\prime}$ de la ORF del gen, el F1 se diseñó en sentido 5'a 3', con los 80 nucleótidos aguas arriba al codón de inicio de ppk18 ${ }^{+}$y 20 nucleótidos que anillan cerca del extremo 3'del gen kanMX6 del plásmido. En el caso del F2, se diseño desde el extremo 5', con los primeros 80 nucleótidos aguas abajo del codón de inicio de $i g o 1^{+}$y 20 nucleótidos que anillan cerca del extremo $3^{\prime}$ del gen nmt1. Con el producto de 2,9 Kb se transformó $S$. pombe. De igual modo, se seleccionaron los clones recombinantes empleando las parejas de oligonucleótidos ppk18-C1/ Kan-C2 y C1-nmt1/ OE 3HA-Ppk18 12, las cuales generaron dos fragmentos de 301 pb y 334 pb respectivamente, y se secuenciaron para confirmar la integración correcta de la construcción.

\subsection{Cruces genéticos}




\section{Materiales y Métodos}

Para construir dobles mutantes, los mutantes sencillos se cruzaron en medio de esporulación MEA y se incubaron a $25^{\circ} \mathrm{C}$ durante 2-4 días. Tras este periodo, se comprobó al microscopio la formación de ascas cigóticas, como producto de una conjugación apropiada. Todos los dobles mutantes empleados en este estudio, excepto aquellos generados en el escrutinio de sintéticos letales y aquellos dobles con el mutante de deleción pab1 $1 \Delta$, fueron obtenidos mediante disección de tétradas. En el caso del escrutinio, los dobles mutantes fueron obtenidos por análisis de esporas al azar y los dobles mutantes con el mutante pab1 $\Delta$ mediante transformación.

\subsubsection{Disección de tétradas}

Para la disección de las tétradas, los mutantes sencillos se cruzaron en MEA durante 2 días. Una vez comprobada la eficiencia del cruce, las 4 esporas de cada asca se separaron ordenamente con un micromanipulador (Singer Instruments) sobre placas de YES-Agar. Una vez germinadas, se analizó el genotipo de cada una y la segregación apropiada.

\subsubsection{Análisis de esporas al azar}

Para comprobar las interacciones genéticas negativas identificadas en el escrutinio de sintéticos letales, se repitieron los cruces de forma manual, sin utilizar el replicador de puntas de acero. Para esto, inicialmente se sembraron tanto las cepas de interés como las cepas diana en placas de YES. Tras 2 días de crecimiento a $25^{\circ} \mathrm{C}$, se resuspendieron por separado, cada cepa diana y de interés con un palillo estéril en placas de 96 pocillos con 40ul de agua estéril. Seguidamente se ajustaron las densidades para ambas cepas y se mezclaron en un mismo pocillo en relación 1:1 (diana: interés). Posteriormente, empleando una micropipeta multicanal, se sembraron $2,5 \mu \mathrm{l}$ del volumen total del cruce en placas de MEA a $25^{\circ} \mathrm{C}$ durante 4 días. Finalmente, las placas se sellaron y se guardaron a $4^{\circ} \mathrm{C}$.

Para el análisis de esporas al azar, se resuspendió un poco de la biomasa de las colonias en placas de 96 pocillos con $150 \mu$ de agua estéril y $5 \%$ de $\beta$-glucoronidasa (Sigma-Aldrich) y se incubaron las placas a $25^{\circ} \mathrm{C}$ durante una noche. Al siguiente día, las colonias fueron sometidas a un pulso de calor de $55^{\circ} \mathrm{C}$ durante $45-60$ minutos para eliminar remanentes de células vegetativas. A continuación, las colonias se lavaron dos veces con agua estéril, se resuspendieron en $100 \mu \mathrm{l}$ de agua estéril y se sembraron 
en relación 1:2:2:4 en placas de YES, YES-Nat, YES-G418 o YES-G418-Nat. Tres días después, se registró el número de colonias viables y se comparó el número y tamaño de las colonias que crecieron sobre el medio con un antibiótico con respecto al medio con dos antibióticos. Finalmente, los resultados se digitalizaron y se describieron las interacciones cualitativamente como: i) interacción sintética y ii) interacción sintética enferma fuerte (del inglés synthethic lethal, synthethic sick).

\section{Técnicas de manipulación del ADN}

\subsection{Métodos de extracción}

\subsubsection{Extracción de ADN genómico de S. pombe}

Para extraer el ADN genómico se recogieron $10 \mathrm{ml}$ de cultivo en fase estacionaria. Tras centrifugar a $3000 \mathrm{rpm}$ durante 5 minutos, las células se resuspendieron en $1 \mathrm{ml}$ de una solución de citrato/fosfato $50 \mathrm{mM}$, EDTA $40 \mathrm{mM}$, sorbitol 1,2 $\mathrm{M}$ a la que se la había añadido 2,5 mg de Zimoliasa 20T (Seikagaku Corporation), la cual rompe la pared celular de la levadura. Las células fueron incubadas a $37^{\circ} \mathrm{C}$ en esta solución durante 30 minutos. Transcurrido este periodo, se comprobó al microscopio que al añadir SDS 1\% las células perdían su refringencia.

A continuación, las células se centrifugaron durante 10 segundos y se resuspendieron en $550 \mu \mathrm{l}$ de TE con SDS 1\%. Las células se incubaron en esta solución durante 15 minutos a $65^{\circ} \mathrm{C}$. Para precipitar las proteínas, se añadió $175 \mu \mathrm{l}$ de acetato potásico $5 \mathrm{M}$ y se incubó la solución en hielo durante 5 minutos. Seguidamente, se centrifugó durante 15 minutos a $4^{\circ} \mathrm{C}$ y se pasaron $500 \mu \mathrm{l}$ del sobrenadante a otro tubo.

Para precipitar los ácidos nucleicos, se añadió $500 \mu \mathrm{l}$ de isopropanol al sobrenadante y se mantuvo a $-20^{\circ} \mathrm{C}$ durante, al menos 10 minutos. A continuación, se centrifugó a $10.000 \mathrm{rpm}$ durante 15 minutos a $4^{\circ} \mathrm{C}$ y se lavó el precipitado con $500 \mu \mathrm{l}$ de etanol $70 \%$ frío.

Para eliminar el ARN, se resuspendió el precipitado en $350 \mu \mathrm{l}$ de TE con $50 \mu \mathrm{g} / \mathrm{ml}$ de RNasa (Roche) y se incubó a $65^{\circ} \mathrm{C}$ durante 10 minutos. 


\section{Materiales y Métodos}

A continuación, se hicieron dos extracciones con fenol utilizando $500 \mu \mathrm{l}$ de fenol: cloroformo 1:1. El ADN se precipitó con $40 \mu \mathrm{l}$ de acetato sódico 3M y $750 u l$ de etanol frío y se mantuvo a $-20^{\circ} \mathrm{C}$ durante, al menos 10 minutos. Por último, se centrifugó a 10.000 rpm durante 10 minutos, se lavó el precipitado de ADN con $1 \mathrm{ml}$ de etanol al $70 \%$ y se dejó secar. El ADN se resuspendió en $50 \mu \mathrm{l}$ de TE.

\subsubsection{Extracción de ADN plasmídico de E. coli}

Para extraer el ADN plasmídico de E. coli, en el caso que el ADN se fuera a emplear para secuenciar, transformar o clonar, se utilizaron columnas Quiaprep Spin Miniprep (Quiagen) siguiendo las instrucciones del fabricante.

Cuando no fue necesario que el ADN fuera de alta calidad, se siguió el protocolo de lisis hervido (Holmes y Quigley, 1981; Sambrook et al., 1989). Para ello, se inocularon 2 $\mathrm{ml}$ de medio LB con ampicilina $(50 \mu \mathrm{g} / \mathrm{ml})$ y se incubaron durante una noche a $37^{\circ} \mathrm{C}$. A continuación, se centrifugaron $1,5 \mathrm{ml}$ de cultivo y las células se resuspendieron en $200 \mu \mathrm{l}$ de tampón de lisis STET (sacarosa 8\%, Triton X-100 0,5\%, EDTA 50 mM y Tris-HCl 10 $\mathrm{mM} \mathrm{pH}$ 8). Se añadieron $140 \mu \mathrm{g}$ de lisozima (Roche) para degradar la pared de las bacterias. Posteriormente, las células se hirvieron durante 1 minuto y se centrifugaron inmediatamente durante 10 minutos a $13.200 \mathrm{rpm}$. Los restos celulares se retiraron con un palillo. Para precipitar el ADN, se añadieron $200 \mu \mathrm{l}$ de isopropanol y se centrifugó a $4^{\circ} \mathrm{C}$ durante 15 minutos. Para lavar el ADN precipitado, se emplearon $500 \mu l$ de etanol $70 \%$ frío y se centrifugó durante 5 minutos a $10.000 \mathrm{rpm}$. El precipitado, una vez seco, se resuspendió en $50 \mu \mathrm{l}$ de TE con $10 \mu \mathrm{g}$ de RNasa (RNasa $10 \mathrm{mg} / \mathrm{ml}$, Roche).

\subsection{Digestión de ADN con enzimas de restricción}

La digestión de moléculas de ADN se llevó a cabo utilizando endonucleasas de restricción de Thermo Scientific y New England Biolabs. Las soluciones tampones utilizadas y la temperatura a las que se realizaron las digestiones fueron, en cada caso, las recomendadas por el fabricante.

\subsection{Electroforesis de fragmentos de ADN}

La separación por tamaños de las moléculas de ADN se llevó a cabo mediante la 
electroforesis en geles de agarosa. En función del tamaño de las moléculas a separar, se prepararon geles entre el $0,5 \%$ y el $3 \%$ de agarosa (Seakem® LE). Para preparar el gel y electroforesis se utilizó TAE (Tris-acetato $40 \mathrm{mM}$ pH 8.0 , EDTA $1 \mathrm{mM}$ ) y se añadió 0,5 $\mathrm{ug} / \mathrm{ml}$ de bromuro de etidio, para su visualización bajo la irradiación con luz UV. Los tamaños de las moléculas se estimaron comparando con el marcador de tamaño molecular 1kB plus DNA ladder (Invitrogen). Se emplearon cubetas de Apelex y fuentes para electroforesis de BioRad. Las separaciones electroforéticas se hicieron a voltaje constante $(90 \mathrm{~V})$.

\subsection{Purificación de fragmentos de ADN}

Para la extracción de ADN de los geles de agarosa y para la purificación de los productos de PCR se utilizaron los kits JETquick Gel Extraction Spin (Genomed) y JETquick PCR Purification (Genomed), respectivamente. EI ADN purificado se eluyó en TE.

\subsection{Plásmidos}

En la Tabla 5 se detallan los plásmidos utilizados en este trabajo y se específica su procedencia y el fin de su uso.

Tabla 5. Plásmidos

\begin{tabular}{|c|c|c|c|}
\hline Nombre & Descripción & Aplicaciones & Procedencia \\
\hline p901 & pBluescriptKS-ura4 ${ }^{+}$ & Deleción de igo1 ${ }^{+}$ & Col. S. Moreno \\
\hline p799 & pFA6a-kanMX6 & Deleción de $i g o 1^{+}, p a b 1^{+}$y $p p k 18^{+}$ & Col. S. Moreno \\
\hline p1134 & pFA6a-natMX6 & Deleción de $p p a 2^{+}$ & Col. S. Moreno \\
\hline p910 & pFA6a-kanMX6-nmt1-3HA & Sobreexpresión fuerte de $3 H A-p p k 18$ & Col. S. Moreno \\
\hline p1064 & pBluescriptSK+ & Clonaje de la ORF de $i g o 1^{+}$ & Col. S. Moreno \\
\hline p1210 & pBluescriptSK+-igo1 ${ }^{+}$ & Integración y mutagénesis del gen $i g o 1^{+}$ & Este trabajo \\
\hline
\end{tabular}

\subsection{Determinación de la concentración de ADN}

La concentración de ADN, tanto de doble como de cadena sencilla, se estimó midiendo la absorbancia a $260 \mathrm{~nm}$ en un espectrofotómetro NanoDrop 1000 (Thermo Scientific), considerando una relación de absorbancia 260/280 de 1,8 como estimación del grado de pureza del ADN. 


\section{Materiales y Métodos}

\subsection{Reacciones de amplificación de ADN (PCR)}

Para amplificar fragmentos de ADN mediante PCR se utilizaron ADN polimerasas Taq de Roche, Stratagene y Bioline, junto con las soluciones tampón recomendadas en cada caso por el fabricante. En algunos casos se utilizaron ADN polimerasas con actividad de corrección de errores, como la High Fidelity de Roche y la PfuTurbo de Stratagene. En otros casos, como PCR de colonia, se empleó la ADN polimerasa Biotaq $^{\text {TM }}$ de Bioline y como ADN molde, biomasa de levadura previamente calentada en el microondas a máxima potencia durante 1,5 minutos antes de llevar a cabo la reacción de amplificación. En todos los casos, la mezcla de reacción contuvo: i) ADN molde (100200 ng de ADN genómico ó 15-20 ng de ADN plasmídico; ii) 100 pmoles de cada oligonucleótido; iii) 25 pmoles de cada dNTP (Roche) y iv) 2,5 U de la polimerasa correspondiente en $100 \mu \mathrm{l}$ de solución tamponada. Las reacciones de amplificación de ADN se realizaron en un termociclador T3000 de Biometra. Las condiciones fueron dependientes del tamaño de la secuencia, las recomendaciones del fabricante de la enzima y los oligonucleótidos utilizados.

\subsubsection{Lista de oligonucleótidos utilizados}

Los oligonucleótidos utilizados como cebadores en las reacciones de amplificación de ADN, fueron sintetizados por Thermo Scientific y Sigma-Aldrich. La Tabla 6 especifica los oligonucleótidos utilizados en este trabajo, junto con sus respectivas aplicaciones.

\subsection{Secuenciación de ADN}

La secuenciación se llevó a cabo en el servicio de Genómica del IBMCC, utilizando un secuenciador ABI Prism 3100 (Applied Biosystem).

\subsection{Mutagénesis dirigida: construcción del mutante igo1-S64A e igo1-S64E}

\subsubsection{Construcción de la cepa igo1::ura4+}

Para la construcción de la cepa igo1::ura4+ se siguió el protocolo descrito por Bähler et al., 1998. Inicialmente, se amplificó el gen marcador $u r a 4^{+}$desde el plásmido pBluescriptKS-ura $4^{+}$utilizando los oligonucleótidos igo1-D1 ura4 ${ }^{+}$y igo1-D2 ura4 ${ }^{+}$. 
Tabla 6. Oligonucleótidos

\begin{tabular}{|c|c|c|}
\hline Nombre & Secuencia & Aplicación \\
\hline wee1-50:nat F1 & $\begin{array}{l}\text { GATCTTGCTGAATGGCAAATAATTGGTTATGTT } \\
\text { TATGGAAAATGCCACGATTTACTAACGAAGTTT } \\
\text { AATAACCCGTTAGACGGATCCCCGGGTTAATT } \\
\text { AA }\end{array}$ & $\begin{array}{l}\text { Construcción de la cepa } \\
\text { wee } 1^{+} \text {:natMx6 } \\
\text { y }\end{array}$ \\
\hline wee1-50:nat R1 & $\begin{array}{l}\text { TTCTAACTTTTCTGTTTCAAAATAAATGTTTATT } \\
\text { TAGATATGAAGTGTTAAACGGGTCATTAAAATC } \\
\text { CTATACTAATTTGGAATTCGAGCTCGTTTAAAC }\end{array}$ & $\begin{array}{l}\text { Construcción de la cepa } \\
\text { wee } 1^{+} \text {:natMx6 y wee1-50:natMx6 }\end{array}$ \\
\hline wee1-50:nat C1 & GTAGACTCGGCTTCAGAGGA & $\begin{array}{l}\text { Construcción de la cepa } \\
\text { wee } 1^{+} \text {:natMx6 y wee1-50:natMx6 }\end{array}$ \\
\hline wee1-50:nat C2 & GCTTCAGAATTTCTCTCATT & $\begin{array}{l}\text { Construcción de la cepa } \\
\text { wee } 1^{+} \text {:natMx6 y wee1-50:natMx6 }\end{array}$ \\
\hline cdc2-3w:nat F1 & $\begin{array}{l}\text { ССTCATTTATACTATATTCTATTTACATATTTTT } \\
\text { TATACTTAAGTATTAAAAAAGGTGTATATTCTTT } \\
\text { AGACTTTAGTTTCGGATCCCCGGGTTAATTAA }\end{array}$ & $\begin{array}{l}\text { Construcción de la cepa cdc2- } \\
3 w: n a t M x 6\end{array}$ \\
\hline cdc2-3w:nat R1 & $\begin{array}{l}\text { TAGACTTAAGCTGTAAATGATGCTCGCTTAGC } \\
\text { GTTCAATATAGTGTGAAATACAAATATTCATAT } \\
\text { CACTTTCATCTTGTAGAATTCGAGCTCGTTTAA } \\
\text { AC }\end{array}$ & $\begin{array}{l}\text { Construcción de la cepa cdc2- } \\
3 w: n a t M x 6\end{array}$ \\
\hline cdc2-3w:nat C1 & GCCATTAAATGTGAATTTAG & $\begin{array}{l}\text { Construcción de la cepa cdc2- } \\
3 \text { w:natMx6 }\end{array}$ \\
\hline cdc2-3w:nat C2 & GTGCATGCGCAGTTTAATGG & $\begin{array}{l}\text { Construcción de la cepa cdc2- } \\
3 w: n a t M x 6\end{array}$ \\
\hline igo1-D1 & $\begin{array}{l}\text { ATCGACAAAATTACGTATGATACCTAATACGTT } \\
\text { AACAGTGCGGTATCTTAGGCTTCGGTAGACAA } \\
\text { GTGGCCGTGTGGTATCGTACGCTGCAGGTCG } \\
\text { AC }\end{array}$ & Deleción de igo1 ${ }^{+}$ \\
\hline igo1-D2 & $\begin{array}{l}\text { ACGACAAGCAATACCAAATTTTAAGAGCCAAG } \\
\text { CCAAATTAAACCTCCAACCTTGTCGCAAAAATA } \\
\text { GCAACGTGTATGACCATCGATGAATTCGAGCT } \\
\text { CG }\end{array}$ & Deleción de igo $1^{+}$ \\
\hline
\end{tabular}




\section{Materiales y Métodos}

\begin{tabular}{|c|c|c|}
\hline igo1-C1 & AGATTAGCTCATTCAGCCGC & $\begin{array}{l}\text { Comprobación de la deleción de } \\
\text { igo } 1^{+} \text {y sobreexpresión de lgo1 }\end{array}$ \\
\hline igo1-C2 & CAGAAGTGTTGTCCTCCATC & $\begin{array}{l}\text { Comprobación de la deleción de } \\
\text { igo } 1^{+}\end{array}$ \\
\hline ppa2-D1 & $\begin{array}{l}\text { CGGTCTCAACTTACCAAAAGCAACACACGGTTAGA } \\
\text { AAGACTTATAACTTGCTTTTTACTATATACAAAATTC } \\
\text { CATAATTACGTACGCTGCAGGTCGAC }\end{array}$ & Deleción de ppa2 $2^{+}$ \\
\hline pab1-D2 & $\begin{array}{l}\text { TTAACTCAAAAATCAGAAAGGTGGATAAATTTTTTG } \\
\text { AAACAATCACAATCGATTGATCACTCATTAGAGAAT } \\
\text { TGAAACTTATCGATGAATTCGAGCTCG }\end{array}$ & Deleción de $p p a 2^{+}$ \\
\hline ppa2-C1 & AGAGTAGCCTGTCACСTCTG & $\begin{array}{l}\text { Comprobación de la deleción de } \\
\text { ppa2 }^{+}\end{array}$ \\
\hline ppa2-C2 & TTCGTATGCGGAGGATGTAC & $\begin{array}{l}\text { Comprobación de la deleción de } \\
\text { ppa2 }{ }^{+}\end{array}$ \\
\hline pab1-D1 & $\begin{array}{l}\text { AAGATCAAGATCTTCGTATACAATTGAAATTGGCAA } \\
\text { AGTGTACCAACGGGAACGAAATCTTAATATAATACG } \\
\text { AGTAGAAGCGTACGCTGCAGGTCGAC }\end{array}$ & Deleción de $p a b 1^{+}$ \\
\hline pab1-D2 & $\begin{array}{l}\text { TCCCGGAAGTTCAATAAAAAAGGAACTATGTTCAGT } \\
\text { CTATCCGTAGATCATAAAAACAAACCAAACTCCACA } \\
\text { TAAGGACAATCGATGAATTCGAGCTCG }\end{array}$ & Deleción de $p a b 1^{+}$ \\
\hline pab1-C1 & CGAAGAGTGGTGTAGATTCG & $\begin{array}{l}\text { Comprobación de la deleción de } \\
\text { pab1 } 1^{+}\end{array}$ \\
\hline pab1-C2 & GATTCACGGCATACATGAAG & Deleción de $p a b 1^{+}$ \\
\hline ppk18-D1 & $\begin{array}{l}\text { AATAACGAAACGCTAATTGTATTCGAATGGTTTTAC } \\
\text { TTGTCGCACATTAGGATCAAAATCTGAATGGAGTTA } \\
\text { TAAAGTTACGTACGCTGCAGGTCGAC }\end{array}$ & Deleción de $p p k 18^{+}$ \\
\hline ppk18-D2 & $\begin{array}{l}\text { TCGAGAAACAAAAAGGAAAAAATTAAAGAGAGTATG } \\
\text { GTAACAACAAAAAATGAGCAATCACGATTAACAAAC } \\
\text { GTTTGAACATCGATGAATTCGAGCTCG }\end{array}$ & Deleción de ppk18 $8^{+}$ \\
\hline
\end{tabular}


Materiales y Métodos

\begin{tabular}{|c|c|c|}
\hline ppk18-C1 & TGACACAGTCATCAAGAGCC & $\begin{array}{l}\text { Comprobación de la deleción de } \\
\text { ppk } 18^{+}\end{array}$ \\
\hline ppk18-C2 & CGTTCAGGAGAAGATGAGCT & $\begin{array}{l}\text { Comprobación de la deleción de } \\
\text { ppk18+ }\end{array}$ \\
\hline igo1-D1 ura4 ${ }^{+}$ & $\begin{array}{l}\text { ATCGACAAAATTACGTATGATACCTAATACGTTAAC } \\
\text { AGTGCGGTATCTTAGGCTTCGGTAGACAAGTGGCC } \\
\text { GTGTGGTATCGCCAGGGTTTTCCCAGTCACGAC }\end{array}$ & Deleción de $i g o 1^{+}$ \\
\hline igo1-D2 ura4 $^{+}$ & $\begin{array}{l}\text { ACGACAAGCAATACCAAATTTTTAAGAGCCAAGCCAA } \\
\text { ATTAAACCTCCAACCTTGTCGCAAAAATAGCAACGT } \\
\text { GTATGACCAGCGGATAACAATTTCACACAGGA }\end{array}$ & Deleción de igo $1^{+}$ \\
\hline igo1-D2 ura4 ${ }^{+}$ & $\begin{array}{l}\text { ACGACAAGCAATACCAAATTTTAAAGAGCCAAGCCAA } \\
\text { ATTAAACCTCCAACCTTGTCGCAAAAATAGCAACGT } \\
\text { GTATGACCAGCGGATAACAATTTCACACAGGA }\end{array}$ & Deleción de $i g o 1^{+}$ \\
\hline 5' igo1-BamHI & TTTTGGATCCGAGTATGCAAAGTCTTCGTC & $\begin{array}{l}\text { Clonaje de } i g o 1^{+} \text {en pBluescript } \\
\text { SK+ }\end{array}$ \\
\hline 3' igo1- EcoRI & TTTTGAATTCACGAAGAAAAGGAATGCGCG & $\begin{array}{l}\text { Clonaje de } i g o 1^{+} \text {en pBluescript } \\
S K+\end{array}$ \\
\hline igo1_S31A_F & $\begin{array}{l}\text { TTAACTGAAATAGAAATTAGCGCCAGAAGAACAGA } \\
\text { AGCTTTTCCG }\end{array}$ & Mutagénesis igo1:S31A \\
\hline igo1_S31A_R & $\begin{array}{l}\text { CGGAAAAGCTTCTGTTCTTCTGGCGCTAATTTCTAT } \\
\text { TTCAGTTAA }\end{array}$ & Mutagénesis igo1:S31A \\
\hline igo1_S64A_F & $\begin{array}{l}\text { AGGTAGAAAATACTTTGATGCCGGCGACTATGCCT } \\
\text { TAAACA }\end{array}$ & Mutagénesis igo1:S64A \\
\hline igo1_S64A_R & $\begin{array}{l}\text { TGTTTAAGGCATAGTCGCCGGCATCAAAGTATTTTC } \\
\text { TACCT }\end{array}$ & Mutagénesis igo1:S64A \\
\hline igo1_S64E_F & $\begin{array}{l}\text { CAAGGTAGAAAATACTTTGATGAAGGCGACTATGC } \\
\text { CTTAAACAAA }\end{array}$ & Mutagénesis igo1:S64E \\
\hline igo1_S64E_R & $\begin{array}{l}\text { TTTGTTTAAGGCATAGTCGCCTTCATCAAAGTATTTT } \\
\text { CTACCTTG }\end{array}$ & Mutagénesis igo1:S64E \\
\hline
\end{tabular}




\section{Materiales y Métodos}

\begin{tabular}{|c|c|c|}
\hline ig01_S102A_F & $\begin{array}{l}\text { CCGTGTTGTCAGTGCTGGGGCTCCTAATAAAGAGC } \\
\text { CGTCTC }\end{array}$ & Mutagénesis igo1:S102A \\
\hline igo1_S102A_R & $\begin{array}{l}\text { GAGACGGCTCTTTATTAGGAGCCCCAGCACTGACA } \\
\text { ACACGG }\end{array}$ & Mutagénesis igo1:S102A \\
\hline igo1_BamHI_out & TGGACGCAGCGATAAAATGC & $\begin{array}{l}\text { Comprobación del clonaje de } \\
\text { igo } 1^{+} \text {en pBluescript SK+ }\end{array}$ \\
\hline igo1_EcoRI_out & $\begin{array}{l}\text { TGGACGCAGCGATAAAATGCACGACAATAGTGCAA } \\
\text { TACGC }\end{array}$ & $\begin{array}{l}\text { Comprobación del clonaje de } \\
\text { igo } 1^{+} \text {en pBluescript SK+ }\end{array}$ \\
\hline pka1-C1 & СGCTCTTTCTATCTACGCTG & $\begin{array}{l}\text { Comprobación de la deleción } \\
\text { de } p k a 1^{+}\end{array}$ \\
\hline pka1-C2 & GTGCTACAAACGTCACTTGC & $\begin{array}{l}\text { Comprobación de la deleción } \\
\text { de } p k a 1^{+}\end{array}$ \\
\hline pka1-I1 & TTCCATGTCGCTGCTGTTCC & $\begin{array}{l}\text { Comprobación de la deleción } \\
\text { de } p k a 1^{+}\end{array}$ \\
\hline OE3HA-Ppk18 F1 & $\begin{array}{l}\text { AATAACGAAACGCTAATTGTATTCGAATGGTTTTAC } \\
\text { TTGTCGCACATTAGGATCAAAATCTGAATGGAGTTA } \\
\text { TAAAGTTAGAATTCGAGCTCGTTTAAAC }\end{array}$ & $\begin{array}{l}\text { Sobreexpresión de la } \\
\text { proteína 3HA-Ppk18 }\end{array}$ \\
\hline OE3HA-Ppk18 R1 & $\begin{array}{l}\text { AAATCTAACTCCAAGACATAAATGTTGTCTATTCCG } \\
\text { TGATTTACTTTGTTATCCTCGTTGGAATTGCGTTCTT } \\
\text { GCATTACGCACTGAGCAGCGTAATCTG }\end{array}$ & $\begin{array}{l}\text { Sobreexpresión de la } \\
\text { proteína 3HA-Ppk18 }\end{array}$ \\
\hline OE 3HA-Ppk18 I2 & GTAACATCGCCCGCTATTCC & $\begin{array}{l}\text { Comprobación de la } \\
\text { sobreexpresión de la proteína } \\
\text { 3HA-Ppk18 }\end{array}$ \\
\hline C1-nmt1 & GTCATTCGGCAATGTGCAGCG & $\begin{array}{l}\text { Comprobación de las } \\
\text { sobreexpresiones }\end{array}$ \\
\hline $\mathrm{ura4}^{+} \mathrm{C} 1$ & GTAGCGATATCATCATTGTTGG & Comprobación de deleciones \\
\hline $\mathrm{ura}^{+} \mathrm{C} 2$ & TGATAACACAGACATAGGGTCCA & Comprobación de deleciones \\
\hline
\end{tabular}




\begin{tabular}{ccc}
\hline swi_F1 & GACATGGAGGCCCAGAATAC & Intercambio de gen marcador \\
swi_R1 & TGGATGGCGGCGTTAGTATC & Intercambio de gen marcador \\
Kan-C1 & AGCTGCGCACGTCAAGACTG & Comprobación deleciones \\
Kan-C & CAGATGCGAAGTTAAGTGCG & Comprobación deleciones \\
\hline
\end{tabular}

Con el fragmento de $2,2 \mathrm{~Kb}$ se transformó células de $S$. pombe auxotróficas para uracilo. Los clones recombinantes se analizaron por PCR utilizando los oligonucleótidos igo1-C1 e igo1-C2. Adicionalmente, se analizó el comportamiento fenotípico de la construcción igo1::ura $4^{+}$comparado con el de la construcción igo1::kanMX6.

\subsubsection{Clonaje de igo1 ${ }^{+}$en pBluescriptSK-ura4+}

Como primer paso, se amplificó un fragmento de 1132 pb a partir de ADN genómico. Dicho fragmento comprendió los 302 pb de la región aguas arriba adyacente al codón de inicio de igo $1^{+}$, los 529 pb correspondientes a la ORF de igo1+ y los 301 pb de la región aguas abajo adyacente al codón de parada del mismo. La reacción de PCR, se realizó empleando oligonucleótidos que incluyeron los sitios de restricción BamHI y EcoRI en el extremo 5'y 3'respectivamente. A continuación, se purificó por columna el producto de PCR y se verificó su tamaño en un gel de agarosa de $0,8 \%$. Para clonar el fragmento de ADN en el plásmido pBluescriptSK + se digirieron el vector y el inserto con las enzimas de restricción apropiadas a $37^{\circ} \mathrm{C}$ durante una noche. Se separaron las moléculas resultantes en geles de agarosa y se purificó el ADN necesario para la ligación. Para evitar la religación del vector, antes de purificarlo se trató con fosfatasa alcalina (CIAP, 20U/ul, Roche) siguiendo las instrucciones del fabricante. Para la ligación, se empleó la enzima

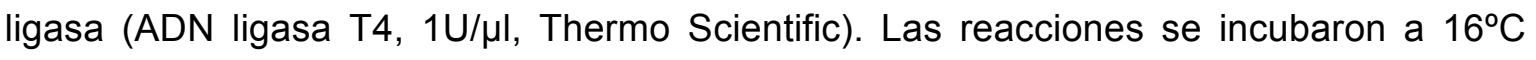
durante la noche. Se empleó la mitad de la reacción para transformar las células competentes de E. coli. Se extrajo el ADN plasmídico de los transformantes obtenidos y se comprobó mediante cortes con enzimas si contenían el inserto. Asimismo, se secuenciaron aquellos clones positivos empleando 400ng en cada reacción (Tabla 5).

\subsubsection{Mutagénesis}

Para la mutagénesis puntual del gen igo $1^{+}$se empleó el Kit QuikChange II XL Site- 


\section{Materiales y Métodos}

Directed Mutagenesis (Agilent Technologies) siguiendo las instrucciones del fabricante. En cada reacción de mutagénesis, se empleó, como ADN molde, 10ng del vector pBluescriptSK+-igo1 ${ }^{+}$y $125 \mathrm{ng}$ de los oligonucleótidos igo1-XXX-F1 y igo1-XXX-R1 que contenían la mutación deseada (Tabla 5), en un volumen de $50 \mu \mathrm{l}$. Posteriormente, los productos de PCR mutados, se trataron con la endonucleasa de restricción Dpnl (Agilent Technologies) para degradar el ADN plasmídico metilado parental y a continuación se transformaron células competentes de $E$. coli con 1/10 de la reacción de mutagénesis. Como paso final, se extrajo el ADN plasmídico de los transformantes y se comprobó si la mutagénesis fue correcta mediante digestiones con enzimas de restricción y secuenciación.

\subsubsection{Integración en el genoma de $S$. pombe}

Con el ADN plasmídico mutado, se transformaron células de $S$. pombe en las cuales el gen $i g 01^{+}$fue reemplazado previamente por el gen marcador $u r a 4^{+}$. Para llevar a cabo la transformación, se digirieron 3-5 $\mu \mathrm{g}$ del plásmido mutado con las enzimas BamHl y EcoRI, con el fin de separar el vector del inserto, y se precipitó dicha digestión para concentrar el ADN transformante. Para favorecer el crecimiento de los clones recombinantes, primero se recuperaron las células transformadas en $\mathrm{MM}$ con uracilo a $25^{\circ} \mathrm{C}$ durante una noche y tras este periodo, se realizó una doble contraselección en medio mínimo con ácido 5-Fluoroorótico 0,1\% (5-FOA; Apollo Scientific) a $25^{\circ} \mathrm{C}$. Finalmente, se comprobaron los clones positivos con la mutación deseada mediante la secuenciación de un fragmento de 1339 pb, amplificado por PCR, que incluía la ORF del gen igo $1^{+}$.

\section{Técnicas de manipulación de proteínas}

\subsection{Obtención de los anticuerpos policlonales anti-igo1}

\subsubsection{Obtención del anticuerpo anti-lgo1-C-terminal}

EI péptido C-GASSRRESVTRHDLE, correspondiente a la región carboxilo terminal de la proteína de Igo1, fue sintetizado por la empresa BioNova Científica S.L. Para obtener el anticuerpo, se inmunizó una coneja de raza neozelandesa. Antes de la inyección, para favorecer la respuesta inmune, el péptido se acopló a la proteína KHL (Keyhole Limpet Hemocyanin; Calbiochem) siguiendo el protocolo descrito por Sambrook et al. 1989. Para preparar la inyección, se utilizó $1 \mathrm{mg} / \mathrm{ml}$ del péptido acoplado con el 
adyuvante de Freund completo (Freund's Complete Adjuvant; Pierce) en relación 1:1 para incrementar la inmunogenicidad. Para las inmunizaciones restantes, se redujo a la mitad el antígeno y se mezcló con el adyuvante de Freund incompleto (Freund's Incomplete Adjuvant; Pierce). En total, se realizaron seis inyecciones de antígeno separadas por un intervalo de tres semanas y a partir, de la tercera inyección, se recogieron muestras de sangre pasados diez días del último pinchazo. Tras la sexta inmunización, se sangró en su totalidad al animal por el corazón. La obtención del suero a partir de la sangre y la purificación se realizó siguiendo la metodología descrita en Harlow y Lane, (1988), dónde previamente se acopló el mismo péptido, que se usó como antígeno, a una columna de afinidad CrBN-activated Sefarosa 4B (Amersharm Pharmacia Biotech). A la columna acoplada con el péptido, se añadió $12 \mathrm{ml}$ de suero. Tras una noche de incubación a $4^{\circ} \mathrm{C}$, la columna se lavó varias veces con $200 \mu \mathrm{l}$ de una solución de Tris- $\mathrm{HCl} 10 \mathrm{mM} \mathrm{pH} \mathrm{7,5} \mathrm{y}$ $0,5 \mathrm{M} \mathrm{NaCl}$, se comprobó una absorbancia $<0,01$ a $280 \mathrm{~nm}$ y se eluyó con glicina- $\mathrm{HCl}$ $100 \mathrm{mM} \mathrm{pH} \mathrm{2,6} \mathrm{para} \mathrm{obtener} \mathrm{el} \mathrm{anticuerpo.} \mathrm{Este} \mathrm{se} \mathrm{obtuvo} \mathrm{repartido} \mathrm{en} \mathrm{varias} \mathrm{fracciones}$ (100 $\mu \mathrm{l}$ de $1 \mathrm{M}$ Tris- $\mathrm{HCl}$ pH 8 y $900 \mu \mathrm{l}$ del eluído). En todos los experimentos de Western Blot se utilizó el anticuerpo purificado de la cuarta sangría.

\subsubsection{Obtención del anticuerpo fosfo-específico anti-S64-Igo1}

Se sintetizó el péptido C-GRKYFDSpGDYALNK fosforilado en la Ser 64 y correspondiente a la región central de la proteína Igo1. Asimismo, se sintetizó el péptido no fosforilado en el mismo residuo. La obtención del anticuerpo fosfo-específico se realizó de manera similar a la descrita en el apartado anterior. Con el fin de obtener el anticuerpo fosfoespecífico de la proteína Igo1, se purificó el suero de la cuarta sangría en dos etapas. En primer lugar, se acopló el péptido no fosforilado, para eliminar los anticuerpos contra el péptido no fosforilado. En la segunda fase, el flow-through de la etapa anterior, se cargó nuevamente en la columna de afinidad, pero en este caso con el péptido fosforilado acoplado. Se lavo y se eluyó de igual forma. Este procedimiento se repitió una vez más. Finalmente, se obtuvo el anticuerpo con alta afinidad por el péptido fosforilado de la proteína lgo1.

\subsection{Inmunodetección por Western Blot}

10.2.1 Preparación de extractos proteicos en condiciones desnaturalizantes 


\section{Materiales y Métodos}

Se empleó ácido tricloroacético (TCA) siguiendo una metodología modificada a la previamente descrito por Foiani et al. 1994. Para preparar los extractos de proteínas, se recogieron $2 \times 10^{8}$ células de $S$. pombe y se lavaron con $1 \mathrm{ml}$ de TCA $20 \%$ frío. Tras este paso, se resuspendieron en un volumen final de $50 \mu \mathrm{l}$ de TCA $20 \%$ y se congelaron a $20^{\circ} \mathrm{C}$.

Para la extracción de proteínas se añadió $500 \mu \mathrm{l}$ de bolas de vidrio (4mm; Sartorius) a las células, previamente descongeladas en hielo. A continuación, se rompieron en una Fast-prep (Bio-101) mediante tres ciclos de 15 segundos a potencia 5,5. A la suspensión de células rotas, se añadió $400 \mu \mathrm{l}$ de TCA $5 \%$ y se homogenizó con el vortex. La mezcla se transfirió a un tubo limpio haciendo un agujero en la base del tubo y centrifugando 10 segundos a $7000 \mathrm{rpm}$. Seguidamente, se centrifugó a $3000 \mathrm{rpm}$ durante 10 minutos y se eliminó el precipitado. Se añadió una solución de SDS-Tris base (60 $\mu \mathrm{l}$ de SDS 10\% y 40 $\mu \mathrm{l}$ Tris-base $1 \mathrm{M}$ en $200 \mu \mathrm{l}$ de agua destilada). Se hirvió la mezcla durante 5 minutos y para recuperar la proteínas, se centrifugó 2 minutos a 13200 rpm. Finalmente, se recuperó el sobrenadante y se congeló a $-20^{\circ} \mathrm{C}$.

\subsubsection{Valoración de la concentración de proteína en los extractos totales}

Antes de congelar se separó $1 \mu \mathrm{l}$ del extracto para valorar la concentración de las proteínas. En este caso, se empleó el kit Pierce тм BCA Protein Assay (Thermo Scientific). Se elaboró una recta patrón utilizando concentraciones conocidas de proteína BSA y se determinó mediante una reacción colorimétrica la concentración de las reacciones problema. Las lecturas de absorbancia se realizaron a $562 \mathrm{~nm}$ utilizando un espectrofotómetro modelo Hitachi U-2001.

\subsubsection{Electroforesis de proteínas en SDS-PAGE}

La separación de moléculas de proteínas se llevo a cabo en geles de poliacrilamida. Según el peso molecular, se prepararon geles entre el $10 \%$ y el $15 \%$ de poliacrilamida, con una mezcla de Protogel 30\% acrilamida: bisacrilamida (37,5:1 ratio; National Diagnostics) y SDS. En un caso particular, se emplearon geles de gradiente entre 8-16\% (Miniprotean TGX Precast gels; BioRad). Antes de la carga del gel, los extractos proteicos se hirvieron durante 5 minutos y se centrifugaron durante 2 minutos a máxima velocidad. Por cada extracto, se cargaron en total $45 \mu \mathrm{g}$ de proteína en un volumen final 
$15 \mu \mathrm{l}$ de SB 2X (Tris-HCl $80 \mathrm{mM} \mathrm{pH} \mathrm{6,8,} \mathrm{DTT} 5$ mM, SDS 2\%, glicerol 7,5\%, EDTA 5 mM y azul de bromofenol 0,002\%).

Para la electroforesis se emplearon cubetas Mini-Protean II (BioRad) y una solución de Tris $\mathrm{HCl} 25 \mathrm{mM}$, Glicina $192 \mathrm{mM}$ y SDS 0,1\% pH 8.3 como tampón de carrera. El apilamiento de las proteínas se llevó a cabo a un voltaje constante de $100 \mathrm{~V}$ y la separación de las proteínas a un amperaje constante de $20 \mathrm{~mA}$. Para estimar el peso molecular, se usó el marcador pre-teñido PageRuler ${ }^{\mathrm{TM}}$ Prestained Protein Ladder (Thermo Scientific). La electroforesis se llevó a cabo sobre una cama de hielo.

\subsubsection{Análisis por Western blot en membranas de PVDF}

Una vez separadas las proteínas fueron transferidas a una membrana de polifluoruro de vinilideno (PVFD), empleando como tampón de transferencia, una solución de CAPS $10 \mathrm{mM} \mathrm{pH} 11$ y metanol 10\%. El tiempo de transferencia fue de 1 hora y 40 minutos a un amperaje constante de $320 \mathrm{~mA}$. Toda la transferencia se llevó a cabo sobre una cama de hielo. Una vez finalizada, se tiñeron las membranas con el colorante Ponceau (BioRad) durante 10 minutos para evaluar la calidad de la transferencia. A continuación, se bloquearon las membranas con leche $5 \%$ (Sveltesse, Nestlé), Tris Base- $\mathrm{NaCl}$ (TBS) y Tween $0,05 \%$ durante, al menos 1 hora a temperatura ambiente. Para la detección de las proteínas, se empleó un anticuerpo específico contra la proteína en cuestión. Dependiendo del anticuerpo, la solución de incubación y el tiempo variaron. En algunos casos, se incubaron las membranas con leche $5 \%$ en TBS-Tween 0,05\% y en otros, con

BSA $5 \%$ (Sigma-Aldrich) en TBS-Tween 0,05\%. Asimismo, el tiempo mínimo de incubación fue de dos horas a temperatura ambiente o el máximo durante una noche a $4^{\circ} \mathrm{C}$. Tras este periodo y lavar el anticuerpo primario con TBS-Tween 0,05\% tres veces, se expusieron las membranas al anticuerpo secundario correspondiente, ligado a la peroxidasa de rábano para amplificar la señal. En todos los casos, la incubación fue de 45 minutos a temperatura ambiente. Seguidamente, se retiró el exceso de anticuerpo lavando cuatro veces con TBS-Tween $0,05 \%$. Para la detección colorimétrica, se emplearon los kits de detección Armersham (ECL ${ }^{\mathrm{TM}}$ Western Blotting Detection reagents, GE Healthcare), Advansta (Western Bright тм Quantum Western Blotting detection) у Thermo Scientific (Supersignal $₫$ West Dura Extended) y películas de revelado Agfa.

Para el control de carga, se incubaron las membranas con el anticuerpo anti-TAT1 o anti-Cdc2. Cuando se requirió incubar con un nuevo anticuerpo, se eliminó en su totalidad 


\section{Materiales y Métodos}

los anteriores con cloruro de guanidinio $7 \mathrm{M}$ y lavados sucesivos con TBS-Tween $0,05 \%$.

\subsection{Anticuerpos utilizados}

En la Tabla 6 se relacionan los anticuerpos utilizados en este estudio, incluyendo el propósito y sus condiciones de uso.

Tabla 6. Anticuerpos

\begin{tabular}{lllll}
\hline Anticuerpo & Organismo & Tipo & Condiciones & Procedencia \\
\hline anti-Igo1 (C-terminal) & conejo & policlonal & WB 1:200 & Este trabajo \\
anti-fosfo-S64-Igo1 & conejo & policlonal & WB 1:100 & Este trabajo \\
anti-HA (12CA5) & ratón & monoclonal & WB 1:5000 & Roche \\
Anti-fosfo-S51-Eif2-a & conejo & policlonal & Wb 1:1000 & Cell signaling \\
anti-AKT substrate & conejo & policlonal & WB 1:1000 & Cell signaling \\
(fosfo-S/T-RpS6) & & & & \\
Anti-Cdc2 & conejo & policlonal & Wb 1:50 & Sergio Moreno \\
anti-TAT1 (tubulina) & ratón & monoclonal & WB 1:3000 & K. Gull \\
anti-IgG-ratón & oveja & policlonal & WB 1:2500 & Amersham \\
anti-IgG-conejo & burro & policlonal & WB 1:3000 & Amersham \\
\hline
\end{tabular}

\section{Microscopía y tinciones}

\subsection{Microscopía de campo claro}

Se utilizó un microscopio Olympus BX60 con objetivos LMPlanFI 20x, 10x y 4x para observar las células durante los experimentos, estudiar el crecimiento de colonias en placa y para hacer recuentos de esporas en cámara Thoma. Para obtener imágenes se empleó una cámara digital Olympus C-5050 acoplada al microscopio.

\subsection{Microscopía de contraste interferencial (DIC) y fluorescencia}

Para capturar imágenes de tinciones con calcoflúor y DAPI se utilizaron los microscopios de fluorescencia verticales Nikon Eclipse 90i y Zeiss Axioplan 2, ambos equipados con una cámara CDD Hamamatsu modelo ORCA-ER y objetivos de inmersión Plan Apo-Chromat VC 60x y 63x respectivamente. Las imágenes fueron capturadas con el programa MetaMorph $®$ (Molecular devices) y Openlab (Improvision) respectivamente 
Para los ensayos de time-lapse se utilizó el microscopio confocal Olympus Spinning Disk con módulo FRAP láser equipado con una cámara IX2-UCB, empleando el objetivo de inmersión $60 x / 1,42 \mathrm{~A} / \mathrm{N}$. Las imágenes se adquirieron y se procesaron con el programa MetaMorph $®$ versión 7-7.10.0 (Molecular devices).

\subsubsection{Tinción de núcleos y septos con DAPI}

Para la tinción de núcleos con DAPI se recogió un volumen de cultivo correspondiente a $10^{7}$ células. Tras centrifugar y lavar una vez con agua destilada, las células se fijaron con $1 \mathrm{ml}$ de etanol frío al $70 \%$ y se guardaron a $4^{\circ} \mathrm{C}$ hasta su procesamiento. De cada muestra, se tomaron $100 \mu \mathrm{l}$ de células fijadas, las cuales se rehidrataron lavándolas con PBS $\left(\mathrm{NaCl} 137 \mathrm{mM}, \mathrm{KCl}\right.$ 2,7 mM, Na $\mathrm{HPO}_{4} 8 \mathrm{mM}, \mathrm{KH}_{2} \mathrm{PO}_{4}$ $1,5 \mathrm{mM} \mathrm{pH}$ 7,2). Seguidamente, se resuspendieron en $2 \mu \mathrm{l}$ de una solución de DAPI 0,1 $\mu \mathrm{g} / \mathrm{ml}$ de PBS (4,6-diamidino-2-fenilindol; Sigma-Aldrich). Se extendió la muestra sobre un portaobjetos previamente tratado con poli-L-lisina según las instrucciones del fabricante (Sigma-Aldrich). Se colocó un cubreobjetos y se observó la tinción nuclear al microscopio de fluorescencia.

\subsubsection{Mediciones celulares in vivo mediante tinción con blankophor}

Para la tinción con calcoflúor se tomaron $200 \mu \mathrm{l}$ de un cultivo en fase exponencial (D. $\mathrm{O}_{595 \mathrm{~nm}}$ entre 0,5 y 0,8 ). Se lavaron las células con PBS, se eliminó el sobrenadante y se resuspendieron en $3 \mu \mathrm{l}$ de blankophor $50 \mu \mathrm{g} / \mathrm{ml}$ (Bayer) y $2 \mu \mathrm{l}$ de PBS. La muestra, se extendió sobre un portaobjetos y se observó la tinción al microscopio de fluorescencia.

Una vez adquiridas las imágenes, se determinó el tamaño celular midiendo la longitud de las células septadas, ya que las células de $S$. pombe en la mitosis y la citoquinesis presentan una longitud celular constante. Los valores de la media y la desviación estándar se determinaron midiendo 100 células. La comparación entre cepas se hizo mediante el test de comparación $\mathrm{T}$ de Student para dos muestras independientes y para una muestra.

\subsubsection{Ensayos de time-lapse con fluorescencia}

Para seguir el comportamiento in vivo de una mitosis mediante fluorescencia, se realizó un ensayo de time-lapse en MM con fenilalanina $20 \mathrm{mM}$ a $32^{\circ} \mathrm{C}$, usando un portaobjeto 


\section{Materiales y Métodos}

durante 24 horas. Seguidamente, se transfirieron a MM con glutamato $20 \mathrm{mM}$, retirando el medio anterior por centrifugación, y se incubaron durante una noche. Al día siguiente, se retiró el medio del mismo modo y se inocularon las células a una D.O.(595nm) inicial de 0,5 en MM con fenilalanina $20 \mathrm{mM}$. Inmediatamente, se pre-incubaron durante 20 minutos en agitación a $32^{\circ} \mathrm{C}$. Durante este periodo, se trató un pocillo con lectina $10 \mathrm{mg} / \mathrm{ml}$ (L1395$5 \mathrm{MG}$ ) según las instrucciones del fabricante (Sigma-Aldrich) y se dejo secar al aire durante 20 minutos. Tras la pre-incubación, se dispensaron $300 \mu l$ del cultivo y se dejaron en contacto con la lectina durante 3 minutos. Finalmente, se retiró todo el volumen y se lavó dos veces con $200 \mu \mathrm{l}$ del mismo medio. A continuación, se tomaron imágenes de las células cada dos minutos durante 2 horas. Cada imagen fue el producto de la proyección máxima de 7 planos transversales de la célula, tomados cada $0,5 \mu \mathrm{m}$.

\section{Citometría de flujo}

\subsection{Fijación y tinción de las células}

Esta técnica se utilizó para analizar el contenido de ADN de las células en las diferentes etapas del ciclo celular, siguiendo el protocolo descrito por Sazer y Sherwood, 1990 y un método adaptado al descrito por Knutsen et al., 2011.

Para obtener las muestras, se recogieron y se fijaron células según el procedimiento para la tinción de núcleos con DAPI del apartado anterior. Se rehidrataron $300 \mu \mathrm{l}$ de células fijadas mediante dos lavados con el mismo volumen de citrato sódico $50 \mathrm{mM}$. A continuación, se incubaron con RNasa $100 \mu \mathrm{g} / \mathrm{ml}$ en $500 \mu \mathrm{l}$ de citrato sódico $50 \mathrm{mM}$ a $37^{\circ} \mathrm{C}$ durante una noche. Al siguiente día, se tiñeron los núcleos con $500 \mu \mathrm{l}$ de una solución de ioduro de propidio $4 \mu \mathrm{g} / \mathrm{ul}$ y citrato sódico $50 \mathrm{mM}$.

\subsection{Adquisición y análisis de resultados}

Antes de examinar las muestras, se sonicaron durante 10 segundos a una amplitud de $20 \%$ con un sonicador Misonix XL2010. Finalmente, se analizaron en un citómetro FACSCalibur utilizando el programa de adquisición y análisis de datos BD Cell Quest Pro тм 6.0.3 (Biosciences). Para este estudio, se tuvieron en cuenta los parámetros de detección del contenido de ADN FL2-A, FL2-H y FL2-W. 


\section{Tratamiento informático y estadístico de los datos}

\subsection{Análisis informático del escrutinio}

Inicialmente, para la organización de los datos y las definiciones de las interacciones genéticas, se empleó Excel 2011 para Mac (Microsoft Corportation) y el programa Serial List 2.3 (http://serialbasics.free.fr/Softwares.html). Para la integración, el análisis y la visualización de los datos en los diagramas de interacción, se utilizó la plataforma informática Cytoscape y su complemento BiNGO (del inglés The Biological Networks Gene Ontology tool) (Saito et al., 2012; Maere et al., 2005; http://www.cytoscape.org/). Para la generación de los perfiles de interacción se combinó literatura relacionada y anotaciones funcionales depositadas en bases de datos como Gene Ontology (Ashburner et al., 2002; http://www.geneontology.org/), YOGY (Penkett et al., 2006; http://128.40.79.33/YOGY/), BioGrid-Database of Protein and Genetic Interactions (Breitkreutz et al., 2003; http://thebiogrid.org/), DRYGIN-Data Repository of Yeast Genetic Interactions (Koh et al., 2010; http://drygin.ccbr.utoronto.ca/), Biobase Biological Database (http://www.biobase-international.com), Pombase-The Scientific Resource for Fission Yeast (Wood et al., 2012; http://www.pombase.org/) y SGD-Sacharomyces Genome Database (Cherry et al., 1998; http://www.yeastgenome.org/). Para la predicción de las redes se empleó la herramienta PInt (Pancaldi et al., 2012; http://www.bahlerlab.info/).

\subsection{Análisis de secuencias}

Las secuencias de ADN y proteína se obtuvieron de las bases de datos Pombase (Wood et al., 2012), SwissProt (http://www.expasy.org.sprot), Prosite (http://www.expasy.org/prosite/) y Sanger (http/l:www.sanger.ac.uk). Se analizaron utilizando los programas 4Peaks (Mekentosj) EditSeq (DNASTAR Inc.), Seqman (DNASTAR Inc.) y Serial Cloner 1-3 (http://serialbasics.free.fr/Softwares.html). Para el alineamiento de las secuencias de proteína, se empleó el programa Clustal W2 (http://www.ebi.ac.uk/Tools/msa/clustalw2/).

\subsection{Análisis estadístico}

Para el análisis estadístico se utilizó el programa IMB SSPSS Statistics 19 para Mac. 


\section{Materiales y Métodos}

\subsection{Presentación de datos}

Para las presentaciones gráficas se emplearon Excel 2011 para Mac (Microsoft Corportation), Powerpoint 2011 para Mac (Microsoft Corportation), Inkscape 2.3.6 (X Window system) y Illustrator CS4 (Adobe) Para digitalizar las imágenes se utilizaron los escáneres ScanMaker i900 MICROTEX y HP Scanjet G4050. Las imágenes de las tinciones celulares con calcoflúor y DAPI se procesaron con el programa ImageJ $1.45 \mathrm{~K}$ (http://rsbweb.nih.gov/ij/index.html) y se editaron utilizando Photoshop CS4 (Adobe). Las 


\section{Bibliografía}


Aligue R, Wu L, Russell P. (1997). Regulation of Schizosaccharomyces pombe Wee1 tyrosine kinase. J Biol Chem 272: 13320-13325.

al-Khodairy F, Carr AM. (1992). DNA repair mutants defining G2 checkpoint pathways in Schizosaccharomyces pombe. EMBO J 11: 1343-1350.

al-Khodairy F, Fotou E, Sheldrick KS, Griffiths DJ, Lehmann AR, Carr AM. (1994). Identification and characterization of new elements involved in checkpoint and feedback controls in fission yeast. Mol Biol Cell 5: 147-160.

Alvarez B, Moreno S. (2006). Fission yeast Tor2 promotes cell growth and represses cell differentiation. J Cell Sci. 119: 4475-4485.

Amano M, Suzuki A, Hori T, Backer C, Okawa K, Cheeseman IM, Fukagawa T. (2009). The CENP-S complex is essential for the stable assembly of outer kinetochore structure. J Cell Biol 186: 173-182.

Archambault V, Zhao X, White-Cooper H, Carpenter AT, Glover DM. (2007). Mutations in Drosophila Greatwall/Scant reveal its roles in mitosis and meiosis and interdependence with Polo kinase. PLoS Genet 3: e200.

Arellano M, Moreno S. (1997). Regulation of CDK/cyclin complexes during the cell cycle. Int J Biochem Cell Biol 29: 559-573.

Ashburner M, Ball CA, Blake JA, Botstein D, Butler H, Cherry JM, Davis AP, Dolinski K, Dwight SS, Eppig JT, et al. (2000). Gene ontology: tool for the unification of biology. The Gene Ontology Consortium. Nat Genet 25: 25-29.

Aslett M, Wood V. (2006). Gene Ontology annotation status of the fission yeast genome: preliminary coverage approaches $100 \%$. Yeast 23: 913-919.

Baber-Furnari BA, Rhind N, Boddy MN, Shanahan P, Lopez-Girona A, Russell P. (2000). Regulation of mitotic inhibitor Mik1 helps to enforce the DNA damage checkpoint. Mol Biol Cell 11: 1-11.

Bähler J, Nurse P. (2001). Fission yeast Pom1p kinase activity is cell cycle regulated and essential for cellular symmetry during growth and division. EMBO $\mathrm{J} 20$ : 1064-1073.

Bähler J, Wu JQ, Longtine MS, Shah NG, McKenzie A 3rd, Steever AB, Wach A, Philippsen P, Pringle JR. (1998). Heterologous modules for efficient and versatile PCR-based gene targeting in Schizosaccharomyces pombe. Yeast 14: 943-951.

Baryshnikova A, Costanzo M, Dixon S, Vizeacoumar FJ, Myers CL, Andrews B, Boone C. (2010). Synthetic genetic array (SGA) analysis in Saccharomyces cerevisiae and Schizosaccharomyces pombe. Methods Enzymol 470: 145-179.

Benito J, Martín-Castellanos C, Moreno S. (1998). Regulation of the G1 phase of the cell cycle by periodic stabilization and degradation of the p25rum1 CDK inhibitor. EMBO J 17: 482-497.

Bernal M, Sanchez-Romero MA, Salas-Pino S, Daga RR. (2012). Regulation of fission yeast morphogenesis by PP2A activator pta2. PLoS One 7: e32823. 
Bettencourt-Dias M, Giet R, Sinka R, Mazumdar A, Lock WG, Balloux F, Zafiropoulos PJ, Yamaguchi S, Winter S, Carthew RW, Cooper M, Jones D, Frenz L, Glover DM. (2004). Genome-wide survey of protein kinases required for cell cycle progression. Nature 432: 980-987.

Bhattacharjee S, Osman F, Feeney L, Lorenz A, Bryer C, Whitby MC. (2013). MHF12/CENP-S-X performs distinct roles in centromere metabolism and genetic recombination. Open Biol 3: 130102.

Bimbó A, Jia Y, Poh SL, Karuturi RK, den Elzen N, Peng X, Zheng L, O'Connell M, Liu ET, Balasubramanian MK, Liu J. (2005). Systematic deletion analysis of fission yeast protein kinases. Eukaryot Cell 4: 799-813.

Binns D, Dimmer E, Huntley R, Barrell D, O'Donovan C, Apweiler R. (2009). QuickGO: a web-based tool for Gene Ontology searching. Bioinformatics 25: 3045-3046.

Blanco MA, Sánchez-Díaz A, de Prada JM, Moreno S. (2000). APC(ste9/srw1) promotes degradation of mitotic cyclins in $\mathrm{G}(1)$ and is inhibited by cdc2 phosphorylation. EMBO J 19: 3945-3955.

Blanco MA. (2001). Tesis Doctoral. Regulación de Ste9 y Mfr1, dos activadores del complejo APC en Schizosaccharomyces pombe. Departamento de Microbiología y Genética. Universidad de Salamanca, Salamanca.

Boke E, Hagan IM. (2011). Polo, greatwall, and protein phosphatase PP2A Jostle for pole position. PLoS Genet 7: e1002213.

Bone N, Millar JB, Toda T, Armstrong J. (1998). Regulated vacuole fusion and fission in Schizosaccharomyces pombe: an osmotic response dependent on MAP kinases. Curr Biol 8: 135-144.

Bontron S, Jaquenoud M, Vaga S, Talarek N, Bodenmiller B, Aebersold R, De Virgilio C. (2013). Yeast endosulfines control entry into quiescence and chronological life span by inhibiting protein phosphatase 2A. Cell Rep 3: 16-22.

Booher R, Beach D. (1986). Site-specific mutagenesis of cdc2+, a cell cycle control gene of the fission yeast Schizosaccharomyces pombe. Mol Cell Biol 6: 3523-3530.

Booher R, Beach D. (1987). Interaction between cdc13+ and cdc2+ in the control of mitosis in fission yeast; dissociation of the $\mathrm{G} 1$ and $\mathrm{G} 2$ roles of the cdc2+ protein kinase. EMBO J 6: 3441-3447.

Booher R, Beach D. (1989). Involvement of a type 1 protein phosphatase encoded by bws $1+$ in fission yeast mitotic control. Cell 57: 1009-1016.

Breeding CS, Hudson J, Balasubramanian MK, Hemmingsen SM, Young PG, Gould KL. (1998). The cdr2(+) gene encodes a regulator of G2/M progression and cytokinesis in Schizosaccharomyces pombe. Mol Biol Cell 9: 3399-3415.

Breitkreutz BJ, Stark C, Tyers M. (2003). The GRID: the General Repository for Interaction Datasets. Genome Biol 4: R23. 
Budovskaya YV, Stephan JS, Deminoff SJ, Herman PK. (2005). An evolutionary proteomics approach identifies substrates of the cAMP-dependent protein kinase. Proc Natl Acad Sci USA 102: 13933-13938.

Bueno A, Richardson H, Reed SI, Russell P. (1991). A fission yeast B- type cyclin functioning early in the cell cycle. Cell 66: 149-159. Erratum in: Cell (1993) 73: 1049.

Bueno A, Russell P. (1993). Two fission yeast B-type cyclins, cig2 and Cdc13, have different functions in mitosis. Mol Cell Biol 13: 2286-2297. Erratum in: Mol Cell Biol (1994) 14: 869.

Burgess A, Vigneron S, Brioudes E, Labbé JC, Lorca T, Castro A. (2010). Loss of human Greatwall results in $\mathrm{G} 2$ arrest and multiple mitotic defects due to deregulation of the cyclin B-Cdc2/PP2A balance. Proc Natl Acad Sci USA 107: 12564-12569.

Byrne AB, Weirauch MT, Wong V, Koeva M, Dixon SJ, Stuart JM, Roy PJ. (2007). A global analysis of genetic interactions in Caenorhabditis elegans. J Biol 6: 8.

Carbon S, Ireland A, Mungall CJ, Shu S, Marshall B, Lewis S; AmiGo Hub; Web Presence Working Group. (2009). AmiGO: online access to ontology and annotation data. Bioinformatics 25: 288-289.

Carr AM, MacNeill SA, Hayles J, Nurse P. (1989). Molecular cloning and sequence analysis of mutant alleles of the fission yeast cdc2 protein kinase gene: implications for cdc2+ protein structure and function. Mol Gen Genet 218: 41-49.

Castilho, P. V., Williams, B. C., Mochida, S., Zhao, Y., Goldberg, M. L. (2009). The M phase kinase Greatwall $(\mathrm{Gwl})$ promotes inactivation of PP2A/B55ס, a phosphatase directed against CDK phosphosites. Mol Biol Cell 20: 4777-4789.

Cheeseman IM, Brew C, Wolyniak M, Desai A, Anderson S, Muster N, Yates JR, Huffaker TC, Drubin DG, Barnes G. (2001). Implication of a novel multiprotein Dam1p complex in outer kinetochore function. J Cell Biol 155: 1137-1145.

Chen BR, Li Y, Eisenstatt JR, Runge KW. (2013). Identification of a lifespan extending mutation in the Schizosaccharomyces pombe cyclin gene clg1+ by direct selection of long-lived mutants. PLoS One 8: e69084.

Chen D, Toone WM, Mata J, Lyne R, Burns G, Kivinen K, Brazma A, Jones N, Bähler J. (2003). Global transcriptional responses of fission yeast to environmental stress. Mol Biol Cell 14: 214-229.

Cherry JM, Adler C, Ball C, Chervitz SA, Dwight SS, Hester ET, Jia Y, Juvik G, Roe T, Schroeder M, et al.(1998). SGD: Saccharomyces Genome Database. Nucleic Acids Res 26: 73-79.

Collins SR, Schuldiner M, Krogan NJ, Weissman JS. (2006). A strategy for extracting and analyzing large-scale quantitative epistatic interaction data. Genome Biol 7: R63.

Collins SR, Roguev A, Krogan NJ. (2010). Quantitative genetic interaction mapping using 


\section{Bibliografía}

mapping the E-MAP approach. Methods Enzymol 470: 205-231.

Correa-Bordes J, Gulli MP, Nurse P. (1997). p25rum1 promotes proteolysis of the mitotic $\mathrm{B}-\mathrm{cyclin}$ p56cdc13 during $\mathrm{G} 1$ of the fission yeast cell cycle. EMBO J 16: 4657-4664.

Costanzo M, Baryshnikova A, Bellay J, Kim Y, Spear ED, Sevier CS, Ding H, Koh JL, Toufighi K, Mostafavi S, et al. (2010). The genetic landscape of a cell. Science 327: 425-431.

Costello, G., Rodgers, L., Beach, D. (1986). Fission yeast enters the stationary phase G0 state from either mitotic G1 or G2. Curr genet 11: 119-125.

Coudreuse D, Nurse P. (2010). Driving the cell cycle with a minimal CDK control network. Nature 468:1074-1079.

Cueille N, Salimova E, Esteban V, Blanco M, Moreno S, Bueno A, Simanis V. (2001). FIp1, a fission yeast orthologue of the S. cerevisiae CDC14 gene, is not required for cyclin degradation or rum1p stabilisation at the end of mitosis. J Cell Sci 114: 26492664.

Damagnez V, Mäkelä TP, Cottarel G. (1995). Schizosaccharomyces pombe Mop1-Mcs2 is related to mammalian CAK. EMBO J 14: 6164-6172.

Deng L, Moseley JB. (2013). Compartmentalized nodes control mitotic entry signaling in fission yeast. Mol Biol Cell 24:1872-1881.

Dixon SJ, Fedyshyn Y, Koh JL, Prasad TS, Chahwan C, Chua G, Toufighi K, Baryshnikova A, Hayles J, Hoe KL, et al. (2008). Significant conservation of synthetic lethal genetic interaction networks between distantly related eukaryotes. Proc Natl Acad Sci USA 105: 16653-16658.

Dixon SJ, Andrews BJ, Boone C. (2009)._Exploring the conservation of synthetic lethal genetic interaction networks. Commun Integr Biol 2: 78-81.

Domingo-Sananes MR, Kapuy O, Hunt T, Novak B. (2011). Switches and latches: a biochemical tug-of-war between the kinases and phosphatases that control mitosis. Philos Trans R Soc Lond B Biol Sci 366: 3584-3594.

Domínguez-Kelly R, Martín Y, Koundrioukoff S, Tanenbaum ME, Smits VA, Medema RH, Debatisse M, Freire R. (2011). Wee1 controls genomic stability during replication by regulating the Mus81-Eme1 endonuclease. J Cell Biol 194: 567-579.

Ducommun B, Brambilla P, Félix MA, Franza BR Jr, Karsenti E, Draetta G. (1991). Cdc2 phosphorylation is required for its interaction with cyclin. EMBO $\mathrm{J}$ 10: 33113319.

Egel, R. (1989). Mating-type genes, meiosis and sporulation, In The Molecular Biology of Fission Yeast (eds E. Nasim, P. Young, B. Johnson) pp 31-77. New York. Academic Press.

Egel R. (2004). DNA Replication: Stalling a fork for imprinting and switching. Curr Biol 14: 915-917. Review. 
Eichhorn PJ, Creyghton MP, Bernards R. (2009). Protein phosphatase 2A regulatory subunits and cancer. Biochim Biophys Acta 1795: 1-15.

Enoch T, Nurse P. (1990). Mutation of fission yeast cell cycle control genes abolishes dependence of mitosis on DNA replication. Cell 60: 665-73.

Enoch T, Nurse P. (1991). Coupling M phase and S phase: controls maintaining the dependence of mitosis on chromosome replication. Cell 65: 921-923. Review.

Enoch T, Carr AM, Nurse P. (1992). Fission yeast genes involved in coupling mitosis to completion of DNA replication. Genes Dev 6: 2035-2046.

Esteban V, Blanco M, Cueille N, Simanis V, Moreno S, Bueno A. (2004). A role for the Cdc14-family phosphatase Flp1p at the end of the cell cycle in controlling the rapid degradation of the mitotic inducer Cdc25p in fission yeast. J Cell Sci 117: 2461-2468.

Evans T, Rosenthal ET, Youngblom J, Distel D, Hunt T. (1983). Cyclin: a protein specified by maternal mRNA in sea urchin eggs that is destroyed at each cleavage division. Cell 33: 389-96.

Fantes P, Nurse P. (1977). Control of cell size at division in fission yeast by a growthmodulated size control over nuclear division. Exp Cell Res 107: 377-386.

Fantes PA. (1977). Control of cell size and cycle time in Schizosaccharomyces pombe. $J$ Cell Sci 24: 51-67.

Fantes P. (1979). Epistatic gene interactions in the control of division in fission yeast. Nature 279: 428-430.

Fantes PA. (1981). Isolation of cell size mutants of a fission yeast by a new selective method: characterization of mutants and implications for division control mechanisms. J Bacteriol 146: 746-754.

Featherstone C, Russell P. (1991). Fission yeast p107wee1 mitotic inhibitor is a tyrosine/serine kinase. Nature 349: 808-811.

Fernández MA, Rueda C, Peddada SD. (2012). Identification of a core set of signature cell cycle genes whose relative order of time to peak expression is conserved across species. Nucleic Acids Res 40: 2823-2832.

Fisher DL, Nurse P. (1995). Cyclins of the fission yeast Schizosaccharomyces pombe. Semin Cell Biol 6: 73-78.

Fisher DL, Nurse P. (1996). A single fission yeast mitotic cyclin B p34cdc2 kinase promotes both S-phase and mitosis in the absence of $\mathrm{G} 1$ cyclins. EMBO J 15: 850860.

Fisher DL, Krasinska L, Coudreuse D, Novak B. (2012). Phosphorylation network dynamics in the control of cell cycle transitions. J Cell Sci 125: 4703-4711. Review.

Fleig UN, Gould KL, Nurse P. (1992). A dominant negative allele of p34cdc2 shows altered phosphoamino acid content and sequesters p56cdc13 cyclin. Mol Cell Biol 12: 2295-2301. 


\section{Bibliografía}

Foiani M, Marini F, Gamba D, Lucchini G, Plevani P. (1994). The B subunit of the DNA polymerase alpha-primase complex in Saccharomyces cerevisiae executes an essential function at the initial stage of DNA replication. Mol Cell Biol 14: 923-933.

Forsburg SL, Nurse P. (1991). Cell cycle regulation in the yeasts Saccharomyces cerevisiae and Schizosaccharomyces pombe. Annu Rev Cell Biol 7: 227-256. Review.

Forsburg SL. (1993). Comparison of Schizosaccharomyces pombe expression systems. Nucleic Acids Res 21: 2955-2956.

Forsburg SL. (2005). The yeasts Saccharomyces cerevisiae and Schizosaccharomyces pombe: models for cell biology research. Gravit Space Biol Bull 18: 3-9.

Frost A, Elgort MG, Brandman O, Ives C, Collins SR, Miller-Vedam L, Weibezahn J, Hein MY, Poser I, Mann M, et al. (2012). Functional repurposing revealed by comparing S. pombe and S. cerevisiae genetic interactions. Cell 149: 1339-1352.

Furnari B, Rhind N, Russell P. (1997). Cdc25 mitotic inducer targeted by chk1 DNA damage checkpoint kinase. Science 277:1495-1497.

Garabedian MV, Noguchi C, Ziegler MA, Das MM, Singh T, Harper LJ, Leman AR, Khair L, Moser BA, Nakamura TM, Noguchi E. (2012). The double-bromodomain proteins Bdf1 and Bdf2 modulate chromatin structure to regulate S-phase stress response in Schizosaccharomyces pombe. Genetics 190: 487-500.

Gharbi-Ayachi A, Labbé JC, Burgess A, Vigneron S, Strub JM, Brioudes E, VanDorsselaer A, Castro A, Lorca T. (2010). The substrate of Greatwall kinase, Arpp19, controls mitosis by inhibiting protein phosphatase 2A. Science 330: 1673-1677.

Gong Y, Kakihara Y, Krogan N, Greenblatt J, Emili A, Zhang Z, Houry WA. (2009). An atlas of chaperone-protein interactions in Saccharomyces cerevisiae: implications to protein folding pathways in the cell. Mol Syst Biol 5:275.

Gould KL, Nurse P. (1989). Tyrosine phosphorylation of the fission yeast cdc2+ protein kinase regulates entry into mitosis. Nature 342: 39-45.

Gould KL, Moreno S, Owen DJ, Sazer S, Nurse P. (1991). Phosphorylation at Thr167 is required for Schizosaccharomyces pombe p34cdc2 function. EMBO 10: 3297-3309.

Goyal A, Simanis V. (2012). Characterization of ypa1 and ypa2, the Schizosaccharomyces pombe orthologs of the peptidyl proyl isomerases that activate PP2A, reveals a role for Ypa2p in the regulation of cytokinesis. Genetics 190: 1235-1250.

Grallert A, Connolly Y, Smith DL, Simanis V, Hagan IM. (2012). The S. pombe cytokinesis NDR kinase Sid2 activates Fin1 NIMA kinase to control mitotic commitment through Pom1/Wee1. Nat Cell Biol 14: 738-745.

Grallert A, Chan KY, Alonso-Nuñez ML, Madrid M, Biswas A, Alvarez-Tabarés I, Connolly Y, Tanaka K, Robertson A, Ortiz JM, et al. (2013). Removal of centrosomal PP1 by NIMA kinase unlocks the MPF feedback loop to promote mitotic commitment in S. pombe. Curr Biol 23: 213-222. 
Hagan I, Hayles J, Nurse P. (1988). Cloning and sequencing of the cyclin-related cdc13+ gene and a cytological study of its role in fission yeast mitosis. J Cell Sci 91: 587-595.

Hanyu Y, Imai KK, Kawasaki Y, Nakamura T, Nakaseko Y, Nagao K, Kokubu A, Ebe M, Fujisawa A, Hayashi T, Obuse C, Yanagida M. (2009). Schizosaccharomyces pombe cell division cycle under limited glucose requires Ssp1 kinase, the putative CaMKK, and Sds23, a PP2A-related phosphatase inhibitor. Genes Cells 14: 539-554.

Hara K, Maruki Y, Long X, Yoshino K, Oshiro N, Hidayat S, Tokunaga C, Avruch J, Yonezawa K. (2002). Raptor, a binding partner of target of rapamycin (TOR), mediates TOR action. Cell 110: 177-189.

Harlow E, Lane D. (1988). Adjuvants. In Antibodies: A Laboratory Manual. (eds E. Harlow, D Lane) pp 96-124. Cold Spring Harbor N.Y. Cold Spring Harbor Laboratory Press.

Hartmuth S, Petersen J. (2009). Fission yeast Tor1 functions as part of TORC1 to control mitotic entry through the stress MAPK pathway following nutrient stress. J Cell Sci 122: $1737-1746$.

Hartwell LH, Weinert TA. (1989). Checkpoints: controls that ensure the order of cell cycle events. Science. 246: 629-634. Review.

Hauf S, Roitinger E, Koch B, Dittrich CM, Mechtler K, Peters JM. (2005). Dissociation of cohesin from chromosome arms and loss of arm cohesion during early mitosis depends on phosphorylation of SA2. PLoS Biol 3: e69.

He X, Jones MH, Winey M, Sazer S. (1998). Mph1, a member of the Mps1-like family of dual specificity protein kinases, is required for the spindle checkpoint in S. pombe. $J$ Cell Sci 111: 1635-1647.

Heitman J, Movva NR, Hall MN. (1991). Targets for cell cycle arrest by the immunosuppressant rapamycin in yeast. Science 253: 905-909.

Higuchi T, UhImann F. (2005). Stabilization of microtubule dynamics at anaphase onset promotes chromosome segregation. Nature 433: 171-176.

Hoffmann I, Clarke PR, Marcote MJ, Karsenti E, Draetta G. (1993). Phosphorylation and activation of human cdc25-C by cdc2--cyclin $B$ and its involvement in the selfamplification of MPF at mitosis. EMBO J 12: 53-63.

Hogan CJ, Aligianni S, Durand-Dubief M, Persson J, Will WR, Webster J, Wheeler L, Mathews CK, Elderkin S, Oxley D, et al. (2010). Fission yeast lec1-ino80-mediated nucleosome eviction regulates nucleotide and phosphate metabolism. Mol Cell Biol 30: $657-674$.

Holmes DS, Quigley M. (1981). A rapid boiling method for the preparation of bacterial plasmids. Anal Biochem 114: 193-197.

Ikai N, Nakazawa N, Hayashi T, Yanagida M. (2011). The reverse, but coordinated, roles of Tor2 (TORC1) and Tor1 (TORC2) kinases for growth, cell cycle and separase-mediated mitosis in Schizosaccharomyces pombe. Open Biol 1: 110007. 


\section{Bibliografía}

Inoue H, Nojima H, Okayama H. (1990). High efficiency transformation of Escherichia coli with plasmids. Gene 96: 23-28.

Irarrazabal CE, Liu JC, Burg MB, Ferraris JD. (2004). ATM, a DNA damage-inducible kinase, contributes to activation by high $\mathrm{NaCl}$ of the transcription factor TonEBP/OREBP. Proc Natl Acad Sci USA 101: 8809-8814.

Jacinto E. (2008). What controls TOR? IUBMB Life 60: 483-496. Review.

Jang YJ, Won M, Yoo HS. (2013). Phosphorylations of Sds23/Psp1/Moc1 by stressactivated kinase and cAMP-dependent kinase are essential for regulating cell viability in prolonged stationary phase. Yeast 30: 379-394.

Janssens V, Goris J. (2001). Protein phosphatase 2A: a highly regulated family of serine/threonine phosphatases implicated in cell growth and signalling. Biochem $J$ 353: 417-439. Review.

Janssens V, Longin S, Goris J. (2008). PP2A holoenzyme assembly: in cauda venenum (the sting is in the tail). Trends Biochem Sci 33: 113-121.

Jeffrey PD, Russo AA, Polyak K, Gibbs E, Hurwitz J, Massagué J, Pavletich NP. (1995). Mechanism of CDK activation revealed by the structure of a cyclinA-CDK2 complex. Nature 376: 313-320.

Jiang W, Hallberg RL. (2000). Isolation and characterization of par1(+) and par2(+): two Schizosaccharomyces pombe genes encoding B' subunits of protein phosphatase $2 \mathrm{~A}$. Genetics 154: 1025-1038.

Jiang W, Hallberg RL. (2001). Correct regulation of the septation initiation network in Schizosaccharomyces pombe requires the activities of par1 and par2. Genetics 158: 1413-1429.

Jiang Y. (2006). Regulation of the cell cycle by protein phosphatase 2A in Saccharomyces cerevisiae. Microbiol Mol Biol Rev 70: 440-449. Review.

Jimenez G, Yucel J, Rowley R, Subramani S. (1992). The rad3+ gene of Schizosaccharomyces pombe is involved in multiple checkpoint functions and in DNA repair. Proc Natl Acad Sci USA 89: 4952-4956.

Jourdain I, Brzezińska EA, Toda T. (2013). Fission yeast Nod1 is a component of cortical nodes involved in cell size control and division site placement. PLoS One 8: e54142.

Juanes MA, Khoueiry R, Kupka T, Castro A, Mudrak I, Ogris E, Lorca T, Piatti S. (2013). Budding yeast greatwall and endosulfines control activity and spatial regulation of PP2A(Cdc55) for timely mitotic progression. PLoS Genet 9: e1003575.

Kakizuka, A., Miller, W. H., Jr, Umesono, K., Warrell, R. P., Jr, Frankel, S. R., Murty, V. V., Dmitrovsky, E. Evans, R. M. (1991). Chromosomal translocation t(15;17) in human acute promyelocytic leukemia fuses RAR alpha with a novel putative transcription factor, PML. Cell 66: 663-674.

Kanoh J, Russell P. (1998).The protein kinase Cdr2, related to Nim1/Cdr1 mitotic inducer, 
regulates the onset of mitosis in fission yeast. Mol Biol Cell 9: 3321-3334.

Kaur R, Kostrub CF, Enoch T. (2001). Structure-function analysis of fission yeast Hus1Rad1-Rad9 checkpoint complex. Mol Biol Cell 12: 3744-3758.

Kawamukai M, Ferguson K, Wigler M, Young D. (1991). Genetic and biochemical analysis of the adenylyl cyclase of Schizosaccharomyces pombe. Cell Regul 2: 155164.

Kim DH, Sarbassov DD, Ali SM, King JE, Latek RR, Erdjument-Bromage H, Tempst P, Sabatini DM. (2002). mTOR interacts with raptor to form a nutrient-sensitive complex that signals to the cell growth machinery. Cell 110: 163-175.

Kim DU, Hayles J, Kim D, Wood V, Park HO, Won M, Yoo HS, Duhig T, Nam M, Palmer G, Han S, et al. (2010). Analysis of a genome-wide set of gene deletions in the fission yeast Schizosaccharomyces pombe. Nat Biotechnol 28:617-623. Erratum in: Nat Biotechnol. (2010) 28: 1308.

Kinoshita N, Ohkura H, Yanagida M. (1990). Distinct, essential roles of type 1 and 2A protein phosphatases in the control of the fission yeast cell division cycle. Cell 63: 405415.

Kinoshita N, Yamano H, Niwa H, Yoshida T, Yanagida M. (1993). Negative regulation of mitosis by the fission yeast protein phosphatase ppa2. Genes Dev 7: 1059-1071.

Kinoshita K, Nemoto T, Nabeshima K, Kondoh H, Niwa H, Yanagida M. (1996). The regulatory subunits of fission yeast protein phosphatase 2A (PP2A) affect cell morphogenesis, cell wall synthesis and cytokinesis. Genes Cells 1: 29-45.

Kishimoto N, Yamashita I. (2000). Cyclic AMP regulates cell size of Schizosaccharomyces pombe through Cdc25 mitotic inducer. Yeast 16: 523-529.

Kitajima TS, Sakuno T, Ishiguro K, lemura S, Natsume T, Kawashima SA, Watanabe Y. (2006). Shugoshin collaborates with protein phosphatase 2A to protect cohesin. Nature 441: 46-52.

Kitamura K, Maekawa H, Shimoda C. (1998). Fission yeast Ste9, a homolog of Hct1/Cdh1 and Fizzy-related, is a novel negative regulator of cell cycle progression during G1-phase. Mol Biol Cell 9: 1065-1080.

Knutsen JH, Rein ID, Rothe C, Stokke T, Grallert B, Boye E. (2011). Cell-cycle analysis of fission yeast cells by flow cytometry. PLoS One. 6: e17175.

Koh JL, Ding H, Costanzo M, Baryshnikova A, Toufighi K, Bader GD, Myers CL, Andrews BJ, Boone C. (2010). DRYGIN: a database of quantitative genetic interaction networks in yeast. Nucleic Acids Res 38: D502-7.

Koyano T, Kume K, Konishi M, Toda T, Hirata D. (2010). Search for kinases related to transition of growth polarity in fission yeast. Biosci Biotechnol Biochem 74: 1129-1133.

Kushner SR. (1978). An improved method for transformation of Escherichia coli with Col El derived plasmids. In: Genetic Engineering (eds HW Boyer, S Nicosia) pp. 17- 23. 
Amsterdam. Elsevier/North Holland.

Lahoz A, Alcaide-Gavilán M, Daga RR, Jimenez J. (2010). Antagonistic roles of PP2APab1 and Etd1 in the control of cytokinesis in fission yeast. Genetics 186: 1261-1270.

Lang BF, Cedergren R, Gray MW. (1987). The mitochondrial genome of the fission yeast, Schizosaccharomyces pombe. sequence of the large-subunit ribosomal RNA gene, comparison of potential secondary structure in fungal mitochondrial large-subunit rRNAs and evolutionary considerations. Eur J Biochem 169: 527-537.

Lee KM, Saiz JE, Barton WA, Fisher RP. (1999). Cdc2 activation in fission yeast depends on Mcs6 and Csk1, two partially redundant Cdk-activating kinases (CAKs). Curr Biol 9: 441-444.

Lee MS, Enoch T, Piwnica-Worms H. (1994). mik1+ encodes a tyrosine kinase that phosphorylates p34cdc2 on tyrosine 15. J Biol Chem 269: 30530-30537.

Liu J, Wang H, Balasubramanian MK. (2000). A checkpoint that monitors cytokinesis in Schizosaccharomyces pombe. J Cell Sci 113: 1223-1230.

Liu X, McLeod I, Anderson S, Yates JR 3rd, He X. (2005). Molecular analysis of kinetochore architecture in fission yeast. EMBO J 24: 2919-2930.

López-Avilés S, Grande M, González M, Helgesen AL, Alemany V, Sanchez-Piris M, Bachs O, Millar JB, Aligue R. (2005). Inactivation of the Cdc25 phosphatase by the stress-activated Srk1 kinase in fission yeast. Mol Cell 17: 49-59.

López-Girona A, Furnari B, Mondesert O, Russell P. (1999). Nuclear localization of Cdc25 is regulated by DNA damage and a 14-3-3 protein. Nature 397: 172-175.

Lu LX, Domingo-Sananes MR, Huzarska M, Novak B, Gould KL. (2012). Multisite phosphoregulation of $\mathrm{Cdc} 25$ activity refines the mitotic entrance and exit switches. Proc Natl Acad Sci USA 109: 9899-9904.

Lundgren K, Walworth N, Booher R, Dembski M, Kirschner M, Beach D. (1991). mik1 and wee1 cooperate in the inhibitory tyrosine phosphorylation of cdc2. Cell. 64: 11111122.

Luo X, Talarek N, De Virgilio C. (2011). Initiation of the yeast G0 program requires Igo1 and Igo2, which antagonize activation of decapping of specific nutrient-regulated mRNAs. RNA Biol 8: 14-17.

Mach KE, Furge KA, Albright CF. (2000). Loss of Rhb1, a Rheb-related GTPase in fission yeast, causes growth arrest with a terminal phenotype similar to that caused by nitrogen starvation. Genetics 155: 611-622.

MacNeill SA, Nurse P. (1989). Genetic interactions in the control of mitosis in fission yeast. Curr Genet 16: 1-6. Review.

MacNeill, S.A. and Nurse, P. (1997). Cell cycle control in fission yeast. In: The Molecular and Cellular Biology of Yeast (eds JR Pringle, JR Broach, EW Jones) pp. 697-763. Cold Spring Harbor N.Y. Cold Spring Harbor Laboratory Press. 
Madrid M, Soto T, Franco A, Paredes V, Vicente J, Hidalgo E, Gacto M, Cansado J. (2004). A cooperative role for Atf1 and Pap1 in the detoxification of the oxidative stress induced by glucose deprivation in Schizosaccharomyces pombe. J Biol Chem 279: 41594-41602.

Madrid M, Soto T, Khong HK, Franco A, Vicente J, Pérez P, Gacto M, Cansado J. (2006). Stress-induced response, localization, and regulation of the Pmk1 cell integrity pathway in Schizosaccharomyces pombe. J Biol Chem 281: 2033-2043.

Maeda T, Mochizuki N, Yamamoto M. (1990). Adenylyl cyclase is dispensable for vegetative cell growth in the fission yeast Schizosaccharomyces pombe. Proc Natl Acad Sci USA 87: 7814-7818.

Maeda T, Watanabe Y, Kunitomo H, Yamamoto M. (1994). Cloning of the pka1 gene encoding the catalytic subunit of the cAMP-dependent protein kinase in Schizosaccharomyces pombe. J Biol Chem 269: 9632-9637.

Maere S, Heymans K, Kuiper M. (2005). BiNGO: a Cytoscape plugin to assess overrepresentation of gene ontology categories in biological networks. Bioinformatics 21: 3448-3449.

Manchado E, Guillamot M, de Cárcer G, Eguren M, Trickey M, García-Higuera I, Moreno S, Yamano H, Cañamero M, Malumbres M. (2010). Targeting mitotic exit leads to tumor regression in vivo: Modulation by Cdk1, Mastl, and the PP2A/B55a, $\delta$ phosphatase. Cancer Cell 18: 641-654.

Mani R, St Onge RP, Hartman JL 4th, Giaever G, Roth FP. (2008). Defining genetic interaction. Proc Natl Acad Sci USA 105: 3461-3466.

Martin SG, Berthelot-Grosjean M. (2009). Polar gradients of the DYRK-family kinase Pom1 couple cell length with the cell cycle. Nature 459: 852-856.

Martín-Castellanos C, Blanco MA, de Prada JM, Moreno S. (2000). The puc1 cyclin regulates the $\mathrm{G} 1$ phase of the fission yeast cell cycle in response to cell size. Mol Biol Cell 11: 543-54.

Martín-Castellanos C, Blanco M, Rozalén AE, Pérez-Hidalgo L, García Al, Conde F, Mata J, Ellermeier C, Davis L, San-Segundo P, et al (2005). A large-scale screen in $S$. pombe identifies seven novel genes required for critical meiotic events. Curr Biol 15: 2056-2062.

Masuda H, Fong CS, Ohtsuki C, Haraguchi T, Hiraoka Y. (2011). Spatiotemporal regulations of Wee1 at the G2/M transition. Mol Biol Cell 22: 555-569.

Matsuo T, Kubo Y, Watanabe Y, Yamamoto M. (2003). Schizosaccharomyces pombe AGC family kinase Gad8p forms a conserved signaling module with TOR and PDK1like kinases. EMBO J 22: 3073-3083.

Matsuo T, Otsubo Y, Urano J, Tamanoi F, Yamamoto M. (2007). Loss of the TOR kinase Tor2 mimics nitrogen starvation and activates the sexual development pathway in fission yeast. Mol Cell Biol 27: 3154-3164. 


\section{Bibliografía}

Matsuzawa T, Fujita Y, Tohda H, Takegawa K. (2012). Snf1-like protein kinase Ssp2 regulates glucose derepression in Schizosaccharomyces pombe. Eukaryot Cell 11:159-167.

Maundrell K. (1990). nmt1 of fission yeast. A highly transcribed gene completely repressed by thiamine. J Biol Chem 265: 10857-10864.

Maundrell K. (1993). Thiamine-repressible expression vectors pREP and pRIP for fission yeast. 123: 127-130.

Millar JB, McGowan CH, Lenaers G, Jones R, Russell P. (1991). p80cdc25 mitotic inducer is the tyrosine phosphatase that activates p34cdc2 kinase in fission yeast. EMBO J 10: 4301-4309.

Millar JB, Lenaers G, Russell P. (1992). Pyp3 PTPase acts as a mitotic inducer in fission yeast. EMBO J 11: 4933-4941.

Mirchenko L, UhImann F. (2010). Sli15(INCENP) dephosphorylation prevents mitotic checkpoint reengagement due to loss of tension at anaphase onset. Curr Biol 20: 1396-1401.

Mitchison JM, Creanor J. (1971). Further measurements of DNA synthesis and enzyme potential during cell cycle of fission yeast Schizosaccharomyces pombe.. Exp Cell Res 69: 244-247.

Mitchison JM. (2003). Growth during the cell cycle. Int Rev Cytol 226: 165-258. Review.

Mochida S, Ikeo S, Gannon J, Hunt T. (2009). Regulated activity of PP2A-B55 delta is crucial for controlling entry into and exit from mitosis in Xenopus egg extracts. EMBO J. 28: $2777-2785$.

Mochida S, Maslen SL, Skehel M, Hunt T. (2010). Greatwall phosphorylates an inhibitor of protein phosphatase 2A that is essential for mitosis. Science 330: 1670-1673.

Mochida S, Hunt T. (2012). Protein phosphatases and their regulation in the control of mitosis. EMBO Rep 13: 197-203.

Mochida, S. (2013), Regulation of a-endosulfine, an inhibitor of protein phosphatase 2A, by multisite phosphorylation. FEBS J 281:1159-1169.

Mondesert O, McGowan CH, Russell P. (1996). Cig2, a B-type cyclin, promotes the onset of S in Schizosaccharomyces pombe. Mol Cell Biol 16: 1527-33.

Moreno S, Hayles J, Nurse P. (1989). Regulation of p34cdc2 protein kinase during mitosis. Cell 58: 361-372.

Moreno S, Nurse P, Russell P. (1990). Regulation of mitosis by cyclic accumulation of p80cdc25 mitotic inducer in fission yeast. Nature 344: 549-552.

Moreno S, Klar A, Nurse P. (1991). Molecular genetic analysis of fission yeast Schizosaccharomyces pombe. Methods Enzymol 194: 795-823. 
Moreno S, Nurse P. (1994). Regulation of progression through the G1 phase of the cell cycle by the rum1+ gene. Nature 367: 236-242.

Morgan DO. (1997). Cyclin-dependent kinases: engines, clocks, and microprocessors. Annu Rev Cell Dev Biol 13: 261-291. Review.

Morgan DO. (2007). The cell cycle: principles of control (pp 297). Primers in biology series. London.New Science Press Ltd.

Morrell JL, Nichols CB, Gould KL. (2004). The GIN4 family kinase, Cdr2p, acts independently of septins in fission yeast. J Cell Sci 117: 5293-5302.

Moseley JB, Mayeux A, Paoletti A, Nurse P. (2009). A spatial gradient coordinates cell size and mitotic entry in fission yeast. Nature 459:857-860.

Moseley JB, Nurse P. (2009). Cdk1 and cell morphology: connections and directions. Curr Opin Cell Biol 21: 82-88.

Mulvihill DP, Petersen J, Ohkura H, Glover DM, Hagan IM. (1999). Plo1 kinase recruitment to the spindle pole body and its role in cell division in Schizosaccharomyces pombe. Mol Biol Cell 10: 2771-2785.

Nakashima A, Sato T, Tamanoi F. (2010). Fission yeast TORC1 regulates phosphorylation of ribosomal S6 proteins in response to nutrients and its activity is inhibited by rapamycin. J Cell Sci 123: 777-786.

Navarro FJ, Nurse P. (2012). A systematic screen reveals new elements acting at the G2/M cell cycle control. Genome Biol 13: R36.

Nefsky B, Beach D. (1996). Pub1 acts as an E6-AP-like protein ubiquitiin ligase in the degradation of cdc25. EMBO J 15: 1301-1312.

Ng SS, Anderson M, White S, Mclnerny CJ. (2001). mik1+ G1-S transcription regulates mitotic entry in fission yeast. FEBS Lett 503: 131-134.

Nguyen AN, Shiozaki K. (1999). Heat-shock-induced activation of stress MAP kinase is regulated by threonine- and tyrosine-specific phosphatases. Genes Dev 13: 16531663.

Novak B, Vinod PK, Freire P, Kapuy O. (2010a). Systems-level feedback in cell-cycle control. Biochem Soc Trans 38: 1242-1246. Review. Erratum in: Biochem Soc Trans (2010) 38:1723.

Novak B, Kapuy O, Domingo-Sananes MR, Tyson JJ. (2010b). Regulated protein kinases and phosphatases in cell cycle decisions. Curr Opin Cell Biol 22: 801-808.

Nurse P. (1975). Genetic control of cell size at cell division in yeast. Nature 256: 547-551.

Nurse P, Thuriaux P, Nasmyth K. (1976). Genetic control of the cell division cycle in the fission yeast Schizosaccharomyces pombe. Mol Gen Genet 146: 167-78.

Nurse P, Thuriaux P. (1977). Controls over the timing of DNA replication during the cell 
cycle of fission yeast. Exp Cell Res 107: 365-375.

Nurse P, Thuriaux P. (1980). Regulatory genes controlling mitosis in the fission yeast Schizosaccharomyces pombe. Genetics 96: 627-37.

Nurse P. (1990). Universal control mechanism regulating onset of M-phase. Nature 344: 503-508. Review.

O'Connell MJ, Raleigh JM, Verkade HM, Nurse P. (1997). Chk1 is a wee1 kinase in the G2 DNA damage checkpoint inhibiting cdc2 by Y15 phosphorylation. EMBO J 16: 545554.

Ohtaki A, Noguchi K, Yohda M. (2010). Structure and function of archaeal prefoldin, a co-chaperone of group II chaperonin. Front Biosci (Landmark Ed) 15:708-717. Review.

Otsubo Y, Yamamato M. (2008). TOR signaling in fission yeast. Crit Rev Biochem Mol Biol 43: 277-283. Review. Pal G, Paraz MT, Kellogg DR. (2008). Regulation of Mih1/Cdc25 by protein phosphatase 2A and casein kinase 1. J Cell Biol 180: 931-945.

Pan X, Yuan DS, Xiang D, Wang X, Sookhai-Mahadeo S, Bader JS, Hieter P, Spencer F, Boeke JD. (2004). A robust toolkit for functional profiling of the yeast genome. Mol Cell 16: 487-496.

Pancaldi V, Saraç OS, Rallis C, McLean JR, Převorovský M, Gould K, Beyer A, Bähler J. (2012). Predicting the fission yeast protein interaction network. G3 (Bethesda) 2: 453-467.

Paoletti A, Chang F. (2000). Analysis of mid1p, a protein required for placement of the cell division site, reveals a link between the nucleus and the cell surface in fission yeast. Mol Biol Cell 11: 2757-2773.

Parker LL, Walter SA, Young PG, Piwnica-Worms H. (1993). Phosphorylation and inactivation of the mitotic inhibitor Wee1 by the nim1/cdr1 kinase. Nature. 363: 736738.

Parrilla-Castellar ER, Arlander SJ, Karnitz L. (2004). Dial 9-1-1 for DNA damage: the Rad9-Hus1-Rad1 (9-1-1) clamp complex. DNA Repair 3: 1009-1014.

Pavletich NP. (1999). Mechanisms of cyclin-dependent kinase regulation: structures of Cdks, their cyclin activators, and Cip and INK4 inhibitors. J Mol Biol 287: 821-828.

Pedruzzi I, Dubouloz F, Cameroni E, Wanke V, Roosen J, Winderickx J, De Virgilio C. (2003). TOR and PKA signaling pathways converge on the protein kinase Rim15 to control entry into G0. Mol Cell 12: 1607-1613.

Penkett CJ, Morris JA, Wood V, Bähler J. (2006). YOGY: a web-based, integrated database to retrieve protein orthologs and associated Gene Ontology terms. Nucleic Acids Res 34: W330-334.

Pérez P, Cansado J. (2010). Cell integrity signaling and response to stress in fission yeast. Curr Protein Pept Sci 11: 680-692. Review. 
Perry JA, Kornbluth S. (2007). Cdc25 and Wee1: analogous opposites? Cell Div 2:12.

Petersen J, Hagan IM. (2005). Polo kinase links the stress pathway to cell cycle control and tip growth in fission yeast. Nature 435: 507-512.

Petersen J, Nurse P. (2007). TOR signalling regulates mitotic commitment through the stress MAP kinase pathway and the Polo and Cdc2 kinases. Nat Cell Biol 9: 12631272.

Petersen J. (2009). TOR signalling regulates mitotic commitment through stress-activated MAPK and Polo kinase in response to nutrient stress. Biochem Soc Trans 37: 273277. Review.

Phillips PC. (2008). Epistasis--the essential role of gene interactions in the structure and evolution of genetic systems. Nat Rev Genet 9: 855-867.

Pluskal T, Hayashi T, Saitoh S, Fujisawa A, Yanagida M. (2011). Specific biomarkers for stochastic division patterns and starvation-induced quiescence under limited glucose levels in fission yeast. FEBS J 278: 1299-1315.

Pomerening JR, Kim SY, Ferrell JE Jr. (2005). Systems-level dissection of the cell-cycle oscillator: bypassing positive feedback produces damped oscillations. Cell 122: 565578.

Poyatos JF. (2011). The balance of weak and strong interactions in genetic networks. PLoS One 6: e14598.

Qian YW, Erikson E, Taieb FE, Maller JL. (2001). The polo-like kinase Plx1 is required for activation of the phosphatase Cdc25C and cyclin B-Cdc2 in Xenopus oocytes. Mol Biol Cell 12: 1791-1799.

Rangone H, Wegel E, Gatt MK, Yeung E, Flowers A, Debski J, Dadlez M, Janssens V, Carpenter AT, Glover DM. (2011). Suppression of scant identifies Endos as a substrate of greatwall kinase and a negative regulator of protein phosphatase $2 \mathrm{~A}$ in mitosis. PLoS Genet 7: e1002225.

Reinders A, Bürckert N, Boller T, Wiemken A, De Virgilio C. (1998). Saccharomyces cerevisiae cAMP-dependent protein kinase controls entry into stationary phase through the Rim15p protein kinase. Genes Dev 12: 2943-2955.

Rhind N, Russell P. (1998). Mitotic DNA damage and replication checkpoints in yeast. Curr Opin Cell Biol 10: 749-758. Review.

Roguev A, Bandyopadhyay S, Zofall M, Zhang K, Fischer T, Collins SR, Qu H, Shales M, Park HO, Hayles J, Hoe KL, Kim DU, Ideker T, Grewal SI, Weissman JS, Krogan NJ. (2008). Conservation and rewiring of functional modules revealed by an epistasis map in fission yeast. Science 322:405-410.

Rowley R. (1992). Radiation-induced mitotic delay: a genetic characterization in the fission yeast. Radiat Res 132: 144-152. Review.

Russell P, Nurse P. (1986). Cdc25 functions as an inducer in the mitotic control of fission 
yeast. Cell 45: 145-153.

Russell P, Nurse P. (1987a). Negative regulation of mitosis by wee1, a gene encoding a protein kinase homolog. Cell 49: 559-567.

Russell P, Nurse P. (1987b). The mitotic inducer nim1+ functions in a regulatory network of protein kinase homologs controlling the initiation of mitosis. Cell 49: 569-576.

Russell P, Moreno S, Reed SI. (1989). Conservation of mitotic controls in fission and budding yeasts. Cell 57: 295-303.

Russo AA, Jeffrey PD, Pavletich NP. (1996). Structural basis of cyclin-dependent kinase activation by phosphorylation. Nat Struct Biol 3: 696-700.

Ryan CJ, Roguev A, Patrick K, Xu J, Jahari H, Tong Z, Beltrao P, Shales M, Qu H, Collins SR, Kliegman JI, et al. (2012). Hierarchical modularity and the evolution of genetic interactomes across species. Mol Cell 46: 691-704.

Sabatinos SA, Forsburg SL. (2009). Measuring DNA content by flow cytometry in fission yeast. Methods Mol Biol 521: 449-461.

Sadhu K, Reed SI, Richardson H, Russell P. (1990). Human homolog of fission yeast cdc25 mitotic inducer is predominantly expressed in G2. Proc Natl Acad Sci USA 87: 5139-5143.

Saito R, Smoot ME, Ono K, Ruscheinski J, Wang PL, Lotia S, Pico AR, Bader GD, Ideker T. (2012). A travel guide to Cytoscape plugins. Nat Methods 9: 1069-1076.

Sambrook J, Fritsch EF, Maniatis T. (1989). Molecular cloning Vol. 2. Cold Spring Harbor N.Y. Cold Spring Harbor Laboratory Press.

Samejima I, Yanagida M. (1994). Identification of cut8+ and cek1+, a novel protein kinase gene, which complement a fission yeast mutation that blocks anaphase. Mol Cell Biol 14: 6361-6371. Erratum in: Mol Cell Biol (1994) 14: 7683.

Sánchez-Díaz A, González I, Arellano M, Moreno S. (1998). The Cdk inhibitors p25rum1 and $\mathrm{p} 40 \mathrm{SIC} 1$ are functional homologues that play similar roles in the regulation of the cell cycle in fission and budding yeast. $J$ Cell Sci 111: 843-851.

Sanchez-Perez I, Renwick SJ, Crawley K, Karig I, Buck V, Meadows JC, FrancoSanchez A, Fleig U, Toda T, Millar JB. (2005). The DASH complex and KIp5/KIp6 kinesin coordinate bipolar chromosome attachment in fission yeast. EMBO J 24: 29312943.

Sazer S, Sherwood SW. (1990). Mitochondrial growth and DNA synthesis occur in the absence of nuclear DNA replication in fission yeast. J Cell Sci 97: 509-516.

Schuldiner M, Collins SR, Thompson NJ, Denic V, Bhamidipati A, Punna T, Ihmels J, Andrews B, Boone C, Greenblatt JF, Weissman JS, Krogan NJ. (2005). Exploration of the function and organization of the yeast early secretory pathway through an epistatic miniarray profile. Cell 123: 507-519. 
Schuldiner M, Collins SR, Weissman JS, Krogan NJ. (2006). Quantitative genetic analysis in Saccharomyces cerevisiae using epistatic miniarray profiles (E-MAPs) and its application to chromatin functions. Methods 40: 344-352.

Seaton BL, Yucel J, Sunnerhagen P, Subramani S. (1992). Isolation and characterization of the Schizosaccharomyces pombe rad3 gene, involved in the DNA damage and DNA synthesis checkpoints. Gene 119: 83-89.

Shabb JB. (2001). Physiological substrates of cAMP-dependent protein kinase. Chem Rev 101: 2381-2411. Review.

Shannon P, Markiel A, Ozier O, Baliga NS, Wang JT, Ramage D, Amin N, Schwikowski B, Ideker T. (2003). Cytoscape: a software environment for integrated models of biomolecular interaction networks. Genome Res 13: 2498-2504.

Shieh JC, Wilkinson MG, Millar JB. (1998). The Win1 mitotic regulator is a component of the fission yeast stress-activated Sty1 MAPK pathway. Mol Biol Cell 9: 311-322.

Shiozaki K, Russell P. (1995a). Cell-cycle control linked to extracellular environment by MAP kinase pathway in fission yeast. Nature 378: 739-743.

Shiozaki K, Russell P. (1995b). Counteractive roles of protein phosphatase 2C (PP2C) and a MAP kinase kinase homolog in the osmoregulation of fission yeast. EMBO J 14: 492-502.

Shiozaki K, Russell P. (1996). Conjugation, meiosis, and the osmotic stress response are regulated by Spc1 kinase through Atf1 transcription factor in fission yeast. Genes Dev 10: $2276-2288$.

Simanis V, Nurse P. (1986). The cell cycle control gene cdc2+ of fission yeast encodes a protein kinase potentially regulated by phosphorylation. Cell 45: 261-268.

Sipiczki M. (2000). Where does fission yeast sit on the tree of life?. Genome Biol 1: reviews1011. Review.

Skerker JM, Prasol MS, Perchuk BS, Biondi EG, Laub MT. (2005). Two-component signal transduction pathways regulating growth and cell cycle progression in a bacterium: a system-level analysis. PLoS Biol 3: e334.

Spirek M, Benko Z, Carnecka M, Rumpf C, Cipak L, Batova M, Marova I, Nam M, Kim DU, Park HO, et al. (2010). S. pombe genome deletion project: an update. Cell Cycle 9: 2399-2402.

Stark C, Breitkreutz BJ, Reguly T, Boucher L, Breitkreutz A, Tyers M. (2006). BioGRID: a general repository for interaction datasets. Nucleic Acids Res 34: D535539.

Stern B, Nurse P. (1996). A quantitative model for the cdc2 control of $S$ phase and mitosis in fission yeast. Trends Genet 12: 345-350. Review.

Suda M, Yamada S, Toda T, Miyakawa T, Hirata D. (2000). Regulation of Wee1 kinase 
in response to protein synthesis inhibition. FEBS Lett 486: 305-309.

Sugiura R, Kita A, Shimizu Y, Shuntoh H, Sio SO, Kuno T. (2003). Feedback regulation of MAPK signalling by an RNA-binding protein. Nature 424: 961-965.

Sunnerhagen P. (2002). Prospects for functional genomics in Schizosaccharomyces pombe. Curr Genet 42: 73-84. Review.

Sveiczer A, Novak B, Mitchison JM. (1999). Mitotic control in the absence of cdc25 mitotic inducer in fission yeast. J Cell Sci 112: 1085-1092.

Takeda T, Toda T, Kominami K, Kohnosu A, Yanagida M, Jones N. (1995). Schizosaccharomyces pombe atf1+ encodes a transcription factor required for sexual development and entry into stationary phase. EMBO J 14: 6193-6208.

Talarek N, Cameroni E, Jaquenoud M, Luo X, Bontron S, Lippman S, Devgan G, Snyder M, Broach JR, De Virgilio C. (2010). Initiation of the TORC1-regulated G0 program requires Igo1/2, which license specific mRNAs to evade degradation via the 5'-3' mRNA decay pathway. Mol Cell 38: 345-355.

Tanaka K, Petersen J, Maclver F, Mulvihill DP, Glover DM, Hagan IM. (2001). The role of Plo1 kinase in mitotic commitment and septation in Schizosaccharomyces pombe. EMBO J 20: 1259-1270.

Tang Z, Shu H, Qi W, Mahmood NA, Mumby MC, Yu H. (2006). PP2A is required for centromeric localization of Sgo1 and proper chromosome segregation. Dev Cell 10: 575-585.

Thuriaux P, Nurse P, Carter B. (1978). Mutants altered in the control co-ordinating cell division with cell growth in the fission yeast Schizosaccharomyces pombe. Mol Gen Genet 161: 215-220.

Toda T, Dhut S, Superti-Furga G, Gotoh Y, Nishida E, Sugiura R, Kuno T. (1996). The fission yeast pmk1+ gene encodes a novel mitogen-activated protein kinase homolog which regulates cell integrity and functions coordinately with the protein kinase C pathway. Mol Cell Biol 16: 6752-6764.

Tong AH, Evangelista M, Parsons AB, Xu H, Bader GD, Pagé N, Robinson M, Raghibizadeh S, Hogue CW, Bussey $\mathbf{H}$, et al. (2001). Systematic genetic analysis with ordered arrays of yeast deletion mutants. Science 294: 2364-2368.

Tyson JJ, Novak B. (2011). Cell cycle: who turns the crank? Curr Biol 21: 185-187.

Ubersax JA, Woodbury EL, Quang PN, Paraz M, Blethrow JD, Shah K, Shokat KM, Morgan DO. (2003). Targets of the cyclin-dependent kinase Cdk1. Nature 425: 859864.

Uhlmann F, Bouchoux C, López-Avilés S. (2011). A quantitative model for cyclindependent kinase control of the cell cycle: revisited. Philos Trans $R$ Soc Lond B Biol Sci 366: 3572-3583. Review.

Uritani M, Hidaka H, Hotta Y, Ueno M, Ushimaru T, Toda T. (2006). Fission yeast Tor2 
links nitrogen signals to cell proliferation and acts downstream of the Rheb GTPase. Genes Cells 11: 1367-1379.

Valbuena N, Moreno S. (2010) TOR and PKA pathways synergize at the level of the Ste11 transcription factor to prevent mating and meiosis in fission yeast. PLoS One 5: e11514.

Valbuena N, Guan KL, Moreno S. (2012). The Vam6 and Gtr1-Gtr2 pathway activates TORC1 in response to amino acids in fission yeast. J Cell Sci 125: 1920-1928.

van der Voet M, Lorson MA, Srinivasan DG, Bennett KL, van den Heuvel S. (2009). C. elegans mitotic cyclins have distinct as well as overlapping functions in chromosome segregation. Cell Cycle 8: 4091-4102.

Vigneron S, Brioudes E, Burgess A, Labbé JC, Lorca T, Castro A. (2009). Greatwall maintains mitosis through regulation of PP2A. EMBO J 28: 2786-2793.

Vigneron S, Gharbi-Ayachi A, Raymond AA, Burgess A, Labbé JC, Labesse G, Monsarrat B, Lorca T, Castro A. (2011). Characterization of the mechanisms controlling Greatwall activity. Mol Cell Biol 31: 2262-2275.

Virshup DM, Shenolikar S. (2009). From promiscuity to precision: protein phosphatases get a makeover. Mol Cell 133: 537-545. Review.

Visintin R, Craig K, Hwang ES, Prinz S, Tyers M, Amon A. (1998). The phosphatase Cdc14 triggers mitotic exit by reversal of Cdk-dependent phosphorylation. Mol Cell 2: 709-718.

Voets E, Wolthuis RM. (2010). MASTL is the human orthologue of Greatwall kinase that facilitates mitotic entry, anaphase and cytokinesis. Cell Cycle 9: 3591-3601.

Wagih O, Usaj M, Baryshnikova A, VanderSluis B, Kuzmin E, Costanzo M, Myers CL, Andrews BJ, Boone CM, Parts L. (2013). SGAtools: One-stop analysis and visualization of array-based genetic interaction screens. Nucleic Acids Res 41: W591596.

Walworth N, Davey S, Beach D. (1993). Fission yeast chk1 protein kinase links the rad checkpoint pathway to cdc2. Nature 363: 368-371.

Wang J, Tadeo X, Hou H, Tu PG, Thompson J, Yates JR 3rd, Jia S. (2013). Epe1 recruits BET family bromodomain protein Bdf2 to establish heterochromatin boundaries. Genes Dev 27: 1886-1902.

Wang P, Pinson X, Archambault V. (2011). PP2A-twins is antagonized by greatwall and collaborates with polo for cell cycle progression and centrosome attachment to nuclei in Drosophila embryos. PLoS Genet 7: e1002227.

Wanke V, Pedruzzi I, Cameroni E, Dubouloz F, De Virgilio C. (2005). Regulation of G0 entry by the Pho80-Pho85 cyclin-CDK complex. EMBO J 24: 4271-4278.

Weisman R, Choder M, Koltin Y. (1997). Rapamycin specifically interferes with the developmental response of fission yeast to starvation. J Bacteriol 179: 6325-6334. 


\section{Bibliografía}

Weisman R, Finkelstein S, Choder M. (2001). Rapamycin blocks sexual development in fission yeast through inhibition of the cellular function of an FKBP12 homolog. J Biol Chem 276: 24736-24742.

Weisman R, Roitburg I, Schonbrun M, Harari R, Kupiec M. (2007). Opposite effects of tor1 and tor2 on nitrogen starvation responses in fission yeast. Genetics 175:11531162.

Williams DR, McIntosh JR. (2002). mcl1+, the Schizosaccharomyces pombe homologue of CTF4, is important for chromosome replication, cohesion, and segregation. Eukaryot Cell 1: 758-773.

Wilson WA, Hawley SA, Hardie DG. (1996). Glucose repression/derepression in budding yeast: SNF1 protein kinase is activated by phosphorylation under derepressing conditions, and this correlates with a high AMP:ATP ratio. Curr Biol 6: 1426-1434.

Wolf F, Sigl R, Geley S. (2007). '... The end of the beginning': cdk1 thresholds and exit from mitosis. Cell Cycle 6: 1408-1411.

Wolfe BA, Gould KL. (2004). Fission yeast Clp1p phosphatase affects G2/M transition and mitotic exit through Cdc25p inactivation. EMBO J 23: 919-929.

Wood PA, Du-Quiton J, You S, Hrushesky WJ. (2006). Circadian clock coordinates cancer cell cycle progression, thymidylate synthase, and 5-fluorouracil therapeutic index. Mol Cancer Ther. 5: 2023-2033. Erratum in: Mol Cancer Ther (2006) 5: 3312.

Wood V, Gwilliam R, Rajandream MA, Lyne M, Lyne R, Stewart A, Sgouros J, Peat N, Hayles J, Baker S, et al. (2002). The genome sequence of Schizosaccharomyces pombe. Nature 415: 871-880.

Wood V, Harris MA, McDowall MD, Rutherford K, Vaughan BW, Staines DM, Aslett M, Lock A, Bähler J, Kersey PJ, Oliver SG. (2012). PomBase: a comprehensive online resource for fission yeast. Nucleic Acids Res 40: D695-699.

Wu JQ, Guo JY, Tang W, Yang CS, Freel CD, Chen C, Nairn AC, Kornbluth S. (2009). PP1-mediated dephosphorylation of phosphoproteins at mitotic exit is controlled by inhibitor-1 and PP1 phosphorylation. Nat Cell Biol 11: 644-651.

Wu L, Russell P. (1997). Nif1, a novel mitotic inhibitor in Schizosaccharomyces pombe. EMBO J 16: 1342-1350.

Wurzenberger C, Gerlich DW. (2011). Phosphatases: providing safe passage through mitotic exit. Nat Rev Mol Cell Biol 12: 469-482.

Yamaguchi S, Murakami H, Okayama H. (1997). A WD repeat protein controls the cell cycle and differentiation by negatively regulating Cdc2/B-type cyclin complexes. Mol Biol Cell 8: 2475-86.

Yamaguchi S, Decottignies A, Nurse P. (2003). Function of Cdc2p-dependent Bub1p phosphorylation and Bub1p kinase activity in the mitotic and meiotic spindle checkpoint. EMBO J 22: 1075-1087. 
Yamawaki-Kataoka Y, Tamaoki T, Choe HR, Tanaka H, Kataoka T. (1989). Adenylate cyclases in yeast: a comparison of the genes from Schizosaccharomyces pombe and Saccharomyces cerevisiae. Proc Natl Acad Sci USA 86: 5693-5697.

Yang H, Jiang W, Gentry M, Hallberg RL. (2000). Loss of a protein phosphatase 2A regulatory subunit (Cdc55p) elicits improper regulation of Swe1p degradation. Mol Cell Biol 20: 8143-8156.

Ye Y, Lee IJ, Runge KW, Wu JQ. (2012). Roles of putative Rho-GEF Gef2 in division-site positioning and contractile-ring function in fission yeast cytokinesis. Mol Biol Cell 23:1181-1195.

Yellman CM, Burke DJ. (2006). The role of Cdc55 in the spindle checkpoint is through regulation of mitotic exit in Saccharomyces cerevisiae. Mol Biol Cell 17: 658-566.

Yu EY, Lee JH, Kang WH, Park YH, Kim L, Park HM. (2013). Fission yeast LAMMER kinase Lkh1 regulates the cell cycle by phosphorylating the CDK-inhibitor Rum1. Biochem Biophys Res Commun 432: 80-85.

Yu J, Fleming SL, Williams B, Williams EV, Li Z, Somma P, Rieder CL, Goldberg ML. (2004). Greatwall kinase: a nuclear protein required for proper chromosome condensation and mitotic progression in Drosophila. J Cell Biol 164: 487-492.

Yu J, Zhao Y, Li Z, Galas S, Goldberg ML. (2006). Greatwall kinase participates in the Cdc2 autoregulatory loop in Xenopus egg extracts. Mol Cell 22: 83-91.

Zeng Y, Forbes KC, Wu Z, Moreno S, Piwnica-Worms H, Enoch T. (1998). Replication checkpoint requires phosphorylation of the phosphatase Cdc25 by Cds1 or Chk1. Nature 395: 507-510.

Zhao Y, Haccard O, Wang R, Yu J, Kuang J, Jessus C, Goldberg ML. (2008). Roles of Greatwall kinase in the regulation of cdc25 phosphatase. Mol Biol Cell 19:1317-1327.

Zimmermann C, Chymkowitch P, Eldholm V, Putnam CD, Lindvall JM, Omerzu M, Bjørås M, Kolodner RD, Enserink JM. (2011). A chemical-genetic screen to unravel the genetic network of CDC28/CDK1 links ubiquitin and Rad6-Bre1 to cell cycle progression. Proc Natl Acad Sci USA 108: 18748-18753.

Zuin A, Carmona M, Morales-Ivorra I, Gabrielli N, Vivancos AP, Ayté J, Hidalgo E. (2010). Lifespan extension by calorie restriction relies on the Sty1 MAP kinase stress pathway. EMBO J 29: 981-991. 


\begin{tabular}{|c|c|}
\hline ADN & Ácido desoxirribonucleico \\
\hline AGC & Familia de las proteína quinasas $A, G$ y C \\
\hline APC & Anaphase-promoting complex \\
\hline ARG & Averaged relative growth \\
\hline ARN & Ácido ribonucleico \\
\hline as & Analogue-sensitive \\
\hline ATP & Adenosín trifosfato \\
\hline BiNGO & Biological networks gene ontology tools \\
\hline BSA & Bovine Serum Albumine \\
\hline CAK & CDK-activating kinase \\
\hline CaMK & Calcium/calmodulin kinase \\
\hline cAMP & Adenosín monofosfato cíclico \\
\hline CDC & Cell division cycle (ciclo de división celular) \\
\hline CDK & cyclin-dependent kinase \\
\hline CESR & Core environmental stress response \\
\hline CKI & Cycling dependent kinase inhibitor \\
\hline CLS & Chronological lifespan \\
\hline CMD & Crecimiento del mutante doble \\
\hline CMS & Crecimiento del mutante sencillo \\
\hline CV & Coeficiente de varianza \\
\hline D.O & Densidad óptica \\
\hline DAPI & 4,6-Diamidinio-2-fenilindol \\
\hline DMSO & Dimetilsulfóxido \\
\hline E-MAP & Epistatic miniarray profiles \\
\hline EDTA & Ethylenediaminetetraacetic acid \\
\hline EMM & Edinburgh minimal medium \\
\hline GEF & Guanine nucleotide exchange factor \\
\hline GO & Gene ontology \\
\hline $\mathrm{Kk}$ & Kilobases \\
\hline
\end{tabular}




\section{Abreviaturas}

MAPK Mitogen-activated protein quinase

MEA Malt extract agar

MM $\quad$ Medio minimo

ORF Open reading frame

pb Pares de bases

PCR Polymerase chain reaction

PEG Polietinilglicol

PInt Pombe interactome

PKA Protein kinase $A$ (proteína quinasa A)

PP2A Protein phosphatase 2A

ppp $\quad$ Punto por pulgada

RF Random forest

RG Relative growth

RNAi Ácido ribonucleico interferente

RSA Random spore analysis

SAC Spindell assembly checkpoint

SCF Skp, Cullin, F-box complex

SDS Sodium dodecyl sulfate

SGA Synthetic genetic array

SPB Spindle pole body

SRP Stress response pathway

SVM Supported vector machine

TOR Target of rapamycin

TORC $\quad$ Complejo TOR 1

ts $\quad$ Termosensibles

YEP Yeast extract with supplements and Phloxine B

YES Yeast extract with supplements 